\title{
ESTUDO DA COAGULAÇÃO E FLOCULAÇÃO DE ÁGUAS SINTETICAS \\ E NATURAIS COM TURBIDEZ E COR VARIÁVEIS
}
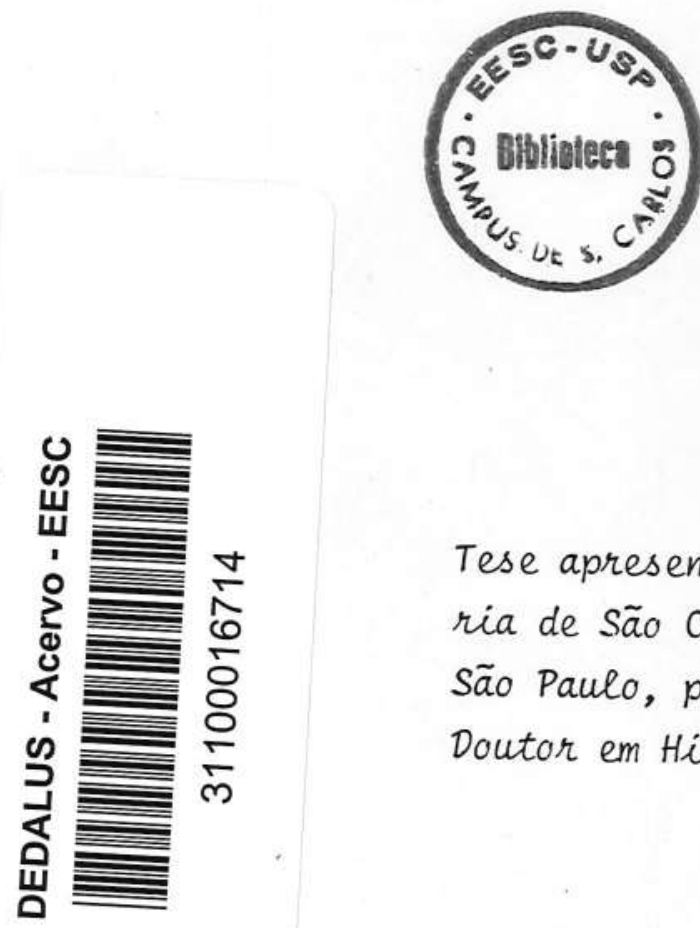

Tese apresentada à Escola de Engenharia de São Carlos, da Universidade de São Paulo, para obtenção do título de Doutor em Hidráulica e Saneamento.

São Carlos

Estado de São Paulo

Dezembro, 1989 


\section{ESTUDO DA COAGULAÇÃO E FLOCULAÇÃO DE AGGUAS SINTETICAS E NATURAIS COM TURBIDEZ E COR VARIÁVEIS}

CARLOS GOMES DA NAVE MENDES

Orientador: LUIZ DI BERNARDO

Tese apresentada à Escola de Engenharia de São Carlos, da Universidade de São Paulo, para obtenção do título de Doutor em Hidraulica e Saneamento

São Carlos

Estado de São Paulo

Dezembro, 1989 
DEDICATORIA

A meus pais Manuel e Maria Cristina;

meus irmãos Josē Manuel e Elisabete Cristina; minha esposa Cristina; meus filhos Marcelo, Lucas e Laura Cristina. 


\section{AGRADECIMENTOS}

Ao Prof. Dr. Luiz Di Bernardo, meu instrutor e orientador.

Ao amigo Austregésilo Ferreira Guimarães, companheiro com quem partilhei todos os momentos principais, iniciais deste estudo.

A FAPESP, pelo auxilio financeiro concedido para aquisição de equipamentos e montagem da instalação e na forma de Bolsa de Douto ramento durante o período de março/86 a agosto/88.

Aos amigos Alvaro Vaz Macia, Valdecir Aparecido de Arruda, Valēria Isabel Peres, João Borsoni Junior, Maria Aparecida Perez Viu dez e Paulo Fragiācomo que dedicaram comigo muitos momentos na realiza ção do presente trabalho.

A COPESP, na qual trabalho desde janeiro/89, principalmente nas pessoas dos amigos José Roberto Custōdio de Lima e Heitor Loba to Diaz Junior que com o apoio permitiram a concretização do presente trabalho. 


\section{RESUMO}

Este trabalho apresenta uma extersa revisão bibliogräfica enfocando os aspéctos quimicos e cinéticos da coagulação e floculação de āguas contendo cor e turbidez. São fornecidos dados de um grande nú mero de ensaios de floculação realizados em instalação especialmente construida para estudar a coagulação e floculação de diversos tipos de āguas preparadas em laboratōrio e naturais, contendo turbidez e cor.

Como resultado, $\bar{e}$ proposta uma metodologia para a determi nação de valores ótimos de dosagem de coagulante e respectivo pH, $\overline{\bar{u}}$ teis para o tratamento de āguas de abastecimento atravēs da coagula ção nos mecanismos de adsorção-neutralizacão e varredura, seguidos de floculação e sedimentação. Ainda com base no trabalho experimental rea lizado, é proposto um novo modelo matemätico para correlacionar os dá dos do gradiente de velocidade ótimo com os períodos de floculação. Es te modelo constitui-se em um aperfeiçoamento daquele apresentado ante riormente por ANDREU-VILLEGAS \& LETTERMAN (4), acrescentando-se um novo parâmetro denominado gradiente de velocidade minimo $\left(G^{\prime}\right)$, para 0 qual obtêm-se crescentes eficências de remoção de particulas floculen tas por sedimentação lação.

com o aumento do período de flocu 
SLIMMARY

An extensive review of the literature, concerning chemical and kinetic aspects of coagulation and flocculation of several inicial qualitys of colored or turbid water is presented herein.

An experimental work was carried out using a special faci lity to study all the aspects related to coagulation and flocculation of several types of synthetic and natural waters.

Based on the results obtained in this work, a new methodo logy to investigate optimum coagulant dosis and respective pH considering both coagulation mechanisms, adsorption-neutralization and sweep coagulation, is presented. In addition, a new mathematical expression was derived to related optimum velocity gradient and mixing time for flocculation. This model is a refinement of that presented earlier by ANDREU-VILLEGAS \& LETTERMAN (4), including a new parameter named mini mum velocity gradient $\left(G^{\prime}\right)$ that permit an increase performance of the remotion of the inicial turbidity and color of water with the increase of the flocculation time. 
LISTA DE SIMBOLOS

LISTA DE ?UADROS

LISTA DE FIGURAS

1. INTRODUCAOA

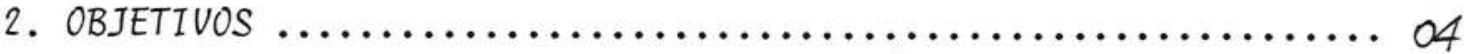

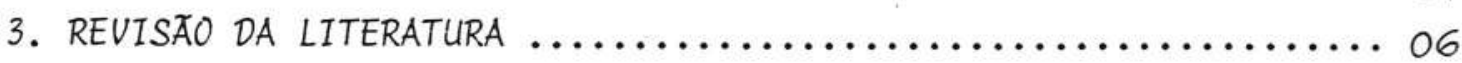

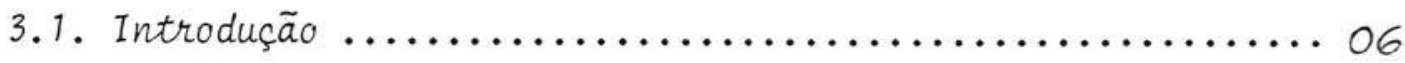

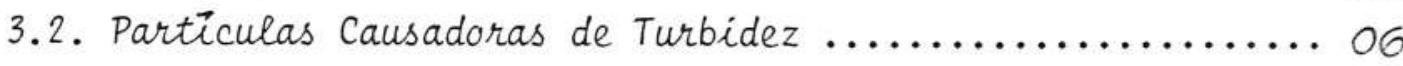

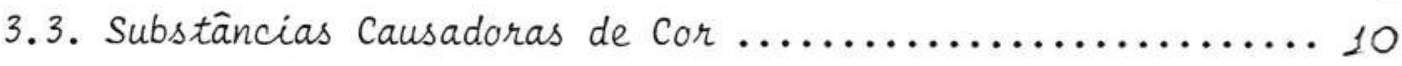

3.3.1. Natureza e Propriedades da Cor de Origem Orgânica . 10

3.3.2. Problemas Relacionados com a Presença de Compos tos Orgânicos em Aguas ....................... 13

3.4. Fundamentos nuímicos da Superfície dos colóides ......... 15 3.4.1. Sistemas Coloidais ....................... 15

3.4.2. Cargas Superficiais das Partículas Coloidais ..... 16

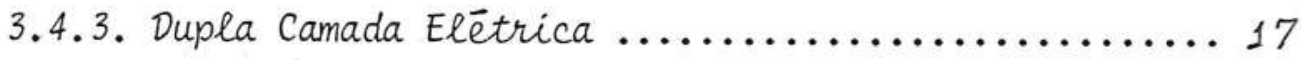

3.4.4. Força de Atração de VAN DER WAALS $\ldots \ldots \ldots \ldots \ldots . \ldots 2$

3.4.5. Fatores de Estabilidade e Instabilidade ......... 22

3.5. Teoria da Coagulação .......................... 23

3.5.1. Mecanismos de Desestabilização .............. 33

3.5.1.1. Ação de Redução das Forças Repulsivas .......23

3.5.1.2. Ação de Mecanismos de Transporte ........... 31

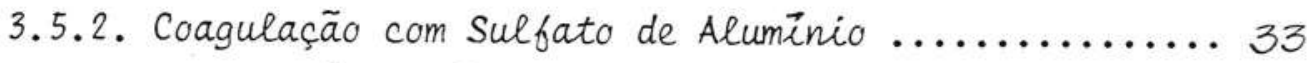

3.5.2.1. Reações Químicas do Sulfato de Aluminio com a

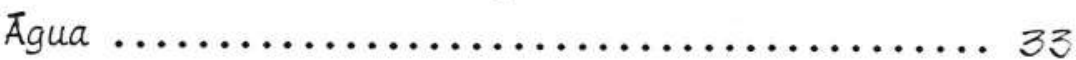

3.5.2.2. Diagrama de Equilïbrio das Espécies de Alumé nio ..................................... 39

3.5.2.3. Mecanismos de Coagulação com Sulfato de Alumę

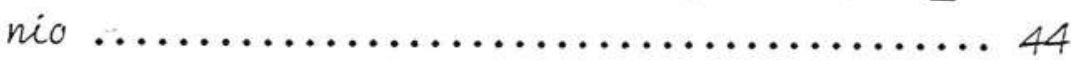

3.6. Estudos Experimentais da Coagulação ................ 47

3.6.1. Coagulação de Aguas para Remoção de Turbidez ....4 47

3.6.2. Coagulação de Aguas para Remoção de Cor ........ 57 
3.6.3. Coagulação de Aguas para Remoção de Cor e Turbidez. 60 3.7. Aspectos Relevantes sobre a Floculação ................ 70 3.8. Breve Discussão sobre a Revisão da Literatura .......... 77

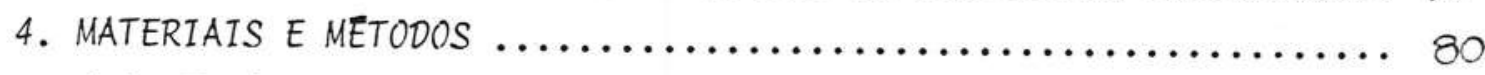

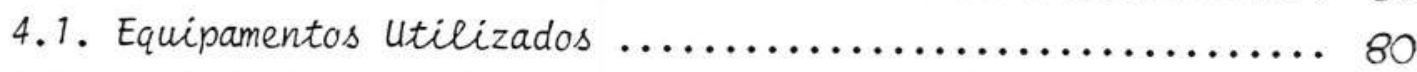

4.2. Instalação para Preparação e Homogeinização das Aguas Ar tificiais e Naturais .............................. 81

4.3. Instalação para os Ensaios de Floculação ............... 82

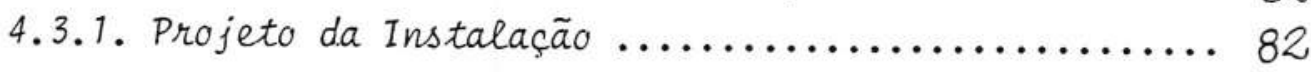

4.3.2. Descrição da Instalação $\ldots . . \ldots \ldots \ldots \ldots \ldots \ldots . \ldots . \ldots . \ldots 4$

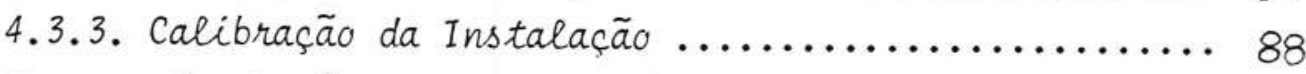

4.4. Preparação das Aguas para Estudo ................... 98

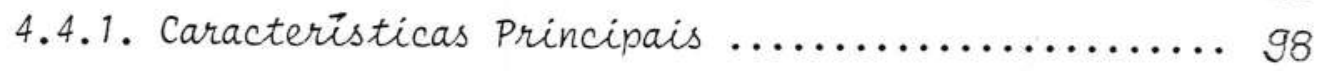

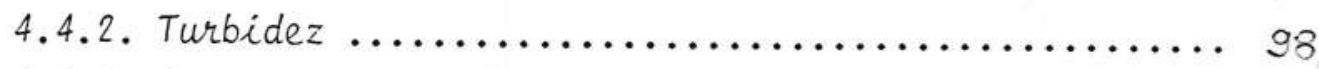

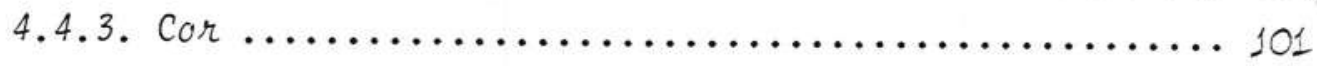

4.4.3.1. Extração .............................. 101

4.4.3.2. Determinação da Cor $\ldots . \ldots \ldots \ldots \ldots \ldots \ldots \ldots$. 01

4.4.4. Alcalinizante, Coagulante e Ajustes de pH .......... 105

4.5. Metodologia para a Realização dos Ensaios de Floculação ..110

4.5.1. Introdução ................................110

4.5.2. Construção do Diagrama de Coagulação .............110

4.5.3. Determinação dos Parâmetros otimos de Mistura Rā pida ....................................112

4.5.4. Determinação dos Parâmetros otimos de Floculação .. 113

4.5.5. Determinação da Influência da concentração da So

lução Estoque do Coagulante $\ldots \ldots \ldots \ldots \ldots \ldots \ldots . \ldots 115$

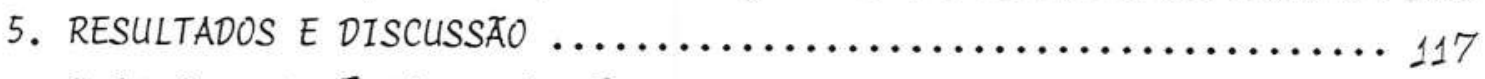

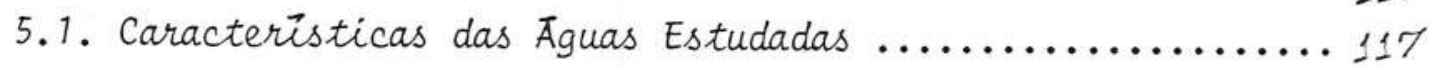

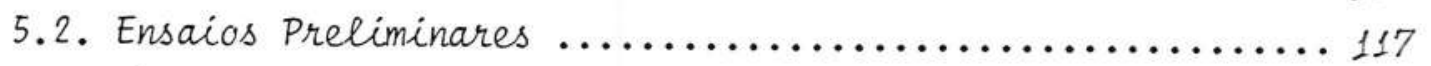

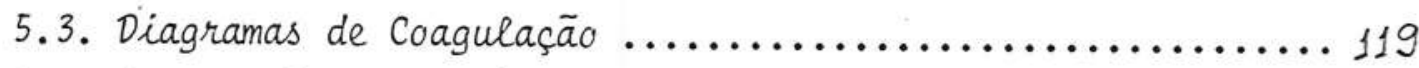

5.4. Otimização dos Parâmetros de Mistura Rapida ............ 134

5.5. Otimização dos Parâmetros de Floculação ............... 135

5.6. Influência da Concentração da Solução Estoque do Coagu

lante ..................................... 142

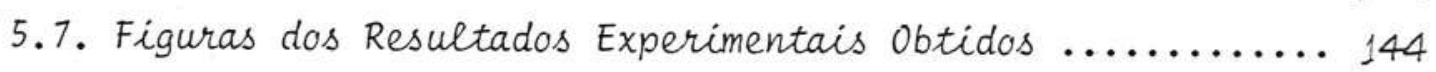

5.7.1. Agua Tipo I ............................... 5.13

5.7.2. Agua Tipo II $\ldots \ldots \ldots \ldots \ldots \ldots \ldots \ldots \ldots \ldots \ldots \ldots \ldots .13-5.22$ 
5.7.3. Agua Tipo III ............................ 5.23-5.32

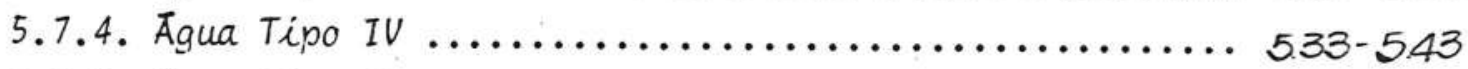

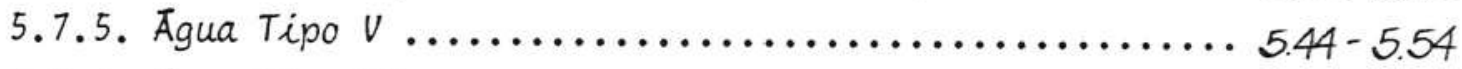

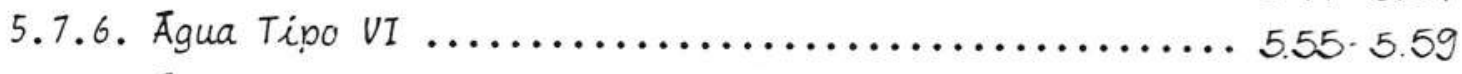

5.7.7. Agua Tipo VII ............................ 5.60-5.69

5.7.8. Agua Tipo VIII .......................... 5.70-5.78

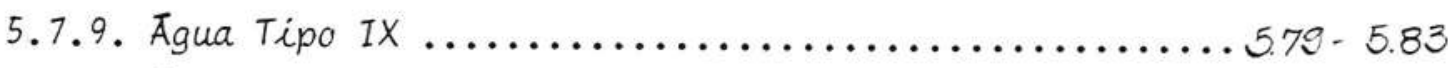

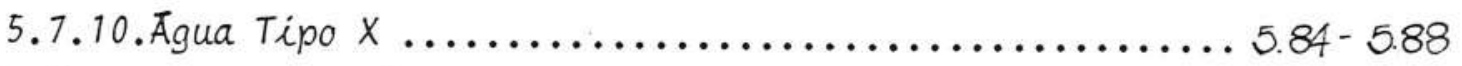

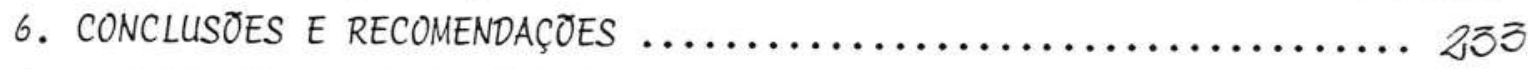

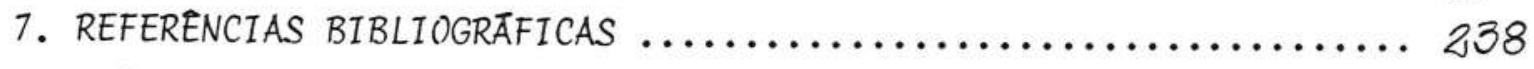
APENDICES

A. Diagramas de Coagulação das Aguas Ensaiadas (Tipos I a V) voLume I

B. Planilhas dos Resultados dos Ensaios de Floculação da $\bar{A}$ voxume $I$ gua Tipo I

C. Planilhas dos Resultados dos Ensaios de Floculação da $\underline{A}$ vounme II gua Tipo II

D. Planilhas dos Resultados dos Ensaios de Floculação da I voLume III gua Tipo III

E. Planilhas dos Resultados dos Ensaios de Floculação da I roxume III gua Tipo IV

F. Planilhas dos Resultados dos Ensaios de Floculação da $\underline{A}$ volume III gua Tipo $V$

G. Planilhas dos Resultados dos Ensaios de Floculação da $\underline{A}$ volume $\mathbb{I}$ gua Tipo VI

H. Planilhas dos Resultados dos Ensaios de Floculação da A voLume III gua Tipo VII

I. Planilhas dos Resultados dos Ensaios de Floculação da I vorume III gua Tipo VIII

J. Planilhas dos Resultados dos Ensaios de Floculação da $\underline{A}$ vokume III gua Tipo IX

k. Planilhas dos Resultados dos Ensaios de Floculação da I volume III gua Tipo $X$ 
$\Psi_{0}$ : potencial elétrico na superfície da partícula;

$K$ : constante de BOLTZMANN $\left(1,38 \times 10^{-16}\right.$ erg/ok);

$T$ : temperatura absoluta $\left(\frac{9}{k}\right)$;

$e$ : carga de um elétron;

$V$ : valência iônica;

C : concentracão iônica na solucão;

$c_{0}$ : concentração iônica na solução no ponto de carga nula, quando $\psi_{0}=0$;

$z_{p}$ : potencial Zeta;

$q$ : carga sobre a particula;

$\delta$ : espessura da zona de influência da carga sobre a partícula;

D : constante dielétrica do liquido;

$\eta$ : viscosidade absoluta da āgua, em poises;

me: mobilidade eletroborética da partícula $(\mu / \mathrm{s} / \mathrm{V} / \mathrm{cm})$;

Vr : potencial de repulsão;

$J_{p k}$ : taxa de variação da concentração das partículas devido a ação da bloculação pericinética;

$N^{0}$ : concentração total de partículas em suspensão no tempo iaual a 0 ;

$\theta$ : fator de eficiência de colisão I fração das colisões favorāveis a agregação I;

$\mu$ : viscosidade do bluido $(\mathrm{g} / \mathrm{cm} . \mathrm{s})$;

$P_{6}$ : peso flutuante da particula $(N)$;

$p$ : densidade da partícula $\left(\mathrm{kg} / \mathrm{m}^{3}\right)$;

$\rho$ : densidade do fluido $\left(\mathrm{kg} / \mathrm{m}^{3}\right)$;

9 : aceleração da gravidade $\left(\mathrm{m} / \mathrm{s}^{2}\right)$;

$d$ : diâmetro da partícula $(\mathrm{m})$;

$J_{o k}$ : taxa de variação da concentração das partículas devido a ação da bloculação ortocinética;

$G$ : gradiente de velocidade $\left(s^{-1}\right)$;

CTC : capacidade de troca de cátions;

CCC : concentração crîtica de coagulante;

CCR : concentração crítica de restabilização;

$P$ : potencia introduzida no sistema;

$V$ : volume do sistema; 
$n_{1}^{0}$ : concentração de particulas primärias no afluente ao sistema;

$n_{1}^{m}$ : concentração de partículas primārias no efluente do m-ésimo reator;

$k_{1}$ : constante de agregação I depende da natureza e tamanho das partículas;

$\oint$ : fração em volume dos flocos;

$T$ : perĩodo de floculação;

$m$ : nümero de reatores em sērie;

$N$ : concentração de partículas primārias;

$K_{A}$ : coeficiente de agregação;

$K_{B}$ : coeficiente de quebra;

$N_{m}$ : concentração de partículas saindo da ültima câmara de flocula ção;

(1) : potencia introduzida por unidade de volume do fluido $\left(\mathrm{Nm} / \mathrm{sm}^{3}\right)$;

$s$ : velocidade de rotação do agitador em rps $\left(s^{-1}\right)$;

$T$ : torque fornecido ao fluido (N.m);

$B$ : braço de torque de uma força;

$r$ : coeficiente de correlação do método dos ménimos quadrados;

$G^{*}$ : gradiente de velocidade ōtimo;

G' : gradiente de velocidade ōtimo quando o período de floculação tende para o infinito;

$T i$ : turbidez inicial da āgua a ser ensaiada (UT);

T6 : turbidez residual da āgua ensaiada (UT);

$\mathrm{Ci}$ : cor aparente inicial da āgua a ser ensaiada (mg Pt-Co/l);

Cf : cor aparente residual da ägua ensaiada (mg Pt-Co/l); 


\section{LISTA DE QUADROS}

QUADRO 3.1 - Efeitos da coagulação sobre diversos constituintes de āguas naturais potabilizāveis (32) .................. 07

OUADRO 3.2 - Argilas comumentemente encontradas e suas fórmulas

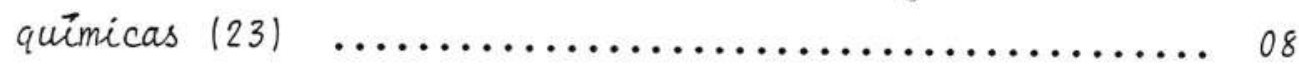

QUADRO 3.3 - Classificação das substâncias hümicas segundo ODEN

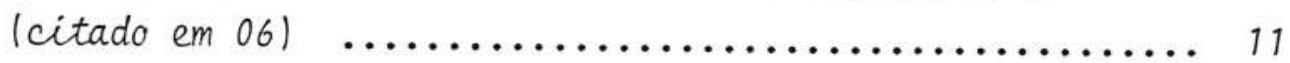

QUADRO 3.4 - Anālise dos elementos químicos presentes nos ācidos hümico e fülvico (segundo SCHNITZER, citado em 06) $\ldots . .12$

QUADRO 4.1 - Dados da calibração do gradiente de velocidade para

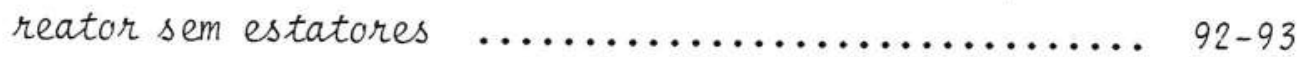

QUADRO 4.2 - Dados de calibração do gradiente de velocidade para reator com estatores .......................... 94-95

QUADRO 4.3 - Fatores de correção a serem multiplicados aos gra dientes de velocidade obtidos da Figura $4.9 \mathrm{em}$ função da temperatura da āgua contida no reator (dados

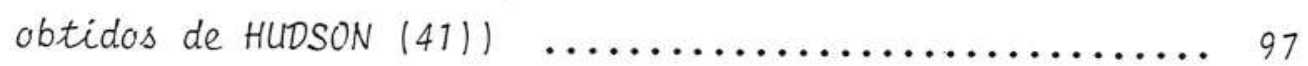

?UADRO 4.4 - Caracteristicas das Aguas Investigadas ................ 99

QUADRO 4.5 - Determinação dos Sólidos Totais, Fixos e Voläteis

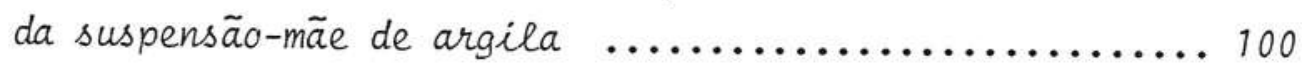

?UADRO 4.6 - Determinação da turbidez em função de diluições da

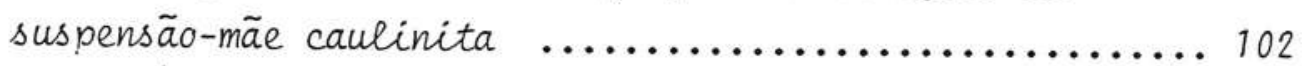

QUADRO 4.7 - Concentração de substâncias hümicas da solução-mãe

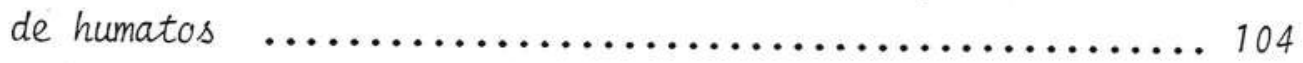

QUADRO 4.8 - Dados da calibração da cor como função da transmitân cia e do valor do $\mathrm{pH}$ para amostras com cor variando entre 10 e $100 \mathrm{mg}$ Pt-Coll e valores de pH entre 3 e $9 . .106$

QUADRO 4.9 - Dados da calibração da cor como função da transmitância e do valor do pH para amostras com cor variando entre 1 e $10 \mathrm{mg}$ Pt-Co/l e valores de pH entre 3 e $9 \ldots 108$

QUADRO 5.1 - Caracteristicas das Aguas Investigadas ............... 118 QUADRO 5.2 - Equações de ajuste dos parâmetros ōtimos de flocu-

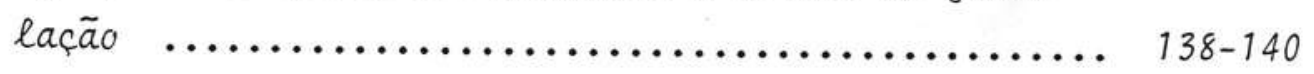


QUADRO 5.3 - Equações de ajuste dos valores de turbidez ou cor aparente residual minima em função do período de bloculação. Seleção de parâmetros ótimos de floculação 


\section{LISTA DE FIGURAS}

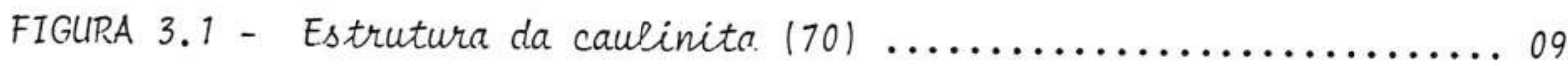

FIGURA 3.2 - Caraas superficiais da particula de caulinita (70) ...... 10

FIGURA 3.3 - Distribuicão do tamanho das particulas presentes na

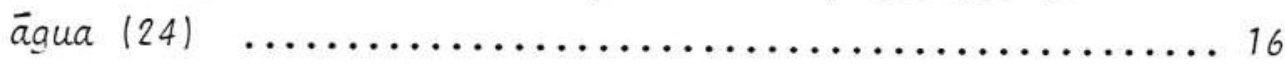

FIGUPA 3.4 - Aquisicão de carga nor partículas de argila e nro -

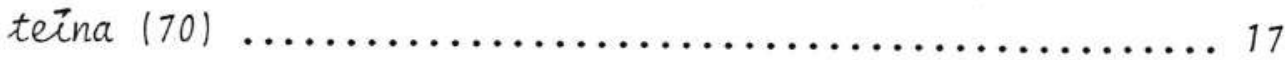

FIGURA 3.5 - Superficie de uma partícula coloidal com a distri buicão de cargas elétricas segundo o modelo de STEPN (70)

FIGURA 3.6 - Distribuição de cargas na camada dunla difusa de uma narticula com carga negatica para duas concentracões de eletrölitos e carga sunerkicial constante (70) .....20

FIGURA 3.7 - Conficuracão do notencial elétrico na camada dunla difusa nara duas concentracões de eletrólitos (70) .....20

FIGURA 3.8 - Energia potencial de iteracão entre as nartículas

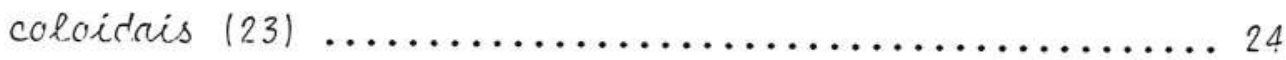

FIGURA. 3.9 - Ejeito da variação da concentração de eletrólitos na compressão da dupla camada elétrica (70) $\ldots \ldots \ldots \ldots \ldots 25$

FIGUPA 3.10 - Representação esquemätica do modelo de nontes na desestabilizacão de colōides nor polimeros (nolieletrō litos) (23)

FIGURA 3.11 - Curvas esquemäticas de coagulacão secundo os diversos mecanismos de destabilização (23)

FTGUIPA 3.12 - Concentracão crítica de coarulação (CCC) do nitrato de aluminio (- ) l com correções de pH heitas com $\mathrm{HNO}_{3}$ quando necessäriol e do sulfato de aluminio ( -..- 1 (com correröes de nt feitas com $\mathrm{H}_{2} \mathrm{SO}_{4}$ quando necessäriol como func.̃o do nt?. Ambas as curvas nara sōis de iodeto de prata $\left(\mathrm{AgI}: 1 \times 10^{-4} \mathrm{M}, \mathrm{KI}: 4 \times 10^{-4}\right.$ M) (55) 36

FIGURA 3.13 - Limites da concentracão crëtica de restabilização (CCR) por reversão de carga devido à espécies hidrolisadas nolinucleares de aluminio nara diversas suspensões coloidais em funcão do valor de nH. (55) SBR (styrene butadiene rubber) (latex); 


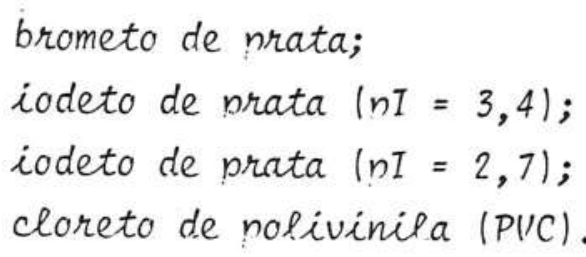

FIGURA 3.14 - Concentração crïtica de coagulação (CCC) como funcão da adicão de fluoreto de potássio, utilizandose perclorato de aluminio e sōis de brometo de nra ta em dois valores de $p^{H}$ (55) ....................40

FIGURA 3.15 - Logaritmo da concentração molar de nitrato de aluminio em função do valor do pH para sōis de iodeto

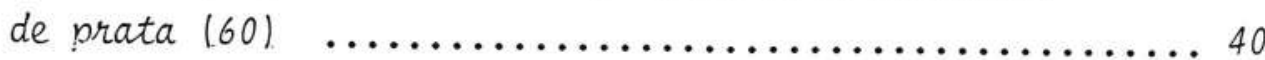

FIGURA 3.16 - Efeito do $\mathrm{pH}$ sobre as espécies residuais de aluménio em solução (74)

$5 \mathrm{ppm}$ de $\mathrm{Al}_{2}\left(\mathrm{SO}_{4}\right)_{3} .18 \mathrm{H}_{2} \mathrm{O}=0,4 \mathrm{ppm} \mathrm{Al}$;

$25 \mathrm{ppm} \mathrm{de} \quad=2,0 \mathrm{pnm} \mathrm{n}$;

$75 \mathrm{ppm}$ de $\quad=6,1 \mathrm{ppm} \mathrm{";}$

$200 \mathrm{pom} \mathrm{de} \quad=16,2$ ppm $" \ldots . . . . . .4 .41$

FIGURA 3.17 - Diagrama de equilïbrio entre as espécies preponderantes de aluminio em função do valor do pH da solução. Para āgua destilada com $25^{\circ} \mathrm{C}$.

FIGURA 3.18 - Desestabilização de suspensões de caulinita com sue fato de aluminio para os pHs de $3(I) ; 5(I I)$ e $8(I \bar{I})$. Concentrações das suspensões originais de caulinita: A ou : 15,8 mg/l; B ou : $31,7 \mathrm{mg} / \mathrm{l}$; C ou : $47,5 \mathrm{mg} / \mathrm{l}$ e $\mathrm{D}$ ou $: 63,3 \mathrm{mg} / \mathrm{l}$ (13) 45

FIGURA 3.19 - Efeito do envelhecimento sobre a mobilidade eletroforética (48)

- mobilidade eletroforética original: $-2,7 \mathrm{~s} / \mathrm{V} / \mathrm{cm}$;

- Ph inicial: 7,7;

- alcalinidade inicial: $1 \mathrm{me} / \mathrm{l}$;

- concentração de caulinita: $100 \mathrm{mg} / \mathrm{l}$;

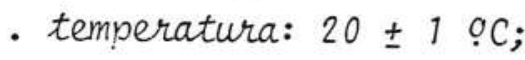

- dosagem de sulfato de aluminio : $A=2$ ppm;

$B=7$ ppm;

$C=14$ ppm....4.49

FIGURA 3.20 - Efeitos da alcalinidade e da dosagem de coagulante sobre o pH ōtimo (48)

- concentração de caulinita: 50 ppm; 
- dosagem de sulfato de aluminio: (a) $4 \mathrm{ppm}$;

(b) $10 \mathrm{ppm}$.

- alcalinidade inicial: $1--10,4 \mathrm{me} / \ell$;

(-) 2,0 me/l.

FIGURA 3.21 - pH isoelētrico $\left(p H_{i}\right)$ em função da concentração de bicarbonato (48)

- Linha A representa a concentração inicial de $\mathrm{HCO}_{3}^{-}$;

- linha B represebta a concentração final de

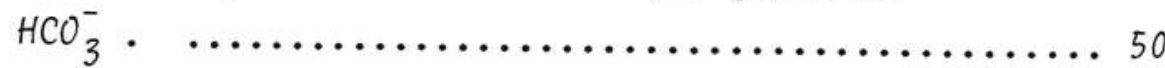

FIGURA 3.22 - Relações entre o CEC e a dosagem de sulfato de aluminio (48)

- alcalinidade inicial : (a) $1 \mathrm{me} / \mathrm{l}$;

(b) $4 \mathrm{me} / \ell$. 51

FIGURA 3.23 - Regĩoes onde é possível a coagulação (com remoção de turbidez por sedimentaçãol (84)

(a) Curvas esquemāticas de coagulação em pHs constantes para quatro concentrações coloidais. Indicam seccões $s_{1}, s_{2}, s_{3}$ e $s_{4}$ da Figura 3.23 (b).

(b) Efeito da concentração coloidal na dosagem de coagulante para a desestabiliza ção, restabilização e precipitação sob pH constante. As regiões hachuradas indicam a ocorrência de coagulação.

FIGURA 3.24 - Influencia da alcalinidade inicial, do pH de coa gulação e da concentração superficial de colōides na dosagem de coagulante $\left(\log C_{t}\right.$ - moles/l) (84)

- concentração da superfície coloidal:

$$
\begin{aligned}
& \text { (a) } 170 \mathrm{~m}^{2} / \mathrm{l} \text {; } \\
& \text { (b) } 1,7 \mathrm{~m}^{2} / \mathrm{l} \text {. }
\end{aligned}
$$

FIGURA 3.25 - Diagrama de projeto e operação para a coagulação de turbidez com sulfato de aluminio $\left(\mathrm{Al}_{2}\left(\mathrm{SO}_{4}\right)_{3} .14,3 \mathrm{H}_{2} \mathrm{O}\right)(03)$ 
FIGURA 3.26 - Turbidez da āgua decantada em função do período de sedimentação, intensidade de mistura rāpida e pH de coagulação (03)

- pH de coagulacão :

$$
\begin{aligned}
& \text { (a) 7,5-7,6; } \\
& \text { (b) 5,8-5,9; } \\
& \text { (c) 7,0; } \\
& \text { (d) 6,4-6,5; } \\
& \text { (e) 7,0; } \\
& \text { (b) 6,4-6,5. }
\end{aligned}
$$

FIGURA 3.27 - Diagrama de coagulação com sulfato de aluminio para remoção de turbidez (02)

FIGURA 3.28 - Diagrama de estabilidade do ácido hümico em concentração inicial de $5 \mathrm{ma} / \mathrm{l}$ em função da dosagem de sulfato de aluminio do pH (53)

FIGURA 3.29 - Influência do pH na coagulação de ācidos hümicos com sulfato de aluminio (segundo EDZINALD, citado em (26))

FIGURA 3.30 - Estequiometria da coagulação de ācidos hümicos com sulfato de aluminio no $\mathrm{pH}$ igual a 6,0. Isegundo EDZWALD, citado em (26))

FIGURA 3.31 - $D_{c} / 2$ para concentração inicial de $25 \mathrm{mg} / \ell$ de $\bar{a}-$ cido búlvico;

Dt/2 para concentração inicial de $50 \mathrm{mg} / \mathrm{l}$ de caulinita (38)

FIGURA 3.32 - Coagulação de uma suspensão contendo concentrações iniciais de $25 \mathrm{mg} / \ell$ de äcido fülvico e $50 \mathrm{mg} / \ell$ de caulinita (38)

FIGURA 3.33 - Influência do pH na remoção de turbidez e compostos orgânicos para uma dosagem de sulfato de aluminio igual a $25 \mathrm{mg} / \mathrm{l}$ (26)

FIGURA 3.34 - Influencia do pH na remoção de turbidez e compostos orgânicos para uma dosagem de sulfato de aluménio igual a $50 \mathrm{mg} / \mathrm{l}$ (26) 65

FIGURA 3.35 - Influência do pH na remoção de turbidez e compostos orgânicos para uma dosagem de sulfato de aluminio igual a $75 \mathrm{mg} / \mathrm{l}$ (26) 66

FIGURA 3.36 - Influência do pH na remoção de turbidez e compos- 
tos orgânicos para uma dosagem de sulfato de alu-

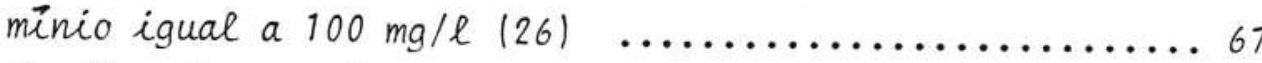

FIGURA 3.37 - Regiões de remocão de cor para concentrações iniciais de ācido hümico igual a $4 \mathrm{mg} / \mathrm{l}$ (100 UC)

(ausência total de turbidez) (30) ..................68

FIGURA 3.38 - Regiões de remoção de cor para concentração ini -

cial de ācido hümico igual a $4 \mathrm{mg} / \mathrm{l}(100$ UC) $e$

turbidez inicial de 27 a 30 UT (30) .................69 69

FIGURA 3.39 - Desempenho da floculação variando-se os parâmetros

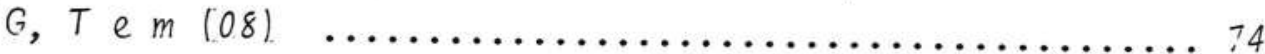

FIGURA 3.40 - Turbidez residual em função do período de floculação para värios valores do gradiente de velocidade.

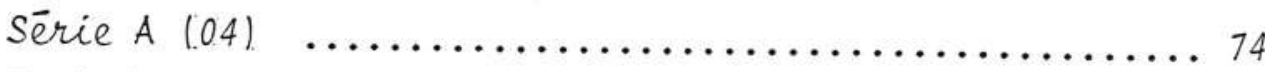

FIGURA 3.41 - Turbidez residual em função do gradiente de velocidade nara vārios períodos de floculação (04) ......... 75

FIGURA 3.42 - Gradiente de velocidade ótimo em função do período de floculação para as sēries $A, B, C$ e $D$ (ver texto)

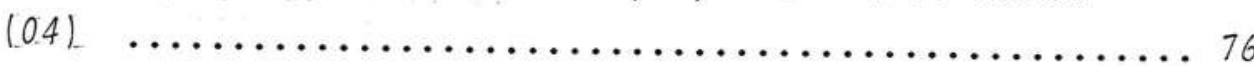

FIGURA 3.43 - Turbidez residual minima em função do neríodo de bloculação para as sēries $A, E, C$ e $D(04) \ldots \ldots \ldots .76$

FIGURA 4.1 - Fotografia da bancada de alguns dos instrumentos (Espectrocolorímetro, Potenciômetro, Turbidímetro, Termô metro, Cronômetro e Tacômetrol ................... 81

FIGURA 4.2 - Fotografia do Zetâmetro da Zeta - meter, modelo 1972. ... 82

FIGURA 4.3 - Fotografia do sistema de preparação e homogeneização das amostras de ägua para investigação

(a) Conjunto motor - redutor;

(b) Turbina;

(c) Reservatōrio de ägua para estudo (V ütil = 200 l);

(d) Recipiente de armazenamento de suspensão-mãe de caulinita;

(e) Pecinientes de armazenamento de substâncias hümicas ..83

FIGURA 4.4 - Esquema geral da instalação para realização de ensaios

de bloculação

(1) variador de corrente

(2) motor

(3) sunorte

(4) placa de fixação 
(5) Pedutor

(6) reator de acrílico

(7) frasco nara coletas

(8) ampliação por polias

(9) suporte de acrüico

FIGURA 4.5 - Fotografia da instalação mostrando os conjuntos motorredutor, reatores e sistema de coleta de amostras ......8 86

FIGURA 4.6 - Caracteristicas do reator, estator e agitador .........87

FIGURA 4.7 - Fotografia de um aparelho de floculação, destacando-se a plataforma e frascos do sistema de coleta de amostras

FIGURA 4.8 - Características da montagem efetuada para a determinação do torque aplicado ao líquido em função da rotação

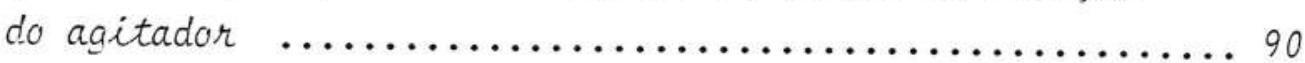

FIGURA 4.9 - Curvas de variação do gradiente de velocidade em fun -

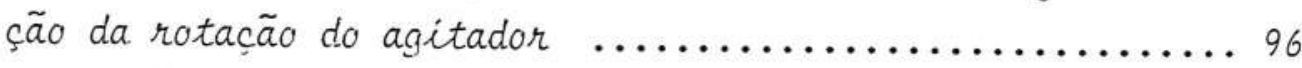

FIGURA 4.10 - Variação da turbidez em função do volume da suspensãomãe de caulinita diluída para 1 (um) litro de suspen são binal

FIGURA 4.11 - Curvas de variação da cor em função da absordancia e

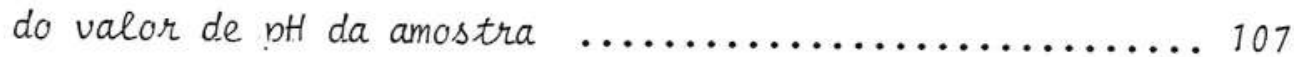

FIGURA 4.12 - Curvas de variação da cor em função da absordância e do valor do $\mathrm{pH}$ da amostra 109

FIGURA 5.1 - Diagrama de coagulação para a Agua Tíno I - Percentagem da turbidez remanescente em função da dosagem de sulfato de aluminio e do pH do sobrenadante

- turbidez inicial: 200 FTU;

- cor verdadeira inicial: $5 \mathrm{mg}$ Pt-Co/l. 5.1

FIGURA 5.2 - Diagrama da mobilidade eletroforética em função da do sagem de sulfato de aluminio e do $\mathrm{pH}$ do sobrenadante para a Agua Tipo I

- turbidez inicial: 200 FTU;

- cor verdadeira inicial: $5 \mathrm{mg}$ Pt-Coll

FIGURA 5.3 - Curvas de variação da mobilidade eletroforética e tur bidez redisual em função da dosagem de sulfato de alu minio para um valor de $\mathrm{pH}$ do sobrenadante igual a 4,65. Agua Tipo I

- turbidez inicial: 200 FTU;

- cor verdadeira inicial: $5 \mathrm{mg}$ Pt-Coll 
FIGURA 5.4 - Curvas de variação da mobilidade eletroforética e tur bidez residual em função do pH do sobrenadante para uma dosagem de sulfato de aluminio igual a $12 \mathrm{mg} / \mathrm{l}$. Ägua Tipo I

- turbidez inicial: 200 FTU;

- cor verdadeira inicial: $5 \mathrm{mg}$ Pt-Co/l

FIGURA 5.5 - Curvas de variação da turbidez residual em função do gradiente de velocidade para vārios períodos de floculação. Agua Tipo I. Mecanismo de adsorção e neutra lização

- turbidez inicial: 200 FTU;

- cor verdadeira inicial: $5 \mathrm{mg}$ Pt-Co/l;

- dosagem de sulfato de aluminio: $10 \mathrm{mg} / \mathrm{l}$;

- pH do sobrenadante: 4,8;

- período de sedimentação: 5 min.

FIGURA 5.6 - Curvas de variação da turbidez em função do gradiente de velocidade para vārios períodos de floculação.

Agua Tipo I. Mecanismo de varredura.

- turbidez inicial: $200 \mathrm{FTU}$;

- cor verdadeira inicial: $5 \mathrm{mg} P t-C o / l$;

- dosagem de sulfato de aluminio: $60 \mathrm{mg} / \mathrm{l}$;

- pH do sobrenadante: 6,55;

- periodo de sedimentação: 5 min

FIGURA 5.7 - Curvas de variação do gradiente de velocidade ótimo

$\left(G^{*}\right)$ em função do período de floculação em papel

bilogarítmico. Mecanismos de adsorção-neutralização

e varredura. Agua Tipo I.

- turbidez inicial: 200 FTU;

- cor verdadeira inicial: $5 \mathrm{mg}$ Pt-Co/l;

- período de sedimentação: 5 min

FIGURA 5.8 - Curvas de variação do gradiente de velocidade ótimo $\left(G^{*}\right)$ em função de $(1 / T)^{n}$ para a Agua Tipo $I$, onde $T$

$\bar{e}$ o período de floculação

- turbidez inicial: 200 FTU;

- cor verdadeira inicial: $5 \mathrm{mg}$ Pt-Co/l;

- período de sedimentacão: 5 min

- dosagens de sulfato de aluminio e pH de coagulação: mecanismo de adsorção-neutralização: $10 \mathrm{mg} / \ell$ e 4,8

- mecanismo de varredura: $60 \mathrm{mg} / \ell$ e $6,55 \ldots \ldots . . . .$. 
FIGURA 5.9 - Curvas de variação do gradiente de velocidade ótimo $\left(G^{*}\right)$ em função do período de floculação em napel bi logaritmico. Modelo de ANDREU-VILLEGAS \& LETTERMAN (04). Agua Tipo 1.

- turbidez inicial 200 FTU;

- cor verdadeira inicial: $5 \mathrm{mg}$ Pt-Co/l;

- periodo de sedimentação: 5 min;

- dosagens de sulfato de aluminio e pH de coagulação: mecanismo de adsorção-neutralização: $10 \mathrm{mg} / \ell$ e 4,8 mecanismo de varredura: $60 \mathrm{mg} / \mathrm{l}$ e $6,55 \ldots \ldots \ldots \ldots . . . . .6$

FIGURA 5.10 - Curvas de variação do gradiente de velocidade $G^{*}$ $\left.G^{\prime}\right)$ em função do período de floculação. Agua Tipo I Modelo proposto.

- turbidez inicial: 200 FTU;

- cor verdadeira inicial: $5 \mathrm{mg} P t-C o / \ell$;

- período de sedimentação: 5 min;

- dosagens de sulfato de aluminio e pH do sobrenadante: mecanismo de adsorção-neutralização:

$10 \mathrm{mg} / \mathrm{l}$ e 4,8

mecanismo de varredura: $60 \mathrm{mg} / \mathrm{l}$ e $6,55 \ldots \ldots \ldots \ldots .10$

FIGURA 5.11 - Curvas de variação da turbidez residual minima em função do período de floculação. Aggua Tipo I.

- turbidez inicial: 200 FTU;

- cor verdadeira inicial: $5 \mathrm{mg}$ Pt-Coll;

- período de sedimentação: 5 min;

- dosagens de sulfato de alumínio e pH do sobrenadante: mecanismo de adsorção-neutralização:

$10 \mathrm{mg} / \mathrm{l}$ e 4,8 mecanismo de varredura: $60 \mathrm{mg} / \ell$ e $6,55 \ldots \ldots \ldots \ldots .11$

FIGURA 5.12 - Variação da percentagem da turbidez inicial que sedimenta em velocidade menor que a estabelecida em função da concentração da solução de estoque de sul bato de aluminio. Agua Tipo I. Mecanismo de adsor ção-neutralização.

- turbidez inicial: 200 FTU;

- cor verdadeira inicial: $5 \mathrm{mg} P t-C o / l$;

- dosagem de sulfato de aluminio: $10 \mathrm{mg} / \ell$;

- pH do sobrenadante: 4,8 
FIGURA 5.13 - Variação da percentagem da turbidez inicial que se dimenta em velocidade menor que a estabelecida em função da concentração da solução de estoque de sulfato de aluminio. Agua Tipo I. Mecanismo de var redura.

- turbidez inicial: 200 FTU;

- cor verdadeira inicial: $5 \mathrm{mg} P t-C o / l$;

- dosagem de sulfato de aluminio: $60 \mathrm{mg} / \mathrm{l}$;

- $n H$ do sobrenadante: 6,55

FIGURA 5.14 - Diagrama de coagulação para a Agua Tipo II - Per centagem da cor aparente remanescente em função da dosagem de sulfato de aluminio e do pH do sobrenadante.

- turbidez inicial: 5 FTU;

- cor verdadeira inicial: $100 \mathrm{mg}$ Pt-Co/l;

- cor aparente inicial: 131,9 mg Pt-Co/l

FIGURA 5.15 - Curvas de variação da cor aparente residual em fun ção do gradiente de velocidade para vārios perío dos de floculação. Agua Tipo II. Mecanismo de ad sorção-neutralização.

- turbidez inicial: 5 FTU;

- cor verdadeira inicial: $100 \mathrm{mg}$ Pt-Co/l;

- cor aparente inicial: 131,9 mg Pt-Co/l;

- dosagem de sulfato de aluminio: $20 \mathrm{mg} / \mathrm{l}$;

- pH do sobrenadante: 4,4;

- período de sedimentação: $10 \mathrm{~min}$

FIGURA 5.16 - Curvas de variação da cor aparente residual em função do gradiente de velocidade para vārios perío dos de floculação. Agua Tipo II. Mecanismo de varredura.

- turbidez inicial: 5 FTU;

- cor verdadeira inicial: $100 \mathrm{mg}$ Pt-Co/l;

- cor aparente inicial: 131,9 mg Pt-Co/l;

- dosagem de sulfato de aluminio: $140 \mathrm{mg} / \mathrm{l}$;

- pH do sobrenadante: 6,15;

- período de sedimentação: $5 \mathrm{~min}$ 
FIGURA 5.17 - Curvas de variação do gradiente de velocidade ōtimo $\left(G^{*}\right)$ em função do período de floculação em pa pel bilogaritmico. Modelo de ANDREU-VILLEGAS \& LETTERMAN (04). Agua Tipo II.

- turbidez inicial: 5 FTU;

- cor verdadeira inicial: $100 \mathrm{mg}$ Pt-Co/l;

- cor aparente inicial: 131,9 mg Pt-Co/l;

- período de sedimentação: $10 \mathrm{~min}$ ladsorção-neutralização) - $5 \mathrm{~min}$ (varredura);

- dosagens de suiffato de aluminio e pH do sobrenadante: mecanismo de adsorção-neutralização:

$20 \mathrm{mg} / \mathrm{l}$ e 4,4

mecanismo de varredura: $140 \mathrm{mg} / \mathrm{l}$ e $6,15 \ldots \ldots \ldots . . .17$

FIGURA 5.18 - Curvas de variação do gradiente de velocidade ōtimo $\left(G^{*}\right)$ em funcão de $(1 / T)^{n}$ para a Agua Tipo II, onde $T \bar{e}$ o período de floculação.

- turbidez inicial: 5 FTU;

- cor verdadeira inicial: $100 \mathrm{mg}$ Pt-Co/l;

- cor aparente inicial: 131,9 mg Pt-Co/l;

- período de sedimentação: 10 min ladsorção-neutralização) - 5 min (varredura);

- dosagens de sulfato de alumínio e pH do sobrenadante: mecanismo de adsorção-neutralização: $20 \mathrm{mg} / \mathrm{l}$ e 4,4 mecanismo de varredura: $140 \mathrm{mg} / \ell$ e 6,15

FIGURA 5.19 - Curvas de variação do gradiente de velocidade $\left(G^{*}-G^{\prime}\right)$ em função do período de bloculação.

Agua Tipo II. Modelo proposto.

- turbidez inicial: 5 FTU;

- cor verdadeira inicial: $100 \mathrm{mg}$ Pt-Co/l;

- cor aparente inicial: 131,9 mg Pt-Co/l;

- período de sedimentação: 10 min ladsorção-neutralização) - 5 min (varredura)

- dosagens de sulfato de aluminio e pH do sobrenadante: mecanismo de adsorção-neutralização: $20 \mathrm{mg} / \mathrm{l}$ e 4,4 mecanismo de varredura: $140 \mathrm{mg} / \ell$ e $6,15 \ldots \ldots \ldots .5 .19$ 
FIGURA 5.20 - Curvas de variação da cor aparente residual minima em função do período de floculação. Agqua Tipo II.

- turbidez inicial: 5 FTU;

- cor verdadeira inicial: $100 \mathrm{mg}$ Pt-Co/l;

- cor aparente inicial: 131,9 mg Pt-Co/l;

- periodo de sedimentação: $10 \mathrm{~min}$ ladsorção-neutralização) - 5 min (varredura);

- dosagens de sulfato de aluminio e pH do sobrenadante: mecanismo de adsorção-neutralização:

$20 \mathrm{mg} / \mathrm{l}: 4,4$

mecanismo de varredura: $140 \mathrm{mg} / \mathrm{l}$ e 6.15

FIGURA 5.21 - Variação da percentagem da cor aparente inicial que sedimenta em velocidade menor que a estabelecida em função da concentração da solução de estoque de sul fato de aluminio. Agua Tipo II. Mecanismo de adsorção-neutralização.

- turbidez inicial: 5 FTU;

- cor verdadeira inicial: $100 \mathrm{mg}$ Pt-Co/l;

- cor aparente inicial: 131,9 mg Pt-Co/l;

- dosagem de sulfato de aluminio: $20 \mathrm{mg} / \mathrm{l}$;

- pH do sobrenadante: 4,4

FIGURA 5.22 - Variação da percentagem da cor aparente inicial que sedimenta em velocidade menor que a estabelecida em função da concentração da solução de estoque de sul fato de aluminio. Agua Tino II. Mecanismo de varredura.

- turbidez inicial: 5 FTU;

- cor verdadeira inicial: $100 \mathrm{mg}$ Pt-Co/l;

- cor aparente inicial: 131,9 mg Pt-Co/l;

- dosagem de sulfato de aluminio: $140 \mathrm{mg} / \ell$;

- nH do sobrenadante: 6,15

FIGURA 5.23 - Diagrama de coagulação para a Agua Tipo III - Per centagem da cor aparente remanescente em função da dosagem de sulfato de aluminio e do $\mathrm{pH}$ do sobrenadante.

- turbidez inicial: 5 FTU;

- cor verdadeira inicial: $5 \mathrm{mg} P t-\mathrm{Co} / \ell$;

- cor anarente inicial: $33,7 \mathrm{mg} P t-C o / l$ 
FIGURA 5.24 - Diagrama de coagulação para a Aggua Tipo III - Per centagem da cor aparente remanescente em função da dosagem de sulfato de aluminio e do $\mathrm{pH}$ do filtrado (biltração em papel (IATMAN 40)

- turbidez inicial: 5 FTU;

- cor verdadeira inicial: $5 \mathrm{mg} P t-C o / \ell$;

- cor aparente inicial: 33,7 mg Pt-Co/l

FIGURA 5.25 - Curvas de variação da turbidez residual em função do gradiente de velocidade para vārios periodos de floculação. Aggua Tipo III. Mecanismo de varreduru.

- turbidez iniical: 5 FTU;

- cor verdadeira inicial: $5 \mathrm{mg}$ Pt-Co/l;

- cor aparente inicial: 33,7 mg Pt-Co/l;

- dosagem de sulfato de aluminio: 17,5 mg/l;

- pH do sobrenadante: 7,30;

- período de sedimentação: $10 \mathrm{~min}$.

FIGURA 5.26 - Curvas de variação da cor aparente residual em função do gradiente de velocidade para värios periodos de floculação. Agua Tino III. Mecanismo de varredura.

- turbidez inicial: 5 FTU;

- cor verdadeira inicial: $5 \mathrm{mg}$ Pt-Co/l;

- cor aparente inicial: 33,7 mg Pt-Coll;

- dosagem de sulfato de aluminio: $17,5 \mathrm{mg} / \mathrm{l}$;

- pH do sobrenadante: 7,30;

- período de sedimentação: $10 \mathrm{~min}$

FIGURA 5.27 - Curva de variação do gradiente de velocidade ótimo $\left(G^{*}\right)$ em função do período de floculação em papel bilogarítmico. Modelo de ANDREU-VILLEGAS \& LETTERMAN (04). Agua Tipo III. Mecanismo de varredura.

- turbidez inicial: 5 FTU;

- cor verdadeira inicial: $5 \mathrm{mg}$ Pt-Co/l;

- cor aparente inicial: 33,7 mg Pt-Co/l;

- período de sedimentação: $10 \mathrm{~min}$;

- dosagem de sulfato de aluminio: $17,5 \mathrm{mg} / \ell$;

- pH do sobrenadante: 7,30 
FIGURA 5.28 - Curva de variação do gradiente de velocidade ōtimo $\left(G^{*}\right)$ em função de $(1 / T)^{n}$ para a Agua Tipo III, onde $T \bar{e}$ o período de floculação. Mecanismo de varredura.

- turbidez inicial: 5 FTU;

- cor verdadeira inicial: $5 \mathrm{mg}$ Pt-Co/l;

- cor aparente inicial: $33,7 \mathrm{mg}$ Pt-Co/l;

- periodo de sedimentação: $10 \mathrm{~min}$;

- dosagem de sulfato de aluminio: $17,5 \mathrm{mg} / \mathrm{l}$;

- pH do sobrenadante: 7,30

FIGURA 5.29 - Curva de variação do gradiente de velocidade $\left(G^{*}-G^{\prime}\right)$ em função do período de floculação. Agua Tipo III. Modelo proposto. Mecanismo de varredura.

- turbidez inicial: 5 FTU;

- cor verdadeira inicial: $5 \mathrm{mg} P t-C o / l$;

- cor aparente inicial: $33,7 \mathrm{mg}$ Pt-Coll;

- periodo de sedimentação: $10 \mathrm{~min}$;

- dosagem de sulfato de aluminio: $17,5 \mathrm{mg} / \ell$;

- pH do sobrenadante: 7,30

FIGURA 5.30 - Curva de variação da turbidez minima em função do perĩodo de floculação. Agua Tipo III. Mecanismo de varredura.

- turbidez inicial: 5 FTU;

- cor verdadeira inicial: $5 \mathrm{mg} P t-C o / l$;

- cor aparente inicial: $33,7 \mathrm{mg} \mathrm{Pt}-\mathrm{Co} / \mathrm{l}$;

- periodo de sedimentação: $10 \mathrm{~min}$;

- dosagem de sulfato de aluminio: $17,5 \mathrm{mg} / \mathrm{l}$;

- pH do sobrenadante: 7,30

FIGURA 5.31 - Curva de variação da cor aparente inicial mínima em função do período de floculação. Agua Tipo III. Mecanismo de varredura.

- turbidez inicial: 5 FTU;

- cor verdadeira inicial: $5 \mathrm{mg} P t-C o / l$;

- cor aparente inicial: 33,7 mg Pt-Co/l;

- periodo de sedimentação: $10 \mathrm{~min}$;

- dosagem de sulfato de aluminio: $17,5 \mathrm{Mg} / \ell$;

- $\mathrm{pH}$ do sobrenadante: 7,30 
FIGURA 5.32 - Variação da percentagem da cor aparente inicial que sedimenta em velocidade menor que a estabelecida em função da concentração da solução de estoque de sul fato de aluminio. Agua Tipo III. Mecanismo de varre dura.

- turbidez inicial: 5 FTU;

- cor verdadeira inicial: $5 \mathrm{mg} P t-C o / l$;

- cor aparente inicial: 33,7 mg Pt-Co/l;

- dosagem de sulfato de aluminio: $17,5 \mathrm{mg} / \mathrm{l}$;

- pH do sobrenadante: 7,30

FIGURA 5.33 - Diagrama de coagulação da Agua Tipo IV - Percenta gem da cor aparente remanescente em função da dosagem de sulfato de aluminio e do pH do sobrenadante.

- turbidez inicial: 50 FTU;

- cor verdadeira inicial: $20 \mathrm{mg}$ Pt-Co/l;

- cor aparente inicial: $340 \mathrm{mg}$ Pt-Co/l.

FIGURA 5.34 - Curvas de variação da cor aparente residual em função do gradiente de velocidade para vārios períodos de floculação. Agua Tipo IV. Mecanismo de adsorçãoneutralização.

- turbidez inicial: 50 FTU;

- cor verdadeira inicial: $20 \mathrm{mg} P t-C o / l$;

- cor aparente inicial: $340 \mathrm{mg} P t-C o / l$;

- dosagem de sulfato de aluminio: $5 \mathrm{mg} / \mathrm{l}$;

- pH do sobrenadante: 5,20;

- período de sedimentação: $10 \mathrm{~min}$

FIGURA 5.35 - Curvas de variação da cor aparente residual em função do gradiente de velocidade para vārios períodos de floculação. Agua Tipo IV. Mecanismo de varredura.

- turbidez inicial: 50 FTU;

- cor verdadeira inicial: $20 \mathrm{mg}$ Pt-Co/l;

- cor aparente inicial: $340 \mathrm{mg}$ Pt-Co/l;

- dosagem de sulfato de aluminio: $35 \mathrm{mg} / \ell$;

- pH do sobrenadante: 6,70;

- período de sedimentacão: $10 \mathrm{~min}$

FIGURA 5.36 - Curvas de variação do gradiente de velocidade ōtimo (G) em função do perĩodo de floculação em papel bilogaritmico. Modelo de ANDREU-VILLEGAS \& LETTERMAN (04). Agua Tipo IV. 
- turbidez inicial: $50 \mathrm{FTU}$;

- cor verdadeira inicial: $20 \mathrm{mg}$ Pt-Co/l;

- cor aparente inicial: $340 \mathrm{mg}$ Pt-Co/l;

- período de sedimentação: $10 \mathrm{~min}$;

- dosagens de sulfato de aluminio e pH do sobrenadante: mecanismo de adsorção-neutralização: $5 \mathrm{mg} / \ell$ e 5,20 mecanismo de varredura: $35 \mathrm{mg} / \ell$ e $6,70 \ldots \ldots \ldots \ldots .3 .36$

FIGURA 5.37 - Curva de variação do gradiente ōtimo $\left(G^{\star}\right)$ em função de $(1 / T)^{n}$ para a Agua Tipo IV, inde $T \bar{e}$ o período de floculação. Mecanismo de adsorção-neutralização.

- turbidez inicial: 50 FTU;

- cor verdadeira inicial: $20 \mathrm{mg}$ Pt-Coll;

- cor aparente inicial: $340 \mathrm{mg}$ Pt-Coll;

- período de sedimentação: $10 \mathrm{~min}$;

- dosagem de sulfato de aluminio: $5 \mathrm{mg} / \mathrm{l}$;

- pH do sobrenadante: 5,20

FIGURA 5.38 - Curva de variação do aradiente de velocidade ótimo $\left(G^{*}\right)$ em função de $(1 / T)^{n}$ para a Ãgua Tipo IV, onde

$T \bar{e}$ o período de floculação. Mecanismo de varredura.

- turbidez inicial: $50 \mathrm{FTU}$;

- cor verdadeira inicial: $20 \mathrm{mg}$ Pt-Coll;

- cor aparente inicial: $340 \mathrm{mg} P t-C o / l$;

- periodo de sedimentação: $10 \mathrm{~min}$;

- dosagem de sulfato de aluminio: $35 \mathrm{mg} / \ell$;

- pH do sobrenadante: 6,70 5.38

FIGURA 5.39 - Curvas de variação do gradiente de velocidade $\left(G^{*}-G^{\prime}\right)$ em função do período de floculação.

Agua Tipo IV. Modelo proposto.

- turbidez inicial: $50 \mathrm{FTU}$;

- cor verdadeira inicial: $20 \mathrm{mg}$ Pt-Co/l;

- cor aparente inicial: $340 \mathrm{mg} P t-C o / l$;

- período de sedimentação: $10 \mathrm{~min}$;

- dosagens de sulfato de aluminio e pH do sobrenadante: mecanismo de adsorção-neutralização: $5 \mathrm{mg} / \mathrm{l}$ e 5,20 mecanismo de varredura: $35 \mathrm{mg} / \mathrm{l}$ e 6,70 
FIGURA 5.40 - Curva de variação da cor aparente residual minima em função do perĩodo de floculação. Agua Tipo IV. Mecanismo de adsorção-neutralização.

- turbidez inicial: 50 FTU;

- cor verdadeira inicial: $20 \mathrm{mg}$ Pt-Co/l;

- cor aparente inicial: $340 \mathrm{mg}$ Pt-Co/l;

- periodo de sedimentação: $10 \mathrm{~min}$;

- dosagem de sulfato de aluminio: $5 \mathrm{mg} / \mathrm{l}$;

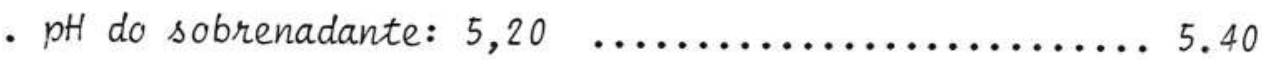

FIGURA 5.41 - Curva de variação da cor aparente residual minima em função do período de floculação. Agua Tipo IV. Mecanismo de varredura.

- turbidez inicial: 50 FTU;

- cor verdadeira inicial: $20 \mathrm{mg}$ Pt-Co/l;

- cor aparente inicial: $340 \mathrm{mg}$ Pt-Co/l;

- período de sedimentação: 10 min;

- dosagem do sulfato de aluminio: $35 \mathrm{mg} / \ell$;

- pH do sobrenadante: $6,70 \ldots \ldots \ldots \ldots \ldots . . .6 .41$

FIGURA 5.42 - Variação da percentagem da cor aparente inicial que sedimenta em velocidade menor que a estabelecida em função da concetração da solução de estoque de sulfato de aluminio. Agua Tipo IV. Mecanis mo de adsorção-neutralização.

- turbidez inicial: 50 FTU;

- cor verdadeira inicial: $20 \mathrm{mg}$ Pt-Co/l;

- cor aparente inicial: $340 \mathrm{mg}$ Pt-Co/l;

- dosagem de sulfato de aluminio: $5 \mathrm{mg} / \ell$;

- pH do sobrenadante: 5,20 5.42

FIGURA 5.43 - Variação da percentagem de cor aparente inicial que sedimenta em velocidade menor que a estabelecida em função da concentração da solução de estoque de sulfato de aluminio. Agua Tipo IV. Mecanismo de varredura.

- turbidez inicial: 50 FTU;

- cor verdadeira inicial: $20 \mathrm{mg}$ Pt-Co/l;

- cor aparente inicial: $340 \mathrm{mg}$ Pt-Co/l;

- dosagem de sulfado de aluminio: $35 \mathrm{mg} / \mathrm{l}$;

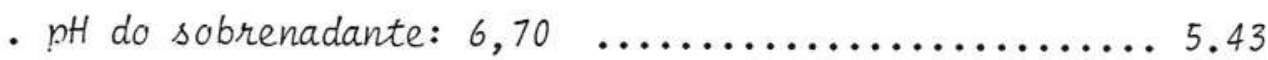


FIGURA 5.44 - Diagrama de coagulacão da Agua Tipo V - Percentagem da cor aparente remanescente em função da dosagem de sulfato de aluminio $e$ do $\mathrm{pH}$ do sobrenadante.

- turbidez inicial: 200 FTU;

- cor verdadeira inicial: $100 \mathrm{mg}$ Pt-Co/l;

- cor aparente inicial: $1064 \mathrm{mg}$ Pt-Co/l ............5.44

FIGURA 5.45 - Curvas de variação da cor aparente residual em função do gradiente de velocidade para värios períodos de floculação. Agua Tipo V. Mecanismo de adsorçãoneutralização.

- turbidez inicial: 200 FTU;

- cor verdadeira inicial: $100 \mathrm{mg}$ Pt-Coll;

- cor aparente inicial: $1064 \mathrm{mg}$ Pt-Co/l;

- dosagem de sulfato de aluminio: $10 \mathrm{mg} / \mathrm{l}$;

- pH do sobrenadante: 5,25;

- período de sedimentação: $10 \mathrm{~min} \ldots \ldots \ldots \ldots \ldots . . \ldots .45$

FIGURA 5.46 - Curvas de variação da cor aparente residual em função do gradiente de velocidade para värios períodos de floculação. Agua Tipo V. Mecanismo de varredura.

- turbidez inicial: 200 FTU;

- cor verdadeira inicial: $100 \mathrm{mg}$ Pt-Co/l;

- cor aparente inicial: $1064 \mathrm{mg}$ Pt-Co/l;

- dosagem do sulfato de alumínio: $60 \mathrm{mg} / \ell$;

- pH do sobrenadante: 7,20;

- período de sedimentação: $5 \mathrm{~min}$ 5.46

FIGURA 5.47 - Curvas de variação do gradiente de velocidade ōtimo (G) em função do perĩodo de floculação em papel bilogaritmico. Modelo de ANDREU-VILLEGAS \& LETTERMAN (04). Agua Tipo V.

- turbidez inicial: 200 FTU;

- cor verdadeira inicial: $100 \mathrm{mg}$ Pt-Co/l;

- cor aparente inicial: $1064 \mathrm{mg}$ Pt-Co/l;

- período de sedimentação: 5 min ladsorção - neutralização) $10 \mathrm{~min}$ (varredura);

- dosagens de sulfato de aluminio e pH do sobrenadante: mecanismo de adsorção-neutralização:

$10 \mathrm{mg} / \mathrm{l}$ e 5,25 - mecanismo de varredura:

$60 \mathrm{mg} / \mathrm{l}$ e 7,20 
FIGURA 5.48 - Curva de variação do gradiente de velocidade ótimo $\left(G^{*}\right)$ em funcão de $(1 / T)^{n}$ para a Agua Tipo $V$, onde $T \bar{e} o$ perīodo de floculação. Mecanismo de adsorçãoneutralização.

- turbidez inicial: 200 FTU;

- cor verdadeira inicial: $100 \mathrm{mg}$ Pt-Co/l;

- cor aparente inicial: $1064 \mathrm{mg}$ Pt-Co/l;

- periodo de sedimentação: $10 \mathrm{~min}$;

- dosagem de sulfato de aluminio: $10 \mathrm{mg} / \mathrm{l}$;

- pH do sobrenadante: 5,25

FIGURA 5.49 - Curva de variação do gradiente de velocidade $\left(G^{\star}\right)$ em função de $(1 / T)^{n}$ para a Agua Tipo $V$, onde $T \bar{e}$

- período de floculação. Mecanismo de varredura.

- turbidez inicial: 200 FTU;

- cor verdadeira inicial: $100 \mathrm{mg}$ Pt-Co/l;

- cor aparente inicial: $1064 \mathrm{mg}$ Pt-Coll;

- período de sedimentação: 5 min;

- dosagem de sulfato de aluminio: $60 \mathrm{mg} / \mathrm{l}$;

- pH do sobrenadante: 7,20 5.49

FIGURA 5.50 - Curvas de variação do gradiente de velocidade $\left(G^{*}-G^{\prime}\right)$ em função do período de floculação.

Agua Tipo V. Modelo proposto.

- turbidez inicial: 200 FTU;

- cor verdadeira inicial: $100 \mathrm{mg}$ Pt-Co/l;

- cor aparente inicial: $1064 \mathrm{mg}$ Pt-Co/l;

- perĩodo de sedimentação: 5 min ladsorçãoneutralização) 10 min (varredura);

- dosagens de sulfato de aluminio e pH do sobrenadante: mecanismo de adsorção-neutralização: $10 \mathrm{mg} / \ell$ e 5,25 - mecanosmo de varredura: $60 \mathrm{mg} / \mathrm{l}$ e 7,20 5.50

FIGURA 5.51 - Curva de variação da cor aparente residual minima em função do período de floculação. Aggua Tipo V. Mecanismo de adsorção-neutralização.

- turbidez inicial: 200 FTU;

- cor verdadeira inicial: $100 \mathrm{mg}$ Pt-Co/l;

- cor aparente inicial: $1064 \mathrm{mg}$ Pt-Co/l;

- período de sedimentação: $10 \mathrm{~min}$; 
- dosagem de sulfato de aluminio: $10 \mathrm{mg} / \mathrm{l}$;

- nt! do sobrenadante: 5,25

FIGURA 5.52 - Curva de variação da cor aparente residual minima em kuncão do período de floculação. Agua Tipo V. Mecanismo de varredura.

- turbidez inicial: 200 FTU;

- cor verdadeira inicial: $100 \mathrm{mg}$ Pt-Co/l;

- cor aparente inicial: $1064 \mathrm{mg}$ Pt-Co/l-;

- período de sedimentação: 5 min;

- dosagem de sulfato de aluminio: $60 \mathrm{mg} / \mathrm{l}$;

- pH do sobrenadante: 7,20

FIGURA 5.53 - Variação da percentagem da cor aparente inicial que sedimenta em velocidade menor que a estabelecida em função da concentração da solução de estoque de sulfato de aluminio. Agua Tipo V. Mecanismo de adsorção-neutralização.

- turbidez inicial: 200 FTU;

- cor verdadeira inicial: $100 \mathrm{mg}$ Pt-Co/l;

- cor aparente inicial: $1064 \mathrm{mg}$ Pt-Co/l;

- dosagem de sulfato de aluminio: $10 \mathrm{mg} / \mathrm{l}$;

- pH do sobrenadsnte: 5,25

FIGURA 5.54 - Variação da percentagem da cor aparente inicial em que sedimenta em velocidade menor que a estabelecida em função da concentração da solução de estoque de sulfato de aluminio. Agua Tipo V. Mecanismo de varredura.

- turbidez inicial: 200 FTU;

- cor verdadeira inicial: $100 \mathrm{mg}$ Pt-Co/l;

- cor aparente inicial: $1064 \mathrm{mg}$ Pt-Co/l;

- dosagem de sulfato de aluminio: $60 \mathrm{mg} / \ell$;

- pH do sobrenadante: 7,20 5.54

FIGURA 5.55 - Diagrama de coagulação da Agua Tipo VI. Percentagem da turbidez remanescente em função da dosagem de sulfato de aluminio e do pH do sobrenadante.

- turbidez inicial: 160 FTU;

- cor verdadeira inicial: $30 \mathrm{mg}$ Pt-Coll;

- cor aparente inicial: $1300 \mathrm{mg}$ Pt-Coll 
FIGURA 5.56 - Curvas de variação da turbidez residual em função do gradiente de velocidade para värios perĩodos de floculação. Aggua Típo VI. Mecanismo de varredura.

- turbidez inicial: 160 FTU;

- cor verdadeira inicial: $30 \mathrm{mg} P t-C o / l$;

- cor aparente inicial: $1300 \mathrm{mg}$ Pt-Co/l;

- dosagem de sulfato de aluminio: $50 \mathrm{mg} / \mathrm{l}$;

- pH do sobrenadante: 6,55;

- período de sedimentacão: $10 \mathrm{~min}$..............5.56

FIGURA 5.57 - Curva de variação do gradiente de velocidade ótimo $\left(G^{*}\right)$ em função de $(1 / T)^{n}$ para a Ãgua Tipo VI, onde $T \bar{e}$ o período de floculação. Mecanismo de varredura.

- turbidez inicial: 160 FTU;

- cor verdadeira inicial: $30 \mathrm{mg}$ Pt-Co/l;

- cor aparente inicial: $1300 \mathrm{mg}$ Pt-Co/l;

- período de sedimentação: $10 \mathrm{~min}$;

- dosagem de sulfato de aluminio: $50 \mathrm{mg} / \mathrm{l}$;

- pH do sobrenadante: 6,55

FIGURA 5.58 - Curva de variação do gradiente de velocidade $\left(G^{*}-G^{\prime}\right)$ em função do período de floculação. Agua Tipo VI. Modelo proposto. Mecanismo de varredura.

- turbidez inicial: 160 FTU;

- cor verdadeira inicial: $30 \mathrm{mg} P t-C o / l$;

- cor aparente inicial: $1300 \mathrm{mg} P t-C o / l$;

- periodo de sedimentação: $10 \mathrm{~min}$;

- dosagem de sulfato de alumínio: $50 \mathrm{mg} / \mathrm{l}$;

- pH do sobrenadante: 6,55 ....................5.58

FIGURA 5.59 - Curva de variação da cor aparente residual minima em função do período de floculação. Aggua Tipo VI. Mecanismo de varredura.

- turbidez inicial: 160 FTU;

- cor verdadeira inicial: $30 \mathrm{mg}$ Pt-Coll;

- cor aparente inicial: $1300 \mathrm{mg}$ Pt-Co/l;

- período de sedimentação: $10 \mathrm{~min}$;

- dosagem de sulfato de alumínio: $50 \mathrm{mg} / \mathrm{l}$;

- pH do sobrenadante: 6,55 
FIGURA 5.60 - Diagrama de coagulação da Agua Tipo VII. Percentagem da cor aparente remanescente em função da dosagem de sulfato de aluminio e do $\mathrm{pH}$ do sobrenadante.

- turbidez inicial: 8,9 FTU;

- cor verdadeira inicial: 18,7 mg Pt-Co/l;

- cor aparente inicial: 58,7 mg Pt-Co/l. 5.60

FIGURA 5.61 - Curvas de variação da cor aparente residual em função do gradiente de velocidade para värios períodos de floculação. Aggua Tipo VII. Mecanismo de adsorção-neutralização.

- turbidez inicial: 8,9 FTU;

- cor verdadeira inicial: 18,7 mg Pt-Co/l;

- cor aparente inicial: 58,7 mg Pt-Co/l;

- dosagem de sulfato de aluminio: $6,0 \mathrm{mg} / \ell$;

- pH do sobrenadante: 4,35;

- período de sedimentação: $10 \mathrm{~min}$................ 5.61

FIGURA 5.62 - Curvas de variação da cor aparente residual em função do gradiente de velocidade para vārios períodos de floculação. Agua Tipo VII. Mecanismo de varredura.

- turbidez inicial: 8,9 FTL;

- cor verdadeira inicial: $18,7 \mathrm{mg}$ Pt-Co/l;

- cor aparente inicial: 58,7 mg Pt-Co/l;

- dosagem de sulfato de alumínio: $25 \mathrm{mg} / \ell$;

- pH do sobrenadante: 6,75;

- periodo de sedimentação: $10 \mathrm{~min}$ 5.62

FIGURA 5.63 - Curva de variação do gradiente de velocidade ótimo $\left(G^{*}\right)$ em função do período de floculação em papel bilogarítmico. Modelo de ANDRELI-VILLEGAS \& LETTERMAN (04). Agua Tipo VII. Mecanismo

- de varredura.

- turbidez inicial: 8,9 FTU;

- cor verdadeira inicial: 18,7 mg Pt-Co/l;

- cor aparente inicial: 58,7 mg Pt-Co/l;

- dosagem de sulfato de aluminio: $25 \mathrm{mg} / \ell$;

- pH do sobrenadante: 6,75;

- período de sedimentação: $10 \mathrm{~min}$ 
FIGURA 5.64 - Curva de variação do gradiente de velocidade ōtimo $\left(G^{\star}\right)$ em função de $(1 / T)^{n}$ para a Agua Tipo VII, onde $T \bar{e}$ o período de floculação. Mecanismo de ad sorção-neutralização.

- turbidez inicial: 8,9 FTU;

- cor verdadeira inicial: $18,7 \mathrm{mg} P t-C o / \ell$;

- cor aparente inicial: $58,7 \mathrm{mg} P t-C o / \ell$;

- dosagem de sulfato de aluminio: $6 \mathrm{mg} / \ell$;

- pH do sobrenadante: 4,35;

- periodo de sedimentação: $10 \mathrm{~min}$............... 5.64

FIGURA 5.65 - Curva de variação do gradiente de velocidade $\left(G^{*}\right)$ em função de $(1 / T)^{n}$ para a Agua Tipo VII, onde $T \bar{e}$ o período de floculacão. Mecanismo de varredura.

- turbidez inicial: 8,9 FTU;

- cor verdadeira inicial: $18,7 \mathrm{mg} P t-C o / \ell$;

- cor aparente inicial: $58,7 \mathrm{mg} P t-C o / l$;

- dosagem de sulfato de aluminio: $25 \mathrm{mg} / \ell$;

- pH do sobrenadante: 6,75;

- periodo de sedimentação: $10 \mathrm{~min}$ 5.65

FIGURA 5.66 - Curva de variação do gradiente de velocidade $\left(G^{*}-G^{\prime}\right)$ em função do período de floculação.

Agua Tipo VII. Mecanismo de adsorção-neutralização. Modelo proposto.

- turbidez inicial: 8,9 FTU;

- cor verdadeira inicial: $18,7 \mathrm{mg} P t-C o / \ell$;

- cor aparente inicial: 58,7 mg Pt-Co/l;

- dosagem de sulfato de aluminio: $6 \mathrm{mg} / \ell$;

- pH do sobrenadante: 4,35;

- período de sedimentação: $10 \mathrm{~min}$

FIGURA 5.67 - Curva de variação do gradiente de velocidade

- $\left(G^{*}-G^{\prime}\right)$ em função do período de floculação. Agua Tipo VII. Mecanismo de varredura. Modelo proposto.

- turbidez inicial: 8,9 FTU;

- cor verdadeira inicial: $18,7 \mathrm{mg} P t-C o / l$;

- cor aparente inicial: 58,7 mg Pt-Co/l;

- dosagem de sulfato de aluminio: $25 \mathrm{mg} / \ell$; 
- pH do sobrenadante: 6,75;

- periodo de sedimentação: $10 \mathrm{~min}$

FIGURA 5.68 - Curva de variação da cor aparente residual mînima em função do perĩodo de floculação. Agua Tipo VII. Mecanismo de adsorção-neutralização.

- turbidez inicial: 8,9 FTU;

- cor verdadeira inicial: $18,7 \mathrm{mg} P t-C o / \ell$;

- cor aparente inicial: $58.7 \mathrm{mg} P t-C o / l$;

- dosagem de sulfato de aluminio: $6 \mathrm{mg} / \ell$;

- pH do sobrenadante: 4,35;

- período de sedimentação: $10 \mathrm{~min}$ 5.68

FIGURA 5.69 - Curva de variação da cor aparente residual mínima em função do período de floculação. Agua Tipo VII. Mecanismo de varredura.

- turbidez inicial: 8,9 FTU;

- cor verdadeira inicial: $18,7 \mathrm{mg} P t-C o / l$;

- cor aparente inicial: 58,7 mg Pt-Co/l;

- dosagem de sulfato de aluminio: $25 \mathrm{mg} / \ell$;

- pH do sobrenadante: 6,75;

- período de sedimentação: $10 \mathrm{~min}$ 5.69

FIGURA 5.70 - Diagrama de coagulação da Agua Tipo VIII. Percentagem da cor aparente remanescente em função da dosagem de sulfato de aluminio e do pH do sobrenadante.

- turbidez inicial: 6,2 FTU;

- cor verdadeira inicial: 56,1 mg Pt-Co/l;

- cor aparente inicial: 83,1 mg Pt-Co/l;

- período de sedimentação: $10 \mathrm{~min}$ 5.70

FIGURA 5.71 - Curvas de variação da cor aparente residual em função do gradiente de velocidade para värios períodos de floculação. Agua Tipo VIII. Meca-

- nismo de adsorção-neutralização.

- turbidez inicial: 6,2 FTU;

- cor verdadeira inicial: 56,1 mg Pt-Co/l;

- cor aparente inicial: 83,1 mg Pt-Co/l;

- período de sedimentação: $10 \mathrm{~min}$;

- dosagem de sulfato de aluminio: $10 \mathrm{mg} / \ell$;

- pH do sobrenadante: 4,50 
FIGURA 5.72 - Curvas de variação da cor aparente residual em função do gradiente de velocidade para värios periodos de floculação. Agua Tipo VIII. Mecanismo de varredu ra.

- turbidez inicial: 6,2 FTU;

- cor verdadeira inicial: 56,1 mg Pt-Co/l;

- cor aparente inicial: 83,1 mg Pt-Co/l;

- período de sedimentacão: $10 \mathrm{~min}$;

- dosagem de sulfato de aluminio: $25 \mathrm{mg} / \mathrm{l}$;

- pH do sobrenadante: 6,85

FIGURA 5.73 - Curva de variação do gradiente de velocidade ötimo $\left(G^{*}\right)$ em função $(1 / T)^{n}$ para a Agua Tipo VIII, onde $T \bar{e}$ o período de floculação. Mecanismo de adsorçãoneutralização.

- turbidez inicial: 6,2 FTU;

- cor verdadeira inicial: 56,1 mg Pt-Co/l;

- cor aparente inicial: 83,1 mg Pt-Co/l;

- período de sedimentação: $10 \mathrm{~min}$;

- dosagem do sulfato de aluminio: $10 \mathrm{mg} / \ell$;

- pH do sobrenadante: 4,50

FIGURA 5.74 - Curva de variação do gradiente de velocidade ótimo $\left(G^{\star}\right)$ em função de $(1 / T)^{n}$ para a Agua Tipo VIII, onde $T \bar{e} o$ período de floculação. Mecanismo de varredura.

- turbidez inicial: 6,2 FTU;

- cor verdadeira inicial: 56,1 mg Pt-Co/l;

- cor aparente inicial: 83,1 mg Pt-Co/l;

- período de sedimentação: $10 \mathrm{~min}$;

- dosagem de sulfato de aluminio: $25 \mathrm{mg} / \ell$;

- pH do sobrenadante: 6,85 5.74

FIGURA 5.75 - Curva de variação do gradiente de velocidade

- $\left(G^{\star}-G^{\prime}\right)$ em função do período de floculação.

Agua Tipo VIII. Mecanismo de adsorção-neutra-

lização. Modelo proposto.

- turbidez inicial: 6,2 FTU;

- cor verdadeira inicial: 56,1 mg Pt-Co/l;

- cor aparente inicial: 83,1 mg Pt-Co/l;

- período de sedimentação: $10 \mathrm{~min}$; 
- dosagem de sulfato de aluminio: $10 \mathrm{mg} / \mathrm{l}$;

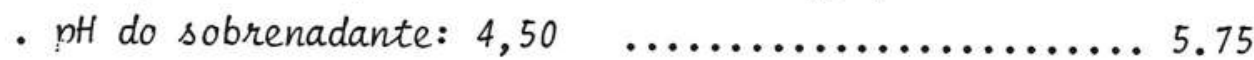

FIGURA 5.76 - Curva de variação do gradiente de velocidade $\left(G^{*}-G^{\prime}\right)$ em função do período de bloculação.

Agua Tipo VIII. Mecanismo de varredura. Mode-

lo proposto.

- turbidez inicial: 6,2 FTU;

- cor verdadeira inicial: 56,1 mg Pt-Co/l;

- cor aparente inicial: 83,1 mg Pt-Co/l;

- período de sedimentação: $10 \mathrm{~min}$;

- dosagem do sulfato de aluminio: $25 \mathrm{mg} / \mathrm{l}$;

- pH do sobrenadante: $6,85 \quad \ldots \ldots \ldots \ldots \ldots \ldots . . \ldots .76$

FIGURA 5.77 - Curva de variação da cor aparente residual minima em função do período de floculação. Aggua

Tipo VIII. Mecanismo de adsorção-neutralização.

- turbidez inicial: 6,2 FTU;

- cor verdadeira inicial: 56,1 mg Pt-Co/l;

- cor aparente inicial: 83,1 mg Pt-Co/l;

- dosagem de sulfato de alumínio: $10 \mathrm{mg} / \ell$;

- pH do sobrenadante: 4,50;

- período de sedimentação: $10 \mathrm{~min}$

FIGURA 5.78 - Curva de variação da cor aparente residual mínima em função do período de floculação. Água

Tipo VIII. Mecanismo de varredura.

- turbidez inicial: 6,2 FTU;

- cor verdadeira inicial: 56,1 ma Pt-Co/l;

- cor aparente inicial: 83,1 mg Pt-Co/l;

- dosagem de sulfato de aluminio: $25 \mathrm{mg} / \mathrm{l}$;

- pH do sobrenadante: 6,85;

- período de sedimentação: $10 \mathrm{~min}$ 5.78

FIGURA 5.79 - Diagrama de coagulação da Agua Tipo IX. Percenta

- gem da cor aparente remanescente em função da do sagem de sulfato de aluminio $e$ do $\mathrm{pH}$ do sobrenadante.

- turbidez inicial: $30 \mathrm{FTU}$;

- cor verdadeira inicial: 47,2 mg Pt-Co/l;

- cor aparente inicial: 188,9 mg Pt-Co/l;

- período de sedimentação: $10 \mathrm{~min}$..............5.79 
FIGURA 5.80 - Curvas de variação da cor aparente residual em função do gradiente de velocidade para värios períodos de floculação. Agua Tipo IX. Mecanismo de varredura.

- turbidez inicial: $30 \mathrm{FTU}$;

- cor verdadeira inicial: 47,2 mg Pt-Co/l;

- cor aparente inicial: $188,9 \mathrm{mg} \mathrm{Pt}-\mathrm{Co} / \mathrm{l}$;

- período de sedimentação: $10 \mathrm{~min}$;

- dosagem de sulfato de aluminio: $25 \mathrm{mg} / \mathrm{l}$;

- pH do sobrenadante: 6,40

FIGURA 5.81 - Curva de variação do gradiente de velocidade ötimo $\left(G^{*}\right)$ em função de $(1 / T)^{n}$ para a Agua Tipo IX, onde

$\bar{e}$ o período de floculação. Mecanismo de varredura.

- turbidez inicial: $30 \mathrm{FTU}$;

- cor verdadeira inicial: 47,2 mg Pt-Co/l;

- cor aparente inicial: $188,9 \mathrm{mg} \mathrm{Pt}-\mathrm{Co} / \mathrm{l}$;

- dosagem de sulfato de aluminio: $25 \mathrm{mg} / \ell$;

- pH do sobrenadante: 6,40;

- período de sedimentação: $10 \mathrm{~min}$ 5.81

FIGURA 5.82 - Curva de variação do gradiente de velocidade $G^{*}$ $\left.G^{\prime}\right)$ em função do período de floculação. Agua Tipo IX. Mecanismo de varredura.

- turbidez inicial: 30 FTU;

- cor verdadeira inicial: 47,2 ma Pt-Co/l;

- cor aparente inicial: $188,9 \mathrm{mg} P t-C o / l$;

- dosagem de sulfato de aluminio: $25 \mathrm{mg} / \ell$;

- pH do sobrenadante: 6,40;

- periodo de sedimentação: $10 \mathrm{~min}$ 5.82

FIGURA 5.83 - Curva de variação da cor aparente residual mínima em função do período de floculação. Agua

Tipo IX. Mecanismo de varredura.

- turbidez inicial: 30 FTU;

- .. cor verdadeira inicial: 47,2 mg Pt-Co/l;

- cor aparente inicial: $188,9 \mathrm{mg} P t-C o / l$;

- dosagem de sulfato de aluminio: $25 \mathrm{mg} / \ell$;

- pH do sobrenadante: 6,40;

- período de sedimentação: $10 \mathrm{~min}$ 
FIGURA 5.84 - Diagrama de coagulação da Agua Tipo X. Percentagem da turbidez remanescente em função da dosagem de sulfato de aluminio e do $\mathrm{pH}$ do sobrenadante.

- turbidez inicial: 300 FTU;

- cor verdadeira inicial: 105,9 mg Pt-Co/l;

- cor aparente inicial: valor não determinado (transmitância igual a zero);

- período de sedimentação: $10 \mathrm{~min}$..............5.84

FIGURA 5.85 - Curvas de variação da turbidez residual em função do gradiente de velocidade de velocidade de vārios períodos de floculação. Agua Tipo X. Mecanismo de varredura.

- turbidez inicial: 300 FTU;

- cor verdadeira inicial: 105,9 mg Pt-Co/l;

- cor aparente inicial: valor não determinado (transmitância igual a zero);

- dosagem de sulfato de aluminio: $50 \mathrm{mg} / \ell$;

- $p H$ do sobrenadante: 6,80;

- período de sedimentação: 5 min 5.85

FIGURA 5.86 - Curva de variação do gradiente de velocidade ötimo $\left(G^{*}\right)$ em função de $(1 / T)^{n}$ para a Agua Tipo $X$, onde $T \bar{e}$ o período de floculação. Mecanismo de varredura.

- turbidez inicial: 300 FTU;

- cor verdadeira inicial: 105,9 mg Pt-Co/l;

- cor aparente inicial: valor não determinado (transmitância igual a zero);

- dosagem de sulfato de aluminio: $50 \mathrm{mg} / \ell$;

- pH do sobrenadante: 6,80;

- período de sedimentação: 5 min 5.86

FIGURA 5.87 - Curva de variação do gradiente de velocidade

- $\left(G^{*}-G^{\prime}\right)$ em função do período de floculação. Agua Tipo X. Mecanismo de varredura.

- turbidez inicial: 300 FTU;

- cor verdadeira inicial: 105,9 mg Pt-Co/l;

- cor aparente inicial: valor não determinado (transmitância igual a zero); 
- dosagem de sulfato de aluminio: $50 \mathrm{mg} / \ell$;

- pH do sobrenadante: 6,80;

- periodo de sedimentação: $5 \mathrm{~min}$

FIGURA 5.88 - Curva de variação da turbidez residual mïnima em função do período de floculação.

Igua Tipo X. Macanismo de varredura.

- turbidez inicial: 300 FTU;

- cor verdadeira inicial: $105,9 \mathrm{mg}$ Pt-Co/l;

- cor aparente inicial: valor não determinado (transmitancia igual a zero);

- dosagem de sulfato de aliminio: $50 \mathrm{mg} / \ell$;

- pH do sobrenadante: 6,80;

- período de sedimentação: $5 \mathrm{~min}$ 5.88 
1. INTRODUÇÃO

A busca incessante de novas tecnologias e o aperfeiçoamento das existentes $\bar{e}$ meta constante da raça humana em todos os campos de $\underline{a}$ plicação da ciência.

No campo das técnicas empregadas para o tratamento de āguas para abastecimento püblico, grandes avanços têm sido obtidos paralela mente com a deteriorização contínua da qualidade das āguas naturais de superficie e a manifestação de entidades sociais frente aos crescentes problemas de poluição ambiental.

A coagulação é considerada a mais importante dentre as ope rações normalmente utilizadas em uma Estação de Tratamento de Agua (ETA), $j \bar{a}$ que as etapas subsequentes (floculação, sedimentação ou flotação, fil tração e desinfecçãol dependem fundamentalmente de seu desempenho.

Inümeros estudos têm sido feitos para correlacionar a dosa gem de produtos químicos coagulantes e alcalinizantes com as caracterís ticas físico-químicas das āguas brutas encontradas em mananciais de su perfície, e, apesar dos esforcos, ainda é imprevisīvel a determinação da dosagem e pH ötimos de coagulação conhecendo-se apenas as caracteristicas iniciais de uma certa ägua a ser tratada.

Tais estudos, aprofundaram o conhecimento a respeito dos possiveis mecanismos de coagulação, tendo-se criado teorias elucidati vas sobre a provāvel ação dos agentes desestabilizantes sobre as parti culas coloidais, e fundamentado que a coagulação depende de inūmeros fa tores, destacando-se: tipo e dosagem de coagulante; características e concentração de partículas coloidais; pH de coagulação; tipo e concen tração de ions em solução; temperatura e intensidade e período de agita ção na mistura rāpida de produtos químicos com a āgua bruta. Tendo - se um nümero tão grande de variāveis a dominar, compreende-se que a obten ção das condições ōtimas de coagulação são difieceis de serem expressas atravēs de uma equação matemātica generalizada para qualquer tipo de $\bar{a}-$ gua encontrada 'na natureza. 
Manifesta-se no presente estudo, a evolução do conhecimento re tratado na literatura especializada sobre a coagulação, principalmente com o uso de sais de aluminio, além de uma extensa pesquisa experimental desse processo com diversos tipos de äguas artificiais e naturais, construindo - se diagramas de coagulação onde $\bar{e}$ possivvel visualizar-se os mecanismos de atuação das espécies de sulfato de aluminio presentes, as dosagens ōtimas $e$ os valores de pH ötimos para cada tipo de āgua ensaiado.

A floculação, etapa normalmente subsequente à coagulação, exce to em sistemas de filtração direta empregados quando a āgua bruta manifes ta-se com baixos valores de cor e/ou turbidez, constitui-se em um processo excencialmente físico, onde as partïculas coloidais prèsentes na āgua bru ta ou adicionadas, desestabilizadas ou não, chocam-se entre si, impulsiona das pela introdução e/ou dissipação de energia cinētica, potencial ou tēr mica das moléculas de āgua (movimento BROWNIANO), gerando compostos flocu lentos capazes de serem removidos nas etapas de tratamento subsequentes, $\underline{e}$ liminando-se aspectos indesejāveis, estēticos ou sanitāios à āgua tratada.

Inümeros estudos têm contribuido para a compreensão da flocula çäo, tendo sido relacionados como fatores influentes ao processo, a inten sidade de agitacão do fluido Imanifestada pelo parâmetro "gradiente de ve locidade $\left.(G)^{\prime \prime}\right)$, o perīodo de floculaçāo $(T)$, a temperatura, a geometria do equipamento e reator de floculação, além do tipo e concentração de coagu lante e particulas coloidais e do $\mathrm{pH}$ de coagulação.

Descobriu-se que, fixadas as condiçōes de coagulação, existe um tamanho limite para o crescimento dos ólocos, contrabalanceado pelas ta $x$ as de agregação e erosão das partículas numa dada intensidade de agitação. Como a eficiência de remoção das partículas por sedimentação $\bar{e}$ diretamente proporcional ao tamanho dọs flocos criados, conclui-se que esta dependa do gradiente de velocidade médio do fluido e do período de formação dos flo cos.

- ARGAMAN \& KALFMAN (8) concluíram que existe um único gradiente de velocidade que maximiza a eficiência de remoção das partículas floculen tas por sedimentação para cada perĩodo de floculação e que perante gradien tes de velocidade ótimos, o aumento do período de floculação proporciona o aumento da eficiência.

ANDREU-VILLEGAS \& LETTERMAN (4) correlacionaram os pares de va lores $G^{*}$ e $T$ que maximizam a eficiência de remoção de partículas por sedí 
mentação através de uma equação do tipo $G^{*^{n}} \cdot T=K$, onde $K \bar{e}$ uma constante para cada tipo de āgua $e$ dosagem de coagulante e $n \bar{e}$ um nūmero positivo. A anālise dessa equação indica que com o aumento do perïodo de floculacão ocorre a diminuicão do gradiente de velocidade ötimo $\left(G^{\star}\right)$ e que quando $T$ tende ao infinito, $G^{*}$ tende a zero.

0 estudo experimental da floculação dos diversos tipos de $\bar{a}$ guas investigados, forneceu subsideos para a proposição de uma equação que melhor representa os parâmetros ötimos de floculação que a proposta por ANDREU-VILLEGAS \& LETTERMAN. Descobriu-se que, para qualquer tipo de água, existe um gradiente de velocidade minimo (G'), que permite o aumento da eficiência de remoção de cor elou turbidez por sedimentacão, indefinidamente, com 0 aumento do perīodo de floculação. Em outras palauras, quan do $T$ tende ao infinito, $G^{*}$ tende para o valor de $G^{\prime}$. Assim sendo, propôs-se a seguinte expressão em substituição a de ANDREU-VILLEGAS \& LETTERMAN $\left(G^{*}-G^{\prime}\right)^{n} \cdot T=K$, e uma metodologia para a determinação experimental de $G^{\prime}$. 


\section{OBJETIVOS}

Os objetivos do presente trabalho são:

a) Projetar, construir e calibrar um aparelho de floculação ti po "Jar-Test" modificado que possibilite a obtenção de grande faixa de va riação de gradientes de velocidade em cada reator, de forma contínua e in dependente, constituido de um dispositivo capaz de permitir a coleta segu ra de sobrenadante de todos os reatores ao mesmo tempo por apenas um opera dor;

b) Propor uma metodologia segura, capaz de permitir grande con fiabilidade na determinação de parâmetros de projeto de ETAs, tais como:

- dosagem ōtima de coagulante;

- pH ótimo de coagulação;

- período ótimo de floculação;

- gradiente de velocidade ōtimo para a floculação;

- velocidade de sedimentação dos flocos.

c) Investigar tais parâmetros para diversos tipos de āguas pre paradas em laboratōrio e naturais, incluindo a determinação dos possīveis mecanismos de coagulação, atravēs da construção de diagramas de eficiência de remoção de turbidez ou cor aparente como função do pH de coagulação e do sagem de sulfato de aluminio $\left(\mathrm{Al}_{2}\left(\mathrm{SO}_{4}\right)_{3} \cdot 18 \mathrm{H}_{2} \mathrm{O}\right)$ :

d) Estudar as curvas de variação do gradiente de velocidade $\underline{\overline{0}}$ timo de floculação como função do perĩodo de floculação para cada tipo de ägua investigado e verificar a validade do modelo proposto por ANDREUVILLEGAS \& LETTERMAN (04); 
e) Investigar a influência da concentração da solução de esto que de sulfato de aluminio na velocidade de sedimentação dos flocos cria dos em condições ótimas de coagulação e floculação para cada tipo de āgua preparada em laboratōrio. 
Quadro 3.1 - Efeitos da coagulação sobre diversos constituintes de äguas na turais potabilizāveis (32).

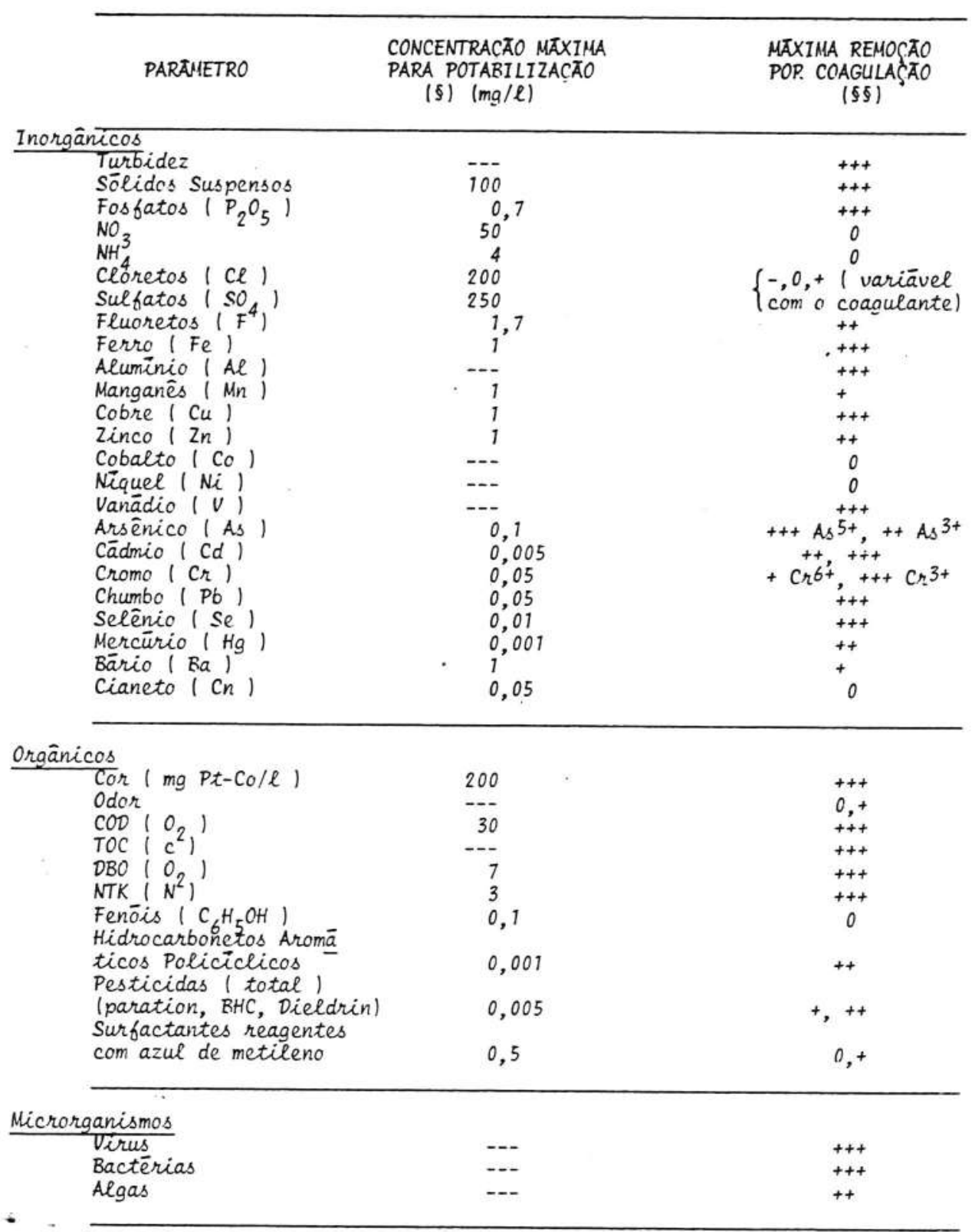

(5) segundo o Jornal Oficial das Comunidades Européias, julho/75.

(इई) 0 sem efeito

+ de 0 a $20 \%$ de remoção

+t de 20 a $60 \%$ de remoçãc

+++ acima de $60 \%$ de remoção. 
catos hidratados de aluminio e ferro, contendo ainda, geralmente, certo teor de elementos alcalinos e alcalino-terrosos. Além dos argilominerais, as argi las contêm outros materiais, tais como : matēria orgânica, partículas de quar tzo, pirita, mica, calcita e outros minerais residuais, podendo conter, tam bém, minerais não cristalinos ou amorfos. Apresenta-se no quadro 3.2 algumas argilas comumente encontradas e suas respectivas fōrmulas químicas.

Quadro 3.2 - Argilas comumentemente encontradas e suas fōrmulas químicas (23).

\begin{tabular}{cl}
\hline ARGILA & FORMULA QUIMICA \\
\hline Caulinita & $\mathrm{Al}_{4}\left(\mathrm{Si}_{4} \mathrm{O}_{10}\right)(\mathrm{OH})_{8}+\mathrm{Al}_{4}\left(\mathrm{Si}_{4} \mathrm{O}_{6}\right)(\mathrm{OH})_{16}$ \\
Montemorilonita & $\mathrm{Al}\{\mathrm{Mg}\}\left(\mathrm{Si}_{8} \mathrm{O}_{20}\right)(\mathrm{OH})_{4} \cdot \mathrm{xH}_{2} \mathrm{O}$ (ई) \\
Ilita & $\mathrm{K}_{4} \mathrm{Al}_{4}\left\{\mathrm{Fe}_{4} \mathrm{Mg}_{4} \mathrm{Mg}_{16}\right\}\left(\mathrm{Si}_{8}-y \mathrm{Al}_{4}\right)_{20}$ \\
& $\mathrm{~K}_{2} \mathrm{Al}_{4}\left(\mathrm{Al}_{2} \mathrm{Si}_{6} \mathrm{O}_{20}\right)(\mathrm{OH})_{4}$ \\
\hline
\end{tabular}

(\$) os elementos entre parentesis podem substituir o ele mento colocado a sua esquerda.

Teoricamente, uma caulinita deve ter as seguintes caracteris ticas :

- perda ao fogo: $13,90 \%$;

- $\mathrm{SiO}_{2}: 46,20 \%$;

- $\mathrm{Al}_{2} \mathrm{O}_{3}: 39,80 \%$

no entanto, esses valores variam sensivelmente conforme a origem do material. - A caulinita é formada pelo empilhamento de duas camadas simples; uma delas consiste de uma folha de tetraedros de $\mathrm{SiO}_{4}$ e a outra, de $\underline{u}$ folha de octaedros de $\mathrm{Al}_{2}(\mathrm{OH})_{6}$, ligadas entre si em uma ünica camada, atra vés de ätomos de oxigênio em comum, originando uma estrutura fortemente po lar.

As particulas de caulinita apresentam-se com 0 formato hexagonal ou irregular, com " diâmetro " de 0,1 $\mu \mathrm{m}$ a 3,0 $\mu \mathrm{m}$. 
A Figura 3.1 apresenta a estrutura da caulinita e a distribuição espacial de seus elementos componentes.
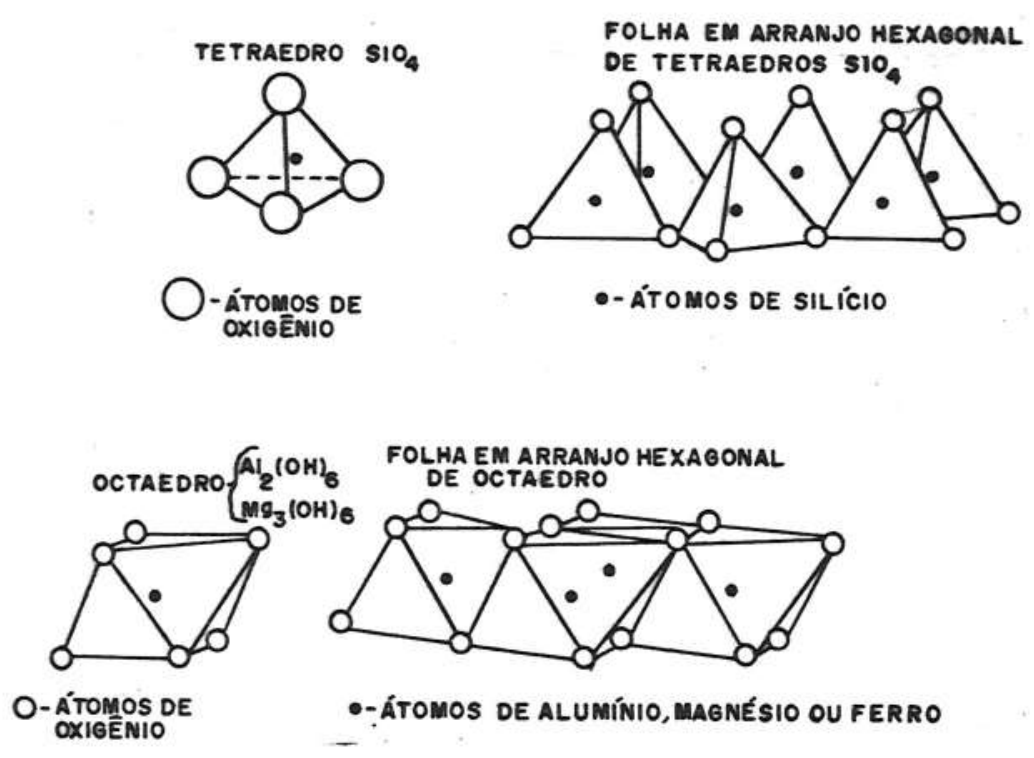

Figura 3.1 - Estrutura da caulinita (70).

Uma propriedade muito importante dos argilominerais $\bar{e}$ a ca pacidade de troca iônica, pois os ions permutāveis influem sensivelmente so bre suas propriedades físico-quimicas. Ouando um ion de maior afinidade encontra-se nas proximidades de um sitio suceptivel à troca iônica, ele subs titui o ion de ordem inferior, ocupando o determinado sitio.

Devido a deficiência de carga na superficie das argilas, es tas apresentam uma elevada capacidade de troca de cätions, que pode variar de 3 a 15 meq/100 g para o pH iqual a 7,0. A origem da carga superficial ne gativa dā-se por substituiçōes isomōrficas de Al por si no tetraedro ou de Mg por Al no cristal octaédrico.

A capacidade de troca de cātions da caulinita é muito variā vel pois depende da fonte do mineral, do tamanho (ärea especifical das par ticulas e do pH. A silica e alumina comportam-se como ácidos fracos cujo grau de ionização é favorecido pela redução da concentração de hidrogênio , assim sendo, a capacidade de troca de cátions aumenta com o aumento do $\mathrm{pH}$. Quando o pH da suspensão encontra-se em valores menores ou iguais a 2,0, a caulinita troca ou adsorve ânions. Para valores de $\mathrm{pH}$ maiores que 2,0, as particulas de caulinita apresentam carga superficial residual negativa rela 
tivamente grande e camada difusa de arande espessura, ocorrendo o inverso pa ra valores de pH baixos.

A particula lamelar de caulinita apresenta, normalmente uma das faces maiores recoberta por ātomos de oxigênio e a outra por hidroxilas. Devido a esse aspecto e a substituicōes isomōrficas no reticulado cristalino, essas faces assumem carga residual negativa ( para $\mathrm{pH}>2$ ). No entanto, nas faces menores, esse reticulado cristalino $\bar{e}$ interrompido, deixando uma defi ciência de cargas negativas pela presença de ions positivos fortemente pola rizantes.

A Figura 3.2 apresenta esquematicamente o que foi descrito anteriormente.
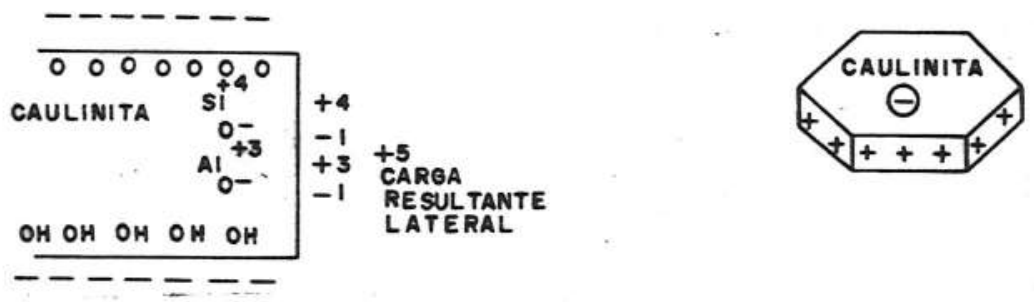

Figura 3.2 - Cargas superficiais da partícula de caulinita (70).

De acordo com VAN OLPHEN (70), uma partícula de argila pode obter carga superficial através de duas maneiras distintas. A primeira delas seria consequência da substituição de cātions de valência elevada ( $\mathrm{Si}^{4+}$ e $\mathrm{Al}^{3+}$ I na estrutura cristalina, por cātions de valência menor $1 \mathrm{Mg}^{2+}, \mathrm{Zn}^{2+}$, $\mathrm{Na}^{+}, \mathrm{Li}^{+}$e outros 1. A segunda seria consequência da adsorção seletiva de cer tos ions do meio, em sittios especifficos da superficie da partícula. Esses si tios seriamoriginados pela ocorrência de forças residuais de valência positi va provocadas pela exposição por clivagem dos ätomos "internos" da estrutura cristalina e também de ātomos localizados na superfície da estrutura.

\subsection{Substâncias Causadoras de Cor}

3.3.1. Natureza e Propriedades da Cor de Origem Orgânica

Muitas āguas superficiais e algumas subterrâneas apresentam 
caracteristicas de cor em tom variando desde o amarelo até o marrom. Essa cor $\bar{e}$ provocada, em grande nümero de casos, pela presença de compostos orgâa nicos de origem vegetal, decompostos pela atividade de microrganismos em meio aquätico ou terrestre, ou ainda, provocada por residuos da atividade hu mana. Tais compostos orgânicos, normalmente denominados de substâncias hümi cas, têm sido extensivamente estudados desde o inicio do século, porém, per manecem muitas incertezas quanto a sua composição $e$ estrutura molecular.

As substâncias hümicas ou humus, têm sido definidas pela li teratura de maneiras diversas, em função de suas mültiplas caracteristicas $e$ de sua natureza heterogênea e complexa. Estas substâncias não constituem uma classe definida de compostos, mas uma mistura heterogênea de substâncias de natureza quimica diversa, constituidas de ācidos amorfos, predominante mente aromáticos, hidrofillicos, com cadeias polieletroliticas com peso mole cular entre $10^{2}$ e $10^{5}$. Nos valores de pH encontrados em àguas naturais, as substâncias hümicas apresentam carga negativa $e$ as dimensões das moléculas, cujo grau de polimerização é função do pH, são da ordem de 3,5 a $10 \mathrm{~nm}$. Sua carga negativa resulta da presença de grupos funcionais carboxil e fenol, que são dissociados com o aumento do pH, aumentando o nümero de cargas nega tivas presentes na solução $e$, consequentemente, a estabilização das macromo léculas causadoras de cor (87).

As substâncias hümicas foram inicialmente classificadas de acordo com sua solubilidade em diferentes condições. A classificação propos ta por ODEN ( citado em 06 ) em 1919, tem sido utilizada por diversos pesqui sadores e é mostrada no Quadro 3.3 .

Quadro 3.3 - Classificação das substâncias hümicas segundo ODEN Icitado em 06).

NOME DA FRAÇAO

CARACTERISTICA

- Acido húmico

Acido fülvico

Acido himatomelânico

Humina
Fração solüvel em $\mathrm{NaOH} e$ inso lūvel em ácidos minerais e ālcool. Fração solüvel em ācidos minerais e NaOH. Fração solūvel em $\mathrm{NaOH}$ e álcool; insolūvel em ācidos minerais. Resîduo da separação dos compostos anteriores (insolüvel em ägua e $\mathrm{NaOH}$ ). 
As três fraçōes de ācidos são estruturalmente similares, di ferenciando-se no peso molecular e conteūdo de grupos funcionais, com o āci do fülvico possuindo menor peso molecular. 0 resumo dos principais elemen tos quimicos constituintes dos ácidos hümico e fülvico $\bar{e}$ apresentado no qua dro 3.4.

Quadro 3.4 - Anälise dos elementos quïmicos presentes nos ācidos hümico $e$ fülvico ( segundo SCHNITZER, citado em 06).

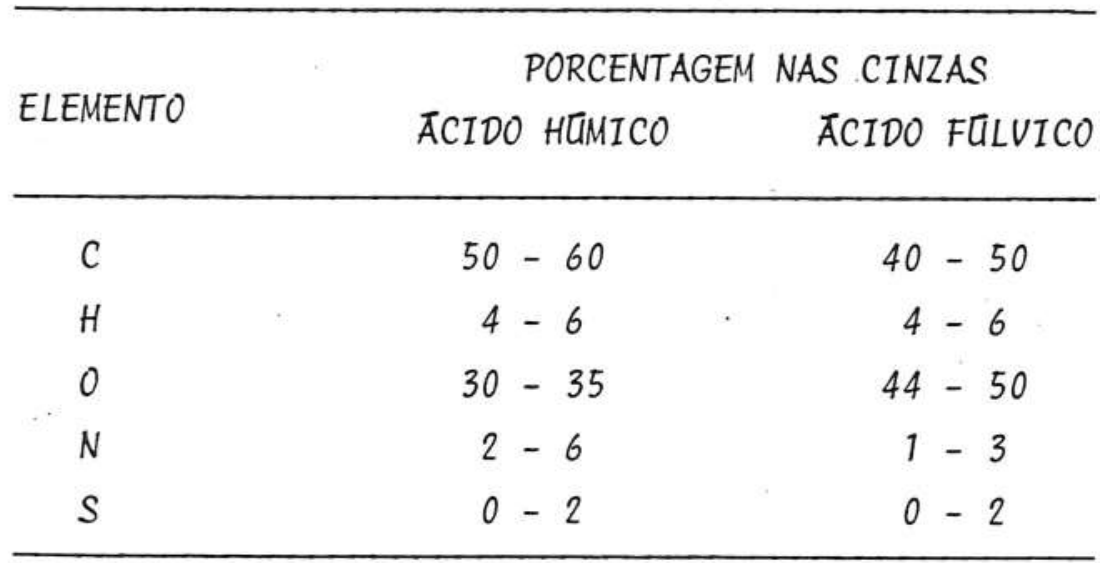

Os ácidos fülvicos contêm mais oxigênio e menos carbono e nitrogênio, apresentando maior nümero de grupos funcionais por unidade de pe so ( dos seguintes tipos : $\mathrm{COOH} ; \mathrm{OH} ; \mathrm{C}=0$ ).

Segundo TOLEDO (87), as substâncias hümicas quando submeti das a uma anälise por espectroscopia, podem apresentar os seguintes grupos funcionais e aromaticos:

a) Grupos funcionais : carboxilicos, fenōlicos, alcoólicos, quinonos, metoxilicos, carbonilicos e outros;

b) Grupos aromäticos:
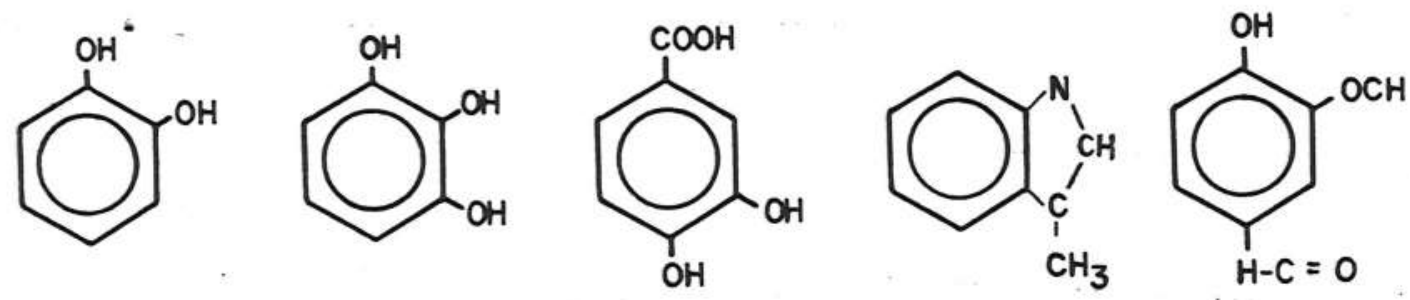

BLACK \& CHRISTMAN (16) separaram as frações dos compostos or 
gânicos causadores de cor em diversas fontes de äguas naturais, atravēs de $\underline{e}$ vaporação à baixa pressão e posterior solubilização em diferentes valores de pH, concluindo que as concentrações desses compostos variaram de 15 a $50 \mathrm{mg} /$ $\ell$, sendo, o ácido fülvico o principal constituinte (87\%), o ācido himatome lânico ( $11 \%$ ) e o ácido hümico (2\%). MIDW00D \& FELBECK (65), também encon traram a predominância da fração de ácido fülvico em relação às demais para solos de turfa, onde a porcentagem deste chegou a $80 \%$. Esse fato torna-se im portante devido ao grande nümero de pesquisas de coagulação feitas com a uti lização de ācidos hümicos, pois estes são submetidos à processos de extração, purificação e secagem muito mais facilmente do que os ācidos fülvicos.

0 aumento da concentração de substâncias hümicas na āgua $\bar{e} \underline{a}$ companhado com a diminuição da capacidade de transmitância da luz pela colu na liquida e aumento das leituras de turbidez e absorbância da amostra. A cor de uma amostra, também é variāvel com o valor do pH, verificando-se um aumen to da cor com o aumento deste. Esse fenômeno é reversível e não é linear (25).

A cor medida na presença de materia suspensa, que pode ser removida por centrifugação, $\bar{e}$ chamada de cor aparente, enquanto que na ausen cia do material em suspensão, $\bar{e}$ denominada de cor verdadeira.

BLACK \& CHRISTMAN (15) verificaram que os ácidos hümico e hi matomelânico seguem a lei de BEER, o que também foi constatado por EDZ(IIALD et alii (31) para o ácido hümico em concentrações variando de 0 a $50 \mathrm{mg} / \ell$.

\subsubsection{Problemas Relacionados com a Presença de Compostos Orgânicos em Aguas}

A presença de compostos orgânicos em äguas pode ocasionar pro blemas na sua utilização para fins domésticos ou industriais devido às seguin tes razões:

- a) A presença de matēria orgânica em āguas é o principal fa tor responsāvel pela manifestação de cor;

b) Certos compostos orgânicos quando presentes em águas de a bastecimento podem provocar problemas de sabor e odor;

c) Podem proporcionar condições para o desenvolvimento de mi crorganismos, prejudicando a qualidade bacteriológica da āgua distribuida;

d) Sua presença tem sido relacionada com problemas de corro 
são nos sistemas de distribuição;

e) Interferem nos processos de desmineralização, proporcionando uma saturação acelerada das resinas ou membranas trocadoras de ions; 6) Interferem com os processos de oxidação e remoção de fer ro e manganês;

g) São precursores de halofórmios e outros compostos orâani cos halogenados, através de reações com cloro;

Dentre todos os problemas causados pela presença de compos tos orgânicos em āguas para abastecimento, este ültimo $\bar{e} 0$ que vem preocu pando mais os organismos sanitärios internacionais, devido à descoberta do grande potencial carcinogênico dos compostos halogenados quando ingeridos por animais, em testes de laboratōrio.

Diversas pesquisas foram realizadas com o objetivo de deter minar os niveis de halofōrmios nas äguas brutas e tratadas, além dos eféi. tos da cloração na concentração de haloförmios. Os resultados mostraram que a concentração de halofōrmios nas āguas brutas $\bar{e}$ inexpressivel face às āguas tratadas e cloradas, sendo sua concentração proporcional ao conteūdo orgâni co da āgua bruta.

Estudos realizados por ROOK (78), mostraram a produção de quatro halofórmios a partir de substâncias hümicas do sistema de tratamento de Roterdan quando a cloração era feita no intervalo de "breakpoint", quais sejam : triclorometano ( $\left.\mathrm{CHCl}_{3}\right)$, tribromometano ( $\left.\mathrm{CHBr}_{3}\right)$, diclorobromometano $\left(\mathrm{CHBRCl}_{2}\right)$ e clorodibromometano ( $\left.\mathrm{CHBr} r_{2} \mathrm{Cl}\right)$.

Em estudo similar, BELLAR et alii (09), demonstrou a presen ça de triclorometano, bromodiclorometano e dibromoclorometano em anälises de cromatografia gasosa de āgua tratada, submetida à desinfecção com cloro.

BABCOOK \& SINGER (09) verificaram que os ācidos hümicos são muito mais importantes na formação de trihalometanos que os ācidos fülvicos. Seu estudo demonstrou que a reação do cloro com os ácidos hümicos é muito mais ativa do que com os ácidos fülvicos, consumindo $75 \%$ mais cloro e produ zindo 117\% mais clorofórmio por unidade de COT ( carbono orgânico total ) e 23\% mais clorofórmio por unidade de cloro consumido. Outra conclusão desses pesquisadores foi que 0 uso de sulfato de aluminio nas operações de coagula ção para remoção de cor, remove substancialmente os precursores de halofōr mio, quando a cloração é posterior à sedimentação.

A Agencia de Proteção Ambiental (EPA) propôs, em 1978, que o limite māximo permitido para a concentração total de trihalometanos em $\underline{a}$ 
guas de abastecimento püblico seja de $0,1 \mathrm{mg} / \mathrm{l}$ e recomenda 0 uso de carvão ativado em processos de tratamento para controle de compostos orgânicos sin téticos, tais como, pesticidas, herbicidas, etc.

DHARMARAJAH (28) recomenda a adoção de três alternativas pa ra o controle de trihalometanos em āguas para abastecimento püblico:

a) Uso de um desinfetante que não reaja com as substâncias hümicas formando trihalometanos;

b) Remoção das substâncias hümicas em fase de tratamento an terior à desinfecção;

c) Remoção de trihalometanos apōs sua formação.

\subsection{Fundamentos Quémicos da Superfície dos Colóides}

Desde que, tanto a turbidez quanto a cor se devem à presença de partículas coloidais em suspensão ou solução, $\bar{e}$ necessāio o conhecimento das caracteristicas e propriedades dos colōides para melhor dicernimento do processo de coagulação.

\subsubsection{Sistemas Coloidais}

Um sistema coloidal $\bar{e}$ definido como um sistema no qual as par ticulas encontram-se em estado finamente dividido e dispersas em um meio con tinuo. As partículas coloidais se caracterizam por ter uma grande superfície específica, ou seja, uma grande relação entre sua ärea superficial e sua mas sa.

As partículas coloidais não são limitadas a um grupo particu lar de substâncias, mas são definidas por seu tamanho. A faixa de variação do tamanho das partículas coloidais encontra-se entre $10^{-6}$ e $10^{-3} \mathrm{~mm}$, tornandose de difícil distinção quanto à soluções e suspensöes em seus limites inf̧e rior e superior, respectivamente.

Os sistemas coloidais podem ser classificados por sua afini dade com a fase dispersante em liofóbicos e liofilicos. Quando a fase disper sante $\bar{e}$ a àgua, denominam-se : hidrofillicos (do grego "philos" (querido)), quando mostram forte atração por moléculas de āgua, tais como proteinas, sa bões, detergentes sintêticos es. hümicas ; hidrofóbicos 1 do grego "phobe" (fobia)), quando mostram fraca atração por moléculas de āgua, tais como argi 
las, ouro e outros metais.

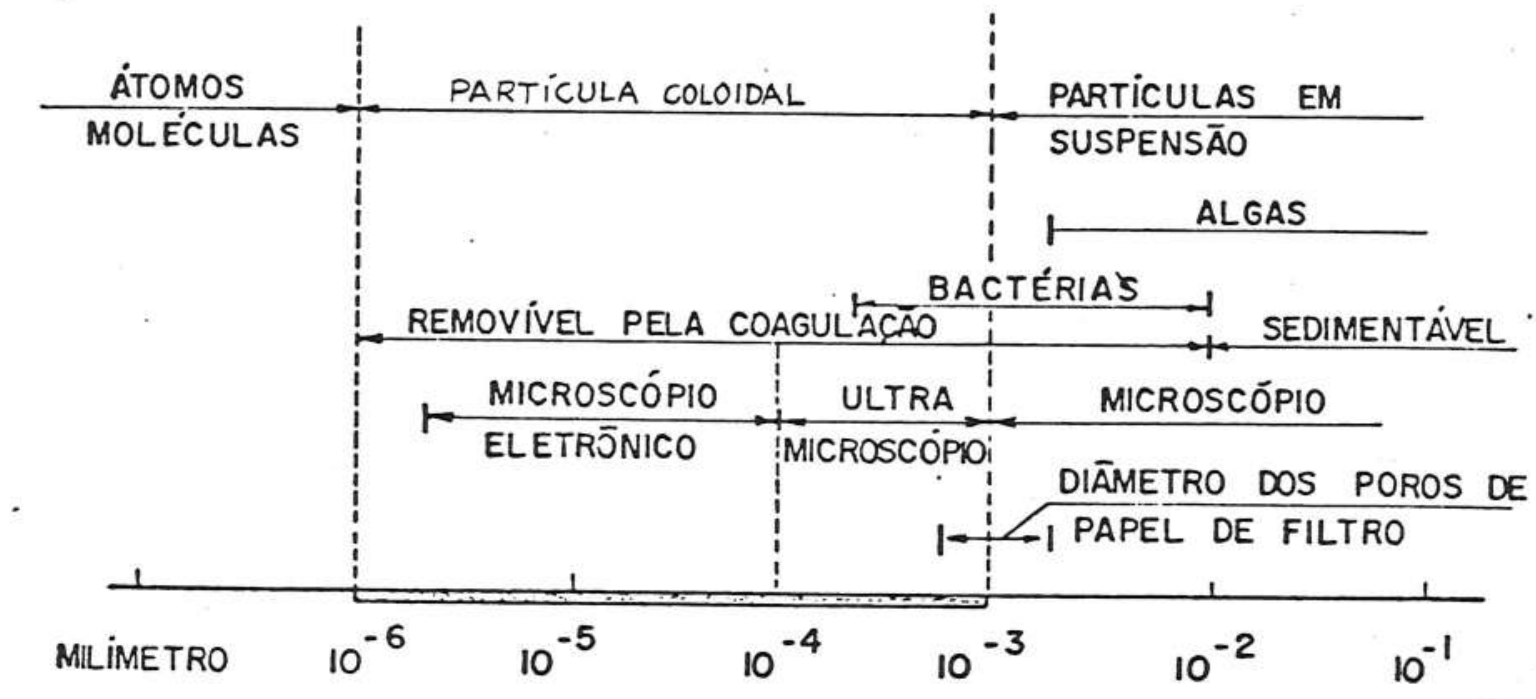

Figura 3.3 - Distribuição do tamanho das partículas presentes na āgua (24).

\subsubsection{Cargas Superficiais das Partículas Coloidais}

Se uma dispersão contendo partículas coloidais for submetida a um campo elétrico, estas mover-se-ão em direção a um dos eletrodos. Es te fenômeno, chamado de eletroforese, indica a existência de cargas elétrí cas nas partículas coloidais. O sinal desta carga e sua magnitude $\bar{e}$ den tre outros fatores,função da natureza do material coloidal. Desde que, că gas semelhantes se repelem, as particulas possuidoras de cargas similares, vão manter-se afastadas umas das outras, não sendo possivel sua agregação em partículas maiores. Esta propriedade $\bar{e}$ a principal responsāvel pela es tabilidade dos colōides e $\bar{e}$ adquirida de diversas maneiras, destacando-se:

a) Imperfeições na estrutura do cristal

- Em certas situações, a partícula coloidal pode adquirir car ga como o resultado de substituições isomörficas dentro do reticulado cris talino, como representado esquematicamente na Figura 3.4 (a) para o tetrae dro de $\mathrm{SiO}_{4}$, no qual um àtomo de Si é substituido por um àtomo de Al, re sultando uma carga negativa (70).

b) Adsorção de ions na superfície da partícula 
Muitas particulas coloidais adquirem cargas como resultado da adsorção preferencial de ions tanto positivos como negativos em sitios es pecíficos da superficie da particula. Esses sitios seriam originados pela $\underline{0}$ corrência de forças residuais de valência devido à exposição por clivagem dos ātomos internos da estrutura cristalina e, também, de àtomos localizados na superfície da estrutura. Um exemplo de ionização é mostrado na Figura $3.4(b)$ para uma molécula de proteina.

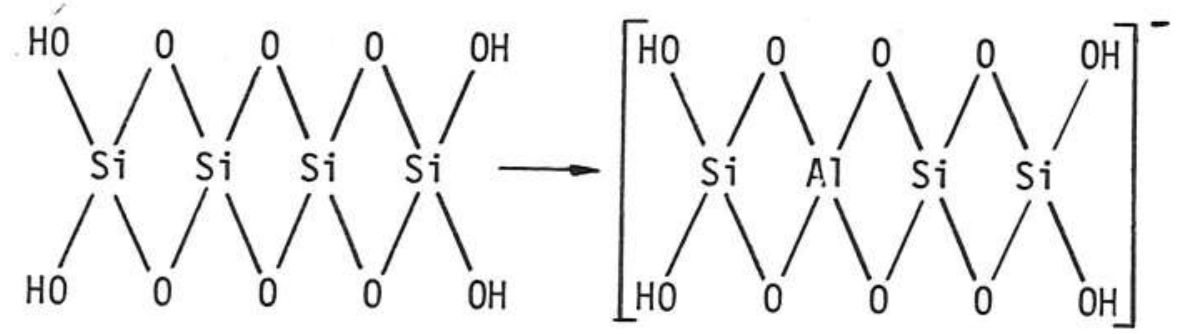

(a) aquisição de carga pela substituição isomörfica de Si por Al.
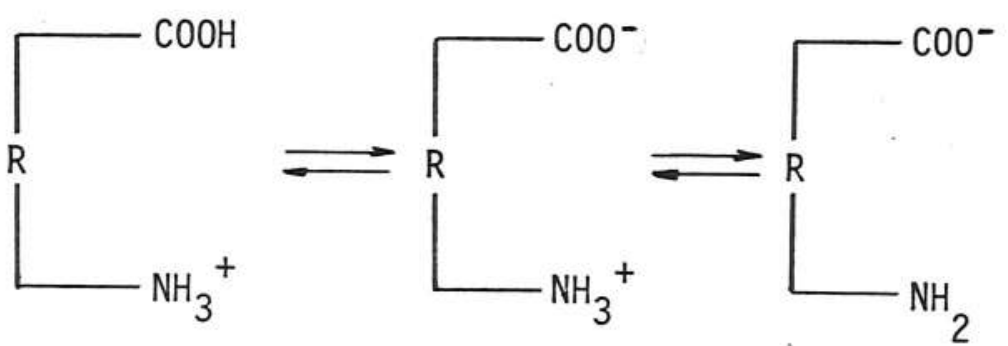

baixo $\mathrm{pH}$ ponto isoelétrico $\mathrm{pH}$ alto (pH 4-6,5)

(b) efeito do pH na ionização de uma partĩcula de proteĩna.

Figura 3.4 - Aquisição de carga por partículas de argila e proteina(70).

\subsubsection{Dupla Camada Elétrica}

Apesar dos colōides hidrófobos possuërem carga elétrica, uma suspensão coloidal, assim como uma solução iônica, não possuem carga elētrí 
ca liquida. Para que haja a eletroneutralidade, as cargas primārias das partículas coloidais devem ser contrabalanceadas por ions de carga conträria $\underline{e}$ xistentes na fase dispersante. Os ions envolvidos nesta eletroneutralidade es tão arranjados em torno das partículas coloidais, formando a chamada camada dupla elétrica. O conceito da camada dupla elétrica foi introduzido por HELM HOLTZ e aprimorado por GOUY (1910), CHAPMAN (1913) e STERN (1924).

os ions de carga conträria são atraídos eletrostaticamente pelas cargas opostas presentes na superficie coloidal. Entretanto, ao mesmo tempo, estes ions possuem a tendência de se difundirem para a fase dispersan te (āgua), onde sua concentração é menor. Esta situação $\bar{e}$ anāloga a da atmos fera terrestre, onde as moléculas gasosas sofrem a ação conträria imposta pela gravidade e a difusividade. A ação conjunta destas tendências opostas leva a uma distribuição equilibrada das moléculas gasosas, na qual sua concentração decresce gradualmente com o aumento da distância da superfície da terra. Es ta distribuição é chamada de atmosférica. 0 mesmo tipo de distribuição é en contrado na camada dupla elētrica. A concentração dos ions de carga contrā ria prōximo à superfície da partícula é elevada, e é decrescente com o aumen to da distância da superfície. Esta "atmosfera" de ions de carga contrāria $\overline{\bar{e}}$ frequentemente chamada de camada difusa de STERN-GOUY.

O modelo proposto por STERN (1924) pode ser usado para descre ver a distribuição do potencial elētrico nas vizinhanças da partícula coloi dal. Considerando uma partícula de argila com sua carga liquida distribuida na superfície, como mostra a Figura 3.5, o potencial elétrico criado por esta carga irā atrair íons de carga conträria em direção da partícula. De acordo com STERN, a distância minima de aproximação destes ions de carga contrāria $\bar{e}$ limitada pelo prōprio tamanho dos ions. STERN, considerando a carga presen te nos ions centrada nos mesmos, e denominando de $\Omega$ a distância entre esta $e$ a superfície coloidal, afirmou que o decréscimo do potencial elétrico da su perfície coloidal $\Psi_{0}$ (também chamado de potencial de NERNST) se dā de forma linear até o valor de $\Psi_{\Omega}$ (potencial de STERN). A partir da distância $\Omega$ ( ca mada difusa de Gouy 1, o decréscimo do potencial elétrico se dā exponencialmente com o aumento da distância da superfície da partícula coloidal I ver Figura 3.9 ).

A Figura 3.6 mostra a distribuição de cargas da camada dupla difusa de uma partícula com carga superficial negativa para uma suspensão co loidal com duas concentrações diferentes de eletrölitos. As linhas BD e B'D', mostram a concentração de ambos os câtions e ânions a uma grande distância 


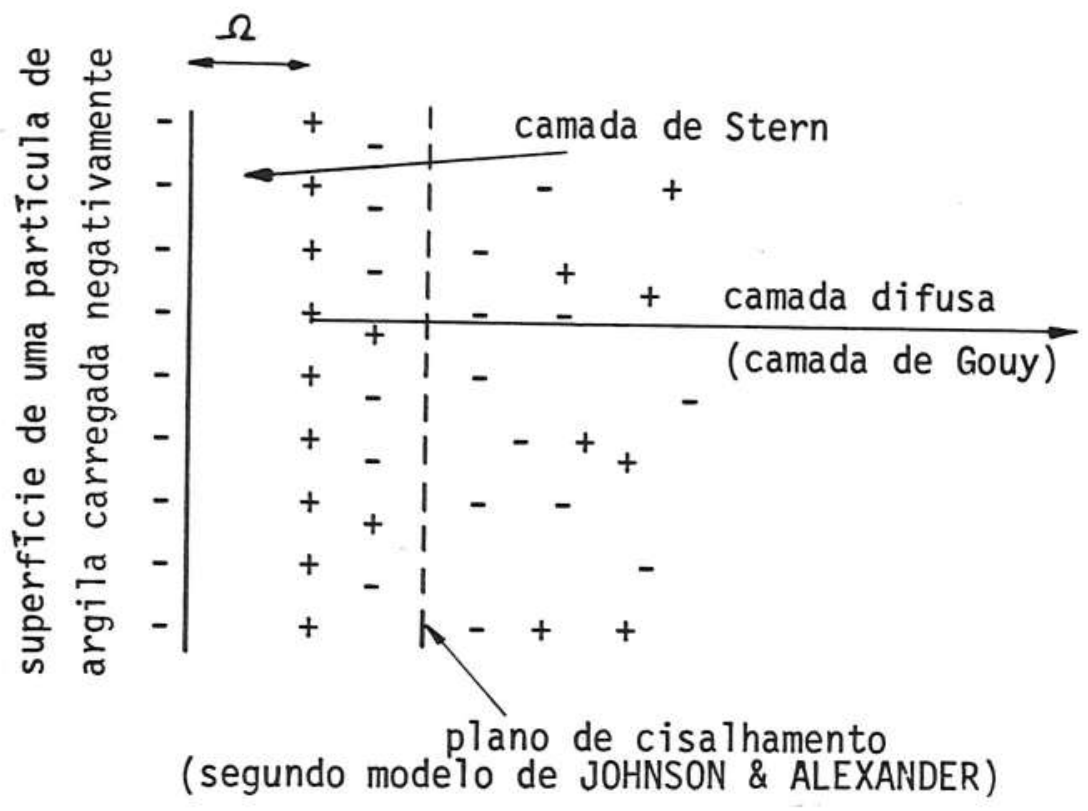

Figura 3.5 - Superfície de uma partícula coloidal com a distribuição de car gas elétricas segundo o modelo de STERN (70).

da superfície da partícula. A concentração média de ions de carga conträria a da superfície da partícula é mostrada pelas linhas AD e A'D', enquanto que a concentração de ions de mesma carga é representada pelas linhas $C D$ e $C^{\prime} D$ ! As superficies delineadas por $A B D$ e $A^{\prime} B^{\prime} D^{\prime}$ representam a quantidade total de ions de carga conträria presentes na vizinhança da partícula e CBD e C'B'D', de ions de mesma carga. Desta forma, as superficies CAD e C'A'D', represen tam o balanco líquido de cargas presentes na camada difusa, que é equivalen te ao apresentado pela carga superficial da partícula.

A Figura 3.7 esquematiza o potencial elétrico como função da distância da superfície de uma partícula coloidal. 0 potencial possui um valor māximo na superfície, como $j \bar{a}$ foi dito anteriormente, e decresce expo nencialmente com a distância da partícula.

Se a camada dupla elētrica é criada pela adsorção preferen cial de ions presentes na solução, o potencial elétrico da superfície da par tícula $\bar{e}$ determinado somente pela concentração (ou atividade) destes ions presentes na solução. Neste caso, o potencial $\bar{e}$ dado pela equação de NERNST, dada a seguir :

$$
\psi_{0}=\frac{K T}{V e} \ln \frac{C}{C_{0}}
$$

onde: $\quad \int \psi_{0}$ : potencial elétrico na superfície da partícula; 


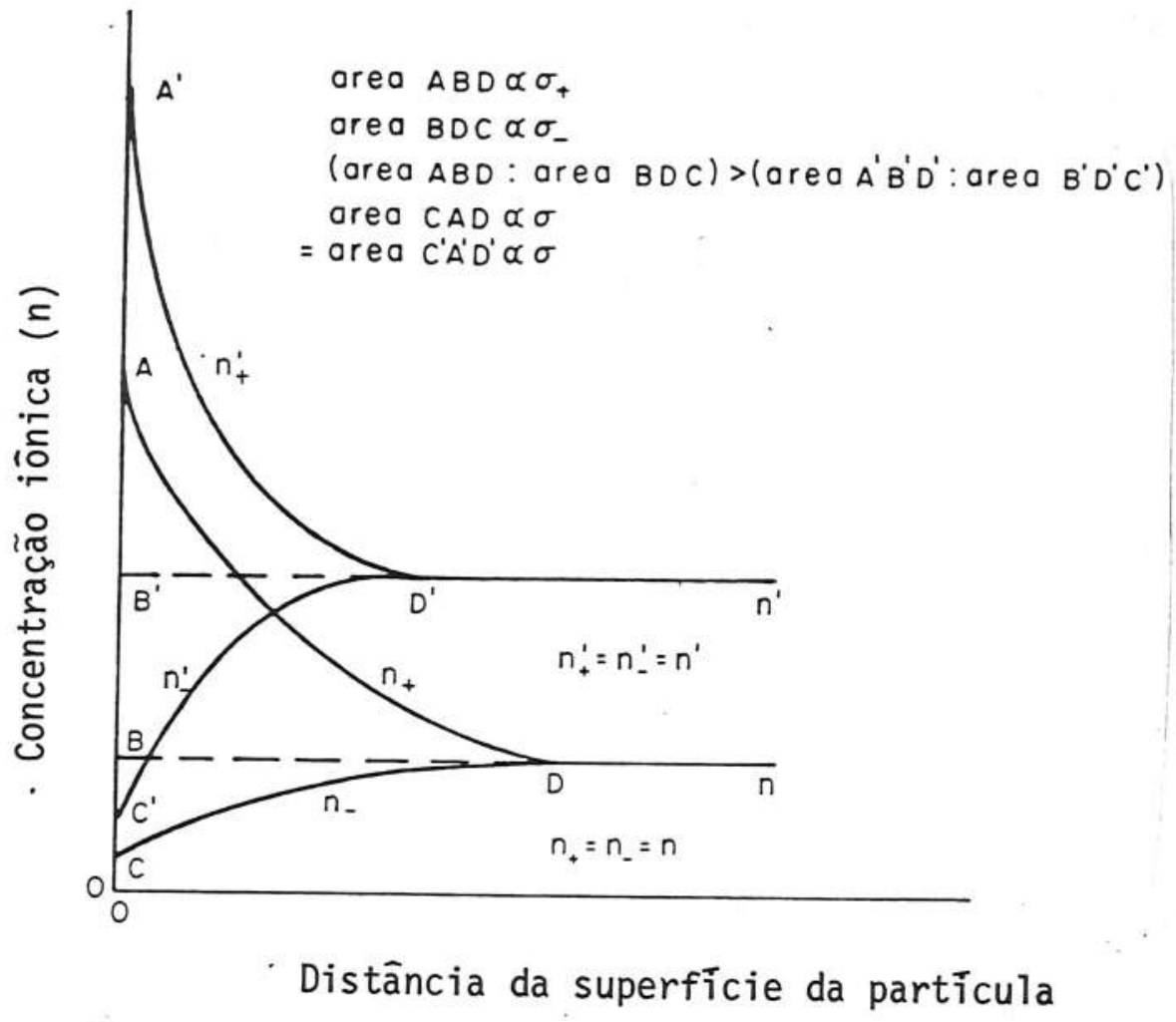

Figura 3.6 - Distribuição de cargas na camada dupla difusa de uma partícula com carga negativa para duas concentrações de eletrólitos e car ga superficial constante (70).

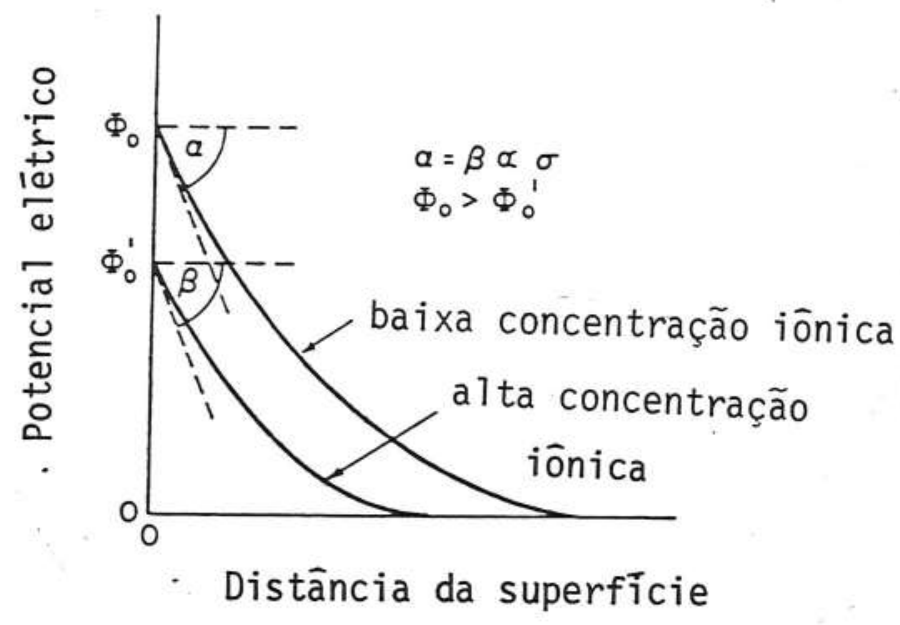

Figura 3.7 - Configuração do potencial elétrico na camada dupla difusa para duas concentrações de eletrólitos (70). 


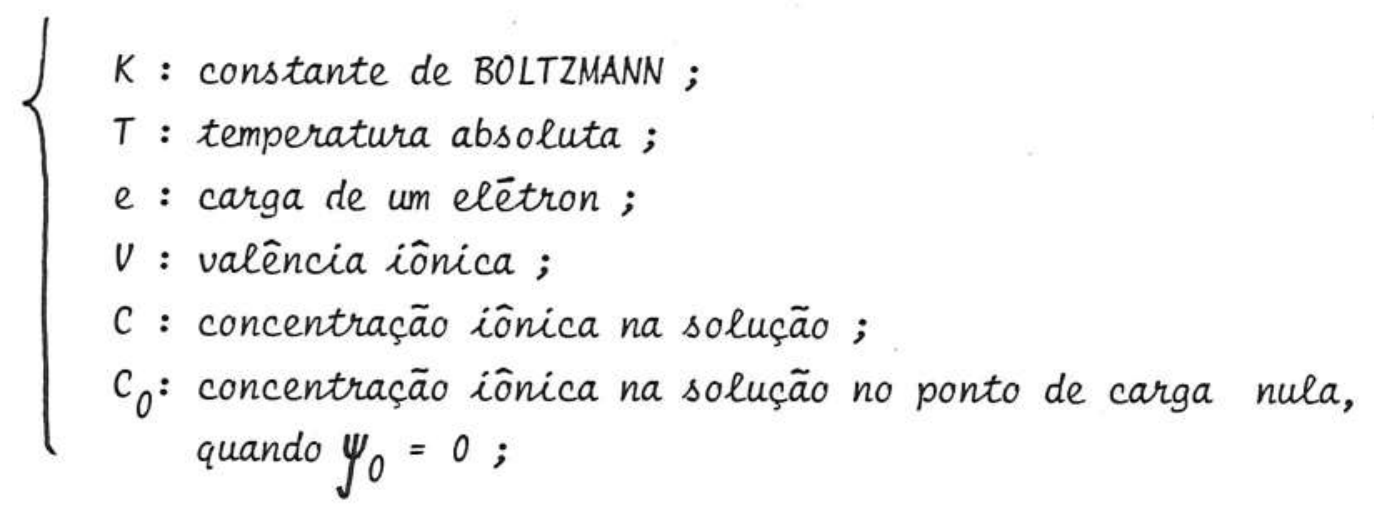

Por outro lado, se a camada resulta de imperfeições no inte rior dos cristais, a carga por unidade de superficie (densidade de carga) $\bar{e}$ um valor pré-fixado que depende unicamente das caracterésticas do colóide.

A magnitude da carga da partícula coloidal não pode ser me dida diretamente, entretanto, é possīvel a determinação do potencial atuan te no plano de cisalhamento da partícula coloidal através de medidas de sua mobilidade eletroforética. Este potencial, chamado de potencial Zeta, $(Z p)$, $\bar{e}$ definido como :

$$
Z p=\frac{4 \pi a \delta}{D}
$$

onde:

Zp: potencial Zeta;

$q$ : carga sobre a particula;

$\{\delta$ : espessura da zona de influência da caraa sobre a partî cula;

D : constante dielētrica do líquido.

Segundo a equação de HELMHOLTZ-SMOLUCHO(ISKI, o potencial Ze ta $\bar{e}$ proporcional à mobilidade eletroforética da partícula :

$$
z_{p}=\left(\frac{4 \pi \eta}{D}\right) m e
$$

onde: $\quad\left\{\begin{aligned} \eta & : \text { viscosidade absoluta da āgua, em poises; } \\ m e & : \text { mobilidade eletroforética da partícula }(\mu / \mathrm{s} / \mathrm{V} / \mathrm{cm}),\end{aligned}\right.$

Assim, o potencial Zeta $\bar{e} 0$ potencial existente no plano de cisalhamento entre o corpo líquido e o invölucro de āgua que se move com a partícula. A posição exata do plano de cisalhamento não $\bar{e}$ conhecida, acredi tando-se que esteja localizado na camada difusa. A magnitude do potencial 
Zeta pode ser interpretada como una estimativa da estabilidade da particula coloidal. Valores elevados, indicam sistemas coloidais de grande estabilida de e vice-versa.

\subsubsection{Força de Atração de VAN DER WAALS}

O fenômeno da floculação demonstra a existência de forças de atração entre as particulas coloidais, de magnitude tal que vençam as for ças repulsivas da camada dupla. As forças atrativas de VAN DER (IAALS, pri meiramente descritas por LONDON, são atribuidas às flutuacões de cargas nos ätomos, resultando numa atração entre os dipolos mutuamente induzidos dos $\bar{a}$ tomos em interação. Para dois àtomos, a força atrativa de VAN DER (IIAALS $\overline{\bar{e}}$ inversamente proporcional à sétima potência da distância entre os mesmos la energia $\bar{e}$ inversamente proporcional à sexta potêncial, porém, para duas par ticulas constituidas de um grande nümero de ätomos, as forças atuantes so bre cada par de àtomos são aditivas, resultando numa energia de atração in versamente proporcional ao quadrado da distância entre as superficies das mesmas.

\subsubsection{Fatores de Estabilidade $e$ Instabilidade}

Assim como foi dito, as suspensões coloidais estão sujeitas a serem estabilizadas ou desestabilizadas. Entre as fatores de estabiliza ção ou repulsão, destacam-se a carga elétrica das particulas e a hidratação das mesmas. A hidratação manifesta-se com maior importância nos colöides hi drofilicos e consiste na propriedade de algumas particulas atraïrem um gran de nümero de moléculas de ägua (solvente) para sua superfície, dificultando a ação de possiveis agentes desestabilizadores.

Os fatores de atração ou desestabilização são proporciona dos pelas forças da gravidade e de VAN DER WAALS além do movimento BROWNIA No, provocado pelos choques das particulas coloidais com as moléculas de $\overline{\bar{a}}$ gua, cuja energia cinética é proporcional à temperatura do fluido:

A interação entre as forças de repulsão pela camada dupla $\underline{e}$ létrica e atração de VAN DER WAALS entre as partículas coloidais difundidas na ägua pelo movimento BROWNIANO, contribui para a estabilidade do sistema, segundo as teorias desenvolvidas por DERJAGUIN e LANDAU (1941) e VERIIEY e $\underline{0}$ VERBEEK (1948) ( teoria chamada de DLVO). 
Quando duas particulas similares se aproximam, suas "atmos $6 \underline{\underline{e}}$ ras" de ions de carga conträria e de suas superficies iniciam uma iteração re pulsiva, resultando no afastamento das particulas. A quantidade de trabälho necessārio para a aproximação de duas particulas coloidais, partindo-se de $\underline{u}$ ma distância infinita $\bar{e}$ chamada de potencial de repulsão (Vr), e $\bar{e}$ tanto maior quanto mais próximas estiverem as particulas. Por outro lado, hā a a ção das forças atrativas de VAN DER WAALS, que combinada com o potencial de repulsão fornece a energia de iteração resultante sobre as partículas colo $\underline{i}$ dais, como mostra a Figura 3.8.

Essa curva, indica que as forças de repulsão predominam a partir de uma certa distância de separação (d), abaixo da qual, as forças a trativas de VAN DER WAALS farão com que as particulas permaneçam unidas. Des ta forma, para que duas particulas sejam unidas, deverão possuir $\underline{e}$ nergia cinética suficiente para vencer a barreira de energia proveniente do efeito combinado dos potenciais de atração e repulsão, ou ainda, atravēs da ação de coagulantes quimicos, diminuir-se a ação do potencial de repulsão com a consequente queda (ou anulação) da barreira de energia original (coagu laçãol.

\subsection{Teoria da Coagulação}

\subsubsection{Mecanismos de Desestabilização}

Segundo STUMM \& O'MELIA (84), para que ocorra a agregação de particulas coloidais presentes numa suspensão, estas deverão sofrer a ação de dois fatores distintos, descritos nos itens 3.5.1.1 e 3.5.1.2.

\subsubsection{Ação de Redução das Forças Repulsivas}

A desestabilização das particulas pode ser alcançada pela $\underline{0}$ corrência de quatro mecanismos de coagulação descritos, resumidamente, a seguir :

a) Compressão da Dupla Camada

E conhecido de longa data, que un sistema coloidal pode ser desestabilizado com a adição de ions de carga conträria a da superficie co loidal. SHULZE, em 1882, verificou que a concentração de cätions necessärios 
para a coagulação de uma suspensão coloidal obedece a razão aproximada de: 1000:10:1, para valores de valência crescentes de 1 para 2 para 3, respecti vamente. Da mesma forma que SHULZE, HARDY, observou o mesmo efeito para os anions, formulando a regra conhecida pelo nome de SCHULZE-HARDY. Esta regra é valida para eletrólitos que não realizam qualquer tipo de reação química com a fase dispersante (eletrölitos indiferentes).

O fenômeno observado por SCHULZE-HARDY é atribuido à compres são da dupla camada elétrica e pode ser explicado pela teoria jā mencionadá de DLVO.

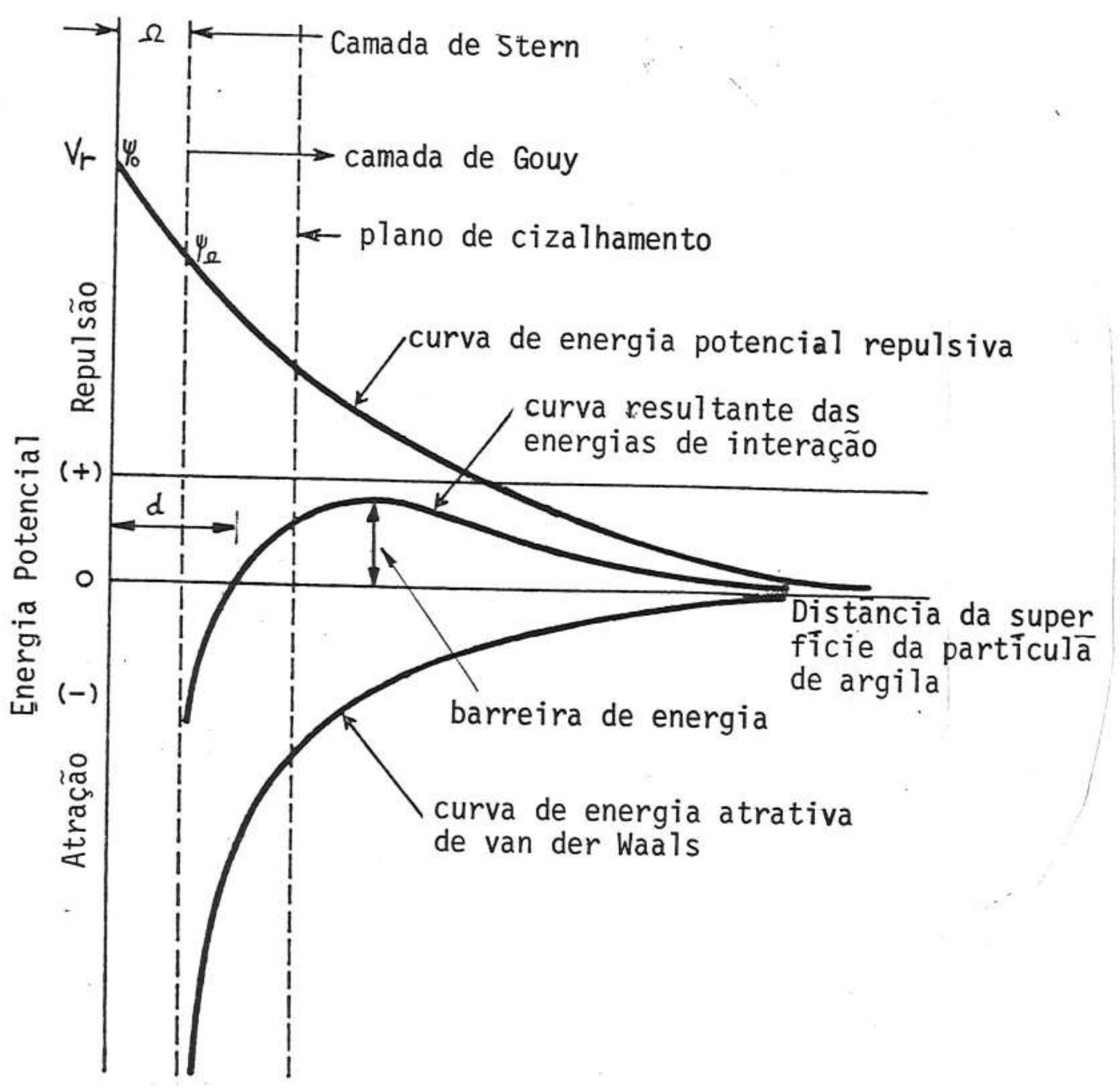

Figura 3.8 - Energia potencial de iteração entre as particulas coloidais (23). 
A adição de um eletrōlito num sistema coloidal irā aumentar a densidade de cargas iônicas presentes na camada difusa das partículas co loidais, resultando numa diminuição do volume desta, necessārio para contra balancear a carga superficial das partículas (ver Figura 3.9 ).

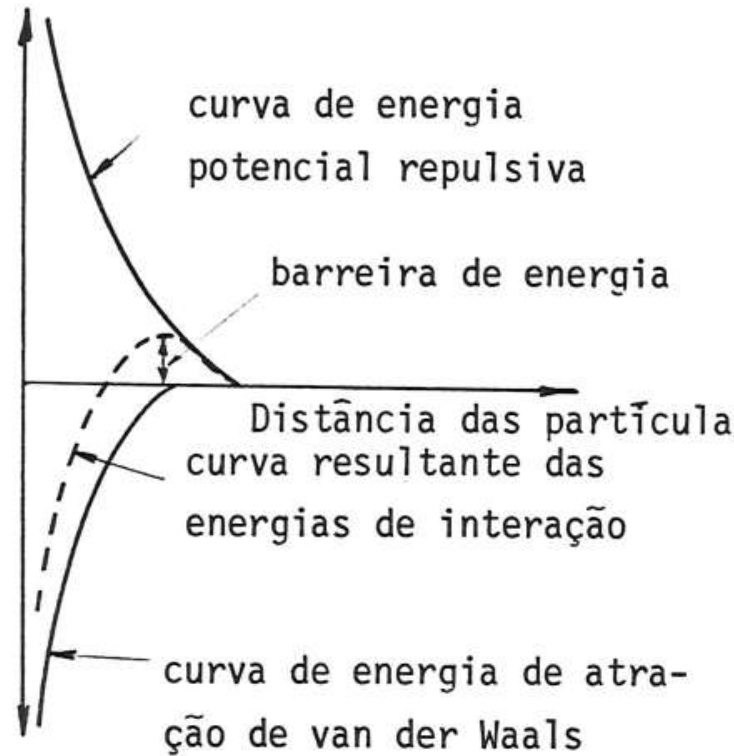

ção de van der Waals

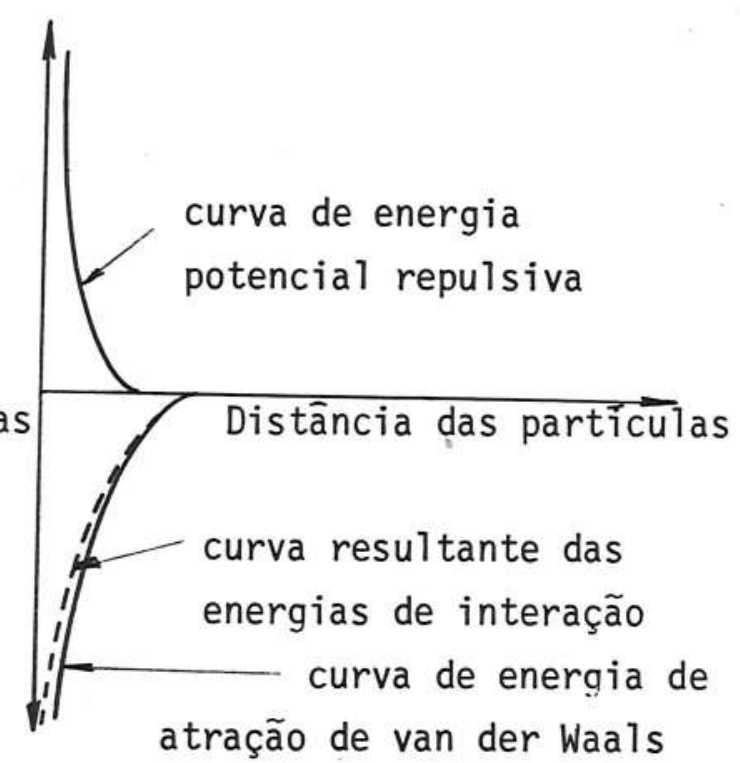

(b) alta concentração de eletrōlitos (eliminação da barreira de energia)

Figura 3.9 - Efeito da variação da concentração de eletrólitos na compressão da dupla camada elétrica (70).

O efeito desta compressão reflete na distribuição das forças repulsivas presentes na vizinhança das partículas, no sentido de diminuí-las, reduzindo ou anulando a barreira de energia existente para a agregação das particulas.

O decréscimo do potencial de superfície decorrente da com pressão da dupla camada irā refletir num decréscimo mütuo do potencial Zeta. E sugerido em diversos trabalhos de pesquisa que as condições ōtimas de coa gulação ocorrem quando o potencial Zeta $\bar{e}$ prōximo de zero, porém, segundo 
VAN OLPHEN (70), este parâmetro não pode ser utilizado como um critērio quantitativo de estabilidade dos colöides devido às incertezas que envol vem o seu cálculo e devido ao não conhecimento exato da localização do pla no de cisalhamento.

A compressão da dupla camada apresenta dois interessantes aspectos que merecem ser destacados :

i) A quantidade de eletrölitos necessārios para conseguir - se a coagulação pela compressão da camada dupla é praticamente independen te da concentração de colōides na suspensão;

ii) Não é possível causar a reversão da carga dos colōides pela compressão da dupla camada ( restabilização) para qualquer quantida de de eletrólitos adicionada.

\section{b) Adsorção e Neutralização}

Existem algumas espécies químicas capazes de serem adsorvi das na superfície das partículas coloidais. Se estas espécies forem carre gadas com caraas conträrias às presentes na superfície dos colōides, have rā a desestabilização dos mesmos. A redução da carga superficial por adsor ção é muito diferente do mecanismo de compressão da dupla camada e o com portamento do sistema desestabilizado não pode ser explicado pela teoria de DLVO.

A atração entre a superfície do colōide e a espécie adsor vida resulta, provavelmente, de interações quimicas, tais como, pontes c'e hidrogênio, reações de coordenação, pontes covalentes e reações de troca $i$ onica. Sua manifestação $\bar{e}$ de intensidade superior aos efeitos eletrostāticos, o que permite explicar a restabilização de particulas coloidais pela reversão da carga superficial.

São três as principais diferenças entre os mecanismos de compressão da camada dupla e de adsorção-neutralização :

i) As espécies adsorvēveis são capazes de desestabilizar os colōides em dosagens muito inferiores às necessärias para a compressão da dupla camada por ions não adsorvỉveis;

ii) A relação existente entre a concentração dos colōides e a quantidade necessāria de espécies desestabilizantes por adsorção segue uma relação estequiomētrica; 
iii) E possivel a reversão da carga superficial das particulas coloidais atravēs de uma dosagem excessiva de espécies adsor vivies.

\section{c) Varredura}

Dependendo da quantidade de sal (coagulante) adicionada, do pH e da concentração de algumas espécies de ions presentes na solução poderā ocorrer a formação de precipitados. As particulas coloidais presentes comportam-se como núclueos de condensação para estes precipitados $e$, desta forma, são removidas por sedimentação. Coagulantes, tais como, $\mathrm{Al}_{2}\left(\mathrm{SO}_{4}\right)_{3}$, $\mathrm{FeCl}_{3}, \mathrm{MgCO}_{3}$ e $\mathrm{Ca}(\mathrm{OH})_{2}$, podem provocar a coagulação de partículas coloidais pela formação de compostos insolüveis como $\mathrm{Al}(\mathrm{OH})_{3}(\mathrm{~s}), \mathrm{Fe}(\mathrm{OH})_{2}(\mathrm{~s}), \mathrm{Mg}(\mathrm{OH})_{2}$ (s), $\mathrm{CaCO}_{3}$ (s).

Segundo PACKHAM (75), a dosagem ótima de coagulante para a desestabilização por varredura ("sweepfloculation"), não mantém uma relação direta com a concentração de colōides. Como este mecanis mo de coagulação não depende da neutralização das cargas superficiais, as condições ötimas de coagulação não correspodem ao ponto de mínimo po tencial Zeta. Entretanto, este processo é bastante influenciado pela relação entre o pH e a solubilidade dos compostos de hidrōxido.

\section{d) Adsorção e Formação de Pontes}

Existe uma grande variedade de compostos naturais

sintēticos caracterizados por uma grande cadeia molecular que gozam da propriedade de apresentar regiões ionizāveis ao longo de sua cadeia, capazes de agirem como eficientes coagulantes. Tais compostos chamados de polieletrólitos podem ser classificados como: aniônicos, catiônicos, antó lïticos e não-iônicos, dependendo da caracteristica do sîtio ionizāvel, que apresenta em solução. A coagulação-floculação com estes compostos apresenta caracteristicas distintas das verificadas quando $\bar{e}$ usado um eletrólito de pequena cadeia. Pesquisas do comportamento destes compostos têm demonstrado que é possivvel a desestabilização de colōides carregados negativamente por ambos tipos de polieletrólitos, catiônicos ou aniônicos. Desta forma, nem o modelo de compressão da dupla camada e tampouco o da neutralização das cargas podem ser utilizados para caracterizar o benô meno. RUEHRIJEIN \& WARD (1952) e LA MER \& HEALY (1963), desenvolveram a 
teoria de pontes quimicas para explicar o comportamento dos polieletrólitos como agentes de coagulação. Este modelo $\bar{e}$ baseado na adsorção dos poliele trōlitos à superfície das partículas coloidais, seguida, ou pela redução da carga, ou pelo "entrelaçamento" das particulas pelos polieletrólitos.

segundo CAMPOS (21), não $\bar{e}$ fäcil destacar esses dois meca nismos que ocorrem na agregação das particulas. Certamente, são envolvidos fatores fisicos e quimicos em conjunto. A Figura 3.10, apresenta alguns es quemas da adsorção e a subsequente interação entre as moléculas dos políme ros $e$ as particulas coloidais.

Segundo O'MELIA (71), as ligações podem režzultar de forças de atração eletrostätica, caso os polímeros $e$ as partículas sejam carregadas com carga conträria, ou troca iônica, pontes de hidrogênio e forças de VAN DER WAALS, caso possuam cargas de mesmo sinal. As ramificações da cadeia dos polimeros podem ser adsorvidas em sitios específicos da superficie das par ticulas coloidais, podendo, uma mesma cadeia polimērica, envolver mais que uma particula coloidal, como mostra a reação 2 da Figura 3.10. Esta ação de pontes entre particulas resulta na formação de flocos de boas caracteristicas de sedimentação. As reações 3 e 4, mostram duas situações em que as par tículas coloidais permanecem estāveis em detrimento da formação de flocos. A agitação excessiva pode ocasionar a ruptura de flocos prèviamente forma dos e provocar o reaparecimento de particulas estāveis, semelhantes as obti das na reação 3.

Na reação 4, o polieletrólito participa como agente de pro teção, pois suas cadeias se estendem de maneira apreciāvel para o interiór. do meio, dificultando a agregação das partículas coloidais. Esse efeito é de nominado de "estabilização estêrica".

A Figura 3.11 apresenta as curvas esquemäticas de desestabi lização e restabilização, segundo os quatro mecanismos descritos. Na Figura 3.11 - A, apresenta-se a variação da turbidez residual como função da dosa gem de coagulantes com ions de $\mathrm{Al}^{3+}, \mathrm{Ca}^{2+}$ e $\mathrm{Na}^{+}$. Verifica-se a validade da regra de SHULZE-HARDY e o modelo teörico de DLVO para eletrólitos indiferen tes. Na Figura 3.11 - B, verifica-se um exemplo de desestabilização de par ticulas de iodeto de prata (AgI), que apresentam carga negativa, através do mecanismo de adsorção-neutralização por meio de ions orgânicos do composto $\mathrm{C}_{12} \mathrm{H}_{25} \mathrm{NH}_{3}^{+}$. Observa-se a restabilização dos colöides por inversão de carga a partir de uma dosagem de coagulante superior a $10^{-4}$ moles/l.

$\mathrm{Na}$ Figura 3.11 - C apresenta-se o efeito do uso de sais de 


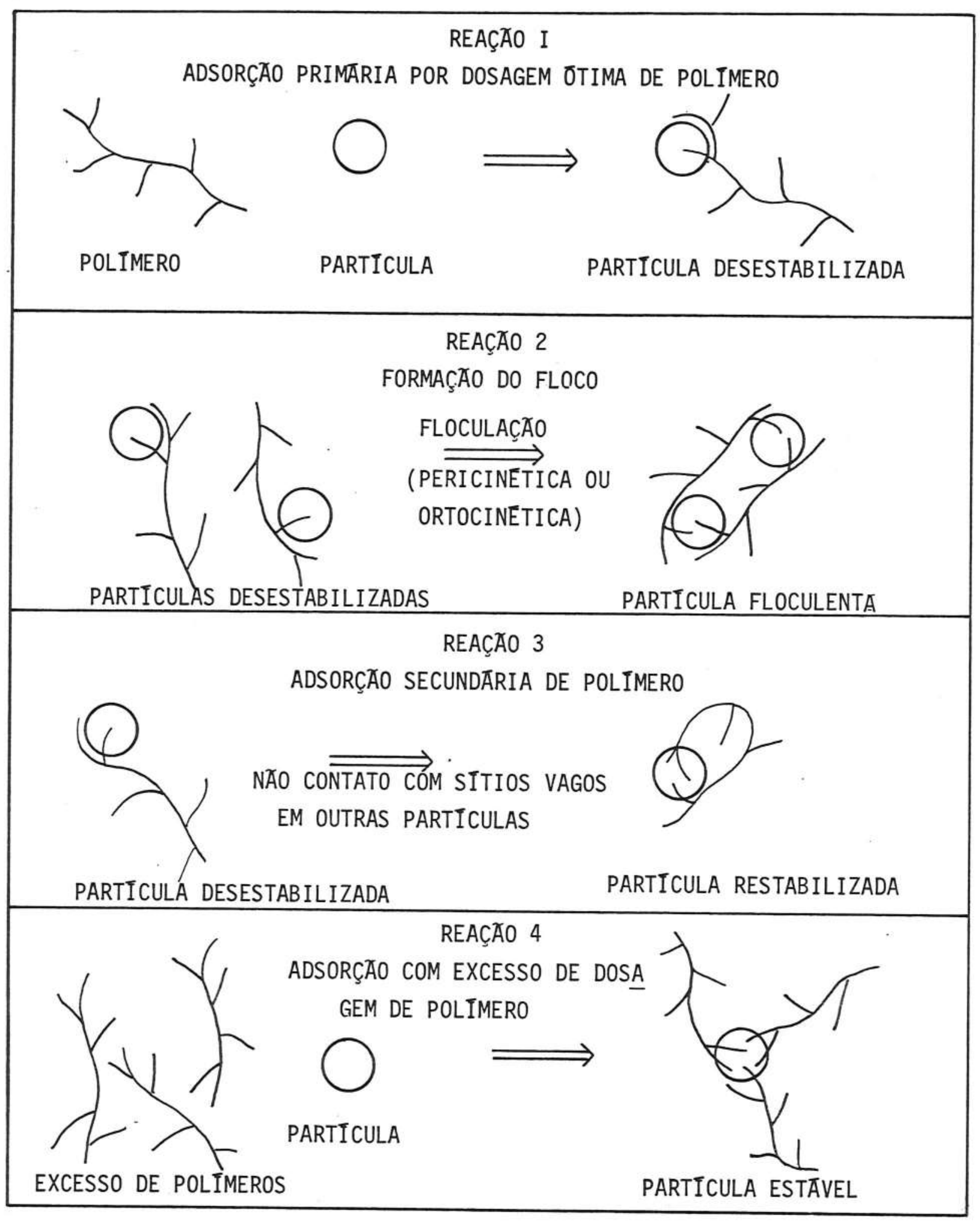

Figura 3.10 - Representação esquemática do modelo de pontes na desestabili zação de colōides por polímeros (polieletrólitos) (23). 


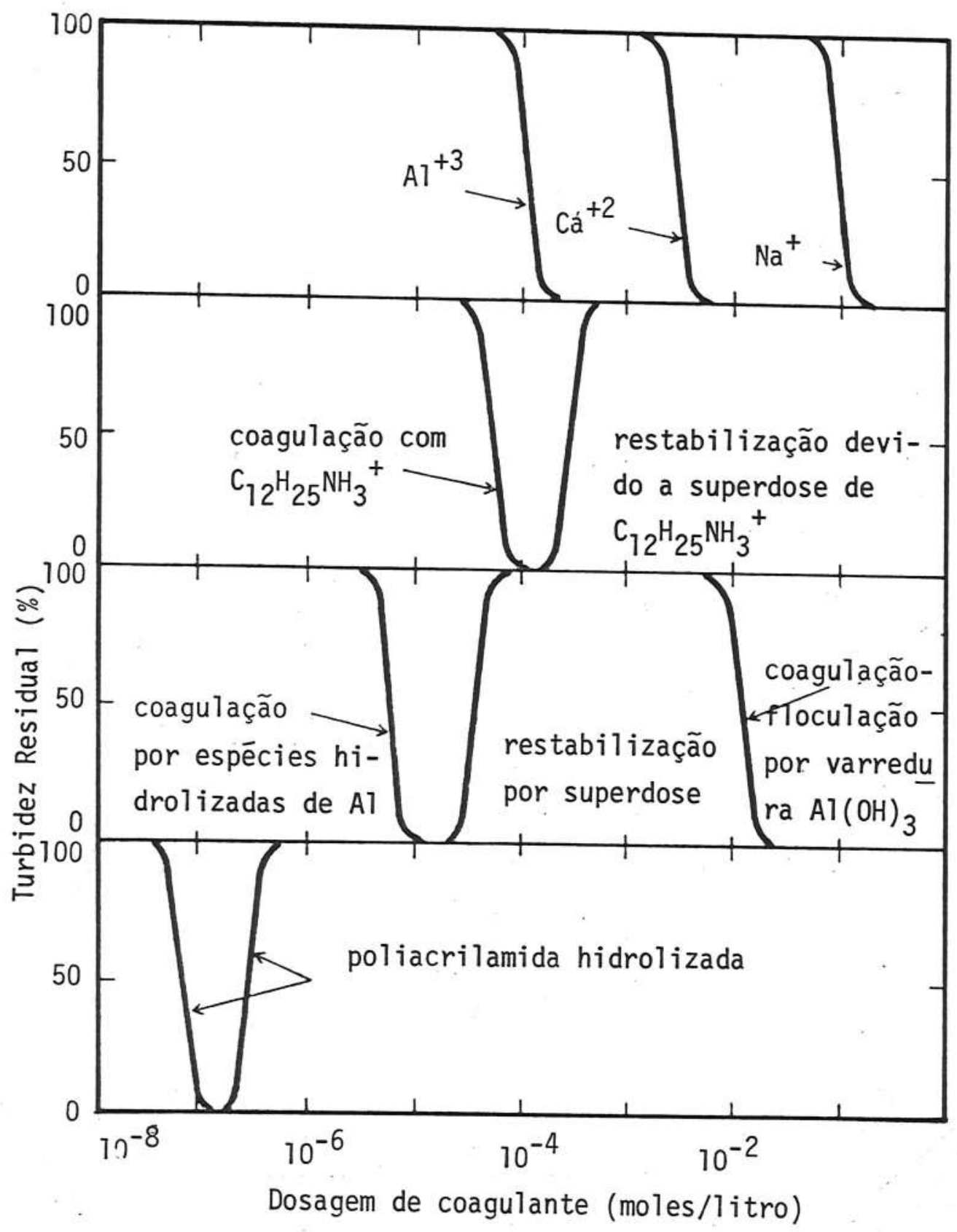

Figura 3.11 - Curvas esquemāticas de coagulação segundo os diversos mecanis mos de desestabilização (23).

aluminio sobre a turbidez residual apōs sedimentação em ensaios realizados em valores de pH constante $e$ igual a 5 . Observa-se os efeitos de adsorção $e$ neutralização, restabilização e varredura para dosagens de $10^{-5}, 10^{-4}$ e $10^{-2}$ moles/l, respectivamente.

Finalmente, a Figura 3.11 - D, demonstra a eficiência de coa 
gulação de um polieletrölito pelo mecanismo de adsorção e formação de ponte sobre uma suspensão de caulinita. Observa-se o inicio de coagulação e a res tabilização dos colōides em dosagens de polieletrölito muito baixas $\cong 10^{-\overline{7}}$ moles $(\ell)$, indicando claramente a ocorrência de adsorção.

\subsubsection{Ação de Mecanismos de Transporte}

Os coagulantes quimicos somente poderão causar a desestabilização das particulas coloidais se forem convenientemente distribuidos na fase dispersante e colocados em contato com os colöides. Da mesma forma, as particulas desestabilizadas necessitam de oportunidades de contato, de modo a formar flocos. Estes contatos podem ser conseguidos por meio de três meca nismos distintos, descritos a seguir.

\section{a) Movimento BROWNIANO (floculação pericinética)}

Como jā foi mencionado, baseia-se na transferência de ener gia cinética das moléculas do fluido para as pequenas partículas coloidais, devido ao bombardeamento continuo pelas moléculas de ägua providas de ener gia térmica. A taxa de variação da concentração das partículas devido a $\underline{a}$ ção da floculação pericinética pode ser expressa pela equação desenvolvida por SUIFT \&FRIEDLANDER, em 1964 :

$$
J_{p k}=\frac{d N^{0}}{d t}=\frac{-4 \theta K T \cdot\left(N^{0}\right)^{2}}{3 \mu}
$$

onde: $\quad\left(N^{0}\right.$ : concentração total de partículas em suspensão no tempo igual a 0 ;

$\theta$ : fator de eficiência de colisão (fração das colisões fa vorâveis a agregaçãol ;

$K$ : constante de BOLTZMANN $\left(1,38 \times 10^{-16}\right.$ erg/ok $)$;

$T$ : temperatura absoluta $(O O K)$;

$\mu$ : viscosidade do fluido $(\mathrm{g} / \mathrm{cm} . \mathrm{s})$.

b) Ação da Força da Gravidade

A força da gravidade proporciona o transporte vertical das particulas e choques entre as mesmas devido à velocidades de sedimentação di 
ferenciadas pelo peso flutuante de cada particula, representado por:

$$
P_{6}=(\pi / 6) \cdot\left(\rho_{p}-\rho\right) \cdot g \cdot d^{3}
$$

onde :

$$
\left\{\begin{array}{l}
P_{f}: \text { peso flutuante da aprticula }(\mathrm{N}) ; \\
\rho_{p}: \text { densidade da particula }\left(\mathrm{kg} / \mathrm{m}^{3}\right) ; \\
\rho: \text { densidade do fluido }\left(\mathrm{kg} / \mathrm{m}^{3}\right) ; \\
g: \text { aceleração da gravidade }\left(\mathrm{m} / \mathrm{s}^{2}\right) ; \\
d: \text { diâmetro da particula }(\mathrm{m}) .
\end{array}\right.
$$

c) Movimento do Fluido

0 contato entre as particulas presentes em suspensão em um bluido em movimento é função dos gradientes de velocidade existentes na dis tribuição espacial do fluido, da concentração e do diâmetro das particulas nele suspensas.

Os efeitos proporcionados pelos mecanismos descritos nos $\underline{i}$ tens (b) e (c), são conhecidos como floculação ortocinética e, segundo $\underline{\omega E}$ BER (1972), sua taxa de variação na concentração de partículas pode ser re presentada por :

$$
J_{o k}=\frac{d N^{0}}{d t}=\frac{-2 \theta G \cdot d^{3}\left(N^{0}\right)^{2}}{3}
$$

onde :

$$
\left\{\begin{aligned}
& J_{o k}: \text { taxa de variação da concentração de particulas; } \\
& N^{0}: \text { concentração total de particulas em suspensão no tem } \\
& \text { po igual a } 0 ; \\
& \theta: \text { fator de eficiência de colisão entre particulas; } \text { gradiente de velocidade }\left(s^{-1}\right) ; \\
& G: \text { diâmetro da particula }(\mathrm{m}) ;
\end{aligned}\right.
$$

A razão entre as taxas de floculação ortocinêtica e perici nética pode ser obtida pela divisão das equações 3.4 e 3.6 .

$$
\frac{J_{o k}}{J_{p k}}=\frac{-2 \theta g \cdot d^{3}\left(N^{0}\right)^{2} / 3}{-4 \theta K T \cdot(N) T^{2} \frac{13 \mu}{13}}=\frac{\mu G \cdot d^{3}}{2 K T}
$$


A anälise da equação 3.7 leva à conclusões bastante interes santes. Para particulas de pequeno diâmetro, a relação $J_{o k} / J_{p k}<1,0$, indi cando que a bloculação pericinética $\bar{e}$ dominante. Mesmo para particulas de diâmetro em torno de $0,10 \mu \mathrm{m}$, o gradiente de velocidade deveria ser prōximo de $10.000 \mathrm{~s}^{-1}$ para que a relação $\mathrm{J}_{o k} / \mathrm{J}_{p k}$ torne-se unitäria. Entretanto, pa ra partículas com diâmetro de $1,0 \mu \mathrm{m}, 0$ valor de $G$ poderā cair para $10 \mathrm{~s}^{-1}$. Isto significa que as partículas são agregadas até o diâmetro de aproximada mente 1,0 $\mu \mathrm{m}$ através da ação do movimento BROWNIANO $e$, a partir deste diâme tro, o crescimento dos flocos é feito pela ação da floculação ortocinética.

\subsubsection{Coagulação com Sulfato de Aluminio}

\subsubsection{Reações quimicas do Sulfato de Aluminio com a Agua}

As reações de hidrölise do ion aluminio com a ägua tem sido amplamente estudadas por mais de. três décadas, com o objetivo de esclarecer - se os mecanismos que regem a coagulação de āguas para abastecimento pübli co que, na sua grande maioria, emprega o sulfato de aluminio como único coa gulante.

Quando o sulfato de aluminio $\bar{e}$ dissolvido em āgua, os cāa tions metälicos de aluminio comportam-se como ācidos fracos no conceito de BRONSTED, apresentando valores de $\mathrm{pH}$ semelhantes às soluçōes de ācido acēti co para as mesmas concentrações molares. Assim sendo, ocorre a formação de espécies de aluminio hidrolisadas, que poderão apresentar carga positiva, ne gativa ou nula, mononucleares $\left(\mathrm{Al}(\mathrm{OH})_{3}\left(\mathrm{~s}_{3}\right), \mathrm{Al}^{3+}, \mathrm{Al}(\mathrm{OH})_{2}^{+}, \mathrm{Al}(\mathrm{OH})_{4}^{-}\right)$e polinu cleares $\left(\mathrm{Al}_{8} \mathrm{OH}\right)_{20}^{4+}, \mathrm{Al}_{7}(\mathrm{OH})_{17}^{4+}, \mathrm{Al}_{13}(\mathrm{OH})_{34}^{53}, \mathrm{Al}_{6}(\mathrm{OH})_{15}^{3+}, \mathrm{Al}_{8}(\mathrm{OH})_{10}\left(\mathrm{SO}_{4} 4_{5}^{+}\right)$.

De acordo com MATIJEVIC, BROSSET, BIEDERMANN e outros, tais espécies de aluminio podem ser encontradas na ägua, dependendo da idade e da temperatura da solução, da concentração e tipo de ânions presentes $1 \mathrm{Cl}^{-}$, $\mathrm{SO}_{4}^{2-}$, etc) e, principalmente do valor do $\mathrm{pH}$. O equilibrio ácido-base para 0 ion aluminio coordenado por seis moléculas de āgua $\bar{e}$ :

$$
\mathrm{Al}\left(\mathrm{H}_{2} \mathrm{O}_{6}^{3+}+\mathrm{H}_{2} \mathrm{O} \rightleftharpoons \mathrm{Al}\left(\mathrm{H}_{2} \mathrm{O}_{5}(\mathrm{OH})^{2+}+\mathrm{H}_{3} \mathrm{O}^{+}\right.\right.
$$

Na transferência de um pröton para a molécula do solvente $\left(\mathrm{H}_{2} \mathrm{O}\right)$, uma molécula de $\mathrm{H}_{2} \mathrm{O}$ coordenada $\bar{e}$ convertida a hidrōxido. A continui 
dade da reação, dependendo do $\mathrm{pH}$, serā :

$$
\mathrm{Al}\left(\mathrm{H}_{2} \mathrm{O}\right)_{5}(\mathrm{OH})^{2+}+\mathrm{H}_{2} \mathrm{O} \rightleftharpoons \mathrm{Al}\left(\mathrm{H}_{2} \mathrm{O}\right)_{4}(\mathrm{OH})_{2}^{+}+\mathrm{H}_{3} \mathrm{O}^{+}
$$

Com a continuidade dessas reações $e$ omitindo-se as molēcu las de ägua para simplificação, tem-se :

$$
\mathrm{Al}^{+3} \Rightarrow \mathrm{Al}(\mathrm{OH})^{2+} \rightleftarrows \mathrm{Al}(\mathrm{OH})_{2}^{+} \rightleftharpoons \mathrm{Al}(\mathrm{OH})_{3(\mathrm{~S})} \rightleftharpoons \mathrm{Al}(\mathrm{OH})_{4}^{-}
$$

Além dessas reações mononucleares, poderão ocorrer reações mais complexas, envolvendo mais de um ätomo de aluminio, criando-se a opor tunidade de formação das espécies polinucleares $j \bar{a}$ anunciadas.

Devido à ocorrência dessas reações, os ions de $\mathrm{Al}^{3+}$ são en contrados em solução, somente quando o valor de pH $\bar{e}$ baixo. Com o aumento do valor do pH da solução aquosa, o equilïbrio da reação $3.10 \bar{e}$ deslocado para a direita até a ocorrência de formação do $\mathrm{Al}(\mathrm{OH})_{3}$. Este composto $\bar{e}$ in solūvel na ägua e forma um precipitado gelatinoso, podendo, em valores de $\mathrm{pH}$ mais elevados, ser redissolvido, formando o ion $\mathrm{Al}(\mathrm{OH})_{4}^{-}$.

As reações de hidrölise sucessivas envolvem a redução da carga efetiva do ion $e$, assim sendo, seria previsivel uma reducão na efi ciência do composto como coagulante. Na realidade, por razões ainda não to talmente esclarecidas, a troca de moléculas de āgua por grupos hidroxilas no campo de coordenação do ion metälico leva ao mesmo um maior poder de ad. sorcão numa grande variedade de superficies coloidais. Assim, apesar de uma carga efetiva menor, os ions metälicos hidrolisados podem ser agentes flo culadores mais eficazes, e em função de sua concentração, provocar a rever são da carga superficial das partículas coloidais e sua consequente resta bilização.

0 fato das espécies hidrolisadas com menor carga efétiva serem agentes de coagulação mais eficazes que o ion metälico e a ohserva ção de que $\bar{e}$ possīvel a reversão da carga superficial das partículas coló dais quando em presença de excesso de ions de carga conträria, mostra que as interações entre o coagulante e o colōide não são de natureza apenas $\underline{e}$ letrostätica, ocorrendo reações químicas com energia de interação mais ele vada.

Os cätions polinucleares de aluminio, além de possuërem $\underline{u}$ ma carga efetiva elevada, apresentam uma arande afinidade química com os co 
loides, tornando-se extremamente eficazes como agentes de coagulação.

Apesar de intensas investigaçōes experimentais da hidrölise de sais de aluminio, a composição das espécies hidrolisadas não $\bar{e}$ conhecida com exatidão. Vārios métodos têm sido empregados com este objetivo, incluin do medições de pH, titulações potenciomētricas, crioscopia, difusão, cinē ticas de reação, condutividade, coagulação, etc. Assim, uma variedade de es pécies complexas de aluminio, iônicas e neutras, mononucleares e polinuclea res têm sido sugeridas. BROSSET e colaboradores, citados em (83), utilizá ram seus estudos potenciométricos para mostrar que as espécies mononuclea res não são os principais produtos da hidrölise do aluminio. Eles postula ram a existência de um complexo polimérico hidroxilado solüvel de aluminio com a relação de $\mathrm{OH}$ :Al igual a 2,5:1 e sugeriram a espécie $\mathrm{Al}_{6}(\mathrm{OH})_{15}^{3+}$. A Fi gura 3.12, resultante do estudo desenvolvido por MATIJEVIC et alii (55), mos tra, na curva continua, a concentração crítica de coagulação (CCC) do uso

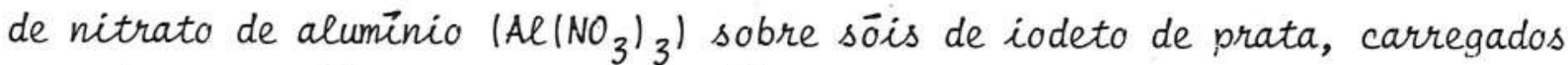
negativamente. Observa-se uma redução brusca da CCC ocorrida entre as valo res de pH iguais a 4 e 4,7 que, segundo os pesquisadores, só pode ser expli cada pelo aumento da carga da espécie, de acordo com a regra de SCHULZE-HAR Dy. Sabendo que, para valores de $\mathrm{pH}$ inferiores a 4 a espécie predominante $\overline{\bar{e}}$ - $\mathrm{Al}^{3+}$, os pesquisadores propuseram um composto com carga positiva igual a 4 , resultando na espécie $\mathrm{Al}_{8}(\mathrm{OH})_{20}^{4+}$.

Segundo MATIJEVIC et alii (55), a seguinte reação de equilí brio pode ser considerada :

$$
8 \mathrm{Al}^{3+}+2 \mathrm{OH}_{2} \mathrm{O} \rightleftharpoons \mathrm{Al}_{8}(\mathrm{OH})_{20}^{4+}+20 \mathrm{H}^{+}
$$

cuja constante de equilibrio pode ser dada por:

$$
K=\frac{\left[\mathrm{Al}_{8}(\mathrm{OH})_{20}^{4+} \pi\left[\mathrm{H}^{+}\right]^{20}\right.}{\left[\mathrm{Al}^{3+}\right]^{8}}
$$

Aplicando-se o logarítmo de ambos os lados e simplificando-se, tem-se :

$$
\log \left[\mathrm{Al}^{3+}\right]=-2,5 \mathrm{pH}+1 / 8 \log \frac{\left[\mathrm{Al}_{8}(\mathrm{OH})_{20}^{4+}\right]}{K}
$$

Segundo os mesmos pesquisadores, admitindo-se que a concen tração da espécie $\mathrm{Al}_{8}(\mathrm{OH})_{20}^{4+}$ necessāria para a restabilização de uma mesma 


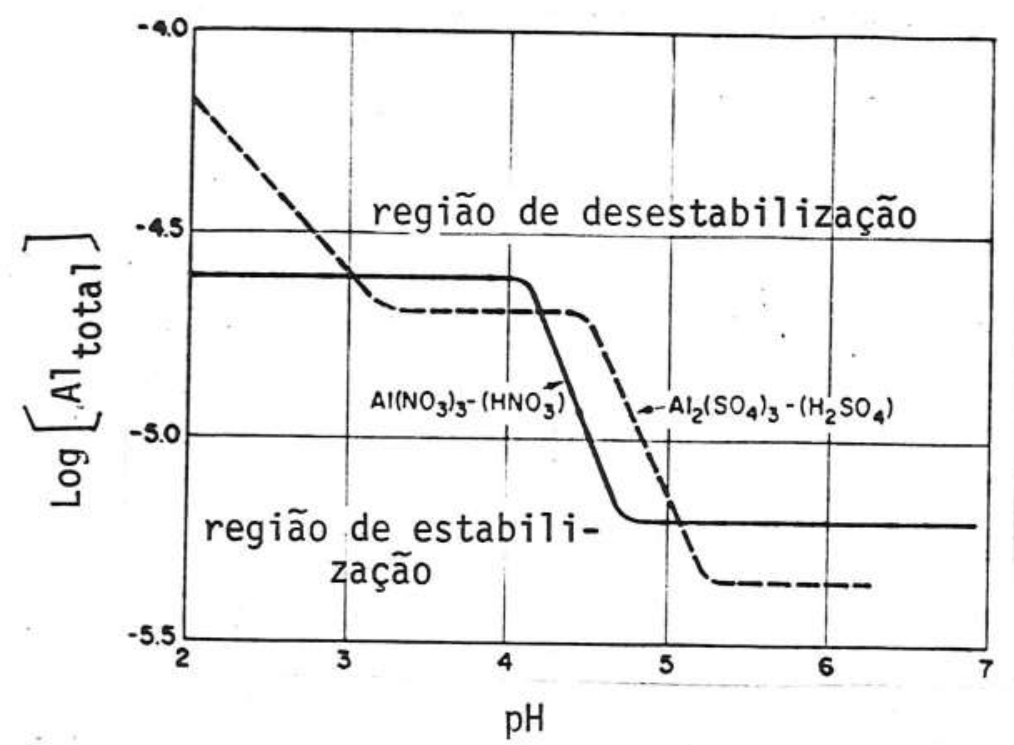

Figura 3.12 - Concentração crítica de coagulação (CCC) do nitrato de alumê nio $1-1$ (com correções de $\mathrm{pH}$ feitas com $\mathrm{HNO}_{3}$ quando ne cessärio) e do sulfato de aluminio (-.--- I/ com correções de $\mathrm{pH}$ feitas com $\mathrm{H}_{2} \mathrm{SO}_{4}$ quando necessärio) como função do pH. Am bas as curvas para soies de iodeto de prata $\left(\mathrm{AgI}: 1 \times 10^{-4} \mathrm{M}\right.$, $\left.K I: 4 \times 10^{-4} \mathrm{M}\right)(55)$.

suspensão coloidal, na faixa de valores de nH apresentada na Fiaura 3.13, seja constante e desprezivel em relação à quantidade total de aluminio adi cionada, tem-se :

$$
\begin{aligned}
& \frac{1 / 8 \log \left[\mathrm{Al}_{8}(\mathrm{OH})_{20}^{4+}\right]}{K}=K^{\prime} \\
& \log \left[\mathrm{Al}{ }^{3+}\right]=\log \left[\mathrm{Al}_{\text {total }}\right]
\end{aligned}
$$

$e$ assim, aplicando-se (3.15) e (3.14) em (3.13), tem-se:

$$
\log \left[\mathrm{Al}_{\text {total }}\right]=-2,5 \mathrm{pH}+\mathrm{K}^{\prime}
$$

Desta forma, plotando-se a curva do logaritmo da concentra ção total adicionada de aluminio ( $\log \left[\right.$ [ $\left.\ell_{\text {total }}\right]$ ) para a restabilização de uma suspensão coloidal contra o valor do pH, teremos a chamada concentra ção crítica de restabilização (CCR), dada por uma curva com inclinação $\underline{i}$ gual a $-2,5$ com o eixo do pH. A Figura $3.13 \bar{e}$ um exemplo da validade des 
sas afirmações, dadas por MATIJEVIC et alii (55).

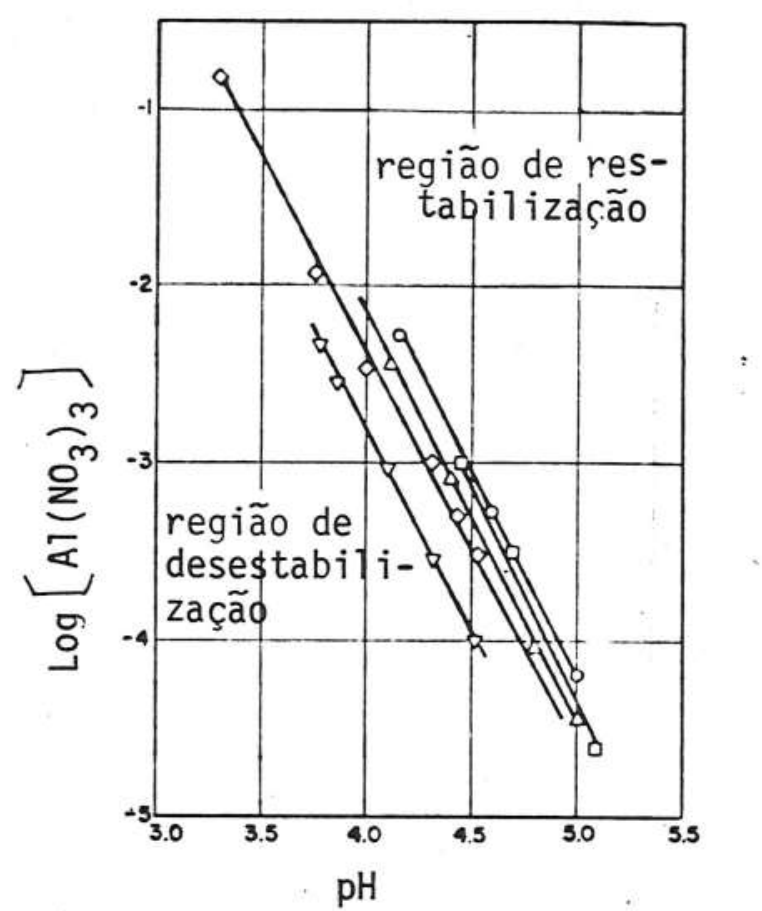

Figura 3.13 - Limites da concentração crítica de restabilização (CCR) por reversão de carga devido à espécies hidrolisadas polinuclea res de aluminio para diversas suspensões coloidais em fun ção do valor de $\mathrm{pH}$ (55).

$\nabla$ SBR (styrene butadiene rubber) ( latex);

$\diamond$ brometo de prata;

$\triangle$ iodeto de prata $(p I=3,4)$;

- iodeto de prata $(p I=2,7)$;

- cloreto de polivinila (PVC) .

E importante salientar que, na realidade, a inclinação do limite da CCR com o eixo do pH permite avaliar a média existente entre as relaçōes $\mathrm{OH}: \mathrm{Al}$ das espécies presentes responsāveis pela restabilização dos colōides. Além disso, grandes erros podem ser cometidos quando considera - se a supremacia absoluta da concentração da espécie $\mathrm{Al}^{3+}$ sobre as demais para valores de $\mathrm{pH}$ maiores que 4 e quando da presença de ânions não indif́e rentes, como é o caso do $\mathrm{SO}_{4}^{2-}$.

MATIJEVIC \& STRYKER (63) pesquisando a reversão de carga de colöides liofóbicos utilizando sulfato de aluminio como coagulante, encon traram para a inclinação da partelinear do contorno de restabilização o va 
lor aproximado de -1,25. A diferença desta inclinação para aquela encontra da para o nitrato de aluminio (55), foi atribuida à formação de espéciés complexas se sulfato com o aluminio. Isto deve acontecer se alguns dos gru pos hidroxila forem substituidos por ions de sulfato na estrutura de coor denação do cātion metälico. A inclinação $-1,25$ deve corresponder à espécie aproximada de $\mathrm{Al}_{8}(\mathrm{OH}) 10\left(\mathrm{SO}_{4}\right)_{5}^{4+}$, embora a possibilidade de formação de uma sērie de espécies contendo variado nümero de ions sulfato não pode ser ex cluida.

A confirmação da existência de espécies hidrolisadas de $\underline{a}$ luminio com sulfato pode ser feita com a observação da curva pontilhada da Figura 3.12. Quando MATIJEVIC et alii (55) utilizaram o sulfato de alumi nio como coagulante e o ácido sulfürico para ajuste de $\mathrm{pH}$ na determina ção da CCC de söis de iodeto de prata, seu valor aumentou juntamente com a variação de $\mathrm{pH}$ de 3,3 até 2 . Esse fato não ocorreu com o nitrato de alumé nio, o que indica claramente que a diminuição da concentração de $\mathrm{Al}^{3+}$ pre sente e responsāvel pela compressão da dupla camada e coagulação dos sōis na faixa de pH investigada, decorreu da formação de espécies do tipo $\mathrm{AlSO}_{4}^{+}$

Esse fato, alerta para o não uso de $\mathrm{H}_{2} \mathrm{SO}_{4}$ juntamente com 0 coagulante $\mathrm{Al}_{2}\left(\mathrm{SO}_{4}\right)_{3}$ para ensaios de coagulação em valores de $\mathrm{pH}$ inferio res $a 4$, pois seriam gastas maiores quantidades de coagulante.

A propriedade de certos ânions tais como o $\mathrm{SO}_{4}^{2-}$ de comple xarem-se com as espécies hidrolisadas de aluminio foi denominada de "efé to antagônico" por LEVINE \& BELL, citados em (55). Outro exemplo dessa propriedade $\bar{e}$ dado pelo ion fluoreto, que complexa-se com o aluminio em especies do tipo $\operatorname{AlF}_{n}(3-n)+$, com $(n)$ variando de 1 a 6. A Figura 3.14 demonstra a existência dessas espécies quando faz a variação da CCC do $\mathrm{Al}\left(\mathrm{ClO}_{4}\right)_{3}$ (per clorato de aluminiol sobre sōis negativos de brometo de prata em função da quantidade de fluoreto de potäsio adicionada para dois valores de pH ( li nha continua 1. A linha pontilhada demonstra o valor da CCC da espécie $\mathrm{Al} \overline{\overline{3}^{+}}$. Para exemplificar a magnitude da intensidade de complexação do ion $F^{-}$com $\mathrm{Al}^{3+}$, basta observar que na presença de $10^{-2} \mathrm{M}$ de KF, a concentração de $\mathrm{Al}^{3+}$ livre, corresponde a $2 \%$ da concentração total do perclorato de alum $\overrightarrow{\underline{\imath}}$ nio necessārio para a coagulação dos sōis. Os restantes $98 \%$ foram "inativa dos" devido à formação de espécies complexadas com o ion $F$.

Autores como MARION \& THOMAS (54), STUMM (82), observaram que $0 \mathrm{pH}$ onde as espécies hidrolisadas de aluminio apresentam carga nula (pH isoelētricol varia com o tipo e concentração de ânions presentes na sus 
pensão. Quando um ânion possui uma tendência de coordenação com o ion alumî. nio maior que o ion hidroxila, o pH isoelétrico decresce com o aumento da concentração desse ânion. Alguns exemplos desse tipo de ânion, além dos jā mencionados, são : fosfato, citrato, tartrato e bicarbonato.

MATIJEVIC \& STRYKER (63) concluiram em suas investigações, que a idade da solução de coagulante pode interferir nos tipos de espécies polinucleares hidrolisadas presentes, podendo-se obter complexos do tipo $\mathrm{Al}_{13}(\mathrm{OH})_{34}^{5+}$ com o envelhecimento artificial através de aquecimento à tempe raturas de 90 o. por período de 24 horas e posterior resfriamento antes do uso. Tais espécies apresentaram uma CCC muito inferiores que as espécies pre sentes em soluções "novas", sendo eficazes, também, em faixas de valores de pH inferiores, como exemplificado na Figura 3.15. As linhas continuas repre sentam os limites da CCR para duas concentraçöes de sois : $\mathrm{AgI}=1 \times 10^{-4}$ (cīr culos) e AgI $=5 \times 10^{-4} \mathrm{M}$ (triângulos). Triângulas e circulos vazios referem -se ao sol "in statu nascendi", enquanto os cheios, referem-se ao sol AgI envelhecido. A linha tracejada representa os limites da CCR porém com o uso de uma solução de coagulante $\left.\left(\mathrm{Al}^{\left(\mathrm{NO}_{3}\right)}\right)_{3}\right)$ envelhecida artificialmente. As 'li nhas pontilhadas indicam a formação do precipitado de hidróxido de aluminio $\left(\mathrm{Al}(\mathrm{OH})_{3(\mathrm{~s})}\right)$ na ausência do iodeto de prata.

Segundo BLACK (11), o conhecimento das constantes de equili brio das reações de formação de espécies hidrolisadas de aluminio são se sü ma importância, pois permitem a previsão da presença destas espēcies em fun ção do pH e possibilitam a determinação das caracteristicas eletrocinéticas dos flocos formados pela interação destas espécies com a turbidez e/ou cor, devido à sua composição, valência e peso molecular.

A Figura 3.16, derivada do trabalho experimental de PACKHAM (74), apresenta a concentração residual de espécies de aluminio em soluções preparadas com $\mathrm{Al}_{2}\left(\mathrm{SO}_{4}\right)_{3} \cdot 18 \mathrm{H}_{2} \mathrm{O}$, cujo $\mathrm{pH}$ foi variado com a introdução de āci do acético e bicarbonato de sódio em função da variação do valor do pH. $\underline{0 b}$ serva-se a presença de espécies solüveis para valores de $\mathrm{pH}$ menores que $5, \overline{5}$ e maiores que 7,2 , com concentrações proporcionais à dosagem de coagulante empregada. Para valores de $\mathrm{pH}$ entre 5,5 e 7,2, observa-se que toda a concen tração de coagulante precipitou sob a forma de $\mathrm{Al}(\mathrm{OH})_{3(s)}$.

\subsubsection{Diagrama de Equilïbrio das Espécies de Aluminio}

De acordo com os trabalhos de BLACK \& CHEN (13), AMIRTHARA 


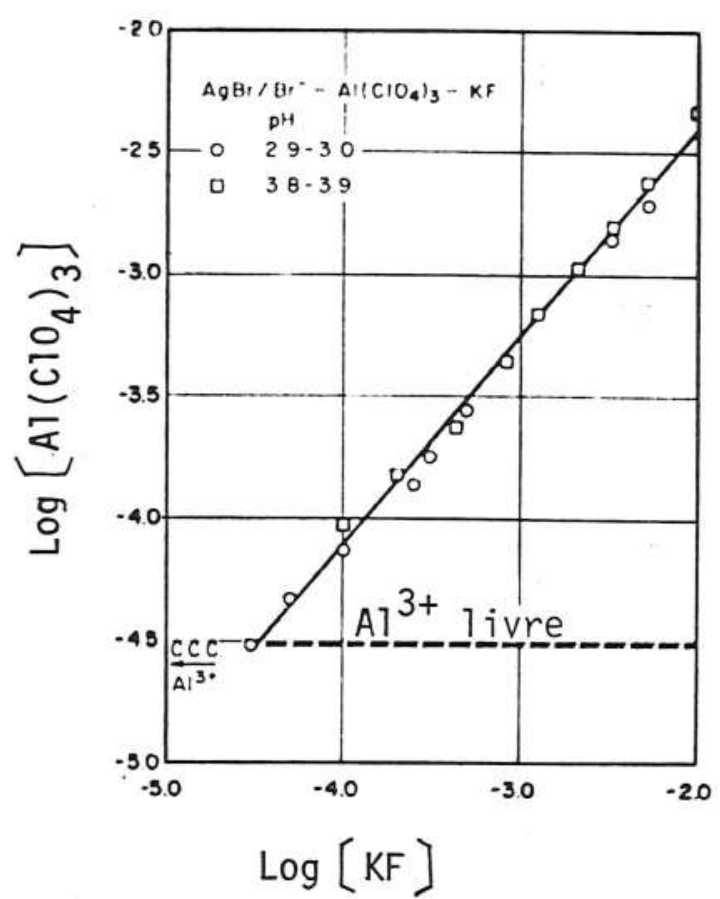

Figura 3.14 - Concentração crítica de coagulação (CCC) como função da adi ção de fluoreto de potássio, utilizando-se perclorato de alu minio e sōis de brometo de nrata em dois valores de pH (55).

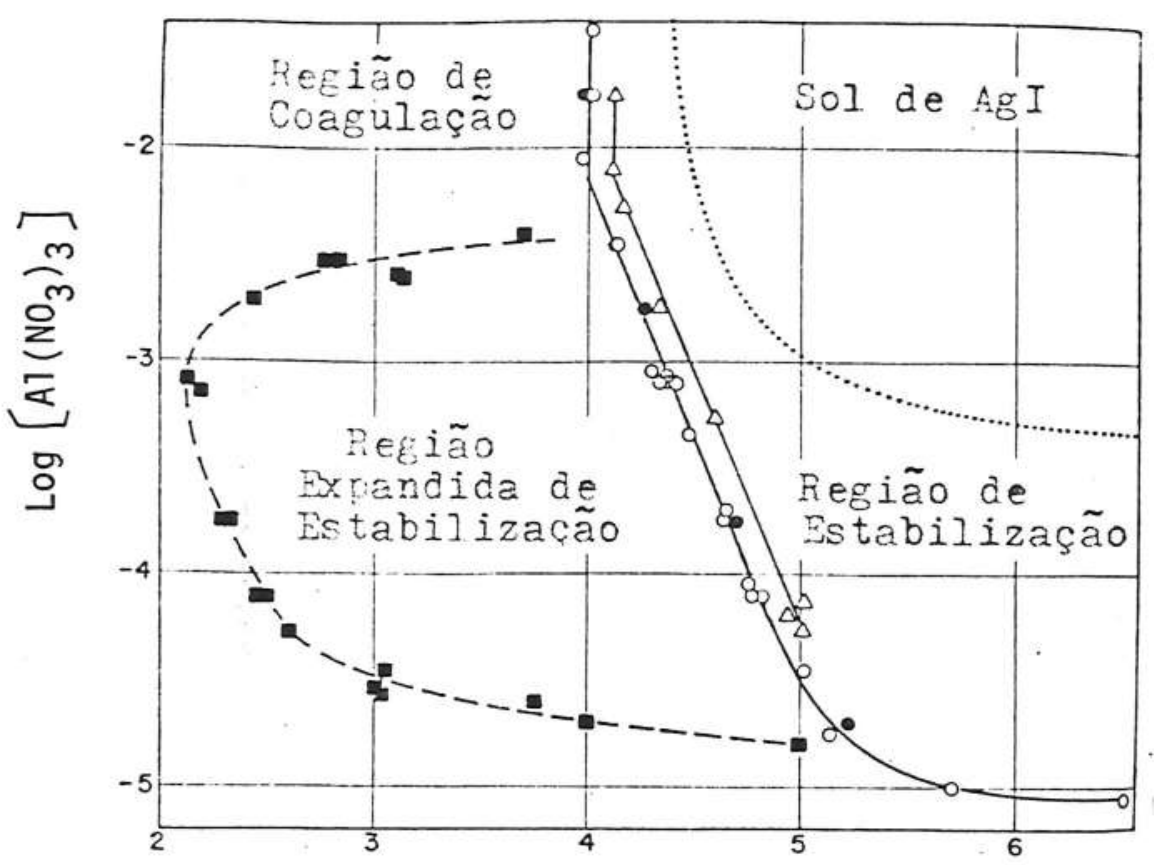

$\mathrm{pH}$

Figura 3.15 - Logarítmo da concentração molar de nitrato de aluminio em fun ção do valor do pH para sóis de iodeto de prata $(60)$. 


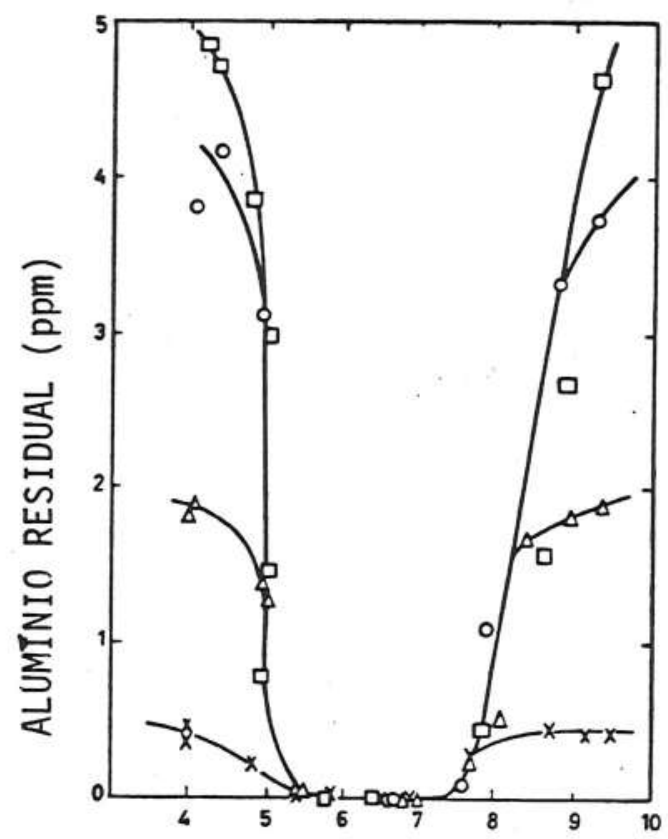

$\mathrm{pH}$

Figura 3.16 - Efeito do pH sobre as espécies residuais de aluminio em solu ção (74).

$\times 5 \mathrm{ppm} \mathrm{de} \mathrm{Al}_{2}\left(\mathrm{SO}_{4}\right)_{3} .18 \mathrm{H}_{2} \mathrm{O}=0,4 \mathrm{ppm} \mathrm{Al}$;
$\triangle 25 \mathrm{ppm}$ de
$=2,0 \mathrm{ppm} "$;
- 75 ppm de
$=6,1 \mathrm{ppm} "$;
- 200 ppm de
$=16,2 \mathrm{ppm} n$.

JAH \& MILLS (03) e STUMM \& O'MELIA (84), a construção do diagrama de equi librio entre as diversas espécies de aluminio presentes baseia-se nas rea çōes quimicas dadas a seguir, juntamente com suas resnectivas constantes de equilïbrio para āgua destilada em pH neutro à temperatura de $250 \mathrm{C}$.
a) $\mathrm{Al}^{3+}+\mathrm{H}_{2} \mathrm{O}=\mathrm{Al}(\mathrm{OH})^{2+}+\mathrm{H}^{+} ;\left(\log \mathrm{K}_{a}=-5,02\right)$
b) $2 \mathrm{Al}^{3+}+2 \mathrm{H}_{2} \mathrm{O}=\mathrm{Al}_{2}(\mathrm{OH})_{2}^{4+}+2 \mathrm{H}^{+} ;\left(\log \mathrm{K}_{b}=-6,27\right)$
c) $6 \mathrm{Al}^{3+}+15 \mathrm{H}_{2} \mathrm{O}=\mathrm{Al}_{6}(\mathrm{OH})_{15}^{3+}+15 \mathrm{H}^{+} ;\left(\log \mathrm{K}_{\mathrm{C}}=-47,00\right)$
d) $8 \mathrm{Al}^{3+}+2 \mathrm{OH}_{2} \mathrm{O} \rightarrow \mathrm{Al}_{8}(\mathrm{OH})_{20}^{4+}+2 \mathrm{OH}^{+} ;\left(\log \mathrm{K}_{d}=-68,70\right)$
e) $13 \mathrm{Al}^{3+}+34 \mathrm{H}_{2} \mathrm{O} \Rightarrow \mathrm{Al}_{13}(\mathrm{OH})_{34}^{5+}+34 \mathrm{H}^{+} ;\left(\log \mathrm{K}_{e}=-97,39\right)$
6) $\mathrm{Al}(\mathrm{OH})_{3(\mathrm{~s})} \rightleftarrows \mathrm{Al}^{3+}+3 \mathrm{HH}^{-} ;\left(\log \mathrm{K}_{6}=-32,34\right)$
g) $\mathrm{Al}(\mathrm{OH})_{3(\mathrm{~s})}+\mathrm{H}_{2} \mathrm{O}=\mathrm{Al}(\mathrm{OH})_{4}^{-}+\mathrm{H}^{+} ;\left(\log \mathrm{K}_{9}=-12,74\right)$ 
A construção do diagrama de equilíbrio das espécies de alu minio como função do pH requer a obtenção de equações que forneçam as con centrações de cada espécie como função do valor do pH. Partindo-se da especie $\mathrm{Al}^{3+}$ e da equação 3.22, que $\bar{e}$ a mais simplificada, tem-se :

$$
K_{6}=\frac{\left[\mathrm{Al}^{3+}\right]\left[\mathrm{OH}^{-}\right]^{3}}{\left[\mathrm{Al}(\mathrm{OH})_{3(\mathrm{~s})}\right]}
$$

como $\left[\mathrm{Al}(\mathrm{OH})_{3(\mathrm{~s})}\right]=1$, aplicando-se o logarétmo de ambos os lados da equa ção (3.24), tem-se :

$$
\log K_{6}=\log \left[\mathrm{Al}^{3+}\right]+3 \log \left[\mathrm{OH}^{-}\right]
$$

como $\log K_{f}=-32,34$ e $\log \left[\mathrm{OH}^{-}\right]=\mathrm{pH}-14$, tem-se:

$$
\begin{aligned}
& \log \left[A l^{3+}\right]=-32,34-3(p H-14) \\
& \log \left[A l^{3+}\right]=9,66-3 p H
\end{aligned}
$$

Analogamente, partindo-se da equação (3.23), para a espe-

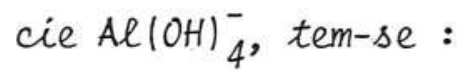

$$
K_{g}=\frac{\left[\mathrm{Al}(\mathrm{OH})_{4}^{-}\right]\left[\mathrm{H}^{+}\right]}{\left[\mathrm{Al}(\mathrm{OH})_{3(\mathrm{~S})}\right]\left[\mathrm{H}_{2} \mathrm{O}\right]}
$$

como $\left[\mathrm{Al}(\mathrm{OH})_{3(\mathrm{~s})}\right]\left[\mathrm{H}_{2} \mathrm{O}\right]=1$, aplicando-se o logarétmo de ambos os lados da equação (3.28), tem-se :

$$
\log K_{g}=\log \left[\mathrm{Al}(\mathrm{OH})_{4}^{-}\right]+\log \left[\mathrm{H}^{+}\right]
$$

como $\log K_{g}=-12,74$ e $\log \left[H^{+}\right]=-p H$, tem-se:

$$
\log \left[\mathrm{Al}(\mathrm{OH})_{4}^{-}\right]=-12,74+\mathrm{pH}
$$

Fazendo-se o mesmo para cada espécie, chegaremos às equa ções dadas a seguir :

$$
\log \left[A l(O H)^{2+}\right]=4,64-2 p H
$$




$$
\begin{aligned}
& \log \left[\mathrm{Al}_{2}(\mathrm{OH})_{2}^{4+}\right]=13,05-4 \mathrm{pH} \\
& \log \left[\mathrm{Al}_{6}(\mathrm{OH})_{15}^{3+}\right]=10,96-3 \mathrm{pH} \\
& \log \left[\mathrm{Al}_{8}(\mathrm{OH})_{20}^{4+}\right]=8,58-4 \mathrm{pH} \\
& \log \left[\mathrm{Al}_{13}(\mathrm{OH})_{34}^{5+}\right]=28,19-5 \mathrm{pH}
\end{aligned}
$$

A Figura 3.17 apresenta o diagrama de equilibrio entre as espécies solūveis de aluminio com a espécie insolüvel precipitāvel Al(OH) ${ }_{3}$, através da representação do logarítmo da concentração de cada espécie como função do valor do pH da solução.

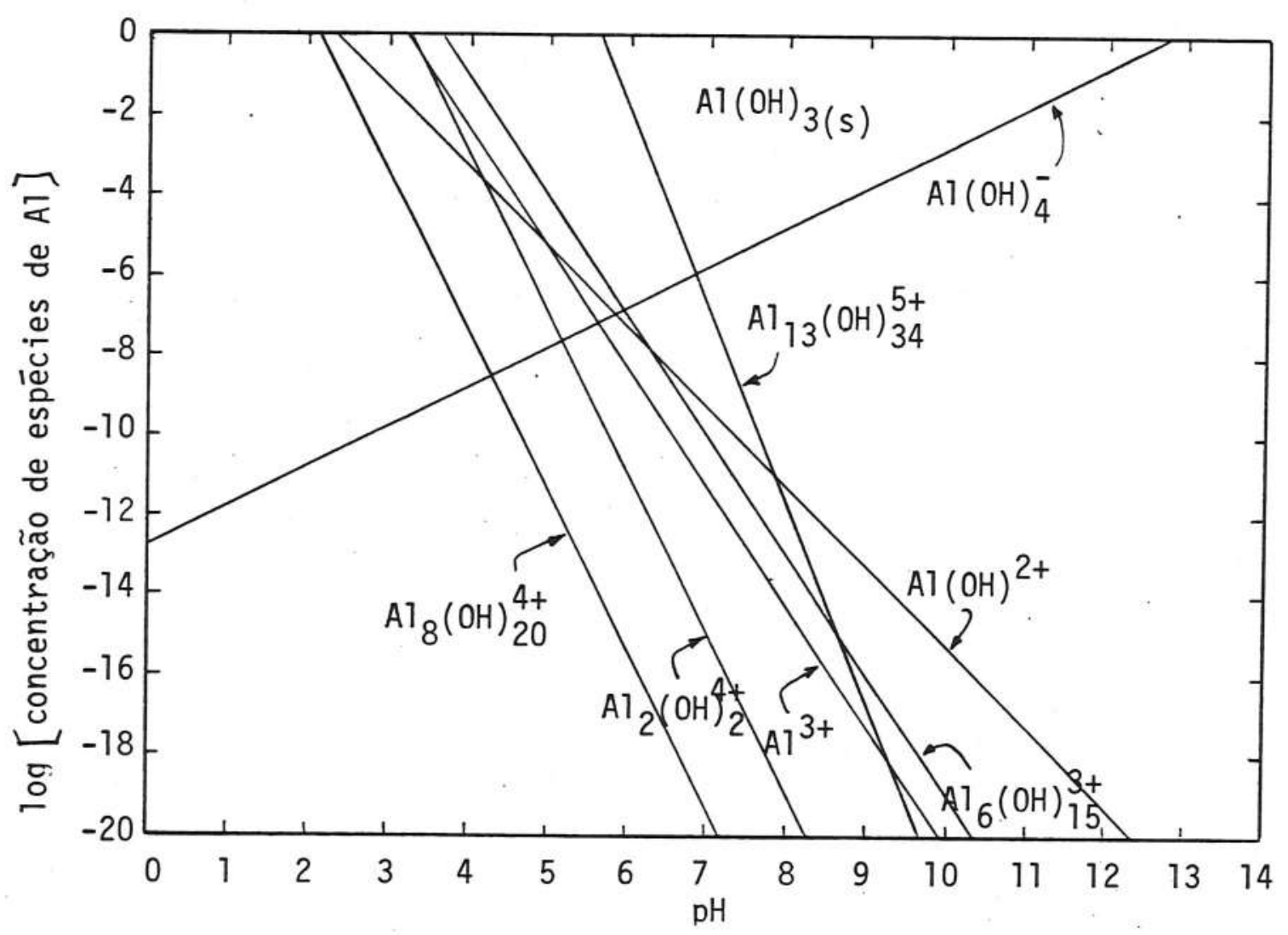

Figura 3.17 - Diagrama de equilibrio entre as espécies preponderantes de aluminio em função do valor do pH da solução para āgua desti lada $\bar{a} 250$ c. 


\subsubsection{Mecanismos de Coagulação com Sulfato de Aluminio}

Segundo O'MELIA (71), as reações de coagulação resultantes da interação entre os produtos da hidrölise do aluminio e as suspensões co loidais, apresentam uma cinētica governada predominantemente por dois meca nismos distintos ou pela ação conjunta de ambos:

i) Adsorção das espécies hidrolisadas na superfície dos colōides com sua consequente desestabilização 1 adsor ção e neutralização I;

ii) Aprisionamento das partículas coloidais pelo precipita do gelatinoso do composto amorfo $\mathrm{Al}(\mathrm{OH})_{3(s)}$ (varredura).

A grande maioria dos recentes estudos de coagulação têm de monstrado a validade da ação dos mecanismos citados acima, havendo algumas discordâncias quanto a forma de ação do mecanismo de adsorção e neutraliza ção sobre as moléculas orgânicas causadoras de cor. Alguns pesquisadores crêem numa reação química entre as espécies de aluminio e as moléculas de ácidos hümicos e fülvicos, formando compostos desestabilizados de humatos ou fulvatos de aluminio; outros, na redução do potencial repulsivo pela com pressão da camada dupla.

0 interessante estudo de BLACK \& CHEN (13) sobre a coagula ção de suspensões de caulinita em diferentes valores de $\mathrm{pH}$, usando 0 com posto $\mathrm{Al}_{2}\left(\mathrm{SO}_{4}\right)_{3} \cdot 18 \mathrm{H}_{2} \mathrm{O}$ como coagulante, ilustra claramente os mecanismos de coagulação mencionados, além do da compressão da camada dupla, que foge às situaçöes convencionais, pois ocorre para faixas de pH inferiores a 4 .

Segundo os mesmos pesquisadores, na gama de variação de do sagens de sulfato de aluminio normalmente empregadas para o tratamento de äguas para abastecimento, a concentração molar do. ion aluminio varia de $10^{-6}$ a $10^{-3}$ e entre valores de $\mathrm{pH}$ variando de 3 ate 10 , podem ser destaca das as seguintes espécies predominantes de aluminio:

i) para valores de $\mathrm{pH}$ inferiores a 4, ocorre a predomi nância da espécie $\mathrm{Al}^{3+}$;

ii) para valores de $\mathrm{pH}$ entre 4 e 6 , manifestam-se os $c \bar{a}$ tions polinucleares de aluminio: $\mathrm{Al}_{6}(\mathrm{OH})_{15}^{3+}, \mathrm{Al}_{8}(\mathrm{OH})_{20}^{4+}, \mathrm{Al}_{7}(\mathrm{OH})_{17}^{4+}$ e $\mathrm{Al}_{13}(\mathrm{OH})_{34}^{5+}$ 
solüvel $\mathrm{Al}(\mathrm{OH})_{3(s)}$;

iii) para valores de pH entre 6 e 8 , predomina a espécie in $\mathrm{Al}(\mathrm{OH})_{4}^{-}$

iv) para valores de $\mathrm{pH}$ superiores a 8 , predomina a espécie

Realizando ensaios para valores de $\mathrm{pH}$ iguais a 3,5 e 8 , va riando-se a concentração de coagulante e caulinita e medindo-se a mobilida de eletroforética, a turbidez residual das particulas e a quantidade de aluminio residual, BLACK \& CHEN (13) chegaram a resultados que possibilitaram a construção das Figuras 3.18 (I; II e III), respectivamente para os pHs de 3,5 e 8 .

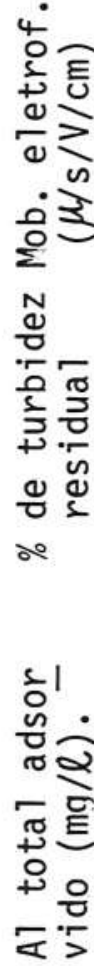

I $(\mathrm{pH}=3)$
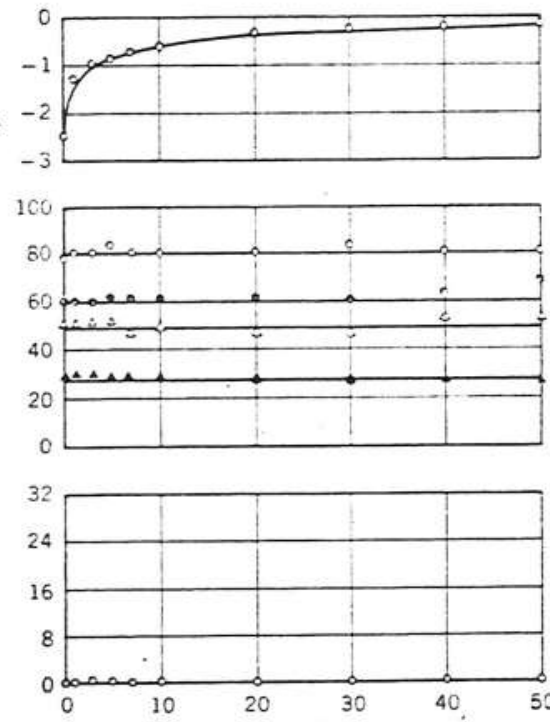

$$
\text { II }(\mathrm{pH}=5 \pm 0,05)
$$
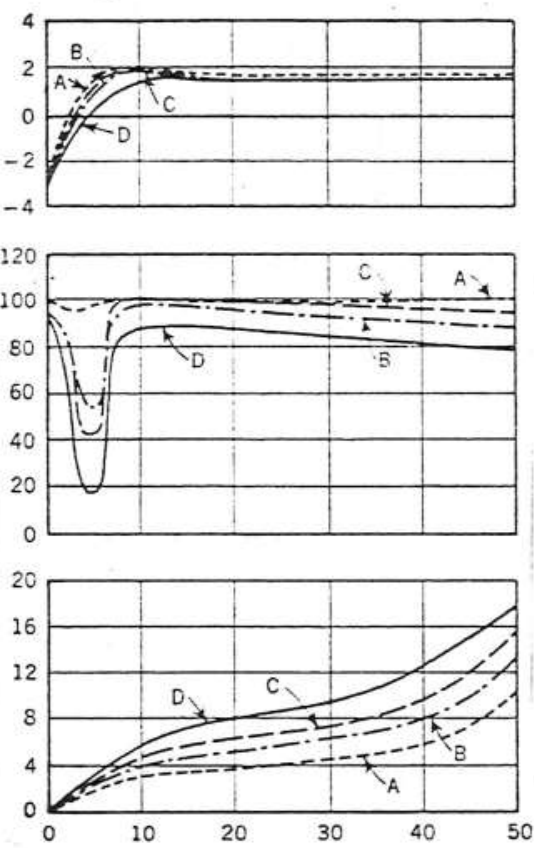

III $(\mathrm{pH}=8 \pm 0,1)$
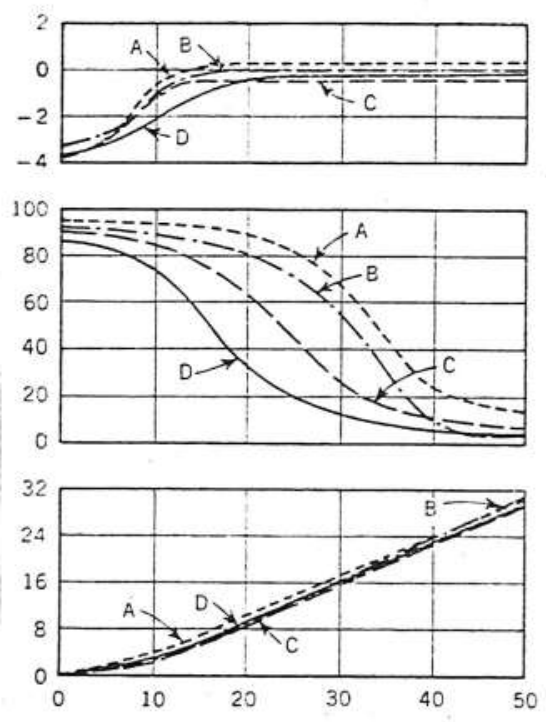

Figura 3.18 - Desestabilização de suspensões de caulinita com sulfato de alu minio para os pHs de $3(I) ; 5(I I)$ e $8(I I I)$. Concentrações das suspensões originais de caulinita: A ou $0: 15,8 \mathrm{mg} / \ell ; B$ ou $\bullet$ : $31,7 \mathrm{mg} / \mathrm{l}$; $C$ ou $\Delta: 47,5 \mathrm{mg} / \mathrm{l}$ e $D$ ou $\Delta: 63,3 \mathrm{mg} / \mathrm{l}$ (13).

A anälise da Figura 3.18 (I) indica que não houve adsorção das espécies de aluminio, no caso o $\mathrm{Al}^{3+}$, para dosagens de sulfato de alum $\overrightarrow{\underline{-}}$ nio ate $50 \mathrm{mg} / \ell$. Por outro lado, para as quatro suspensões de caulinita in 
vestigadas, a mobilidade eletroforética das particulas foi reduzida de $-2,5$ para $-0,3 \mu / \mathrm{s} / \mathrm{V} / \mathrm{cm}$. Tal fato sō pode ser explicado pela ocorrência do meca nismo de redução da espessura da camada dupla que é proporcional a concen tração de ions de carga conträria em solução e independente da concentração dos colöides.

De acordo com MATIJEVIC e a teoria de DLVO os cātions de $\mathrm{Al}^{3+}$, não são canazes de reverter a carga superficial dos colóides, assim como observado.

Os dados de proporcionalidade entre a concentração dos $\underline{c o}$ lóides e a remoção de turbidez podem ser explicados pela teoria de SMOLUCHOWSKI que baseia-se na probabilidade de colisão entre as particulas, por sua vez, proporcional ao nümero destas.

$\mathrm{Na}$ Figura 3.18 (II), observa-se a manifestação do mecanismo de adsorção e neutralização pelas espécies polinucleares adsorvëveis de alu minio (ver quadro inferior). Assim como esperado, tais espécies apresenta ram uma CCC pequena (da ordem de $3 \mathrm{mg} / \mathrm{l}$ de sulfato de aluminio) e provoca ram a restabilização das partículas de caulinita por inversão da carga su perficial devido ao excesso de espécies de aluminio adsorvidas.

Na Figura 3.18 (III), verifica-se a ocorrência do mecanismo de varredura que, também pode ser interpretado como o mecanismo de coagula ção mütua entre as colöides de carga negativa (partículas de caulinita) e os colóides de carga positiva, representados pelas espécies insolüveis de hi drōxido de aluminio $\left(\mathrm{Al}(\mathrm{OH})_{3}^{n+}\right)$. Segundo AMIRTHARAJAH (OZ), o ponto isoelētri co (mobilidade eletroforética igual a zero) da espécie $\mathrm{Al}(\mathrm{OH})_{3(s)}$, encontra -se na faixa de variação de pH entre 7,0 e 9,0, dependendo da concentração $e$ tipo de ânions presentes na solução.

observando-se as curvas de mobilidade eletroforética de ca da suspensão caulinita como função da dosagem de sulfato de aluminio, ve rifica-se que, a desestabilização das particulas coloidais ocorre para dosá gens superiores a $10 \mathrm{mg} / \ell$ de coagulante $e$ que o sinal residual das cargas $\underline{e}$ létricas das particulas desestabilizadas depende da concentração inicial dos colöides. Assim, altas concentrações iniciais de partículas a serem desesta bilizadas tendem a manter uma carga residual negativa e vice-versa.

As curvas de eficiência de remoção de turbidez e de alumî nio total consumido permitem observar que a clarificação por sedimentação dos flocos formados é proporcional a concentração de colöides no sistema, indicando a necessidade de uma dosagem de coagulante inversamente proporcio 
nal ao aumento da concentração de colōides para a obtenção de uma mesma efí ciência de remoção de turbidez.

\subsection{Estudos Experimentais da Coagulação}

\subsubsection{Coagulação de Aguas para Remoção de Turbidez}

Em 1949, LANGELIER \& LUDWIG (50) evidenciaram a importancia da capacidade de troca de cātions (CEC) de suspensões de argila sobre o pro cesso de coagulação. Eles demonstraram a necessidade de se adicionar uma quantidade de coagulante proporcional ao CEC para que ocorresse a desestabi lização das particulas em suspensão e uma quantidade extra para possibili tar a agregação das mesmas em flocos. Além desta contribuição, o trabalho $\underline{e}$ videnciou a importância da alcalinidade na determinação da dosagem de coagu lante, que se manifesta atravēs da variação do pH da amostra de água coagu lada e indica a existência de um valor de pH ötimo, no qual a eficiência de remoção de turbidez para uma mesma dosagem de coagulante $\bar{e}$ maximizada.

Estimulados pelas críticas feitas por PACKHAM (73) ao traba tho de LANGELIER \& LUDWTG (50) que não mantiveram um valor de pH constante nos testes de CEC versus a dosagem de coagulante e pelo uso de novas técni cas na medição do potencial Zeta atravēs da determinação da mobilidade ele troforética com o auxilio de microscópio, demonstradas por PILIPOVICH (76), BLACK (11) e RIDDICK (77), KIM; LUDWIG e BISHOP (48), em 1965, publicaram um estudo onde divulgaram diversas conclusões interessantes sobre a coagula ção de äguas com concentrações variāveis de caulinita e bentonita com o uso de sulfato de aluminio, dentre as quais, pode-se destacar :

a) Sobre a mobilidade eletroforética de particulas de argi la :

As medidas de mobilidade eletroforética apōs a coagulação são afetadas pelo tempo, tendendo aos valores originais, como mostra a Figu ra 3.19. Este fato deve-se ao equilibrio químico dado pelas reaçōes seguin tes :

$$
\mathrm{Al}_{2}\left(\mathrm{SO}_{4}\right)_{3}+6 \mathrm{NaHCO}_{3}+6 \mathrm{H}_{2} \mathrm{O} \rightleftharpoons 2 \mathrm{Al}(\mathrm{OH})_{3}(\mathrm{~s})+3 \mathrm{Na}_{2} \mathrm{SO}_{4}+6 \mathrm{H}_{2} \mathrm{CO}_{3} .
$$




$$
{ }_{2 \mathrm{HCO}_{3}^{-}} \rightleftharpoons \mathrm{H}_{2}^{\mathrm{CO}} \mathrm{CO}_{3} \text { (atmosférico) }
$$

Ocorre que, nos instantes iniciais apōs a adição de sulfato de aluminio com a ägua, manifesta-se uma supersaturação de $\mathrm{H}_{2} \mathrm{CO}_{3} \mathrm{com}$ a con sequente queda do valor do pH. Tal desequilibrio é corrigido lentamente com a troca de $\mathrm{CO}_{2}$ com a atmosfera, cuja solubilidade a uma pressão atmosférica unitaria, na temperatura de 20 oc e $1 \mathrm{me} / \ell$ de alcalinidade a bicarbonato $\bar{e}$ de 0,51 ppm num valor de pH próximo de 8,2.

Segundo os pesquisadores, o aumento gradual do $\mathrm{pH}$ pode in terferir com a carga dos complexos de aluminio adsorvidos, causando a rever são da carga das particulas de argila.

\section{b) Sobre o pH de coagulação}

Definindo os termos pH ötimo como sendo o correspondente a obtenção de "boa coagulação com formação de flocos grandes e de fácil sedi mentação para a menor dosagem de sulfato de aluminio" e pH isoelétrico (pH ${ }_{i}$ ) no qual a "carga elétrica líquida dos complexos hidroxos de aluminio corres pondem ao valor zero", ou ainda "de minima solubilidade dos compostos de a luminio", KIM, LUDWIG e BISHOP concluiram que :

$$
\text { i) o pH ötimo de coagulação depende da alcalinidade }
$$

inicial presente na suspensão $e$ o aumento desta $\bar{e}$ inversamente proporcional. ao valor deste;

ii) o pH ótimo de coagulação independe da dosagem de sulfá to de aluminio empregada, porém, sua faixa de variação é tanto maior quanto maior for a dosagem;

As conclusões $(i)$ e (ii) podem ser comprovadas através da ob servação da Figura 3.20 .

iii)o pH ötimo de coagulação $\bar{e}$ coincidente com o pH $i$ de $\mathrm{Al}(\mathrm{OH})_{3(s)}$ para suspensões de argila com valores de CTC inferiores a 10 $\mu e / \ell$. Para suspensões com CTC superiores a $10 \mu \mathrm{e} / \ell$ o pH ötimo deve ser infe rior ao $\mathrm{pH}_{i}$.

A Figura 3.21 fornece os valores do $\mathrm{pH}_{i}$ como função da con 


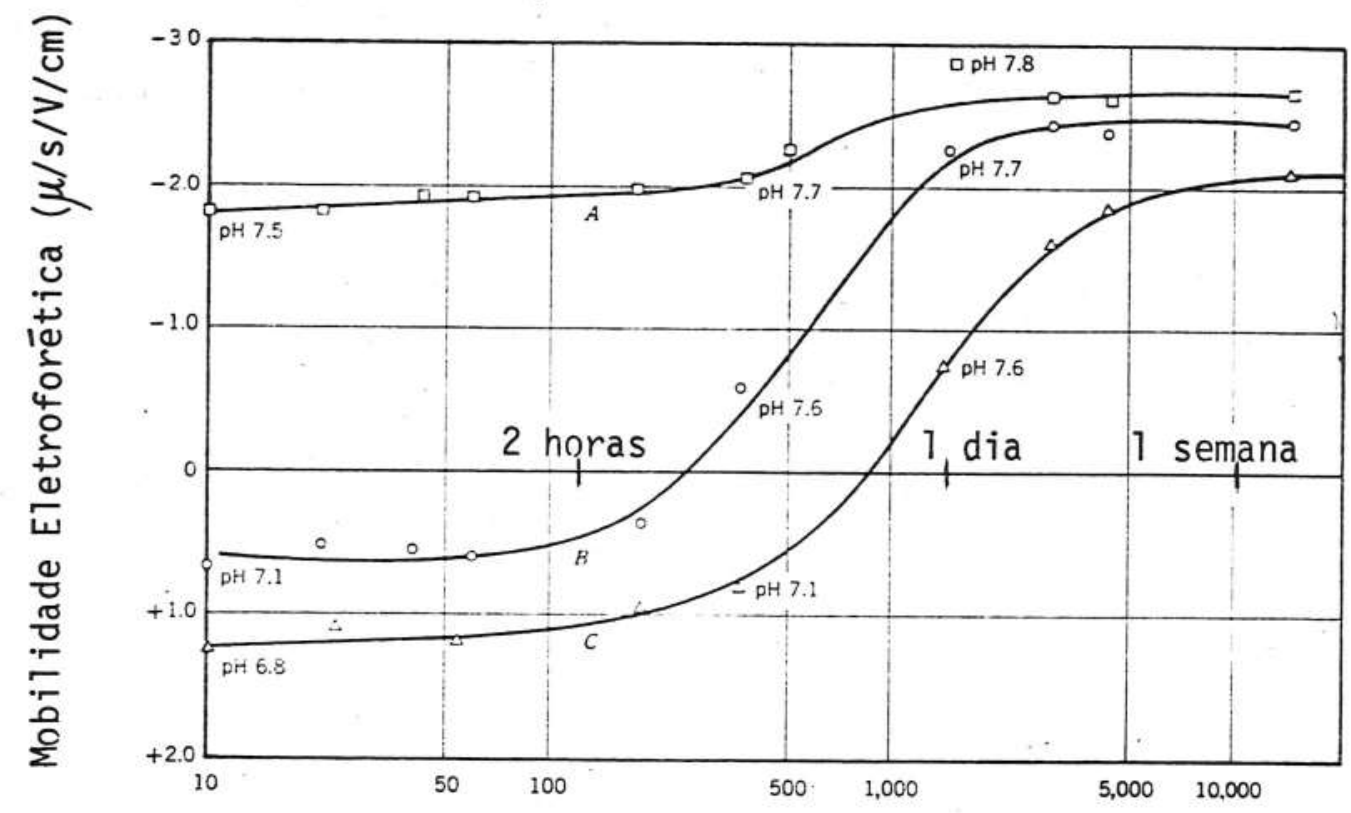

Intervalo de tempo apōs a coagulação (minutos)

Figura 3.19 - Efeito do envelhecimento sobre a mobilidade eletroforética (48). - mobilidade eletroforética original : $-2,7 \mu / \mathrm{s} / \mathrm{V} / \mathrm{cm}$;

- pH inicial : 7,7 ;

- alcalinidade inicial : $1 \mathrm{me} / \mathrm{l}$;

- concentração de caulinita : $100 \mathrm{mg} / \ell$;

- temperatura : $20 \pm 1 \mathrm{oC}$;

- dosagem de sulfato de aluminio: $\left\{\begin{array}{l}A=2 \mathrm{ppm} ; \\ B=7 \mathrm{ppm} ; \\ C=14 \mathrm{ppm} .\end{array}\right.$

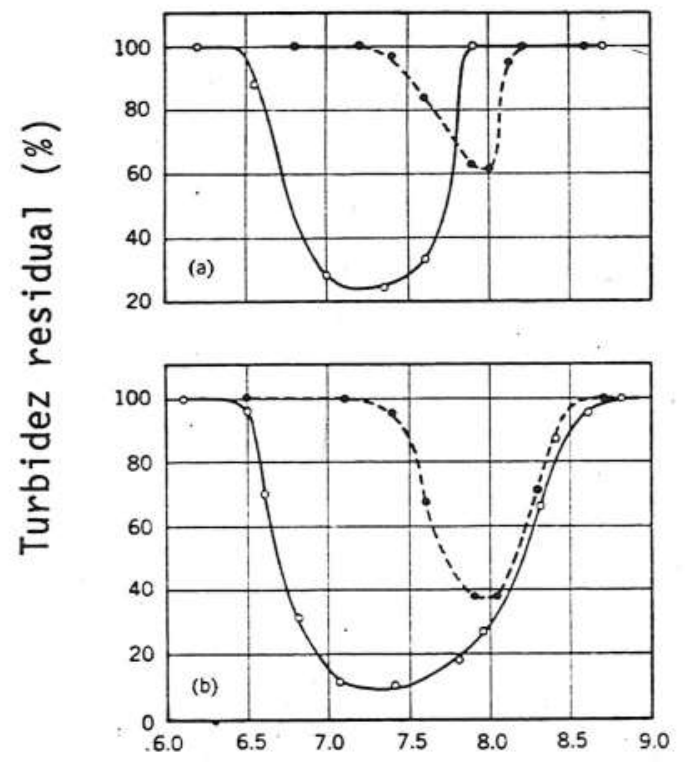

Figura 3.20 - Efeitos da alcalini dade e da dosagem de coagulante sobre o pH ótimo (48).

- concentração de caulinita : $50 \mathrm{ppm}$;

- dosagem de sulfato de alumi nio : (a) 4 ppm;

(b) 10 ppm.

- alcalinidade inicial :

(---) 0,4 me/l;

(-) $2,0 \mathrm{me} / \ell$.

$\mathrm{pH}$ final da suspensão 
centração de bicarbonato.

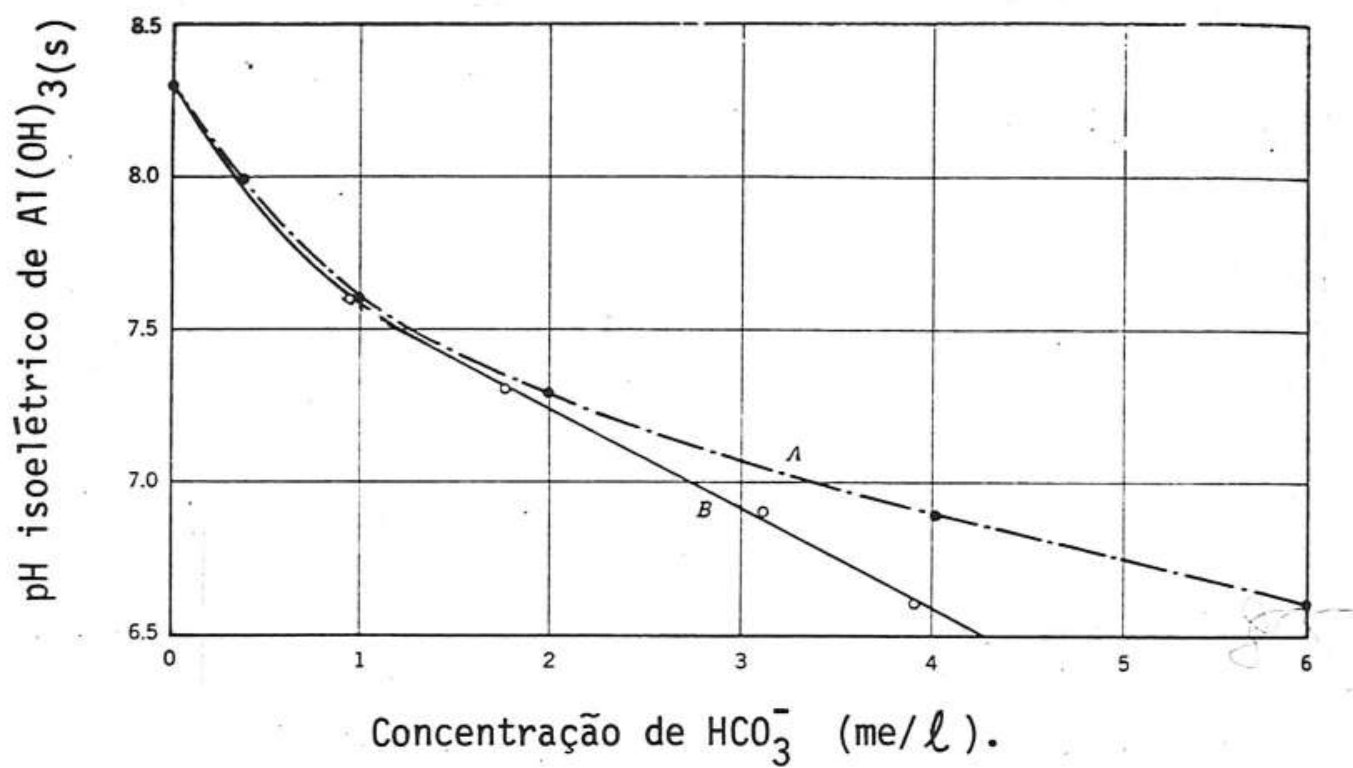

Figura 3.21 - pH isoelétrico $\left(\mathrm{pH}_{i}\right)$ em função da concentração de bicarbonato (48).

- linha A representa a concentração inicial de $\mathrm{HCO}_{3}^{-}$;

- linha $B$ representa a concentração final de $\mathrm{HCO}_{3}^{-}$.

A explicação para a conclusão (iii) pelos autores $\bar{e}$ trans crita a seguir : " Para suspensões de argila com altas concentrações de par ticulas por unidade de volume ( CTC $>10 \mu \mathrm{e} / \mathrm{l}$ ), uma pequena reducão da car ga das partículas pronorcionarā uma boa coagulação pela ação da floculação pericinética. Desta forma, as espēcies hidrolisadas solüveis de aluminio de carga positiva são mais eficientes que as espécies neutras ou negativas, As sim, o pH ötimo manifesta-se em valores de $\mathrm{pH}$ inferiores ao $\mathrm{pH}_{i}$. Sabendo-se que a concentração das espécies hidrolisadas de aluminio com carga positiva $\bar{e}$ inversamente proporcional ao valor do $\mathrm{pH}$, espera-se que o conträrio ocor ra com relação à dosagem de sulfato de aluminio necessāria para desestabilí zar uma suspensão com CTC constante, Por outro lado, mantido o pH constante, a dosagem de sulfato de aluminio necessäria é proporcional à concentração de particulas por unidade de volume ou ao CTC ( ver Figura 3.22 )".

Para suspensões cujo CTC $\bar{e}$ inferior a $10 \mu \mathrm{e} / \mathrm{l}$, ou seja, quan do a taxa de variação da concentração de partĩculas pela ação da floculação pericinética é pequena, o nümero de partículas deve ser aumentado através do aumento da concentração de $\mathrm{Al}(\mathrm{OH})_{3(s)}$, que se dā em maiores proporcões no $\mathrm{pH}$ isoelétrico (ver Figura 3.22). 

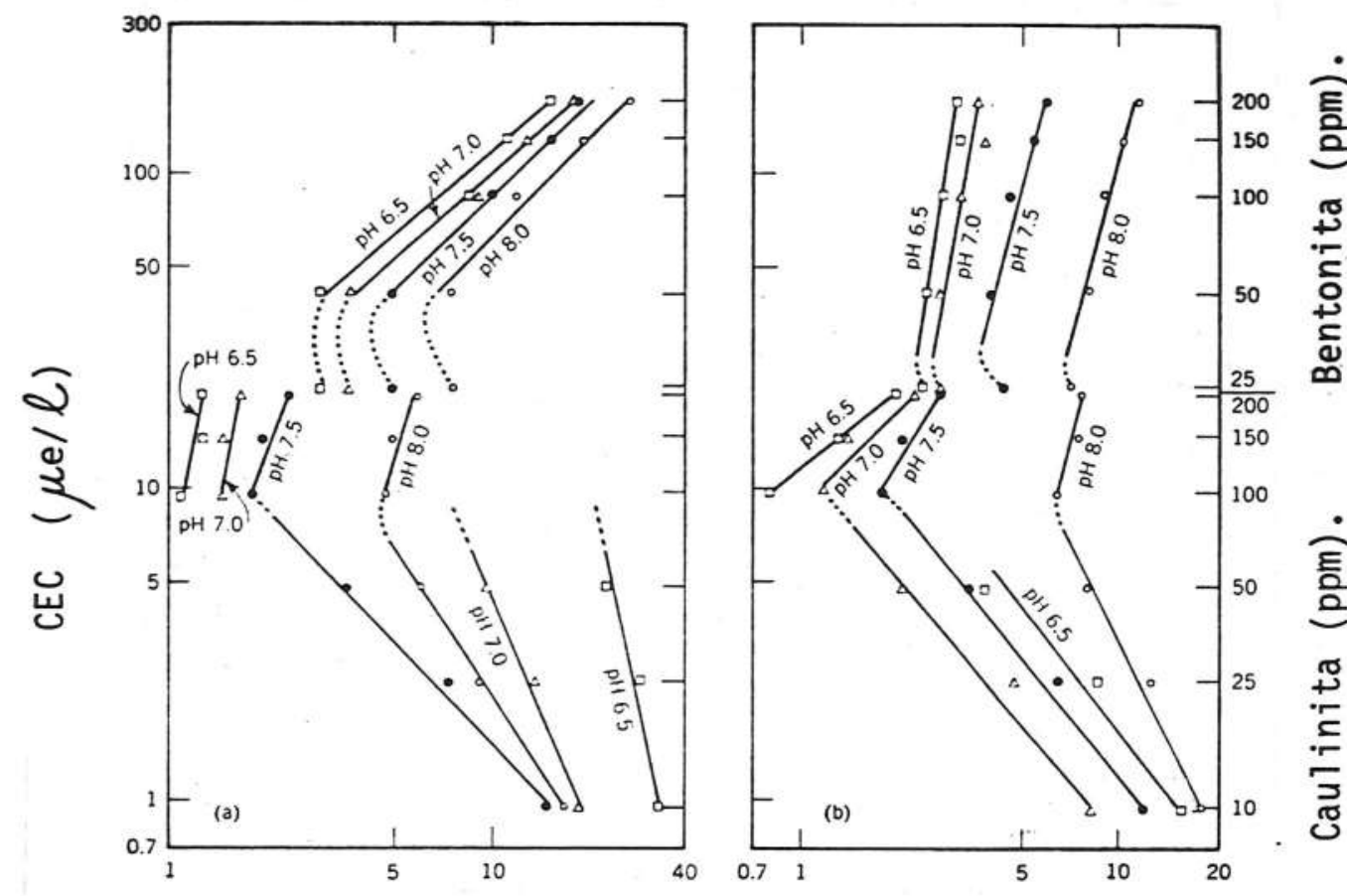

Dosagem de sulfato de alumīnio necessāria para redu zir a turbidez inicial para a metade $(\mathrm{mg} / \mathrm{l})$.

Figura 3.22 - Relações entre o CTC e a dosagem de sulfato de aluminio (48). - alcalinidade inicial : (a) $1 \mathrm{me} / \mathrm{l}$;

$$
\text { (b) } 4 \mathrm{me} / \mathrm{l} \text {. }
$$

Em 1968, STUMM \& O'MELIA (84), publicaram um estudo de pes quisa, no qual descreveram os mecanismos de coagulação envolvidos para dí versos valores de $\mathrm{pH}$ e concentração de colöides. Entre as suas conclusöes, destaca-se que, para altas concentrações de superficie coloidal, a coagula ção $\bar{e}$ realizada pela adsorção de compostos multinucleares hidrolisados de aluminio, enquanto que, para baixas concentrações, particularmente de cau linita $(<100 \mathrm{mg} / \mathrm{l})$, a remoção das partículas $\bar{e}$ feita por emanharamento com - hidrōxido de aluminio insolūvel, caso o valor do $\mathrm{pH}$ da suspensão seja fa vorável a sua formação lperfeitamente de acordo com os dados de KIM; LUD WIG e BISHOP (48) ).

A Figura 3.23 resume as conclusões obtidas por STUMM \& $0^{\prime}$ MELIA. Para baixas concentrações, a coagulação segue uma relação não esté quiomētrica, através do mecanismo de floculação por emanharamento ou varre dura (zona 4). Como pode ser observado, na zona 2, a relação entre a con centração superficial dos colōides e a dosagem de coagulante é estequiometrica.

Segundo os mesmos pesquisadores, o fenômeno da coagulação depende das relações entre, pelo menos, três variāveis : a concentração de 

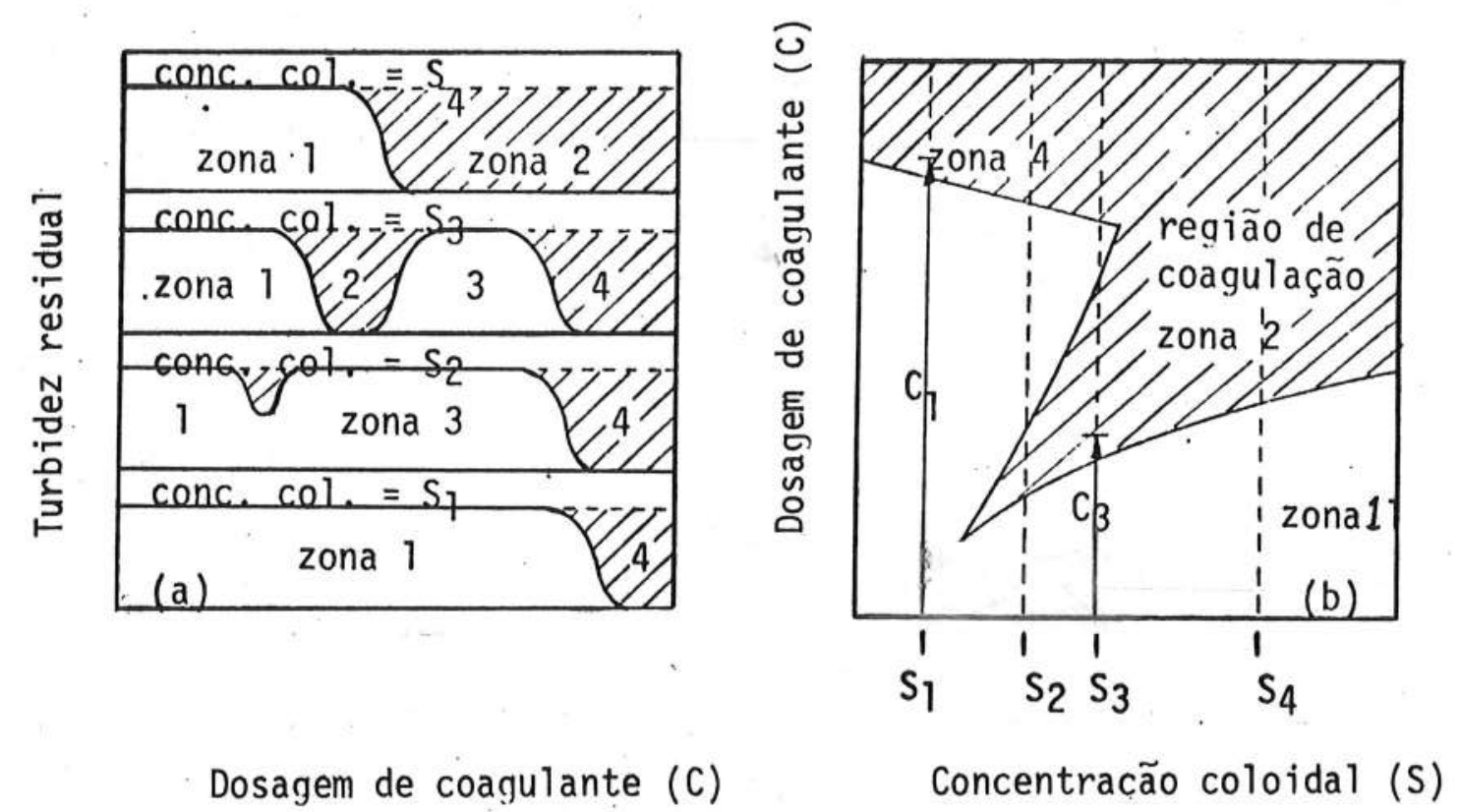

Figura 3.23 - Regiões onde é possivvel a coagulação (com remoção de turbidez por sedimentação) (84).

(a). Curvas esquemäticas de coagulação em pHs constantes para quatro concentra ções coloidais. Indicam secçōes $s_{1}, s_{2}, s_{3}$ e $s_{4}$ da Figura 3.23 (b).

(b) Efeito da concentração coloidal na dosagem de coagulante para a desestabi lização, restabilização e precipitação sob pH constante.

As regiöes hachur adas indicam a ocorrência de coagulação. 
coagulante, o pH e a concentração da superficie coloidal. Dessa forma, a de sestabilização, restabilização e a coagulacão por varredura seriam melhor representadas em três dimensões com cada eixo representando as três varīā veis influentes.

A Figura 3.24 apresenta os dominios da desestabilização, restabilização e coagulação por varredura em função da concentração do coa gulante ( no caso o Fe $\left.\left(\mathrm{ClO}_{4}\right)_{3} \cdot 6 \mathrm{H}_{2} \mathrm{O}\right)$ e do $\mathrm{pH}$ para dispersões contendo con centrações média e alta de superfícies coloidais.

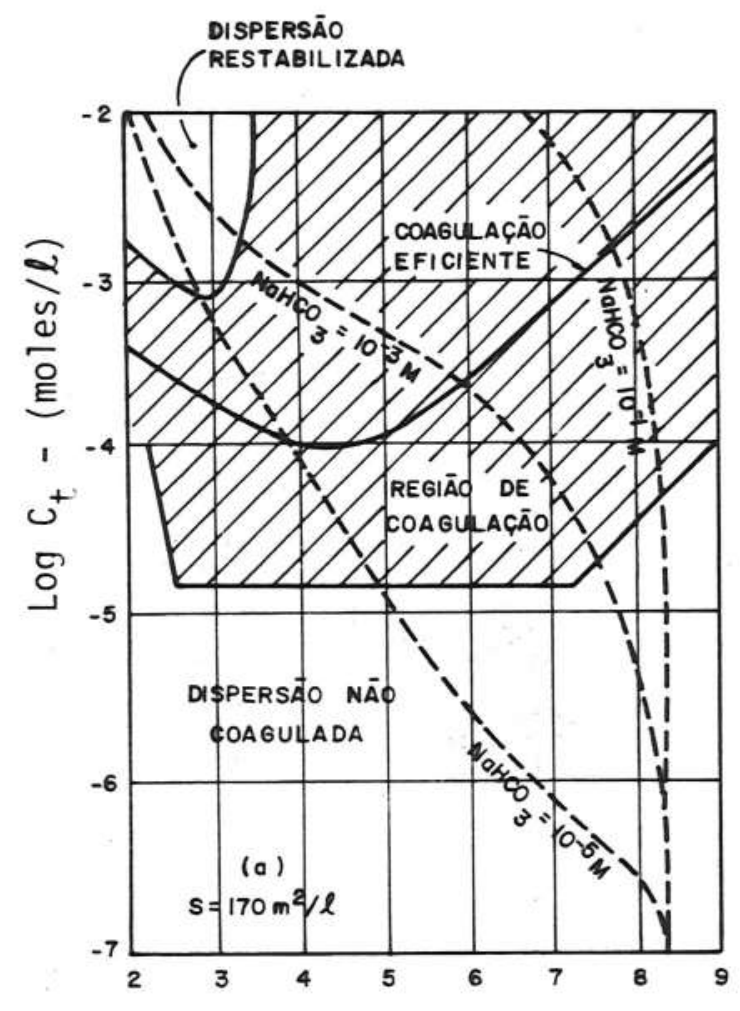

$\mathrm{pH}$

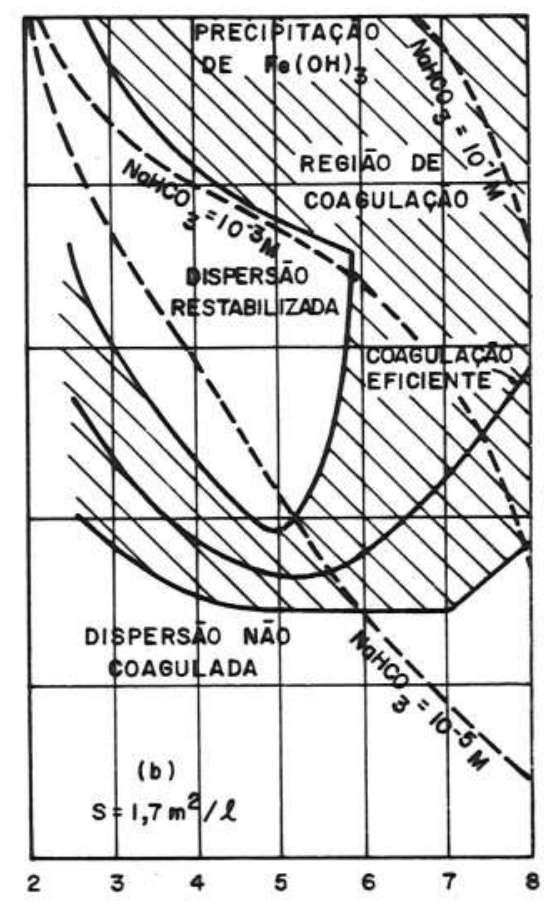

$\mathrm{pH}$

Figura 3.24 - Influência da alcalinidade inicial, do pH de coagulacão e da concentração superficial de colöides na dosagem de coagulan te $\left(\log C_{t}-\right.$ moles/l) (84).

- concentração da superficie coloidal : (a) $170 \mathrm{~m}^{2} / \ell$;

(b) $1,7 \mathrm{~m}^{2} / \ell$.

Para dispersões contendo alta concentração de superfície co loidal, a reducão da alcalinidade pode resultar numa redução da dosagem ne cessāria de coagulante. Por outro lado, a coagulação de āguas contendo con 
centrações intermediārias de superficie coloidal, pode ser feita com bai xas dosagens de coagulante se a alcalinidade também for baixa, mas os $\overline{l i}$ mites estabelecidos pela concentração crítica de coagulante (CCC), abaixo da qual não ocorre coagulação, e pela concentração critica de restabiliza ção (CCR), acima da qual ocorre a restabilização das partículas coloidais, tornam-se prōximos, dificultando a operação de coagulação nesta região Ain da, segundo STUMM \& O'MELIA, a coagulação de dispersões contendo baixa con centração de superfície coloidal e baixa alcalinidade somente com a utili zação de ions metälicos hidrolisados, torna-se impraticāvel, e deve ser $\underline{e}$ xecutada por varredura, com a adição de uma base ( por exemplo cal), que promoverā a formação de hidrōxido de aluminio insolüvel em concentrações mais baixas de coagulante.

Em 1982, AMIRTHARAJAH \& MILLS (03), propuzeram um diagra ma de projeto é operação para a coagulação empregando o sulfato de alum $\underline{\underline{\imath}}$ nio $\left(\mathrm{Al}_{2}\left(\mathrm{SO}_{4}\right)_{3} \cdot 14,3 \mathrm{H}_{2} \mathrm{O}\right)$, onde apresentam-se as regiōes especificas de $\underline{0}$ corrência dos diversos mecanismos de coagulacão como função do valor do ph de coagulação e da dosagem de coagulante empregada juntamente com a re presentação do equilíbrio entre as espécies solüveis de aluminio com a es pécie insolüvel $\mathrm{Al}(\mathrm{OH})_{3(s)}$.

Nesse diagrama, mostrado na Figura 3.25, visualizam-se as regiōes de ocorrência do mecanismo de adsorção-desestabilização Ineutrali zaçãol, de varredura e da combinação de ambos os mecanismos, assim como as regiões de restabilização, cujos limites variam com a concentração super ficial das particulas a serem coaguladas.

Os mesmos autores realizaram uma investigação experimen tal, com o objetivo de confirmar a validade do diagrama e determinar a in fluência do periodo de dispersão do coagulante (mistura rāpida) na massá liquida sobre a cinética da coagulação nos vārios mecanismos. Utilizando suspensöes com turbidez variāvel entre 17 e 27 UT, alcalinidade inicial de $80 \mathrm{mg} / \ell$ de $\mathrm{CaCO}_{3}$, dosagens de sulfato de aluminio entre 1 e $40 \mathrm{mg} / \mathrm{l}$, gra dientes de velocidade na mistura rápida de 300,1000 e $16.000 \mathrm{~s}^{-1}$ e va riando o pH de coagulacão desde 4 atē 9 com a introdução de HCl, eles de monstraram a validade do diagrama e conclüram que o aumento da intensidade de mistura rāpida $\bar{e}$ benéfica apenas à coagulação no mecanismo de adsor ção-desestabilização (ver Figura 3.26). A explicação para tal fato, base $\underline{i}$ a-se em que a formação das espécies solüveis de aluminio manifesta-se ins tantaneamente apōs sua adição na água, enquanto a formação do precipitado 
de $\mathrm{Al}(\mathrm{OH})_{3(s)}$ se dā em periodos variāveis entre 1 e 7 segundos.

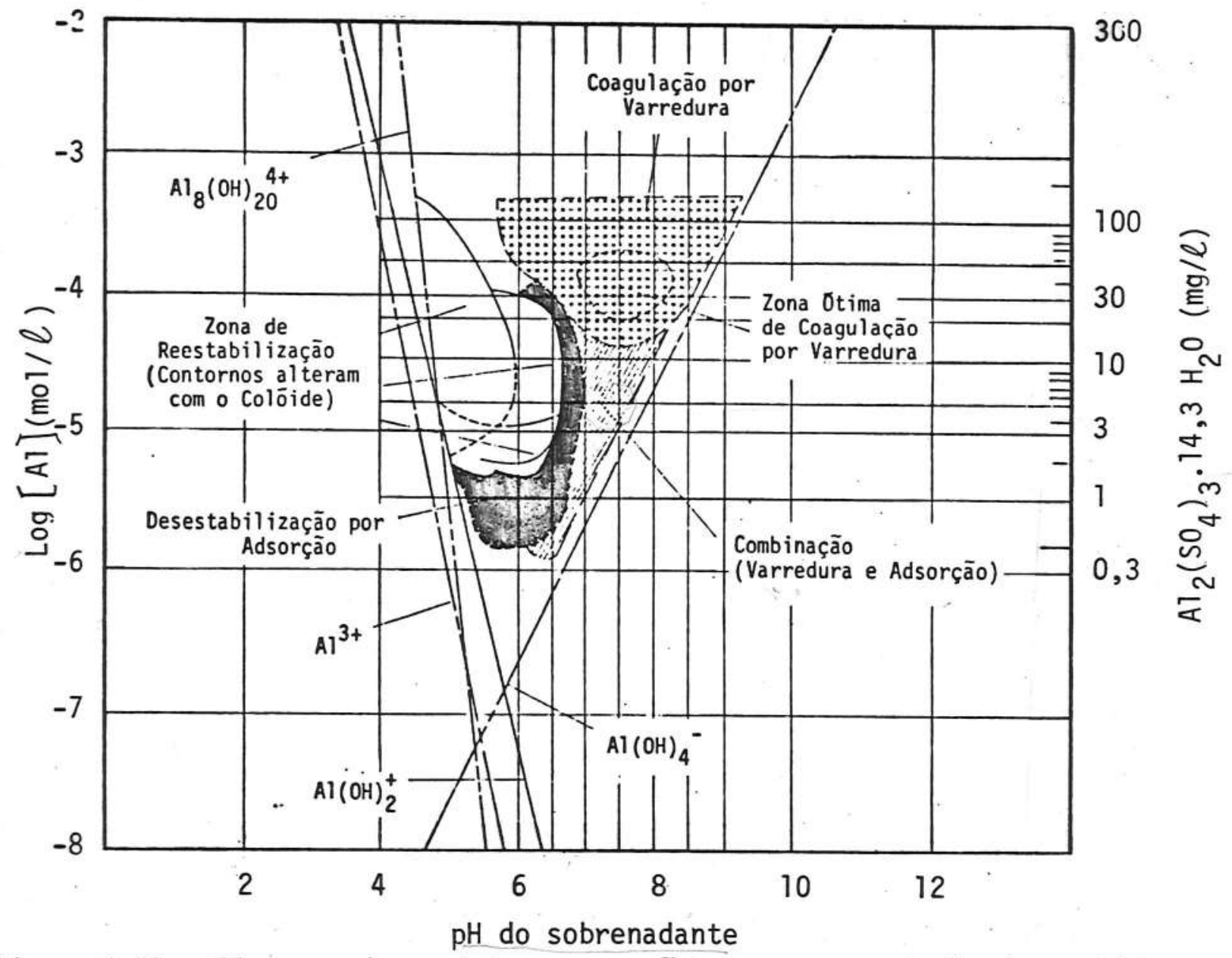

Figura 3.25 - Diagrama de projeto e operação para a coagulação de turbidez com sulfato de aluminio $\left(\mathrm{Al}_{2}\left(\mathrm{SO}_{4}\right)_{3} \cdot 14,3 \mathrm{H}_{2} \mathrm{O}\right)(03)$.

Em 1988, AMIRTHARAJAH (O2) admitiu a existência de uma se gunda região de adsorção-desestabilização lagora denominada de coagulação por neutralização de cargas), compreendida entre valores de pH de 4,2 e 5,3 $e$ dosagens de sulfato de aluminio de 2 a $70 \mathrm{mg} / \ell$ (ver Figura 3.27). Segun do AMIRTHARAJAH, a "nova" região manifesta-se atravēs da adsorção das especies solüveis de aluminio carregadas positivamente, enquanto na região descrita anteriormente, a desestabilização se dā atravēs do revestimento das particulas coloidais com a espécie insolüvel $\mathrm{Al}(\mathrm{OH})_{3(s)}$ que, nesta fai $x a$ de valores de pH, encontra-se carregada positivamente $\left(p H<p H_{i}\right)$. Obser vou, ainda, que em ambas as regiões ocorre a anulação do potencial Zeta. 


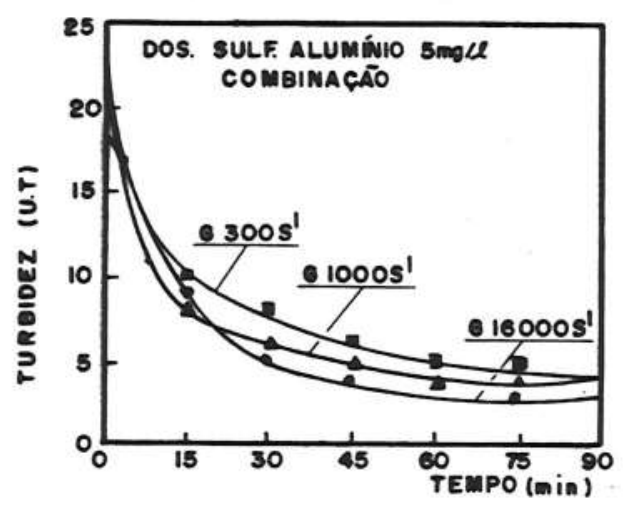

(a)

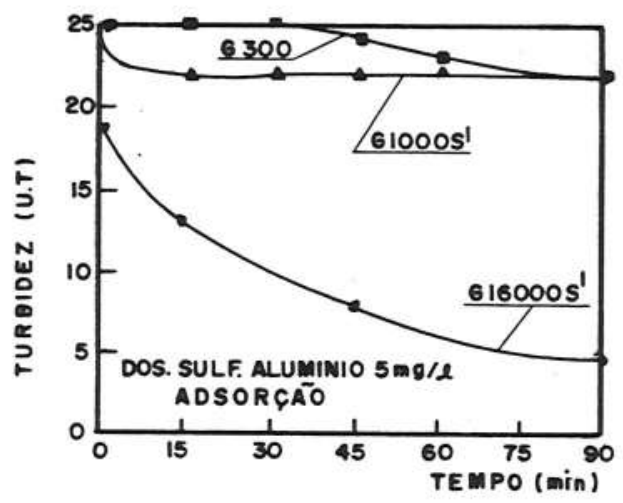

(c)

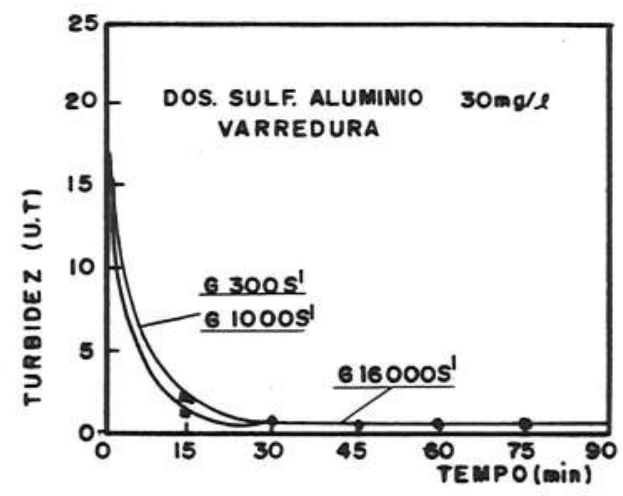

(e)

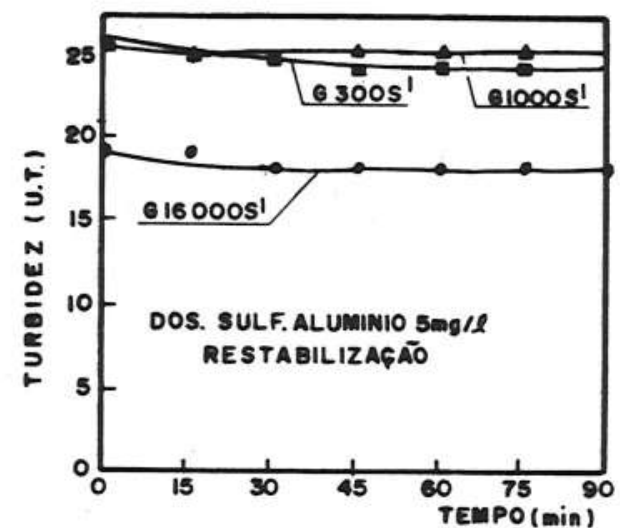

(b)

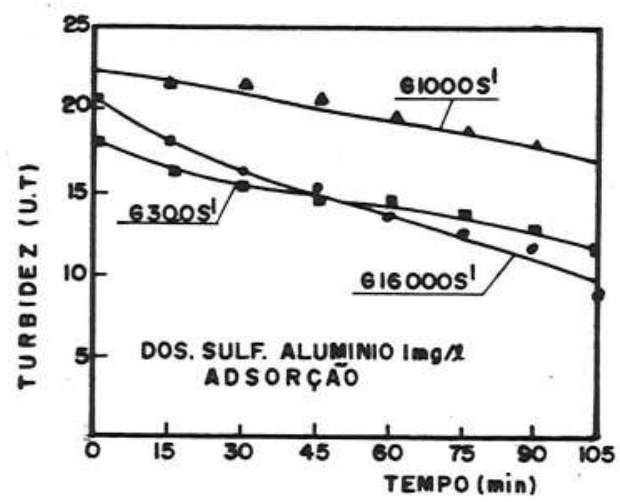

(d)

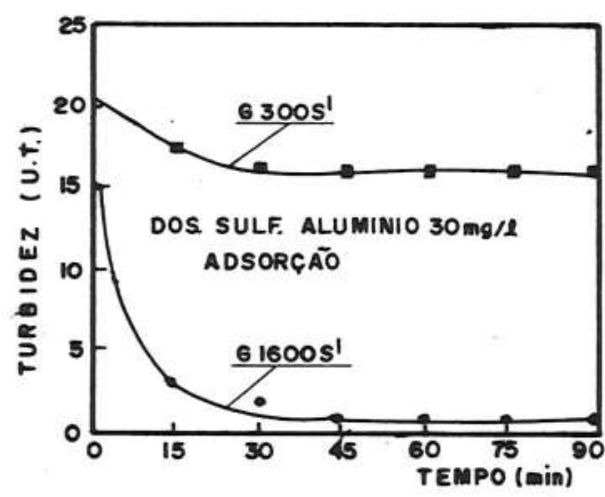

(f)

Figura 3.26 - Turbidez da āgua decantada em função do período de sedimenta ção, intensidade de mistura rāpida e pH de coagulação (03).

- $\mathrm{pH}$ de coagulação : (a) 7,5-7,6;
(b) $5,8-5,9$;
(c) 7,0 ;
(d) 6,4-6,5;
(e) 7,0;
(6) $6,4-6,5$. 


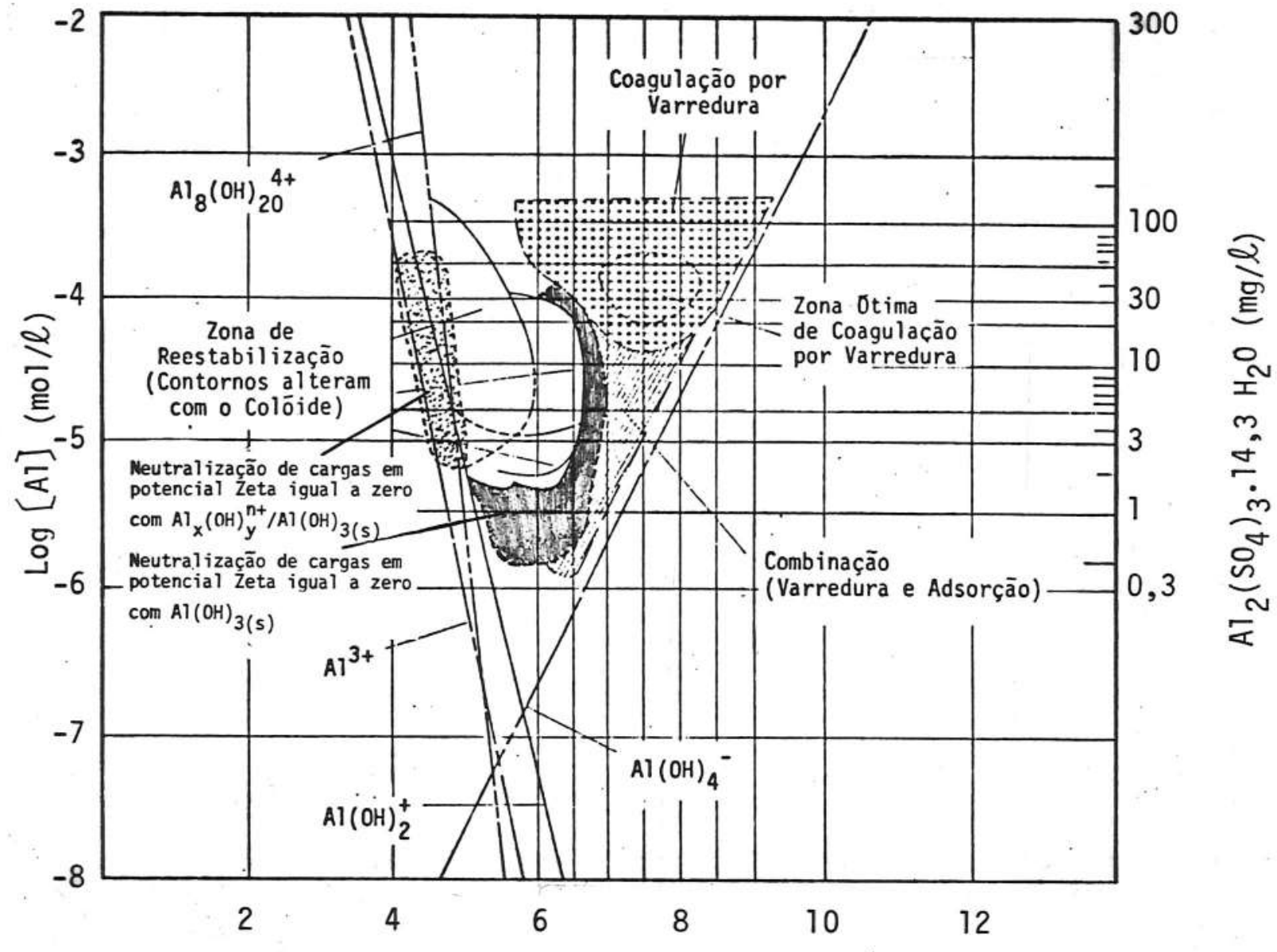

$\mathrm{pH}$ do sobrenadante

Figura 3.27 - Diagrama de coagulação com sulfato de aluminio para remoção de turbidez (02).

3.6.2. Coagulação de Aguas para Remoção da Cor

A coagulação $\bar{e} o$ processo de tratamento mais utilizado pa ra a remoção de substâncias hümicas presentes em āguas de abastecimento $\underline{p \bar{u}}$ blico. Os mecanismos de desestabilização de matērias hümicas, que, segun do PACKHAM (75), encontram-se como soluções verdadeiras com algumas molculas de dimensões tais que apresentam certas caracteristicas coloidais, ainda não são tão esclarecidos quanto os que governam a desestabilização de partículas causadoras de turbidez. Acredita-se que ocorra a neutraliza ção de grupos carregados negativamente das moléculas de substâncias hümí cas, através de interações quỉmicas com espécies de aluminio carreaadas po 
sitivamente. A maioria dos pesquisadores defende que as interações entre coagulante e substâncias hümicas são muito mais de natureza química do que física. BLACK \& WILLEMS (18) e KA(I)AMURA (47) demonstraram que os flocos pro duzidos pela coagulação com pequenas dosagens de coagulante apresentam cá racteristicas eletrocinēticas negativas, tornando-se positivas para dosa gens elevadas. EDZ(1)ALD, citado em (26), observou que, ao conträrio das dis persões de argila, a reversão de carga das substâncias hümicas não $\bar{e}$ acōm panhada da restabilização das moléculas, concluindo que os mecanismos de coagulação de substâncias hümicas devem ser diferentes dos que governam a remoção de turbidez.

ONG \& BISQUE, citados em (26), ễ̃clareceram os efeitos pro vocados nas propriedades químicas das substâncias hümicas pela adição de sais, assumindo que estas comportam-se de forma anäloga a polieletrólitos aniônicos. "Quando os polieletrölitos são dissolvidos na āgua, seus gru pos funcionais (carboxil e hidroxil) são dissociados. Como consequência, os diversos sitios carregados negativamente dispostos ao longo da estruturada molécula se repelem mutuamente, fazendo com que a molécula do polieletröli to assuma uma configuração expandida. A adição de sais, promove a intera ção dos cātions com os sittios ionizados das moléculas, favorecendo a com pressão das mesmas, devido a redução das cargas repulsivas intramolecula res. Esse fato, provoca uma mudança da forma da estrutura da cadeia molecu lar, acompanhada da expulsão de moléculas de āgua presentes nas vizinhan ças do polieletrōlito. A redução do grau de hidratação das moléculas de $\overline{\bar{a}}$ cidos hümicos e fülvicos, muda o comportamento dos colōides de hidrofili cos para hidrofóbicos".

BLACK \& (IILLEMS (18) constataram que a remoção de cor tor na-se eficiente quando os colōides coagulados mantinham-se prōximos do pon to isoelétrico. Concluiram que os produtos da hidrölise de sais de ferro $\bar{e}$ aluminio são mais importantes que os ions metälicos trivalentes para a de sestabilização desses compostos.

BLACK et alii (19), utilizando sulfato férrico como coagu lante e fazendo medidas de mobilidade eletroforética dos colóides em sus pensão, encontraram uma relação estequiomētrica entre a concentração iñ cial de cor e a dosagem ötima de coagulante.

HALL \& PACKHAM (38) pesquisaram a coagulação de ācidos hü mico e fülvicos extraĩdos de äguas superficiais e purificados. Segundo és 
ses pesquisadores, a remoção de cor é feita pela precipitação de humatos ou fulvatos insolūveis, que são formados pela interação entre as espécies hi drolisadas de aluminio ou ferro com os grupos carboxilicos das moléculas de substâncias hümicas. Eles constataram uma relação estequiométrica entre a do sagem ötima de coagulante e a concentração de ācido hümico ou fülvico na $\overline{\bar{a}}$ gua bruta para uma remoção de 50\%, com o ácido fúlvico requerendo uma dosa gem de coagulantes maior que o ácido hümico. 0 pH ötimo para a coagulação com sulfato de aluminio variou entre 5 e 6 , e entre 3,5 e 4,5 para 0 . clore to fêrrico. Essa faixa ötima de $\mathrm{pH}$ tornava-se mais estreita e transladava - se para valores mais baixos a medida que a concentração de substâncias hü micas aumentava.

MANGRAVITE et alii (53) investigaram a influência da concen tração de ácidos húmicos, dosagem de sulfato de aluminio e do pH na estabí lidade de sōis de ácidos hümicos. A Figura 3.28 apresenta o diagrama de es tabilidade dos ácidos hümicos presentes na ägua bruta em concentração igual a $5 \mathrm{mg} / \mathrm{l}$, em função do $\mathrm{pH} e$ a dosagem de sulfato de aluminio empregada.

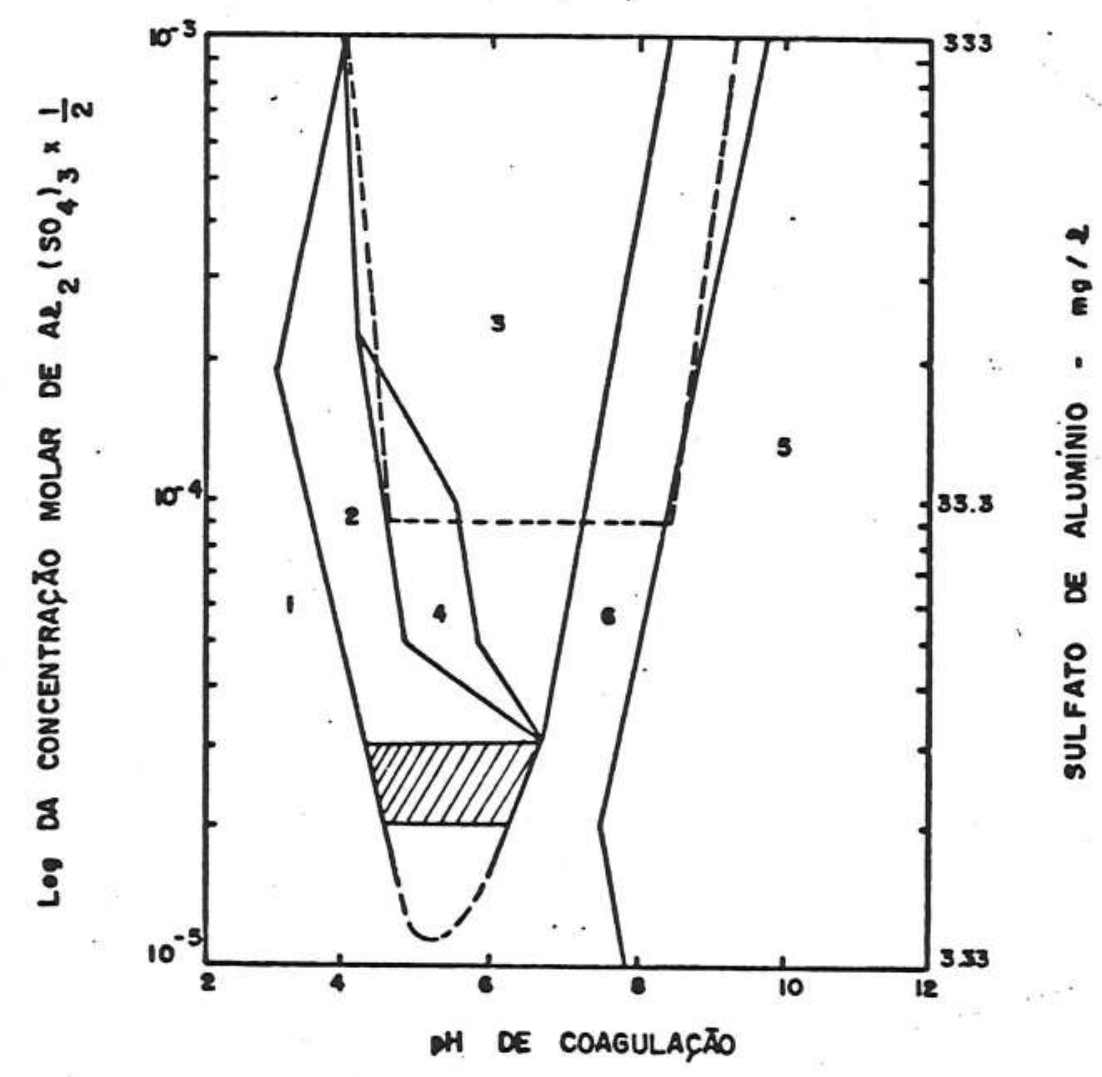

Figura 3.28 - Diagrama de estabilidade do ācido hümico em concentração ini cial de $5 \mathrm{mg} / \ell$ em função da dosagem de sulfato de aluminio $e$ do $\mathrm{pH}(53)$. 
Nas regiōes 1 e 5, as sōis de äcido hümico permaneceram es tāveis. Na região 6 , as sois permaneceram estāveis, porém apresentaram tur bidez maior que quando não coagulados. Na região delimitada pelas linhas pontilhadas, ocorreu a precipitação do hidróxido de aluminio (região 3). . Nas regiões 5 e 6 os ânions de aluminato não interagiram com os ācidos hü micos. Na região 2, as sōis foram desestabilizados pelas espēcies hidroli sadas solüveis de aluminio. Na região 4 , os pesquisadores afirmaram que os sōis encontravam-se agregados, apresentando altos valores de turbidez; po rém, permaneceram estāveis.

As Figuras 3.29 e 3.30 apresentam os resultados obtidos por EDZWALD, citado em (26), durante pesquisa de coagulação de ācidos hümicos com sulfato de aluminio para diferentes valores de $\mathrm{pH}$ de coagulação. Na $\mathrm{F}_{\underline{i}}$ gura 3.29, observa-se que a partir de valores de pH superiores a 6 , a dosa gem de sulfato de aluminio necessāria para a remoção de ācidos hümicos tor nou-se muito elevada. Na Figura 3.30, verifica-se a relação estequiométrica existente entre a dosagem de coagulante e a concentração de ácidos hümi cos para coagulação no $\mathrm{pH}$ igual a 6 .

Segundo EDZWALD, as interações entre os cätions de alumi nio formados entre os $\mathrm{pHs}$ de 4 a 6 , e as ácidos hümicos são especificamen te quimicas, resultando na neutralização e desestabilização dos mesmos.

\subsubsection{Coagulação de Aguas para Remoção de Cor e Turbidez}

HALL \& PACKHAM (38) verificaram que a presença de ácidos fülvicos altera profundamente o pH ötimo para a remoção de turbidez propor cionada por caulinita. Quando suspensões de caulinita e ācidos fülvicos são coagulados separadamente, seus respectivos pHs ótimos de coagulação são 7,0 e 5,5, como mostrado na Figura 3.31. Por outro lado, a coagulação conjunta de ambos; proporciona uma queda do valor ótimo do pH de coagulação, demons trado pela observação da Figura 3.32. A anälise conjunta das Figuras 3.31 e 3.32 indica que a remoção de $50 \%$ de turbidez e de ácidos fülvicos requer uma dosagem de sulfato de aluminio maior quando coagulados conjuntamente, sendo crítica para a remoção de turbidez.

A conclusão do estudo realizado por MOORE (67) difere da de HALL \& PACKHAM (38), pois afirma que a dosagem de coagulante $\bar{e}$ determinada pela remoção de ácidos fúlvicos. Segundo esse pesquisador, o mecanismo de coagulação responsāvel pela desestabilização de uma suspensão de ācidos fül 


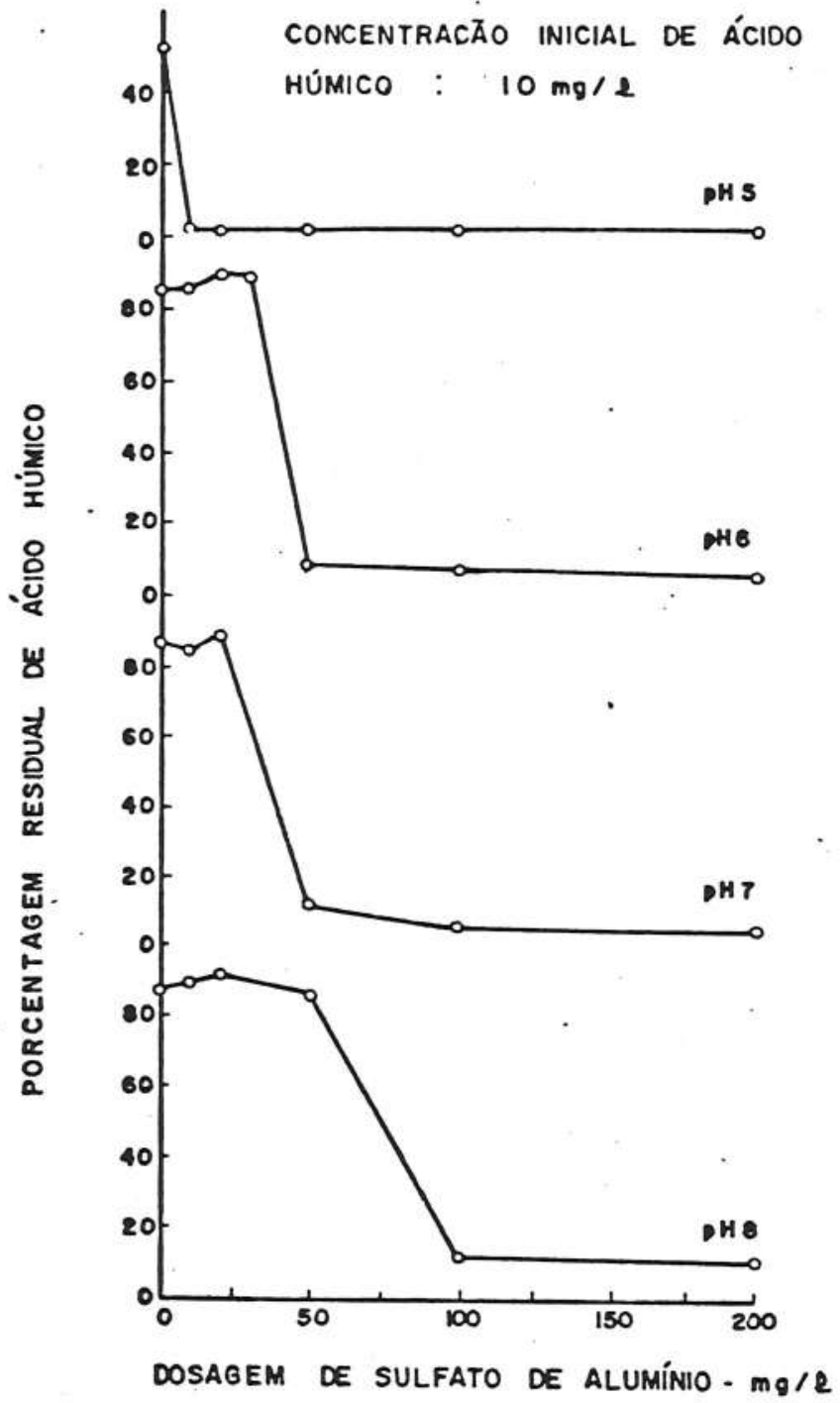

Figura 3.29 - Influência do pH na coagulação de ácidos hümicos com sulfato de aluminio ( segundo EDZWIALD, citado em (26)). 


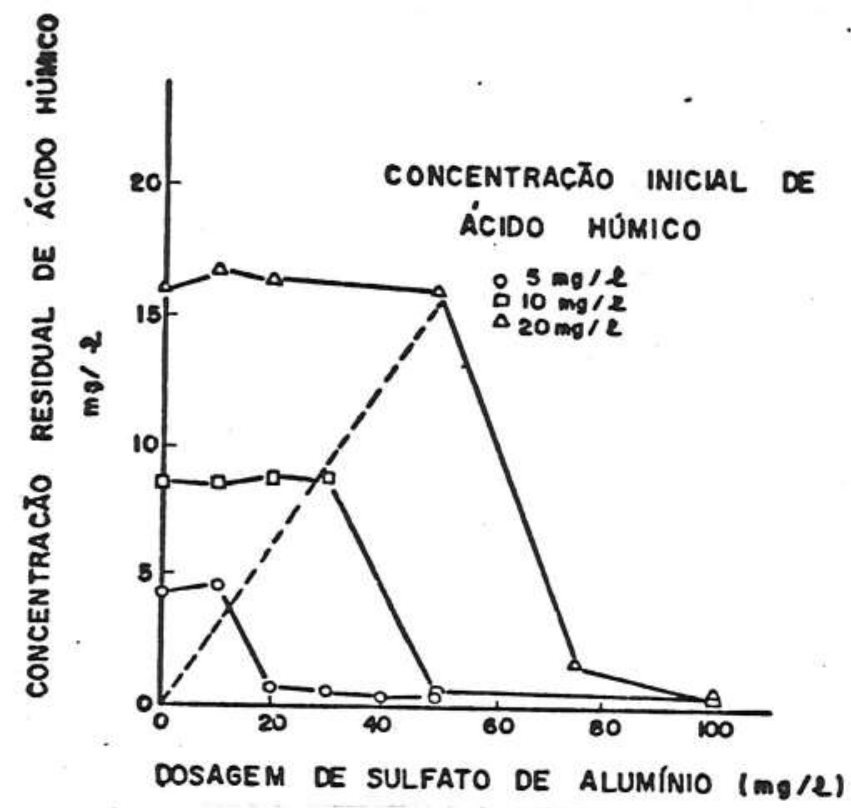

Figura 3.30 - Estequiometria da coagulação de ācidos hümicos com sulfato de aluminio no $\mathrm{pH}$ igual a 6,0. (segundo EDZWALD, citado em $(2 \dot{6})$ ).

vicos e caulinita consiste na precipitação de um composto da reação entre 0 ácido fülvico e o aluminio, que envolve fisicamente as partículas de cauli nita.

As Figuras 3.33 a 3.36 mostram os resultados de estudas fei tos com āgua bruta do rio Mississipe por SEMENS \& FIELD, citados em (26), que demonstraram que o valor do pH ötimo para a remoção conjunta de turbi dez e compostos orgânicos pode ser o mesmo para ambas substâncias, dependen do da dosagem de coagulantes empregada.

A Figura 3.33 mostra a influência do pH na remoção de turbi dez e compostos orgânicos para uma dosagem de sulfato de aluminio igual a $25 \mathrm{mg} / \ell$. Observa-se que a remoção de turbidez foi otimizada no pH de 3, 8, en quanto que para a remoção de compostos orgânicos, o pH ótimo foi igual a $5, \overline{0}$. A elevação do $\mathrm{pH}$ de 3,8 para 5,0, prejudicou a eficiência de remoção de tur bidez, que diminuiu de 75 para $45 \%$.

As Figuras 3.34 a 3.36 , são similares à 3.33 , porém, elevan do-se as dosagens de sulfato de aluminio para 50,75 e $100 \mathrm{mg} / \ell$, respectiva mente. 0 aumento da dosagem proporcionou aumentos na eficiência de remoção de compostos orgânicos, mantendo o pH ótimo de remocão constante, em torno de 5,0. Ao mesmo tempo, verificou-se que a faixa ötima de valores de pH pa ra remoção de turbidez foi ampliada à medida que a dosagem de sulfato de $\underline{a}$ luminio era elevada. 


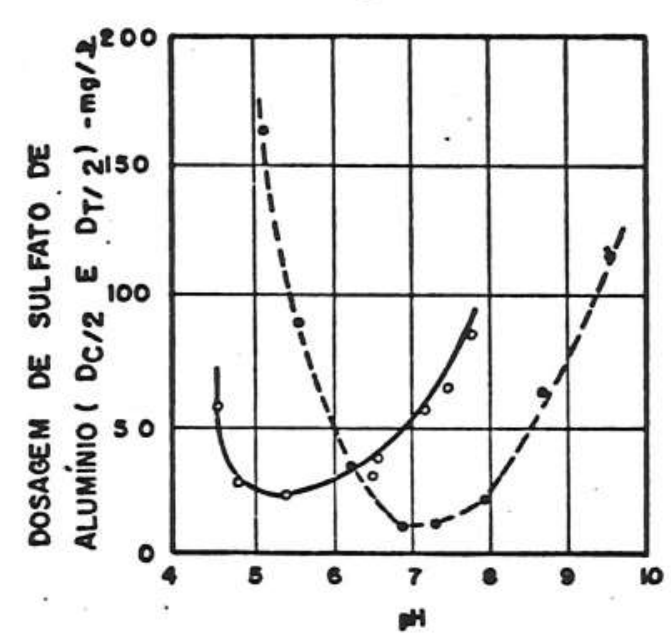

Nota: $D_{\chi} / 2$ - dosagem de coagulante necessāria para $50 \%$ de remoção da concentração inicial de $x$. (---) ácido fülvico;

(-) caulinita.

Figura $3.31-D_{c} / 2$ para concentração inicial de $25 \mathrm{mg} / \ell$ de äcido fúlvico; $D_{t^{\prime}} / 2$ para concentração inicial de $50 \mathrm{mg} / \ell$ de caulinita (38).

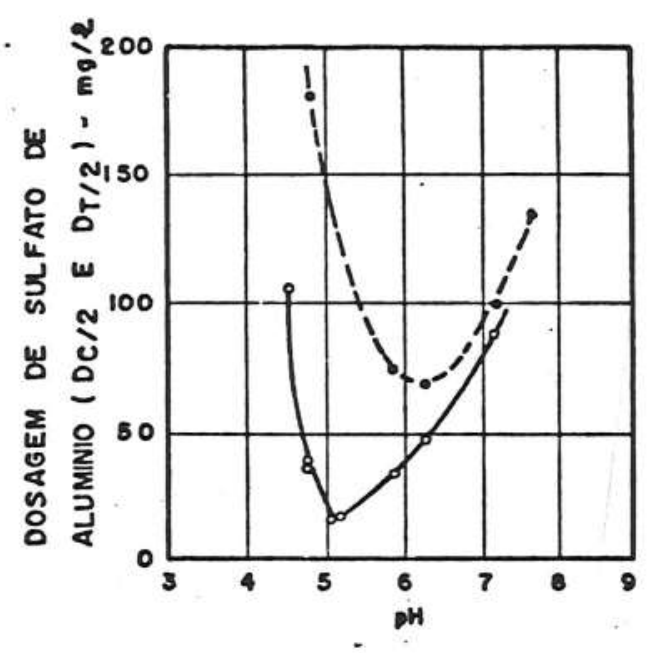

(---) äcido fülvico;

(-) caulinita.

Figura 3.32 - Coagulação de uma suspensão contendo concentrações iniciais de $25 \mathrm{mg} / \ell$ de ácido fúlvico e $50 \mathrm{mg} / \ell$ de caulinita (38). 


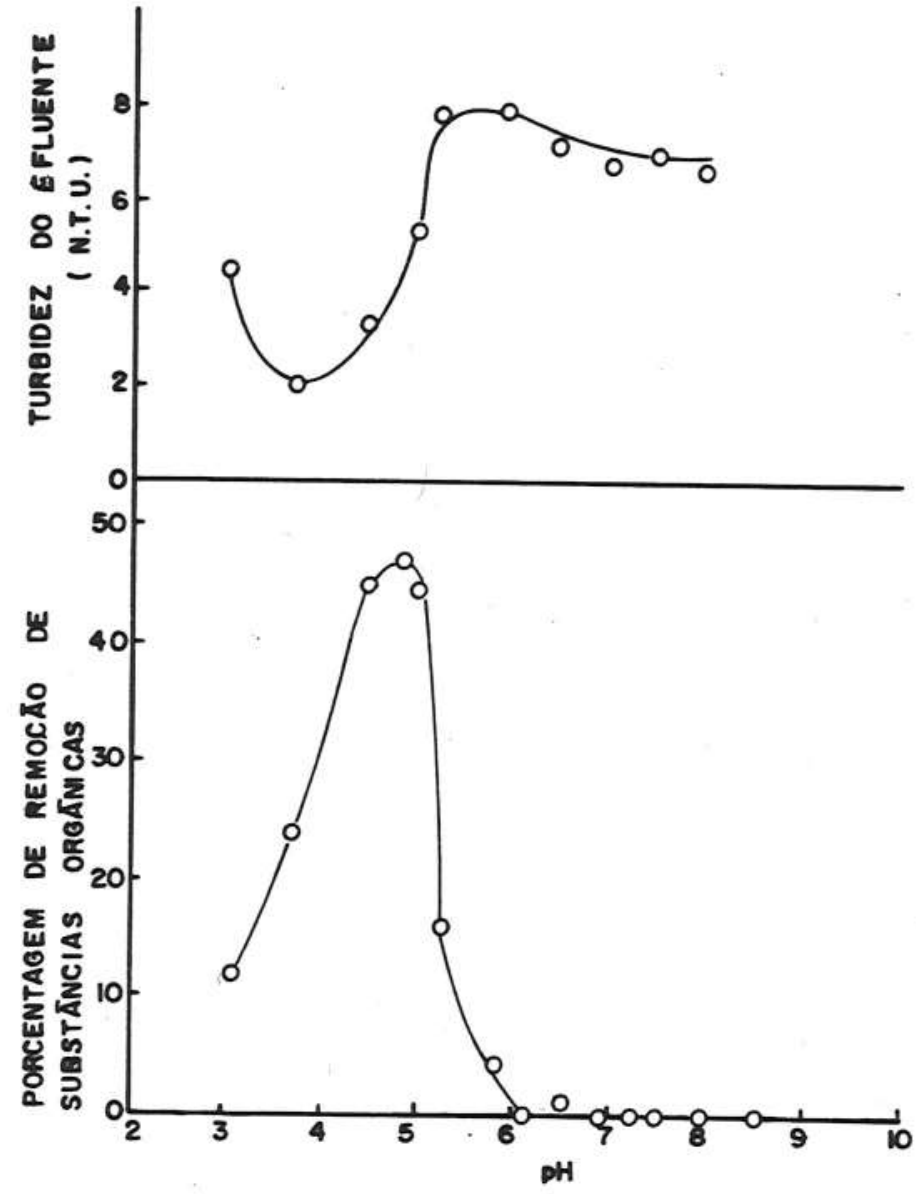

Figura 3.33 - Influência do pH na remoção de turbidez e compostos orgânicos para uma dosagem de sulfato de aluminio igual a $25 \mathrm{mg} / \mathrm{l}(26)$.

Segundo EDIIARDS \& AMIRTHARAJAH (30), os parâmetros que in terferem na coagulação de compostos causadores de cor em äguas são :

i) sua concentração inicial;

ii) dosagem de coagulantes;

iii) pH de coagulação.

Trabalhando com dispersões preparadas com diversas concen trações de ācidos hümicos e turbidez, esses pesquisadores concluiram que a coagulação de ácidos hümicos é feita por dois mecanismos distintos ou pela conjunção de ambos, dependendo do pH de coagulação. Na faixa de pH de 6,0 a 8,0 , onde existem condições para a formação do composto de $\mathrm{Al}(\mathrm{OH}) 3(\mathrm{~s})$, a re moção ocorre devido à adsorção dos ácidos húmicos no precipitado desse com posto. Ouando o valor do $\mathrm{pH}$ encontra-se entre 4,0 e 5,5, os äcidos hümicos são desestabilizados devido à reação quỉmica entre as espécies hidrolisadas 


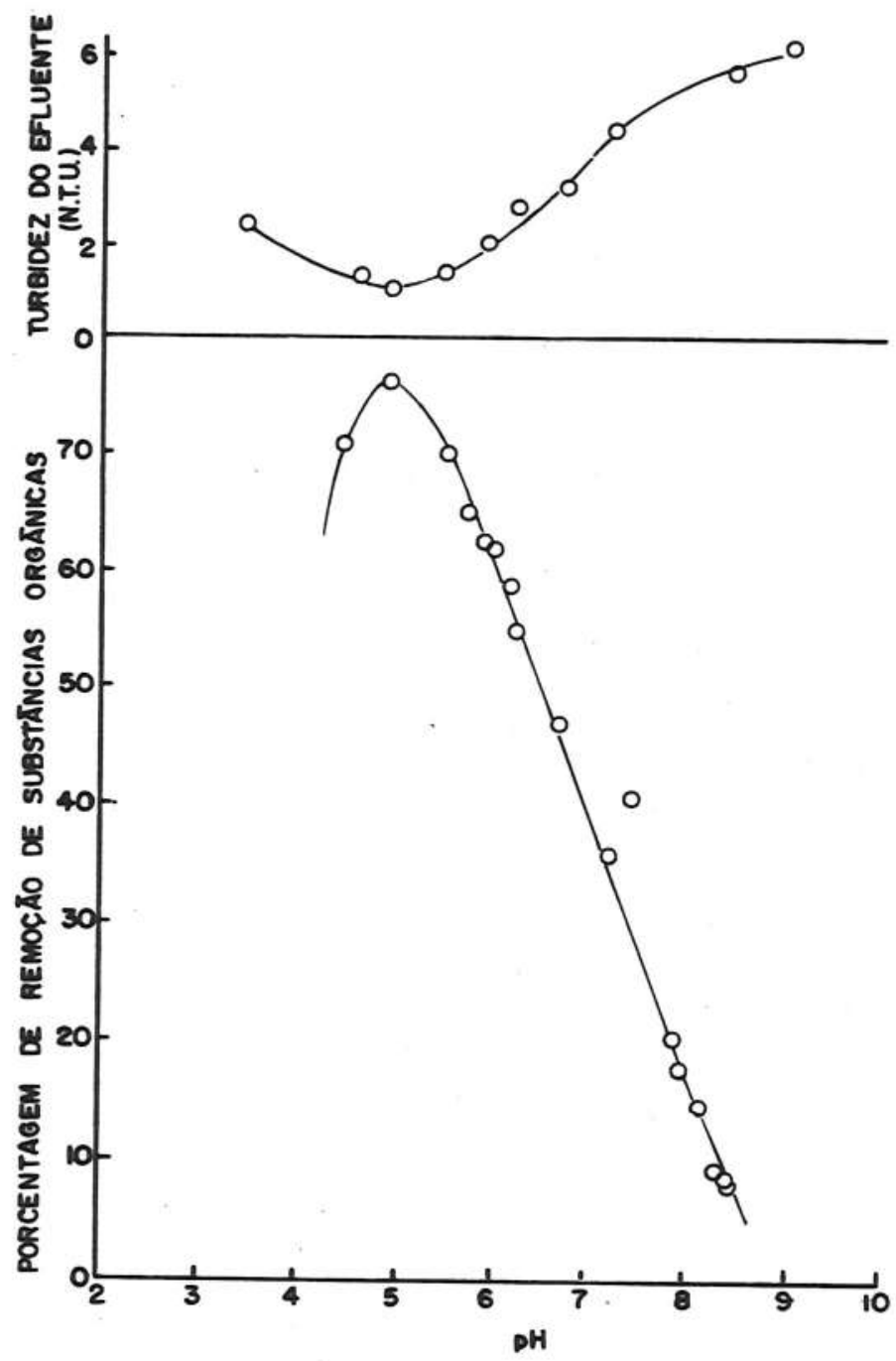

Figura 3.34 - Influência do pH na remoção de turbidez e compostos orgânicos para uma dosagem de sulfato de aluminio igual a $50 \mathrm{mg} / \ell$ (26). 


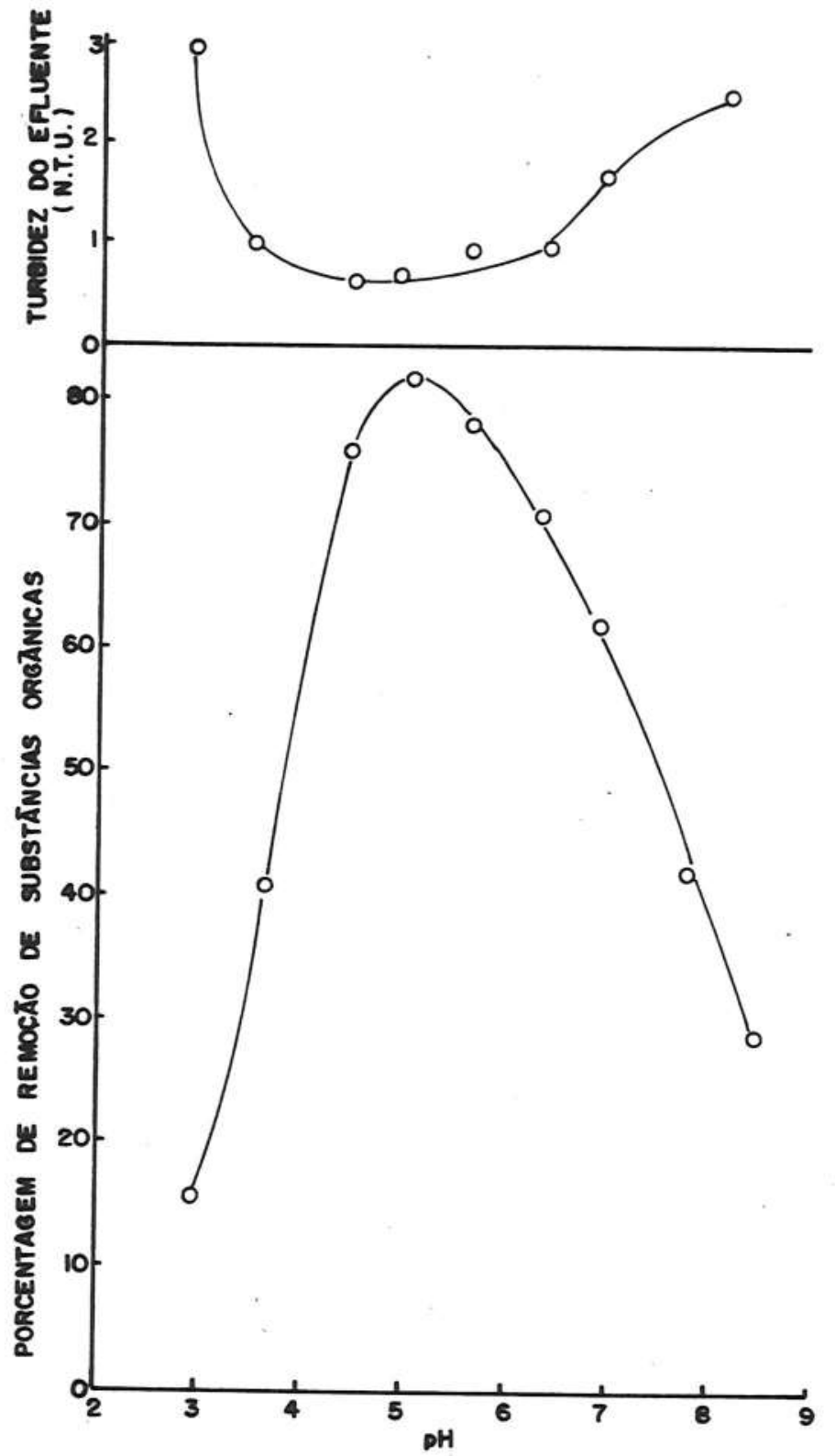

Figura 3.35 - Influência do pH na remoção de turbidez e compostos orgânicos para uma dosagem de sulfato de aluminio igual a $75 \mathrm{mg} / \mathrm{l}(26)$. 


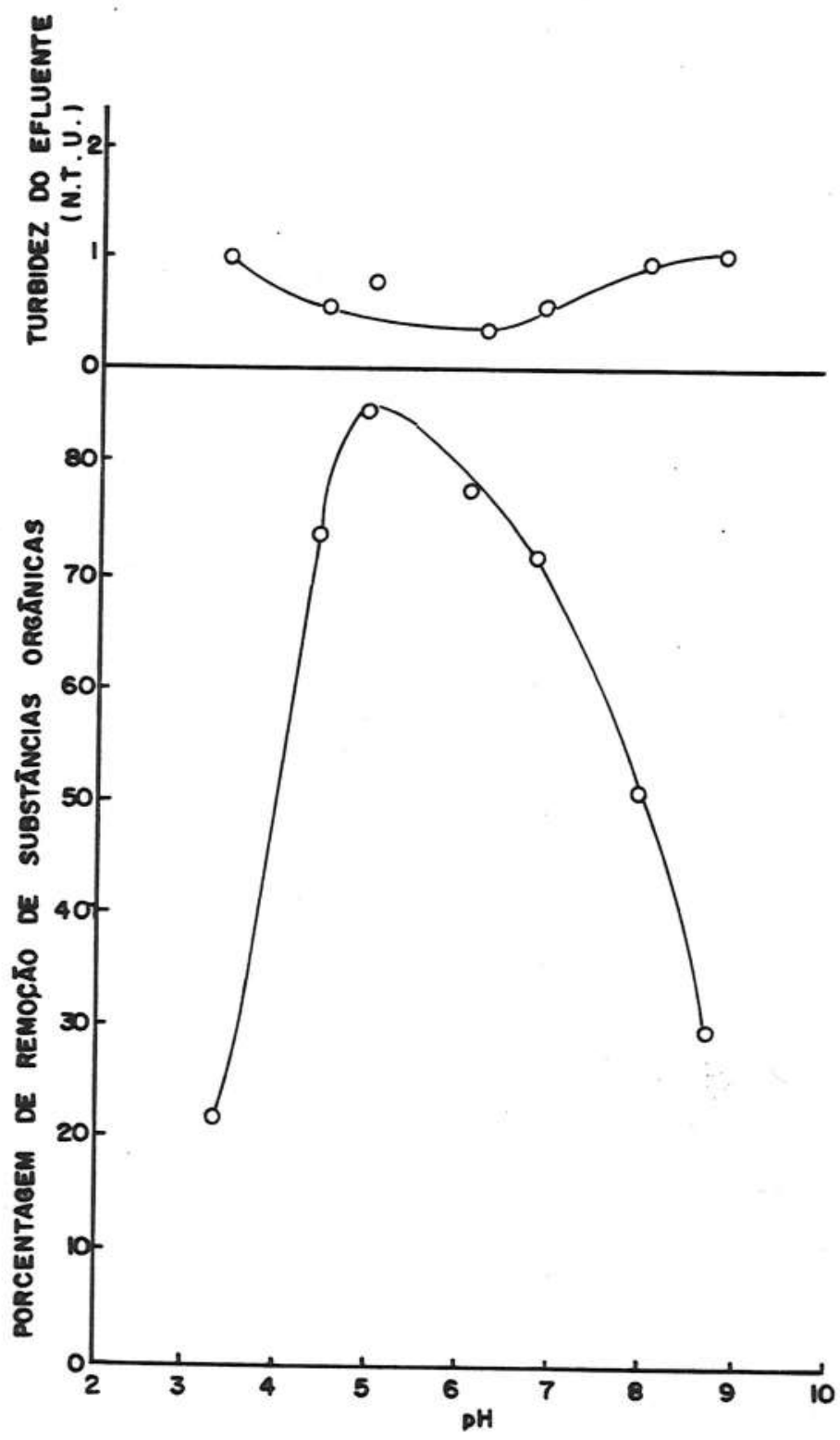

Figura 3.36 - Influência do pH na remoção de turbidez e compostos orgânicos para uma dosagem de sulfato de aluminio igual a $100 \mathrm{mg} / \ell(26)$. 
de aluminio, carregadas positivamente $e$ os sittios negativos das moléculas dos ácidos hümicos.

As Figuras 3.37 e 3.38 apresentam as diagramas de coagula ção com sulfato de aluminio obtidos por esses pesquisadores, onde foram traçadas as regiões ótimas de remoção de cor verdadeira em função do $\mathrm{pH}$ de coagulação e da dosagem de coagulante. A Figura 3.37 refere-se a uma dis persão com uma concentração inicial de ácidos hümicos igual a $4 \mathrm{mg} / \ell$, en quanto, a Figura 3.38, resultou de ensaios realizados com uma dispersão $\bar{i}$ gual a anterior, com a adição de turbidez variando entre 27 e 30 UT. Ob serva-se em ambas as Figuras a existência de duas regiöes onde a eficiência de remoção de cor é superior a $80 \%$. A região de $\mathrm{pH}$ mais elevado 16,0 a 8,0 / e dosagens de sulfato de aluminio maiores que $12 \mathrm{mg} / \ell$, é provocada pela ação da precipitação do composto $\mathrm{Al}(\mathrm{OH})_{3(s)}$. Na região localizada entre os valores de pH de 4,0 e 5,6, o mecanismo de coagulação é feito pela ação dos compostos hidrolisados de aluminio que neutralizam as cargas dos compostos hümicos, desestabilizando-os. A introdução de colöides cau sadores de turbidez proporcionou a diminuição da dosagem ōtima de coagulá ção, fato este, atribuido ao aumento de frequência de colisões durante $\bar{a}$ fase de floculação.

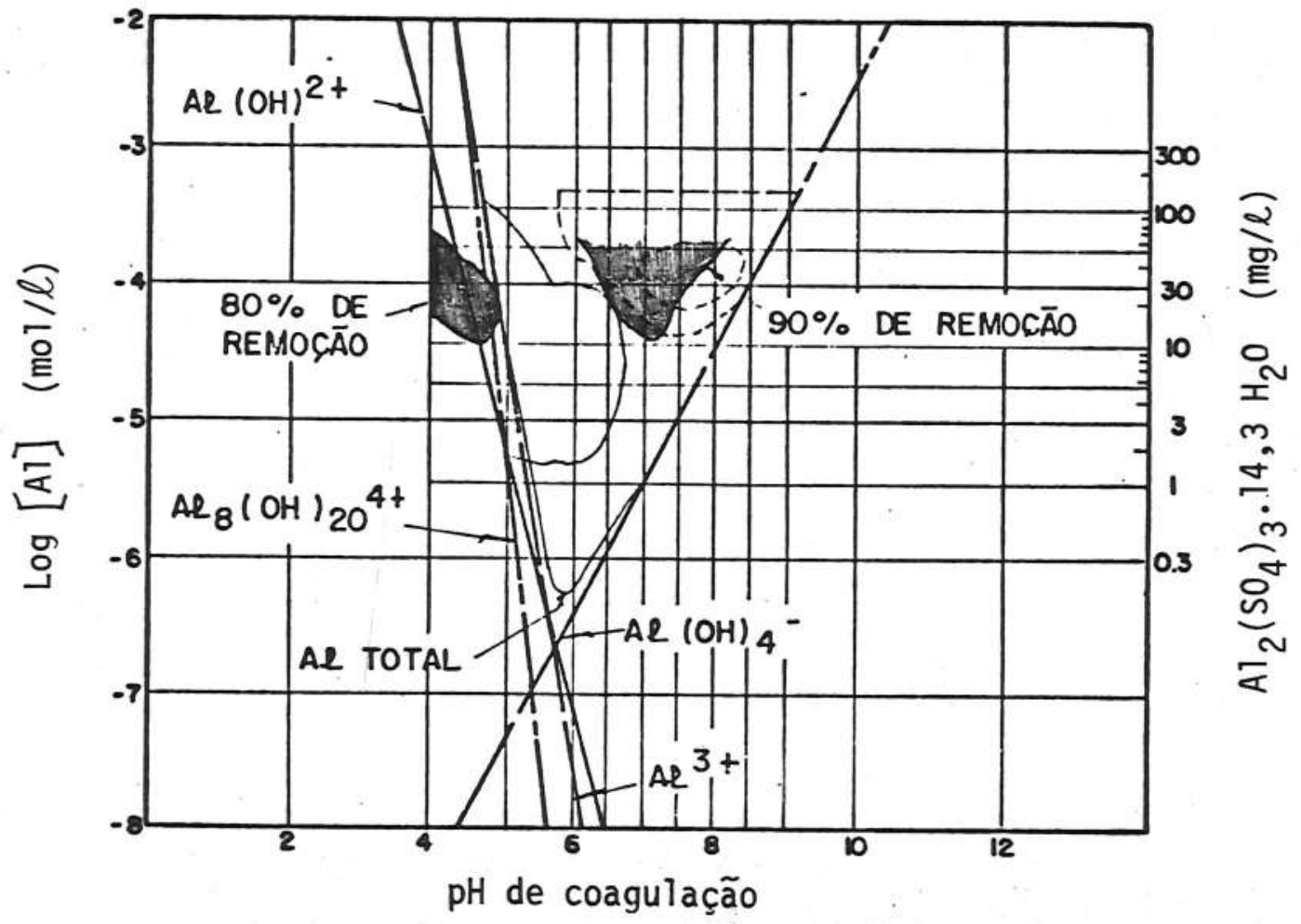

Figura 3.37 - Regiões de remoção de cor para concentrações iniciais de âci do hümico igual a $4 \mathrm{mg} / \ell$ (100 UC) (ausencia total de turbidez) (30). 


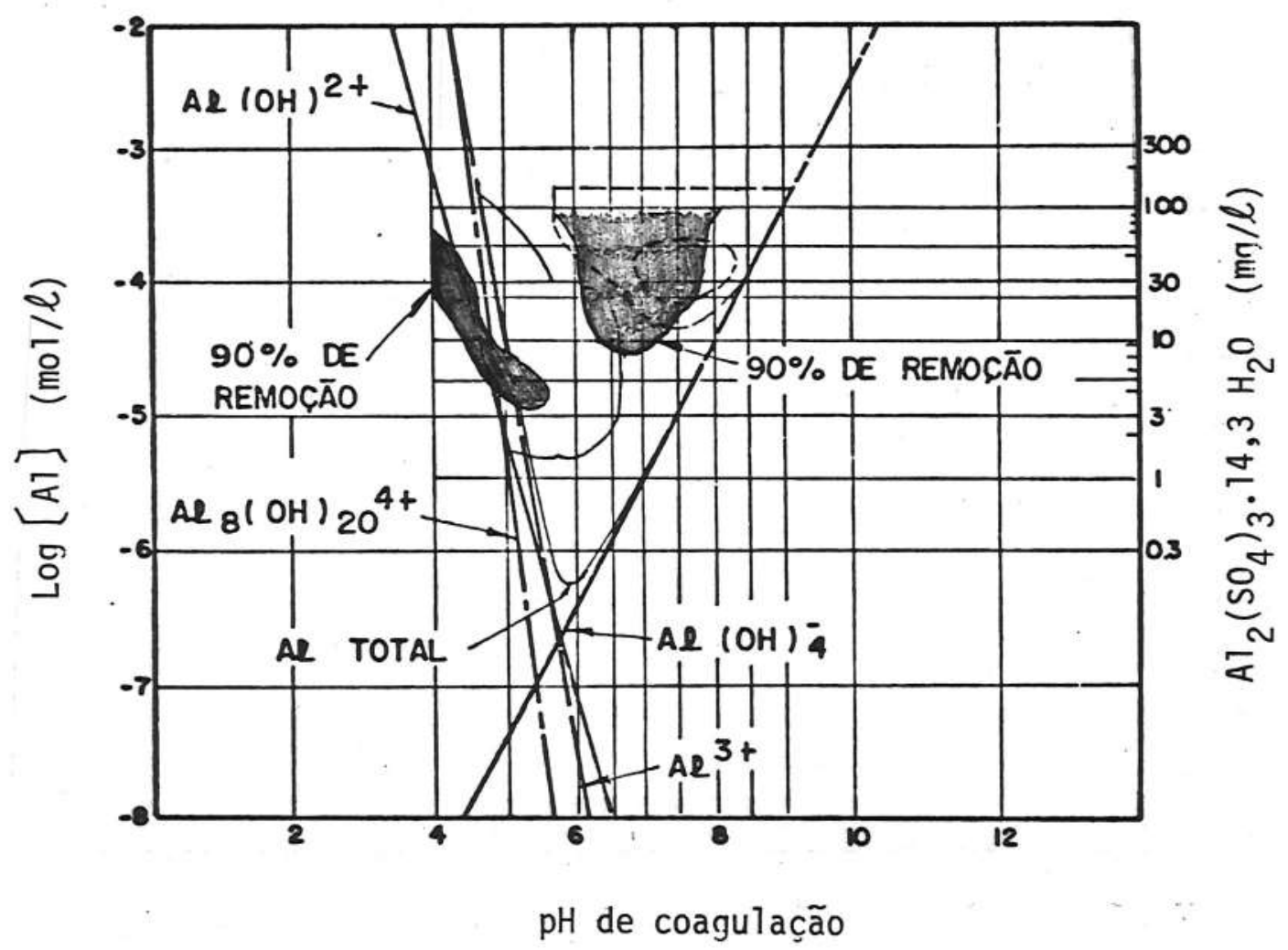

Figura 3.38 - Regiões de remoção de cor para concentração inicial de āci do hümico igual a $4 \mathrm{mg} / \ell$ (100 UC) e turbidez inicial de 27 a 30 UT (30). 


\subsection{Aspectos Relevantes sobre a Floculacão}

A floculação consiste no processo fisico de movimentação das particulas coloidais impulsionadas pelos $j \bar{a}$ mencionados movimento BROWNIA No, força da gravidade e agitação do fluido que as contém. Nesta movimen tação, ocorre o choque de umas com as outras e promove-se 0 agrupamento das mesmas em flocos, para posterior remoção em unidades de sedimentação, flotação ou filtração.

As dimensões e caracteristicas do floco dependem de diversos fatores, tais como:

i) nümero e caracteristicas das particulas primärias;

ii) tipo e dosagem de coagulantes e auxiliares de coagulação empregados;

iii) $\mathrm{pH}$ de coagulação;

iv) temperatura do fluido;

v) caracteristicas geométricas do reator e equipamentos de a gitação empregados para a bloculação;

vi) intensidade de agitação do fluido (representada pelo gra diente de velocidade médiol;

vii) período de floculação.

Dadas as inümeras variāveis influentes, a otimização dos pro cessos de floculação, tendo em vista a maior eficiência possivel da(s) $\underline{u}$ nidade(s) subsequente(s) do tratamento, $\bar{e}$ tarefa ärdua, porém, exequivel.

Fixado o tipo de āgua a ser tratado e otimizadas as variāveis (ii) e (iii) através de ensaios de floculação submetidos à constância das variāieis (v), (vi) e (vii), resta ao projetista, escolher o tipo de unida de (e equipamento) de floculação a ser empregado e determinar a intensida de e periodo ötimos de introdução (dissipação) de energia ao fluido.

A teoria inicial da floculação ortocinêtica foi desenvolvida, originalmente, por VON SMOLUCHOWSKI, que, em 1917, formulou a seguinte ex pressão:

$$
\frac{d N}{d t}=\frac{G}{6} n_{1} n_{2}\left(d_{1}+d_{2}\right)^{3}
$$


onde:

$$
\left\{\begin{array}{l}
d N / d t: \text { taxa de colisão entre as partículas } 1 \text { e 2; } \\
G \text { : gradiente de velocidade; } \\
n_{1} \text { e } n_{2} \text { : são os nümeros de partículas } 1 \text { e } 2 \text {, respectivamente; } \\
d_{1} \text { e } d_{2}: \text { são os diâmetros das partículas } 1 \text { e } 2 \text {, respectivamente. }
\end{array}\right.
$$

CAMP \& STEIN (ZO) representaram o gradiente de velocidade médio (G) pela seguinte equação:

$$
G=\sqrt{P / \mu v}
$$

onde: $\left\{\begin{array}{l}P: \text { potência introduzida no sistema; } \\ V: \text { volume do sistema; } \\ \mu: \text { viscosidade dinâmica do líquido. }\end{array}\right.$

Diversos autores estudaram as formas integrais da equação 3.38 $e$ destaca-se a equação de HARRIS, KAUFMAN e KRONE (39) que demonstraram a seguinte relação para uma série idêntica de reatores de mistura completa:

$$
\frac{n_{1}^{0}}{n_{1}^{m}}=\left[1+k_{1} \emptyset \in \frac{T}{m}\right]^{m}
$$

onde: $\quad\left(n_{1}^{0}\right.$ e $n_{1}^{m}$ : concentrações de particulas primärias no afluente ao sistema e no éfluente do m-ésimo reator;

$k_{1}$ : constante que depende da natureza e tamanho das partículas;

$\emptyset$ : fração em volume dos flocos;

$T$ : tempo de detenção total;

$m$ : nümero de reatores em sērie.

Em estudos recentes, confirmou-se a existência de um tamanho li mite para os flocos formados, que traz uma relação inversa com 0 gradiente de velocidade aplicado e uma relação de proporcionalidade entre a densidade e o mesmo. Em 1971. ARGAMAN, citado em (92), proclamou os efeitos de agrega ção e quebra dos flocos através da seguinte equação:

$$
\frac{d N}{d t}=-(\text { função de agregação) }+ \text { ( função de quebra) }
$$


A função de agregação, ou taxa de crescimento dos flocos, $\bar{e}$ de finida por ARGAMAN \& KALFMAN (08) através da seguinte equação:

$$
\frac{d N}{d t}=-K_{A} N G
$$

onde: $\quad\left\{\begin{array}{l}N: \text { concentração de particulas primärias; } \\ K_{A} \text { : coeficiente de agregação. }\end{array}\right.$

A função de quebra ou erosão dos flocos pode ser representada:

$$
\frac{d N}{d t}=K_{B} N_{0} G^{2}
$$

onde: $\left\{\begin{aligned} N_{0}: \text { concentração inicial de particulas primärias ao entrar no } \\ \\ \text { floculador; } \\ K_{B}: \text { coeficiente de quebra. }\end{aligned}\right.$ Combinando as equações 3.42 e 3.43 , a equação 3.41 torna-se:

$\frac{d N}{d t}=-K_{A} N G+K_{B} N_{0} G^{2}$

Integrando-se para $\left(t=0 ; N=N_{0}\right)$ e $\left(t=T ; N=N_{t}\right)$, vem:

$\frac{N_{0}}{N_{t}}=\frac{1+K_{A} G T}{1+K_{B} G^{2}} \frac{T}{T}$

Esta equação é vätida para um ünico reator.

Admitindo-se que os coeficientes $K_{A}$ e $K_{B}$ mantém-se constantes em um floculador com um nümero $(m)$ de câmaras em série, tem-se:

$$
\frac{N_{0}}{N_{m}}=\frac{\left(1+K_{A} G T / m\right)^{m}}{1+K_{B} G^{2} T / m \sum_{i=0}^{m-1}\left(1+K_{A} G T / m\right)^{i}}
$$


onde: $\left\{\begin{array}{l}N_{m}: \begin{array}{l}\text { concentração de partículas saindo da ültima câmara de blo } \\ \text { culação; }\end{array} \\ T: \text { tempo médio total de floculação. }\end{array}\right.$

A validade das equações 3.45 e 3.46 foram demonstradas por $A R$ GAMAN \& KAUFMAM (OB) utilizando-se de floculadores em escala piloto com quatro compartimentos, onde uma suspensão de argila na concentração de 25 $\mathrm{mg} / \ell$ foi floculada numa dosagem de $25 \mathrm{mg} / \ell$ de sulfato de aluminio. Tais re sultados são apresentados na Figura 3.39 e sua observação permite chegar nas seguintes conclusões:

i) A obtenção de um determinado grau de eficiência requer um tempo minimo de detenção. Associado a este tempo de detenção, existe um va lor ótimo do gradiente de velocidade e qualquer outro valor deste ültimo provocará um decréscimo na eficiência do tratamento;

ii) 0 aumento da compartimentalização de um sistema de flocula ção implica na diminuição do tempo de detenção necessärio para a obtenção de uma determinada eficiência de tratamento.

ANDREU-VILLEGAS \& LETTERMAN (04) estudaram a coagulação de $\underline{\bar{a}}$ guas brutas com diversos valores de turbidez, variando os seguintes parâme tros: gradiente de velocidade e períodos de bloculação e dosagem de coagu lante. A Figura 3.40 mostra os valores de turbidez medidos em. função do va lor de $G$ e $T$, quando foi usada uma dosagem de sulfato de aluminio igual a $10 \mathrm{mg} / \mathrm{l}, 3$ minutos de mistura rāpida com $G$ igual a $800 \mathrm{~s}^{-1}$, seguida por um periodo de floculação submetida a parâmetros variāveis e um periodo de se dimentação igual a 45 minutos. Observa-se que para cada valor de gradiente de velocidade existe um período de floculação que maximiza a remoção de tur bidez (exceto para $G=25 \mathrm{~s}^{-1}$ ).

A Figura 3.41 apresenta os valores de turbidez em função de $G$ para värios períodos de floculação. De acordo com o observado, existe um gradiente de velocidade ótimo associado a cada período de floculação o que vem de acordo com o observado por ARGAMAN \& KALFMAM.

A Figura 3.42 apresenta uma sērie de retas construídas em pa pel bilogarítmico onde apresenta-se os pares de valores ótimos de $G$ contra $T$. Os resultados dos experimentos realizados por ANDREU-VILLEGAS \& LETTER 

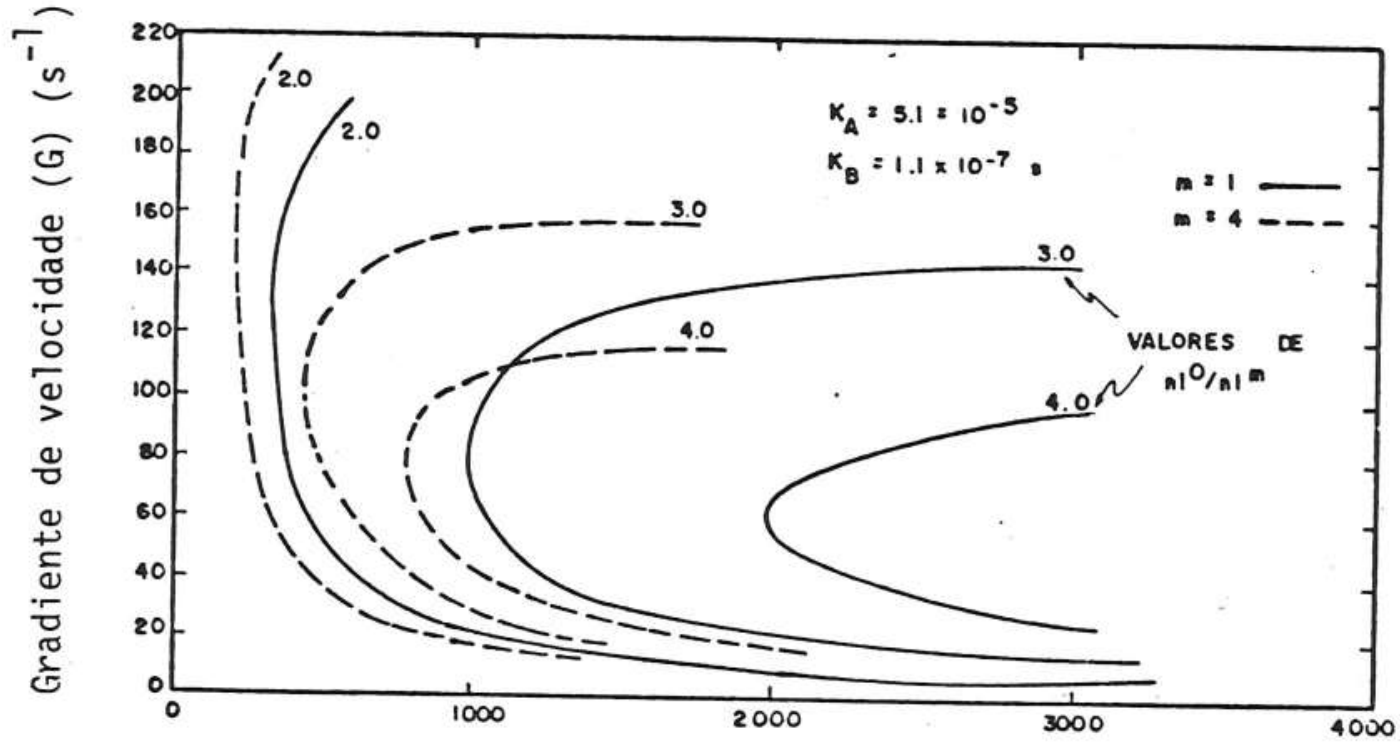

Perĩodo de floculação (T) (s)

Figura 3.39 - Desempenho da floculação variando-se os parâmetros $G, T$ e m (08).

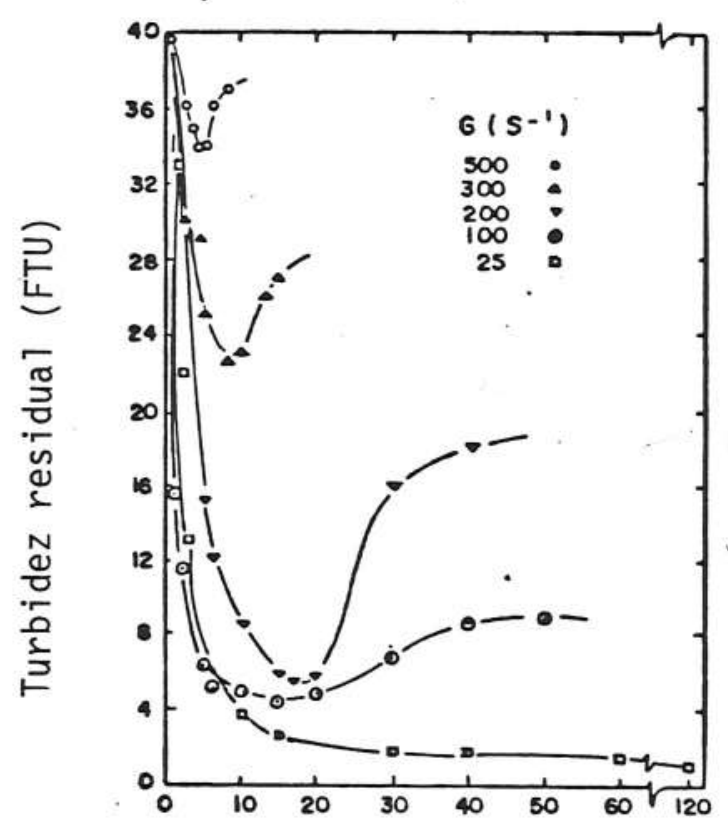

Perīodo de floculação (T) (min.)

Figura 3.40 - Turbidez residual em função do período de floculação para vā rios valores do gradiente de velocidade. Série A (04). 
MAN (04) foram denominados de série $A$, quando submetidos a 3 minutos de mis tura rāpida com um valor de $G$ igual a $800 \mathrm{~s}^{-1}$; série $B$, no mesmo valor de dosagem de coagulante que a série $A(10 \mathrm{mg} / \ell)$, porém com 5 minutos de mistu ra rāpida com $G$ iqual a $500 \mathrm{~s}^{-1}$; sēries $C$ e $D$ com as mesmas condições de mis tura rápida que a sērie A, porém com dosagens de coagulante iguais a 25 e $50 \mathrm{mg} / \ell$, respectivamente.

As retas da Figura 3.42 podem ser representadas por equações do tipo:

$$
G^{n} T=K
$$

onde $n=2,8$ e $K=4,0 \times 10^{5} ; 1,9 \times 10^{5}$ e $0,7 \times 10^{5}$, respectivamente para dosagens de sulfato de aluminio iguais a $10 ; 25$ e $50 \mathrm{mg} / \ell$. As mudanças de condições na mistura rápida (sēries $A$ e $B$ ), não refletiram sobre os parâmetros que go vernam a floculação. Ao aumentar-se a dosagem de coagulante, as curvas apro ximam-se do eixo das abcissas, mantendo praticamente as mesmas declividades.

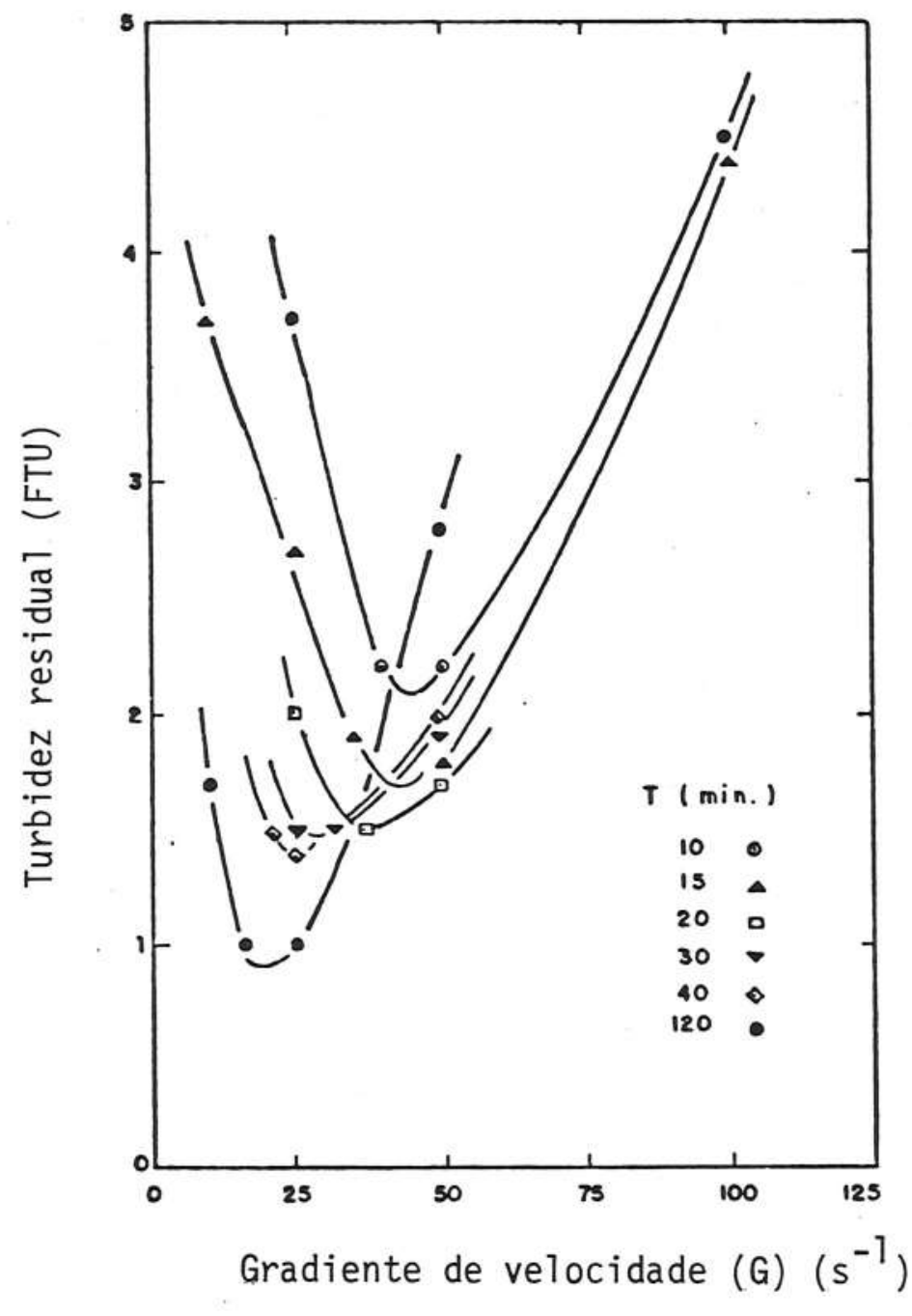

Figura 3.41 - Turbidez re sidual em função do gra diente de velocidade pa ra vārios períodos de bloculação (04). 


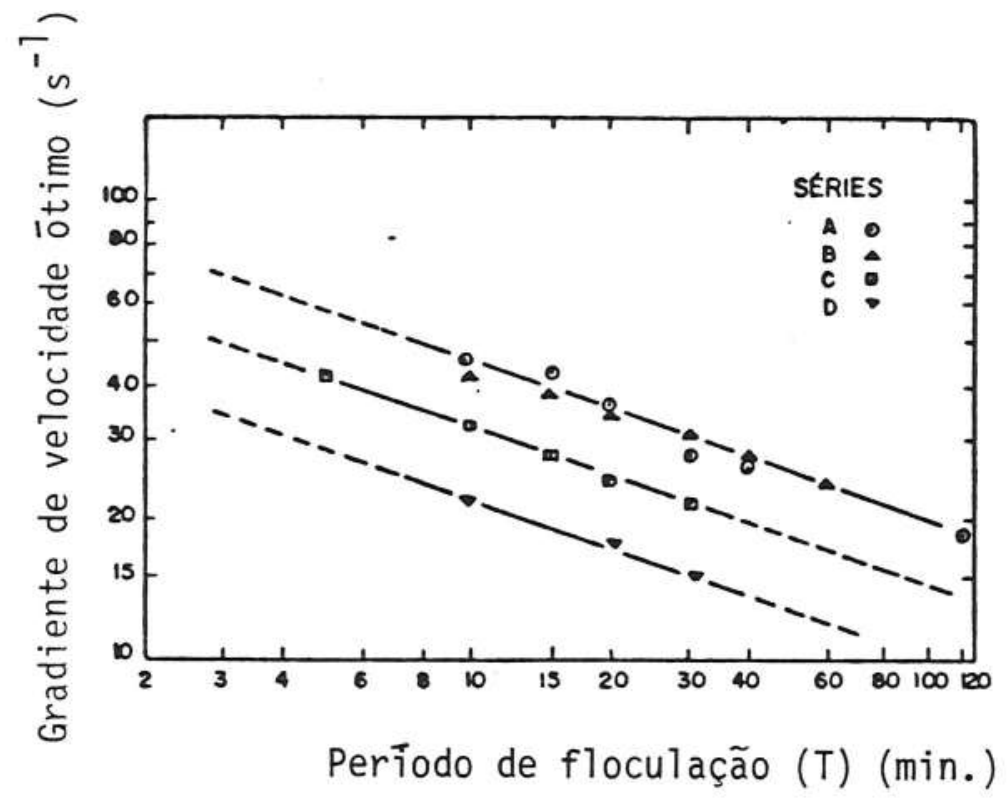

Figura 3.42 - Gradiente de velocidade ótimo em função do perĩodo de flocu lação para as séries A, B, C e D (ver texto) (04).

Segundo ANDREU-VILLEGAS \& LETTERMAN, as coeficientes $n$ e $K$ de pendem da qualidade da āgua bruta e da dosagem de coagulante.

A Figura 3.43 representa as curvas de turbidez residual minima como função do periodo de floculação e indica que a partir de um certo pe riodo, a eficiência de remoção torna-se insignificante.

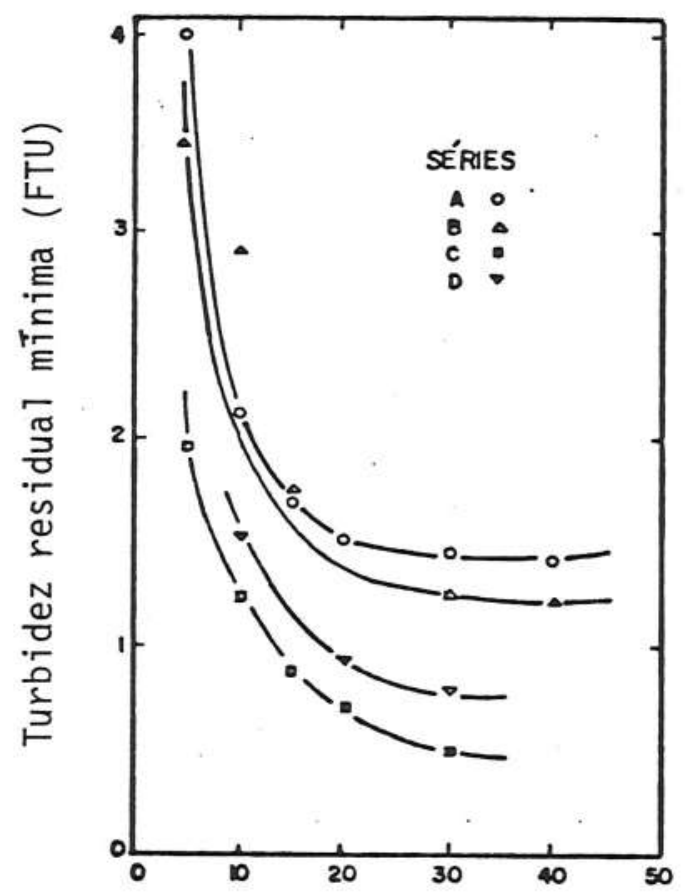

Figura 3.43 - Turbidez residual minima em função do período de floculação para as series $A, B, C$ e $D(04)$.

Perĩodo de floculação (T) (min.) 


\subsection{Breves Comentärios sobre a Revisão Bibliogräfica}

Assim como foi visto nos itens anteriores, inumeros foram os estudos da coagulação de āguas contendo diversificadas concentrações de particulas causadoras de turbidez e/ou cor verdadeira com o emprego de. sais de aluminio.

-

Verificou-se que mecanismos de coagulação desse composto sobre as particulas coloidais dependem fundamentalmente do valor do pH de coagulação e da dosagem de coagulante empregada.

As reações de hidrólise do sulfato de aluminio com a āgua proporcionam a formação de espécies de aluminio diversificadas, que, em função do pH, responsabilizam-se pela ocorrência dos possíveis mecanis mos de coagulação. Nas faixas de valores de pH normalmente empregadas pa ra o tratamento de āguas de abastecimento, manifestam-se os mecanismos de adsorção-neutralização e varredura, ou a ação conjunta de ambos.

0 mecanismo de adsorção-neutralização dā-se em valores de $\mathrm{pH}$ superiores a 4,0 e inferiores a 7,0, quando ocorre a predominância das espécies adsorviveis mononucleares ou polinucleares de aluminio, tais co mo: $\mathrm{Al}(\mathrm{OH})_{2}^{+}, \mathrm{AlOH}^{2+}, \mathrm{Al}_{2}(\mathrm{OH})_{2}^{4+}, \mathrm{Al}_{6}(\mathrm{OH})_{15}^{3+}, \mathrm{Al}_{8}(\mathrm{OH})_{20}^{4+}, \mathrm{Al}_{13}(\mathrm{OH})_{34^{+}}^{5+}$ As ca racterísticas bāsicas de atuação desse mecanismo podem ser visualizadas pelas Figuras $3.18(I I), 3.23,3.24,3.28$ (região 2), 3.37 e 3.38 . Verifica-se a ocorrência de desestabilização das partículas coloidais com pe quenas dosagens de coagulante e anulação da mobilidade eletroforética dás partículas. A amplitude da região ōtima de coagulação por este mecanismo depende das caracteristicas e concentração das partículas coloidais. nuan to maior for a concentração das partículas coloidais presentes, maior $\overline{\bar{e}}$ a faixa de valores de dosagens de sulfato de aluminio que poderiam ser cmpregadas c maiores seriam as eficiências de remoção por sedimentação pa ra un dado valor de pH constante.

Tal fato pode ser visualisado nas Figuras 3.18 (II), $3.231 \mathrm{com}$ parando-se $S_{2} \mathrm{ccm} S_{3}$ ), 3.24 (comparando-se $S=170 \mathrm{~m}^{2} / \ell$ e $1,7 \mathrm{~m}^{2} / \ell$ ) e pe fa comparação entre as figutas 3.37 e 3.38 , sendo explicado pela maior o portunidade de cheques no uididade de volume e tempo entre as partículas coloidais descstabilizadrs. Acredita-se que a coagulação por este meca nismo seja possivel para ourfucer tipo e concentração de partículas coloidais presentes, poten, nitis dispersões muito diluidas, sua manifestação pode ser não detectada pir sedimentacão dos flocos formados. Assim, $\underline{\underline{u}}$ 
ma dispersão coloidal com baixa concentração de partículas coloidais sa tisfatoriamente desestabilizadas poderā fornecer resultados de baixa ou nenhuma remoção de partículas por sedimentação devido à ineficiência do processo de floculação e não de coagulação.

outra caracteristica da ação desse mecanismo, consiste no fato de que a medida que o valor do pH de coagulação aumenta de valores próximos de 4,0 atē 5,0, a dosagem ötima de sulfato de aluminio decres ce, devido ao aumento da concentração das espécies adsorvīveis de alum $\bar{\imath}$ nio, com a consequente diminuição da concentração da espécie $\mathrm{Al}^{3+}$, rés ponsāvel pela atuação do mecanismo de compressão da dupla camada.

o controle das dosagens de coagulante nesse mecanismo deve ser feita criteriosamente, pois as espécies de aluminio presentes pode rão causar a restabilização das partículas coloidais por inversão de suas cargas superficiais, provocada pelo excesso de espécies adsarvidas, caso estejam presentes e disponiveis no meio dispersante (águá).

AMIRTHARAJAH (02), através da Figura 3.27, responsabiliza a ação do mecanismo de adsorção-neutralização entre os valores de $\mathrm{pH}$ 5,0 e 7,0 , as espécies de $\mathrm{Al}(\mathrm{OH})_{3(s)}$ carregadas positivamente (região mais escura do diagrama de coagulaçãol. Particularmente, 0 autor não acredi ta em tal afirmação, pois, caso tais espécies existam; deveriam possuír um "poder" de desestabilização maior que as espécies adsorviveis de alu minio $j \bar{a}$ citadas, $j \bar{a}$ que as dosagens de sulfato de aluminio para estare gião poderiam ser ainda menores. Apesar da falta de dados comprobatórios, poder-se-ia lançar a hipōtese da ação conjunta dos mecanismos de adsor ção-neutralização e varredura. Como as espēcies adsorvïveis solüveis en contram-se em baixa concentração nessa faixa de valores de $\mathrm{pH} e$ sua rea ção com as particulas coloidais aparentemente manifestam-se atravēs de uma interação quimica forte, poder-se-ia considerar que, a medida que houvesse a adsorção de uma espécie solüvel, o equilïbrio entre as especies solüveis e insolüveis $(\mathrm{Al}(\mathrm{OH}) 3(\mathrm{~s})$ ) provocaria a formação de uma no va espécie solüvel, até que ocorresse a desestabilização das partículas coloidais.

Jā o mecanismo de varredura, causado potencialmente pela es pécic $\mathrm{Al}(\mathrm{OH})_{3}(\mathrm{~s})$, pode ser observado pelas mesmas figuras, porém, em va lores de pH $e$ dosagens de coagulante mais elevadas.

Das Figuras 3.18(III), 3.23 e da comparação entre as Figu ras 3.37 e 3.38 , observa-se que a eficiência de remoção de particulas co 
loidais por este mecanismo aumenta com a concentração inicial das mesmas para uma dosagem constante de coagulante. Tal relação não estequiométrica pode ser explicada se considerarmos que o coagulante adicionado mani besta-se como um colöide cuja barreira de energia de iteração repulsiva com o colöide pré existente (turbidez elou substâncias hümicas) è nula.. Assim sendo, para una dada dosagem de coagulante, superior a um certo va lor minimo, o aumento da concentração inicial de particulas coloidais cor responde ao aumento na oportunidade de choques $e$, assim, a melhores efí ciências na formação de flocos e na remoção dos mesmos por sedimentação. Cabe aqui ressaltar, que, a Figura 3.23, extraida do traba tho de STUMM \& O'MELIA (84) não faz distincẫo entre as zonas onde $\bar{e}$ pos sivel a coagulação (denominadas de zona 2 e 4). Pelos aspectos observa dos, a zona 2 corresponde ao mecanismo de adsorção-neutralização e a zo na 4 ao de varredura. Sendo assim, para a concentraçäo coloidal $s_{4}$, pas sou-se a idéia errônea de que a coagulação manifestaria-se apenas pelo me canismo de adsorção-neutralização $e$, na verdade, dependendo do valor do pH (no caso não mencionado), ambos os mecanismos de coagulação poderiam ser eficiêntes. 


\section{MATERIAIS E METODOS}

\subsection{Equipamentos Utilizados}

A coleta de dados dos ensaios envolveu a determinação de di versos parâmetros físico-químicos, caracterizados através da utilizacão dos seguintes equipamentos:

a) Turbidímetro, da Micronal, modelo B 250, com faixa de va riação de leitura entre 0 e 1000 FTU;

b) Potenciômetro, da Micronal, modelo B 371;

c) Espectrocolorímetro, da Micronal, modelo B 242, com faixa de variação do comprimento de onda entre $400 \mathrm{~nm}$ e $700 \mathrm{~nm}$, para leituras de transmitância;

d) Aqua-Tester, da Hellige, para leituras de cor em disco;

e) Zetâmetro, da Zeta - Meter Inc., modelo do ano de 1972, pa ra determinaçoes de mobilidade eletroforética e condutância específica;

6) Bureta, da Metrohm - Herisau, Multi - Burette, modelo E 485 (erro $\pm 0,01 \mathrm{ml}$ ), para medições de alcalinidade e padronização de so lucōes de hidrōxido de sōdio e ácido clorídrico;

g) Balança Elētrica, da Mettler, modelo H 20T, com leitura de centésimos de miligrama;

h) Tacômetro Digital, da Dako, com faixa de leitura entre 0 e $1000 \mathrm{rpm}$, para medições da rotação da paleta do agitador;

i) Cronômetro Digital, para determinações de períodos de mis tura rāpida, floculação e sedimentação, além de aferições do tacômetro;

j) Outros, tais como: Termômetro, Aquecedor (do tipo usado cm aquārios), vidrarias diversas de laboratōrio; Seringas para aplicacão de produtos químicos nos reatores, etc.

As Figuras 4.1 e 4.2 mostram alguns dos instrumentos utiliza 
dos neste estudo.

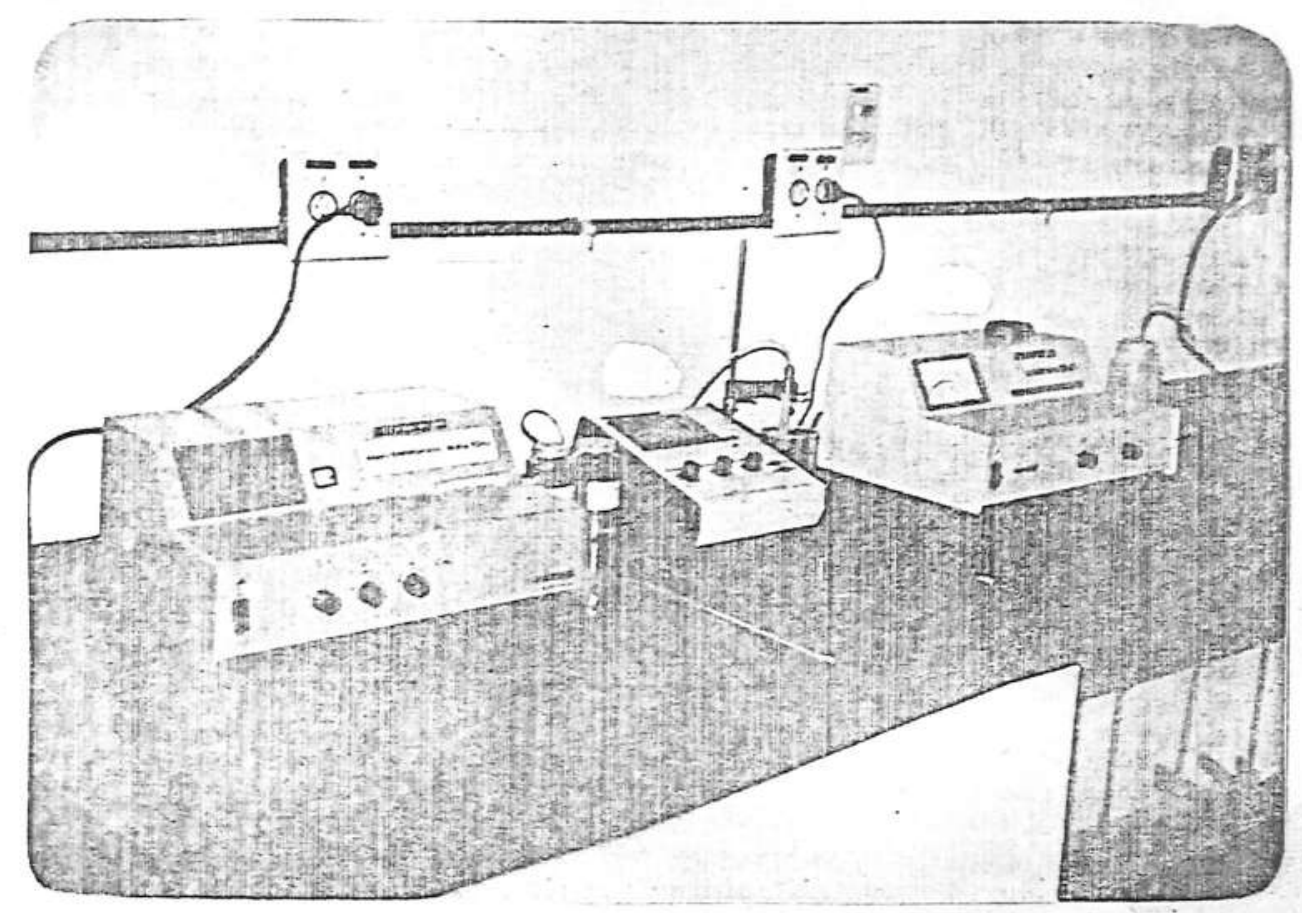

Figura 4.1 - Fotografia da bancada de alguns dos instrumentos (Espectro colorímetro, Potenciômetro, Turbidímetro, Termômetro, Cro nômetro e Tacômetro).

\subsection{Instalação para Preparação e Homogeinização das Aguas Artifí ciais e Naturais}

Devido à necessidade de uso de grandes volumes de āgua para a realização dos ensaios de floculação propostos laproximadamente 1000 $l$ para cada tipo de āgua artificial e $300 l$ para cada tipo de āgua natu ral), desenvolveu-se a instalação mostrada na Figura 4.3, cujos objeti vos principais foram, permitir a homogeinização perfeita das amos tras coletadas para cada reator e cada ensaio, além de minimizar os er ros de preparação das āguas artificiais devido ao grande volume de cada batelada produzida $(200$ l).

A instalação consiste de um conjunto motor - redutor por meio de polias e correias, com rotação ajustāvel entre 100 e $800 \mathrm{rpm}$, 
provido de eixo prolongado e turbina de material acrílico com quatro pás inclinadas a 450 .

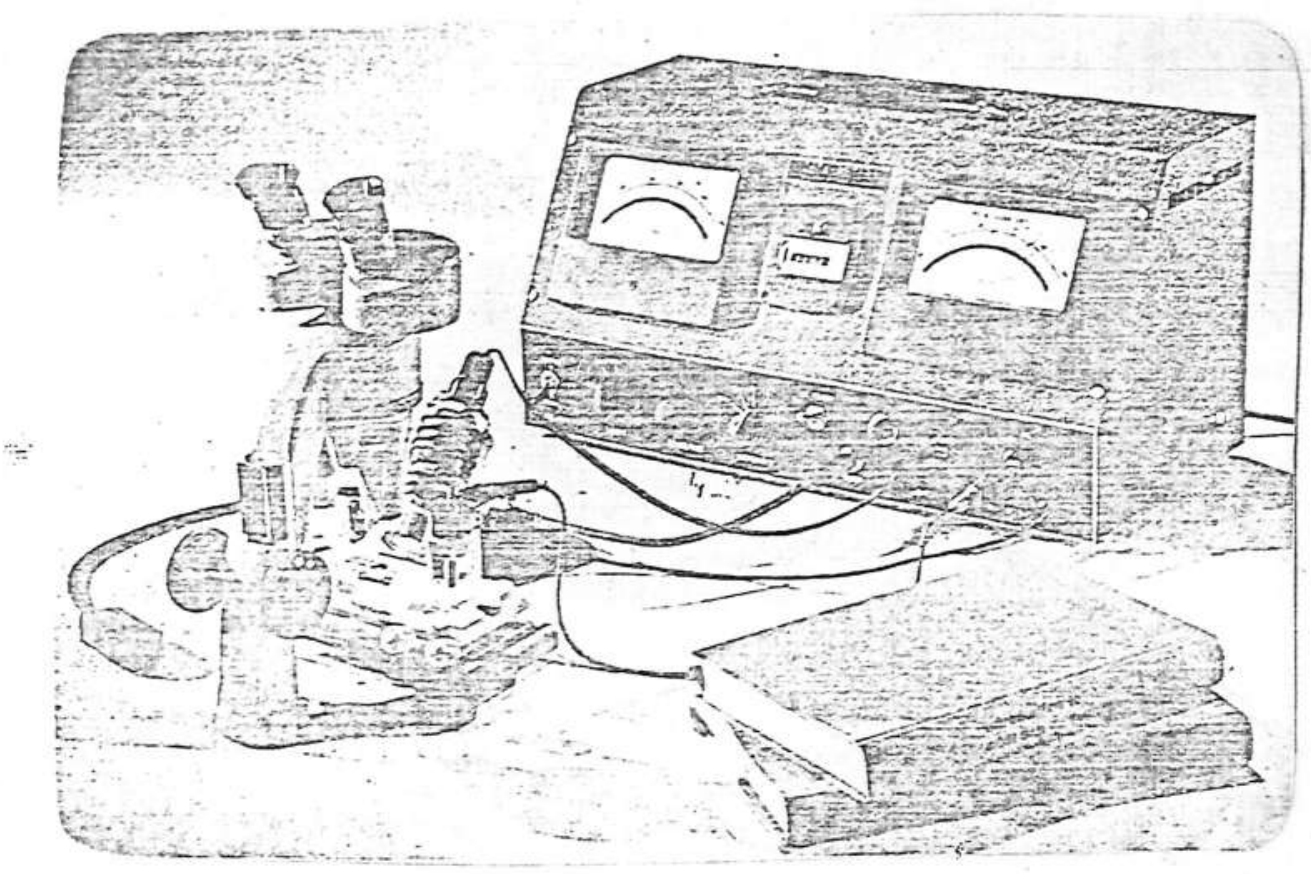

Figura 4.2 - Fotografia do Zetâmetro da Zeta - meter, modelo 1972.

\subsection{Instalação para os Ensaios de Floculação}

A instalação para a realização dos ensaios de floculação foi projetada, executada e calibrada, de forma a permitir uma grande flexibi lidade na execução dos ensaios e uma grande segurança e eficiência na de terminação e manutenção dos parâmetros físico-químicos que governam a coagulação e floculação.

\subsubsection{Projeto da Instalação}

Foi dada especial atenção ao projeto da instalação, de modo a atender aos seguintes requisitos:

a) Possibilidade de se alterar a rotação do agitador, de for 


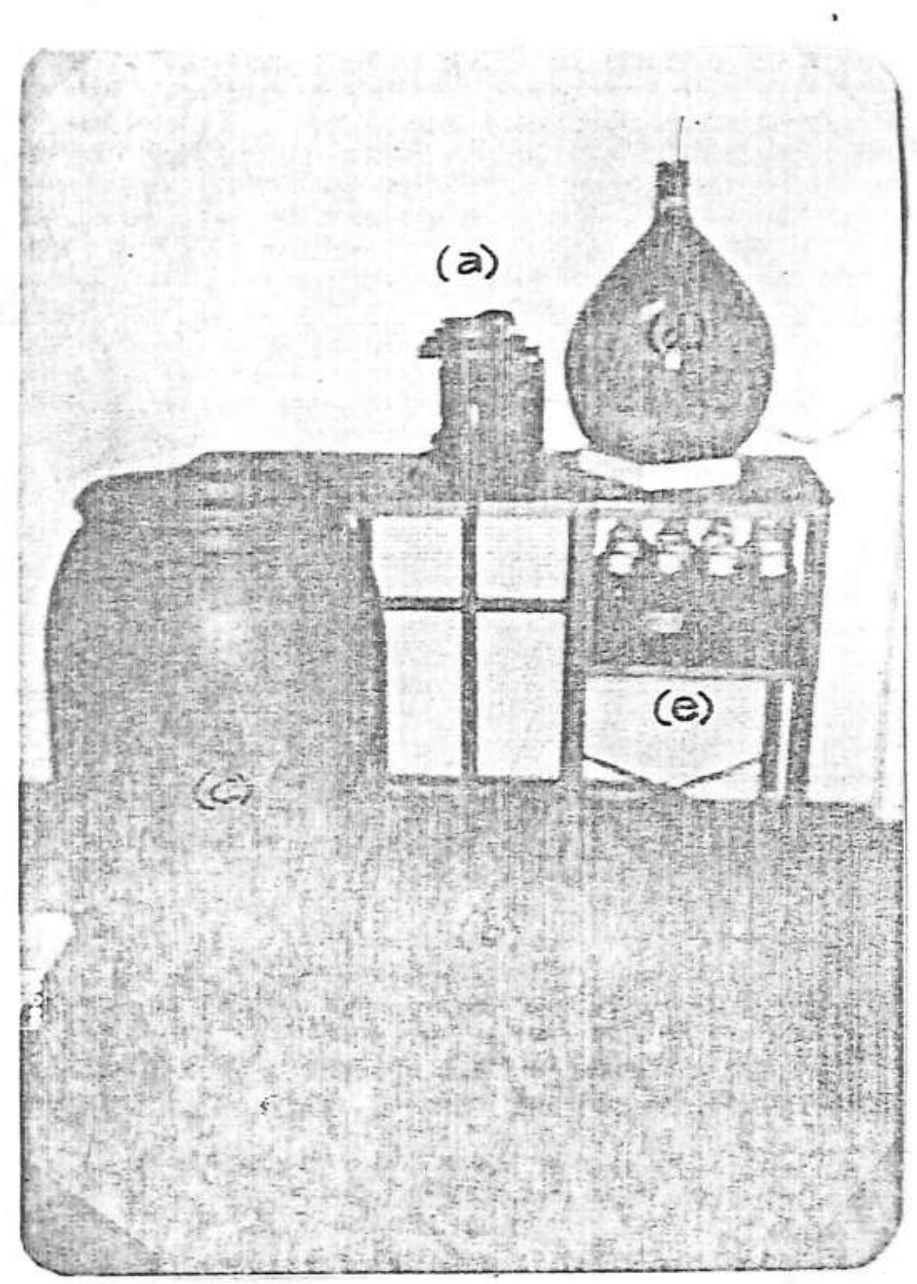

Figura 4.3 - Fotografia do sistema de preparação e homogeinização das a mostras de āgua para investigação.

(a) Conjunto motor - redutor;

(b) Turbina;

(c) Reservatōrio de āgua para estudo $(\mathrm{V}$ ütil $=200 \mathrm{l})$;

(d) Recipiente de armazenamento de suspensão-mãe de cauli nita;

(e) Recipientes de armazenamento de substâncias hümicas;

ma independente e continua para cada reator (jarro);

b) Possibilidade de coletar amostras individuais e conjun tas dos reatores durante qualquer fase de execução dos ensaios por ape nas um operador;

c) Dispor de reatores com un volume util de dois litros, de 
material transparente $e$ de formato quadrado em planta;

d) Dispor de conjunto motor-redutor que permita velocidades de rotação do agitador entre zero e $500 \mathrm{rpm}$, de forma a atender a gra dientes de velocidade variāveis entre zero e $1200 \mathrm{~s}^{-1}$ e torque suficien te para impulsionar o agitador, mesmo para baixos valores de velocidade de rotação;

\subsubsection{Descrição da Instalação}

A instalação, cujo esquema geral $e$ apresentado nas Figuras 4.4 e 4.5 é composta por:

a) Conjunto motor - redutor - agitador

- nümero de unidades: 6;

- motor de 75 u, de corrente continua;

- redutor de 1:5,6;

- polias de transmissão do eixo do redutor ao eixo do a gitador, com redução de 1:3;

- agitador constituído de um eixo de $4,8 \mathrm{~mm}$ de diâmetro

e paleta de $25 \times 75 \mathrm{~mm}$, construídos em aço inoxidāvel;

- variador de corrente com escala graduada de zero a 100 $\%$

- base metälica para apoio, suporte e variação da altu ra do eixo do agitador;

b) Reatores

Os reatores, com dois litros de volume ütil, foram executa dos artczanalmente em acrilico transparente, com parede de espessura $i$ gual a $6 \mathrm{~mm}$, cujos detalhes são apresentados na Figura 4.6. Para possi bilitar que sejam obtidos gradientes de velocidade relativamente altos na mistura rāpida, foram construídas seis armações com arame e paletas de aço inox, que podem ser introduzidas ou removidas com o agitador em funcionamento. esses conjuntos de estatores também podem ser observa dos na Figura 4.6 .

c) Sistema de Coleta de Amostras

Para permitir a realização de coleta simultânea $e$ indepen dente do conteūido de cada reator por apenas um operador, foi construída uma piaca de acrílico de $10 \mathrm{~mm}$ de espessura, na qual foram executa- 

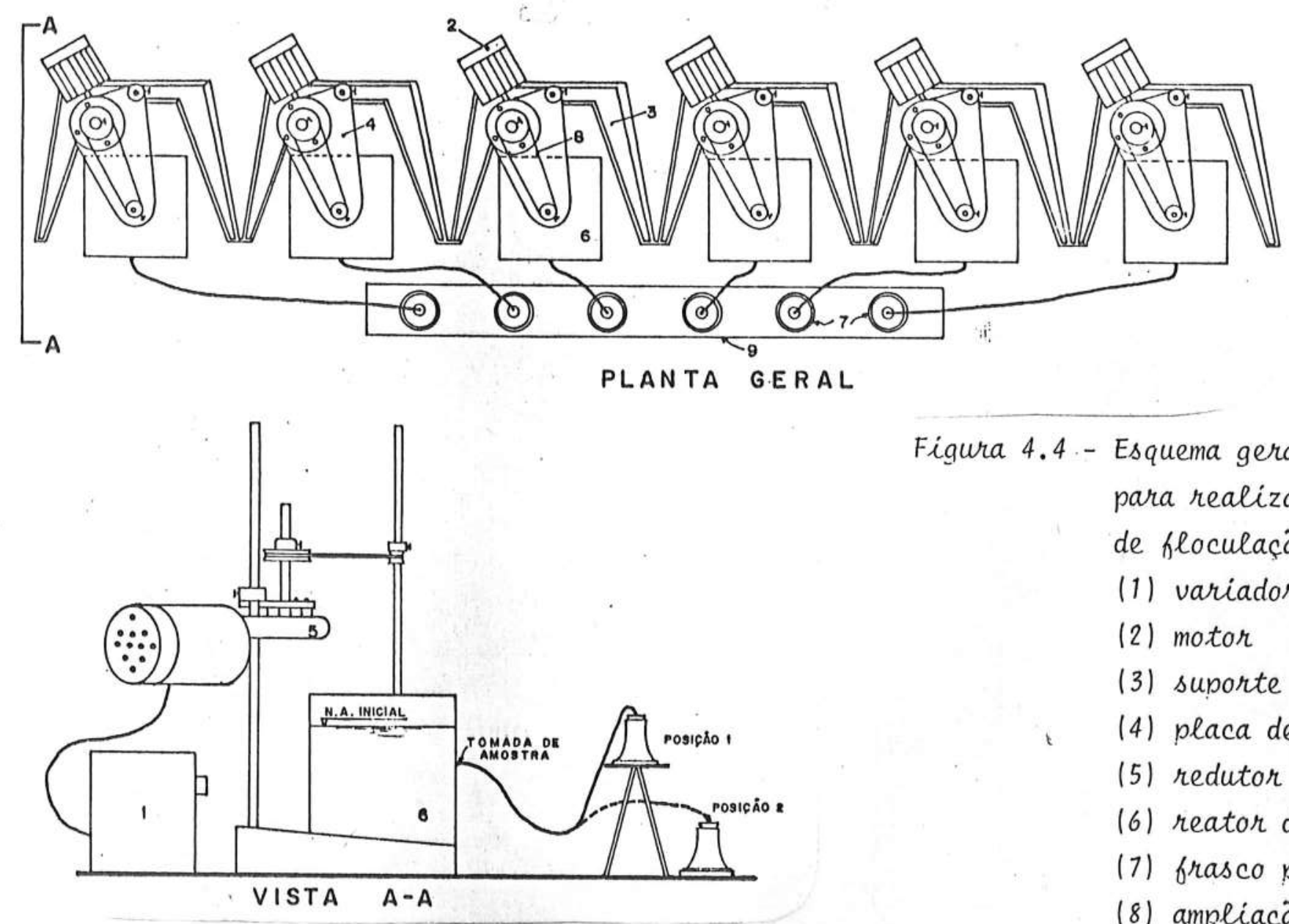

Figura 4.4 - Esquema geral da instalação para realização de ensaios de floculação.

(1) variador de corrente

(2) motor

(3) suporte

(4) placa de fixação

(5) redutor

(6) reator de acrílico

(7) frasco para coletas

(8) ampliacão por polias

(9) suporte de acrílico

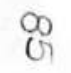




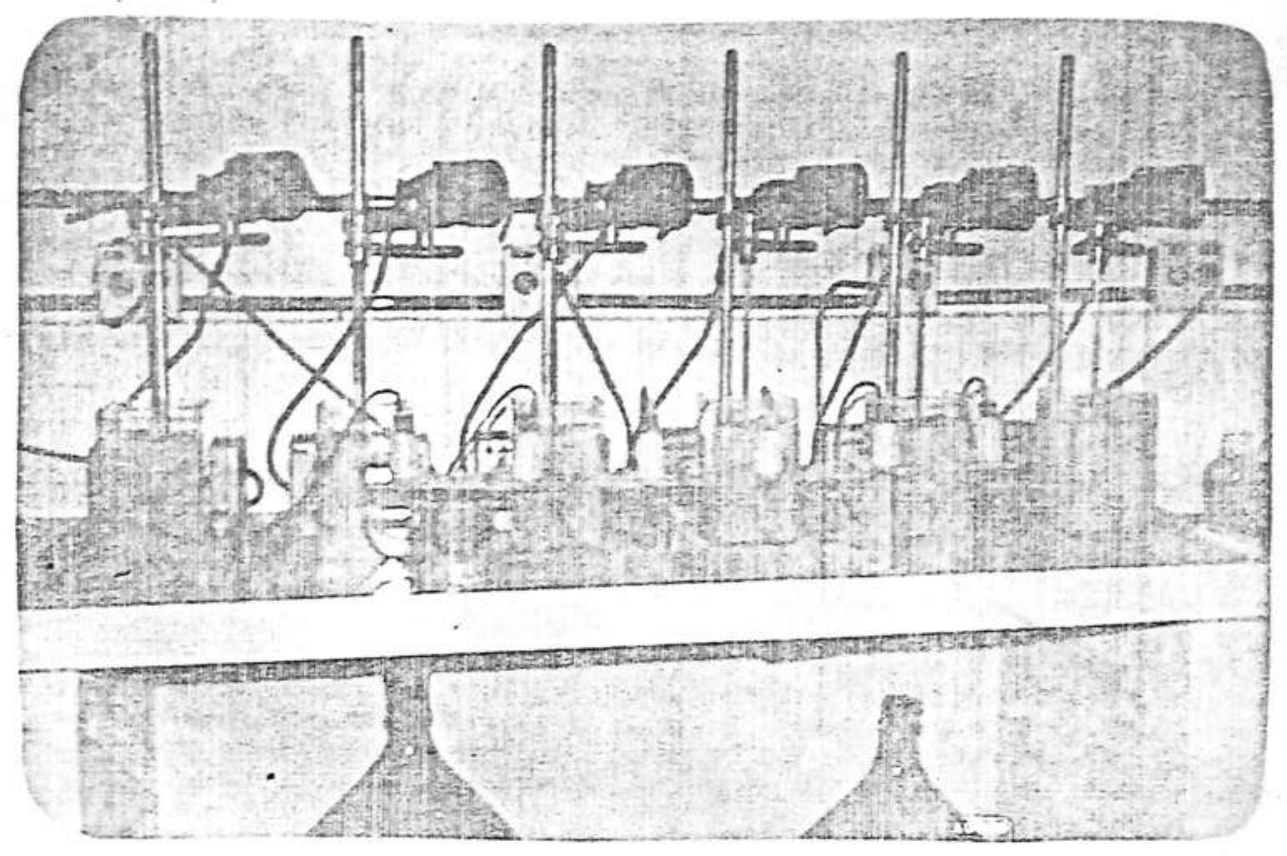

Figura 4.5 - Fotografia da instalação mostrando os conjuntos motor-redu tor, reatores e sistema de coleta de amostras.

das duas fileiras de seis orificios circulares, onde são fixados os fras cos de coleta e descarte. Para cada tempo de coleta, tem-se seis frascos de $100 \mathrm{ml}$ fixados na placa que pode ser localizada em duas posições dis tintas. Na superior, a placa encontra-se acima do nivel de āgua no inte rior dos reatores, e na posição inferior, ocorre o sifonamento do volume de amostra desejado.

0 ponto de tomada de amostra do jarro encontra-se localizado a $100 \mathrm{~mm}$ abaixo do nivel de ägua inicial, correspondente ao volume de dois litros. A partir do nivel inicial de ägua, tem-se, na parede de ca da jarro, uma escala graduada em milimetros, que permite conhecer a dis tancia entre o nivel de āgua no interior do jarro e o ponto de tomada, correspondente ao tempo de coleta.

As dimensões dos orifícios e mangueiras de coleta foram de terminadas de modo a manter uma uniformidade de coleta em todos os reato res, evitando-se o arraste de sedimentos.

A Figura 4.7 mostra 0 sistema de coleta de amostras e a pla taforma na posição de não coleta. 

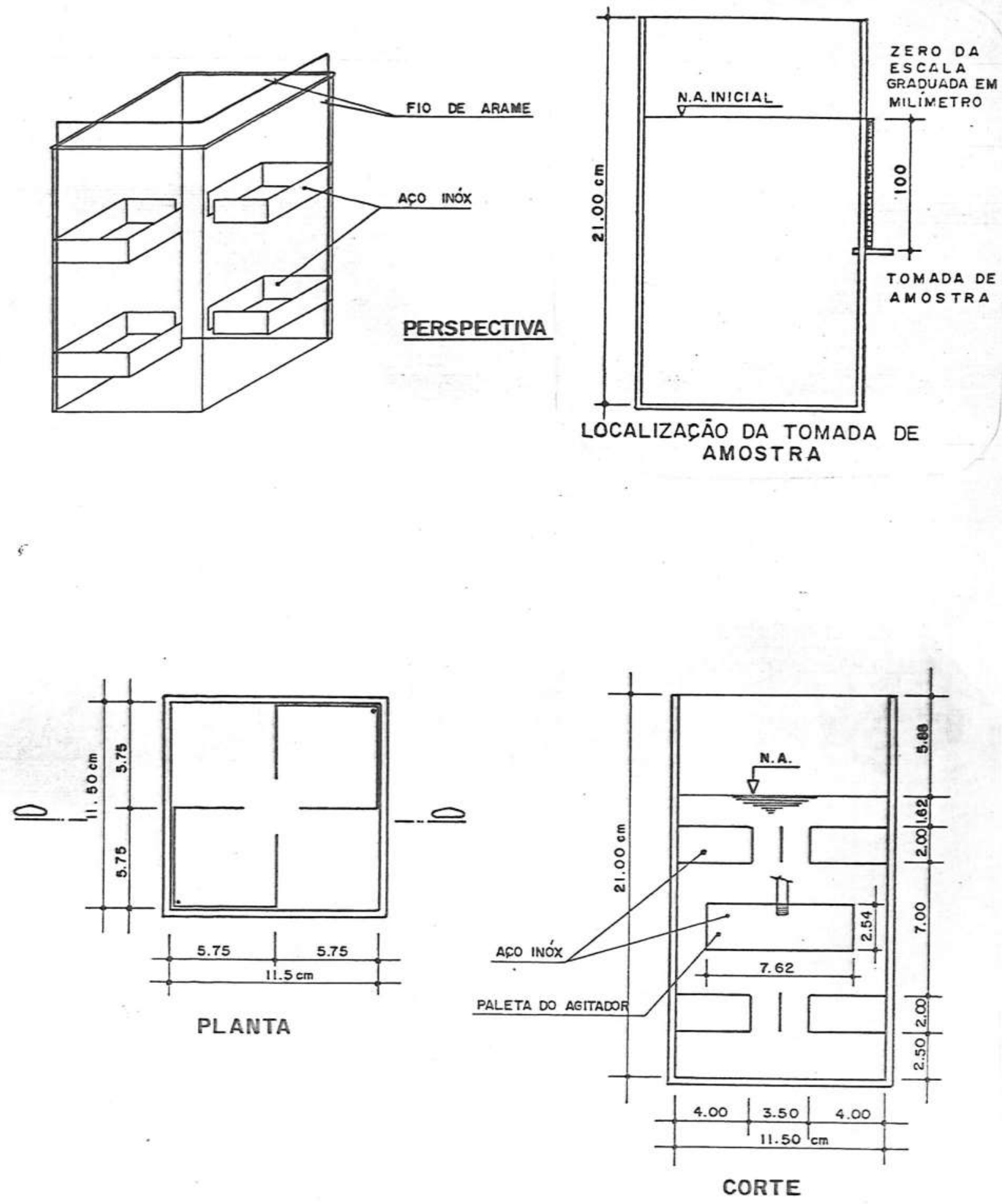

Figura 4.6 - Características do reator, estator e agitador. 


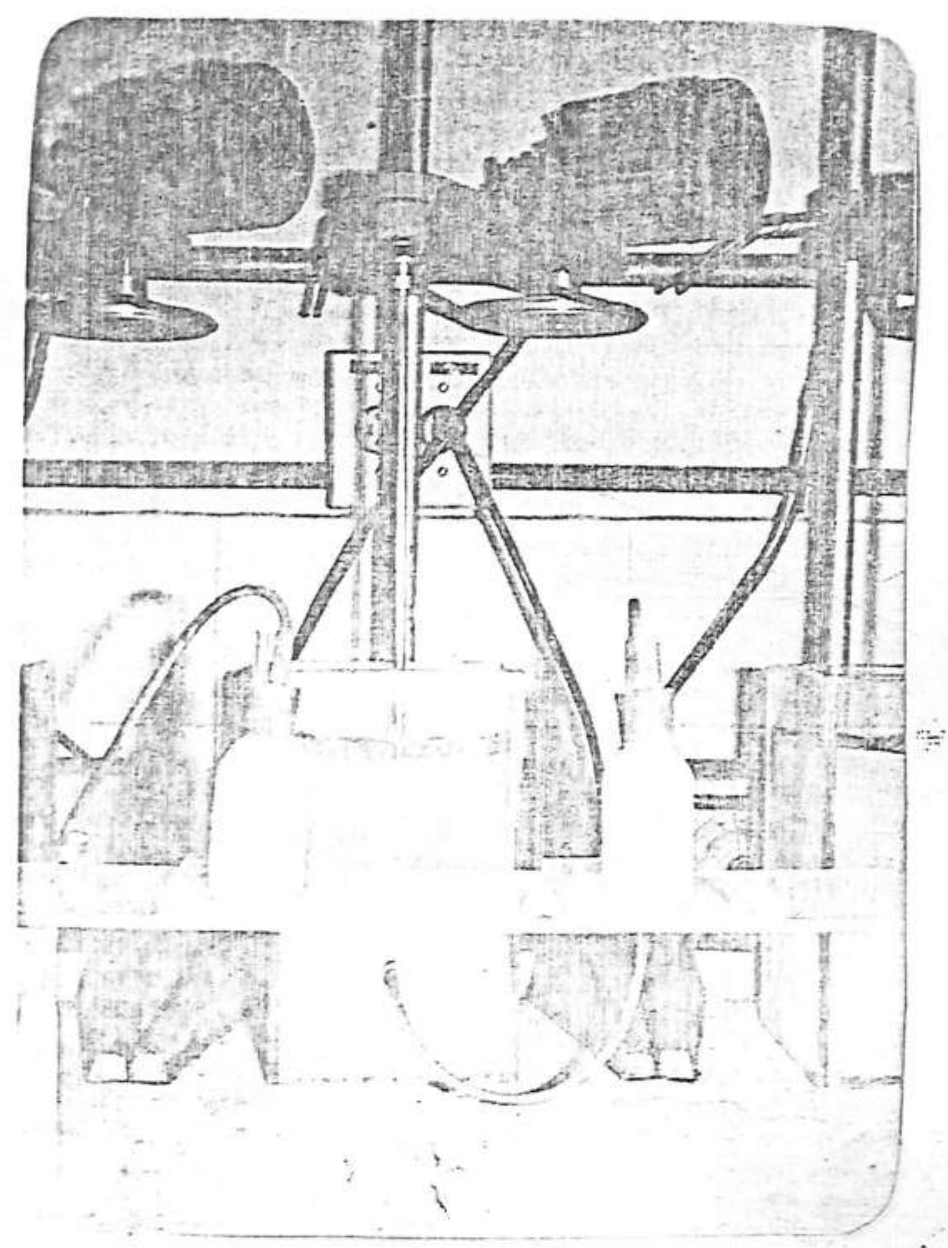

Figura 4.7 - Fotografia de um aparelho de floculação, destacando-se a plataforma e frascos do sistema de coleta de amostras.

\section{d) Sistema de Dosagem}

A dosagem de coagulante foi feita por meio de seringas de material plástico descartāveis, desprovidas de agulha, de volumes pro porcionais à quantidade de solução adicionada. O tempo de aplica ção não ultrapassou a um segundo para todos os ensaios e se deu em lo cal o mais próximo possivel da paleta do agitador.

\subsubsection{Calibração da Instalação}

Para que fosse possivel a obtenção da curva de variacão do gradiente de velocidade em funcão da rotação do agitador, foi feito um levantamento bibliográfico e adotou-se a metodologia apresentada por RU EY; HUDSON e SINGLEY (49), com algumas modificações, para a construção 
de um torquïmetro que permitisse o cálculo da potência introduzida pelo agitador por unidade de volume do fluido em função de sua velocidade de rotacão.

Segundo CAMP \& STEIN (20), o gradiente de velocidade $(G) \bar{e}$ dado pela seguinte equação:

$$
G=\sqrt{\omega / \mu} ;
$$

onde: $\quad \omega$ : potencia introduzida por unidade de volume do fluido $\left(\mathrm{N} . \mathrm{m} / \mathrm{s} . \mathrm{m}^{3}\right)$;

$\mu$ : viscosidade absoluta do fluido $\left(N . \check{s} / \mathrm{m}^{2}\right)$.

O valor de $(\omega)$ depende principalmente da velocidade de ro tação dos agitadores, além da geometria dos estatores, propulsores $\bar{e}$ do reator. Segundo a literatura $(24 ; 41 ; 49)$, a obtenção de $(\omega)$ pode ser feita através da determinação experimental do torque fornecido ao flui do $(T)$, para diversos valores de velocidade de rotação do agitador em valores constantes de temperatura.

$$
w=\frac{2 \cdot \pi \cdot s \cdot T}{V}
$$

onde: $\quad\left\{\begin{array}{l}\text { s: velocidade de rotação do agitador em rps }\left(\mathrm{s}^{-1}\right) \text {; } \\ T \text { : torque fornecido ao fluido }(\mathrm{N} . \mathrm{m}) ; \\ V: \text { volume de fluido }\left(\mathrm{m}^{3}\right) .\end{array}\right.$

A obtenção do torque introduzido ao fluido foi feita atra vés da instalação mostrada na Figura 4.8 .

O reator foi suspenso no ar através de quatro fios de aço com espessura de $0,5 \mathrm{~mm}$, presos em uma placa circular de acrilico em cujo centro foi amarrado um barbante de algodão com sua outra extremi dade presa ao teto. 0 arranjo foi feito de modo que o reator ficasse perfeitamente nivelado e livre para qualquer movimento de rotação. A través de duas linhas de algodão (no 24) amarradas nos pontos $A$ e $B$, foi possivel transmitir-se uma força $(M)$ conhecida ao reator, de modo que, para uma certa rotação do agitador lobtida através do tacômetro! o reator permanecia em equilíbrio, isto $\bar{e}$, com as linhas $l_{1} e l_{2}$ for 

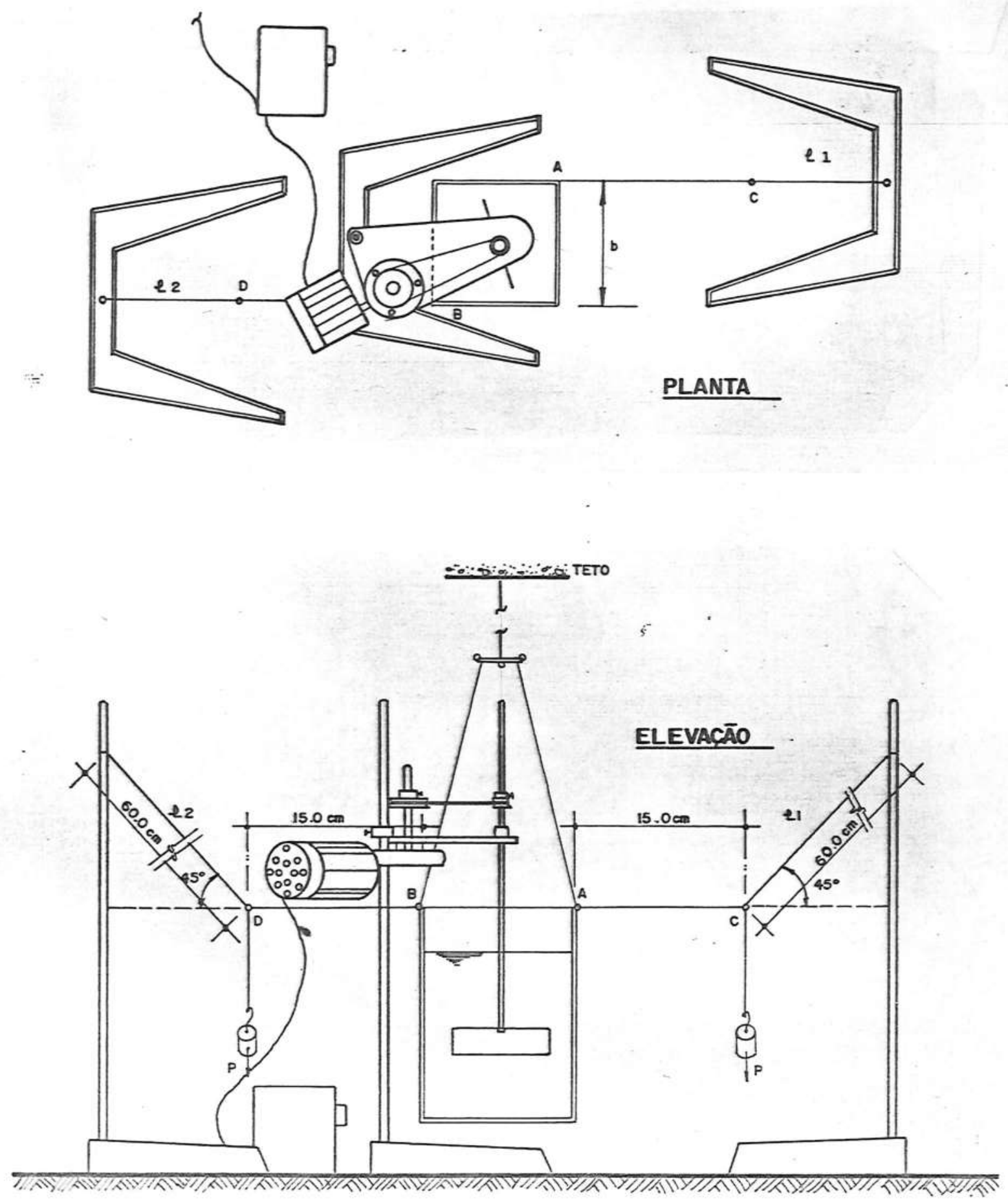

Figura 4.8 - Caracteristicas da montagem efetuada para a determinação do torque aplicado ao líquido em função da rotação do a gitador. 
mando um ângulo de 450 com a horizontal (ver Figura 4.8). Conhecendo-se o braço de torque da força $(M)$, denominado de $\left(B_{1}\right)$, foi possivel a ob tenção do torque $(T)$ aplicado ao reator, através da equação a seguir:

$$
T=\text { B.M.g ; }
$$

onde:

$$
\left\{\begin{array}{l}
M \text { : massa aplicada nos pontos } C \text { e } D(\mathrm{Kg}) ; \\
B \text { : braço de torque da força }(M) \text { (no caso, } 0,118 \mathrm{~m}) ; \\
g \text { : aceleracão da gravidade }\left(9,81 \mathrm{~m} / \mathrm{s}^{2}\right) .
\end{array}\right.
$$

Foram feitas diversas taras cortando-se dois pedaços de mes mo comprimento de arame de aço com espessura de $0,5 \mathrm{~mm}$ e pesando-se em balança com precisão de até centésimo de gramo, obtendo-se valores com preendidos entre 0,11 e 5,40 g. Para valores acima de 5,40 g foi utili zado areia colocada em recipiente de plástico.

o levantamento dos pontos da curva de rotação do agitador em função do gradiente de velocidade foi feito para o reator com estato res e sem estatores, medindo-se a temperatura e volume da āgua contida no reator, além da rotação necessāria para manter o reator submetido ao torque criado por massas $(M)$ conhecidas, em equilíbrio. Os dados obti dos estão listados nos quadros 4.1 e 4.2 . A Figura 4.12 apresenta a cur va de gradiente de velocidade em função da rotação do agitador.

Os cálculos de gradiente de velocidade apresentados nos qua dros 4.1 e 4.2, foram feitos e corrigidos para a temperatura de $260 \mathrm{C}$, pois durante a realização do experimento, a temperatura da āgua sofreu variaçoes de temperatura de 23 a 260 C. O quadro 4.3 apresenta os coefí cientes de correção do gradiente de velocidade em função da temperatura da āgua em (OOC), extraído dos dados apresentados por HUDSON (41) e adap tados para a temperatura de $260 \mathrm{C}$.

A calibração do reator sem 0 uso de estatores apresentou $\underline{u}$ ma reta com inclinação ligeiramente diferente da obtida por HUDSON (41) para o mesmo tipo de reator (ver Figura 4.12). Essa diferença pode ter sido causada por erros na determinação experimental, ou mesmo, por difue rentes metodólogias adotadas para a calibração IHUDSON não cita a meto dologia utilizada). Apesar disso, existe uma boa concordância entre os valores na faixa de gradientes de velocidade inferiores a $150 \mathrm{~s}^{-1}$, onde - reator sem estatores foi mais utilizado. 
Quadro 4.1 - Dados da calibração do gradiente de velocidade para reator sem estatores

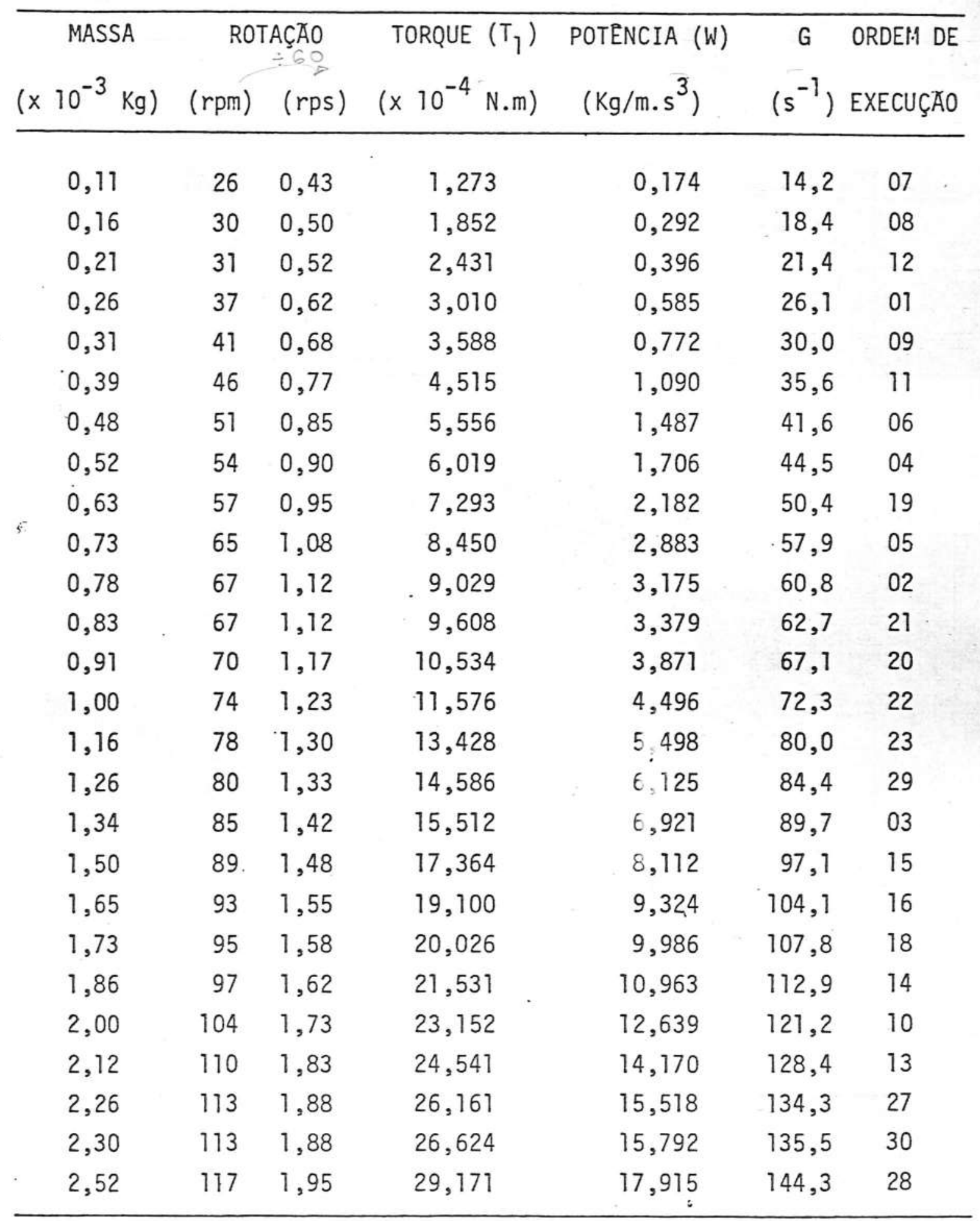


Quadro 4.1 - Dados da calibração do gradiente de velocidade para reator sem estatores. (continuação)

\begin{tabular}{crrrrrrr}
\hline MASSA & ROTP.ÇAO & TORQUE $\left(T_{1}\right) \cdot$ POTENCIA (W) & $G$ & ORDEM DE \\
$\left(\times 10^{-3} \mathrm{Kg}\right)$ & $(\mathrm{rpm})$ & $(\mathrm{rps})$ & $\left(\times 10^{-4} \mathrm{~N} . \mathrm{m}\right)$ & $\left(\mathrm{Kg} / \mathrm{m} . \mathrm{s}^{3}\right)$ & $\left(\mathrm{s}^{-1}\right)$ & EXECUÇÃO \\
\hline 2,73 & 124 & 2,07 & 31,602 & 20,569 & 154,7 & 24 \\
2,86 & 127 & 2,12 & 33,107 & 22,070 & 160,2 & 26 \\
3,12 & 134 & 2,23 & 36,116 & 25,404 & 171,9 & 25 \\
3,34 & 137 & 2,28 & 38,663 & 27,804 & 179,8 & 17 \\
3,64 & 145 & 2,42 & 42,136 & 30,271 & 193,1 & 31 \\
4,16 & 153 & 2,55 & 48,155 & 38,674 & 212,1 & 33 \\
4,56 & 161 & 2,68 & 52,786 & 44,610 & 227,8 & 35 \\
5,08 & 174 & 2,90 & 58,805 & 53,709 & 249,9 & 36 \\
5,64 & 180 & 3,00 & 65,288 & 61,686 & 267,8 & 32 \\
5,66 & 181 & 3,02 & 65,519 & 62,249 & 269,0 & 37 \\
6,13 & 185 & 3,08 & 70,960 & 68,908 & 283,1 & 40 \\
7,66 & 210 & 3,50 & 88,671 & 97,743 & 337,1 & 38 \\
9,00 & 221 & 3,68 & 104,182 & 120,857 & 374,9 & 39 \\
10,00 & 240 & 4,00 & 115,758 & 145,830 & 411,8 & 41 \\
12,00 & 259 & 4,32 & 138,910 & 188,850 & 468,6 & 50 \\
15,03 & 288 & 4,80 & 173,984 & 263,020 & 553,0 & 44 \\
17,40 & 312 & 5,20 & 201,419 & 329,868 & 619,3 & 51 \\
20,00 & 328 & 5,47 & 231,516 & 398,603 & 680,8 & 42 \\
22,00 & 350 & 5,83 & 254,668 & 467,872 & 737,6 & .49 \\
25,03 & 369 & 6,15 & 289,742 & 561,208 & 807,8 & 45 \\
27,40 & 389 & 6,48 & 317,177 & 647,645 & 867,8 & 48 \\
30,00 & 404 & 6,73 & 347,274 & 736,443 & 925,4 & 43 \\
32,00 & 419 & 6,98 & 370,426 & 814,706 & 973,3 & 47 \\
35,03 & 438 & 7,30 & 405,500 & 932,290 & 1041,2 & 46 \\
\hline & & & & & & \\
\hline
\end{tabular}


nuadro 4.2 - Dados de calibração do gradiente de velocidade para reator com estatores.

MASSA ROTAÇAOO TORQUE $\left(T_{1}\right)$ POTENCIA (W) G ORDEM DE EXECU

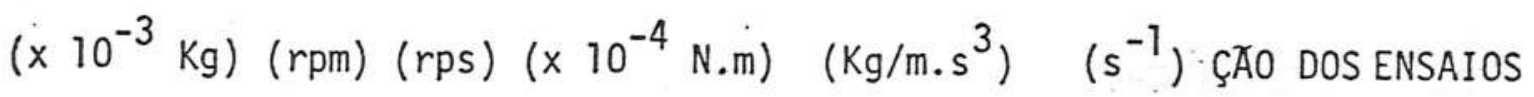

\begin{tabular}{rrrrrrr}
\hline 0,21 & 27 & 0,45 & 2,431 & 0,344 & 19,9 & 03 \\
0,26 & 31 & 0,52 & 3,010 & 0,489 & 23,7 & 08 \\
0,43 & 38 & 0,63 & 4,978 & 0,990 & 33,7 & 10 \\
0,52 & 43 & 0,72 & 6,019 & 1,355 & 39,5 & 01 \\
0,73 & 51 & 0,85 & 8,450 & 2,257 & 51,0 & 09 \\
0,78 & 52 & 0,87 & 9,029 & 2,458 & 53,2 & 05 \\
1,34 & 64 & 1,07 & 15,512 & 5,198 & 77,3 & 04 \\
1,77 & 75 & 1,25 & 20,489 & 8,046 & 96,2 & 11 \\
2,00 & 77 & 1,28 & 23,152 & 9,334 & 103,6 & 02 \\
2,30 & 83 & 1,38 & 26,624 & 11,571 & 115,4 & 06 \\
2,73 & 89 & 1,48 & 31,602 & 14,727 & 130,2 & 13 \\
3,03 & 90 & 1,50 & 35,075 & 16,529 & 137,9 & 15 \\
3,34 & 95 & 1,58 & 38,663 & 19,232 & 148,7 & 12 \\
4,30 & 110 & 1,83 & 49,776 & 28,669 & 174,8 & 07 \\
5,40 & 124 & 2,07 & 62,509 & 40,585 & 215,4 & 40 \\
5,64 & 129 & 2,15 & 65,288 & 44,098 & 224,5 & 14 \\
6,74 & 138 & 2,30 & 78,021 & 56,375 & 253,8 & 43 \\
7,70 & 146 & 2,43 & 89,134 & 68,139 & 275,5 & 41 \\
9,04 & 158 & 2,63 & 104,645 & 86,572 & $.310,5$ & 42 \\
10,00 & 167 & 2,78 & 115,758 & 101,220 & 335,7 & 18 \\
12,30 & 184 & 3,07 & 142,382 & 137,174 & 390,8 & 20 \\
15,03 & 198 & 3,30 & 173,984 & 180,374 & 448,2 & 19 \\
\hline
\end{tabular}


Quadro 4.2 - Dados da calibração do gradiente de velocidade para reator com estatores. ( continuação )

MASSA ROTAÇÃO TOROQUE $\left(T_{1}\right)$ POTENCIA $(W)$ G ORDEM DE EXECU $\left(x 10^{-3} \mathrm{Kg}\right)(\mathrm{rpm})(\mathrm{rps})\left(\times 10^{-4} \mathrm{~N} . \mathrm{m}\right)\left(\mathrm{Kg} / \mathrm{m} . \mathrm{s}^{3}\right) \quad\left(\mathrm{s}^{-1}\right)$ çÃO DOS ENSAIOS

$\begin{array}{rrrrrrr}17,70 & 214 & 3,57 & 204,892 & 229,581 & 505,6 & 21 \\ 20,00 & 231 & 3,85 & 231,516 & 280,022 & 558,4 & 16 \\ 22,30 & 243 & 4,05 & 258,140 & 328,444 & 604,7 & 22 \\ 25,03 & 255 & 4,25 & 289,742 & 386,857 & 656,3 & .17 \\ 27,70 & 271 & 4,52 & 320,650 & 454,987 & 711,8 & 23 \\ 30,00 & 280 & 4,67 & 347,274 & 509,130 & 762,8 & 27 \\ 32,30 & 291 & 4,85 & 373,898 & 569,699 & 806,9 & 26 \\ 35,40 & 310 & 5,17 & 409,783 & 665,142 & 871,8 & 24 \\ 37,70 & 318 & 5,30 & 436,408 & 726,638 & 911,2 & 25 \\ 40,00 & 324 & 5,40 & 463,032 & 785,515 & 947,4 & 28 \\ 42,30 & 329 & 5,48 & 489,656 & 843,502 & 981,8 & 30 \\ 45,40 & 341 & 5,68 & 525,541 & 938,339 & 1035,5 & 31 \\ 47,70 & 350 & 5,83 & 552,166 & 1011,896 & 1075,3 & 29 \\ 50,00 & 355 & 5,92 & 578,790 & 1075,841 & 1108,8 & 32 \\ 52,30 & 370 & 6,17 & 605,414 & 1172,879 & 1157,7 & 34 \\ 55,40 & 379 & 6,32 & 641,299 & 1272,620 & 1205,9 & 35 \\ 57,70 & 385 & 6,42 & 667,924 & 1346,437 & 1240,4 & 33 \\ 60,00 & 398 & 6,63 & 694,548 & 1447,385 & 1286,1 & 36 \\ 65,40 & 423 & 7,05 & 757,057 & 1676,748 & 1384,3 & 37 \\ 70,00 & 435 & 7,25 & 810,306 & 1845,597 & 1452,3 & 39 \\ 75,40 & 443 & 7,38 & 872,815 & 2024,532 & 1521,1 & 38\end{array}$




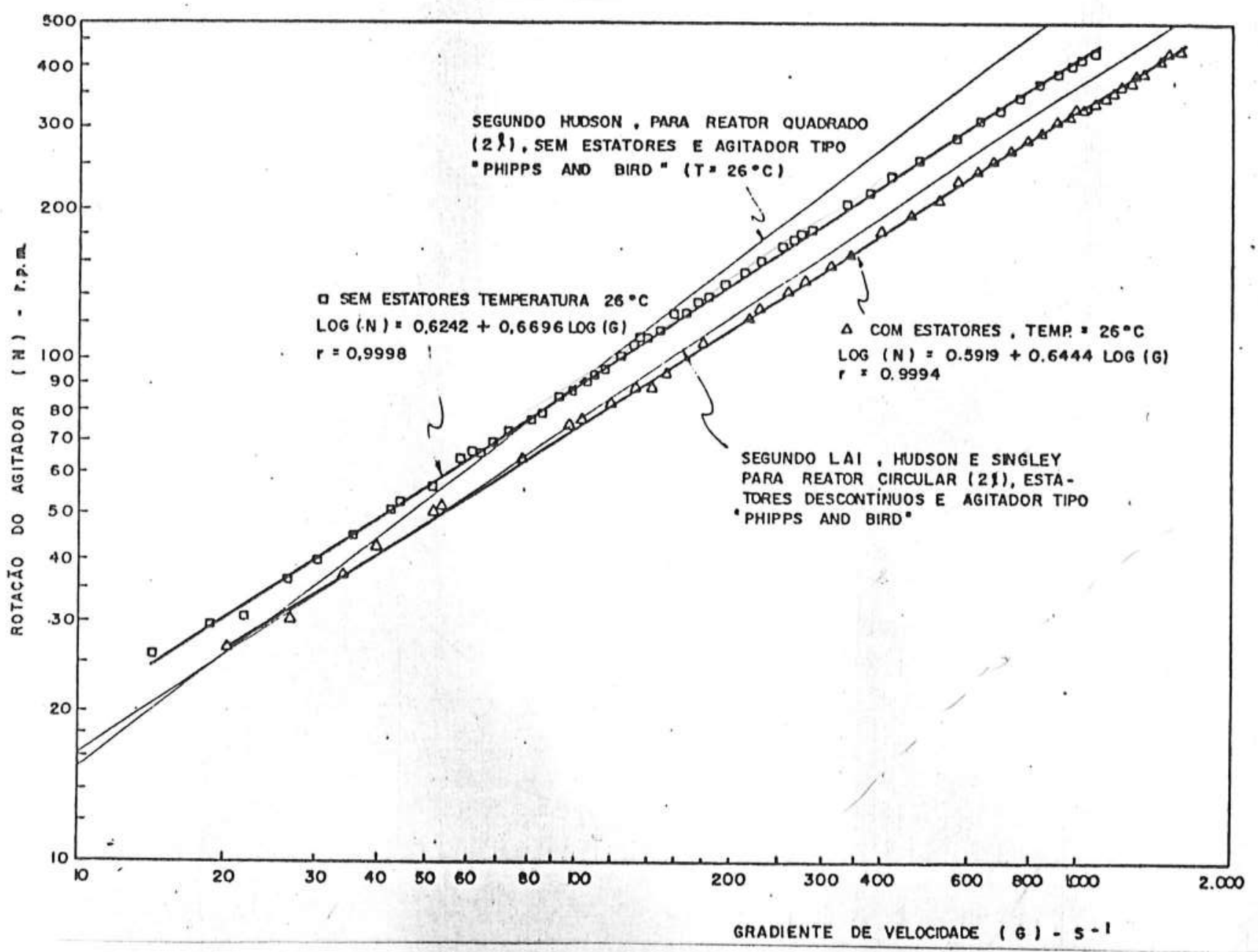

Figura 4.9 - Curvas de variação do gradiente de velocidade em função da rotação do agitador. 
Quadro 4.3 - Fatores de correção a serem multiplicados aos gradientes de velocidade obtidos da Figura 4.9 em função da temperatura da ägua contida no reator ( dados obtidos de HUDSON (41)).

\begin{tabular}{cc}
\hline $\begin{array}{c}\text { TEMPERATURA } \\
\text { DA AGUA }\end{array}$ & FATOR DE \\
$(\underline{O C})$ & CORRECAO \\
\hline & \\
18,0 & 0,903 \\
18,5 & 0,907 \\
19,0 & 0,910 \\
19,5 & 0,918 \\
20,0 & 0,925 \\
20,5 & 0,933 \\
21,0 & 0,940 \\
21,5 & 0,948 \\
22,0 & 0,955 \\
22,5 & 0,959 \\
23,0 & 0,963 \\
23,5 & 0,970 \\
24,0 & 0,978 \\
24,5 & 0,981 \\
25,0 & 0,985 \\
25,5 & 0,993 \\
26,0 & 1,000 \\
26,5 & 1,004 \\
27,0 & 1,007 \\
27,5 & 1,015 \\
28,0 & 1,022 \\
\hline &
\end{tabular}


A calibraçāo do reator com estatores apresentou uma grande semelhança com os dados obtidos por RUEY, HUDSON \& SINGLEY (49) para rea tor circular de 2.litros com estatores descontinuos. Como era esperado, - reator quadrado apresentou um gradiente de velocidade ligeiramente su perior que o reator circular, para uma mesma rotação do agitador.

A calibração foi feita até uma velocidade de rotação igual a $450 \mathrm{rpm}$, pois para valores superiores, havia a entrada de ar em gran de quantidade, prejudicando sensivelmente a obtenção do equilïbrio dinâa mico.

0 ajuste dos dados pelo M.M.?. resultou nas seguintes equa ções:

$$
\begin{aligned}
& \log (N)=0,6242+0,6696 \cdot \log (G) ;(r=0,9998) \\
& \text { para reator sem estatores. } \\
& \log (N)=0,5919+0,6444 \cdot \log (G) ;(r=0,9994) \\
& \text { para reator com estatores }
\end{aligned}
$$

onde: $\left\{\begin{array}{l}N: \text { rotação do agitador }(\text { rpm }) ; \\ G: \text { gradiente de velocidade médio no reator }\left(s^{-1}\right) ; \\ r: \text { coeficiente de correlação do M.M.O.. }\end{array}\right.$

\subsection{Preparação das Aguas para Estudo}

\subsubsection{Caracteristicas Principais}

A investigação experimental foi feita com dez tipos de ägua distintos na turbidez.e cor verdadeira, sendo cinco deles preparados ar tificialmente em laboratōrio e os cinco demais, coletados de mananciais de superficie.

Com a intenção de cobrir com o estudo uma ampla faixa de va riação de qualidades de āgua usadas para o abastecimento püblico, foram investigados os seguintes tipos de ägua, com as caracteristicas apresenta das no Quadro 4.4 .

\subsection{2 - Turbidez}


Quadro 4.4 - Caracteristicas das Aguas Investigadas

\begin{tabular}{|c|c|c|c|c|c|}
\hline TIPO & QUALIDADE & $\begin{array}{c}\text { TURBIDEZ } \\
\text { (FTU) }\end{array}$ & $\begin{array}{c}\text { COR VERDADEIRA } \\
(m g \text { Pt-Co/l) }\end{array}$ & $\begin{array}{l}\text { COR APARENTE } \\
(m g \text { Pt-Co/l) }\end{array}$ & $\begin{array}{l}\text { ALCALINIDADE } \\
\left(\mathrm{mg} \mathrm{CaCO}_{3} / \ell\right)\end{array}$ \\
\hline
\end{tabular}

\begin{tabular}{|c|c|c|c|c|c|}
\hline I & $\begin{array}{l}\text { turbidez alta } \\
\text { e cor verdadei } \\
\text { ra baixa }\end{array}$ & 200 & 5 & --- & 30 e 35 \\
\hline II & $\begin{array}{l}\text { turbidez baixa } \\
\text { e cor verdadei } \\
\text { ra alta }\end{array}$ & 5 & 100 & 132 & 40 \\
\hline III & $\begin{array}{l}\text { turbidez e cor } \\
\text { verdadeira bai } \\
\text { xas }\end{array}$ & 5 & 5 & 33,7 & 30 a 30,6 \\
\hline IV & $\begin{array}{l}\text { turbidez e cor } \\
\text { verdadeira mo } \\
\text { deradas }\end{array}$ & 50 & 20 & 340 & 29,4 a 35,9 \\
\hline v & $\begin{array}{l}\text { turbidez e cor } \\
\text { verdadeira al } \\
\text { tas }\end{array}$ & 200 & 100 & 1064 & 28,9 a 31,6 \\
\hline VI & $\begin{array}{l}\text { turbidez alta } \\
\text { e cor verdadei } \\
\text { ra moderada }\end{array}$ & 160 & 30 & 1300 & 14,9 \\
\hline VII & $\begin{array}{l}\text { turbidez baixa } \\
\text { e cor verdadei } \\
\text { ra moderada }\end{array}$ & 8,9 & 18,7 & 58,7 & 12,5 \\
\hline UIII & $\begin{array}{l}\text { turbidez baixa } \\
\text { e cor verdadei } \\
\text { ra alta }\end{array}$ & 6,2 & 56,1 & 83,1 & 17,3 \\
\hline$I X$ & $\begin{array}{l}\text { turbidez mode } \\
\text { rada e cor ver } \\
\text { dadeira alta }\end{array}$ & 30 & 47,2 & 188,9 & 20,5 \\
\hline$x$ & $\begin{array}{l}\text { turbidez e cor } \\
\text { verdadcira al } \\
\text { tas }\end{array}$ & 300 & 105,9 & --- & 28,3 \\
\hline
\end{tabular}

A argila escolhida para produzir turbidez na preparação das ancstras de ägua bruta artificiais foi a caulinita (Kaulim K-3, da Fisher Scientific Companyl, analisada nos laboratōrios da Universidade Fe derat de São Carlos-LFSCar, por CAMPOS(21), tendo sido obtidos os se guintes resultados: . capacidade de troca de cátions: $8,8 \mathrm{meq} / 100 \mathrm{~g} ;$. su peróicic especifica: $68,6 \mathrm{~m}^{2} / \mathrm{g}$; $\mathrm{SiO}_{2}: 45,44 \%$; $\mathrm{Al}_{2} \mathrm{O}_{3}+\mathrm{TiO}_{2}: 42,11 \%$; - $\mathrm{FC}_{2} \mathrm{O}_{3}: 0,39 \%$. 
Foi preparada uma suspensão-mãe de argila em āgua destilada $e$ deionizada com a finalidade de reduzir os erros na preparação das a mostras $e$ de remover as partículas mais grosseiras da argila. Sua prepa ração sequiu as recomendações da referencia (21). Foram adicionados 300 9 de caulinita a quinze litros de āgua destilada; apōs duas horas de a gitação intensa por meio do equipamento mostrado na Figura 4.3, seguí das de quinze horas de repouso, foi retirado o sobrenadante que consti tuiu a suspensão-mãe de caulinita.

O resultado da determinação dos sólidos da suspensão-mãe $\bar{e}$ mostrado no Quadro 4.5 .

Quadro 4.5 - Determinação dos Sólidos Totais, Fixos e voläteis da sus pensão-mãe de argila.

\begin{tabular}{|c|c|c|c|c|c|c|c|}
\hline AMOSTRA & CAPSULAS & $\begin{array}{c}P_{0}(g) \\
(\S)\end{array}$ & $\begin{array}{l}P_{1}(g) \\
(\S \S)\end{array}$ & $\begin{array}{l}P_{2}(g) \\
(\S \S \S)\end{array}$ & $\begin{array}{l}\text { SOLIDOS } \\
\text { TOTAIS } \\
(\mathrm{mg} / \mathrm{l})\end{array}$ & $\begin{array}{l}\text { SOLIDOS } \\
\text { FIXOS } \\
(\mathrm{mg} / \mathrm{l})\end{array}$ & $\begin{array}{c}\text { SOLIDOS } \\
\text { VOLATEIS } \\
(\mathrm{mg} / \mathrm{\ell})\end{array}$ \\
\hline$I 5$ & 73 & 86,72024 & 87,09853 & 87,02312 & 3783 & 3029 & 754 \\
\hline II & 43 & 81,53738 & 81,92245 & 81,85650 & 3851 & 3191 & 660 \\
\hline III & 72 & 82,97945 & 83,36116 & 83,30560 & 3817 & 3261 & 556 \\
\hline \multirow[t]{2}{*}{ IV } & 29 & 81,84285 & 82,22605 & 82,17000 & 3832 & 3271 & 561 \\
\hline & $M E$ & $D I A=$ & & & 3821 & 3189 & 633 \\
\hline
\end{tabular}

(\$) peso das cāpsulas secas;

(\$§) peso das cāpsulas mais peso dos sólidos apōs evaporação à temperatura de $103 . \mathrm{C}$, ate peso constante;

(\$\$\$) peso das cāpsulas mais peso dos sólidos apōs calcinação à temperatura de $550 . \mathrm{C}$, até peso constante.

Com o objetivo de determinar o volume necessärio da suspensão-mãe para preparar 1 litro de ägua para os ensaios, foi construí da a curva apresentada na Figura 4.10, com base na determinação da tur

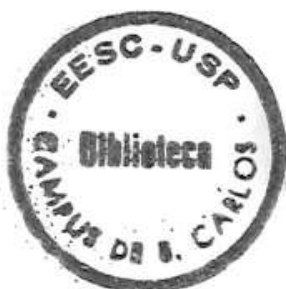


bidez da suspensão resultante da diluição de diferentes volumes da sus pensão-mãe. 0 quadro 4.6 mostra a obtenção dos pontos utilizados para a construcão da Figura 4.10, repetindo-se 5 (cinco) vezes cada determi nação, para a verificação da confiabilidade do método adotado.

\subsubsection{Cor}

\subsubsection{Extração}

As substâncias hümicas utilizadas para providenciar cor às äguas preparadas artificialmente, foram extraídas do sedimento da Represa do Lobo, localizada próxima a São Carlós, Estado de São Pau lo. A metodologia utilizada na extração foi proposta por TOLEDO (87).

O sedimento foi coletado do fundo da represa, em um ponto prōximo ao seu centro.

A extracão das substâncias hümicas foi efetuada usando- se solução de hidróxido de sōdio $0,5 \mathrm{~N}$ na relação de un volume de sedimen to para dois volumes de solucão. Esta mistura foi agitada vigorosamente durante alguns minutos e colocada em repouso por um periodo de doze ho ras, apōs o qual, foi retirado o sobrenadante e adicionado nova quanti dade de solução alcalina ao sedimento. Este processo foi repetido até a obtenção de um sobrenadante clarificado.

Os värios sobrenadantes obtidos foram misturados, concentra dos por evaporação à temperatura de 35 ọ e centrífugados à $2.000 \mathrm{rom}$, durante um perĩodo de duas horas para a eliminacão de argilas.

A purificação das substâncias hümicas obtidas pelo procedi mento acima, poderia ser feita através de diälise em meio a água deioni zada acidulada a pH igual a 2, como também atravēs de passagem por colu na trocadora de ions. Entretanto, TOLEDO (86), lembrou haver uma melhor simulação das äguas naturais através do uso da solução-mãe obtida 1 sem purificação 1, que deve se encontrar, preponderantemente, na forma de humatos, razão pela qual, não foi realizada a etapa de purificação.

\subsubsection{Determinacão da Cor}

Da mistura homogeinizada da solucão-mãe de humatos, 
Quadro 4.6 - Determinação da turbidez em função de diluições da suspen são-mãe de caulinita.

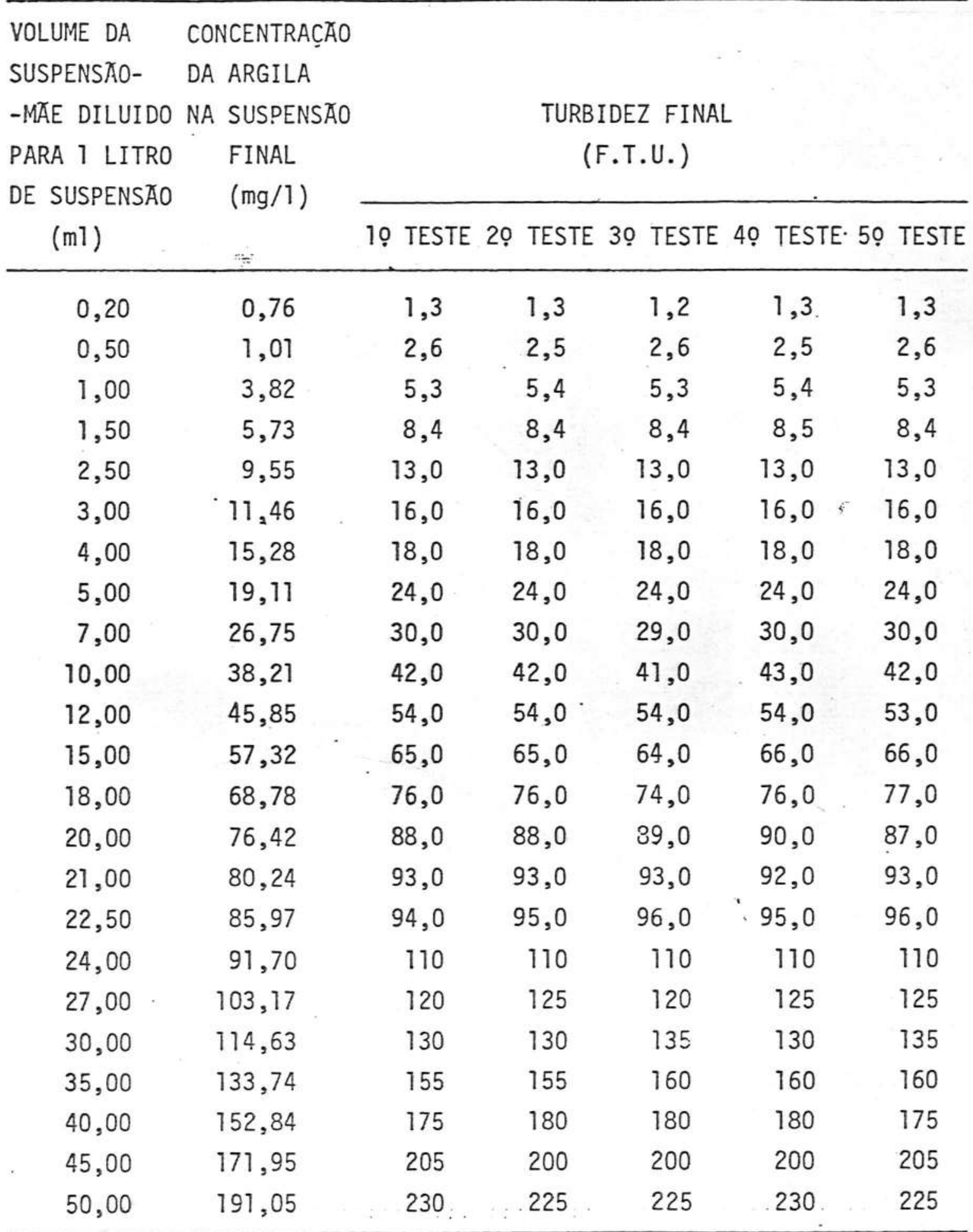




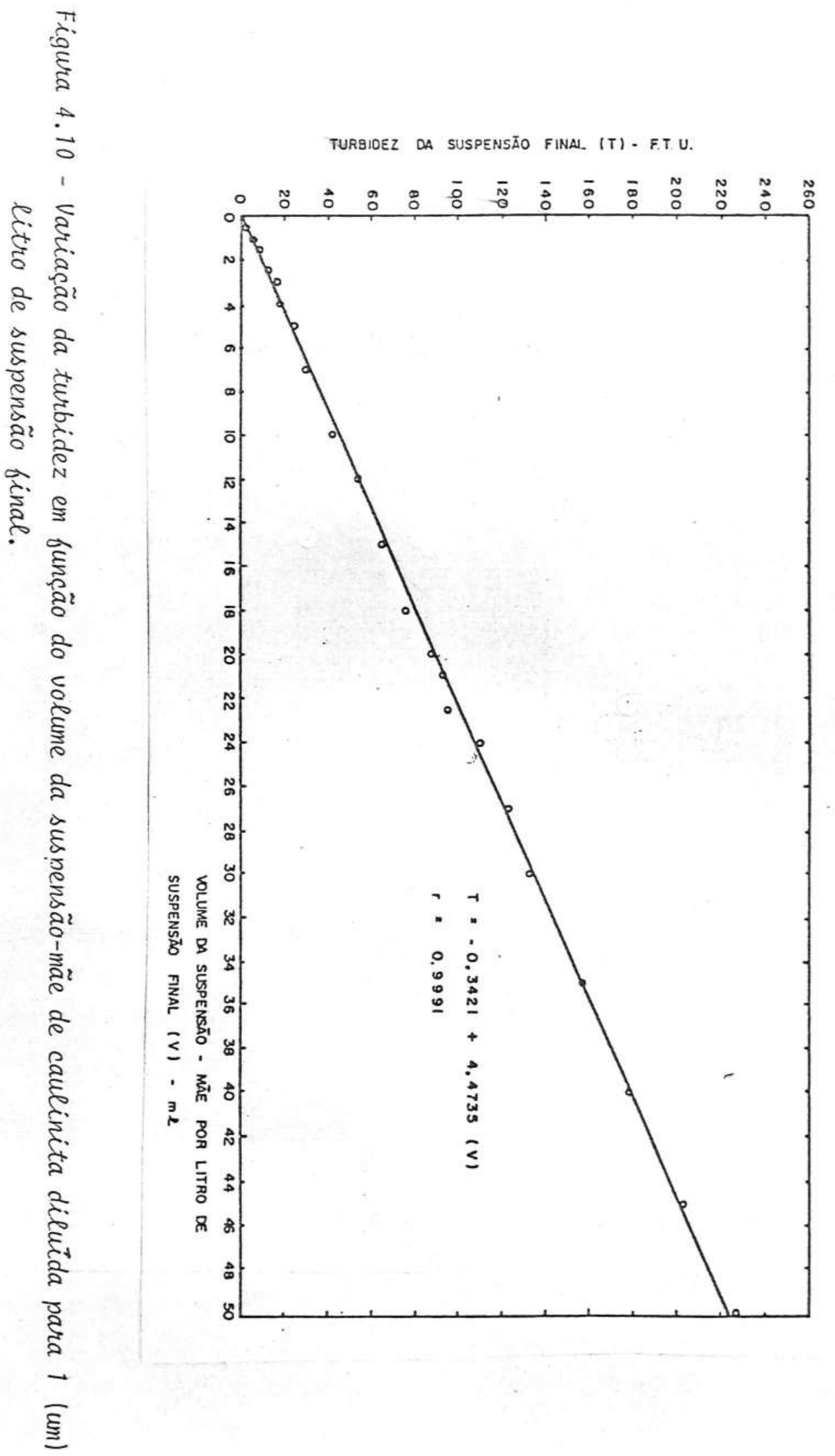


separadas três amostras de $100 \mathrm{ml}$ para determinação da concentração de humatos através da evaporação à temperatura de 35 o. . Os resultados são apresentados no ?uadro 4.7 .

nuadro 4.7 - Concentração de substâncias hümicas da solução-mãe de huma tos.

\begin{tabular}{|c|c|c|c|c|}
\hline $\begin{array}{l}\text { CAPSSULA } \\
\text { Nọ }\end{array}$ & $\begin{array}{l}\text { UOLLUME } \\
(\mathrm{ml})\end{array}$ & $\begin{array}{l}P_{0}(g) \\
(\S)\end{array}$ & $\begin{array}{l}P_{1}(g) \\
(\S \S)\end{array}$ & $\begin{array}{c}\text { CONCENTRACÃO DE SUBS } \\
\text { TANCIAS HUMICAS } \\
(\mathrm{mg} / \mathrm{l})\end{array}$ \\
\hline & & & & \\
\hline 43 & 100 & 81,57274 & 83,62864 & $20.559,0$ \\
\hline 72 & 100 & 83,04356 & 85,16631 & $21.227,5$ \\
\hline 73 & 100 & 86,73167 & 88,90097 & $21.693,0$ \\
\hline & $M$ & $A=$ & & $21.159,8$ \\
\hline
\end{tabular}

(\$) peso. das cāpsulas secas;

(\$\$) peso das cāpsulas mais peso dos sólidos apos evaporação $\bar{a}$ tempe ratura de $35 . \mathrm{C}$, até peso constante.

Com o objetivo de reduzir erros decorrentes de leituras em disco comparador, tomou-se uma amostra homogeneizada da solucão-mãe de humatos e promoveram-se vārias diluições da mesma com āgua destilada, ob tendo-se diversas amostras. Para cada uma dessas amostras, foram efetua das leituras de cor, por quatro pessoas distintas. Utilizando-se de todos os valores obtidos, foi determinado o valor médio da cor da soluçãomãe de humatos.

A partir da solução-mãe, preparou-se uma diluição, denominada de solução-padrão, de cor conhecida e igual a $500 \mathrm{mg} P t-C o / l$, da qual partiram todas as amostras para o levantamento da curva de calibração da cor em função da absorbância, calculada a partir de dados de transmitância de cada amostra.

As amostras, preparadas com cor variando entre 10 e $100 \mathrm{mg}$ 
Pt-Co/l, foram submetidas a leituras de transmitância nos comprimentos de onda de 400,450,500,550,600,650 e $700 \mathrm{~nm}$. Verificou-se que no comprimento de onda igual a $400 \mathrm{~nm}$, utilizando-se cubeta de $40 \mathrm{~mm}$ de profundidade, a amplitude de leitura foi maior entre os padröes de cor extremos, fornecendo, portanto, erros de leitura menores.

As amostras foram, então, ajustadas para cada um dos valo res de $\mathrm{pH}: 3,5,7$ e 9 e lidos os valores de transmitância. 0 quadro 4.8 apresenta os resultados dessa calibração e a Figura 4.11 as curvas de variacão da cor em função do absorbância e do jH de cada amostra.

As equações das retas da Figura 4.11 foram utilizadas para a determinação da cor verdadeira $e$ aparente de todas as amostras com esses valores superiores a $10 \mathrm{mg} P t-C o / l$, mesmo quando apresentaram va lores de pH diferentes dos quatro usados na calibração. Neste caso, bêz-se uma interpolação logaritmica entre os resultados das duas equações mais prōximas.

Para a determinação de valores de cor inferiores a $10 \mathrm{mg}$ $P t-\mathrm{Co} / \ell$, caso das amostras das āguas tipo III e outras que dependeram das eficiências de remoção de cor e turbidez de cada ensaio realizado, fêz-se uma nova calibração, pois, os resultados da calibração inicial apresentaram valores negativos de cor para dados de absorbância inferiores a 0,02 .

Desta vez, procedeu-se de forma idêntica, com amostras en tre os limites de 1 e $10 \mathrm{mg} P t-C o / l$, ajustadas para os seguintes valores de $\mathrm{pH}: 3,6, e$. Tais resultados são fornecidos no quadro $4.9 \mathrm{e}$ na Figura 4.12 .

\subsubsection{Alcalinizante, Coagulante e Ajustes de pH}

A alcalinidade das āguas preparadas foram proporcionadas pela adicão de bicarbonato de sōdio. Todas as amostras de āgua foram feitas com um volume de $200 \mathrm{l}$, introduzindo-se as quantidades necessā rias de suspensão-mãe de caulinita e solução-mãe de humatos. A seguir, introduziu-se uma quantidade tal de solucão de bicarbonato de sódio sujiciente para a obtenção de uma alcalinidade de aproximadamente 30 $m g \mathrm{CaCO}_{3} / \ell$.

Para se conseguir variar o pH de coagulação na pesquisa da ḉiciência de remoção de cor elou turbidez para uma determinada dosa 
ouadro 4.8 - Dados da calibração da cor como função da transmitância e do valor do pH para amostras com cor variando entre 10 e $100 \mathrm{mg}$ Pt-Co/l e valores de $\mathrm{pH}$ entre $3 \mathrm{e} 9$.

DILUIÇAOAO DILUIÇĀO COR DA SOL. VOLUME DA SOLUÇAO VOLUME DA SOLU VOLUME DE A- TRANSMITANCIR DA SOLU- DA SOLUÇAO RESULTANTE RESULTANTE TOMADO ÇAO PADRAO USA GUA DESTILA- $\mathrm{pH}=3,0 \mathrm{pH}=5,0 \mathrm{pH}=7,0 \mathrm{pH}=9,0$ ÇAO-MAE PADRAO (mg Pt-Co/1) P/ ANALISE (m1) DO NA DILUIÇAOO DA (ml) . (ml)

\begin{tabular}{llllllllll}
\hline $1: 1500$ & $1: 50$ & 10 & 100 & 2 & 98 & 93,4 & 92,4 & 91,3 & 89,5 \\
$1: 750$ & $1: 25$ & 20 & 100 & 4 & 96 & 89,3 & 89,1 & 87,7 & 85,3 \\
$1: 500$ & $1: 16,67$ & 30 & 100 & 6 & 94 & 84,7 & 83,3 & 83,3 & 80,6 \\
$1: 375$ & $1: 12,5$ & 40 & 100 & 8 & 92 & 80,6 & 78,8 & 78,4 & 76,6 \\
$1: 300$ & $1: 10$ & 50 & 100 & 10 & 90 & 76,8 & 75,5 & 74,1 & 71,9 \\
$1: 250$ & $1: 8,33$ & 60 & 100 & 12 & 88 & 73,0 & 71,2 & 70,1 & 68,3 \\
$1: 214$ & $1: 7,14$ & 70 & 100 & 14 & 86 & 69,4 & 67,8 & 66,6 & 64,5 \\
$1: 187,5$ & $1: 6,25$ & 80 & 100 & 16 & 84 & 65,8 & 63,9 & 63,0 & 60,6 \\
$1: 166,67$ & $1: 5,55$ & 90 & 100 & 18 & 82 & 62,2 & 60,8 & 59,4 & 56,1 \\
$1: 150$ & $1: 5,00$ & 100 & 100 & 20 & 80 & 59,3 & 57,7 & 56,5 & 53,5 \\
\hline
\end{tabular}




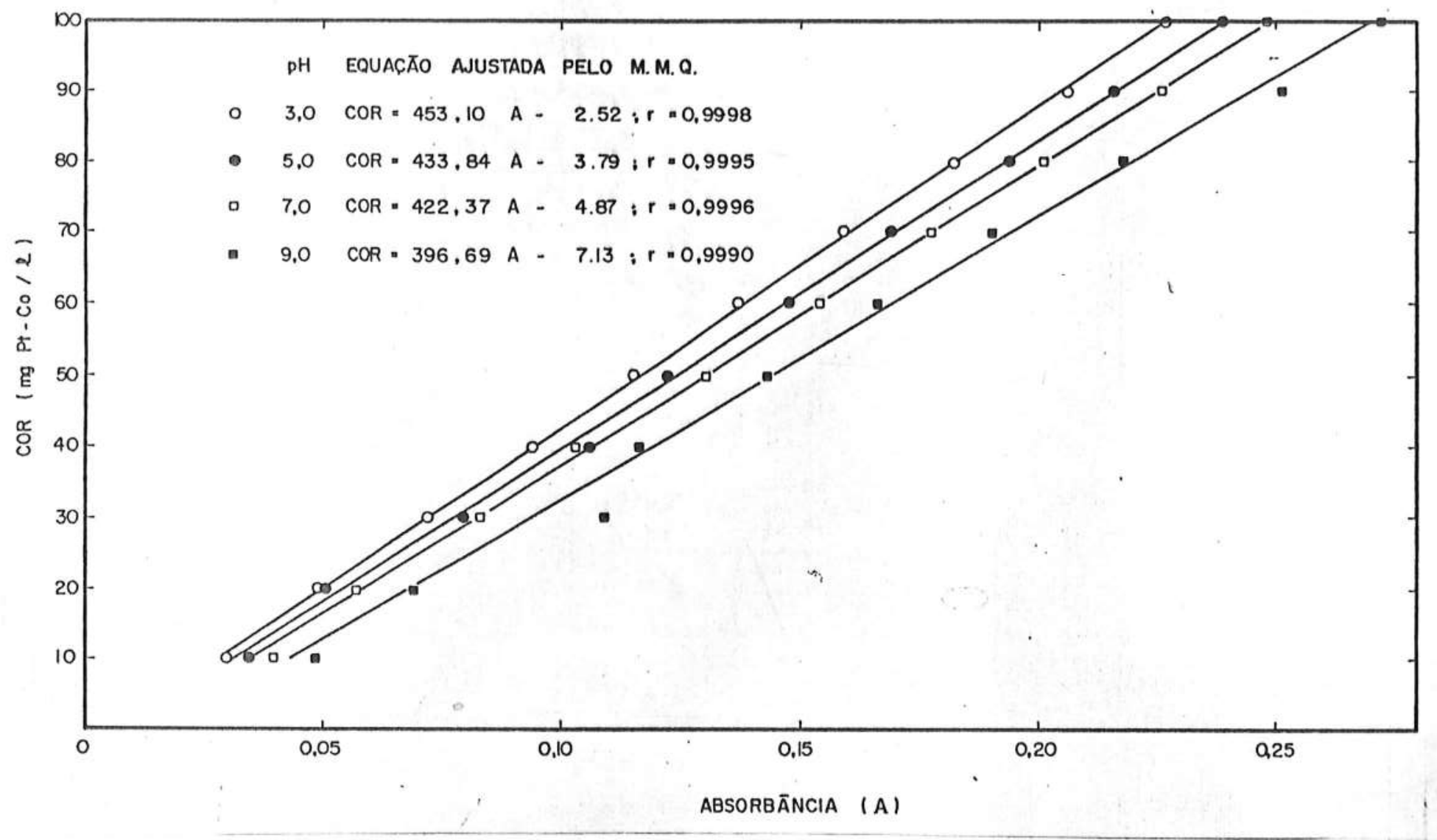

Figura 4.11 - Curvas de variação da cor em função da absorbância e do valor de pH da amostra. 
Quadro 4.9 - Dados da calibração da cor como função da transmitância e do valor do pH para amostras com cor variando entre 1 e 10 $m g$ Pt-Coll e valores de $\mathrm{pH}$ entre 3 e 9 .

Cor

$m g \mathrm{Pt}-\mathrm{Co} / \mathrm{l}$
TRANSMITANCIA

$(\%)$
ABSORBANCIA

(A)

$p H=3,0 \quad p H=6,0 \quad p H=9,0 \quad p H=3,0 \quad p H=6,0 \quad p H=9,0$

\begin{tabular}{|c|c|c|c|c|c|c|}
\hline 10 & 93,7 & 93,4 & 92,9 & 0,0282 & 0,0296 & 0,0319 \\
\hline 9 & 94,4 & 94,0 & 93,5 & 0,0250 & 0,0268 & 0,0291 \\
\hline 8 & 95,0 & 94,7 & 94,2 & 0,0222 & 0,0236 & 0,0259 \\
\hline 7 & 95,5 & 95,4 & 94,8 & 0,0200 & 0,0204 & 0,0231 \\
\hline 6 & 96,2 & 95,8 & 95,5 & 0,0168 & 0,0186 & 0,0200 \\
\hline 5 & 96,8 & 96,5 & 96,4 & 0,0141 & 0,0154 & 0,0159 \\
\hline 4 & 97,5 & 97,3 & 97,0 & 0,0110 & 0,0118 & 0,01323 \\
\hline 3 & 98,0 & 97,8 & 97,7 & 0,0087 & 0,0096 & 0,0101 \\
\hline 2 & 98,6 & 98,5 & 98,4 & 0,0061 & 0,0065 & 0,0070 \\
\hline 1 & 99,3 & 99,3 & 99,0 & 0,0030 & 0,0030 & 0,0043 \\
\hline 0 & 100,0 & 100,0 & 100,0 & 0,0000 & 0,0000 & 0,0000 \\
\hline
\end{tabular}




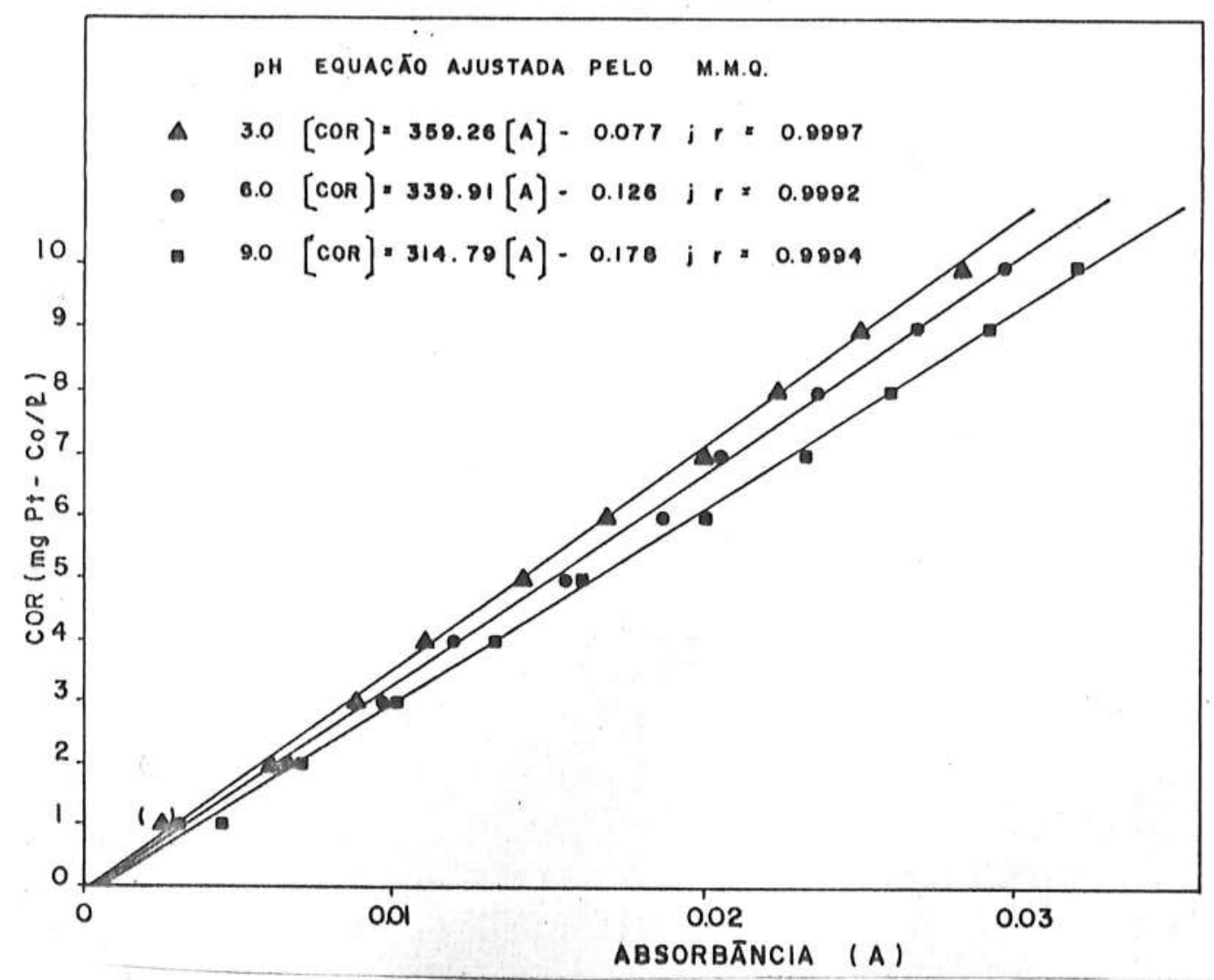

Figura 4.12 - Curvas de variacão da cor em função da absorbância e do valor do $\mathrm{pH}$ da amostra. 
gem de sulfato de aluminio, alterou-se o valor da alcalinidade em cada reator por meio da adição de soluções padronizadas de hidróxido de sōdio ou ācido clorídrico $(0,1 \mathrm{~N}$, aproximadamente).

o coagulante utilizado foi o sulfato de aluminio na forma de $\mathrm{Al}_{2}\left(\mathrm{SO}_{4}\right)_{3} \cdot 18 \mathrm{H}_{2} \mathrm{O}$, fornecido pela Merck.

se ( $P A)$.

Todos os reagentes utilizados foram especificados para anäli

\subsection{Metodologia para a Realização dos Ensaios de Floculação}

\subsubsection{Introdução}

Os ensaios de floculação para cada tipo de āgua estudada, tive ram como finalidade a determinação dos parâmetros ótimos de tratabilidade necessārios para o projeto e operacão de sistemas de tratamento de $\bar{a}$ guas de abastecimento, particularmente as etapas de coagulação e flocula çāo, quais sejam:

a) mecanismos de coagulação e, para cada um deles, os pares ótimos de valores de dosagem de coagulante e pH final de coagulação para a remoção de turbidez e/ou cor;

b) gradientes de velocidade e períodos de agitação ótimos pa ra a mistura rāpida e floculação em cada mecanismo viāvel;

c) influência da concentração da solução de estoque do coagu lante na velocidade de sedimentação dos flocos.

\subsubsection{Construcão do Diagrama de Coagulação}

A construção do diagrama de coagulação para cada tipo de $\bar{a}$ gua foi feita a partir da obtenção do maior nümero possível de pontos, ca racterizados por três parâmetros variāveis distintos:

i) dosagem de coagulante;

ii) $\mathrm{pH}$ de coagulação;

iii) eficiência de remoção de turbidez e/ou cor aparente lou mesmo, turbidez e/ou cor aparente remanescentes). 
Os demais parâmetros influentes devem ser mantidos constantes $e$, para não fixa-los sem base alguma, executou-se ensaios prelimi nares para a escolha de:

- gradientes de velocidade de mistura rāpida e floculação;

- perĩodos de agitação de mistura rāicida e floculação;

- tempo de sedimentação para coleta do sobrenadante.

- procedimento dos ensaios para levantamento dos dados para a construção do diagrama de coagulação é dado a seguir :

- a) homogeneizar o volume da amostra bruta e determinar as valores de temperatura, turbidez, cor aparente, pH e alcalinidade;

b) apōs o enchimento dos reatores, ligar as agitadores de modo a obter-se o gradiente de velocidade escolhido para a mistura rạpi da igual para todos os reatores

c) pipetar e adicionar os volumes desejados de solução de hidrōxido de sōdio ou ācido clorídrico $(0,1 \mathrm{~N})$ para cada reator, de forma a alterar-se ( se desejado I o pH original da amostra bruta;

d) sempre com os agitadores ligados, coletar amostras de ca da reator e efetuar leitura dos valores do $\mathrm{pH}$;

e) pipetar os volumes desejados da solução estoque de sulfá to de aluminio ( normalmente na concentração de $1 \%$ ), de modo a variar-se ( ou não) a dosagem de reator para reator, colocando-se os conteú dos em bequers instalados defronte aos respectivos reatores;

6) succionar o conteūdo de cada bequer através das seringas para injeção do coagulante;

g) injetar o coagulante concomitantemente em todos os reato res no menor tempo possivel, direcionando o jato sobre a paleta do agi tador e disparar o cronômetro;

h) deixar a mistura rāpida ocorrer pelo período fixado;

i) apōs o período de mistura rāpida, baixar a rotação dos a gitadores, de modo que o gradiente de velocidade para a floculação seja mantido igual ao escolhido para todos os reatores;

j) deixar a floculação ocorrer pelo período fixado, aferin do-se constantemente a rotação de todos os agitadores;

k) apōs o período de floculação, desligar os agitadores, le 
vantar as paletas e conectar as mangueiras coletoras de amostras nos re cipientes de descarte (operação que pode ser feita logo no inicio do ensaio 1;

l) apōs o período de sedimentação desejado, descontado de 30 segundos, aproximadamente, baixar a plataforma dos frascos coletores, de modo a descartar-se um volume de aproximadamente $10 \mathrm{ml}$;

m) apōs a troca dos bocais das mangueiras dos frascos de descarte para os frascos coletores de amostras e o periodo de sedimenta ção desejado, baixar novamente a plataforma, de modo a coletar-se um vo lume de aproximadamente $40 \mathrm{ml}$ em cada frasco;

n) proceder às leituras de pH, turbidez e/ou cor aparente de cada amostra ;

o) repetir o ensaio, variando-se a dosagem de coagulante $e$ o pH de coagulação até a caracterização completa do diagrama de coagulação.

Caso seja desejado efetuar-se leituras de condutancia especifica e mobilidade eletroforética, devem ser tomadas amostras entre as passos $(i)$ e $(j)$, de preferência, logo apōs o término do período de mistura rāpida.

\subsubsection{Determinação dos Parâmetros otimos de Mistura Rāpida}

Com a dosagem de sulfato de aluminio e o pH de coagulação $\underline{0}$ timos estabelecidos ( para cada mecanismo de coagulação) e, fixados os parâmetros de floculacão e tempo de sedimentacão iguais aos utilizados para a construção do diagrama de coagulação, estudou-se a influência do gradiente de velocidade e tempo de mistura rápida na eficiência de remocão de turbidez elou cor aparente.

Devido à limitação da velocidade de rotação māxima do agita dor e da impossibilidade de determinação do gradiente de velocidade quan do ocorre a entrada de ar por vörtices no reator I para rotaçōes supe riores a $400 \mathrm{rpm}$ ), foram investigadas as seguintes faixas de variação dos parametros influentes:

- gradiente de velocidade: de 500 ate $1200 \mathrm{~s}^{-1}$ (sem estatores);

- periodos de mistura: de 2 até $90 \mathrm{~s}$; 
0 procedimento dos ensaios $\bar{e}$ dado a seguir :

a) homogeneizar o volume total de amostra de água bruta e de terminar os valores de temperatura, turbidez, cor aparente, pH e alcali nidade;

b) apōs o enchimento dos reatores, ligar os agitadores de mo do a obter-se o gradiente de velocidade escolhido para a mistura rápida de cada reator;

c) pipetar e adicionar os volumes de solução de hidrōxido de sódio ou ácido cloridrico $(.0,1 \mathrm{~N})$ determinados para fornecer o pH öti mo de coagulação em todos os reatores;

d) pipetar volumes iguais de solução de sulfato de aluminio, de forma a obter-se a dosagem ötima determinada, colocando-se os conteū dos em bequers, instalados defronte aos respectivos reatores;

e) succionar o conteüdo de cada bequer através das seringas para injeção do coagulante;

6) injetar o coagulante em tempos defasados para cada reator, $\checkmark$ de modo que o tempo de mistura rápida se esgote conjuntamente para todos as reatores e disparar o cronômetro;

g) baixar a rotação dos agitadores, mantendo-se o mesmo gra diente de velocidade para a floculação fixado para todos os reatores;

h) deixar a floculação ocorrer pelo periodo fixado, aferindo - se constantemente a rotação de todos as agitadores;

i) desligar os agitadores, levantar as paletas e conectar as mangueiras coletoras de amostras nos frascos de descarte;

j) apōs o período de sedimentação fixado, descontado de apro ximadamente 30 segundos, baixar a plataforma dos frascos coletores e des cartar um volume de aproximadamente $10 \mathrm{ml}$ para cada frasco;

k) apös a troca dos bocais das mangueiras para os frascos co letores de amostra e o período de sedimentação fixado ter-se esgotado., baixar a plataforma e coletar um volume próximo de $40 \mathrm{ml}$;

l) proceder às leituras de pH, turbidez elou cor aparente de cada amostra;

m) repetir o ensaio, investigando-se novas parâmetros de mis tura rāpida. 
Para cada um dos pontos ōtimos obtidos no diagrama de coagu lação e utilizando-se dos parâmetros ōtimos de mistura rāpida determina dos, estudou-se a influencia de variação dos parâmetros de floculação nas seguintes faixas:

- gradiente de velocidade : de 2 até $200 \mathrm{~s}^{-1}$;

- período de floculação : de 1 até 120 minutos;

o procedimento dos ensaios $\bar{e}$ dado a seguir :

a) homogeneizar o volume total de amostra bruta e determi nar os valores de temperatura, turbidez, cor aparente, pH e alcalinidade;

b) apōs o enchimento dos reatores, ligar os agitadores de modo a aplicar-se o gradiente de velocidade ōtimo de mistura rāpida, $\underline{i}$ gual para todos os reatores;

c) pipetar e adicionar os volumes de solução de hidrōxido de sōdio ou ācido clorídrico. $(0,1 \mathrm{~N})$ determinado para fornecer o pH ōti mo de coagulação em todos os reatores;

d) pipetar volumes iguais de solução de sulfato de aluminio, de forma a obter-se a dosagem ótima para todos os reatores, colocando - se os conteūdos em bequers, instalados defronte aos respectivos reato res;

e) succionar o conteūdo de cada bequer através das seringas para injeção do coagulante e aferir a rotação de cada agitador;

6) injetar o coagulante concomitantemente nos reatores, no menor tempo possivel, direcionando o jato para a paleta do agitador $e$ disparar o cronômetro;

g) baixar a rotação dos agitadores, de forma que cada um a plique o gradiente de velocidade desejado e distinto para cada reator;

h) deixar a floculação ocorrer pelo perĩodo fixado para o ensaio, aferindo-se constantemente a rotação de todos os agitadores;

i) desligar os agitadores, levantar as paletas e conectar as mangueiras coletoras de amostras nos frascos de descarte;

j) apōs o período de sedimentação fixado, descontado de $\underline{a}$ proximadamente 30 segundos, baixar a plataforma e descartar um volume $\underline{i}$ gual a $10 \mathrm{ml}$ para cada frasco; 
k) providenciar a troca dos frascos e apōs completado e ve ríodo de sedimentacão, coletar um volume de amostra de $40 \mathrm{ml}$ de cada rea tor;

l) proceder às leituras de $\mathrm{pH}$, turbidez e/ou cor aparente de cada amostra;

m) providenciar novo ensaio idêntico ao descrito, alterando-se os gradientes de velocidade de floculação de cada reator e subme tendo-se o ensaio a um novo periodo de floculação.

\subsubsection{Determinação da Inffluência da Concentração da Solução Es toque do Coagulante}

Para cada um dos pontos ótimos obtidos no diagrama de coagu lação e utilizando-se os parâmetros ótimos de mistura rāpida e flocula ção, foi variada a concentração da solução estoque de sulfato de alum $\overrightarrow{\underline{\imath}}$ nio e verificada sua influência nas velocidades de sedimentacão dos flo cos criados.

Foram investigadas as seguintes concentrações da solucão de estoque de sulfato de aluminio: $0,05,0,10,0,25,0,50,0,75,1,0,2,0$, $3,5,5,0,7,0$, e $10 \%$

As velocidades de sedimentação foram função da altura da lâa mina liquida no reator sobre o ponto de tomada de amostras e dos seguin tes tempos de sedimentação $: 1,3,7,12,20$, e 30 minutos.

0 procedimento dos ensaios $\bar{e}$ dado a seguir :

a) homogeneizar o volume total de amostra bruta e determi nar os valores de temperatura, turbidez, cor aparente, pH e alcalinida de;

b) apōs o enchimento dos reatores, ligar os agitadores de modo a imprimir o gradiente de velocidade ótimo para a mistura rāpida, igual para todos os reatores;

c) pipetar e adicionar o volume de solução de hidrōxido de sódio ou ācido clorídrico $(0,1 \mathrm{~N})$ determinado para fornecer o pH ōti mo de coagulação em todos os reatores;

d) tomando-se dos recipientes contendo as soluções de sulfá to de aluminio preparadas préviamente nas concentrações desejadas 1 com idade não superior a 24 horas 1, pipetar os volumes correspondentes à do sagem ötima para todos as reatores, colocando-se os conteūdos em bequers 
instalados defronte aos respectivos reatores;

e) succionar o conteūdo de cada bequer através das seringas para injeção de coagulante e aferir a rotacão de cada reator;

6) injetar o coagulante concomitantemente nos reatores, no menor tempo possivel e direcionando o jato para a paleta do agitador, dis parando o cronômetro;

g) decorrido o período de mistura rāpida, baixar a rotação dos agitadores de forma que apliquem o gradiente de velocidade ótimo pa ra todos os reatores;

h) deixar a floculação decorrer pelo período determinado, a ferindo-se constañtemente a rotação de todos os reatores;

i) desligar os agitadores, levantar as paletas e conectar as mangueiras coletoras de amostras nos frascos de descarte;

j) decorridos 30 segundos antes de cada tempo de sedimentação para coleta de amostras, descartar um volume de $10 \mathrm{ml}$ de cada rea tor e proceder a mudança de bocais das mangueiras para os frascos de co leta. Como serão seis tempos de sedimentação, serão necessärias seis ba terias de frascos de coleta, numeradas para cada reator e tempo de cole ta, além da bateria de frascos para descarte;

k) coletar em cada bateria um volume aproximado de $40 \mathrm{ml} \mathrm{em}$ cada frasco, anotando na planilha do ensaio a altura da superfície do li quido em relação ao ponto de tomada de amostra;

l) proceder às leituras de pH, turbidez e/ou cor aparente de cada amostra;

m) providenciar novo ensaio idêntico, variando-se as concen tracões da solucão de estoque de sulfato de aluminio (caso necessārio).

\subsubsection{Simulação de Filtração Direta com Papel de Filtro}

a) prenarar uma bancada de funis de vidro providos de nanel de filtro tipo Whatman 40 e umedecer toda a superficie dos papēis de fil tro com ägua destilada;

5) apōs a drenagem de toda āgua destilada dos filtros, homo geinizar o volume da amostra bruta e determinar os valores de temperatu ra, turbidez, cor aparente, pH e alcalinidade;

c) (teste em branco) passar um volume de aproximadamente 40 ml de amostra de āgua bruta por um dos funis e coletar o volume filtrado 
para determinação dos valores de turbidez, cor aparente e pH. Tais parâ metros serão os utilizados para comparação de eficiências de remoção de turbidez e/ou cor aparente das amostras ensaiadas com o uso de coagulan te;

d) proceder identicamente aos passos descritos nos itens 4. 5.2. b) ate 4.5.2. jl;

e) apōs o período de floculação desejado, descontado de 30 segundos, baixar a plataforma dos frascos coletores, de modo a descar tar-se un volume de aproximadamente $10 \mathrm{ml}$;

6) apōs a troca dos bocais das mangueiras dos frascos de des carte para os frascos coletores de amostras e o término do periodo de floculação desejado, baixar novamente a plataforma, de modo a coletar -se um volume de aproximadamente $40 \mathrm{ml}$ em cada frasco;

g) passar o conteūdo de cada frasco pelo seu correspondente papel de filtro e coletar o volume filtrado;

h) proceder às leituras de pH, turbidez e/ou cor aparente de cada amostra. 


\section{RESULTADOS E DISCUSSAO}

\subsection{Caracteristicas das Aguas Investigadas}

0 2uadro 5.1, a exemplo do 2uadro 4.4, apresenta as caracte risticas de cada uma das āguas ensaiadas.

No inëcio da pesquisa experimental (ensaios da Água Tipo I), procurou-se apoiar no maior nümero de parâmetros possíveis e assim, o le vantamento de pontos do diagrama de coagulação desenvolveu-se paralela mente à leituras da mobilidade eletroforētica (m.e.), que, antes da coagu lação, apresentou um valor de $-2,81 \mu / \mathrm{s} / \mathrm{V} / \mathrm{cm}$.

Devido à impossibilidade de determinação dos valores de mobí lidade eletroforētica da Agua Tipo. II com o Zetâmetro disponível Inão ví sualização das partículas em movimentol, interrompeu-se, daí em diante, a determinação desse parâmetro, $j \bar{a}$ que constituia-se em tarefa de extrema dificuldade e de pequeno valor prätico.

\subsection{Ensaios Preliminares}

O objetivo de tais ensaios consistiu em fixar as condições de mistura rāpida, floculação e período de sedimentação para as quais reali zou-se os ensaios para a construção do diagrama de coagulação.

Como serā visto no îtem 5.3, o diagrama de coagulação permi te visualizar as regiões ötimas de coagulação possiveis, desde que, regis tram-se as curvas de eficiência de remocão de turbidez e/ou cor aparente em função da dosagem de coaaulante e do pH de coagulação (sobrenadante). Evidentemente, tais curvas de eficiência são extremamente inf̧luenciadas, não sō pelas condições de coagulação, como também pelas condições de mis tura rāpida e de floculação e pelo período de sedimentação, apōs o qual, coletou-se o sobrenadante. 
Quadro 5.1 - Caracteristicas das Águas Investigadas

TIPO QUALIDADE

TURBIDEZ COR VERDADEIRA COR APARENTE ALCALINIDADE (FTU) (mg Pt-Co/l) (mg Pt-Co/l) $\left(m g \mathrm{CaCO}_{3} / \ell\right)$

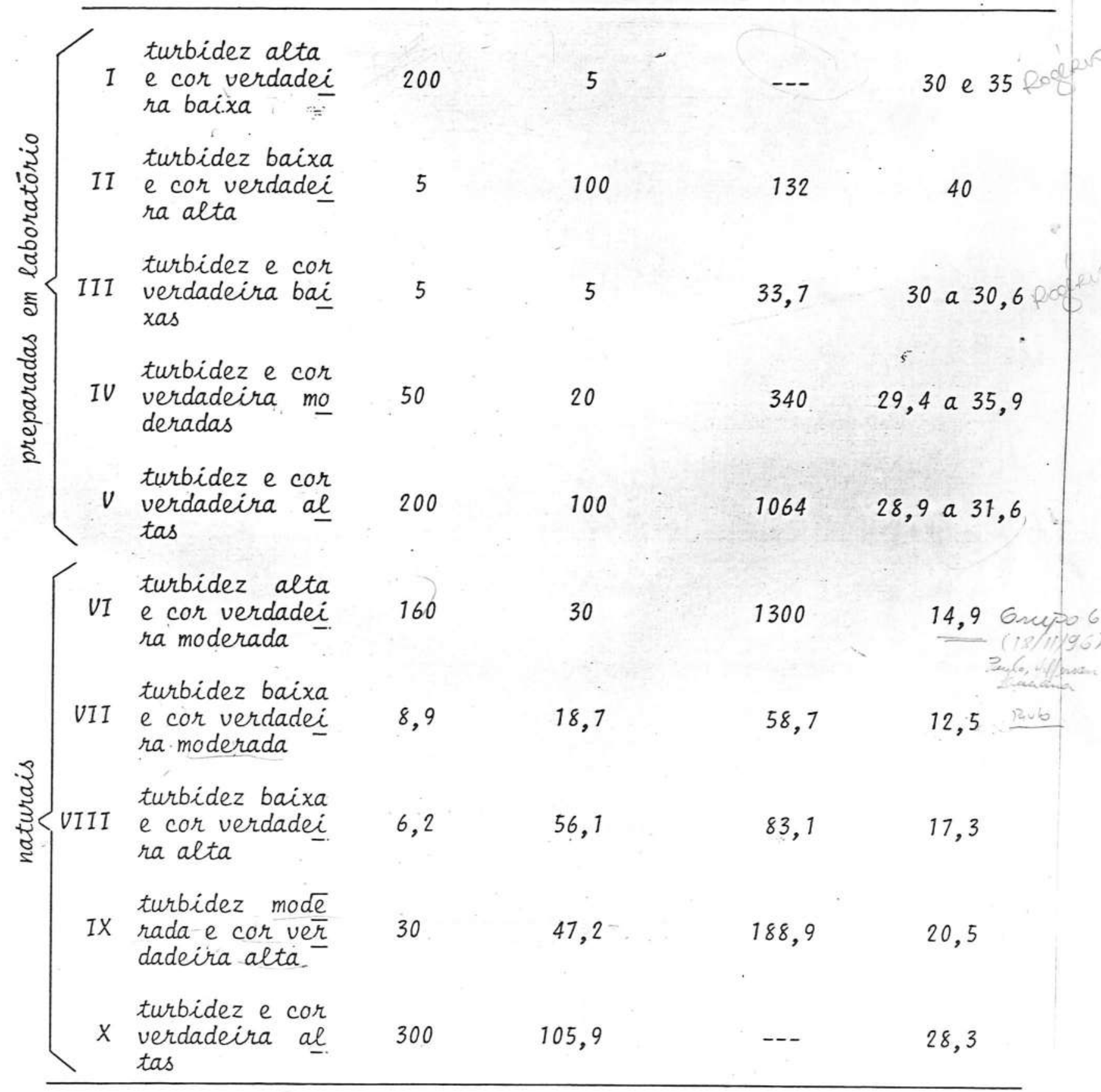


Assim sendo, por exemplo, caso o operador deixe os reatores em repouso por 5, 10 ou 20 minutos apōs o período de floculação, a mesma cur va de eficiência a ser traçada no diagrama, teoricamente assumiria valores crescentes, podendo prejudicar a sensibilidade na detecção das regiões ōti mas de coagulação. O mesmo poderā ocorrer, caso tome-se períodos de flocu lação muito elevados com gradientes de velocidade baixos ou vice-versa.

As planilhas dos ensaios n! 01 a 10, 01 a 03, 01 a 03, 01 e 02 e 01 e 02, respectivamente, para as Aguas Tipo I, II, III, IV e V, apresen tam os resultados obtidos nessa fase do experimento ( ver APENDICES $B, C$, D, $E$ e Fl.

Apōs tais ensaios, pode-se afirmar que:

a) As condições de mistura rāpida podem ser efetuadas com ara dientes de velocidade prōximos de $1000 \mathrm{~s}^{-1}$ e períodos de agitação infjerióres a 15 segundos, pois pouco influenciam no resultado. Foram adotadas as seguintes condições para todos os ensaios de contrução dos diaaramas de coa gulação: $G=900 \mathrm{~s}^{-1}$ e $T=5$ segundos;

b) Os parâmetros de floculação podem ser adotados entre os se guintes valores: $15 \leqslant G \leqslant 30 \mathrm{~s}^{-1}$ e $20 \leqslant T \leqslant 30$ minutos. Como regra geral, pode-se dizer que quanto maior for a presença de substâncias hümicas na a mostra, menor deve ser o gradiente de velocidade e quanto menor o valor de turbidez, maior deve ser o período de floculação. Foram os seguintes os pa râmetros adotados:

Agua Tipo I II. III IV. $V$ VI VII VIII IX $x$

\begin{tabular}{ccccccccccc}
\hline$G\left(s^{-1}\right)$ & 30 & 15 & 20 & 30 & 20 & 30 & 30 & 30 & 30 & 30 \\
$T(\min )$. & 20 & 30 & 30 & 20 & 20 & 20 & 20 & 20 & 20 & 20 \\
\hline & & & \\
& & & adotados sem a realização de preliminares.
\end{tabular}

\subsection{Diagramas de Coagulação}

Os diagramas de coagulação foram construidos com o levantamento do maior nümero de dados possíveis, representados por pontos caracteri 
zados por três valores: dosagem de coagulante, pH do sobrenadante $e$ turbidez ou cor aparente residual (em porcentagem de seus valores iniciais). Para as Aguas Tipo I a V (preparadas em laboratörio), foram construidos diagramas de coagulação completos para faixas de variação de $\mathrm{pH}$ do sobre nadante entre 3,5 e 8,5. Jā para as āguas naturais (VI a X), construi - se diagramas de coagulação mais simplificados, com menor nümero de en saios, simulando o que deveria ser feito no levantamento de parâmetros de projeto de uma ETA convencional.

As eficiências de remoção foram sempre que possivel, determi nadas em relação a cor aparente inicial, pois além de cáracterizarem faí xas de variação mais amplas entre as amostras brutas e tratadas, estão su jeitas a menores erros de leitura. Quanto não, foram feitas em termos de turbidez, caso das Aguas Tipo I, VI e X.

Foram plotados as pontos de turbidez ou cor aparente residual $e$ traçadas as curvas atravēs de interpolação linear entre os mesmos, que deram origem às figuras abaixo relacionadas. A consulta aos resultados des sa fase do estudo poderā ser feita da seguinte forma:

.Agua Tipo I : Figuras 5.1 a 5.4;

Diagrama de coagulação: Apêndice A;

Planilhas dos ensaios: Apêndice B, n! 11 a 47.

. Agua Tipo II: Figura 5.14;

Diagrama de coagulação: Apêndice A;

Planilhas: Apêndice C, n? 04 a 63.

.Agua Tipo III: Figuras 5.23 e 5.24;

Diagrama de Coagulação: Apêndice A;

Planilhas : Apêndice D, no 04 a 50.

.Agua Tipo IV: Figura 5.33;

Diagrama de coagulação: Apêndice A;

Planilhas: Apêndice E, no 03 a 35.

. Agua Tipo V : Figura 5.44;

Diagrama de coagulação: Apêndice A;

Planilhas : Apêndice F, nọ 03 a 33. 
.Agua Tipo VI : Figura 5.55;

Planilhas : Apêndice G, n! 01 a 08.

.Agua Tipo VII : Figura 5.60;

Planilhas : Apêndice $H$, nọ 01 a 14.

. Agua Tipo VIII : Figura 5.70;

Planilhas : Apêndice I, n! 01 a 10.

.Agua Tipo IX :- Figura 5.79;

Planilhas: Apêndice $J, n ! 01$ a 10.

. Agua Tipo X : Figura 5.84;

Planilhas : Apêndice $K, n$ no 01 a 08.

\section{a) Āgua Tipo I}

Foram utilizadas dosagens de sulfato de aluminio variando en tre 3 e $10.0 \mathrm{mg} / \mathrm{l}$, preparadas a partir de uma solução de estoque a $1 \%$. $\overline{0}$ pH do sobrenadante foi variado desde 3,7 a 9,3 com o uso de soluções pa dronizadas $(0,1 \mathrm{~N})$, de hidrōxido de sōdio ou ācido clorídrico, conforme a metodologia apresentada.

Devido à execução dos ensaios no inverno ( maio a julho/86) e até então, a não preocupação com a manutenção da temperatura constante du rante os ensaios, tivemos variações desde $14 . \mathrm{C}$ ate $22 . \mathrm{C}$, o que, apesar da correção dos valores dos gradientes de velocidade aplicados, pode ter influido nas velocidades de sedimentação dos flocos.

Através da anālise das Figuras 5.1 e do diagrama de coagula ção apresentado no Apêndice A, distingue-se, nitidamente, a existência de duas regiões onde $\bar{e}$ possivvel a remoção de turbidez por sedimentação, rea lizada por un período de dez minutos, assim como em todos os diagramas de coagulação aqui construidos.

A primeira região, se for caracterizada pela curva de turbi dez residual igual a $20 \%$, manifestou-se entre as dosagens de sulfato de $\underline{a}$ luminio variando de 7 a $12 \mathrm{mg} / \ell$ e entre valores do pH de coagulação I so brenadante I variando desde 4,6 a 5,1.

Esta região de coagulação coincide perfeitamente com a descri 
ta por AMIRTHARAJAH (02), apresentada na Figura 3.27, correspondente $\bar{a}$ ad sorção-neutralização de cargas com potencial zeta igual a zero, devido $\bar{a}$ ação de espécies de aluminio do tipo $\mathrm{Al}_{\chi}(\mathrm{OH})_{y}^{n+}$. Assim como foi visto na revisão bibliogräfica, tais espécies hidrolisadas desestabilizam as partī culas coloidais por adsorção, podendo provocar sua reversão de carga $e$, consequentemente, sua restabilização. Os dados obtidos correspondem fiel mente ao descrito, podendo-se observar a reversão das cargas das particu las de caulinita com a análise das Figuras 5.2, 5.3, 5.4 e do diagrama de pontos de mobilidade eletroforética apresentado no Apêndice A.

Pela figura 5.3, observa-se que, num valor de pH constante $e$ igual $a 4,65$, o aumento da dosagem de sulfato de aluminio diminui os valo res negativos da mobilidade eletroforética, anulando-a para uma dosagem prōxima de $11 \mathrm{mg} / \mathrm{l}$ e revertendo seu sinal para dosagens superiores a esta. As maiores remoções de turbidez por sedimentação ocorrem para valores de mobilidade eletroforética próximas de zero.

$\mathrm{Na}$ figura 5.4, mantendo-se uma dosagem de susfato de aluminio constante $e$ igual a $12 \mathrm{mg} / \mathrm{l}$, variou-se $0 \mathrm{pH}$ do sobrenadante e verificou se que os melhores desempenhos correspondem a anulação do valor da mobili dade eletroforética, ocorrida entre valores de $\mathrm{pH}$ variando desde 4,6 a 5,1 , onde, manifesta-se a maior concentração das espécies adsorviéveis de aluminio.

Os flocos formados nessa região constítuiram-se em agrega dos pequenos $(\tilde{\approx} 2 \mathrm{~mm})$, com baixa velocidade de sedimentação, porém, resis tentes à bruscas elevações do gradiente de velocidade, sendo ideais para a operação de instalações de filtração direta devido ao pequeno volume de lodo gerado e às altas eficiências de remoção observadas nos ensaios no $21,23,25,29,71$ e 72 (Apêndice B), quando realizou-se testes de filtra ção em papel Whatman 40 .

A segunda região de coagulação observada, manifestou-se em va lores de pH e dosagens mais elevados, características da ação do mecanismo de varredura devido à predominância da espécie $\mathrm{Al}(\mathrm{OH})_{3}(\mathrm{~s})$. Esta região, delimitada inferiormente pela dasagem de $20 \mathrm{mg} / \mathrm{l}$ (para eficiência de re moção de turbidez por sedimentação superiores a $80 \%$ l e pHs do sobrenadante variando entre 7,2 e 7,6, não possui limites superiores de dosagem, po dendo ocorrer em faixas cada vez mais amplas de valores de pH a medida que eleva-se a dosagem de sulfato de aluminio (p.ex.: p/ a dosagem de 60 $\mathrm{mg} / \ell$, a faixa de valores de $\mathrm{pH}$ correspondentes a remoções superiores a 
$80 \%$, extende-se desde 6,1 a 8,21

observou-se que, nesta região, a mobilidade eletroforētica das particulas coloidais não necessariamente manifesta-se valores prōximos à eletroneutralidade, existindo partículas com m.e. posi tivas e negativas.

A esquerda dessa região, as particulas encontram-se restabili zadas por espécies adsorvīveis de aluminio com carga positiva e, a direita, mantēm-se estāveis, com m.e. negativas, devido à predominância da espécie $\mathrm{Al}(\mathrm{OH})_{4}^{-}$(ver diagrama de m.e. - Apêndice A e Figura 5.2).

os flocos formados nesse macanismo de coagulação apresentaram grandes dimensões $(\cong 5 \mathrm{~mm})$, altas velocidades de sedimentaçã், porém, pequena coesão, sendo facilmente erodidos por aumentos bruscos do gradiente de velocidade.

E importante observar que a operação de coagulação da Agua Tí po I não evidenciou demais regiōes onde poder-se-ia obter eficiencias razoāveis, caracterizando-se a descontinuidade entre as mesmas. A ação de mecanismos de coagulação combinados (varredura e adsorção) ou de neutrali zação de cargas em potencial zeta igual a zero pela ação de espécies de $\mathrm{Al}(\mathrm{OH})_{3}(\mathrm{~s})$ carregadas positivamente, como afirmado por AMIRTHARAJAH (02) e caracterizado na Figura 3.27, não foram detectados e, caso existam, pro porcionam baixas eficiencias ao processo lver Figura 5.1 , para dosagens inferiores a $20 \mathrm{mg} / \mathrm{l}$ e pHs do sobrenadante superiores a 5,701 .

os pontos considerados ōtimos para a coagulação em ambas as regiões foram caracterizados pelos seguintes parâmetros:

- região de adsorção-neutralização:

$\left\{\begin{array}{l}\text { dosagem de sulfato de aluminio: } 10 \mathrm{mg} / \ell ; \\ \text { pH de coagulação: } 4,8 .\end{array}\right.$

- região de varredura:

$\left\{\begin{array}{l}\text { dosagem de sulfato de aluminio: } 60 \mathrm{mg} / \mathrm{l} \text {; } \\ \text { pH de coagulação: 6,55. }\end{array}\right.$

b) Agua Tipo II

Foram utilizadas dosagens de sulfato de aluminio variando en- 
tre 10 e $200 \mathrm{mg} / \mathrm{l}$, preparadas a partir de uma solução de estoque a $1 \%$. 0 pH do sobrenadante foi variado desde 3,30 até 8,70.

A exemplo da Agua Tipo I, e apesar das características comple tamente distintas entre os dois tipos de ägua, verificou-se a ocorrência de duas regiões ōtimas de coagulação com características bastantes simi lares às observadas para a āgua. tipo I, como pode ser observado pela Figu ra 5.14 e pelo Apêndice A.

Na primeira região, caracterizada por eficiencia de remoção de cor aparente superiores a $60 \%$ e inferiores a $71,7 \%$, as dosagens de sul - fato de alumínio empregadas foram de 14 a $80 \mathrm{mg} / \mathrm{l} \mathrm{em}$ pHs de coagulação de 4,9 a 3,8. Dois fatos são relevantes na coagulação, pelo mecanismo de adsorção-neutralização da āgua Típo II nessa região: (i) a díminuição do pH de coagulação requer uma dosagem de sulfato de aluminio mais elevada para a obtenção de mesma eficiência. Tal fato deve-se a diminuição da concentração das espécies hidrolizadas de aluminio presentes em solução a medida que o pH diminui, paralelamente com o aumento da concentração do ion não hidrolizado Al+3, o que provoca a diminuição da adsorção e desestabilização das cargás negativas presentes nos sitios ionizāveis das molecu las de substâncias hümicas. (ii) essa região $\bar{e}$ delimitada superiormente por zona onde não ocorre coagulação, ou seja, para um mesmo pH de coagula ção, o aumento da dosagem de sulfato de aluminio passa, a partir da dosagem ötima, a provocar a redução da eficiencia de coagulação até que os sōis permaneçam novamente estabilizados; Esse fato $\bar{e}$ anälogo ao verificado para coagulação de turbidez, indicando que, possivelmente, também ocor ra a reestabilização dos sōis por reversão de carga provocada pela adsorção excessiva de espécies hidrolizadas de aluminio carregadas positivamen te.

$\mathrm{Na}$ segunda região, as eficiências de remoção de cor aparente são muito superiores que as obtidas na primeira, chegando a $97,6 \%$. Nessa região, onde o mecanismo de coagulação $\bar{e}$ a varredura e os sōis são remo vidos devido ao arraste juntamente com o precipitado amorfo de hidroxi do de aluminio insolūvel $\left(\mathrm{Al}(\mathrm{OH})_{3}(s)\right.$, os flocos criados possuem dimensões muito superiores que os formados na região $I \mathrm{e}$, apesar de sua fragilidade, apresentam velocidades de sedimentação muito superiores, levando a efi ciências maiores para um mesmo período de sedimentação.

Essa região é delimitada inferiormente pela dosagem de sulfato de aluminio em torno de $40 \mathrm{mg} / \mathrm{l}$ e por uma faixa de pH ōtimo de coagu - 
lação de 5,5 a 6,8. Com o aumento da dosagem de coagulante, verificou-se - alargamento da faixa de pH, concordando com os resultados obtidos nessa região para a Agua Tipo I.

Devido à impossibilidade de visualização dos coägulas de cor formados tanto na região I como na II, não foi possivel a determinação de valores de mobilidade eletroforética para construção de diagrama semelhan te ao beito para a Agua Tipo I.

As condições ötimas de coagulação da Agua Tipo II foram encon tradas nos ensaios n? 62 e 33 (ver Apêndice C) e dadas a seguir:

- mecanismo de adsorção-neutralização:

$\left\{\begin{array}{l}\text { dosagem de sulfato de aluminio: } 20 \mathrm{mg} / \ell ; \\ \mathrm{pH} \text { de coagulação: } 4,40 .\end{array}\right.$

- mecanismo de varredura

$\left\{\begin{array}{l}\text { dosagem de sulfato de aluminio: } 140 \mathrm{mg} / \ell \text {; } \\ \text { pH de coagulação: } 6,15 .\end{array}\right.$

c) Agua Tipo III

O levantamento de dados para a construção do diagrama de eficiência de coagulação da Agua Tipo III é apresentado no Apêndice $D$ e sintetizado nas Figuras 5.23, 5,24 e Apêndice A.

Estes ensaios foram feitos mantendo-se constan tes os parâmetros de mistura rāpida, floculação e sedimentação determinados nos ensaios preliminares, com coleta do sobrenadante a uma profundi dade de $10 \mathrm{~cm}$ abaixo da superfície liqquida da amostra ensaiada, após 10 minutos de sedimentação.

Foram utilizadas dosagens de sulfato de aluminio variando entre 1,5 e $40 \mathrm{mg} / l$, preparadas a partir de uma solução de estoque com concentração de $1 \%$ e $0,1 \%$ para dosagens superiores a $5 \mathrm{mg} / \ell$ e inferiores a $5 \mathrm{mg} / \ell$, respectivamente. $O \mathrm{pH}$ da amostra a ser ensaiada foi variado desde 3,65 a 9,85 .

Foram feitas leituras de turbidez residual e transmitancia das amostras do sobrenadante, calculando-se os respectivos valores de absorbância e de cor aparente residual com o auxilio das equações de cali - 
bração das Figuras 4.11 e 4.12 e interpolação logaritmica feita por calcu ladora programāvel, entre os valores de pH das amostras $e$ das equações de calibração.

A Figura 5.23 mostra a existência de apenas uma região ötima para remoção de colóides causadores de cor e turbidez em baixa concentração por coagulação, floculação e sedimentação, contrariando os resultados obtidos nos estudos feitos para as Aguas Tipo I e II onde a concentra ção de colóides causadores de turbidez e/ou cor verdadeira eram muito superiores.

Nesta região onde foram encontradas eficiências de remo ção de ate $94,2 \%$, predomina a ação do mecanismo de varredura onde as sōis são removidos devido ao arraste juntamente com o precipitado amorfo de hidrōxido de aluminio insolüvel $\left(\mathrm{Al}(\mathrm{OH})_{3}\right)$.

A regĩa ótima de coagulação determinada é limitada pela dosa gem de sulfato de aluminio em torno de $10 \mathrm{mg} / \mathrm{l}$ e por uma faixa de pH ötimo de coagulação entre 6,8 e 7,3. Com o aumento da dosagem de coagulante, verificou-se o alargamento da faixa de pH, concordando com resultados obtidos para as Aguas Tipo I e II quando o mecanismo de varredura era pre dominante.

observou-se que na região de coagulação por varredura, os coā gulos formados apresentavam um crescimento continuo ao longo do perío do de floculação, chegando a tamanhos da ordem de alguns milímetros, en quanto que em dosagens de sulfato de aluminio menores que $10 \mathrm{mg} / l$ e valores de pH inferiores a 6,5. (região de coagulação por adsorção-neutraliza ção) as mesmos coägulas eram observados visualmente, porém, devido à baixa concentração de colōides e à inexistência do composto $\left(\mathrm{Al}(\mathrm{OH})_{3}\right)$, estes não apresentaram crescimento suficiente para permitir a posterior remoção por sedimentação.

As condições ötimas de coagulação da Agua Tipo III pelo mecanismo de varredura foram encontradas no ensaio no 19 cujos resultados foram:

$\left\{\begin{array}{l}\text { - dosagem de sulfato de aluminio: } 17,5 \mathrm{mg} / \ell ; \\ \text { - pH de coagulação: } 7,30 ;\end{array}\right.$ 
Devido à impossibilidade de remoção dos coāgulos formados pe la ação do mecanismo de adsorção-neutralização por sedimentação, partiu- se para a construção de um diagrama de coagulação nesta região com o au xïlio da técnica de simulação da filtração-direta com o uso de papel de filtro tipo (1)

Os resultados destes ensaios encontram-se nas planilhas de $n$ ? 38 a 50 e no diagrama de coagulação apresentado no Apêndice A, sintetizado na Figura 5.24 .

A metodologia de realização destes ensaios foi idêntica à exe cutada para a determinação da região ótima do mecanismo de varredura, po rém, apōs o período de floculação, eram retiradas amostras de cada reator que em seguida, eram filtradas em funil provido de papel de filtro do ti po whatman 40.

As eficiências de remoção de turbidez e cor aparente foram de terminadas como função do resultado obtido no teste em branco realizado no ensaio n! 38 (reatores n! 1 e 2), onde não foi introduzido o sulfato de $\underline{a}$ luminio e cuja filtragem resultou:

teste de filtração
em branco imédia
de dois resultados $\left\{\begin{array}{l}\text {.turbidez residual: } 2,15 \mathrm{FTU} ; \\ \text {.cor aparente residual: } 16,8 \mathrm{mg} \mathrm{Pt}-\mathrm{Co} / \mathrm{l}\end{array}\right.$

Foram utilizadas dosagens de sulfato de aluminio variando en tre 1,0 e $7,5 \mathrm{mg} / \ell$, preparadas a partir de uma solução de estoque a $0,1 \%$. $0 \mathrm{pH}$ da amostra a ser ensaiada foi variado desde 3,70 ate $8,55 \mathrm{com}$ a in trodução de soluções padronizadas de ācido clorídrico $(0,0970 \mathrm{~N})$ e hidrō xido de sódio $(0,0938 \mathrm{~N})$ antes da adição de sulfato de aluminio.

os resultados obtidos evidenciaram a existência de uma segun da região onde é possível a coagulação por adsorção-neutralização da Āgua Tipo III com dosagens de sulfato de aluminio compreendidas entre 1,5 e 5,0 $m g / l$, faixa de valores de pH de coagulação variando entre 5,8 e 6,8 e efi ciências de remoção de cor aparente e turbidez de atē $95 \%$ com o uso da técnica da filtração direta.

As condições ötimas de coagulação da Água Tipo III pelo meca nismo de adsorção-neutralização foram encontradas no ensaio n? 43, cujos resultados foram: 
$\left\{\begin{array}{l}\text { - dosagem de sulfato de aluminio: } 3,0 \mathrm{mg} / \mathrm{l} \\ \text {. pH de coagulação: } 6,30\end{array}\right.$

E interessante observar que, a faixa de valores de pH ötimos registrados para a ocorrência do mecanismo de adsorção-neutralização para a Agua Tipo III $(5,8$ e 6, 8) com o uso de papel de filtro foi bem superior as obtidas para as Aguas Tipo I e II $(4,6$ e 5,1/3,8 e 4,9). Tal fato vem concordar com o exposto por. AMIRTHARAJAH (02) que responsabiliza a ocor rência do mecanismo de adsorção-neutralização para valores de pH entre 5,5 e 7,0 devido à espécies de $\mathrm{Al}(\mathrm{OH})_{3}(s)$ carregadas positivamente e neutras. Esta região, também denominada de "corona", seria a que melhores re sultados forneceriam em instalações de filtração, direta (02).

A inexistência da região de coagulação por adsorção-neutralização com espécies polinucleares hidrolizadas de aluminio carregadas po sitivamente, pode ser explicada pelo fato da Agua Tipo III apresentar um nümero de particulas insuficiente para a ocorrência de um nümero de cho ques tal que promova o crescimento dos flocos. Isso talvez fosse conse guido, aplicando-se gradientes de velocidade elou períodos de floculação mais elevados. Na região denominada de corona por. AMIRTHARAJAH (02), a ocorrência de espécies de $\mathrm{Al}(\mathrm{OH})_{3}(s)$ devido aos valores mais elevados do pH, aumenta o nümero de colōides presentes, causando a elevação do nümero de choques e proporcionando o chamado éfeito de "coagulação mútua" entre os colöides pré existentes e os adicionados $(\mathrm{Al}(\mathrm{OH}) 3(s))$.

\section{d) Agua Tipo IV}

O diagrama de coagulação da Agua Típo IV pode ser observado no Apêndice A $e$, de forma reduzida, na Figura 5.33. Para sua construção, foram cmpregadas dosagens de sulfato de aluminio variando de 2 a $50 \mathrm{mg} / \ell$ c pht' de coagulação entre 3,75 e 8,15.

0 aumento da concentração de partículas coloidais causadoras de turbidez c cor verdadeira em relação a Agua Tipo III, causou novamen te, a ocorrência de duas regiōes de coagulação a exemplo das Aguas Tipo I c II.

0 mecanismo de adsorção-neutralização manifestou-se com efi ciências de remoção de cor aparente superiores a $60 \%$ e inferiores a $76,7 \%$ 
para dosagens variando entre 3,0 e $10 \mathrm{mg} / \mathrm{l}$ (não atingindo-se limite superior) e ptls de coagulação entre 4,2 e 5,2. A exemplo das Águas Tipo II e I, a diminuição do pH promoveu a necessidade de aumento da dosagem de sul fato de aluminio devido à diminuição da concentração das espécies adsorvé veis de aluminio.

A regĩa do mecanismo de varredura, bastante similar à obtida pela Āgua Tipo I, caracterizou-se por altas eficiências de remoção de cor aparente (até 99,4\%). Tomando-se como referencia a curva de $95 \%$ delimitou-se pela dosagem minima de $12 \mathrm{mg} / \mathrm{l}$ entre faixas de $\mathrm{pH}$ iguais a $6,45^{\circ} \mathrm{e}$ 7,10, alargando-se, a medida que a dosagem fosse elevada.

As condições ötimas de coagulação foram assim determinadas:

- mecanismo de adsorção-neutralização

$$
\left\{\begin{array}{l}
\text { dosagem de sulfato de aluminio: } 5,0 \mathrm{mg} / \mathrm{l} ; \\
\text { pH de coagulação: 5,2; }
\end{array}\right.
$$

- mecanismo de varredura:

$$
\left\{\begin{array}{l}
\text { dosagem de sulfato de aluminio: } 35 \mathrm{mg} / \ell ; \\
\text { pH de coagulação: } 6,70 \mathrm{mg} / \ell .
\end{array}\right.
$$

e) Agua Tipo V

Foram utilizadas dosagens de sulfato de aluminio variando entre 5 e $70 \mathrm{mg} / \ell$, submetidas a pHs de coagulação entre 3,45 e 8,30 para a construção do diagrama de coagulação apresentado no Apêndice A e na Figura 5.44 .

Tendo em vista a alta concentração de partículas coloidais causadoras de turbidez e cor verdadeira, a coagulação manifestou-se satis fatōria em uma ampla faixa de valores de pH, não havendo a distinção evidente entre ambos os mecanismos de coagulação até então observados.

Devido à grande aportunidade de choques entre partículas de sestabilizadas ou não, a região de ocorrência do mecanismo de adsorção neutralização confunde-se com os limites inferiores da região do mecanismo de varredura, criando uma faixa de boas eficiências (maiores que 95\%) entre valores de dosagens de 9,0 a $15 \mathrm{mg} / \mathrm{l}$ que estende-se desde valores de $\mathrm{pH}$ iguais a 4,5 ate 6,0 . 
Acima desta faixa, observa-se drästicas quedas de eficiência provocadas pela restabilização dos colōides. Seus limites inferiores e da direita, caracterizam-se pela manifestação de inalteração da estabilidade dos colóides. Assim como jā observado para outras águas, a medida que 0 pH diminui, necessita-se de maiores dosagens, evidenciando a grande importância das espécies adsorvíveis de aluminio que tornarn-se ineficazes a me dida que transformam-se na espécie $\mathrm{Al}^{+3}$, predoninante para valores de $\mathrm{pH}$ inferiores a 4,0. Os dados observados correspondem perfeitamente ao des crito pelos pesquisadores EDWARDS \& AMIRTHARAJAH (30).

Consideraram-se as seguintes condições de coagulação para a Agua Típo V.

- mecanismo de adsorção-neutralizacão:

$\left\{\begin{array}{l}\text { dosagem de sulfato de aluminio: } 10 \mathrm{mg} / \mathrm{l} ; \\ \mathrm{pH} \text { de coagulação: } 5,25 .\end{array}\right.$

- mecanismo de varredura:

$$
\left\{\begin{array}{l}
\text { dosagem de sulfato de aluminio: } 60 \mathrm{mg} / \mathrm{l} ; \\
\text { pH de coagulação: } 7,2 .
\end{array}\right.
$$

Coincidentemente, as dosagens de sulfato de aluminio para ambos as mecanismos de coagulação foram as mesmas obtidas para a Agua Tịo I. Isto implica dizer que o aumento da concentração de substâncias hümi cas não obrigatoriamente leva ao aumento da dosagem de coagulação, desde que a concentração de particulas causadoras de turbidez seja elevada 1200 FTU para as āguas Tipo I e VI. Por outro lado, äguas contendo altas con centrações de substâncias hümicas podem ser coaguladas com dosagens inferiores de sulfato de aluminio caso eleve-se o teor de particulas causadoras de turbidez (no caso caulinita). Verifique-se que, para a Agua Tipo II, cuja concentração de substâncias hümicas foi a mesma que para a Aggua Tipo V, as dosagens ötimas foram, respectivamente, de 20 e $140 \mathrm{mg} / \mathrm{l}$ para os mecanismos de adsorção-neutralização e varredura.

Comparando-se as pHs ótimos de coagulação para ambos as mecanismos de coagulação entre as Äguas Tipo I, II e V, verificam-se valores mais elevados para esta ültima, principalmente quando comparados com a Agua Tipo II, de baixa turbidez. 


\section{6) Agua Tipo VI}

O diagrama de coagulação para a Agua Tipo VI é apresentado de forma simplificada na Figura 5.55. Devido a alta concentração de turbidez (160 FTU), a Agua Natural Tipo VI deveria ser tratada em uma ETA pela ação do mecanismo de varredura, razão pela qual, objetivou-se a constru ção do diagrama apenas para esta condição.

Verificou-se que, com apenas oito ensaios lno 01 a 08 Apêndice G), utilizando-se dosagens de sulfato de aluminio yariando entre 10 e 60 $\mathrm{mg} / \ell$ pHs de coagulação entre 5,50 e 8,80, foi possivel a determinação das condições ötimas de coağulação, caracterizada pelos seguintes parâmetros:

- mecanismo de varredura:

$$
\left\{\begin{array}{l}
\text { dosagem de sulfato de aluminio: } 50 \mathrm{mg} / \ell \\
\text { pH de coagulação: } 6,55
\end{array}\right.
$$

Apesar das caracteristicas das particulas causadoras de turbi dez serem desconhecidas e da maior concentração de substancias hümicas

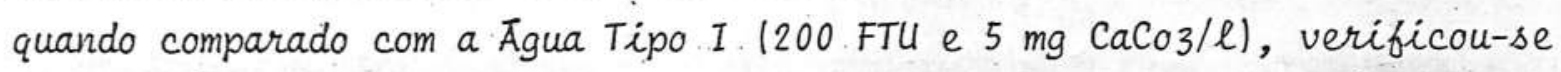
o mesmo pH ótimo de coagulação e uma dosagem de sulfato de aluminio pouco inferior $(60 \mathrm{mg} / \mathrm{l} \mathrm{p} / \mathrm{a}$ Agua Tipo. I).

De tais fatos pode-se destacar a grande flexibilidade de operaçāo quando utiliza-se o mecanismo de varredura, sua rāpida determina ção e sua grande eficiência de remoção de partículas coloidais por sedi mentação (no caso superiores a $98 \%$ ).

\section{g) Aguas Tipo VII}

A Figura 5.60 representa o diagrama de coagulação para a Agua Tipo VII, pesquisado para dosagens de sulfato de aluminio e pHs de coagulaşão variando cntre 2 e $40 \mathrm{mg} / \mathrm{l}$ e 3,80 e 8,75, respectivamente.

Verifica-se que, mesmo na pesquisa de ambos as mecanismos pos siveis de coagulação, a construção do diagrama de coagulação constitui-se cm artifício de rāpida e fácil determinação frente à sua potencialidade.

Considerada pela literatura como una água de difiécil tratabilidade devido ao mediano valor de cor verdadeira e a baixa turbidez, ve - 
rifica-se não ser injusta essa afirmação. Observando-se a Figura 5.60, no ta-se uma ampla faixa de valores de $\mathrm{pH}(4,60$ ate 6,30$)$ que não correspondeu a boas eficiências de remoção de cor aparente por sedimentação. Isto deve-se a insuficiência de choques entre as partículas ou ainda, à facili dade com que se restabilizam devido a sua baixa concentração.

Apesar de suas baixas eficiências de remoção de cor aparen te (nunca esquecendo que a sedimentação perdurou por apenas 10 minutos), tornou-se evidente a região onde manifestou-se o mecanismo de adsorção neutralização com características muito similares as $j \bar{a}$ descritas.

Foram as seguintes as condições ōtimas de coagulação obtidas para a Agua Tipo VII.

- mecanismo de adsorção-neutralização:

$$
\left\{\begin{array}{l}
\text { dosagem de sulfato de aluminio: } 6,0 \mathrm{mg} / \mathrm{l} ; \\
\text { pH de coagulação: 4,35; }
\end{array}\right.
$$

- mecanismo de varredura:

$$
\left\{\begin{array}{l}
\text { dosagem de sulfato de aluminio: } 25 ; \\
\text { pH de coagulação: } 6,75 .
\end{array}\right.
$$

\section{- h) Agua Tipo VIII}

Utilizando-se dosagens de sulfato de aluminio entre 2 e $60 \mathrm{mg}$ le e pHs de coagulação entre 3,75 e 9,0, construiu-se o diagrama de coagu lação simplificado para a. Agua Tipo VIII, mostrado na Figura 5.70.

Com caracteristicas bastante similares ao obtido para a Agua Tipo VII, registraram-se as seguintes condições ötimas de coagulação:

- mecanismo de adsorção-neutralização:

$$
\left\{\begin{array}{l}
\text { dosagem de sulfato de aluminio: } 10 \mathrm{mg} / \mathrm{l} ; \\
\text { pH de coagulação: 4,50. }
\end{array}\right.
$$

- mecanismo de varredura:

$$
\left\{\begin{array}{l}
\text { dosagem de sulfato de aluminio: } 25 \mathrm{mg} / \ell ; \\
\text { pH de coagulação: } 6,85 .
\end{array}\right.
$$

Comparando-se os diagramas de coagulação das Agguas Tipo II, 
VII e VIII, cujos valores de turbidez pouco variaram $15,8,9$ e 6,2 FTU, respectivamente), verifica-se uma certa estequiometria entre as dosagens de sulfato de aluminio $e$ as concentrações de substâncias húmicas para a coagulação no mecanismo de adsorção-neutralização, registrando-se $6,0 \mathrm{mg} /$ $\ell$ para uma cor verdadeira inicial igual a $18,7 \mathrm{mg} / \mathrm{Pt}-\mathrm{Co} / \ell, 10 \mathrm{mg} / \ell$ para $56,1 \mathrm{mg} P t-C o / \ell$ e $20 \mathrm{mg} / \ell$ para $100 \mathrm{mg} \mathrm{Pt}-\mathrm{Co} / \ell$, respectivamente para as Aguas Tipo VII, VIII e II. Ressalta-se que os pHs ótimos de coagulação po dem ser considerados os mesmos $14,35,4,50$ e 4,40 , respectivamente para as Aguas Tipo VII, VIII e II).

\section{i) Agua Tipo IX}

Estudou-se apenas o mecanismo de varredura, utilizando-se dosagens de 5 a $50 \mathrm{mg} / l$ de sulfato de aluminio e variando-se o pH de coagulação de 4,85 a 7,60. A Figura 5.79 apresenta o diagrama de coagulação simplificado para a Agua Tipo IX.

Foram obtidas eficiências de remoção de cor aparente superiores a $90 \%$ para dosagens acima de $20 \mathrm{mg} / l$ com ampla faixa de variação possivel para o pH de coagulação $(5,8$ a 7,3$)$, caracteristica intrinseca do mecanismo de varredura.

0 melhor resultado foi obtido para as seguintes condiçoes:

- mecanismo de varredura

$$
\left\{\begin{array}{l}
\text { dosagem de sulfato de aluminio: } 25 \mathrm{mg} / \mathrm{l} ; \\
\mathrm{pH} \text { de coagulação: } 6,4
\end{array}\right.
$$

\section{j) Agua Tipo $X$}

Com caracteristicas similares a Agua Tipo V lalta turbidez e cor verdadeira), porém de origem natural, a Agua Tipo $x$ foi investigada a penas no mecanismo de varredura. Para isso, variou-se a dosagem de sulfato de aluminio entre 30 e $60 \mathrm{mg} / \mathrm{l}$ e o pH de coagulação entre 5,90 e 8,60 .

os resultados obtidos confirmou a hipötese de que o aumen.to da turbidez proporciona uma queda do valor de dosagem ótima de sulfato de aluminio quando em presença de valores de cor verdadeira elevados, assim como observado para a Água Tipo V quando comparada com a Ägua Tipo II. 
0 ponto ótimo de coagulação $\bar{e}$ dado a seguir:

- mecanismo de varredura:

$\left\{\begin{array}{l}\text { dosagem de sulfato de aluminio: } 50 \mathrm{mg} / \mathrm{l} \text {; } \\ \text { pH de coagulação: } 6,80 .\end{array}\right.$

\section{4 - Otimização dos Parâmetros de Mistura Rápida}

O estudo de otimização de parâmetros de mistura rápida ficou grandemente prejudicado devido às caracteristicas do aparelho de floculação utilizado, que impossibilitou a obtenção de gradientes de velocida de superiores a $1200 \mathrm{~s}^{-1}$, devido à limitações da rotação dos agitadores $e$ $\bar{a}$ entrada de ar no reator para altas velocidades, inviabilizando a determinação do parâmetro $G$.

Assim mesmo, foram pesquisados os gradientes de velocidade de

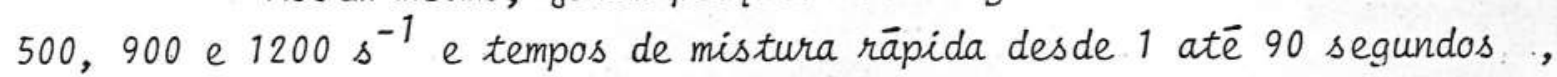
registrados nos ensaios n? 48 a 53 (Apêndice B), 64 a 68 (Apêndíce C), 51 e 52 (Apêndice D), 36 e 37 (Apêndice E), 34 e 35 (Apêndice F), respectiva mente para as Aguas Tipo I, II, III, IV e V.

De uma maneira geral, o uso de gradientes de velocidade na faixa de valores investigada não sensibilizou mudanças de eficiências que pudessem levar a una conclusão objetiva. quanto aos períodos de mistura rápida, verificou-se que o uso de valores acima de 10 segundos prejudicou sensivelmente os resultados, principalmente quando a operação de coagulação deu-se pelo mecanismo de varredura.

Dä-se, a seguir, os melhores resultados obtidos dessa investi gação:

- Agua Tipo I

$$
\begin{cases}\text { mecanismo de adsarção-neutralização } & \left\{\begin{array}{l}
G=500 \mathrm{~s}^{-1} \\
T=5 \mathrm{~s}
\end{array}\right. \\
\text { mecanismo de varredura } & \left\{\begin{array}{l}
G=500 \mathrm{~s}^{-1} \\
T=2 \mathrm{~s}
\end{array}\right.\end{cases}
$$

- Agua Tipo II

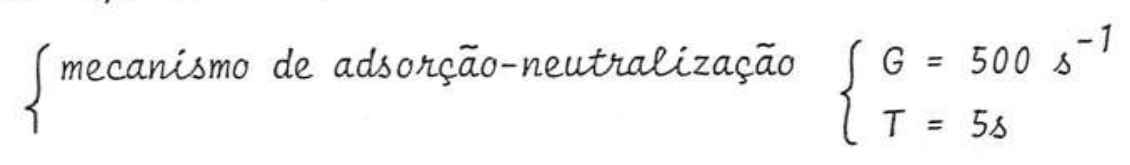


$\left\{\right.$ mecanismo de varredura $\quad\left\{\begin{array}{l}G=500 \mathrm{~s}^{-1} \\ T=2 \mathrm{~s}\end{array}\right.$

- Agua Tipo III

mecanismo de varredura

$$
\left\{\begin{array}{l}
G=900 \mathrm{~s}^{-1} \\
T=5 \mathrm{~s}
\end{array}\right.
$$

- Agua Tipo IV

mecanismo de varredura

$$
\left\{\begin{array}{l}
G=900 s^{-1} \\
T=5 s
\end{array}\right.
$$

- Agua Típo V mecanismo de adsorção-neutralização $\left\{\begin{array}{l}G=900 \mathrm{~s}^{-1} \\ T=5 \mathrm{~s}\end{array}\right.$

Tendo em vista a pouca influência dos parâmetros de mistura rāpida nos resultados finais para periodos inferiores a 10 segundos, fi xou-se para as demais äguas de estudo as condições:

$$
\left\{\begin{array}{l}
G=900 \mathrm{~s}^{-1} \\
T=5 \text { segundos }
\end{array}\right.
$$

\section{5 - Otimização dos Parâmetros de Floculação}

O estudo da floculação realizado pode ser consultado pela anā lise dos seguintes elementos:

- Agua Tipo I:

- Agua Tipo II:

- Agua Tipo III:

- Agua Tipo IV:

- Agua Tipo V:
Figuras 5.5 a 5.11

Apêndice $B$, ensaios n! 54 a 70

Figuras 5.15 a 5.20

Apêndice C, ensaios n! 69 a 92

Figuras 5.25 a 5.31

Apêndice $D$, ensaios n! 53 a 61

Figuras 5.34 a 5.42

Apêndice $E$, ensaios n! 38 a 52

Figuras 5.45 a 5.52

Apêndice $F$, ensaios no 36 a 51 
- Agua Tipo VI:

- Agua Tipo VII:

- Agua Tipo VIII:

- Agua Tipo IX:

- Agua Típo X:
Figuras 5.56 a 5.59

Apêndice $G$, ensaios no 09 a 15

Figuras 5.61 a 5.69

Apêndice H, ensaios no 15 a 23

Figuras 5.71 a 5.78

Apêndice $I$, ensaios no 11 a 19

Figuras 5.80 a 5.83

Apêndice $J$, ensaios no 11 a 15

Figuras 5.85 a 5.88

Apêndice K, ensaios no 09 a 13

Os ensaios foram realizados de forma que, para cada período de floculação investigado, cada reator fosse submetido a gradientes de velocidades diferentes, crescentes, de modo que houvesse a obtenção de um pon to minimo de turbidez elou cor aparente residual do sobrenadante. (ca racterizando o gradiente de velócidade ótimo $G^{*}$ para aquele período de floculaçãol. As coletas de sobrenadante foram realizadas apōs 5 ou $10 \mathrm{mi}$ nutos de sedimentação, dado este, que dependeu das caracteristicas dos flo cos formados para cada tipo de água e mecanismo de coagulação. Para flocos com altas velocidades de sedimentação / características de āguas com grande concentração de partículas coloidais elou quando coaguladas no mecanismo de varredural escolheu-se o período de sedimentação menor de modo que as eficiências de remoção de turbidez elou cor aparente fossem mais. acentuadas para cada período de floculação.

os resultados foram plotados em curvas onde a porcentagem de turbidez e/ou cor aparente remanescente $\bar{e}$ função do gradiente de velocida de para cada período de floculação.

Os gradientes de velocidade ótimos foram plotadas em fun ção dos respectivos períodos de floculação em papel bilogarítmico, confor me metodologia proposta por ANDREU-VILLEGAS \& LETTERMAN (04). Segundo estes pesquisadores, este tipo de curva pode ser ajustado por uma reta descrita por uma equação do tipo:

$$
\left(G^{*}\right)^{n} \cdot T=K
$$

onde: $\left(G^{*}\right.$ : gradiente de velocidade ótimo; $T$ : período de floculação; neK são constantes que dependem da dosagem de coagulante, caracteristicas dos colóides e pH de coagulação. 
Observa-se, desta equação, que quando o período de bloculação tende para valores elevados, o valor de $G^{*}$ tende para zero, o que não foi verificado no presente estudo. A anälise da Figura 5.7, demonstra que., quando aumentou-se o período de floculação, o valor $G^{*}$ decrescia para um valor minimo, abaixo do qual, as eficiências de remoção eram prejudicadas

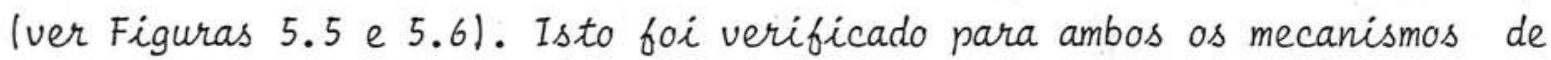
coagulação em todos os tipos de āgua investigados. Desta forma, conclui se que, para o tipo de āgua em estudo existe um gradiente de velocidade $\underline{m \vec{\imath}}$ nimo $\left(G^{\prime}\right)$, abaixo do qual não são caracterizadas as condiçães ötimas de bloculação para un dado período de floculação.

Propõe-se, com base no verificado, uma nova equação representativa para os parâmetros ótimos de floculação, dada a seguir:

$$
\left(G^{*}-G^{\prime}\right)^{n} \cdot T=K
$$

No inicio, propôs-se a determinação gráfica do parâmetro $G^{\prime}$, através de curvas do tipo representado na Figura 5.7 (Ägua Tipo I). Ao realizar-se os ensaios para a Agua Tipo II, verificou-se grande dificulda de na determinação do parâmetro G' (ver Figura 5.17).

Partiu-se, então, para uma determinação analitica baseada na construção de curvas onde são plotados os valores ótimos dos gradientes de velocidade em função da relação inversa dos períodos de floculação elevadas por um expoente $k\left[(1 / T)^{k}\right]$ (ver Figura 5.8). A determinação do valor de $k$ foi feita com o auxilio de uma calculadora programāvel (HP-15-C). , através de método iterativo de forma a obter-se o melhor ajuste possivel da equação 5.3 , dada a seguir:

Da equação 5.2 , pode-se efetuar:

$$
\begin{aligned}
& \left(G^{*}-G^{\prime}\right)^{n} \cdot T=K \\
& \left(G^{*}-G^{\prime}\right)^{n}=(1 / T) \cdot K \\
& \left(G^{*}-G^{\prime}\right)=(1 / T)^{1 / n} \cdot K^{1 / n} \text { (se fizermos } 1 / n=k \text { ) } \\
& \left(G^{*}-G^{\prime}\right)=(1 / T)^{k} \cdot K^{k} \\
& G^{*}=K^{\prime}(1 / T)^{k}+G^{\prime} \quad \text { (onde } K^{\prime}=K^{k} \text { ) }
\end{aligned}
$$

A equação 5.3 representa uma reta se plotarmos $G^{*}$ contra $(1 / T)^{k} e$, cada valor de $k$, obtem-se os valores de $K^{\prime} e G^{\prime}$, pelo método dos minimos quadrados (m.m.q.) e seu respectivo coeficiente de correlação (r). A indejinição do problema resolve-se tomando-se o valor de $k$ que maximiza o valor do coeficiente de correlação, ajustando-se da melhor forma possi- 
vel os dados experimentais como a equação proposta.

A título de comparação entre o modelo proposto e o de ANDREUVILLEGAS \& LETTERMAN, são traçadas as retas representativas das equações 5.3 e 5.1 e seus respectivos coeficientes de correlação $r$.

São dadas no quadro $5 .{ }^{2}$ as equações ajustadas pelo modelo proposto e pelo de ANDREU-VILLEGAS \& LETTERMAN, para cada tipo de āgua in vestigado nas condições ötimas dos mecanismos de coagulação por adsorçãoneutralização e varredura, determinadas anteriormente:

Quadro 5.2 - Equações de ajuste dos parâmetros ötimos de floculação.

\begin{tabular}{|c|c|}
\hline \multirow[t]{2}{*}{ Agua Tipo } & Mecanismo de Adsorção-neutralização \\
\hline & $\begin{array}{l}\text { Modelo Proposto } \\
\text { Modelo de ANDREU-VILLEGAS \& LETTERMAN }\end{array}$ \\
\hline$I$ & $\begin{array}{l}\left(G^{*}-7,9\right)=292,10(T)^{-1,6657} ; r=-0,9997 \\
G^{*}=85,02(T)^{-0,6198} ; r=-0,9067\end{array}$ \\
\hline II & $\begin{array}{l}(G *-5,2)=264,15(T)^{-1,0116} ; r=-0,9956 \\
G *=136,74(T)^{-6474} ; r=-0,9754\end{array}$ \\
\hline III & 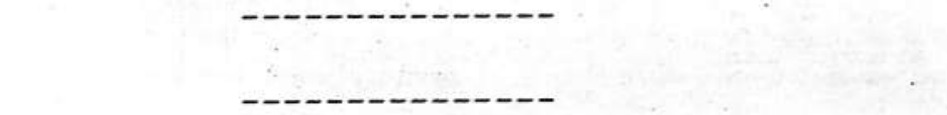 \\
\hline IV & $\begin{array}{l}\left(G^{*}-25,6\right)=281,38(T)^{-0,990} ; r=-0,9958 \\
G^{*}=93,372(T)^{-0,2787} ; r=-0,9884\end{array}$ \\
\hline V & $\begin{array}{l}\left(G^{\star}-18,5\right)=756,69(T)^{-1,75} ; r=-0,9969 \\
G^{*}=110,163(T)^{-0,4791} ; r=-0,9361\end{array}$ \\
\hline$V I$ & --- \\
\hline VII & $\left(G^{*}-47,2\right)=10,833(T)^{-1,89} ; r=0,99998$ \\
\hline VIII & $\left(G^{*}-19,1\right)=5132(T)^{-1,83}, r=-0,9985$ \\
\hline
\end{tabular}


continuação do ouadro 5.2

\begin{tabular}{|c|c|}
\hline \multirow[t]{2}{*}{ Agua Tipo } & Mecanismo de Adsorção-Neutralização \\
\hline & $\begin{array}{c}\text { Modelo Proposto } \\
\text { Modelo de ANDREU-VILLEGAS \& LETTERMAN }\end{array}$ \\
\hline IX & - \\
\hline$x$ & - - n-n- \\
\hline \multirow[t]{2}{*}{ Agua Tipo } & Mecanismo de Varredura \\
\hline & $\begin{array}{l}\text { Modelo Proposto } \\
\text { Modelo de ANDREU-VILLEGAS \& LETTERMAN }\end{array}$ \\
\hline I & $\begin{array}{l}\left(G^{*}-11,5\right)=309,98(T)^{-1,8940} ; r=0,9999 \\
G^{*}=81,36(T)^{-0,5591} ; r=-0,8843\end{array}$ \\
\hline II & $\begin{array}{l}\left(G^{*}-2,8\right)=95,90(T)^{-1,0661} ; r=-0,9882 \\
G^{*}=80,56(T)^{-0,8146} ; r=-0,9726\end{array}$ \\
\hline III & $\begin{array}{l}\left(G^{*}-14,9\right)=1699,9(T)^{-1,731} ; r=-0,9990 \\
G^{*}=332,905(T)^{-0,81052 ; r=-0,9669}\end{array}$ \\
\hline IV & $\begin{array}{l}\left(G^{*}-2,5\right)=152,0(T)^{-0,505} ; r=-0,9954 \\
G^{*}=147,903(T)^{-0,4704} ; r=-0,9920\end{array}$ \\
\hline V & $\begin{array}{l}\left(G^{*}-13,1\right)=157,98(T)^{-1,42} ; r=0,9910 \\
G^{*}=65,190(T)^{-0,4617} ; r=-0,9700\end{array}$ \\
\hline VI & $\left(G^{*}-10,3\right)=252,01(T)^{-0,89} ; r=-0,9930$ \\
\hline VII & $\begin{array}{l}\left(G^{*}-13,7\right)=1299(T)^{-2,01} ; r=0,9955 \\
G^{*}=156,4(T)^{-0,673} ; r=-0,9610\end{array}$ \\
\hline
\end{tabular}


continuação do ouadro 5.2

\begin{tabular}{|c|c|}
\hline \multirow{2}{*}{ Agua Tipo } & $\begin{array}{r}\text { Mecanismo de Varredura } \\
\text { Modelo Proposto }\end{array}$ \\
\cline { 2 - 3 } & $\begin{array}{r}\text { Modelo de ANDREU-VILLEGAS \& LETTERMAN } \\
\text { VIII }\end{array}$ \\
\hline & $(G \star 16,2)=150,5(T)^{-0,98} ; r=-0,9914$ \\
\hline IX & $\left(G^{*}-16,7\right)=237,51(T)^{-1,22} ; r=-0,9994$ \\
\hline$X$ & $\left(G^{*}-7,21\right)=45,21(T)^{-0,46} ; r=-0,9870$ \\
\hline
\end{tabular}

Pelos dados obtidos, observa-se que para cada período de blo culação, corresponde um unico valor de gradiente de velocidade que maxi miza as caracteristicas de sedimentabilidade dos flocos.

Assim como observado por ARGAMAN \& KALFMAN (08), as dados ob tidos comprovam que o aumento indefinido do período de floculação permi te aumentos continuos nas eficiencias de remoção de cor aparente eloutur bidez por sedimentação, desde que se opere em seu respectivo gradiente de velocidade ótimo lque para valores altos de $T$, aproxima-se assintotica mente de G'; fato este, não caracterizado na equação proposta de ARGAMAN \& KALIFMAN, apresentada no texto sob os nümeros de 3.45 e 3.46 , respectivamente, para um e " $m$ " reatores dispostos em sērie).

Devido a esse fato, a escolha do período de floculação torna -se um problema relacionado ao custo e a eficiência do tratamento deseja da.

No presente estudo, traçam-se as curvas correspondentes aos valores de turbidez ou cor aparente residual minima correspondente a ca da período de floculação e verificou-se bons ajustes entre os resultados e a equação matemática dada a seguir:

$$
y=a T^{b}
$$

onde: $\quad\{y:$ turbidez ou cor aparente residual minima $(\%)$; 


$$
\left\{\begin{array}{l}
T: \text { perĩodo de floculação (min.); } \\
a \text { e } b: \text { constantes a determinar. }
\end{array}\right.
$$

A equação 5.4 pode ser linearizada aplicando-se o logarîtmo de ambos os lados:

$$
\log (y)=\log (a)+b \cdot \log (T)
$$

Utilizando-se o m.m.q., obtém-se os valores das constantes a $e$, permitindo o traçado das curvas executadas.

São dadas no Quadro 5.3 as equações para as Aguas investigadas para cada mecanismo de coagulação, os periodos de floculação escolhi dos e seus respectivos gradientes de velocidade ōtimos, calculados pelo modelo proposto cujas equações foram apresentadas no quadro 5.2 .

Quadro 5.3 - Equações de ajuste dos valores de turbidez ou cor aparente residual minima em função do perĩodo de floculação. Seleção de parâmetros ótimos de floculação.

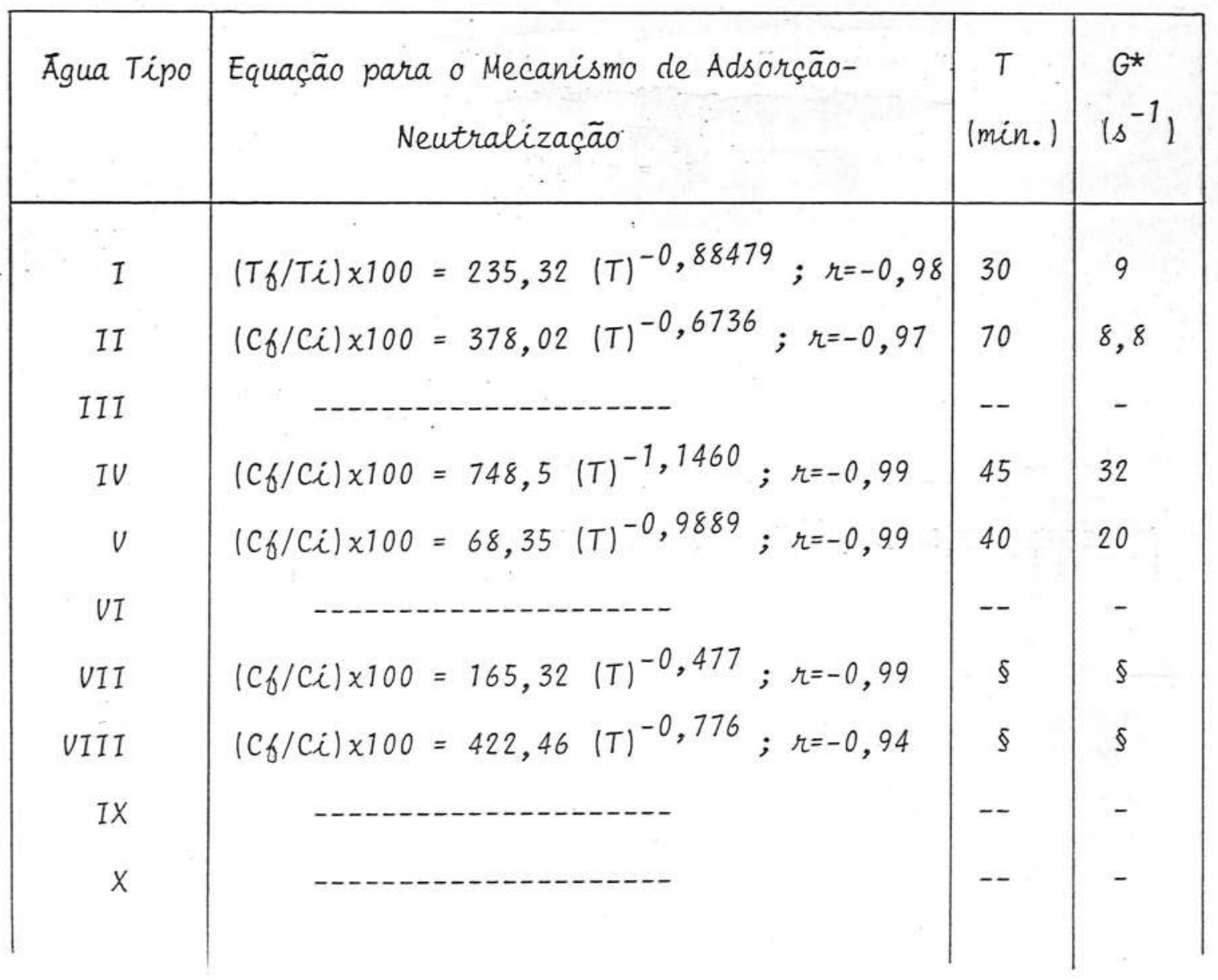


continuação do Quadro 5.3

\begin{tabular}{|c|c|c|c|}
\hline Agua Tipo & Equação para o Mecanismo de Varredura & $\begin{array}{c}T \\
(\min .)\end{array}$ & $\begin{array}{l}G^{*} \\
\left(s^{-1}\right)\end{array}$ \\
\hline I & $(T f / T i) \times 100=142,55(T)^{-1,23036} ; r=-0,99$ & 20 & 13 \\
\hline II & $\left(C_{6} / C_{i}\right) \times 100=78,70(T)^{-0,8092} ; r=-0,9650$ & 30 & 5,4 \\
\hline III & $(T 6 / T i) \times 100=648,5(T)^{-1,1646} ; r=-0,973$ & 45 & 17 \\
\hline IV & $(C 6 / C i) \times 100=27,57(T)^{-1,0277} ; r=-0,988$ & 20 & 36 \\
\hline V & $\left(C_{6} / C_{i}\right) \times 100=7,02(T)^{-0,6608} ; r=-0,959$ & 25 & 15 \\
\hline VI & $(T 6 / T i) \times 100=17,74(T)^{-0,8794} ; r=-0,964$ & $\S$ & $\S$ \\
\hline VII & $\left(C_{6} / C_{i}\right) \times 100=109,0(T)^{-1,045} ; r=-0,983$ & $\S$ & $\S$ \\
\hline VIII & $\left(C_{6} / C_{i}\right) \times 100=148,83(T)^{-0,855} ; r=-0,932$ & $\S$ & $\S$ \\
\hline IX & $\left(C_{6} / C_{i}\right) \times 100=127,38(T)^{-0,9630} ; r=-0,978$ & $\S$ & $\S$ \\
\hline$x$ & $\left(T_{f} / T_{i}\right) \times 100=8886(T)^{-0,4441} ; r=-0,076$ & $\S$ & $\S$ \\
\hline
\end{tabular}

(\$) valores não determinados devido a suas não necessidades para continuida de do estudo.

E interessante observar que a coagulação no mecanismo de adsor ção-neutralização requer períodos de floculação muito superiores aos neces sārios nara o mecanismo de varredura. Tal fato pode ser explicado pela teo ria de VON SMOLUCHOWSKI que equaciona a taxa de colisão entre as partícu las como proporcional ao nümero destas. Como no mecanismo de adsorção-neu tralização as espécies de aluminio encontram-se predominantemente na forma solüvel, o nümero de colōides presentes é inferior ao ocorrido no mecanis mo de varredura, dar a necessidade de maiores períodos de floculação.

outro fator relevante, consiste na ocorrência de baixos valo res de gradicntes de velocidade ótimos em ambos os mecanismos de coagula ção (exceto para a Água Tipo IV), comparado com os normalmente recomenda dos para a operação de ETAs.

5.6. Influência da Concentracão da Solução de Estoque do Coagulante 
tração da solução de estoque de sulfato de aluminio sobre as etapas de coa gulação, floculação e sedimentação das āguas investigadas foram executados sómente para as Aguas Tipo I a $V$ e apresentados da seguinte forma:

\author{
.Agua Tipo I: Figuras 5.12 3 5.13; \\ Apêndice $B$, ensaios $n$ ? 71 a 74 . \\ . Agua Tipo II: Figuras 5.21 e 5.22 \\ Apêndice C, ensaios no 93 a 96 \\ .Agua Tipo III : Figura 5.32 \\ - Apêndice D, ensaios n! 62 e 63 \\ .Agua Tipo IV : Figura 5.42 e 5.43 \\ Apêndice $E$, ensaios no 53 e 54 \\ . Agua Tipo V: Figuras $5.53 \cdot$ e 5.54 \\ Apêndice $F$, ensaios nọ 52 e 53
}

A anälise das Figuras mencionadas permite observar a relativa homogeneidade dos resultados com o uso de diferentes concentracões de so luções de estoque de sulfato de aluminio, evidenciando sua não influência sobre as caracteristicas de sedimentabilidade dos flocos na faixa de valo res estudada. 
5.7. Figuras dos Resultados Experimentais Obtidos

Apresentam-se, a seguir as figuras correspondentes aos en saios realizados para todos os tiopos de águas ( I a X).

A numeração das pāginas obedece o mesmo nümero das figu ras de modo a facilitar a consulta durante a leitura do texto do item 5.

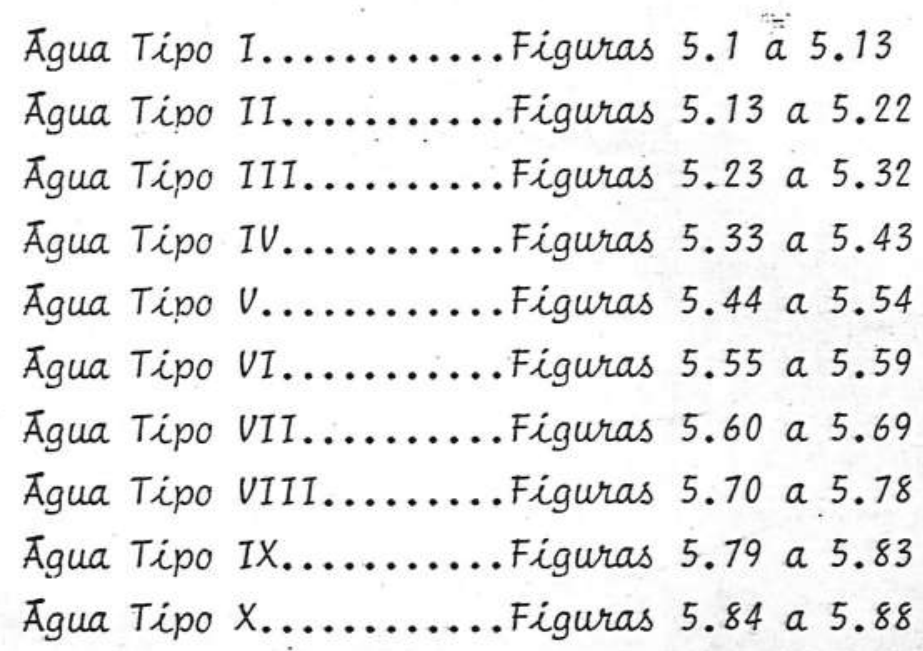




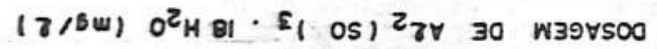

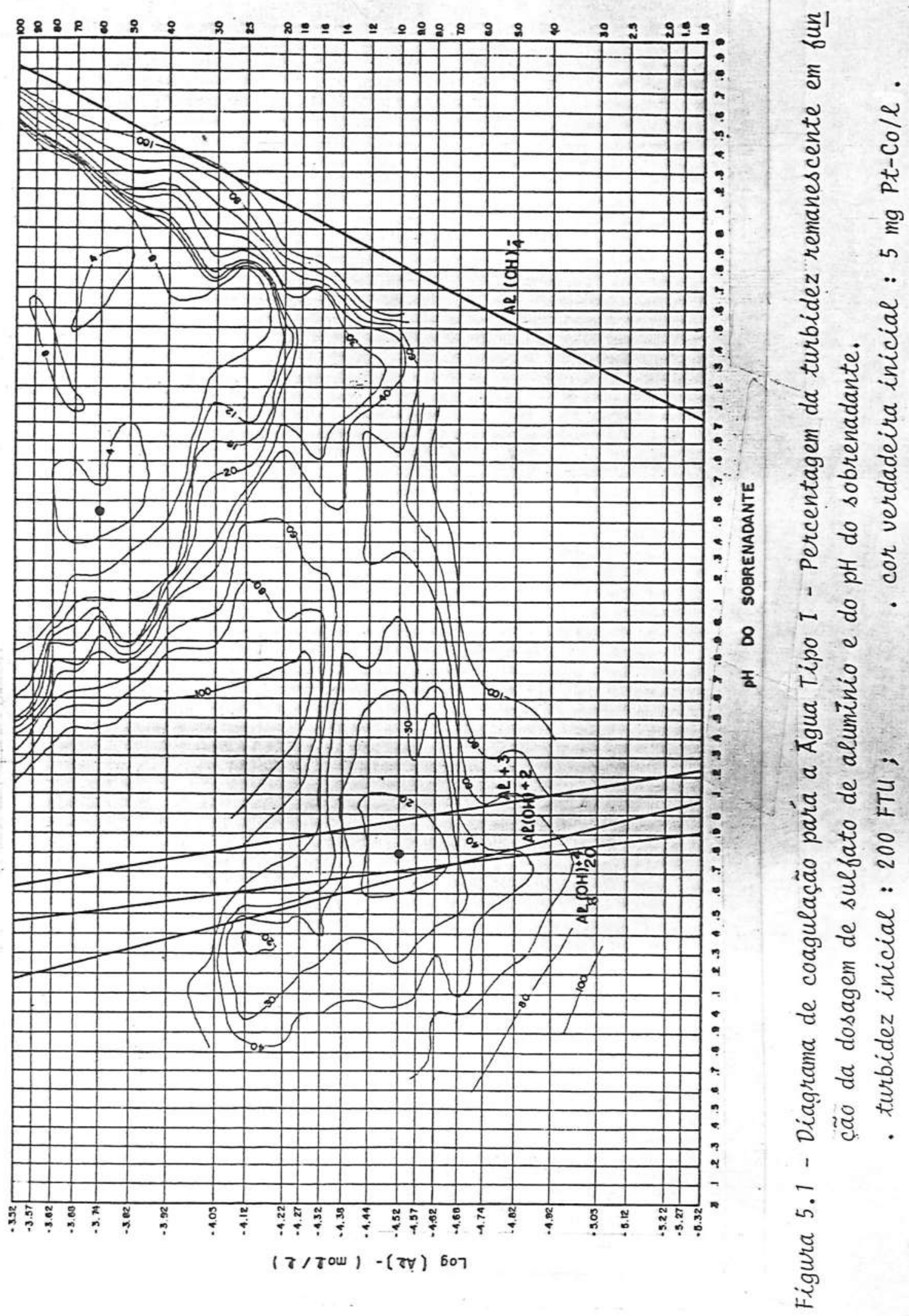




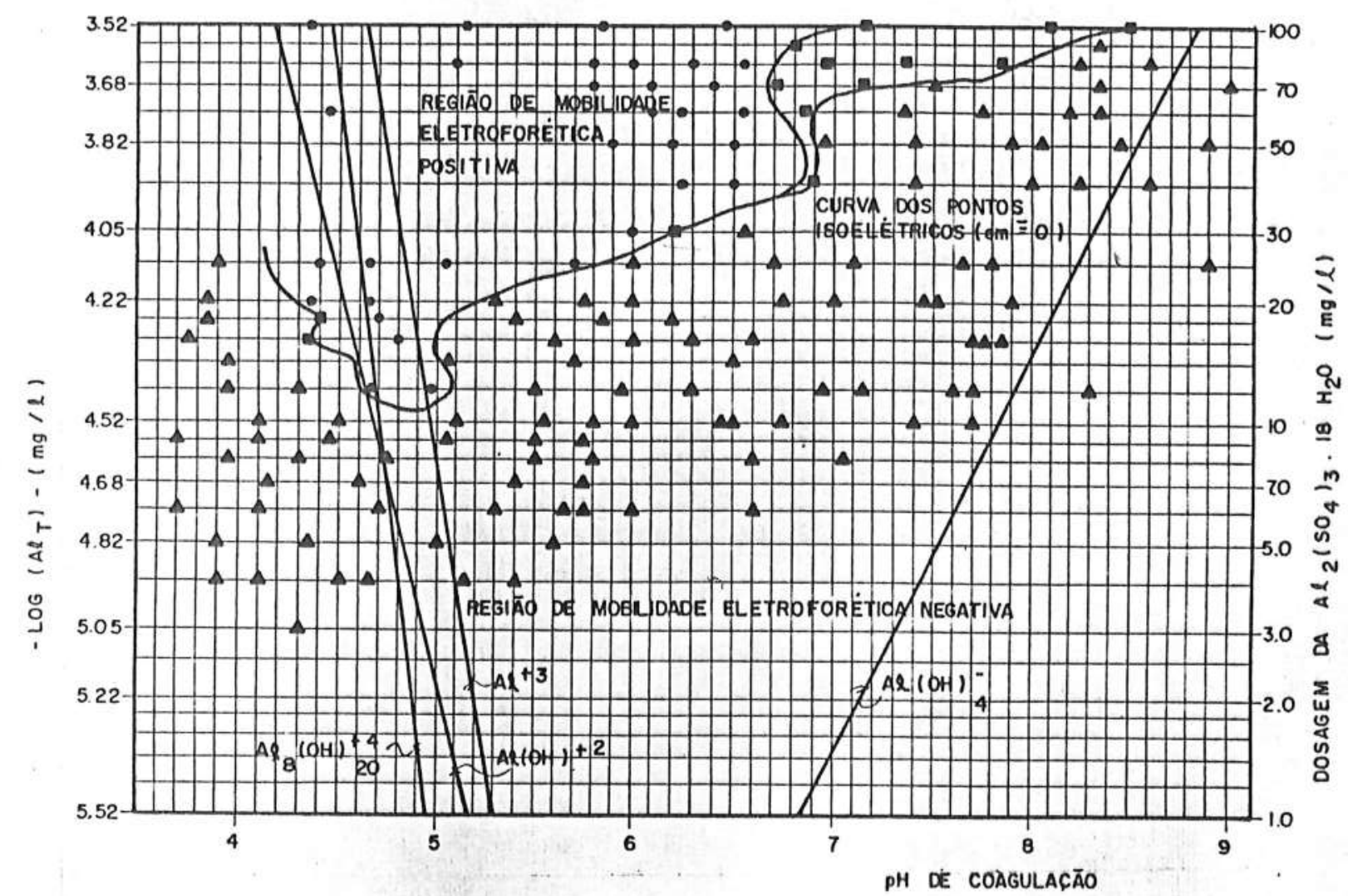

Figura 5.2 - Diagrama da mobilidade eletroforética em funç̧ão da dosagem de sulfato de aluminio e do pH do sobrenadante para a Agua Tipo I.

- turbidez inicial : 200 FTU;

- cor verdadeira inicial: $5 \mathrm{mg} \mathrm{Pt}-\mathrm{Co} / \ell$. 


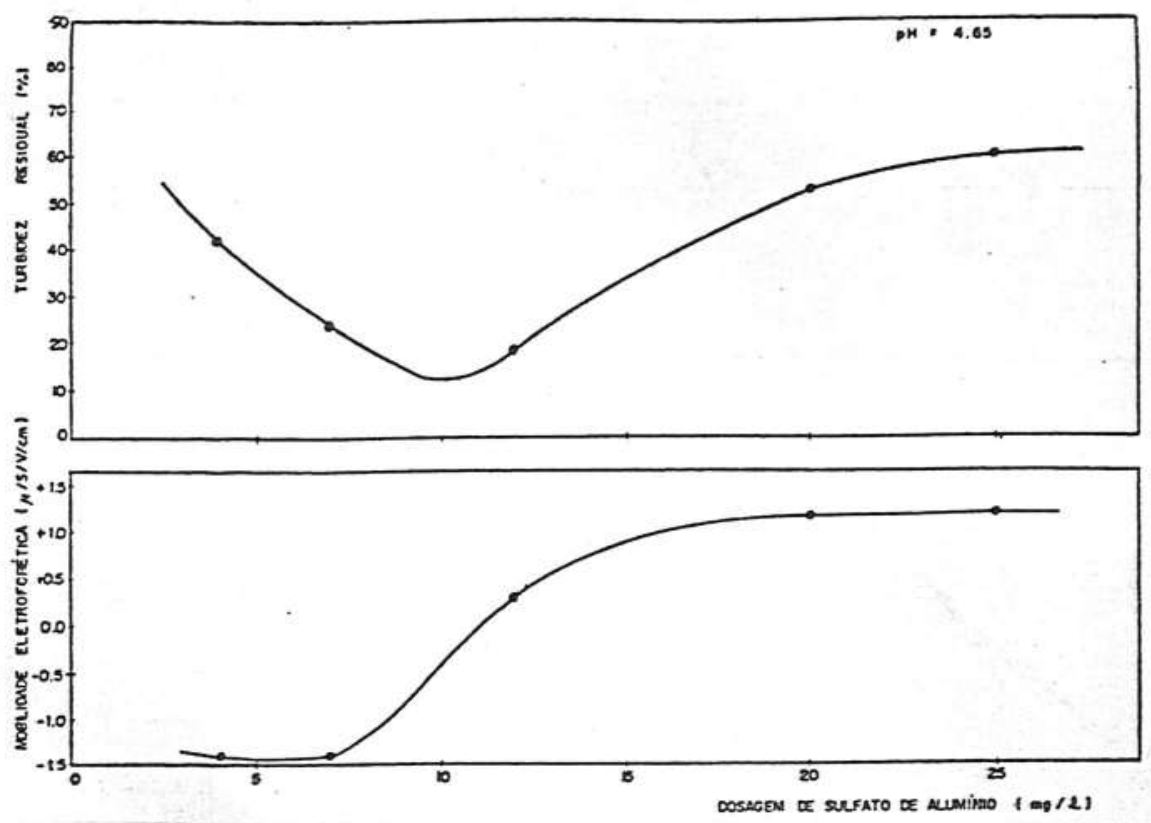

Figura 5.3 - Curvas de variação da mobilidade eletroforética e turbidez residual em função da dosagem de sulfato de aluminio para um valor de $\mathrm{pH}$ do sobrenadante $i$ gual a 4,65. Agua Tipo I.

-turbidez inicial: 200 FTU;

- cor verdadeira inicial: $5 \mathrm{mg}$ Pt-Co/l.
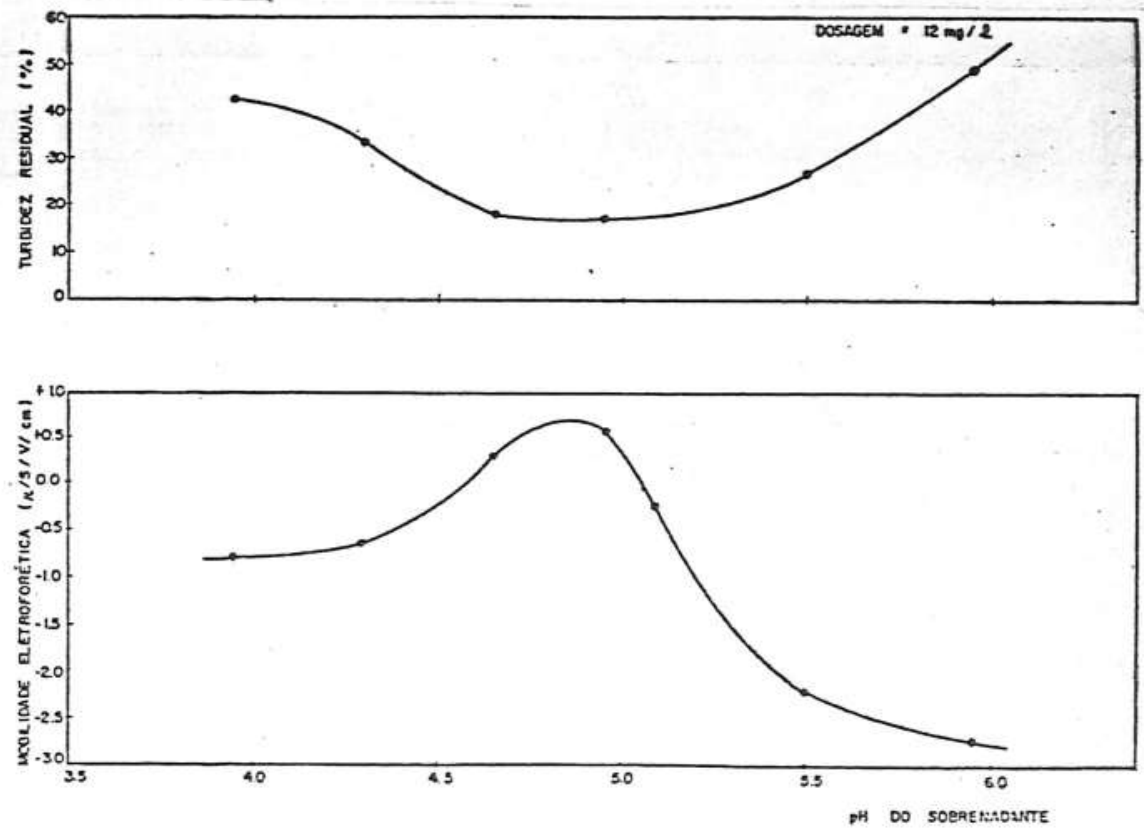

Figura 5.4 - Curvas de variação da mobilidade eletroforética e turbidez residual em função do pH do sobrenadante para una dosagem de sulfato de aluminio igual a $12 \mathrm{mg} / \mathrm{l}$. Água Tipo 1 .

.turbidez inicial: 200 FTU;

- cor verdadeira inicial: $5 \mathrm{mg} P t-C o / l$. 


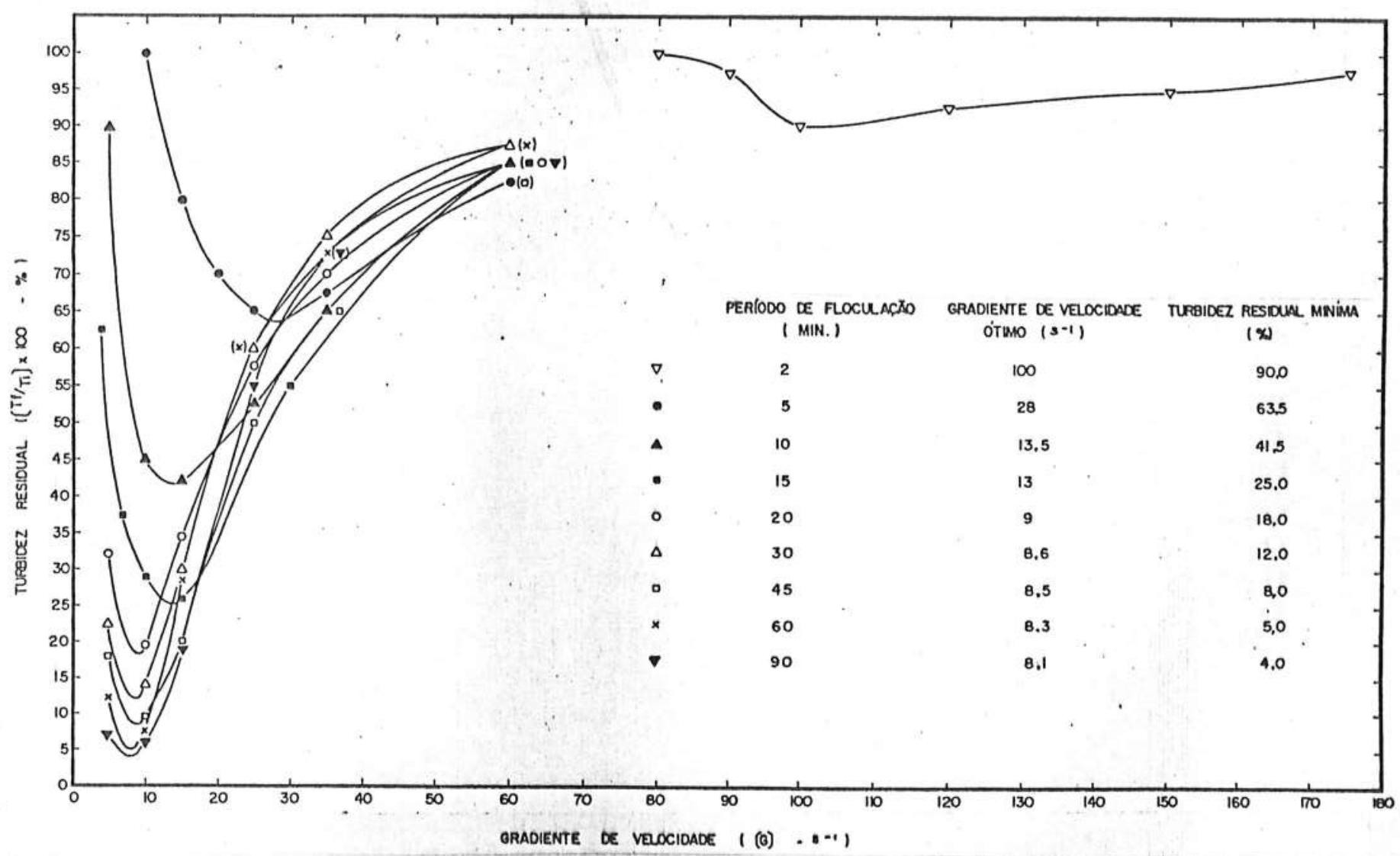

Figura 5.5 - Curvas de variação da turbidez residual em funcão do gradiente de velocidade para värios períodos de floculação. Agua Tipo I. Mecanismo de adsorção e neutralização.

- turbidez inicial : $200 \mathrm{FTU}$; cor verdadeira inicial : $5^{\mathrm{mg}} \mathrm{Pt}$-Co/l; . dosagem de sul fato de aluminio : $10 \mathrm{mg} / \ell$; $\mathrm{pH}$ do sobrenadante : 4,8; . perído de sedimentação : $5 \mathrm{~min}$. 


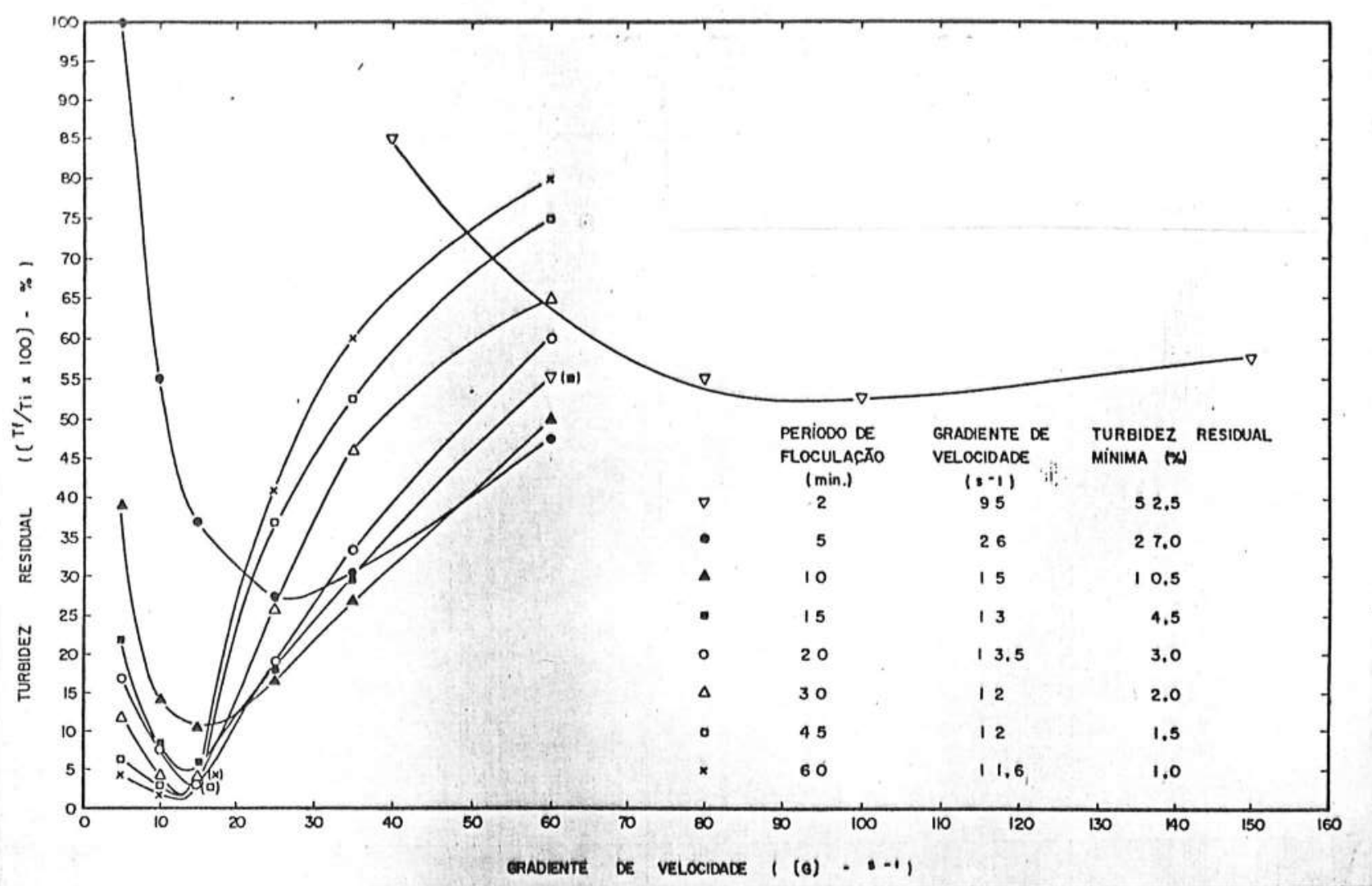

Figura 5.6 - Curvas de variação da turbidez residual em função do gradiente de velocidade para värios períodos de floculação. Agua Tipo I. Mecanismo de varredura.

- turbidez inicial : $200 \mathrm{FTU}$; cor verdadeira inicial : $5 \mathrm{mg} \mathrm{Pt}$-Co/ $\ell$; dosagem de sul fato de aluminio : $60 \mathrm{mg} / \ell$; . pH do sobrenadante : 6,55; . periodo de sedimentação: 5 min. 


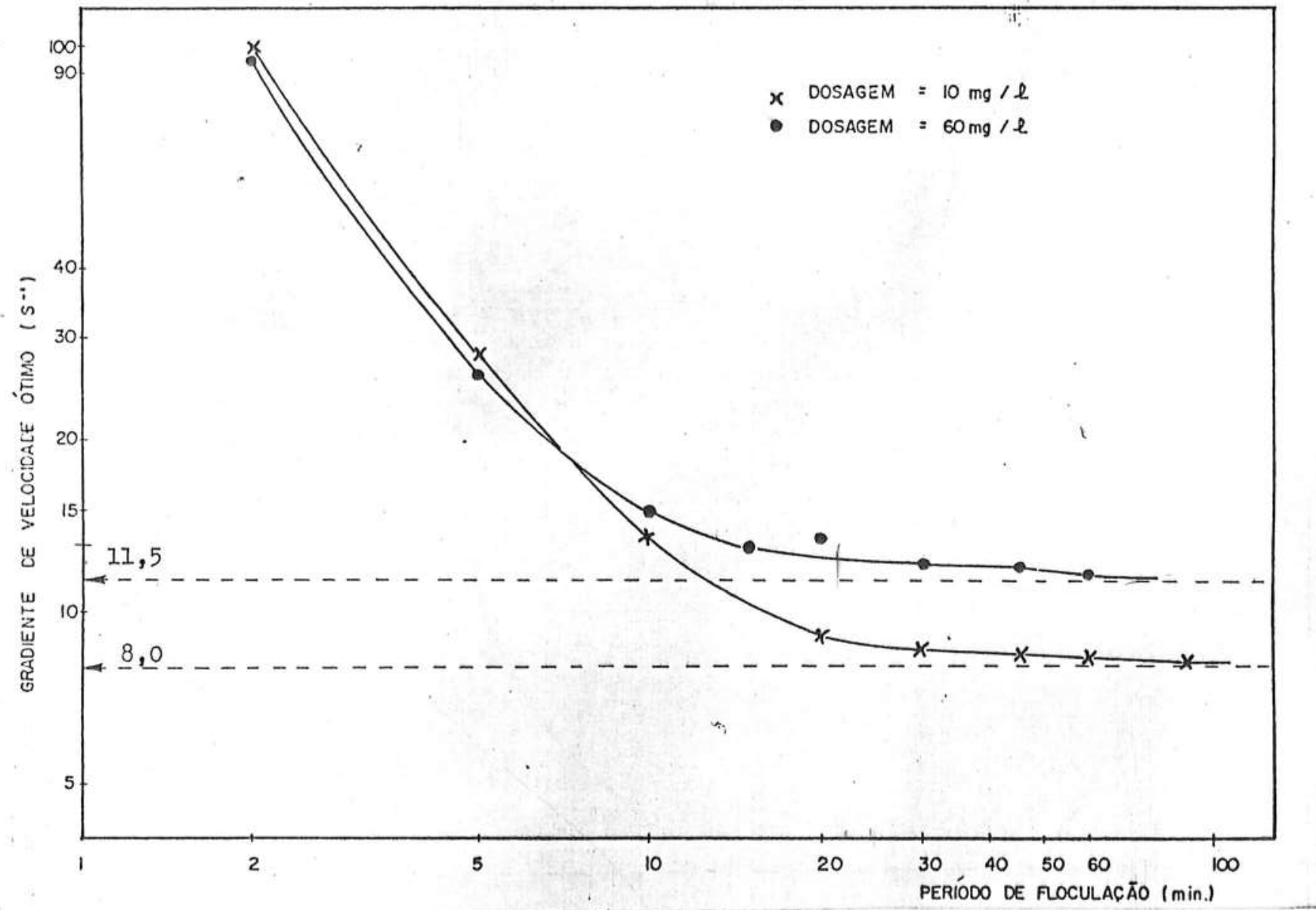

Figura 5.7 - Curvas de variação do gradiente de velocidade ötimo $\left(G^{*}\right)$ em função do perĩodo de flocula ção em papel bilogaritmico. Mecanismos de adsorção - neutralização e varredura. Agua Tipo I. . turbidez inicial : $200 \mathrm{FTU}$; . cor verdadeira inicial : $5 \mathrm{mg} \mathrm{Pt}$-Co/ $\ell$; periodo de sedimentação : 5 min. 


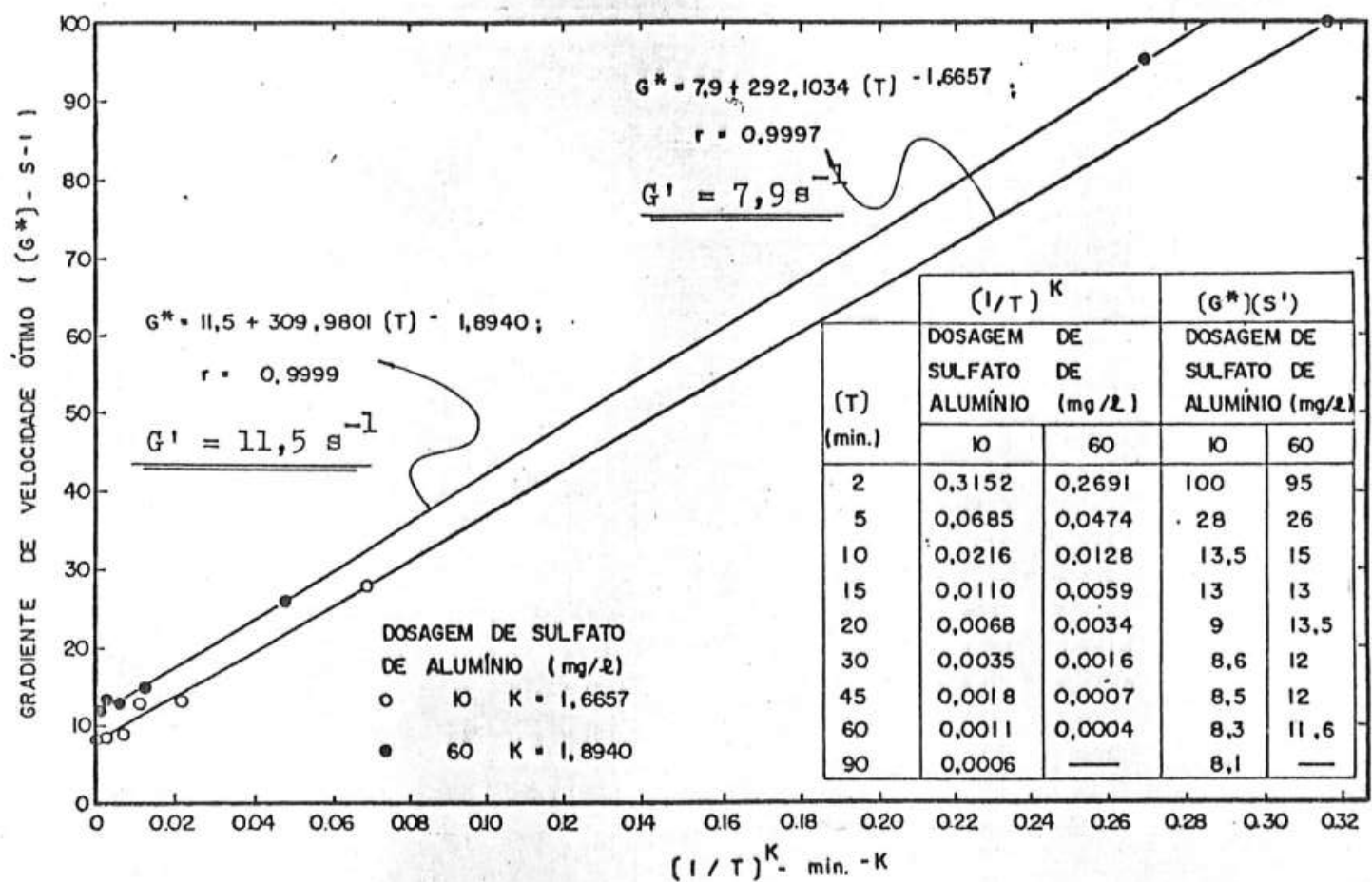

Figura 5.8 - Curvas de variação do gradiente de velocidade ōtimo $\left(G^{*}\right)$ em função de $(1 / T)^{n}$ para a Agua Tipo $T$, onde $T \bar{e}$ o periodo de floculação.

- turbidez inicial : $200 \mathrm{FTU}$; cor verdadeira inicial : $5 \mathrm{mg} \mathrm{Pt}-\mathrm{Co} / \mathrm{l}$; periodo de sedi mentação : 5 min.; dosagens de sulfato de aluminio e pH de coagulação: mecanismo de ad sorção-neutralização: $10 \mathrm{mg} / \ell$ e 4,8 - mecanismo de varredura: $60 \mathrm{mg} / \ell$ e 6,55 . 


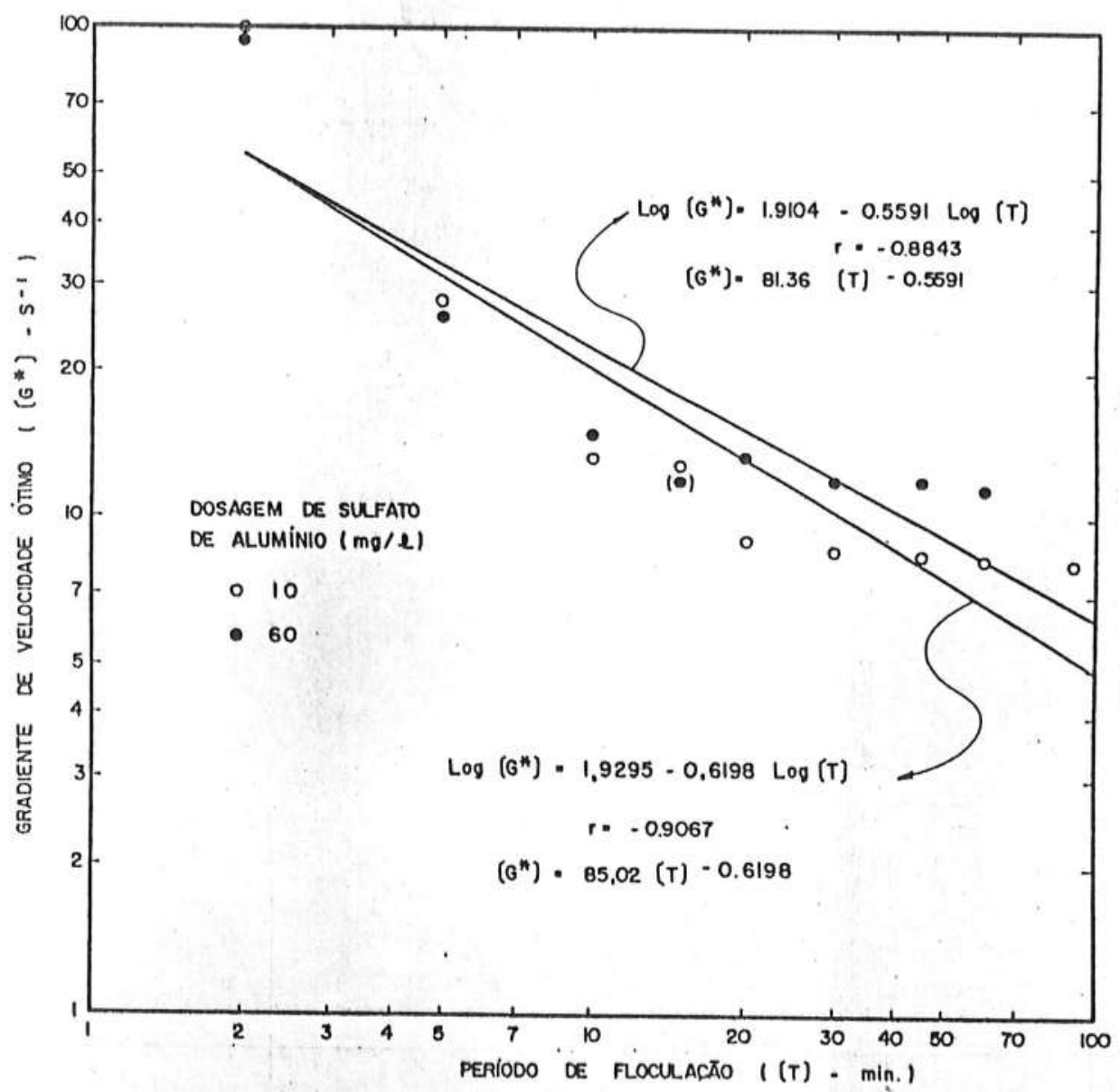

Figura 5.9 - Curvas de variação do gradiente de velocidade ötimo $\left(G^{*}\right)$ em função do perĩodo de flocula ção em papel bilogaritmico. Modelo de ANDREU-VILLEGAS \& LETTERMAN (0.4). Agua Tipo 1. - turbidez inicial:200 FTU; . cor verdadeira inicial: $5 \mathrm{mg}$ Pt-Co/l; . periodo de sedimen tação: 5 min.;.dosagens de sulfato de aluminio e pH de coagulação: mecanismo de adsorção -neutralização: $10 \mathrm{mg} / \ell$ e 4,8 - mecanismo de varredura: $60 \mathrm{mg} / \ell$ e 6,55 . 


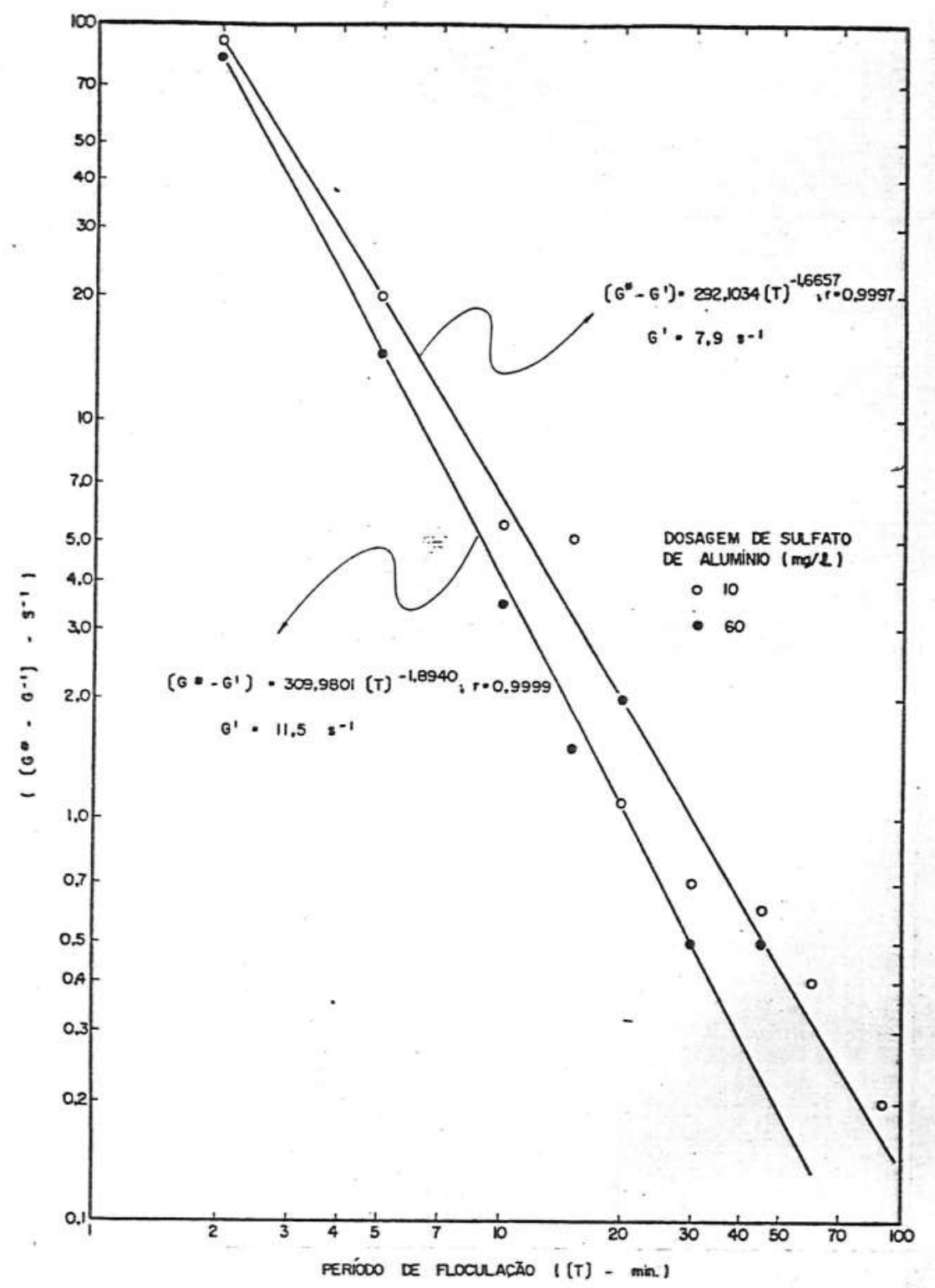

Figura 5.10 - Curvas de variação do gradiente de velocidade $\left(G^{*}-G^{\prime}\right)$ em função do perĩodo de floculação. Agua Tipo I. Modelo proposto.

- turbidez inicial: 200 FTU; . cor verdadeira inicial: $5 \mathrm{mg} \mathrm{Pt-Co/l}$; período de sedimentação: $5 \mathrm{~min}$.; . dosa gens de sulfato de aluminio e pH do sobrenadante: meca nismo de adsorção-neutralização: $10 \mathrm{mg} / \ell$ e 4,8 - meca nismo de varredura: $60 \mathrm{mg} / \mathrm{l}$ e 6,55 . 


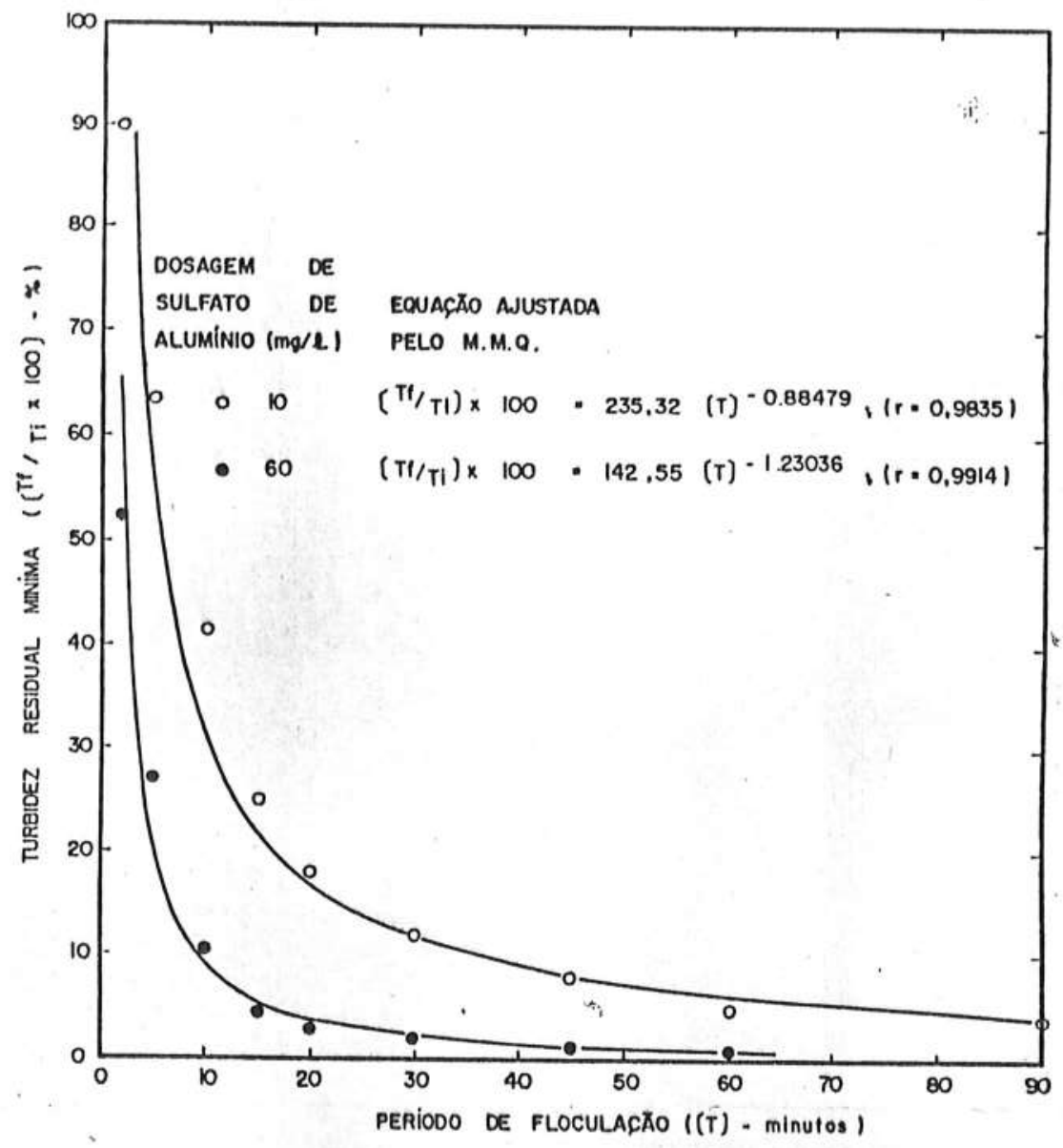

Figura 5.11 - Curvas de variação da turbidez residual minima em função do período de floculação. Aggua Tipo I.

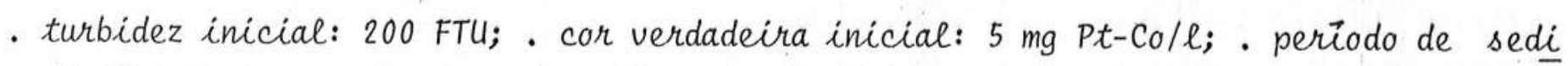
mentação: 5 min.; . dosagens de sulfato de aluminio e pH do sobrenadante: mecanismo de adsorção-neutralização: $10 \mathrm{mg} / \ell$ e 4,8 - mecanismo de varredura: $60 \mathrm{mg} / \ell$ e 6,55. 


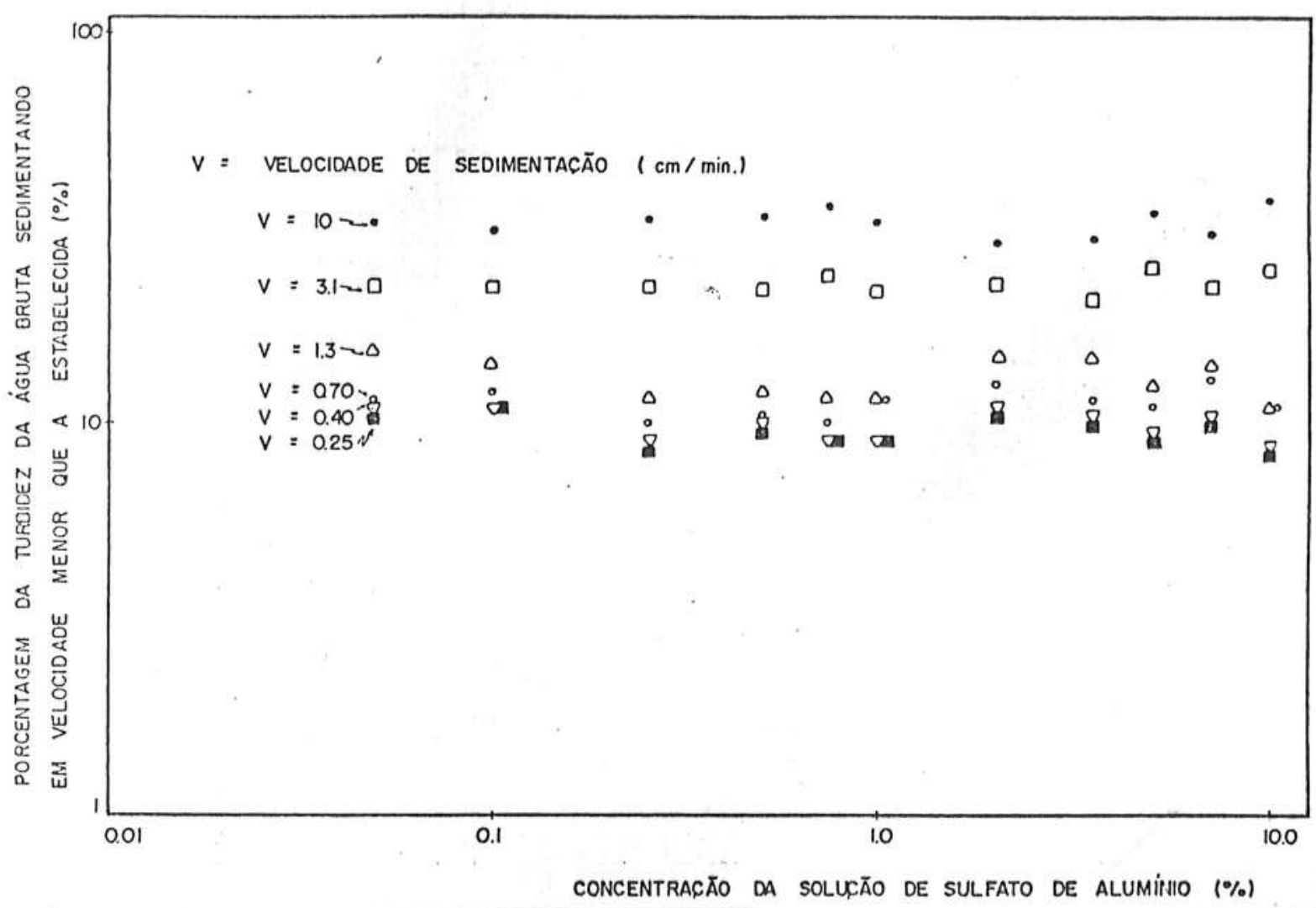

Figura 5.12 - Variação da percentagem da turbidez inicial que sedimenta em velocidade menor que a es tabelecida em função da concentração da solução de estoque de sulffato de aluminio. $\bar{A}$ gua Tipo I. Mecanismo de adsorção-neütralização.

- turbidez inicial: $200 \mathrm{FTU}$; cor verdadeira inicial: $5 \mathrm{mg}$ Pt-Coll; . dosagem de sul fato de aluminio: $10 \mathrm{mg} / \mathrm{l}$; . pH do sobrenadante: 4,8 . 


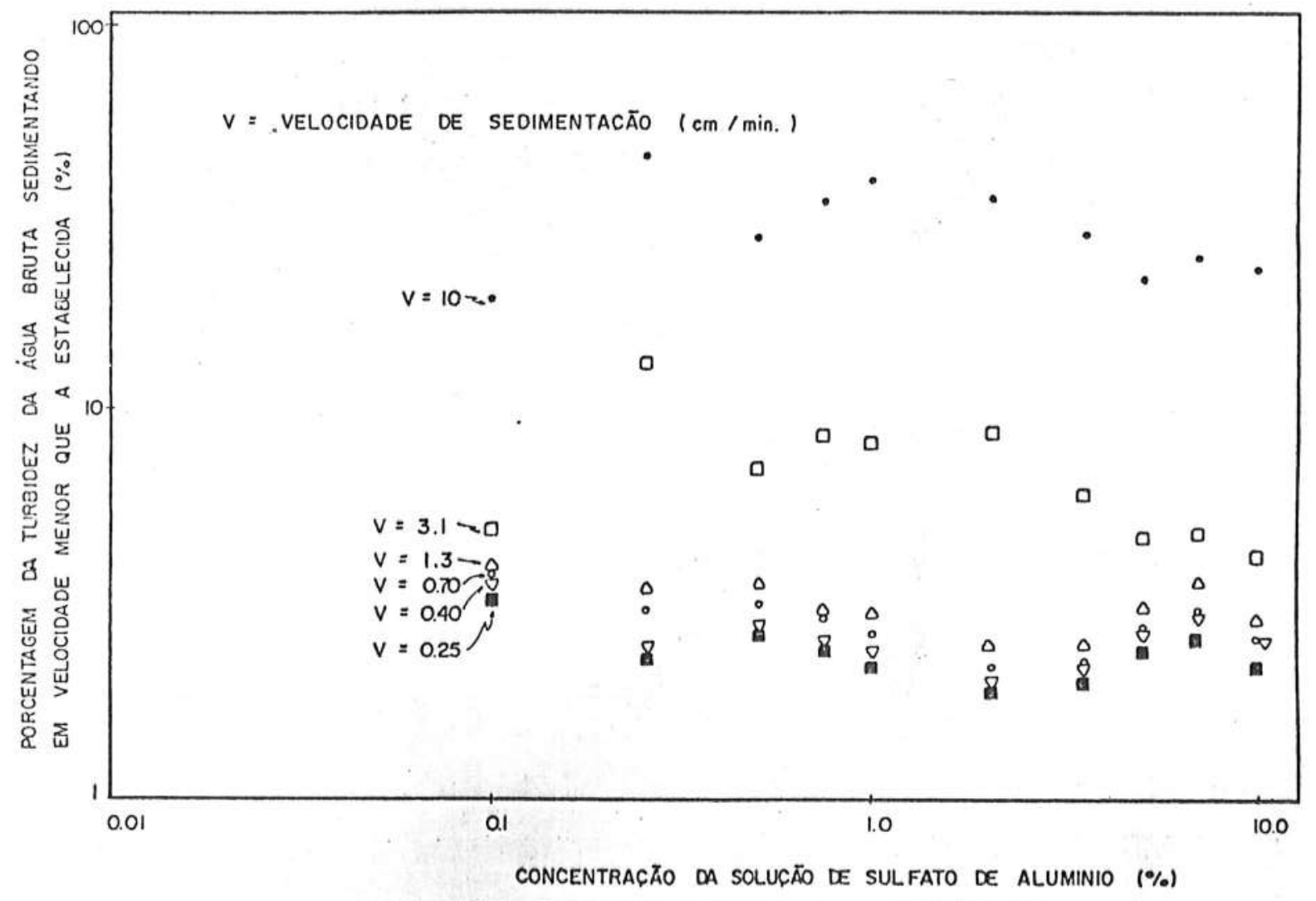

Figura 5.13 - Variação da percentagem da turbidez inicial que sedimenta em velocidade menor que a es tabelecida em função da concentração da solução de estoque de sulfato de aluminio. $\bar{A}$ gua Tipo I. Mecanismo de varredura.

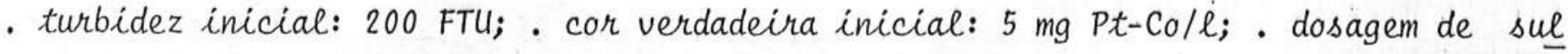
fato de aluminio: $60 \mathrm{mg} / \mathrm{l}$; . pH do sobrenadante: 6,55 . 


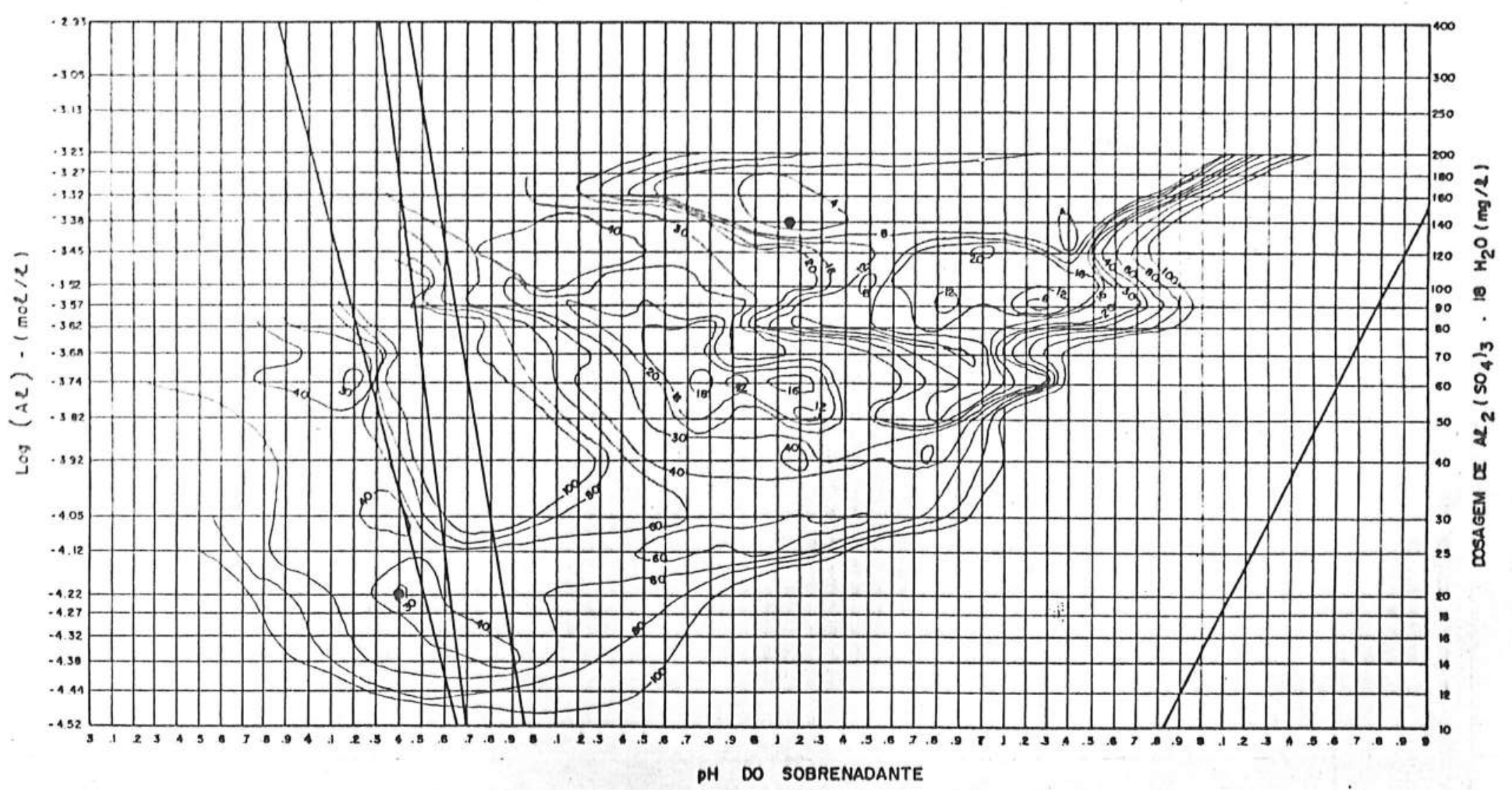

Figura 5.14 - Diagrama de coagulação para a Agua Tipo II - Percentagem da cor aparente remanescente em função da dosagem de sulfato de aluminio e do pH do sobrenadante.

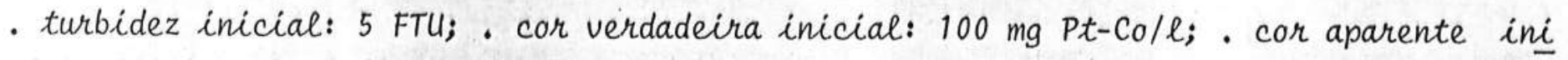
cial: $131,9 \mathrm{mg}$ Pt-Co/l. 


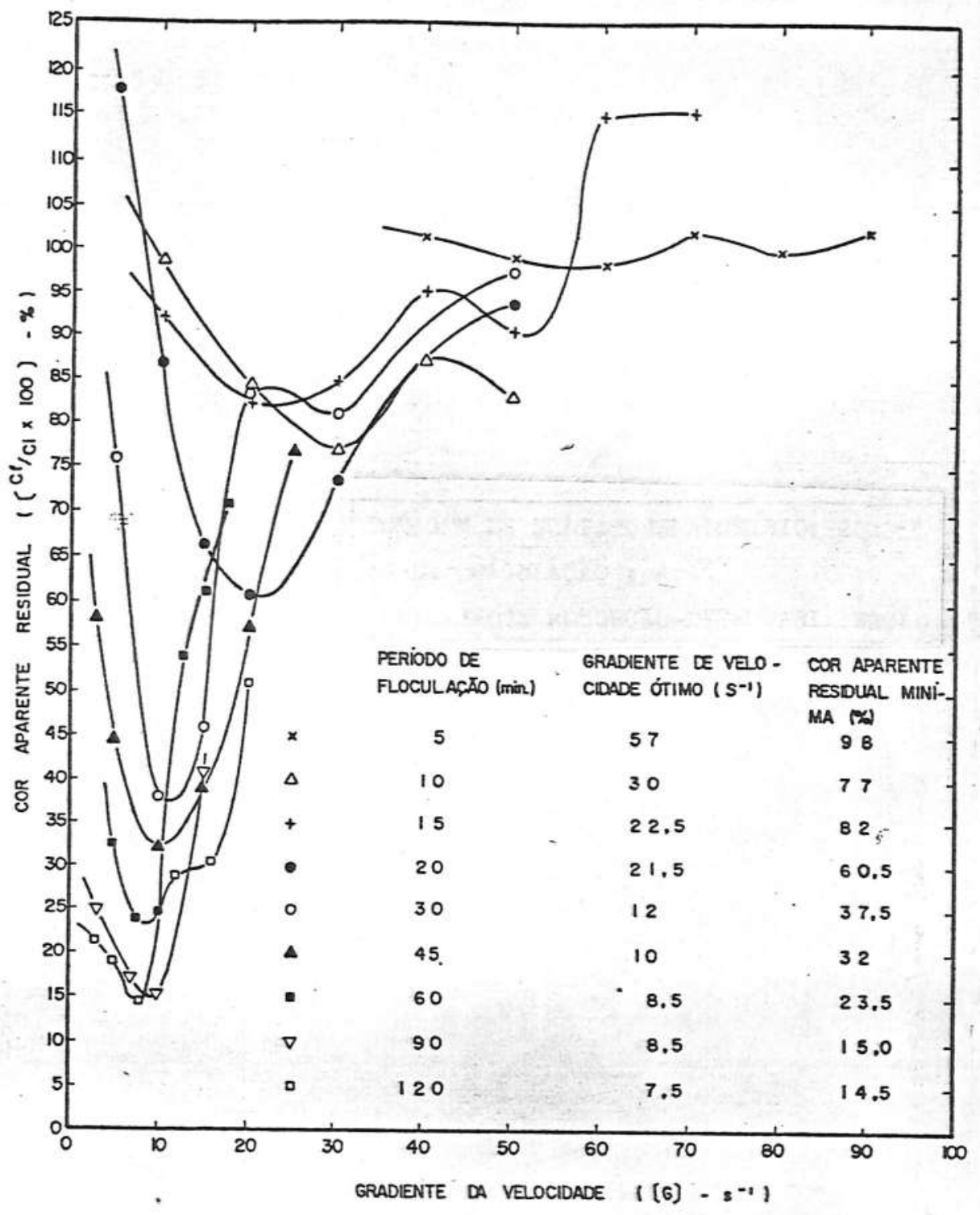

Figura 5.15 - Curvas de variação da cor aparente residual em função do gradiente de velocidade para värios períodos de flocula ção. Agua Tipo II. Mecanismo de adsorção-neutralização. - turbidez inicial: 5 FTU; . cor verdadeira inicial: 100 mg Pt-Coll; . cor aparente inicial: $131,9 \mathrm{mg}$ Pt-Coll;.do sagem de sulfato de aluminio: $20 \mathrm{mg} / \ell$;. $\mathrm{pH}$ do sobrenadan te: 4,4 ; . período de sedimentação: $10 \mathrm{~min}$. 


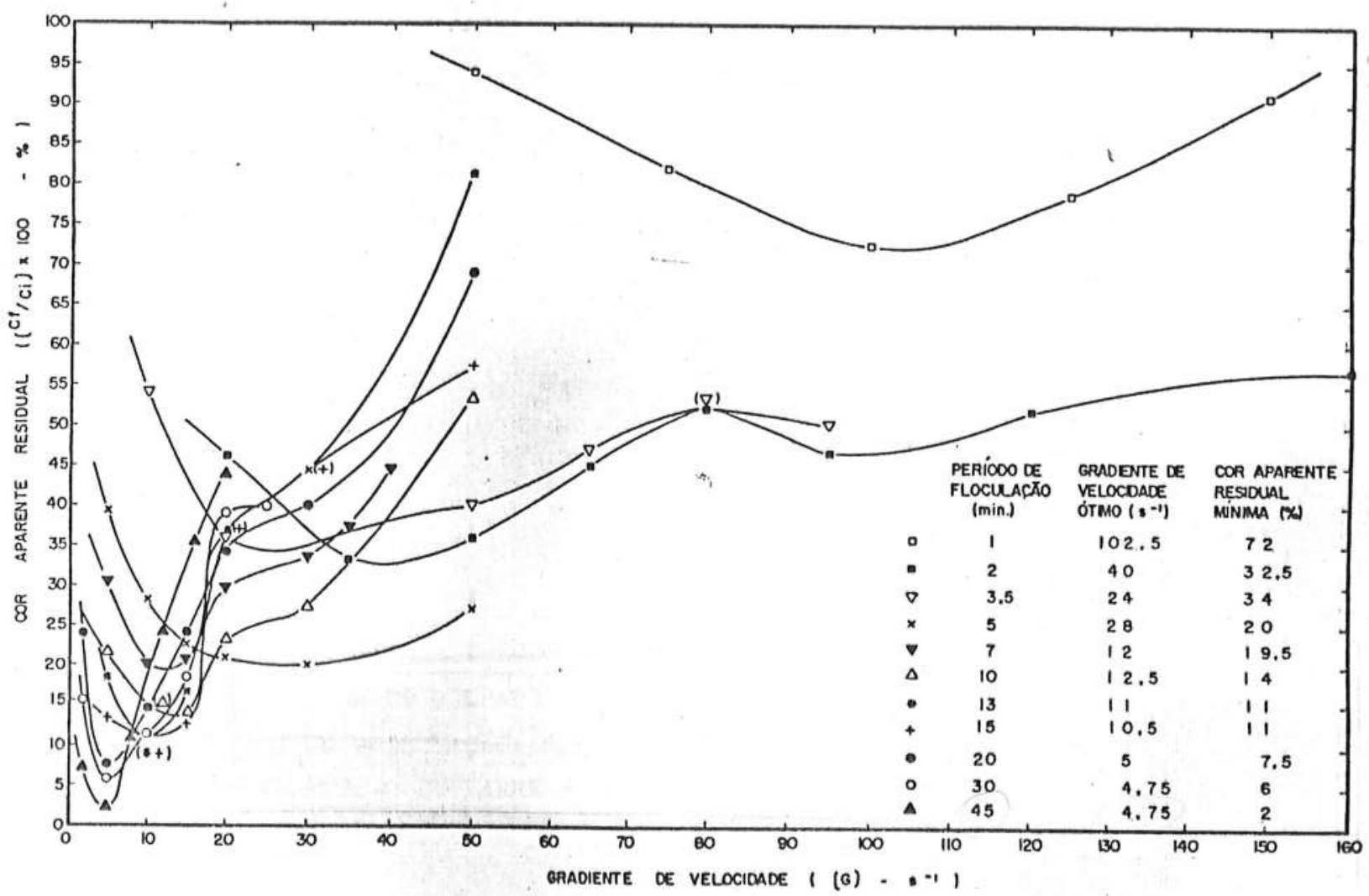

Figura 5.16 - Curvas de variação da cor aparente residual em função do gradiente de velocidade para vărios periodos de floculação. Agua Tipo II. Mecanismo de varredura.

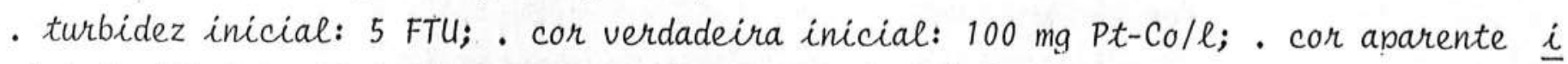
nicial: $131,9 \mathrm{mg}$ Pt-Co/l; . dosagem de sulfato de aluminio: $140 \mathrm{mg} / \ell$; . pH do sobrena dante: 6,15 ; período de sedimentação: $5 \mathrm{~min}$. 


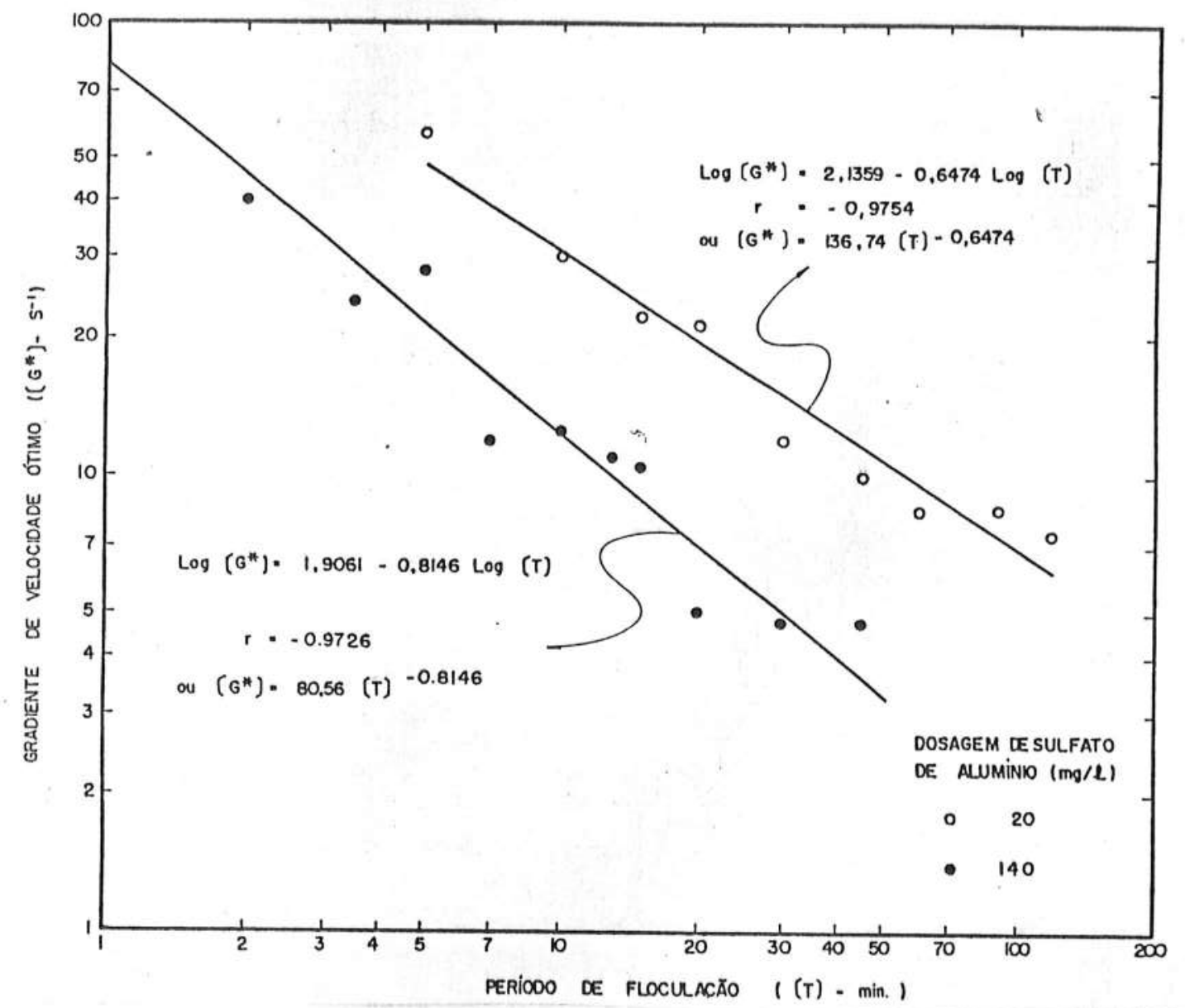

Figura 5.17 - Curvas de variação do gradiente de velocidade ótimo $\left(G^{*}\right)$ em função do periodo de flocula ção em papel bilogaritmico. Modelo de ANDREU-VILLEGAS \& LETTERMAN (04). Agua Tipo II.

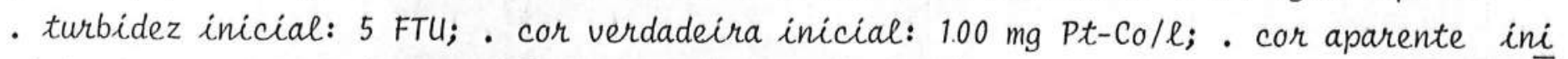
cial: $131,9 \mathrm{mg}$ Pt-Co/l; . período de sedimentação: $10 \mathrm{~min}$. (adsorção-neutralização) - 5 min. ( varredura); . dosagens de sulfato de aluminio e pH do sobrenadante: mecanismo de adsorção-neutralização: $20 \mathrm{mg} / \ell$ e 4,4 - mecanismo de varredura: $140 \mathrm{mg} / \ell$ e 6,15. 


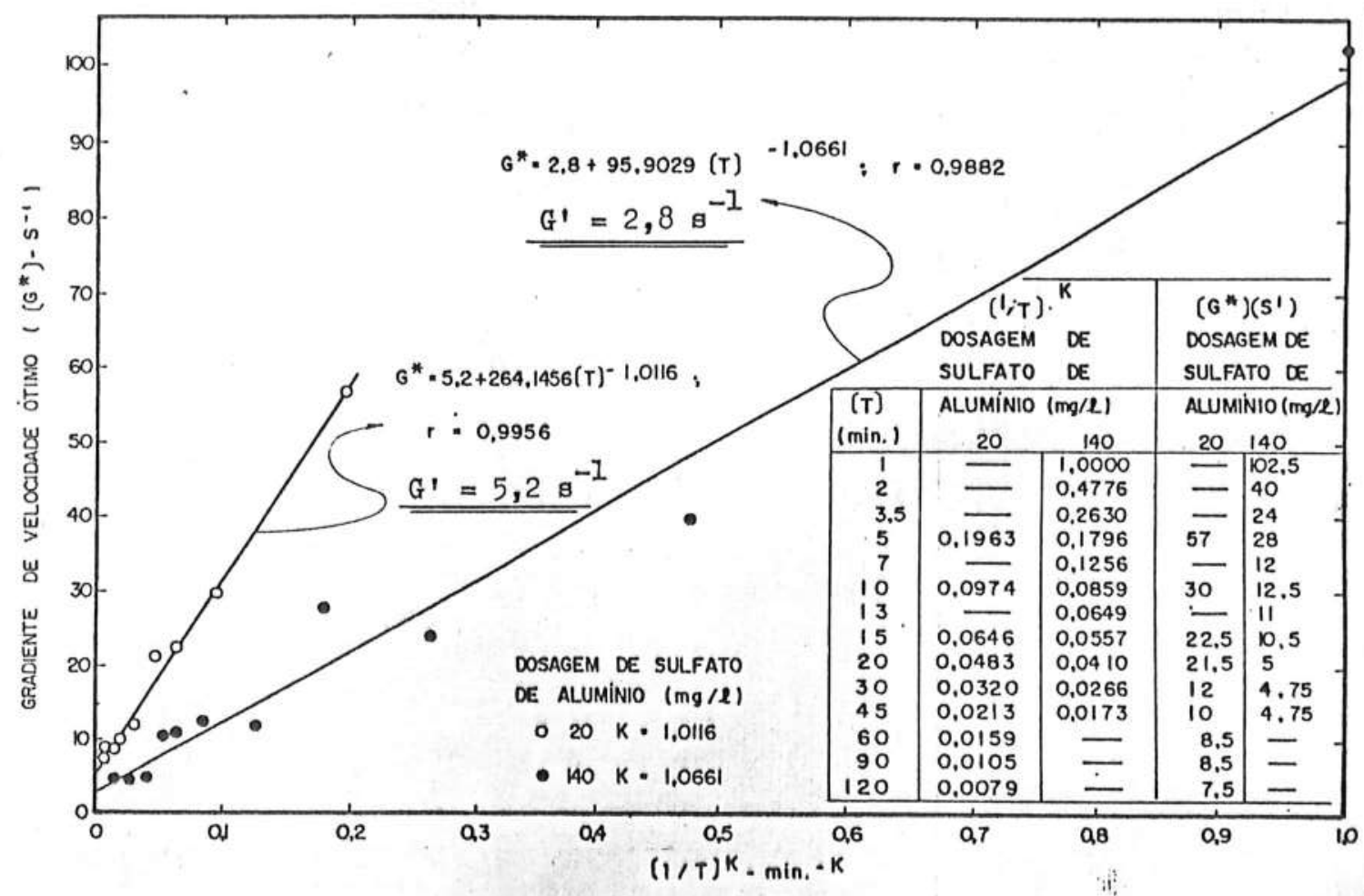

Figura 5.18 - Curvas de variação do gradiente de velocidade ötimo $\left(G^{*}\right) \mathrm{em}$ função de $(1 / T)^{n}$ para a Agua Tipo II, onde $T \vec{e}$ o periodo de floculação.

- turbidez inicial: $5 \mathrm{FTU}$; cor verdadeira inicial: $100 \mathrm{mg} P t-\mathrm{Co} / \ell$; cor aparente ini cial: $131,9 \mathrm{mg}$ Pt-Co/l ; perïodo de sedimentação: $10 \mathrm{~min}$. (adsorção-neutralização ) - $\overline{5}$ min. (varredura ); . dosagens de sulfato de aluminio e pH do sobrenadante: mecanismo de adsorção-neutralização: $20 \mathrm{mg} / \ell$ e 4,4 - mecanismo de varredura: $140 \mathrm{mg} / \ell$ e 6,15. 


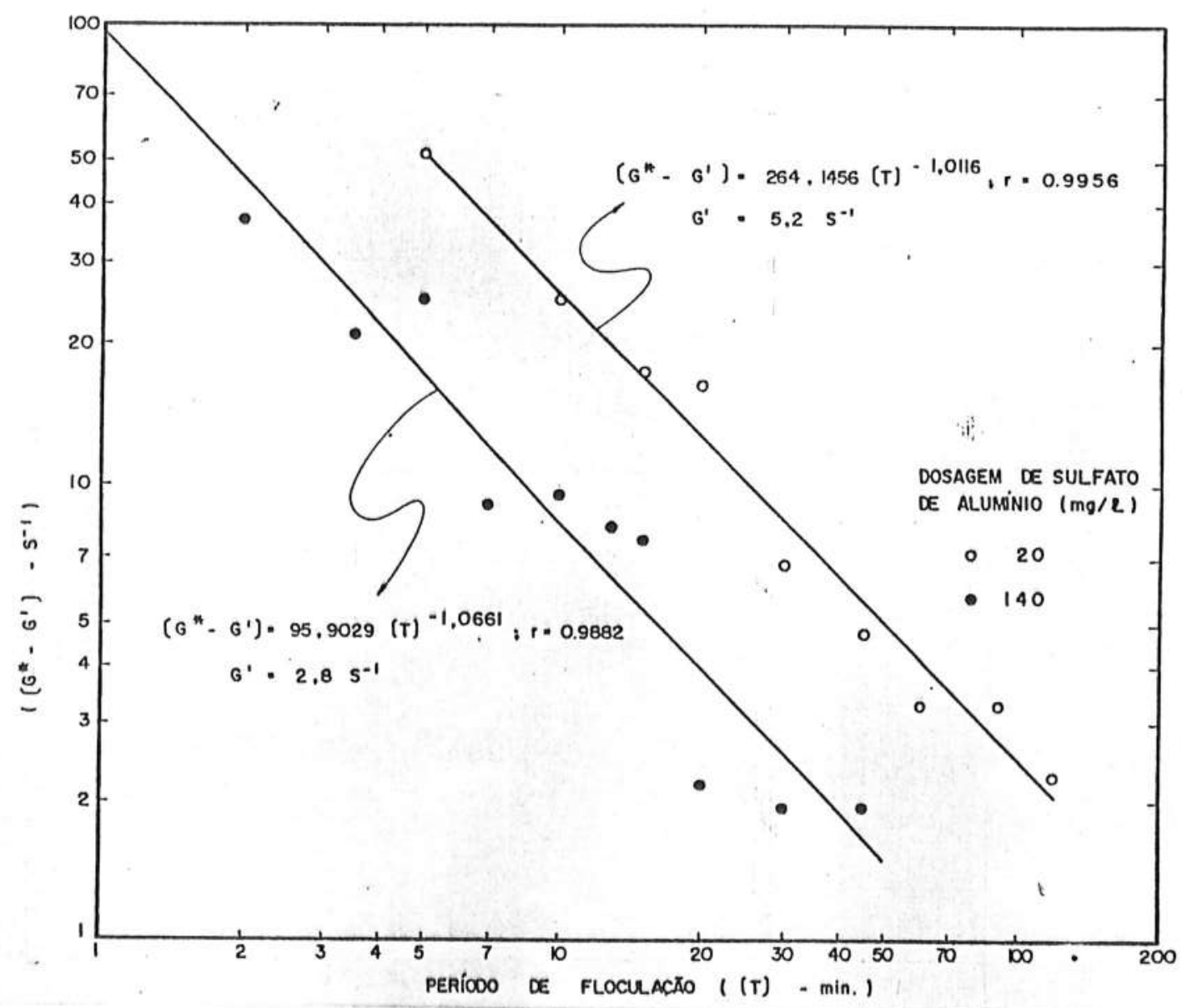

Figura 5.19 - Curvas de variação do gradiente de velocidade $\left(G^{*}-G^{\prime}\right)$ em função do período de flocula ção. Agua Típo II. Modelo proposto.

- turbidez inicial: 5 FTU; . cor verdadeira inicial: $100 \mathrm{mg}$ Pt-Co/l; . cor aparente ini cial: $131,9 \mathrm{mg}$ Pt-Co/l; . perïodo de sedimentação: $10 \mathrm{~min}$. ( adsorção-neutralização ) 5 min. ( varredura ); . dosagens de sulfato de aluminio e pH do sobrenadante: mecanismo de adsorção-neutralização: $20 \mathrm{mg} / \ell$ e 4,4 - mecanismo de varredura: $140 \mathrm{mg} / \ell$ e 6,15. 


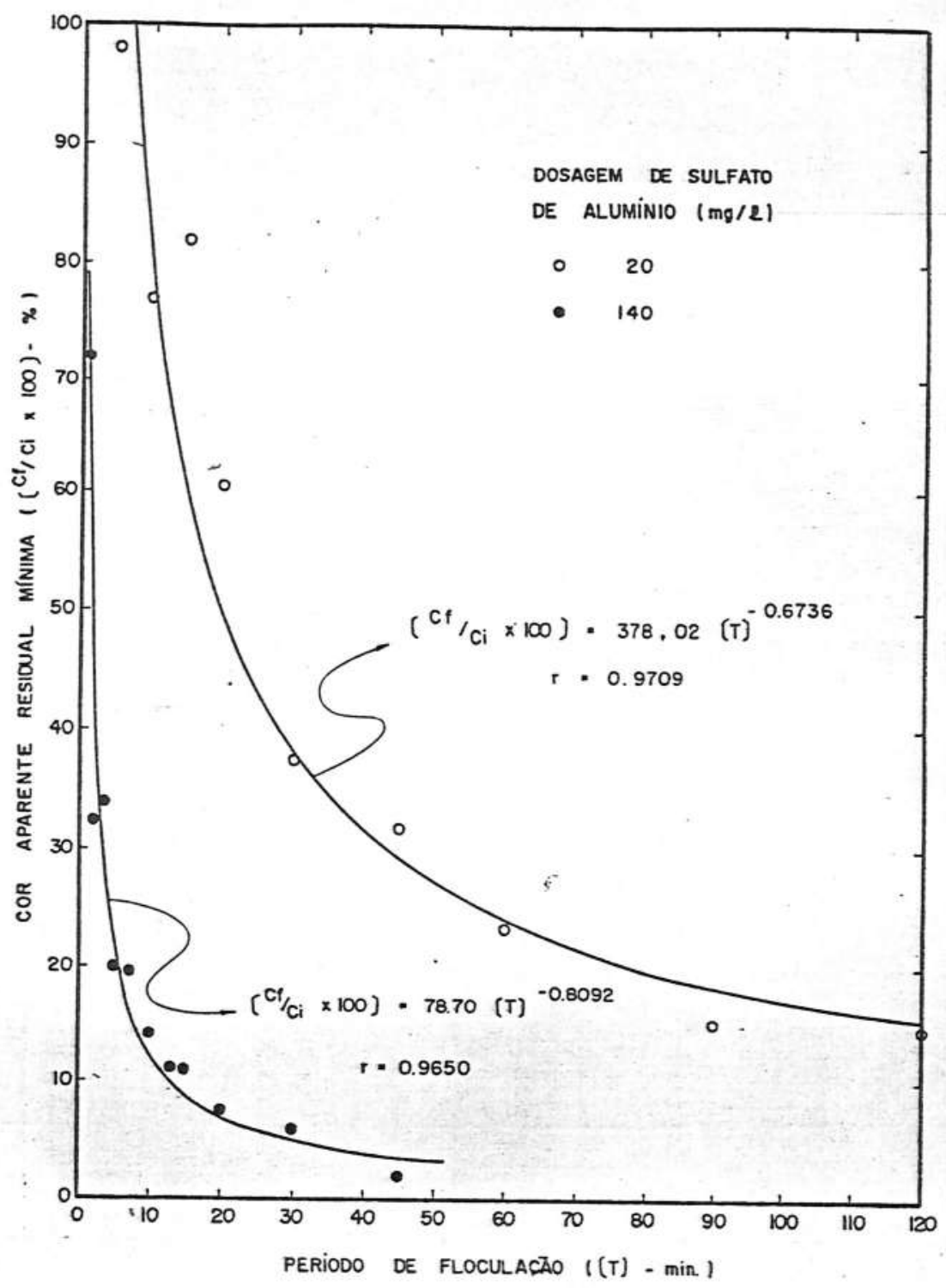

Figura 5.20 - Curvas de variação da cor aparente residual minima em fun ção do perĩodo de floculação. Agua Tipo II.

- turbidez inicial: 5 FTU; . cor verdadeira inicial: 100 mg Pt-Coll; . cor aparente inicial: $131,9 \mathrm{mg}$ Pt-Coll; pe rĩodo de sedimentação: $10 \mathrm{~min}$. (adsorção-neutralização)5 min. (varredura); . dosagens de sulfato de aluminio e pH do sobrenadante: mecanismo de adsorção-neutralização: $20 \mathrm{mg} / \ell$ e 4,4 - mecanismo de varredura: $140 \mathrm{mg} / \mathrm{l}$ e 6,15. 


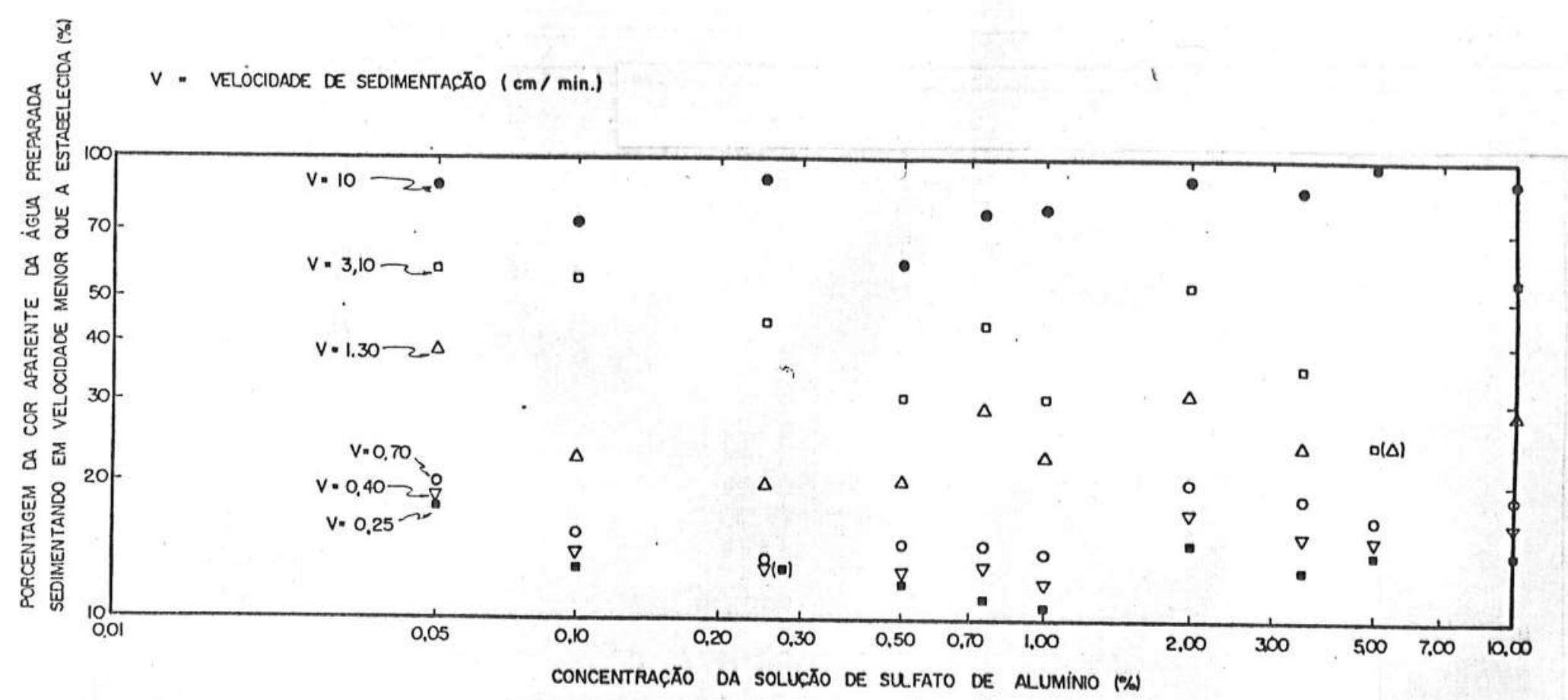

Figura 5.2.1 - Variação da percentagem da cor aparente inicial que sedimenta em velocidade menor que a estabelecida em função da concentração da solução de estoque de sulfato de aluminio. $\bar{A}$ gua Tipo II. Mecanismo de adsorção-neutralização.

- turbidez inicial: $5 \mathrm{FTU}$; . cor verdadeira inicial: $100 \mathrm{mg} \mathrm{Pt}-\mathrm{Co} / \ell$; . cor aparente ini cial: $131,9 \mathrm{mg}$ Pt-Co/l; . dosagem de sulfato de aluminio: $20 \mathrm{mg} / \ell$; . pH do sobrenadante : 4,4. 


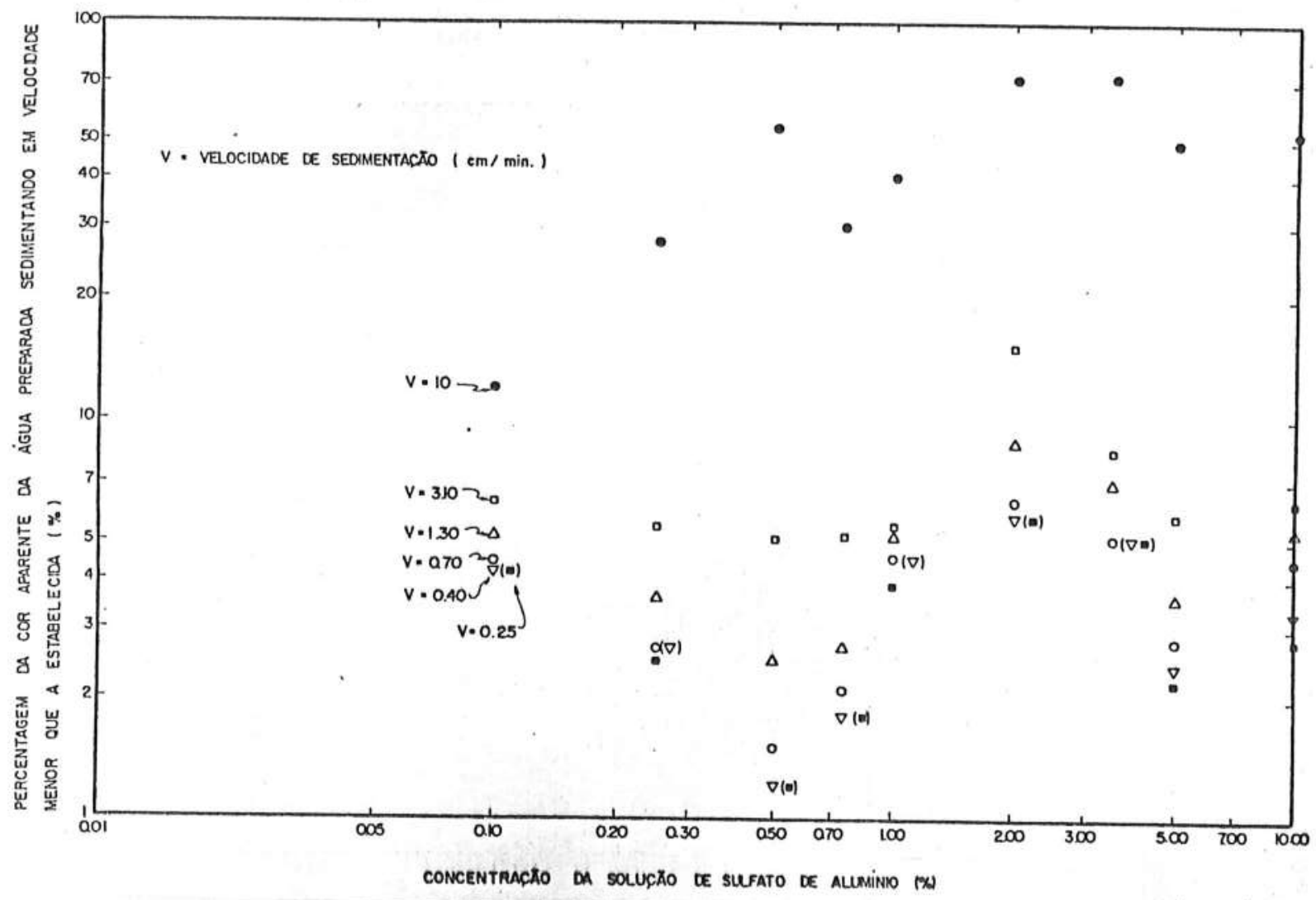

Figura 5.22 - Variação da percentagem da cor aparente inicial que sedimenta em velocidade menor que a estabelecida em função da concentração da soluçäo de estoque de sulfato de aluminio. $\bar{A}$ gua Tipo II. Mecanismo de varredura.

- turbidez inicial: $5 \mathrm{FTU}$; . cor verdadeira inicial: $100 \mathrm{mg} \mathrm{Pt}-\mathrm{Co} / \ell$; . cor aparente ini cial: 131,9 mg Pt-Co/l; . dosagem de sulfato de aluminio: $140 \mathrm{mg} / \mathrm{l}$; . pH do sobrenadante: 6,15 . 


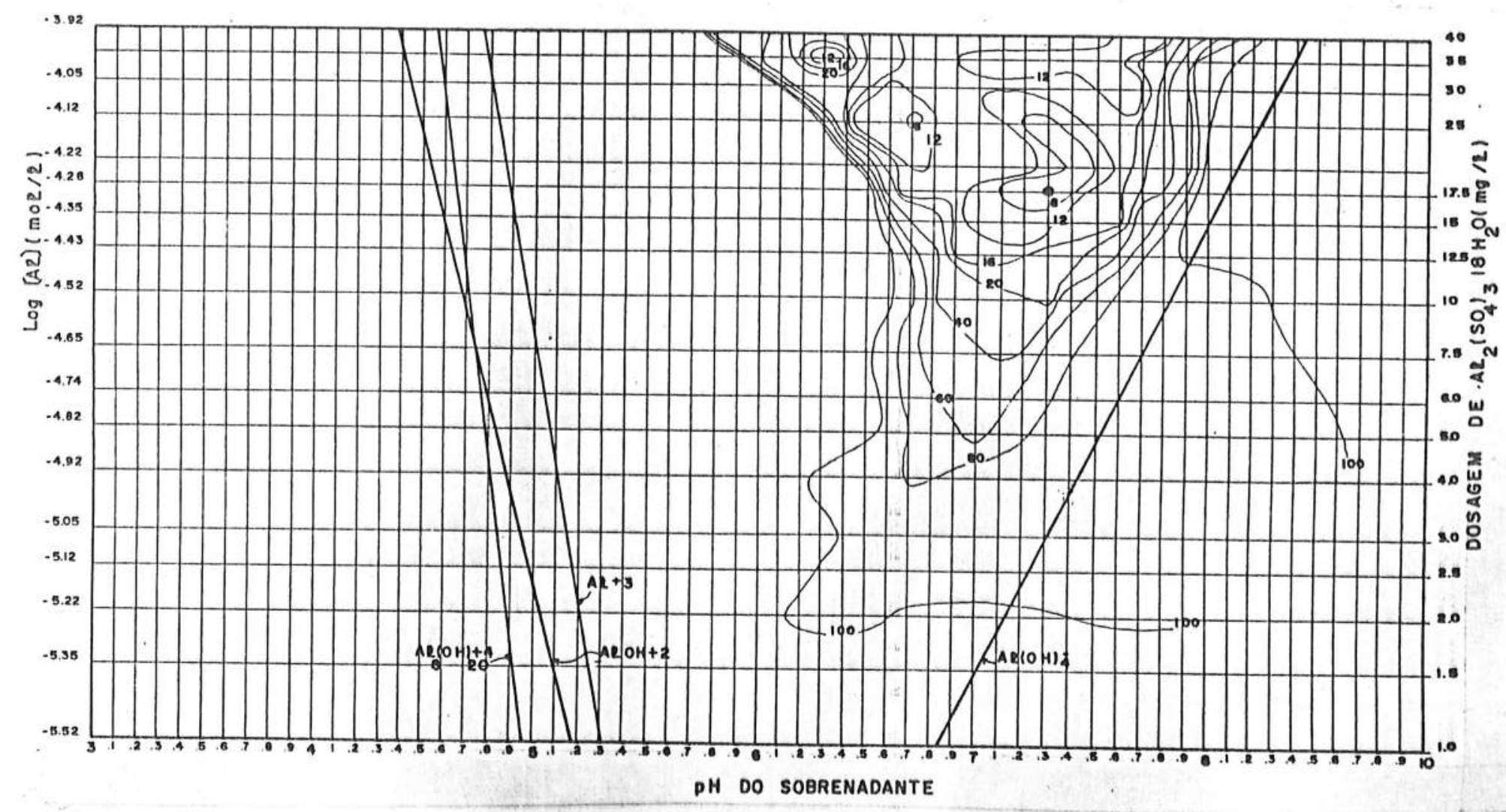

Figura 5.23 - Diagrama de coagulação para a Ägua Tipo III - Percentagem da çor aparente remanescente em função da dosagem de sulfato de aluminio e do $\mathrm{pH}$ do sobrenadante.

- turbidez inicial: 5 FTU; . cor verdadeira inicial: $5 \mathrm{mg}$ Pt-Co/l; . cor aparente inicial : $33,7 \mathrm{mg} \mathrm{Pt}-\mathrm{Co} / \ell$. 


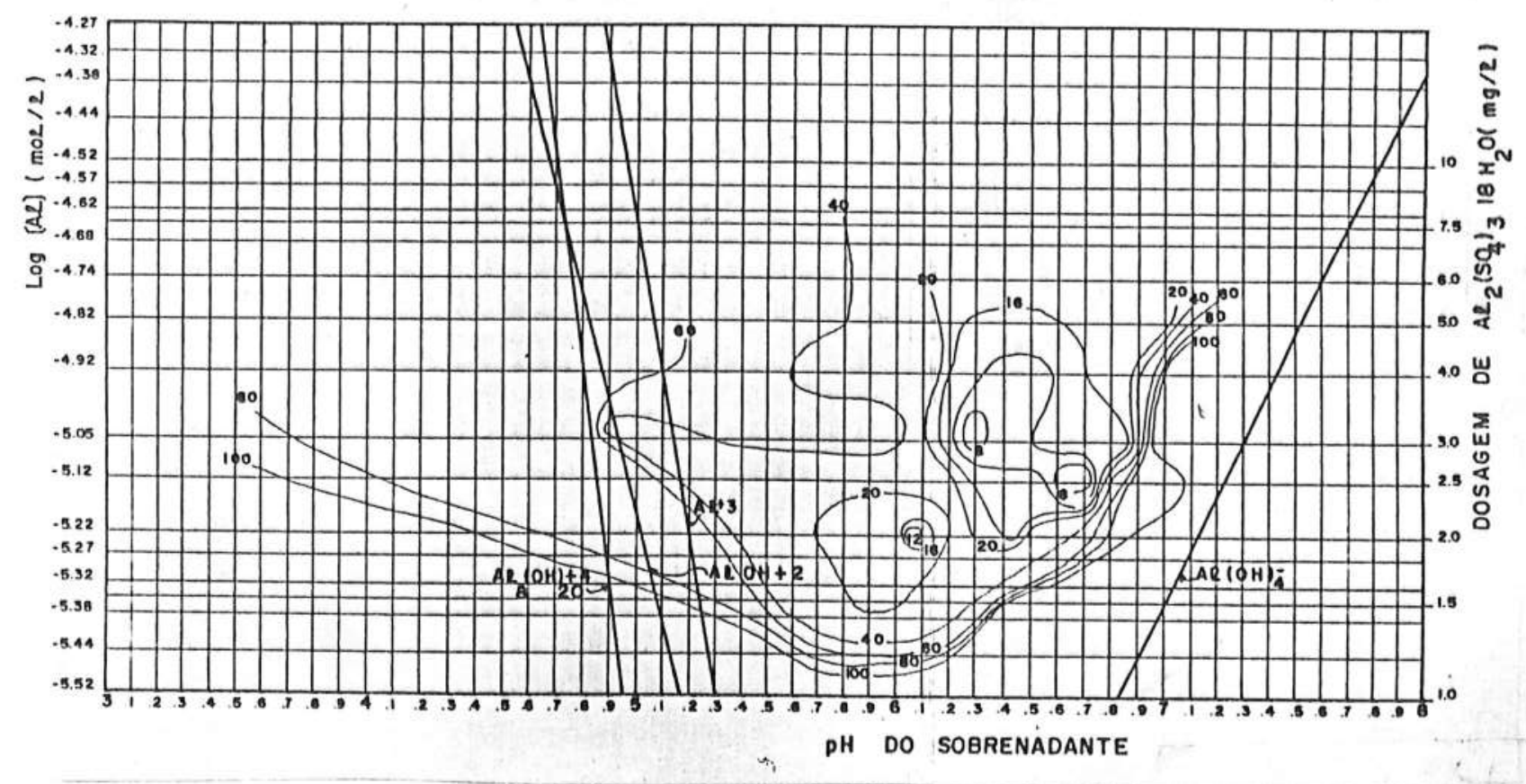

Figura 5.24 - Diagrama de coagulação para a Ägua Tipo III - Percentagem da cor aparente remanescente em função da dosagem de sulfato de aluminio e do $\mathrm{pH}$ do filtrado (filtração em papel WATMAN 40) - turbidez inicial: $5 \mathrm{FTU}$; cor verdadeira inicial: $5 \mathrm{mg}$ Pt-Co/l; . cor aparente inicial : $33,7 \mathrm{mg}$ Pt-Coll. 


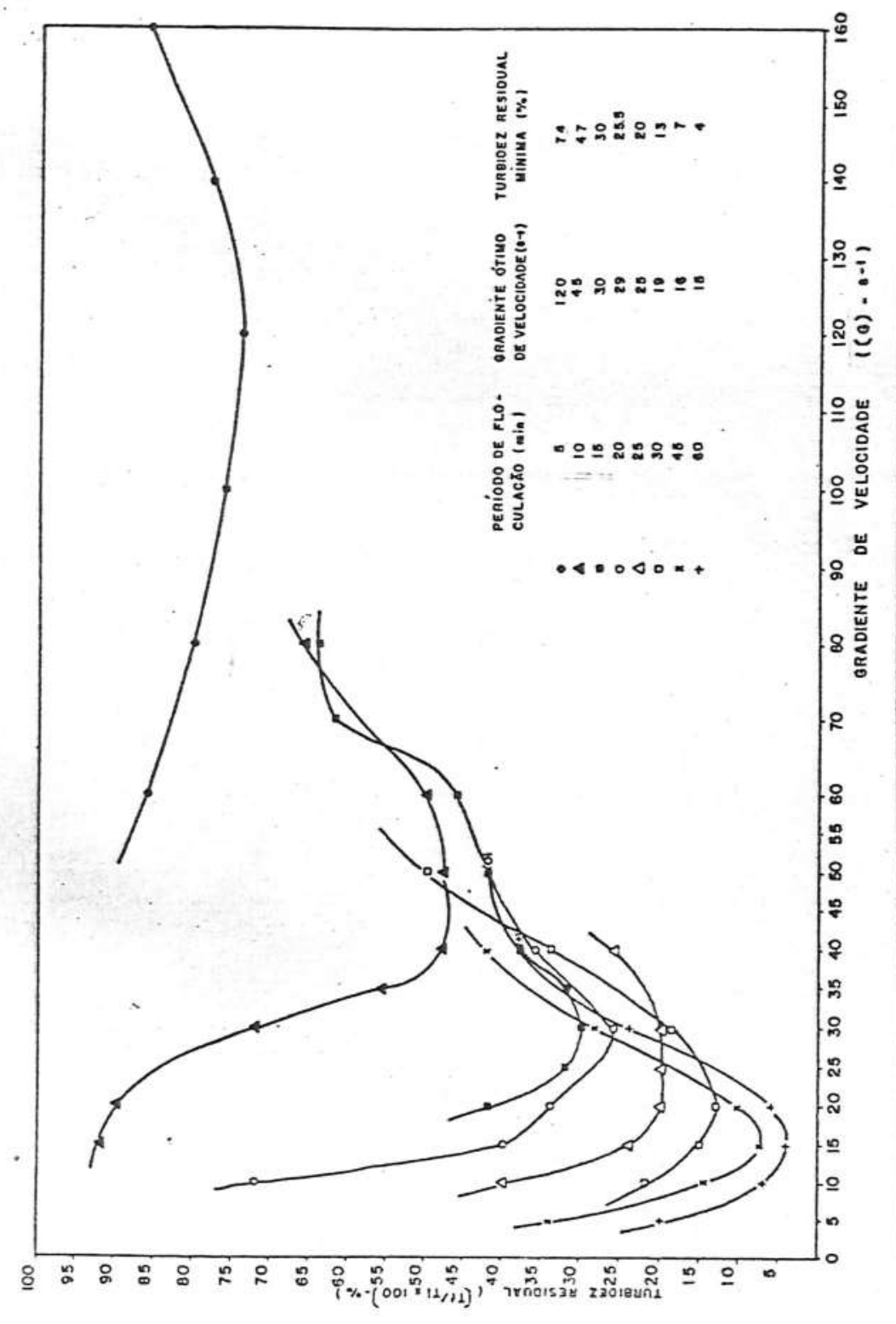

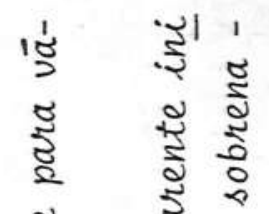

छี

ป 용

वे

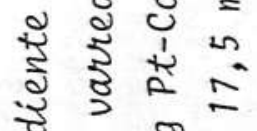

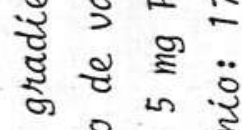

ช ․ำ

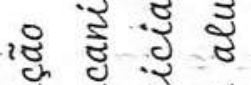

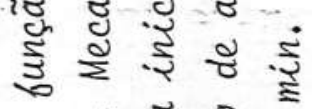

₹高

ఫ

ก它

: $\dot{0}$.

३

₹

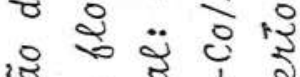

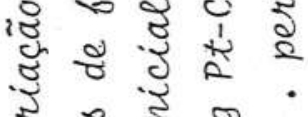

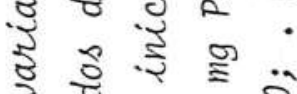

2 范

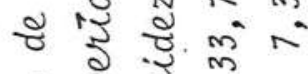

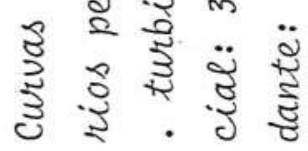

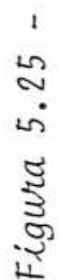




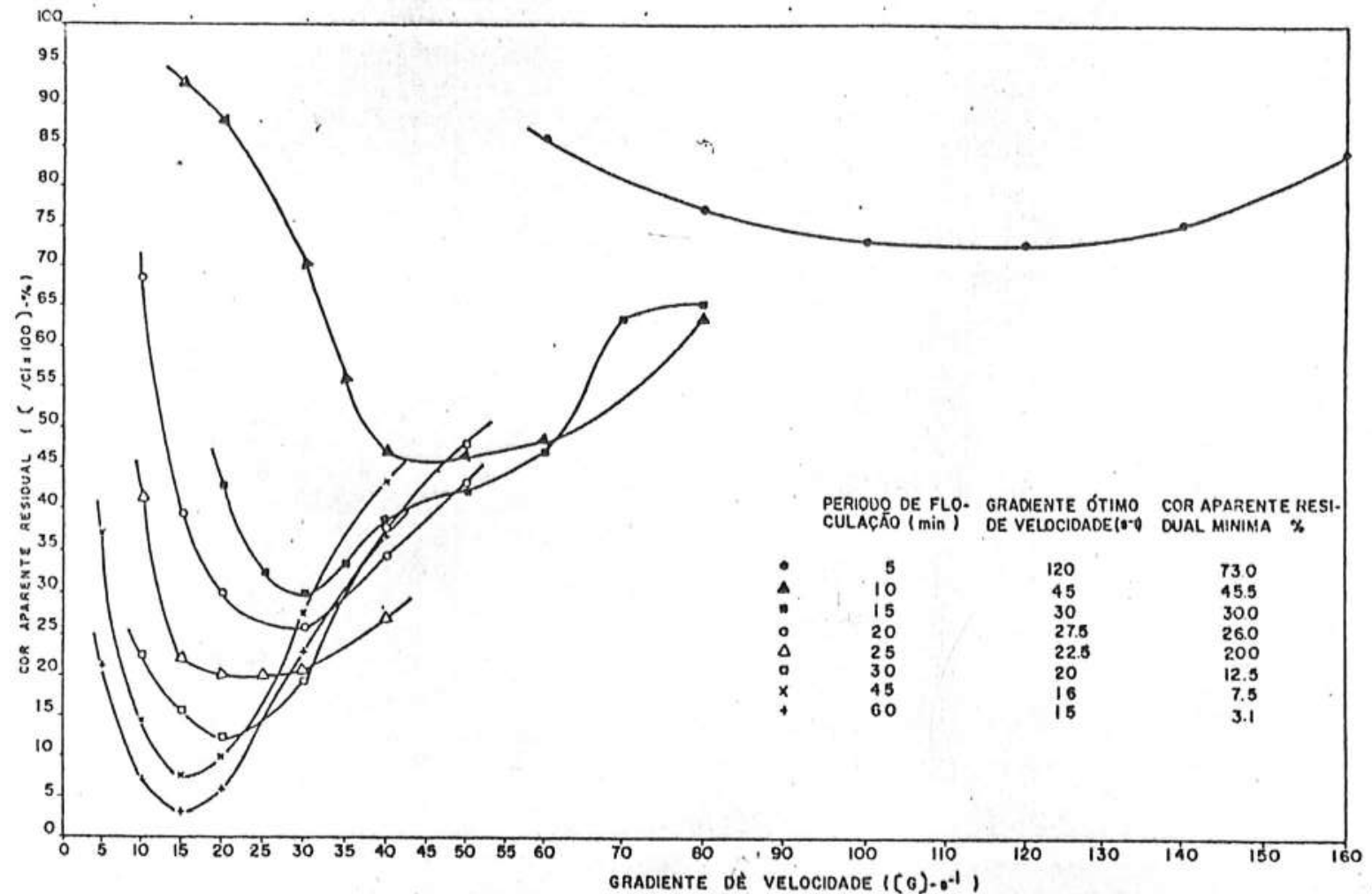

Figura 5.26 - Curvas de variação da cor aparente residual em função do gradiente de velociade para värios períodos de floculação. Agua Tipo III. Mecanismo de varredura.

- turbidez inicial: $5 \mathrm{FTU}$; . cor verdadeira inicial: $5 \mathrm{mg} \mathrm{Pt}-\mathrm{Co} / \ell$; cor aparente $\underline{i}$ nicial: $33,7 \mathrm{mg}$ Pt-Co/l; . dosagem de sulfato de aluminio: $17,5 \mathrm{mg} / \ell$; . pH do sobrenadante: 7,30 ; . perïodo de sedimentação: $10 \mathrm{~min}$. 


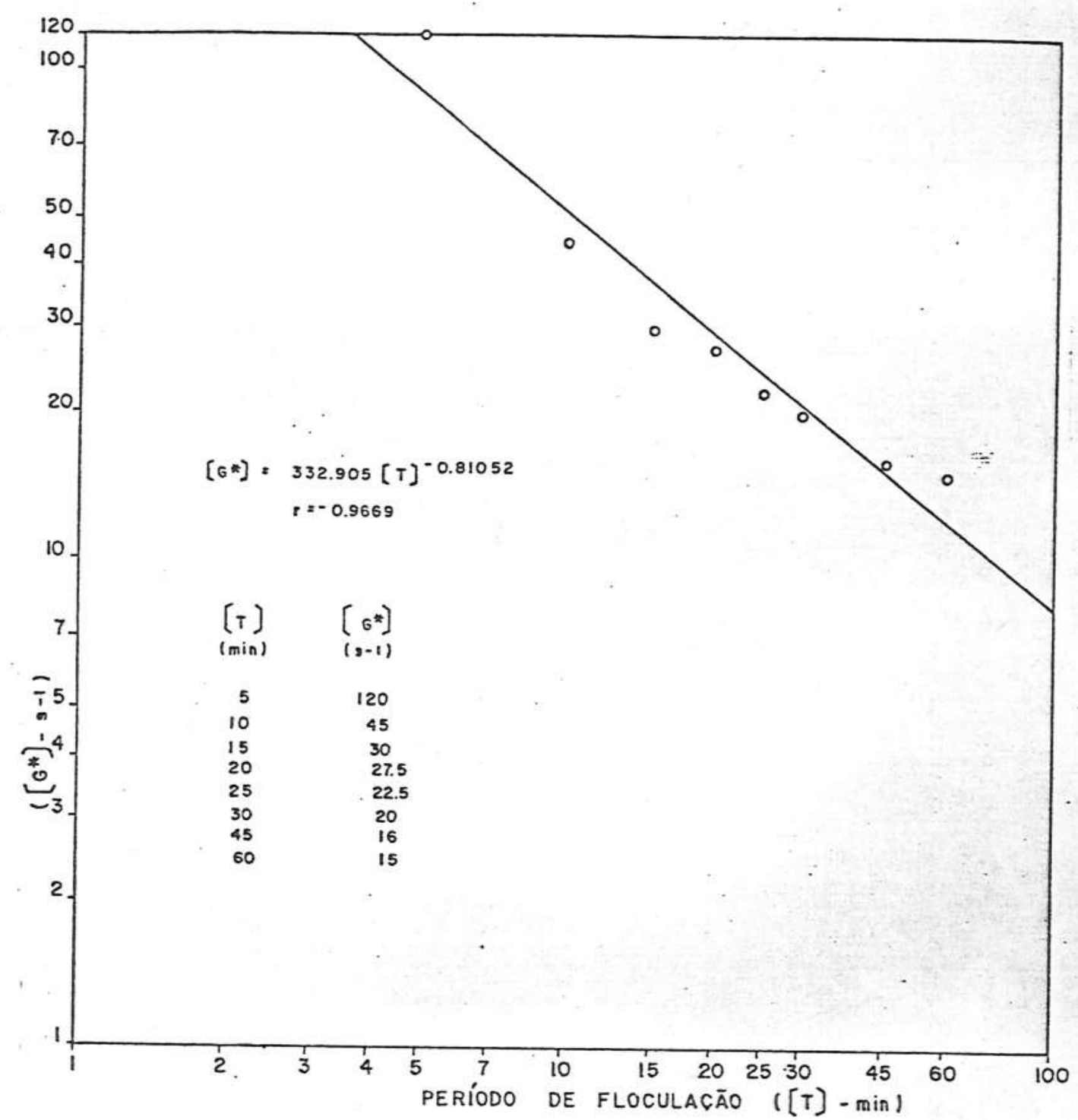

Figura 5.27 - Curva de variação do gradiente de velocidade ótimo $\left(G^{*}\right)$ em função do período de floculação em papel bilogaritmico. Modelo de ANDREU-VILLEGAS \& LETTERMAN (04). Agua Tí po III. Mecanismo de varredura.

- turbidez inicial: 5 FTU; . cor verdadeira inicial: 5 mg Pt-Coll; . cor aparente inicial: $33,7 \mathrm{mg} P t-C o / l$; . pe ríodo de sedimentação: $10 \mathrm{~min}$; . dosagem de sulfato de aluminio: $17,5 \mathrm{mg} / \mathrm{l}$; . pH do sobrenadante: 7,30 . 


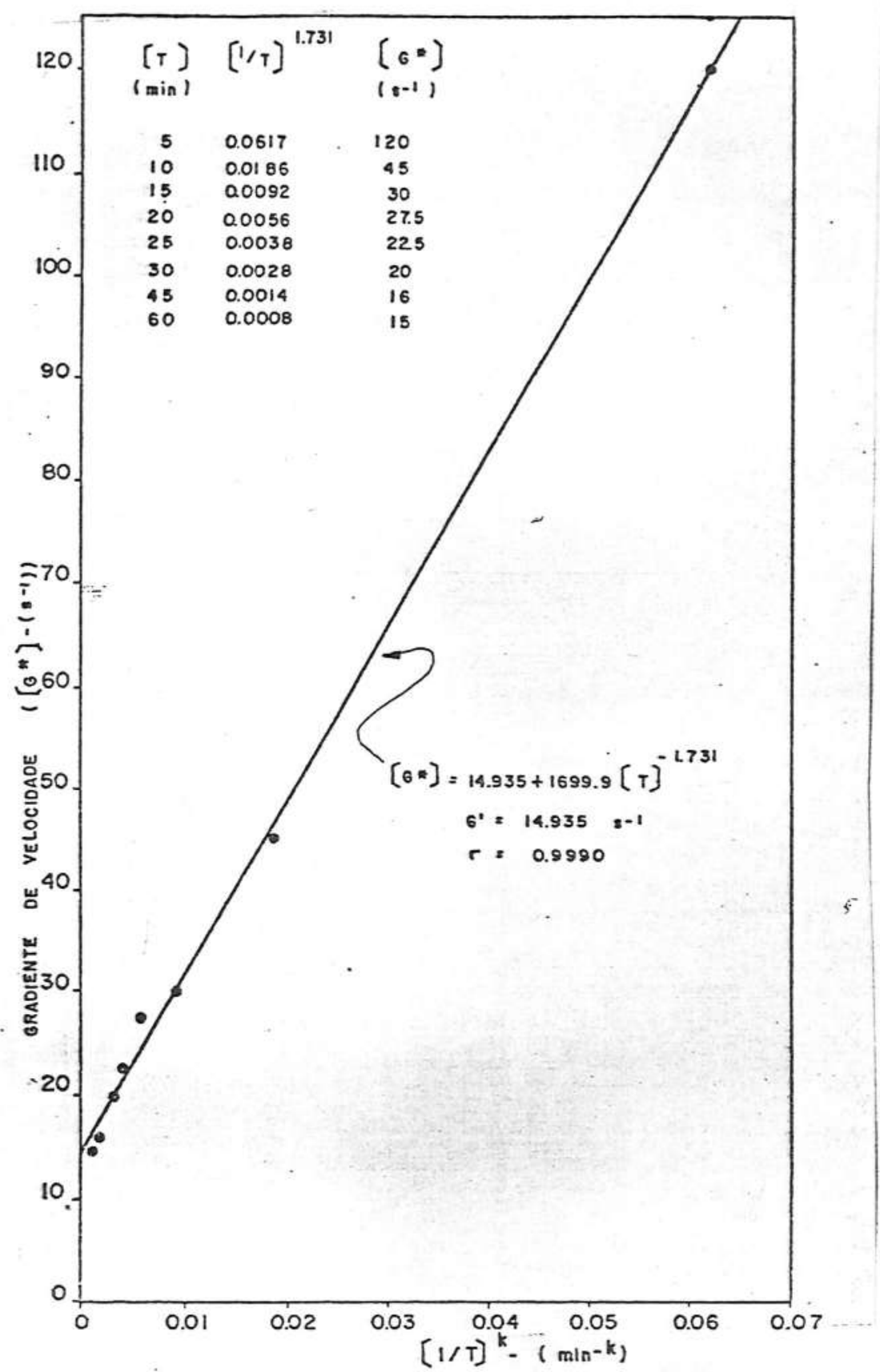

Figura 5.28 - Curva de variação do gradiente de velocidade ótimo (G*) em função de $(1 / T)^{n}$ para a Agua Tipo III, onde $T \bar{e} o$ pe rĩodo de floculação. Mecanismo de varredura.

- turbidez inicial: 5 FTU; . cor verdadeira inicial: 5 mg Pt-Coll; . cor aparente inicial: $33,7 \mathrm{mg} P t-C o / l$; .pe rĩodo de sedimentação: $10 \mathrm{min.;}$. dosagem de sulfato de aluminio: $17,5 \mathrm{mg} / \mathrm{l}$; . pH do sobrenadante: 7,30 . 


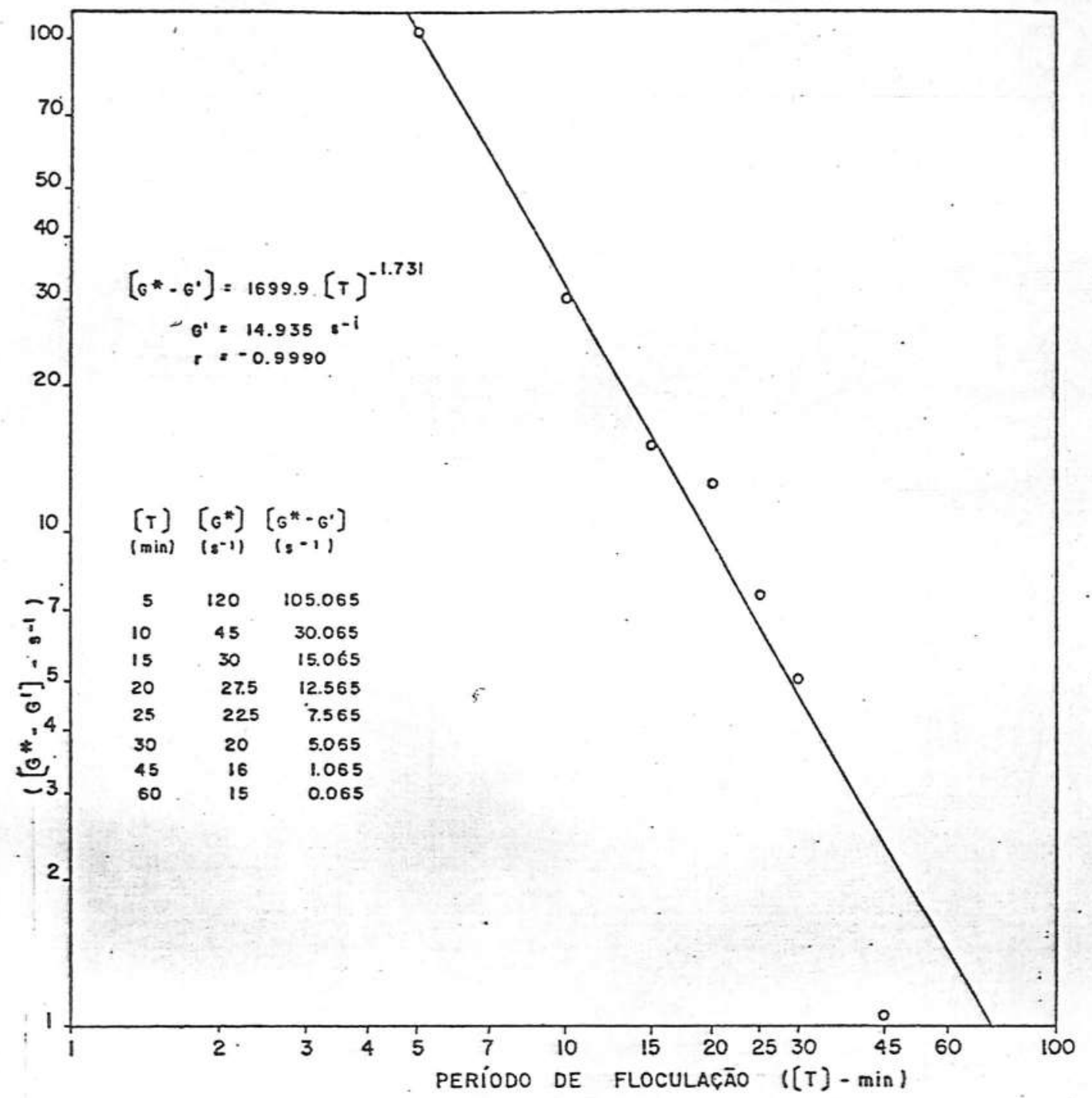

Figura 5.29 - Curva de variação do gradiente de velocidade $\left(G^{*}-G^{\prime}\right) \mathrm{em}$ função do período de floculação. Agua Tipo III. Modelo pro posto. Mecanismo de varredura.

- turbidez inicial: 5 FTU; . cor verdadeira inicial: $5 \mathrm{mg}$ Pt-Coll; . cor aparente inicial: $33,7 \mathrm{mg} P t-C o / l$; perīo do de sedimentaçāo: $10 \mathrm{~min}$; . dosagem de sulfato de alu minio: 17,5 mg/l; pH do sobrenadante: 7,30. 


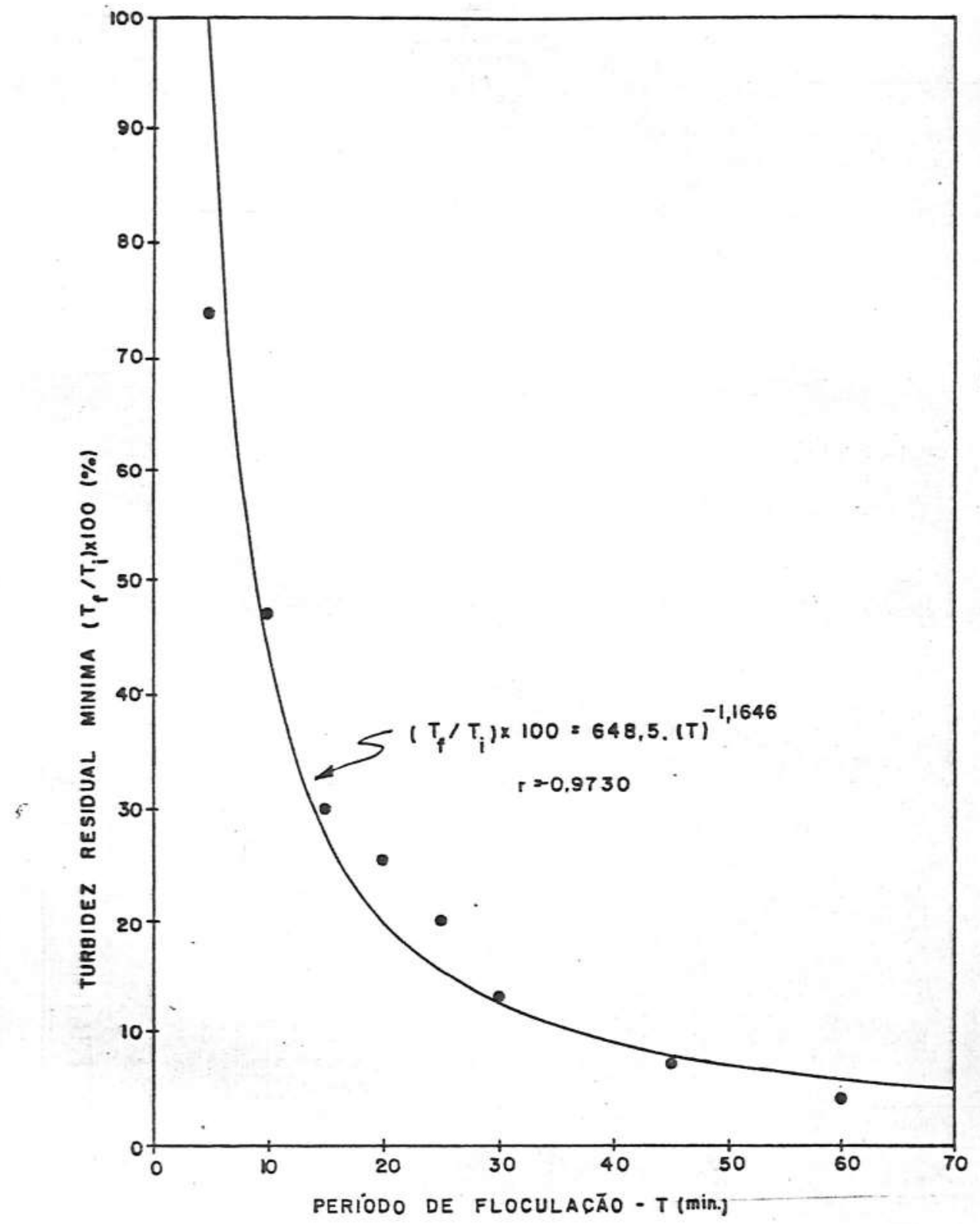

Figura 5.30 - Curva de variação da turbidez residual minima em função do período de floculação. Água Tipo III. Mecanismo de varredura.

- turbidez inicial: 5 FTU; . cor verdadeira inicial: 5 mg Pt-Coll; . cor aparente inicial: $33,7 \mathrm{mg}$ Pt-Co/l; . período de sedimentação: $10 \mathrm{~min}$.; . dosagem de sulfato de aluminio: $17,5 \mathrm{mg} / \mathrm{l}$; $\mathrm{pH}$ do sobrenadante: 7,30 . 


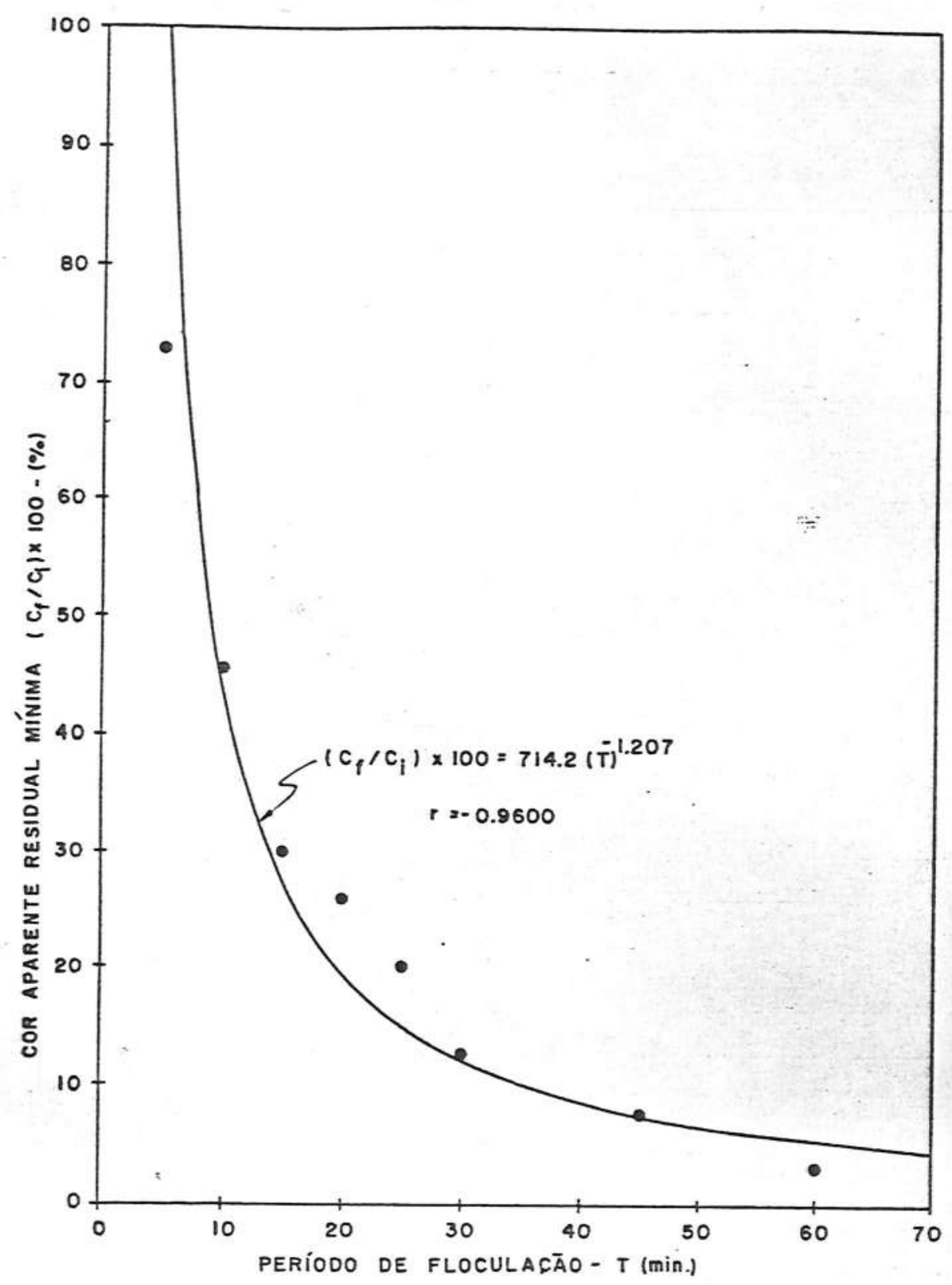

Figura 5.31 - Curva de variação da cor aparente residual minima em fun ção do período de floculação. Aggua Tipo III. Mecanismo de varredura.

- turbidez inicial: 5 FTU; . cor verdadeira inicial: 5 mg Pt-Coll; . cor aparente inicial: $33,7 \mathrm{mg}$ Pt-Co/l; . pe rĩodo de sedimentação: $10 \mathrm{~min}$; . dosagem de sulfato de aluminio: $17,5 \mathrm{mg} / \mathrm{l}$; $\mathrm{pH}$ do sobrenadante: 7,30 . 


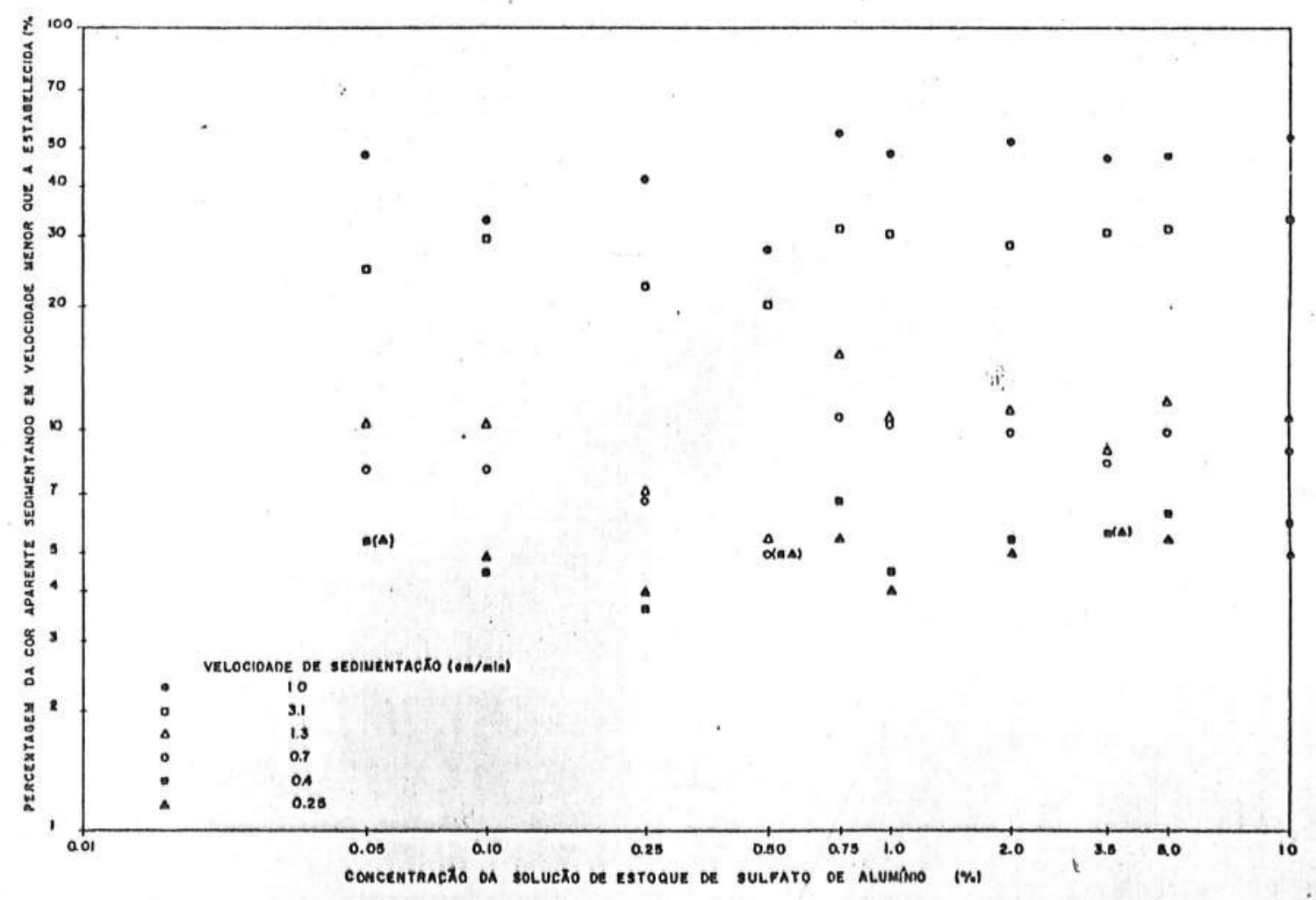

Figura 5.32 - Variação da percentagem da cor aparente inicial que sedimenta em velocidade menor que a estabelecida em função da concentração da solução de estoque de sulfato de aluminio. $\underline{A}$ gua Tipo III. Mecanismo de varredura.

- turbidez inicial: $5 \mathrm{FTU}$; cor verdadeira inicial: $5 \mathrm{mg} \mathrm{Pt}-\mathrm{Co} / \ell$; . cor aparente ini cial: $33,7 \mathrm{mg}$ Pt-Co/l; . dosagem de sulfato de aluminio: $17,5 \mathrm{mg} / \ell$; . pH do sobrenadante: 7,30 . 


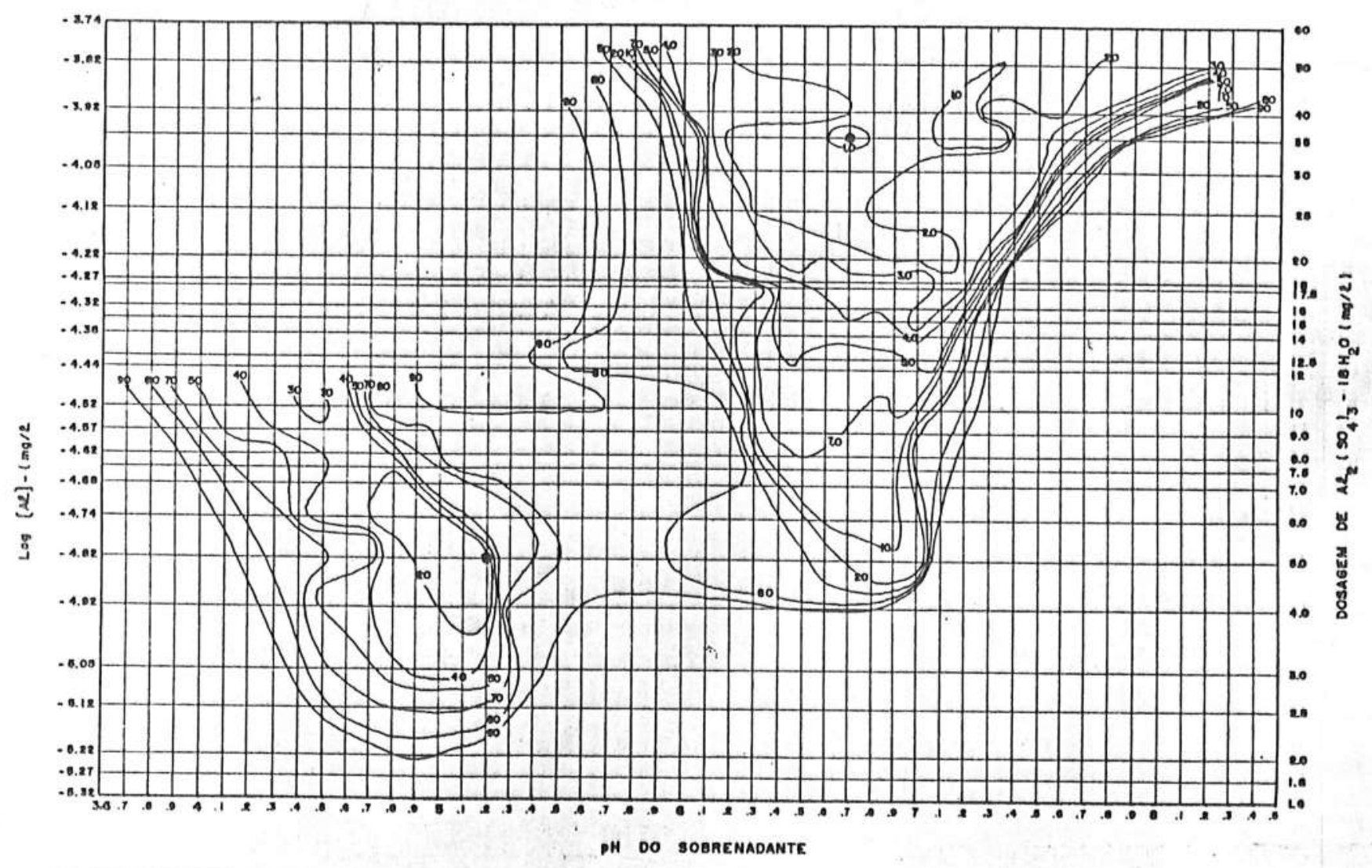

Figura 5.33 - Diagrama de coagulação da Água Tipo IV - Percentagem da cor aparente remanescente em função da dosagem de sulfato de aluminio e do $\mathrm{pH}$ do sobrenadante.

- turbidez inicial: $50 \mathrm{FTU}$; . cor verdadeira inicial: $20 \mathrm{mg} \mathrm{Pt}$-Co/ $\ell$; . cor aparente inicial: $340 \mathrm{mg}$ Pt-Coll. 


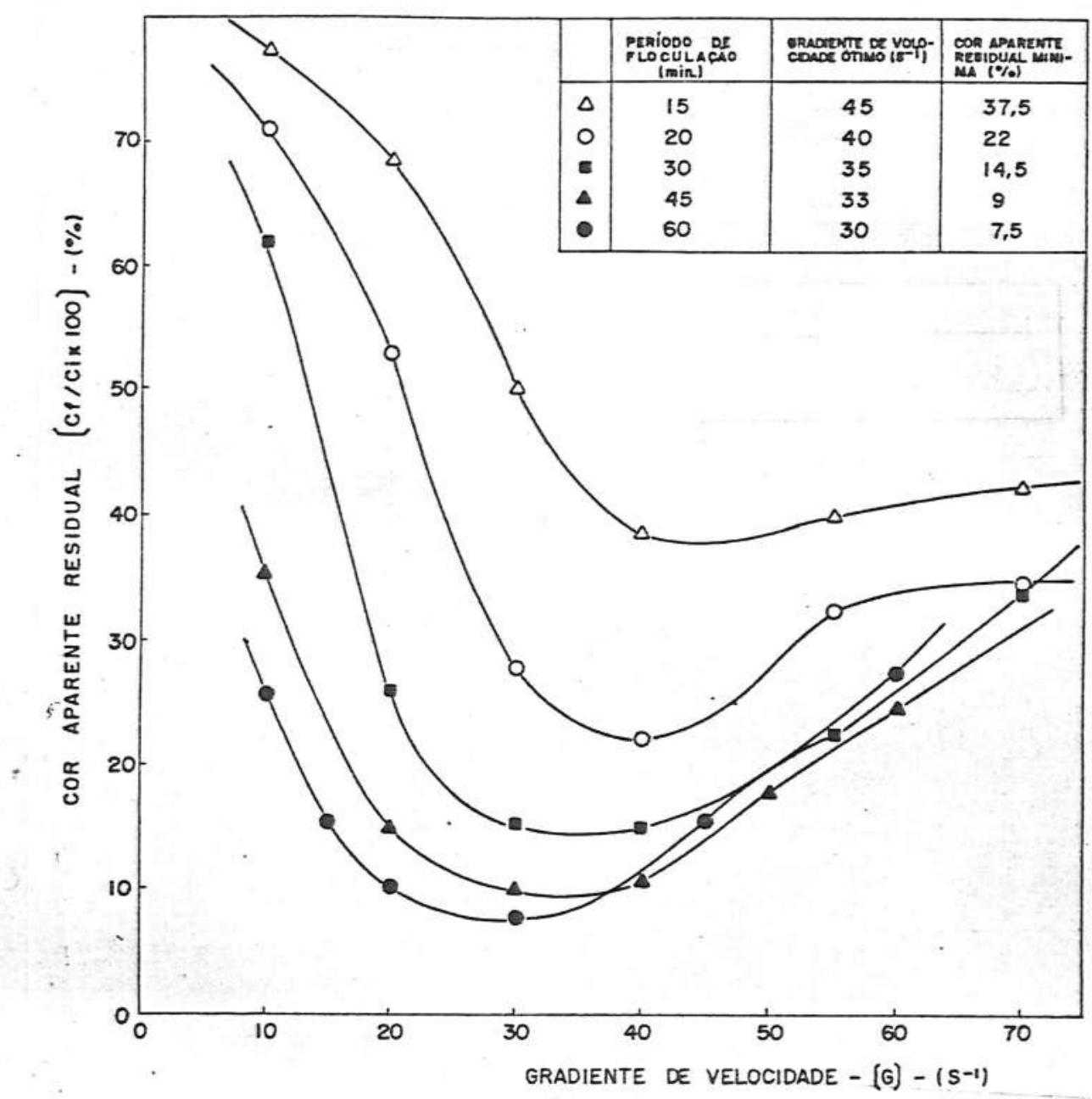

Figura 5.34 - Curvas de variação da cor aparente residual em função do gradiente de velocidade para vārios períodos de flo culação. Agua Tipo IV. Mecanismo de adsorção-neutrali zação.

- turbidez inicial: 50 FTU; . cor verdadeira inicial: $20 \mathrm{mg} P t-\mathrm{Co} / \mathrm{l}$; . cor aparente inicial: $340 \mathrm{mg} \mathrm{Pt}-\mathrm{Co} / \mathrm{l}$ - dosagem de sulfato de aluminio: $5 \mathrm{mg} / \ell$; $\mathrm{pH}$ do so brenadante: 5,20; . período de sedimentação: $10 \mathrm{~min}$. 


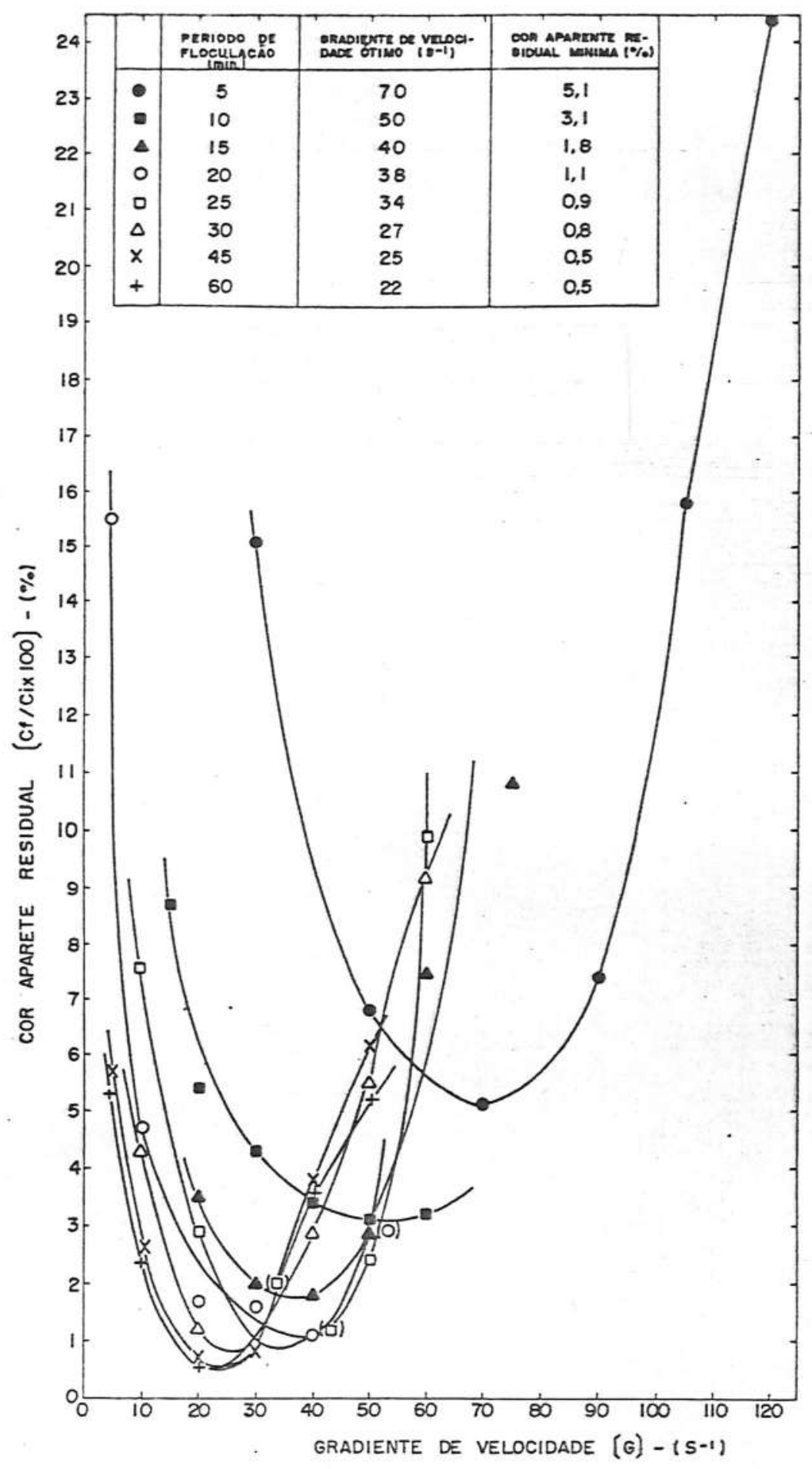

Figura 5.35 - Curvas de variação da cor aparente residual em função do gradiente de velocidade para värios períodos de flo culação. Agqua Tipo IV. Mecanismo de varredura.

- turbidez inicial: 50 FTU; . cor verdadeira inicial: $20 \mathrm{mg}$ Pt-Co/l; . cor aparente inicial: $340 \mathrm{mg} P t-\mathrm{Co} / \mathrm{l}$ - dosagem de sulfato de aluminio: $35 \mathrm{mg} / \ell ;$. pH do so brenadante: 6,70; . período de sedimentação: $10 \mathrm{~min}$. 


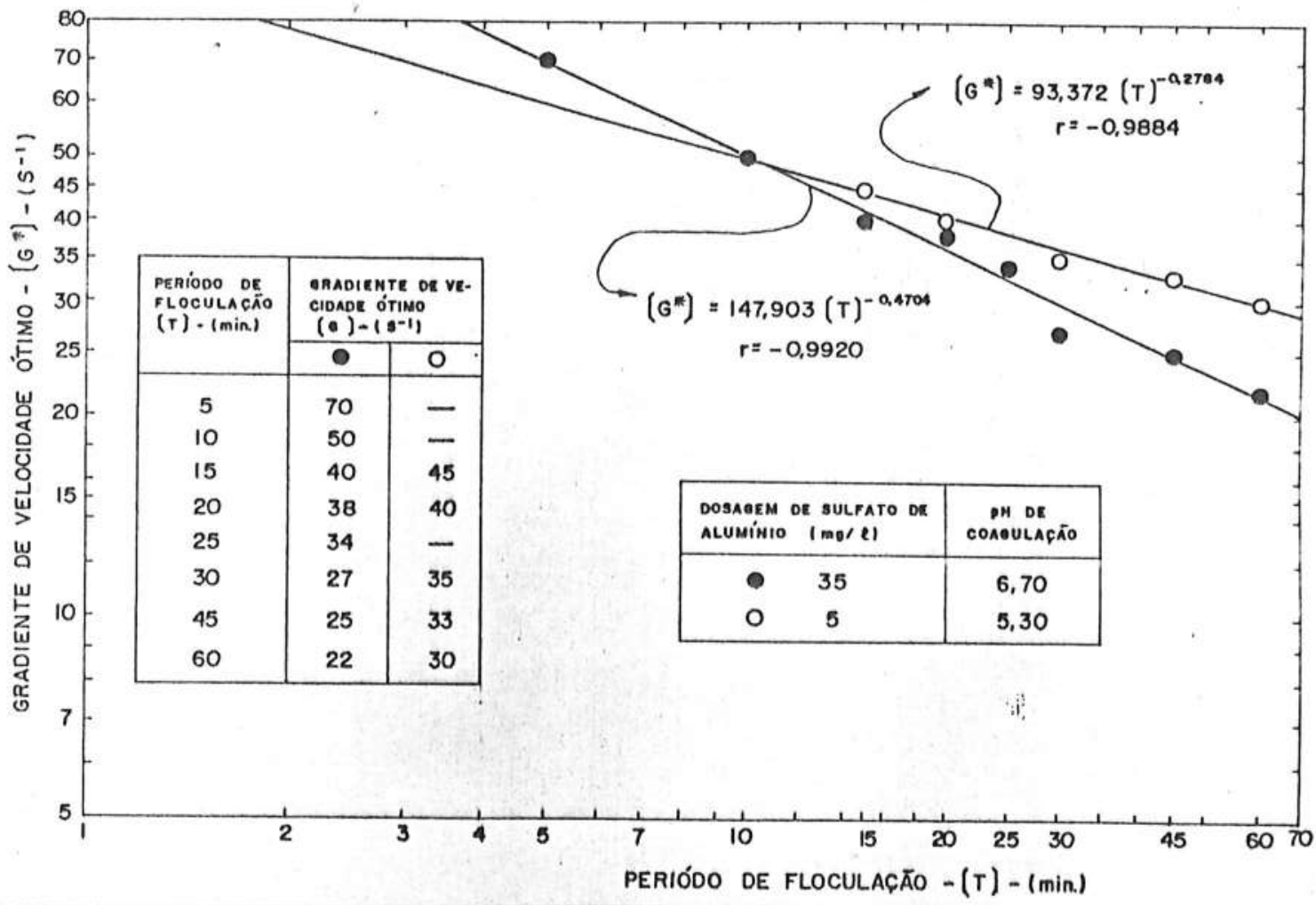

Figura 5.36 - Curvas de variação do gradiente de velocidade ötimo $\left(G^{*}\right)$ em função do perïodo de flocula ção em papel bilogaritmico. Modelo de ANDREU-VILLEGAS \& LETTERMAN (04). Agua Tipo IV. - turbidez inicial: $50 \mathrm{FTU}$; . cor verdadeira inicial: $20 \mathrm{mg} \mathrm{Pt}$-Coll; . cor aparente ini cial: $340 \mathrm{mg}$ Pt-Co/l; . perĩodo de sedimentação: $10 \mathrm{~min}$.; . dasagens de sulfato de alum $\overrightarrow{\underline{\imath}}$ nio e pH do sobrenadante: mecanismo de adsorção-neutralização: $5 \mathrm{mg} / \ell$ e 5,20 - mecanismo de varredura: $35 \mathrm{mg} / \mathrm{l}$ e 6,70 . 


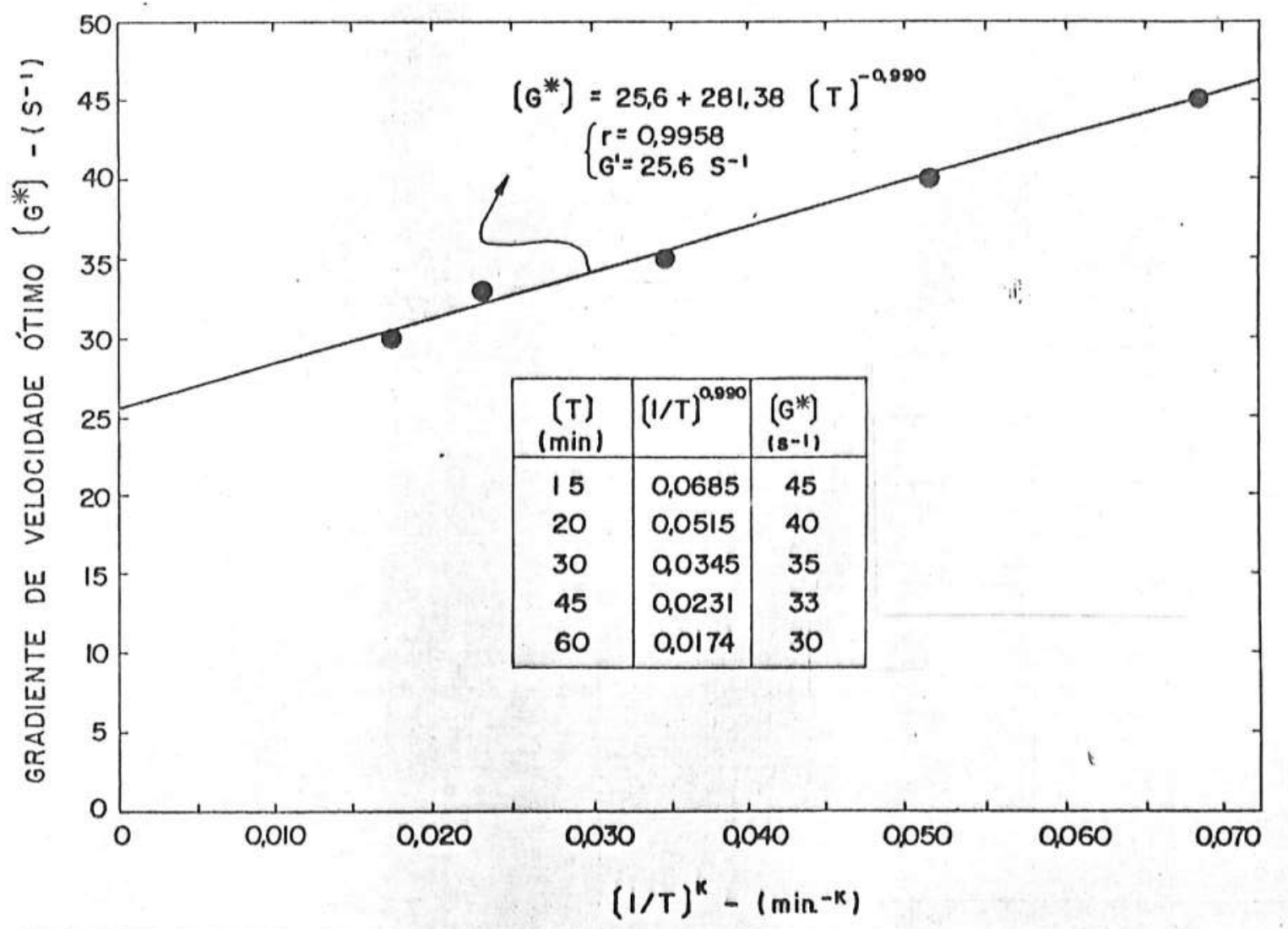

Figura 5.37 - Curva de variação do gradiente de velocidade ōtimo $\left(G^{*}\right)$ em função de $(1 / T)^{n}$ para a Agua Tipo IV, onde $T \bar{e}$ o periodo de bloculação. Mecanismo de adsorção-neutralização.

- turbidez inicial: $50 \mathrm{FTU}$; cor verdadeira inicial: $20 \mathrm{mg}$ Pt-Co/l; . cor aparente ini cial: $340 \mathrm{mg}$ Pt-Coll; . periodo de sedimentação: $10 \mathrm{~min}$; . dosagem de sulfato de alumí nio: $5 \mathrm{mg} / \ell$; $\mathrm{pH}$ do sobrenadante: 5,20 . 


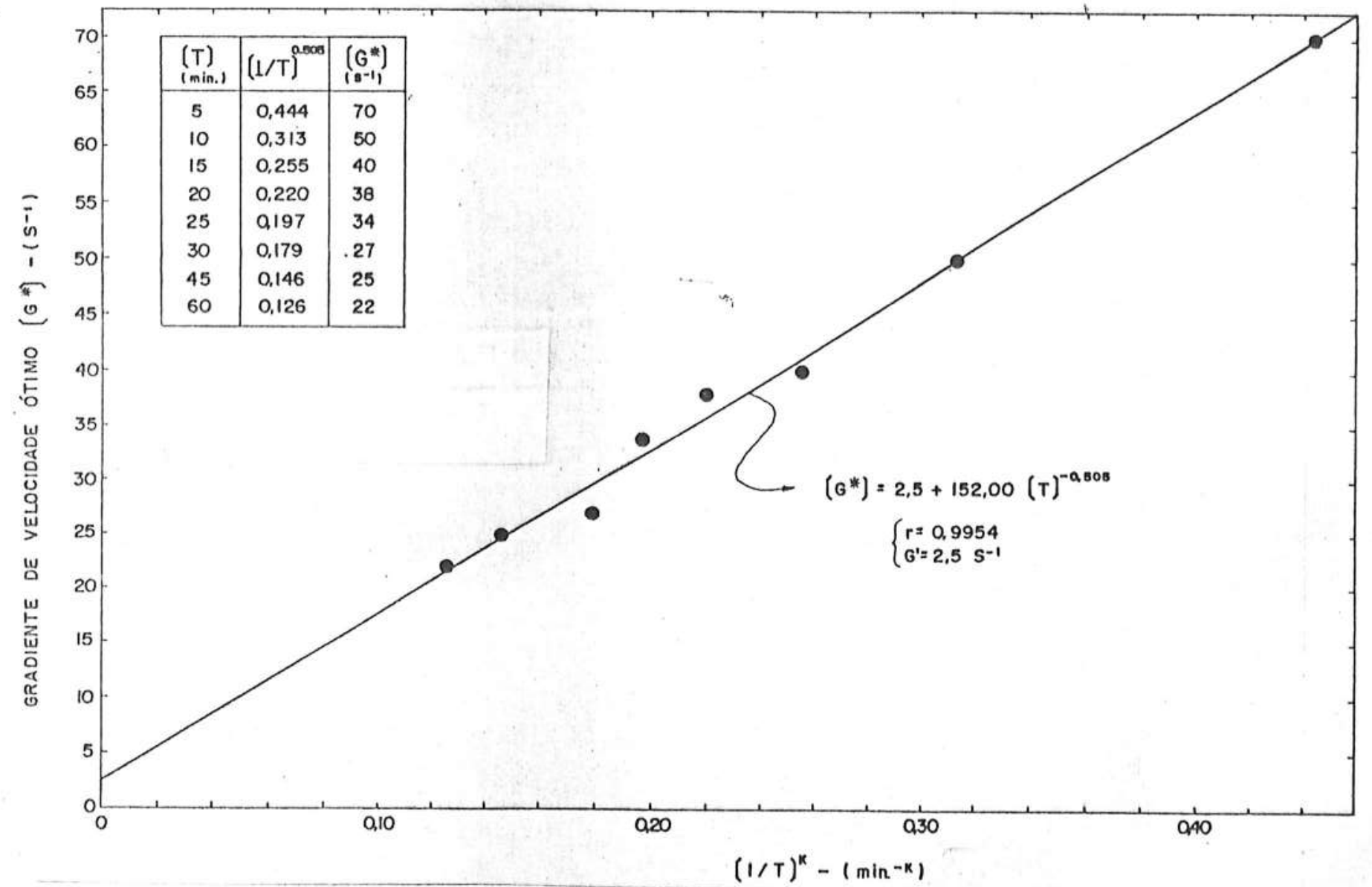

Figura 5.38 - Curva de variação do gradiente de velocidade ötimo $\left(G^{*}\right)$ em função de $(1 / T)^{n}$ para a Agua Tipo IV, onde $T \bar{e}$ o perïodo de floculação. Mecanismo de varredura.

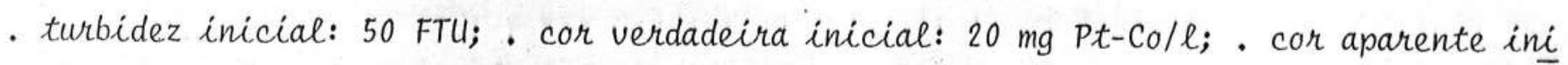

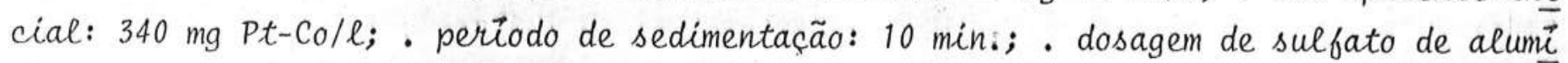
nio: $35 \mathrm{mg} / \ell$;. $\mathrm{pH}$ do sobrenadante: 6,70 . 


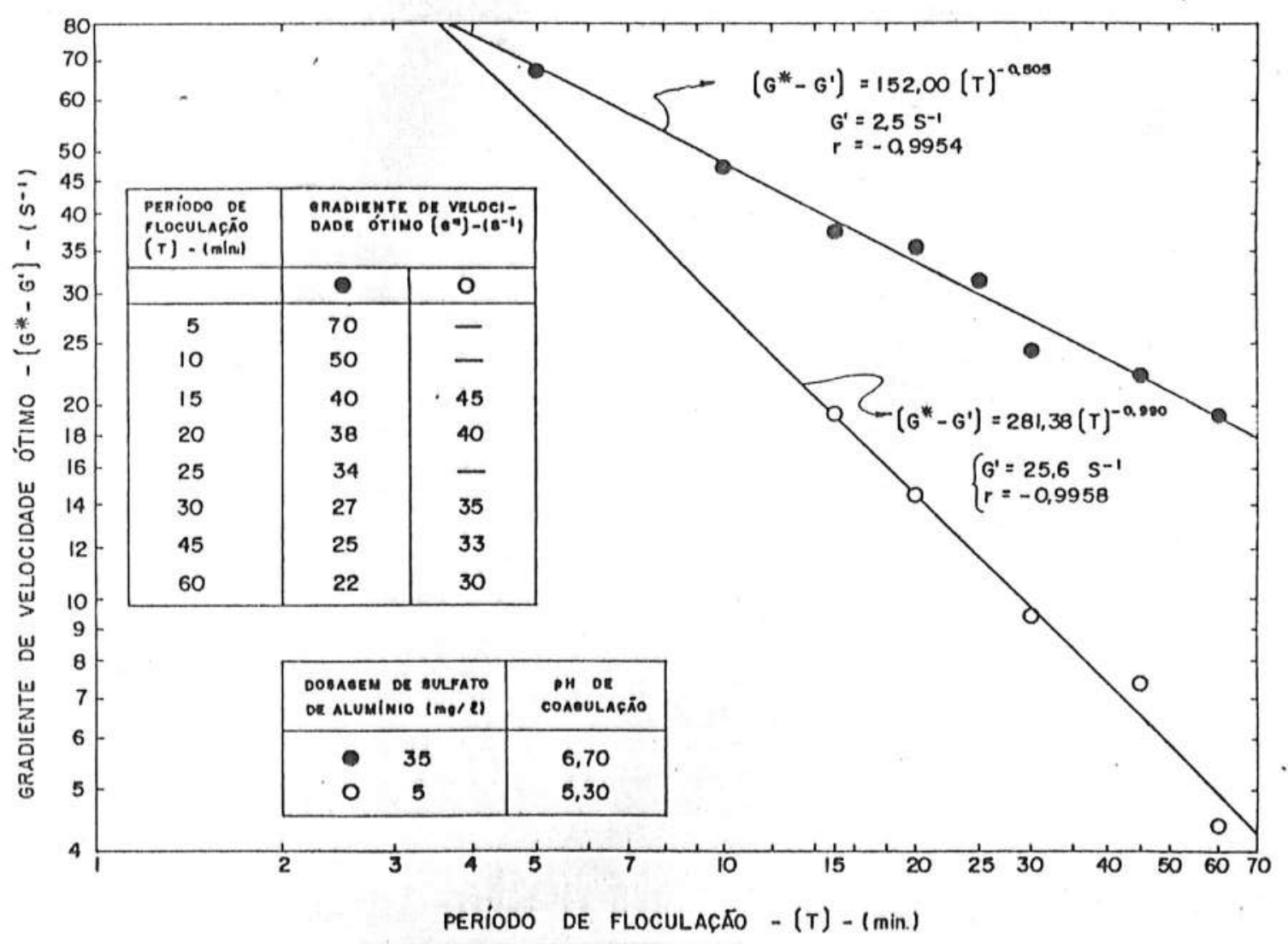

Figura 5.39 - Curvas de variação do gradiente de velocidade $\left(G^{*}-G^{\prime}\right)$ em função do perĩodo de flocula ção. Agua Típo IV. Modelo proposto.

- turbidez inicial: 50 FTU; . cor verdadeira inicial: $20 \mathrm{mg}$ Pt-Co/l; . cor aparente ini cial: $340 \mathrm{mg} \mathrm{Pt}$-Co/l; . periodo de sedimentação: $10 \mathrm{~min} . ;$. dosagens de sulfato de alu minio e pH do sobrenadante: mecanismo de adsorção-neutralização: $5 \mathrm{mg} / \ell$ e 5,20 - meca nismo de varredura: $35 \mathrm{mg} / \mathrm{l}$ e 6,70 . 


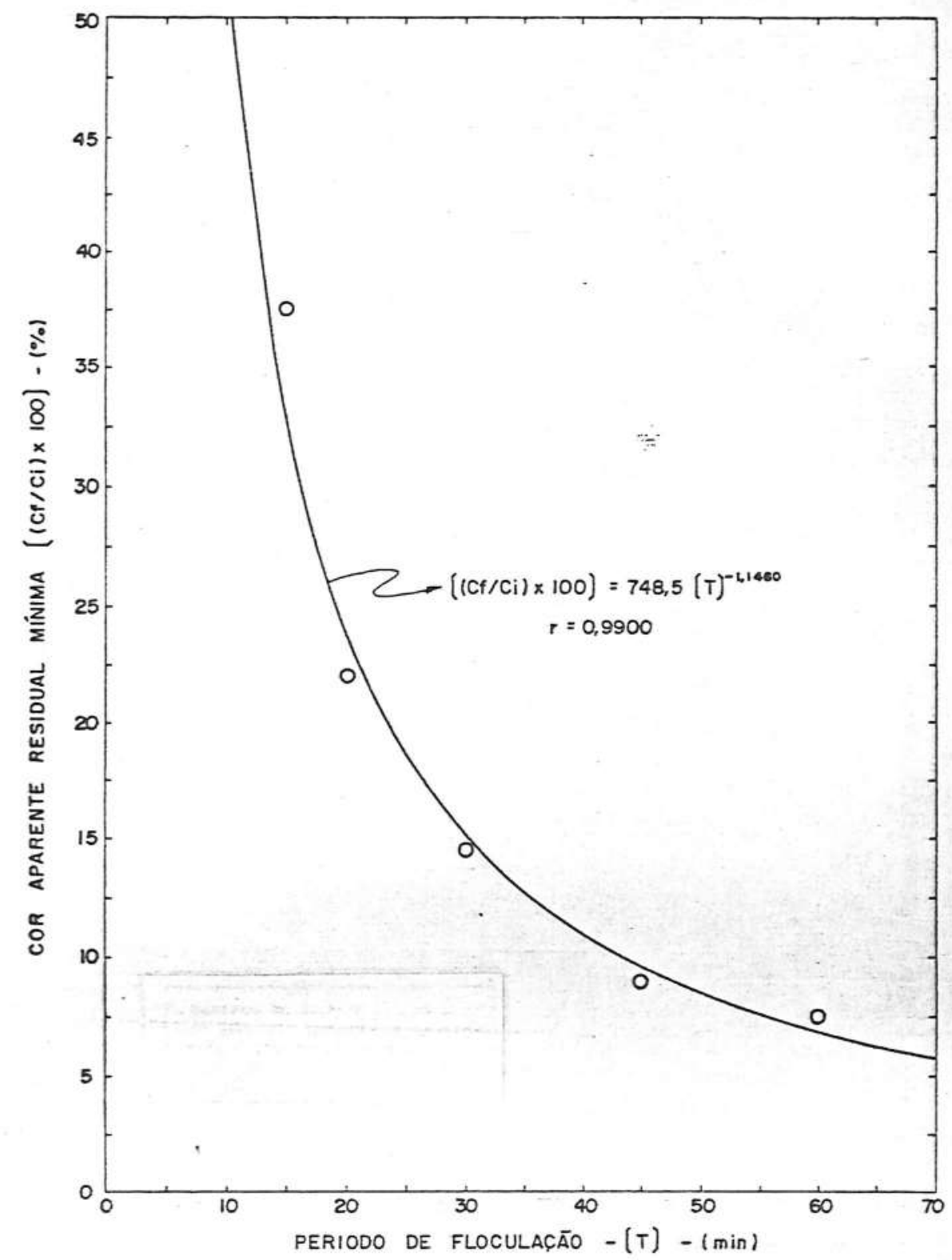

Figura 5.40 - Curva de variação da car aparente residual minima em fun ção do período de floculação. Água Tipo IV. Mecanismo de adsorção- neutralização.

- turbidez inicial: 50 FTU; . cor verdadeira inicial: 20 mg Pt-Coll; . cor aparente inicial: $340 \mathrm{mg}$ Pt-Co/l; . pe ríodo de sedimentação: 10 min.; . dosagem de sulfato de aluminio: $5 \mathrm{mg} / \ell$; . pH do sobrenadante: 5,20 . 


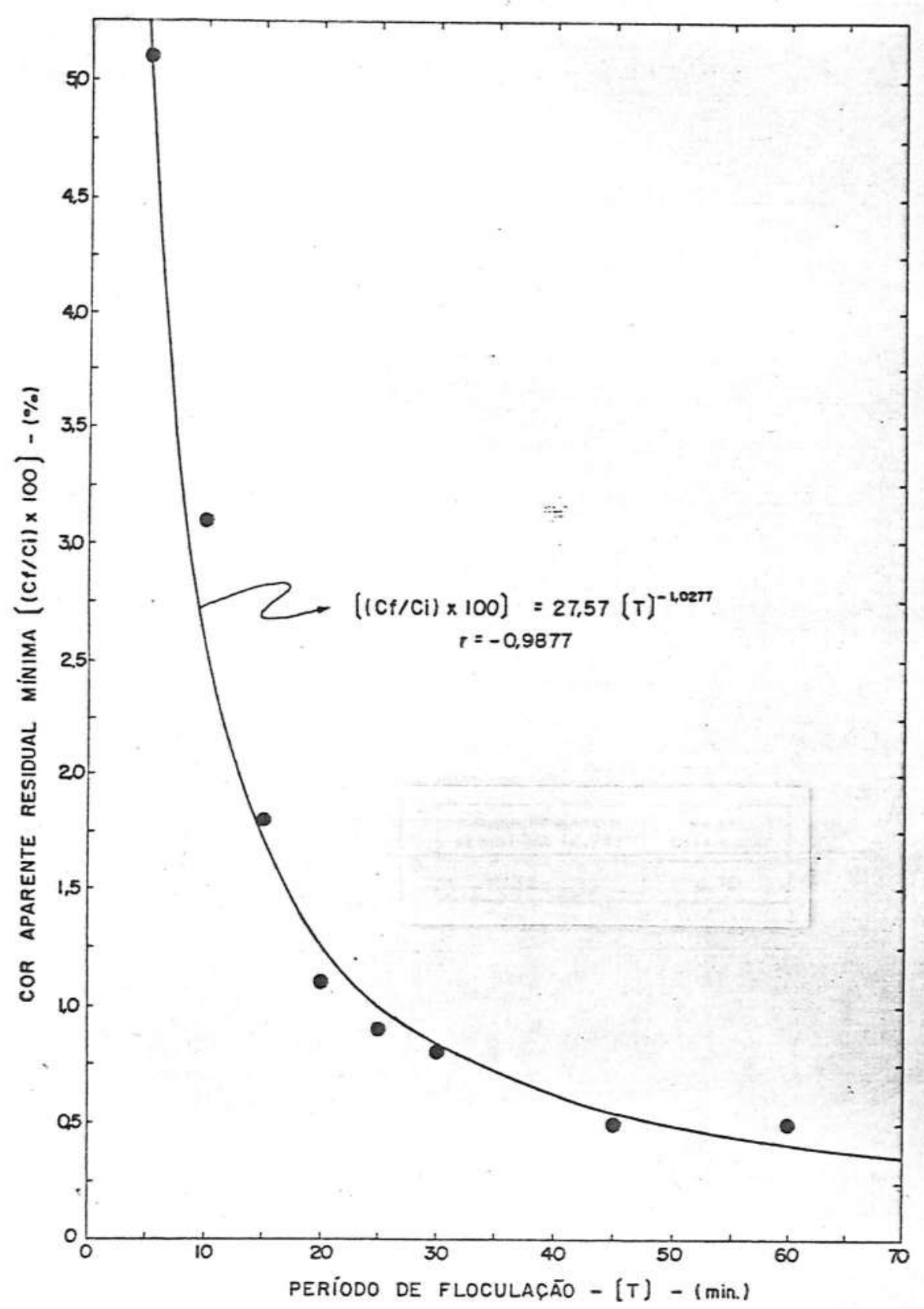

Figura 5.41 - Curva de variação da cor aparente residual minima em fun ção do período de floculação. Agua Tipo IV. Mecanismo de varredura.

- turbidez inicial: 50 FTU; . cor verdadeira inicial: 20 mg Pt-Coll; . cor aparente inicial: $340 \mathrm{mg} P t-C o / l$; . pe rïodo de sedimentação: $10 \mathrm{min.;}$. dosagem de sulfato de aluminio: $35 \mathrm{mg} / \mathrm{l}$; . pH do sobrenadante: 6,70. 


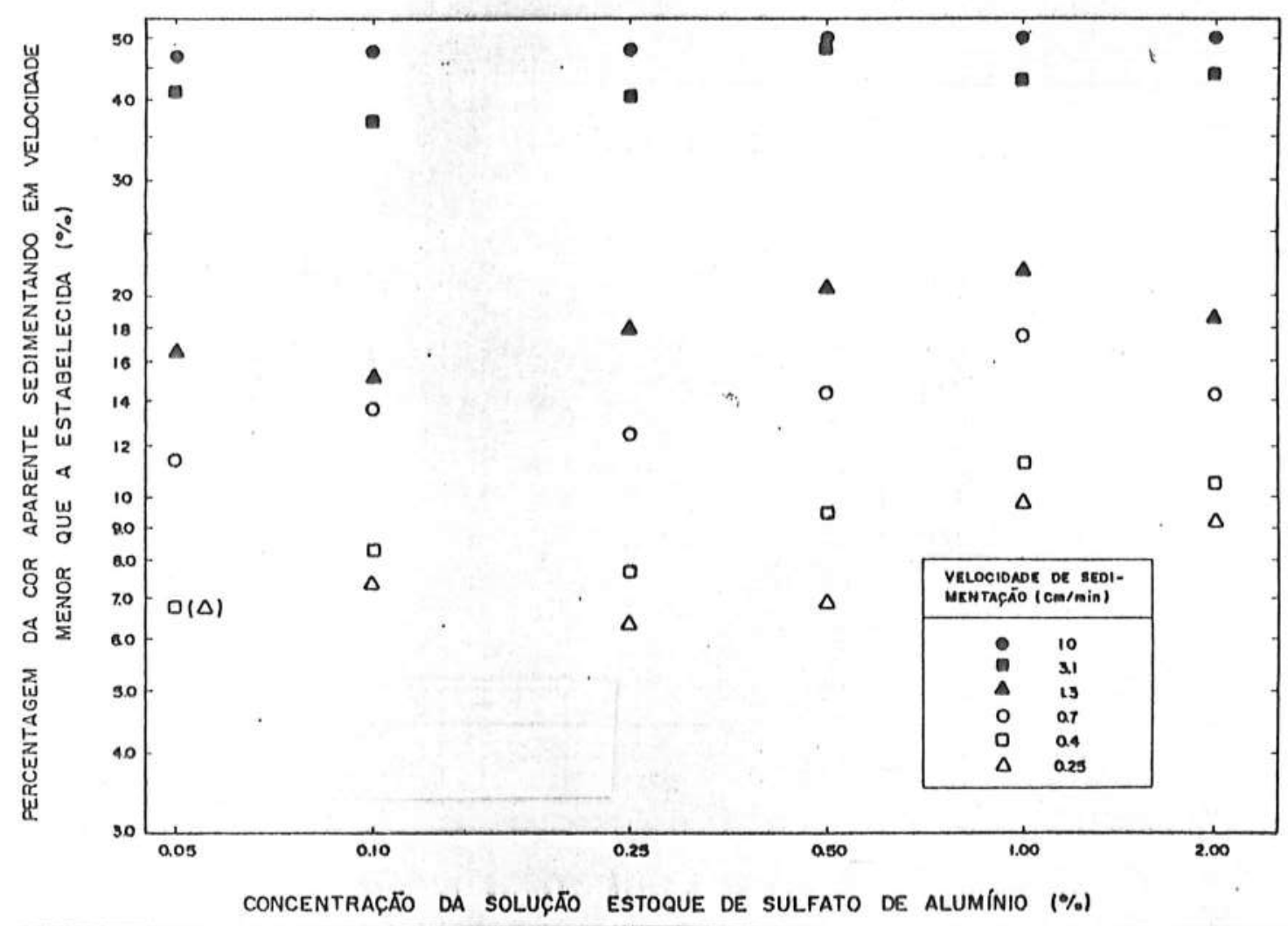

Figura 5.42 - Variação da percentagem da cor aparente inicial que sedimenta em velocidade menor que a estabelecida em função da concentração da solução de estoque de sulfato de aluménio. $\bar{A}$ gua Tipo IV. Mecanismo de adsorção-neutralização.

- turbidez inicial: $50 \mathrm{FTU}$; . cor verdadeira inicial: $20 \mathrm{mg} \mathrm{Pt-Co} / \mathrm{l}$; cor aparente ini cial: $340 \mathrm{mg}$ Pt-Co/l; . dosagem de sulfato de aluminio: $5 \mathrm{mg} / \ell$; $\mathrm{pH}$ do sobrenadante : 5, 20 . 


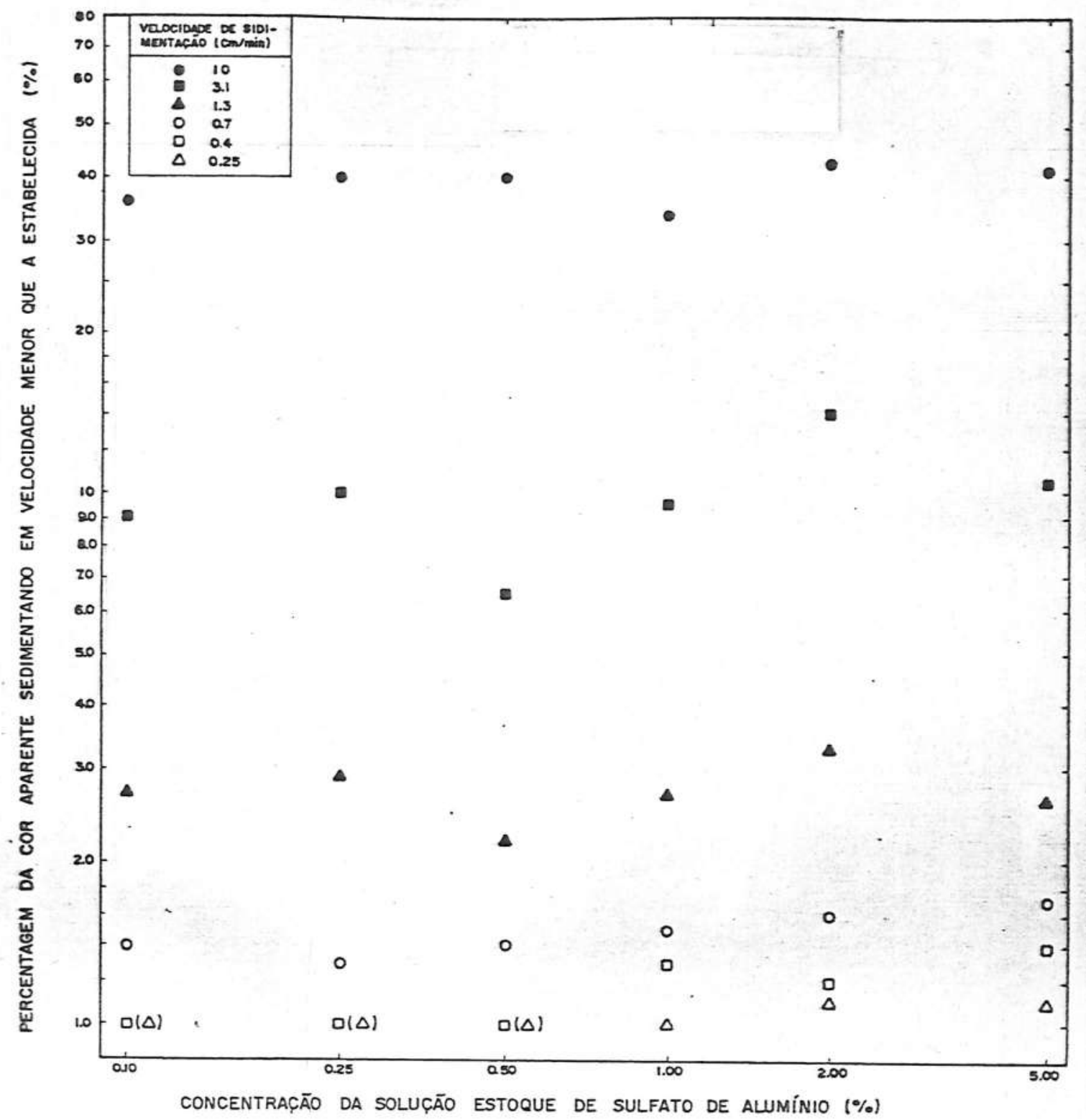

Figura 5.43 - Variação da percentagem de cor aparente inicial que se dimenta em velocidade menor que a estabelecida em fun ção da concentração da solução de estoque de sulfato de aluminio. Agua Tipo IV. Mecanismo de varredura.

- turbidez inicial: 50 FTU; . cor verdadeira inicial: $20 \mathrm{mg}$ Pt-Coll; . Cot aparente inicial: $340 \mathrm{mg}$ Pt-Co/l; - dosagem de sulfato de aluminio: $35 \mathrm{mg} / \mathrm{l}$; . pH do so brenadante: 6,70 . 


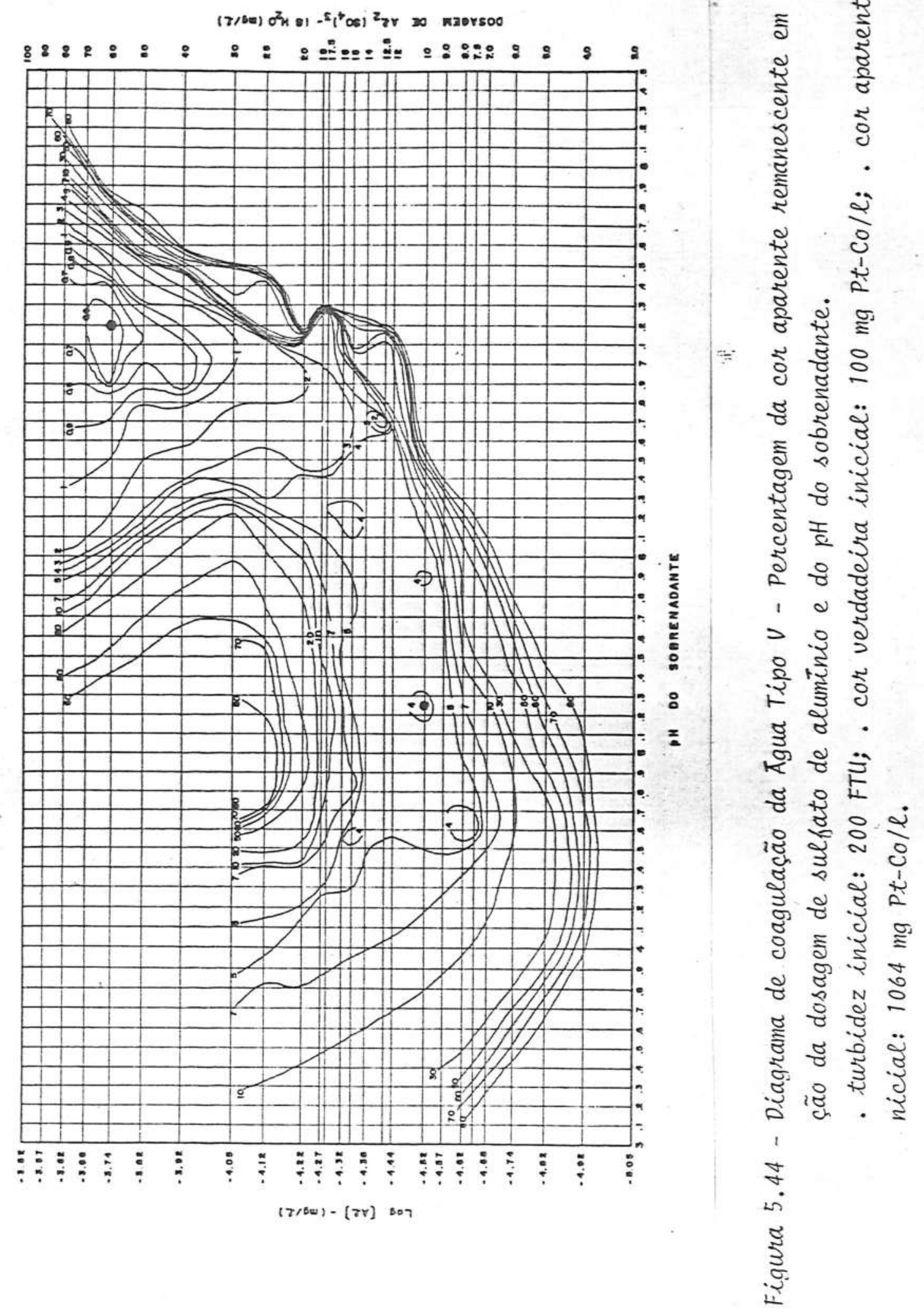




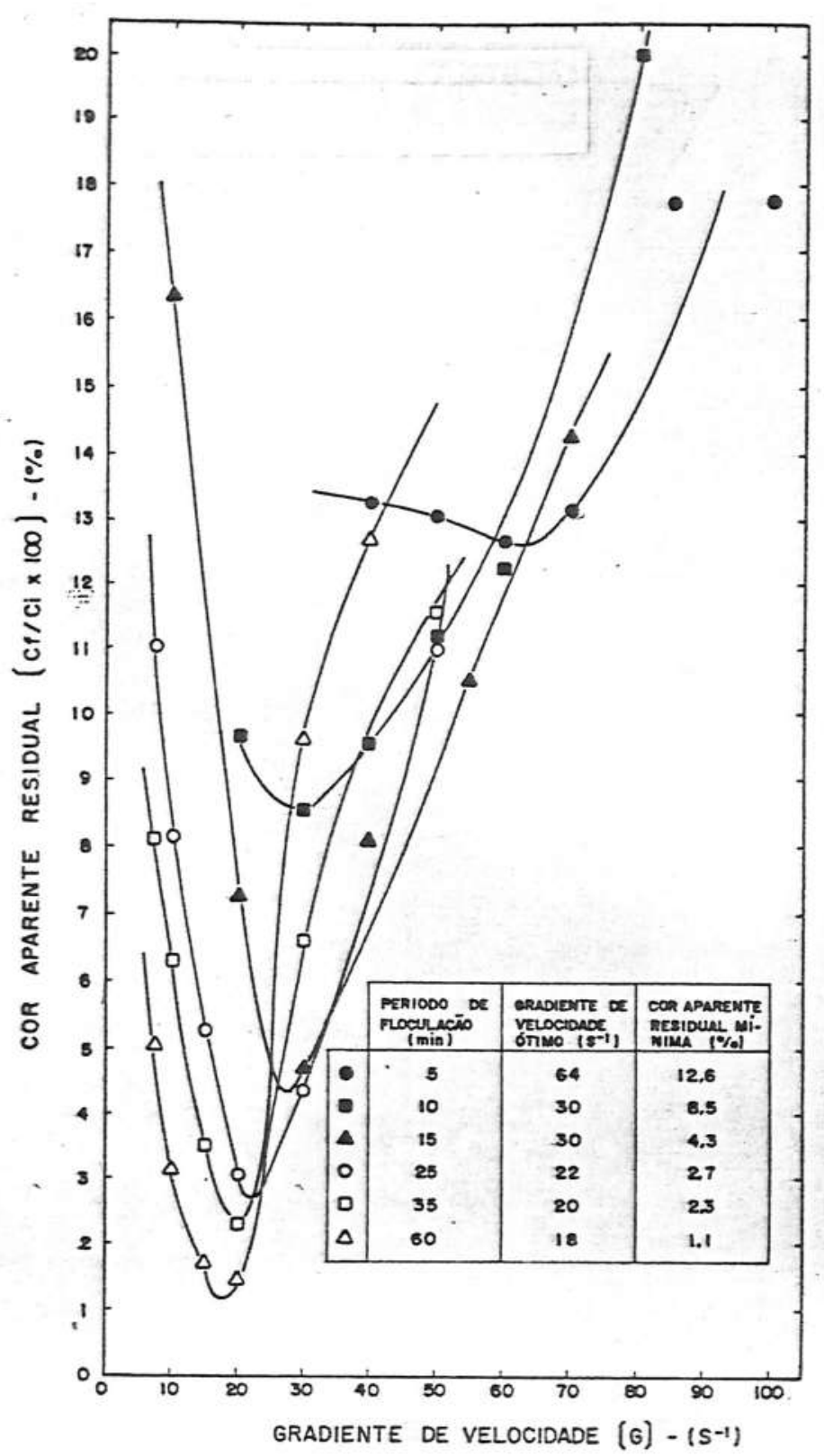

Figura 5.45 - Curvas de variação da cor aparente residual em função do gradiente de velocidade para värios períodos de flo culação. Agua Tipo V. Mecanismo de adsorção-neutralização.

- turbidez inicial: 200 FTU; . cor verdadeira inicial : $100 \mathrm{mg}$ Pt-Co/l; . cor aparente inicial: $1064 \mathrm{mg}$ PtColl; . dosagem de sulfato de aluminio: $10 \mathrm{mg} / \mathrm{l}$; . pht do sobrenadante: 5,25; . período de sedimentação: $10 \mathrm{~min}$. 


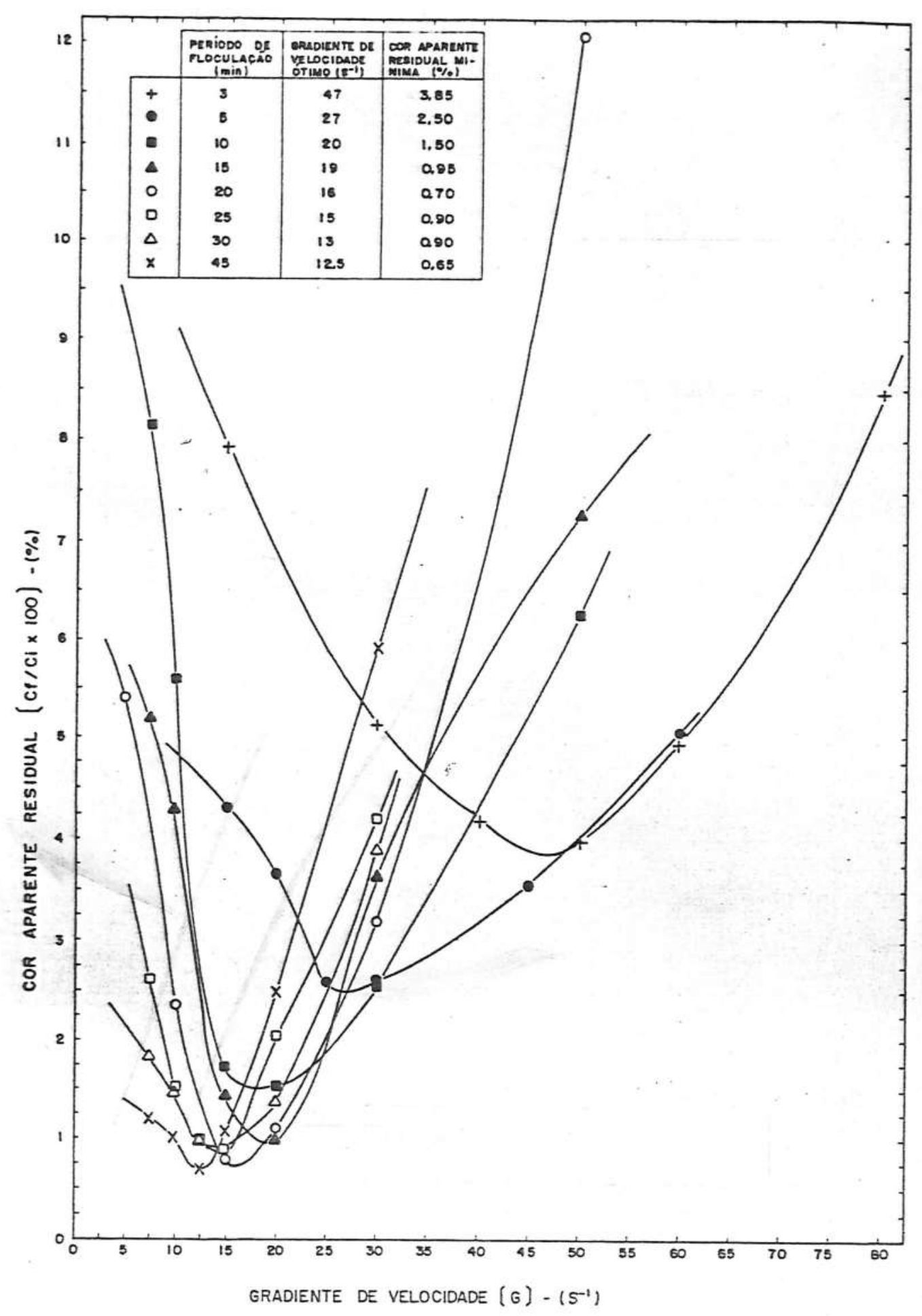

Figura 5.46 - Curvas de variação da cor aparente residual em função do gradiente de velocidade para värios períodos de flo culação. Agua Tipo V. Mecanismo de varredura.

- turbidez inicial: 200 FTU; . cor verdadeira inicial : $100 \mathrm{mg}$ Pt-Coll; . cor aparente inicial: $1064 \mathrm{mg}$ PtColl; . dosagem de sulfato de aluminio: $60 \mathrm{mg} / l$; $\mathrm{pH}$ do sobrenadante: 7,20 ; . período de sedimentação: 5 $\min$. 


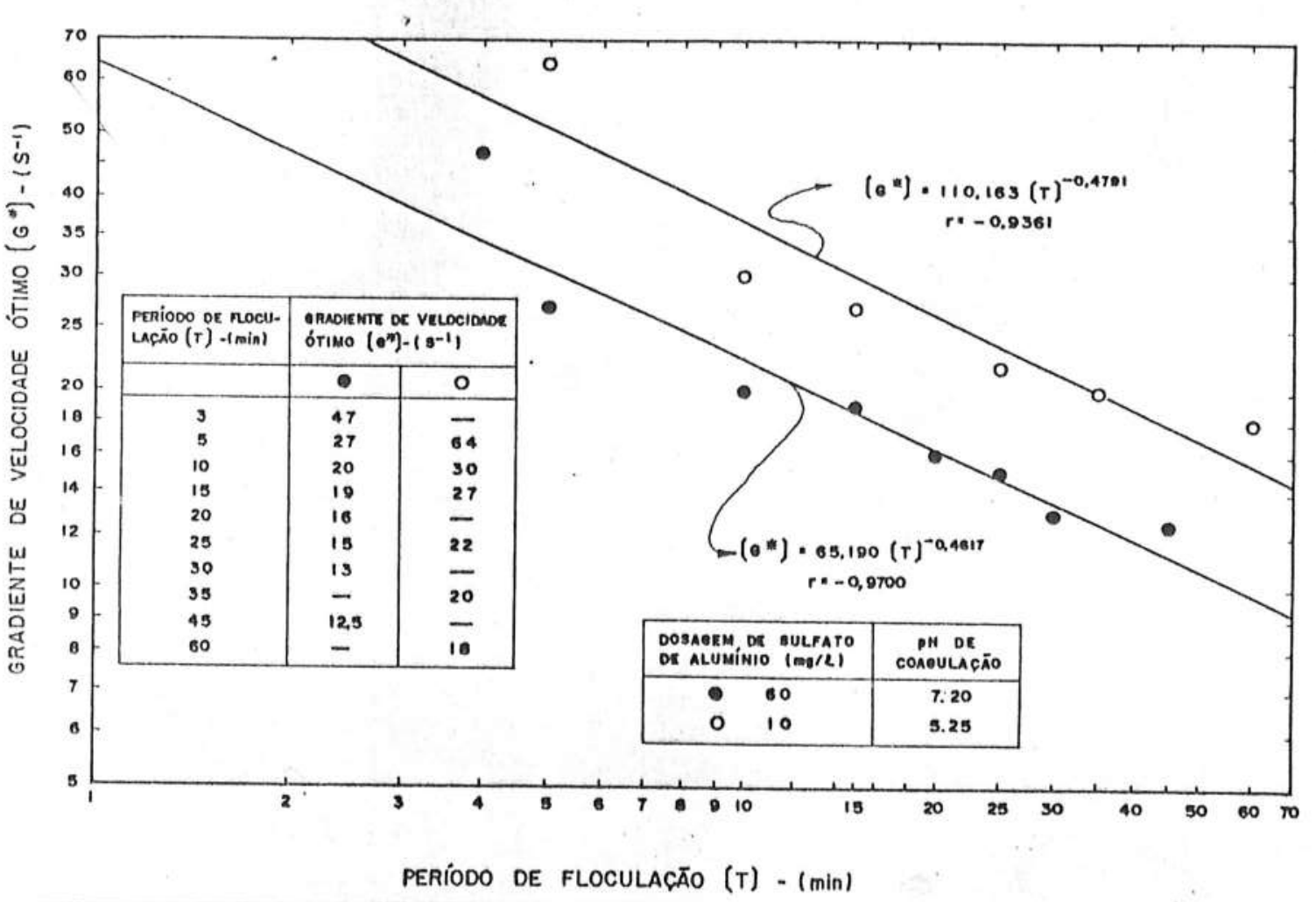

Figura 5.47 - Curvas de variação do gradiente de velocidade ötimo (G*) em função do período de flocula ção em papel bilogaritmico. Modelo de ANDREU-VILEEGAS \& LETTERMAN (04). Agua Tipo $V$. - turbidez inicial: $200 \mathrm{FTU}$; cor verdadeira inicial: $100 \mathrm{mg} \mathrm{Pt}-\mathrm{Co} / \ell$; . cor aparente $i$ nicial: $1064 \mathrm{mg}$ Pt-Co/l; . perïodo de sedimentação: $5 \mathrm{~min}$. (adsorção-neutralizaçäo) - 10 min. (varredura); . dosagens de sulfato de aluminio e pH do sobrenadante: mecanismo de adsorção-neutralização: $10 \mathrm{mg} / \ell$ e 5,25 - mecanismo de varredura: $60 \mathrm{mg} / \ell$ e 7,20. 


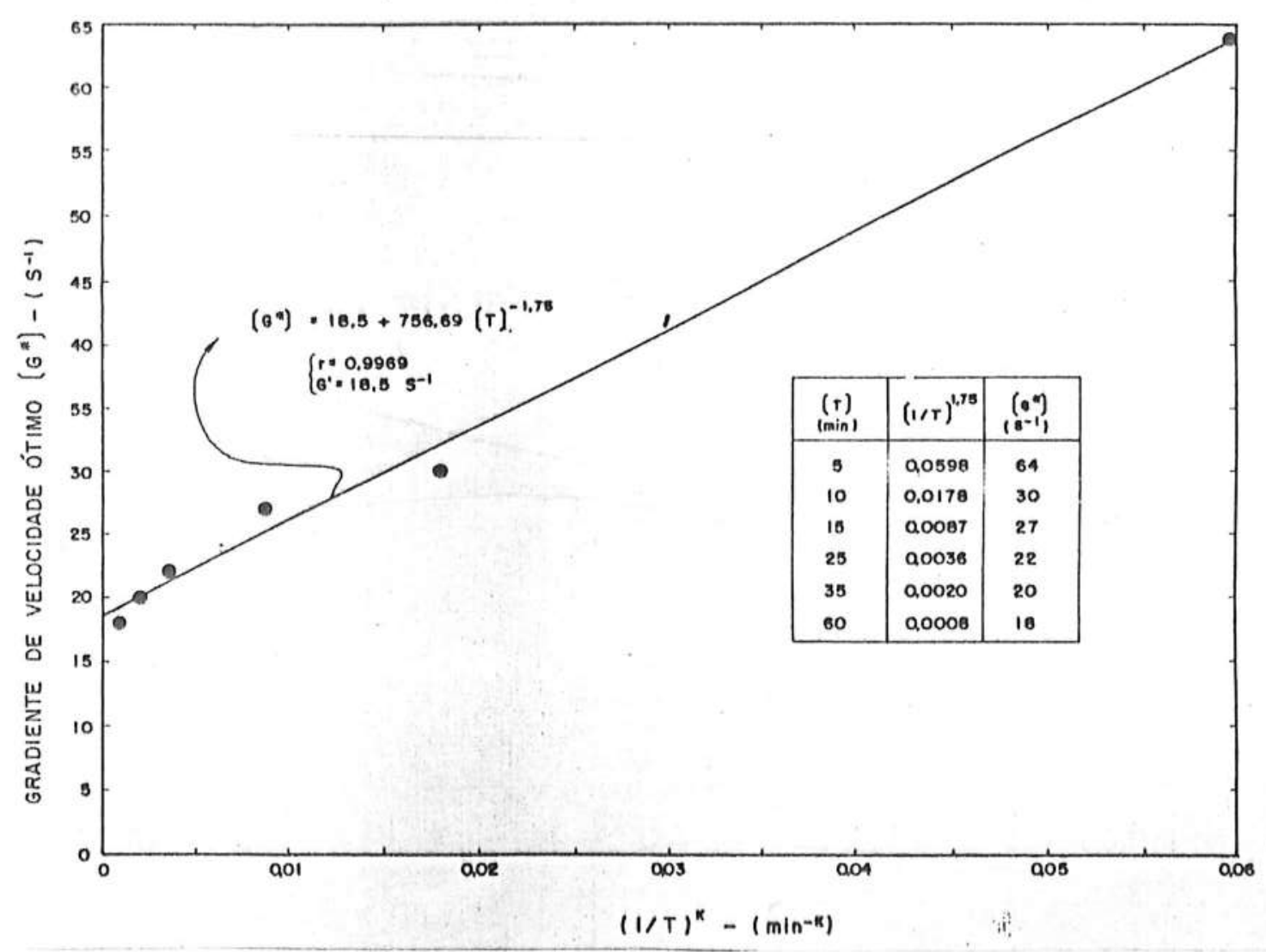

Figura 5.48 - Curva de variação do gradiente de velocidade ötimo $\left(G^{*}\right)$ em função de $(1 / T)^{n}$ para a Aggua Tipo V, onde $T$ é o período de floculação. Mecanismo de adsorção-neutralização.

- turbidez inicial: $200 \mathrm{FTU}$; cor verdadeira inicial: $100 \mathrm{mg}$ Pt-Co/l; . cor aparente $i$ nicial: $1064 \mathrm{mg}$ Pt-Co/l ; periodo de sedimentação: $10 \mathrm{~min}$;; . dosagem de sulfato de $\underline{a}$ luminio: $10 \mathrm{mg} / \mathrm{l}$;. $\mathrm{pH}$ do sobrenadante: 5,25 . 

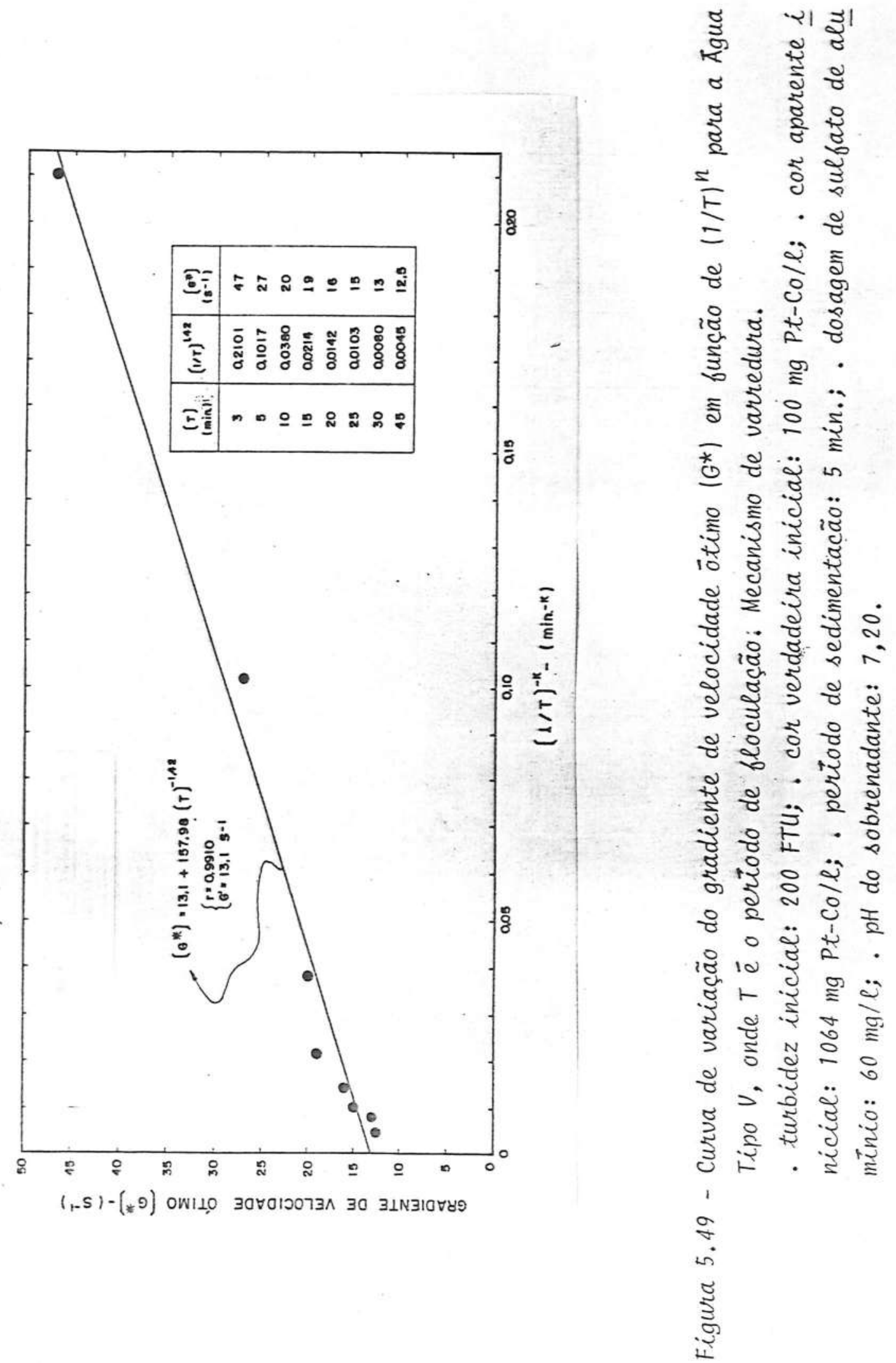


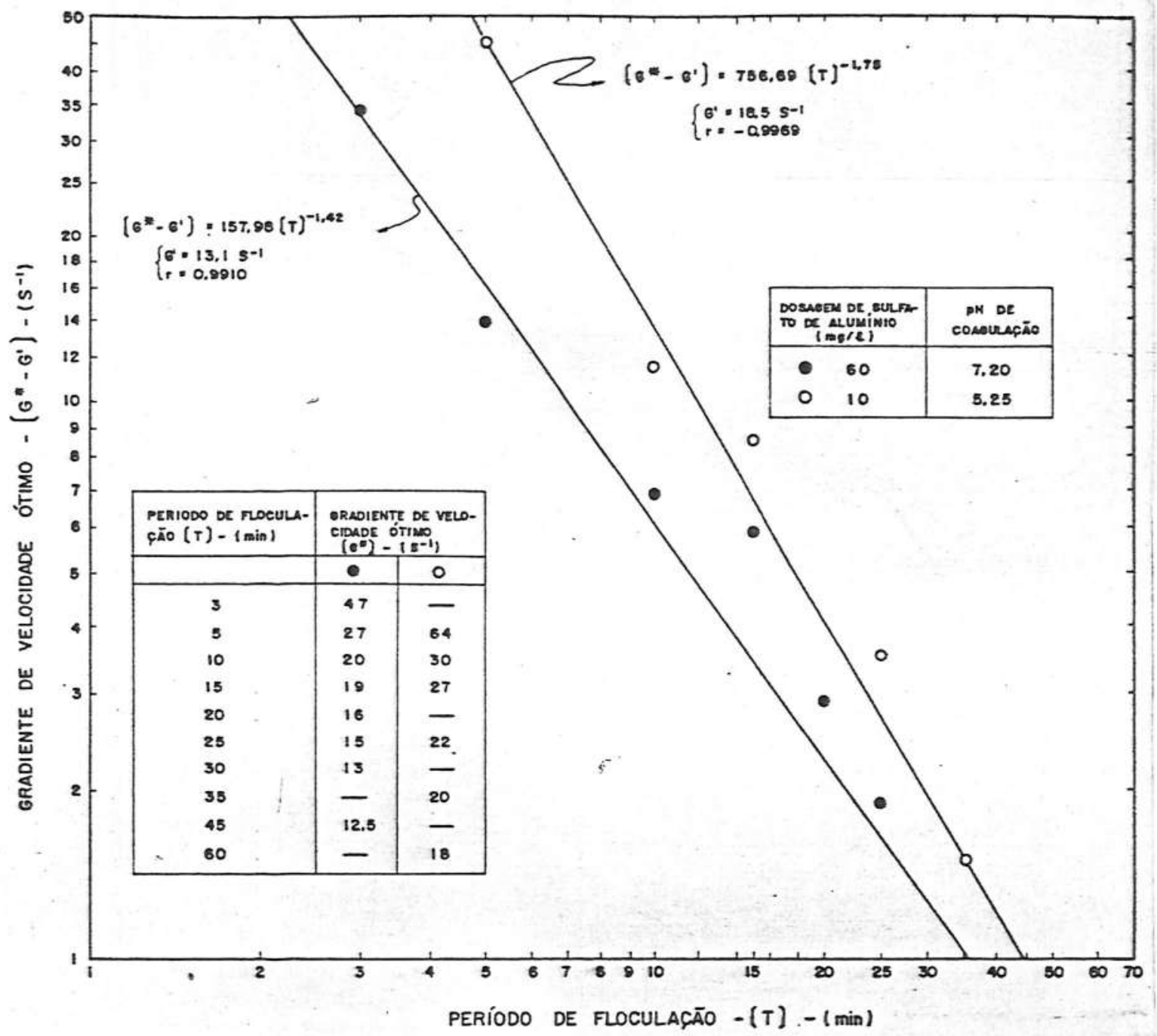

Figura 5.50 - Curvas de variação do gradiente de velocidade (G* - $\left.G^{\prime}\right)$ em função do período de floculação. Água Típo V. Modelo proposto.

- turbidez inicial: $200 \mathrm{FTU}$; cor verdadeira inicial : $100 \mathrm{mg}$ Pt-Co/l; . cor aparente inicial: $1064 \mathrm{mg}$ Pt-Coll - período de sedimentação: 5 min. I adsorção-neutraliza ção) - 10 min. (varredura); . dosagens de sulfato de a luminio e pH do sobrenadante: mecanismo de adsorção-neu tralização: $10 \mathrm{mg} / \mathrm{l}$ e 5,25 - mecanismo de varredura: 60 $\mathrm{mg} / \mathrm{l}$ e 7,20 . 


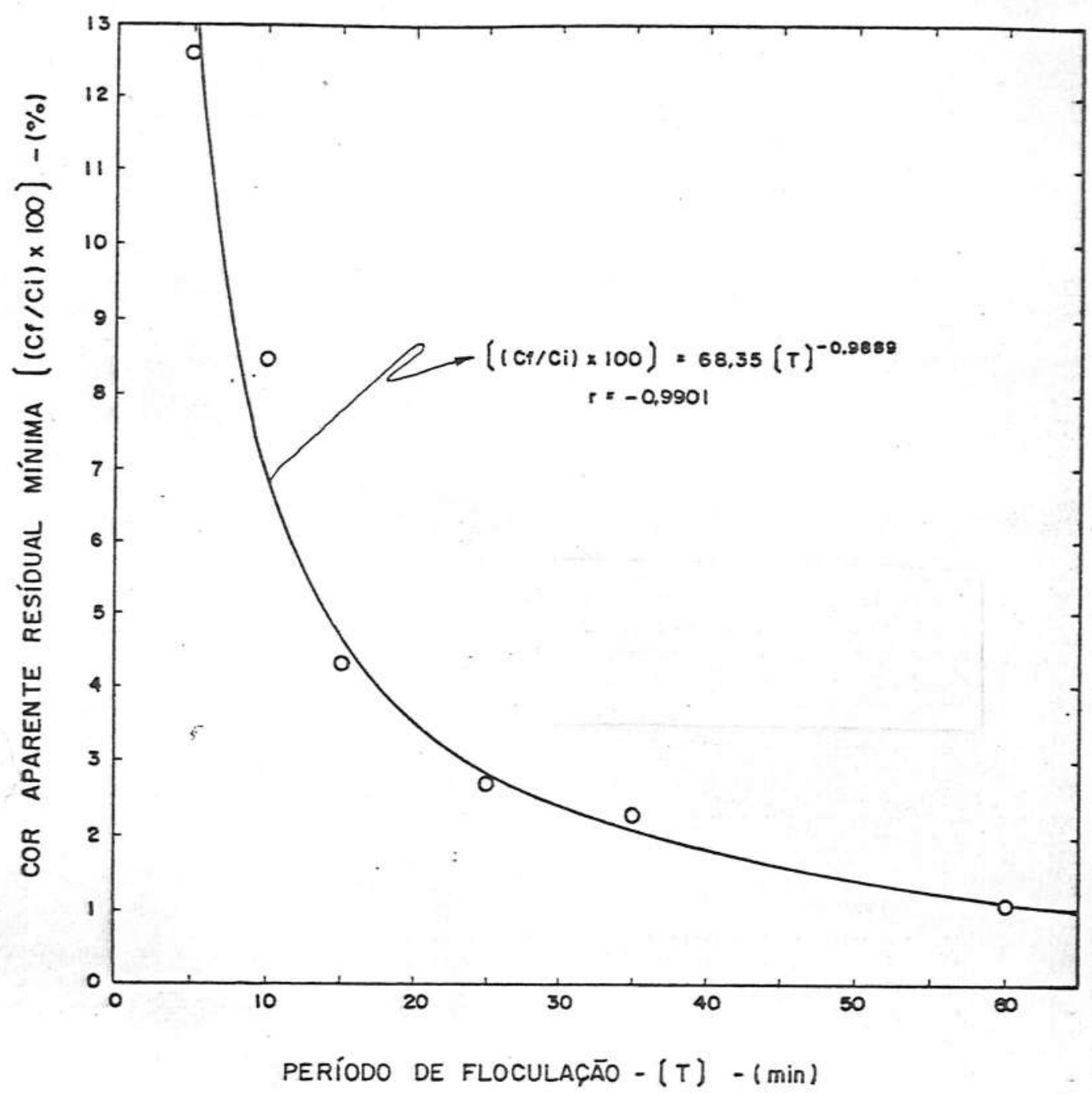

Figura 5.51 - Curva de variação da cor aparente residual minima em fun ção do período de floculação. Agua Tipo V. Mecanismo de adsorção-neutralização.

- turbidez inicial: 200 FTU; . cor verdadeira inicial : $100 \mathrm{mg}$ Pt-Co/l; . cor aparente inicial: $1064 \mathrm{mg}$ Pt-Co/l; - período de sedimentação: 10 min.; . dosagem de sulfato de aluminio: $10 \mathrm{mg} / \mathrm{l}$; . pH do sobrenadante: 5,25. 


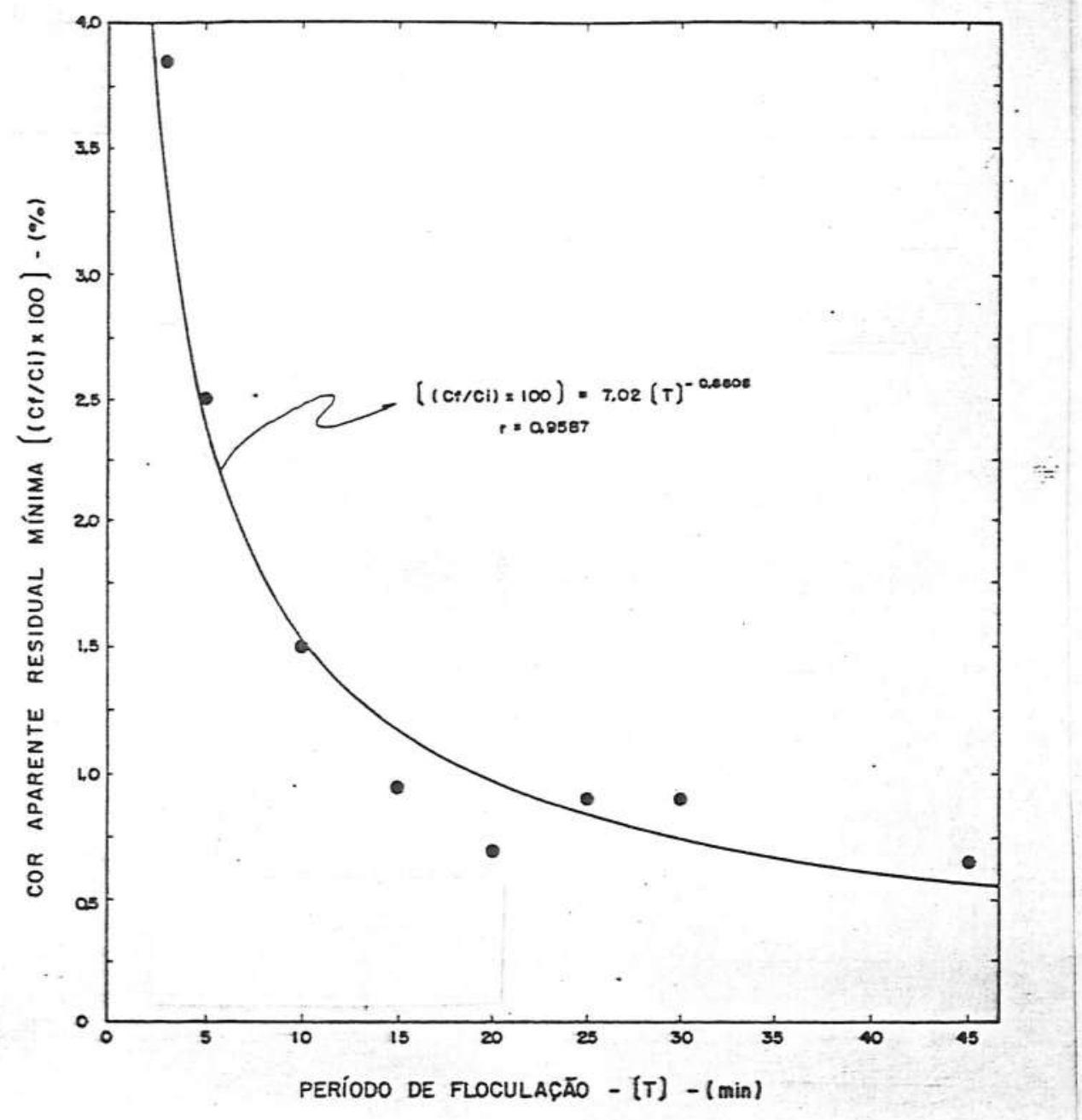

Figura 5.52 - Curva de variação da cor aparente residual minima em fun cão do período de floculação. Água Tipo V. Mecanismo de varredura.

- turbidez inicial: 200 FTU; . car verdadeira inicial : $100 \mathrm{mg}$ Pt-Co/l; . cor aparente inicial: $1064 \mathrm{mg}$ Pt-Co/l; - período de sedimentação: 5 min.; . dosagem de sulfato de aluminio: $60 \mathrm{mg} / \mathrm{l}$; . pH do sobrenadante: 7,20. 


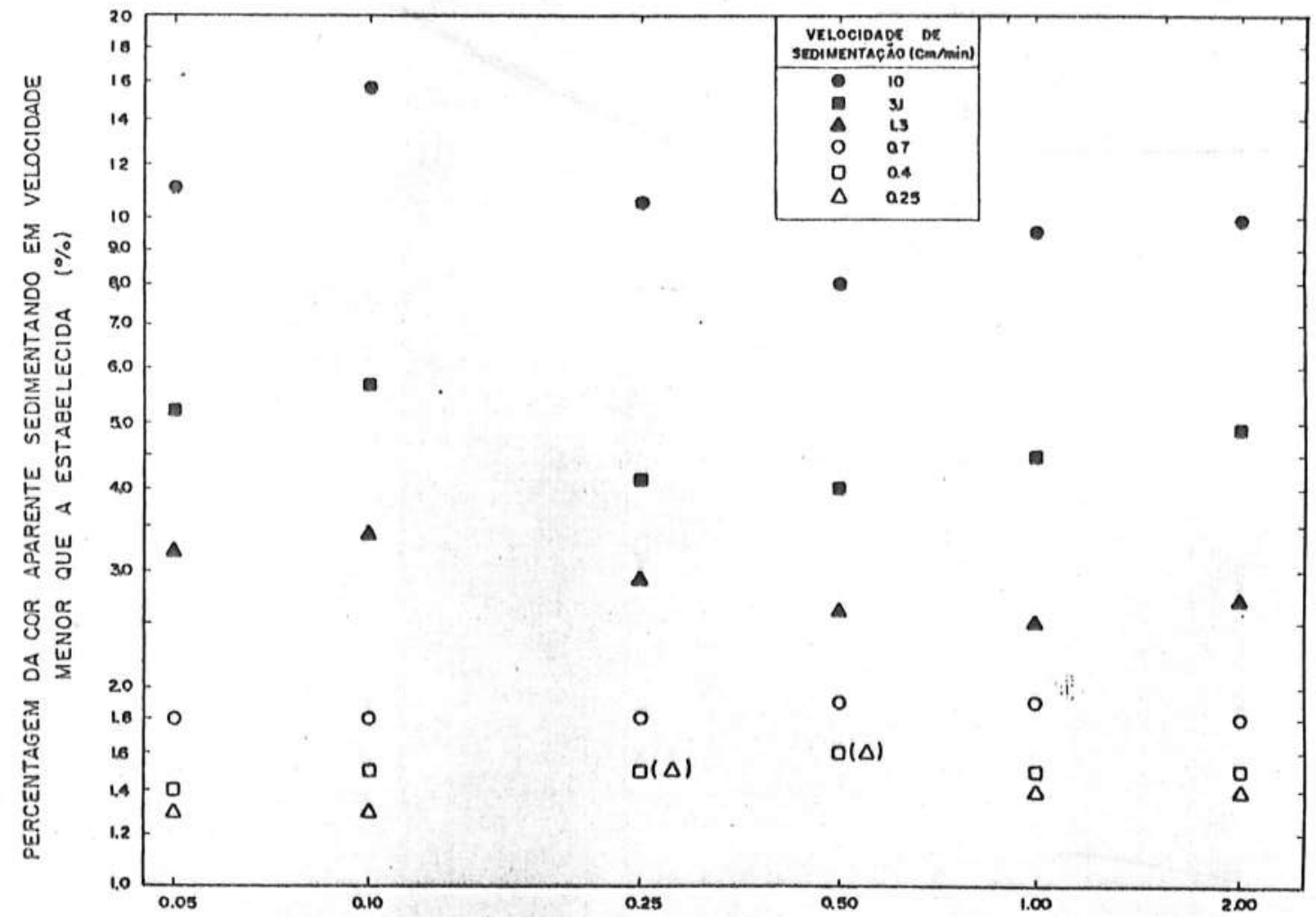

CONCENTRAÇÃo DA SOLUÇÃo ESTOQUE dE SULFATO DE ALUMÍNIO $(\%)$

Figura 5.53 - Variação da percentagem da cor aparente inicial que sedimenta em velocidade menor que a estabelecida em função da concentração da solução de estoque de sulfato de aluminio. $\mathbb{A}$ gua Tipo V. Mecanismo de adsorção-neutralização.

- turbidez inicial: $200 \mathrm{FTU}$; cor verdadeira inicial: $100 \mathrm{mg} \mathrm{Pt-Co} \ell$; . cor aparente $\underline{i}$ nicial: $1064 \mathrm{mg}$ Pt-Co/l; . dosagem de sulfato de aluminio: $10 \mathrm{mg} / \ell$; . pH do sobrenadan te: 5,25. 


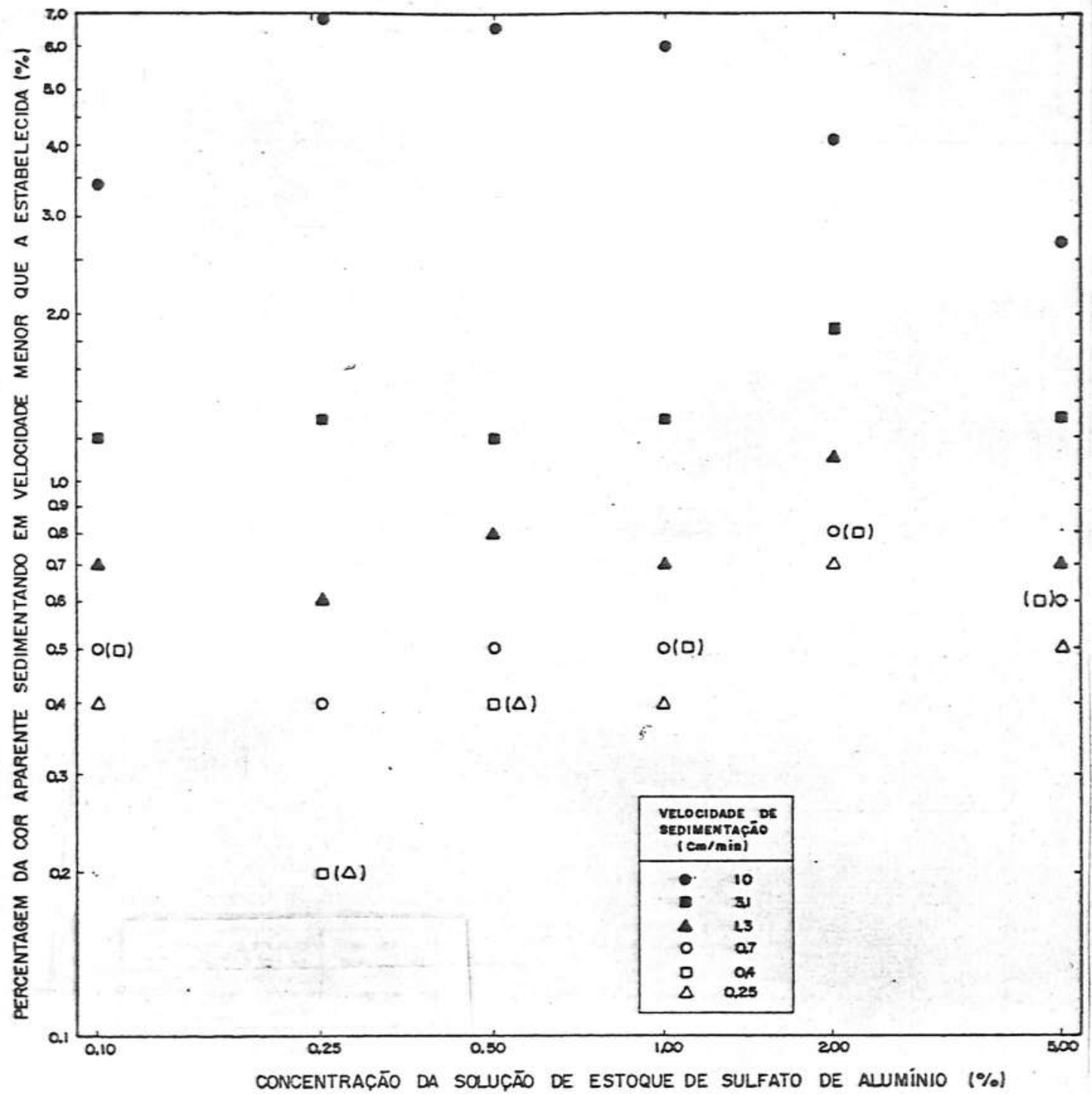

Figura 5.54 - Variação da percentagem da cor aparente inicial que sedi menta em velocidade menor que a estabelecida em função da concentração da solução de estoque de sulfato de alumi nio. Agua Tipo V. Mecanismo de varredura.

- turbidez inicial: 200 FTU; . cor verdadeira inicial : $100 \mathrm{mg}$ Pt-Co/l; . Cor aparente inicial: $1064 \mathrm{mg}$ Pt-Co/l; - dosagem de sulfato de aluminio: $60 \mathrm{mg} / \mathrm{l}$; . pH do sobre nadante: 7,20 . 


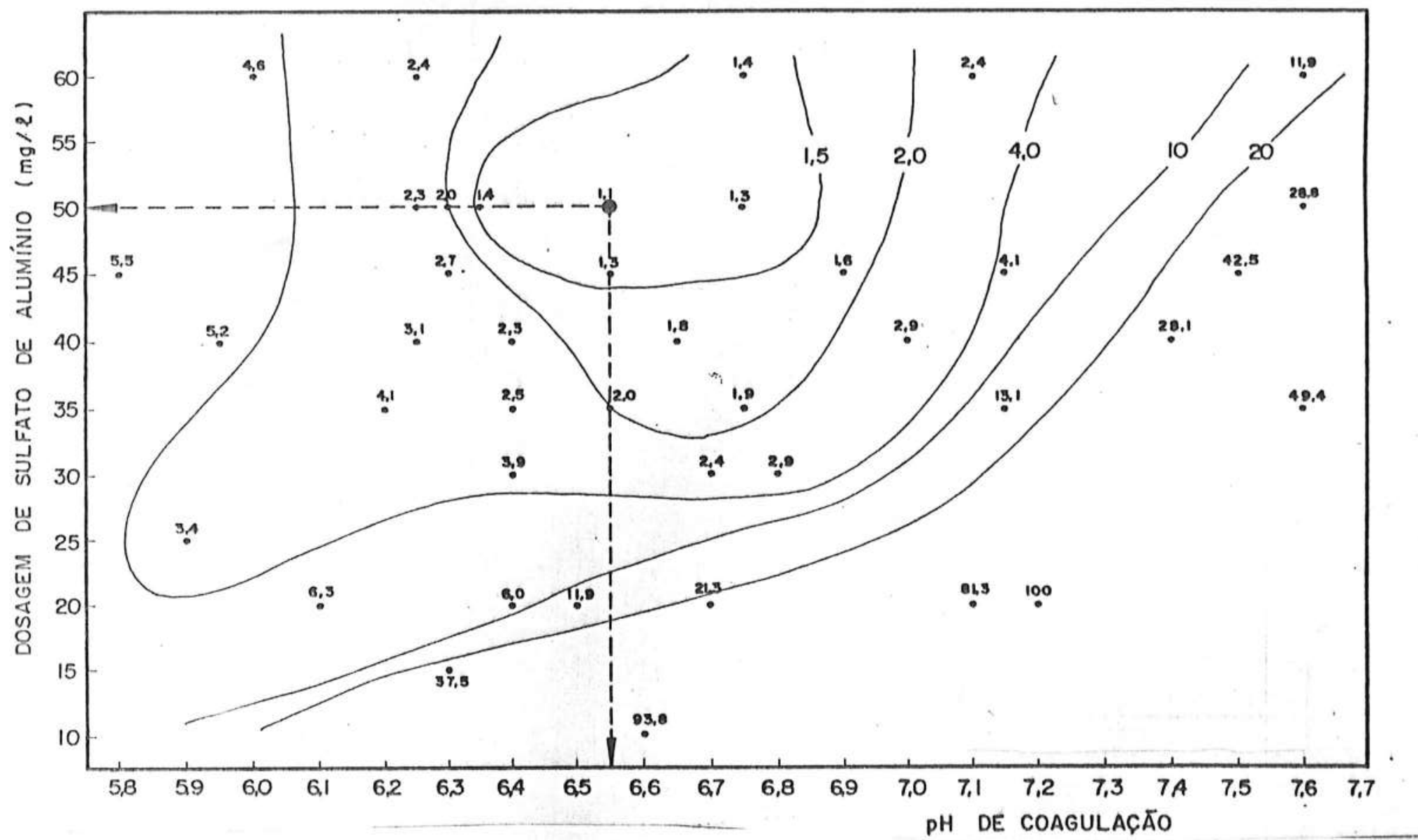

Figura 5.55 - Diagrama de coagulação da Ãgua Tipo VI. Percentagem da turbidez remanescente em função da dosagem de sulfato de aluménio e do $\mathrm{pH}$ do sobrenadante.

- turbidez inicial: $160 \mathrm{FTU}$; cor verdadeira inicial: $30 \mathrm{mg} \mathrm{Pt-Co/ \ell ;} \mathrm{cor} \mathrm{aparente} \underline{i}$ nicial: $1300 \mathrm{mg}$ Pt-Co/l. 


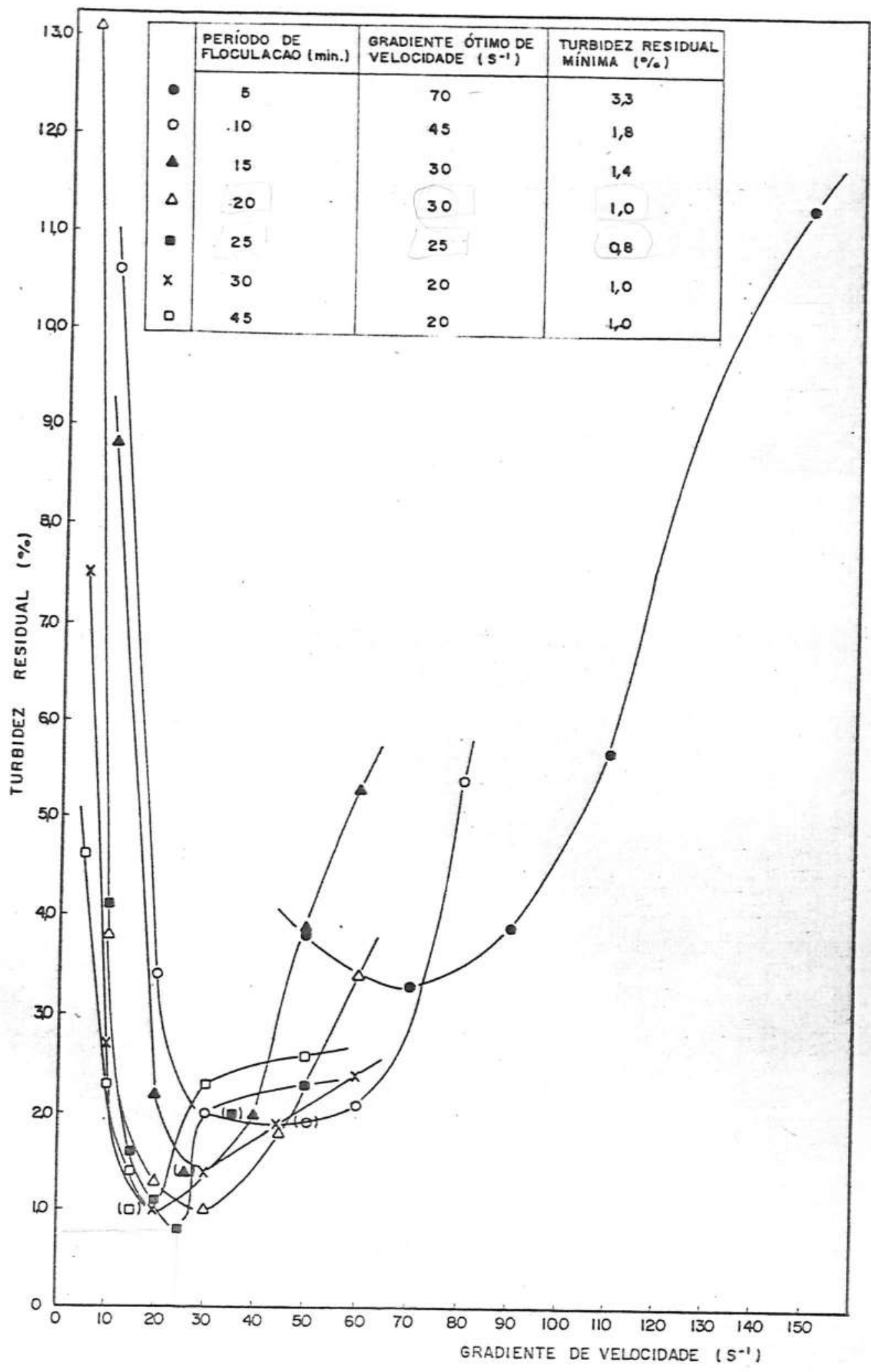

Figura 5.56 - Curvas de variação da turbidez residual em função do gra diente de velocidade para vārios períodos de floculação. Agua Tipo VI. Mecanismo de varredura.

- turbidez inicial: 160 FTU; cor verdadeira inicial: 30 mg Pt-Coll; . cor aparente inicial: $1300 \mathrm{mg}$ Pt-Co/l; . do sagem de sulfato de aluminio: $50 \mathrm{mg} / \mathrm{l}$; . pH do sobrena dante: 6,55; . perīodo de sedimentação: $10 \mathrm{~min}$. 


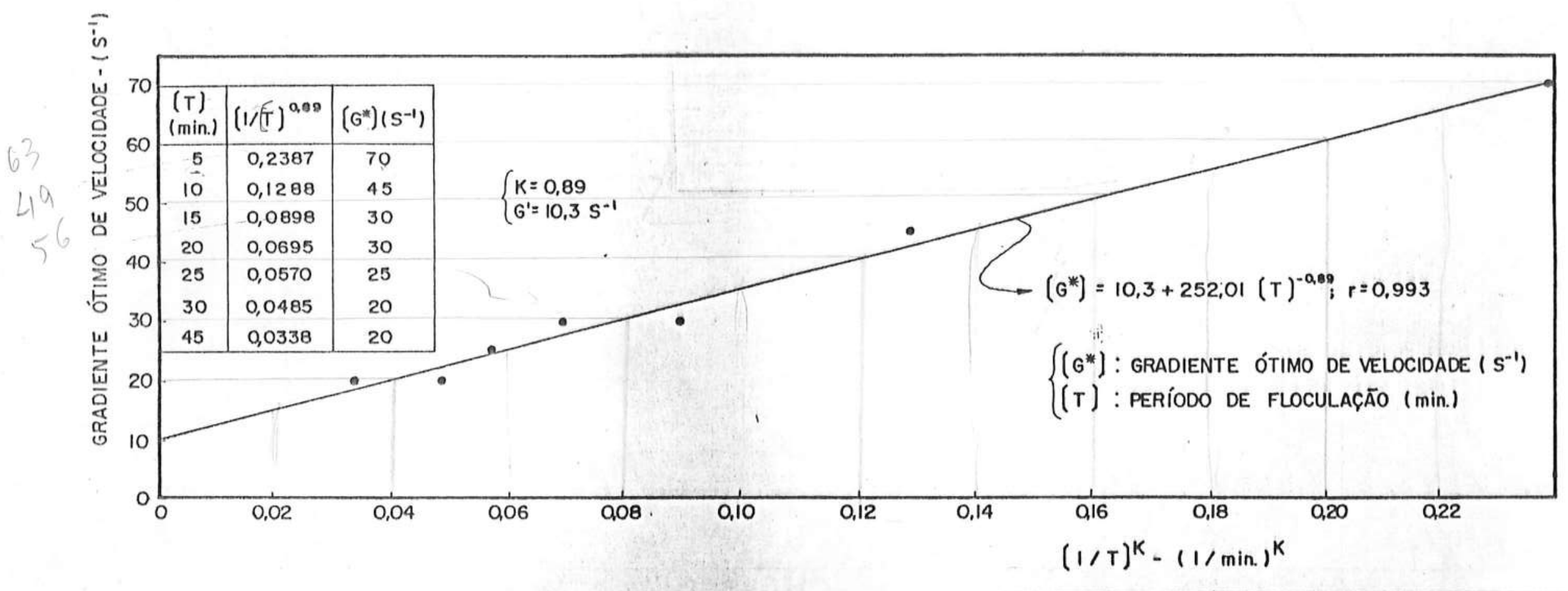

Figura 5.57 - Curva de variação do gradiente de velocidade ötimo $\left(G^{*}\right)$ em função de $(1 / T)^{n}$ para a Agua Tipo VI, onde $T \bar{e}$ o perïodo de floculação. mecanismo de varredura.

- turbidez inicial: $160 \mathrm{FTU}$; . cor verdadeira inicial: $30 \mathrm{mg} \mathrm{Pt}-\mathrm{Co} / \ell$; . cor aparente $i$ nicial: $1300 \mathrm{mg}$ Pt-Co/l; . perĩodo de sedimentação: $10 \mathrm{~min}$; . dosagem de sulfato de a euminio: $50 \mathrm{mg} / \ell$; . pH do sobrenadante: 6,55 . 


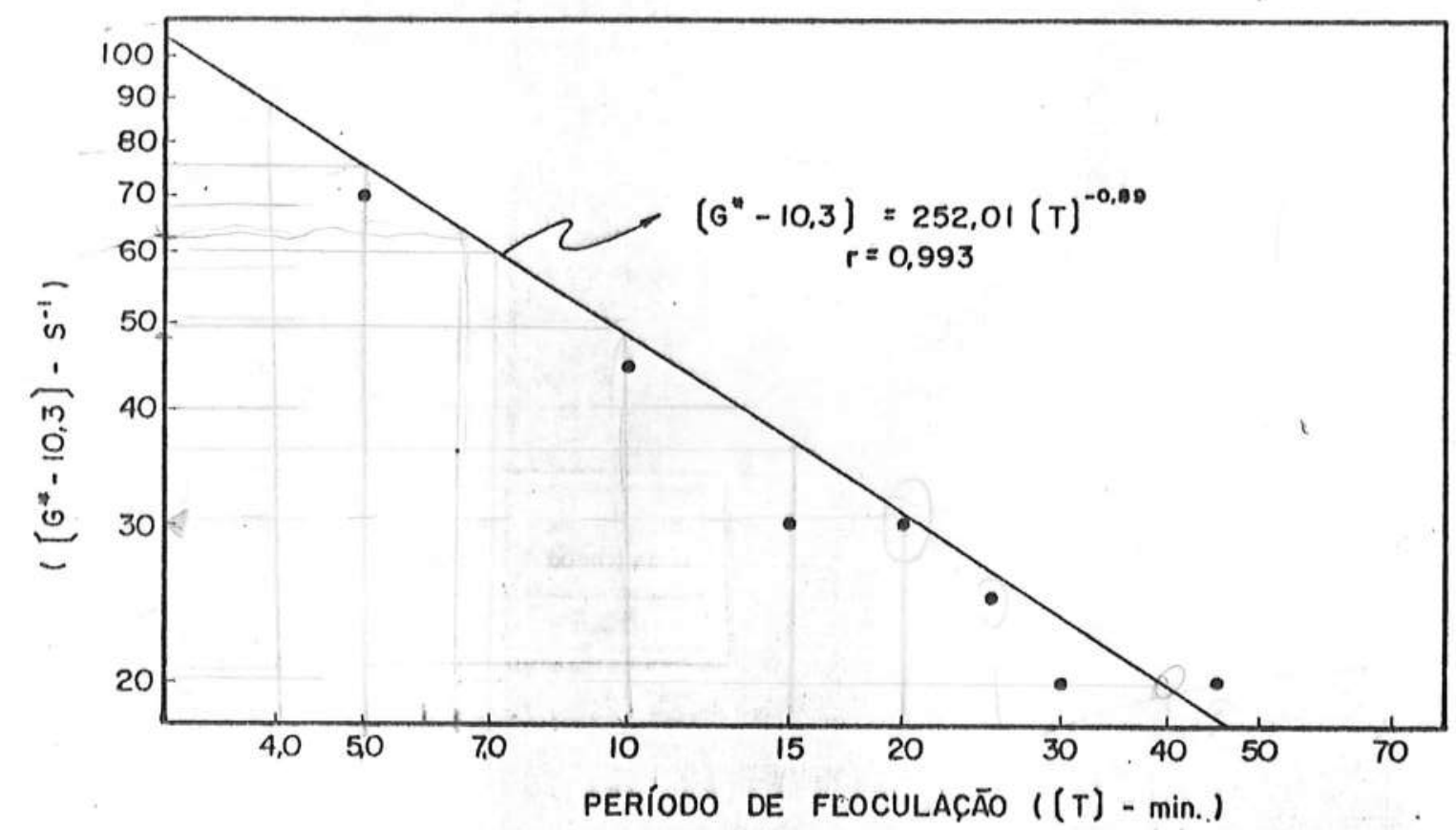

Figura 5.58 - Curva de variação do gradiente de velocidade $\left(G^{*}\right.$ - $\left.G^{\prime}\right)$ em função do perïodo de flocula ção. Agua Tipo VI. Modelo proposto. Mecanismo de varredura.

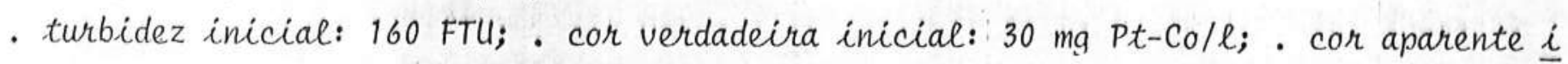
nicial: $1300 \mathrm{mg}$ Pt-Coll; . perïodo de sedimentação: $10 \mathrm{~min}$; . dosagem de sulfato de $\underline{a}$ luminio: $50 \mathrm{mg} / \ell$; $\mathrm{pH}$ do sobrenadante: 6,55 . 


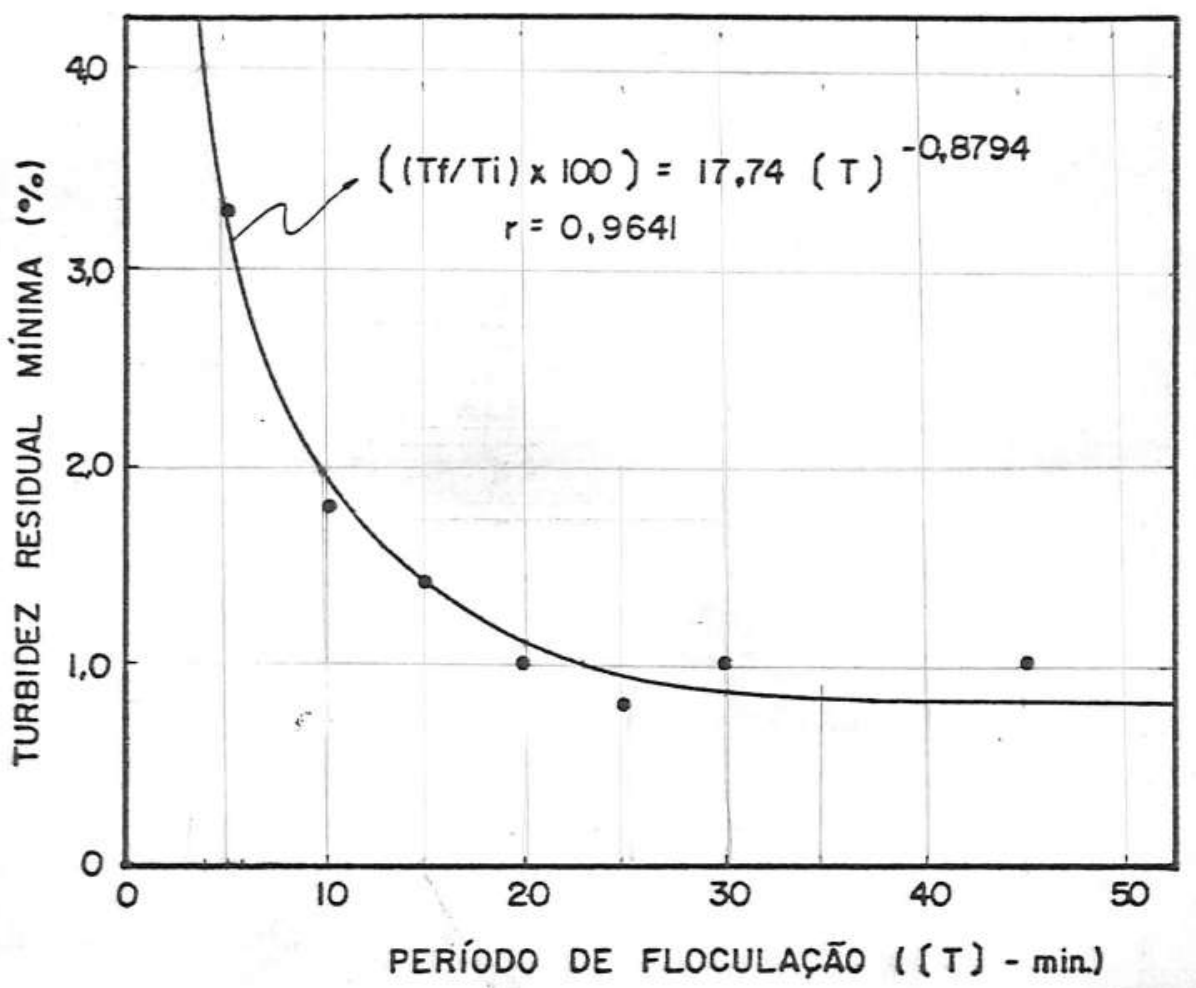

Figura 5.59 - Curva de variação da cor aparente residual minima em fun ção do período de floculacão. Agua Tipo VI. Mecanismo de varredura.

- turbidez inicial: 160 FTU; . cor verdadeira inicial : $30 \mathrm{mg}$ Pt-Co/l; . Cor aparente inicial: $1300 \mathrm{mg}$ Pt-Coll; - periodo de sedimentação: 10 min.; . dosagem de sulfato de aluminio: $50 \mathrm{mg} / \mathrm{l}$; . pH do sobrenadante: 6,55 . 


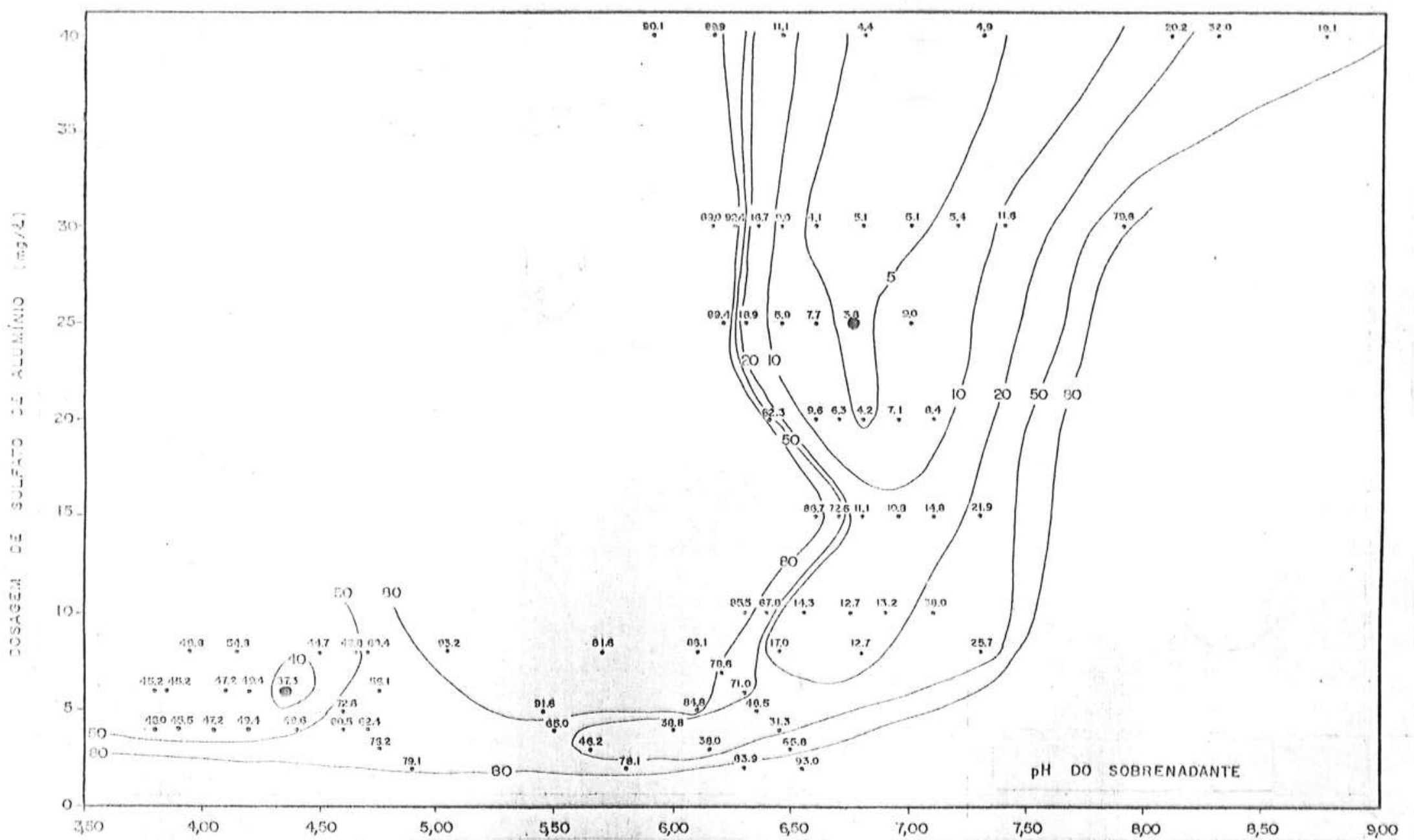

Figura 5.60 - Diagrama de coagulação da Agua Tipo VII. Percentagem da cor aparente remanescente em fun cão da dosagem de sulfato de aluminio e do $\mathrm{pH}$ do sobrenadante.

- turbidez inicial: 8,9 FTU; cor verdadeira inicial: 18,7 mg Pt-Cole; . cor aparente ini cial: 58,7 ma Pt-Coll. 

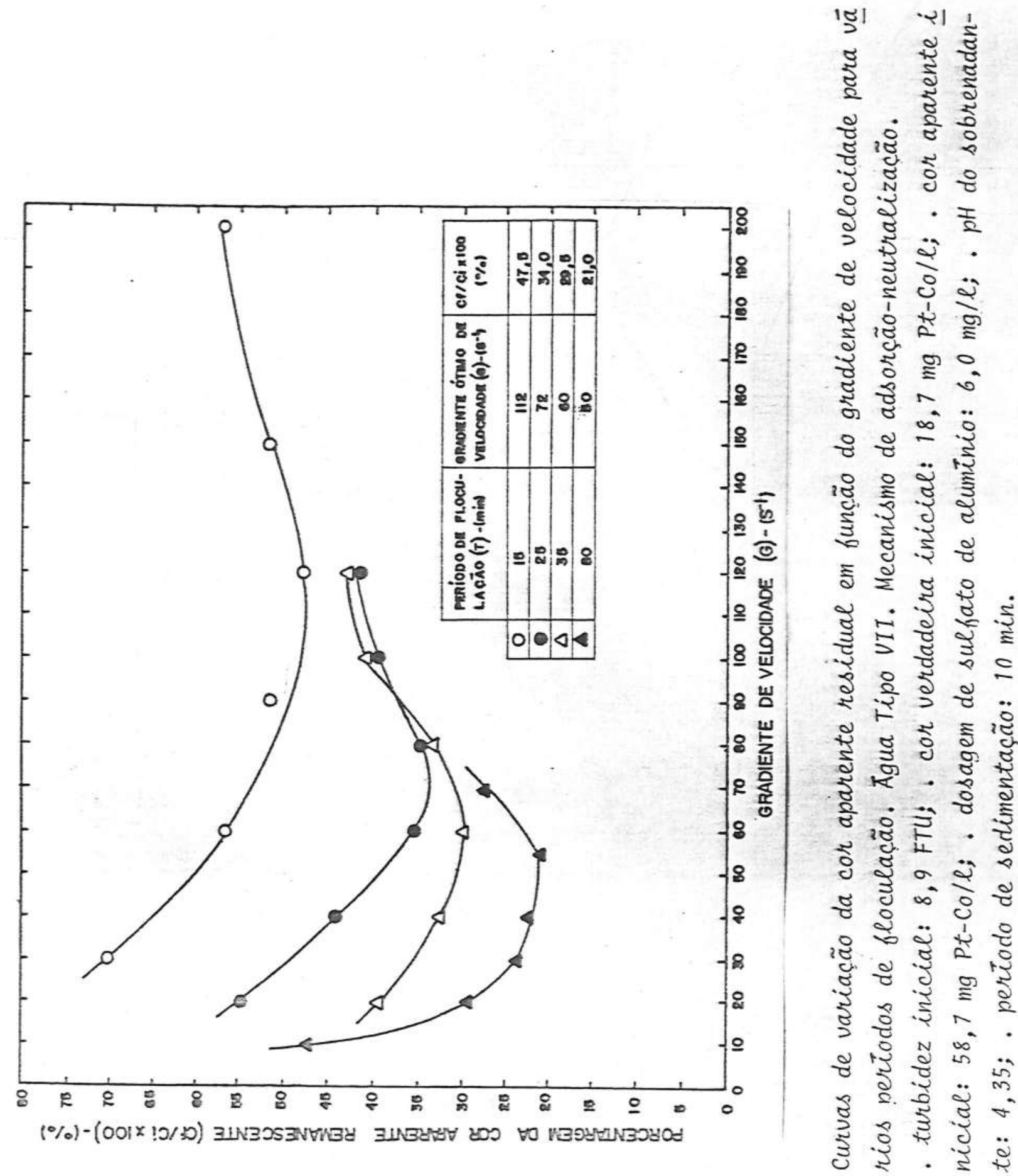

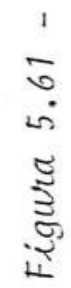




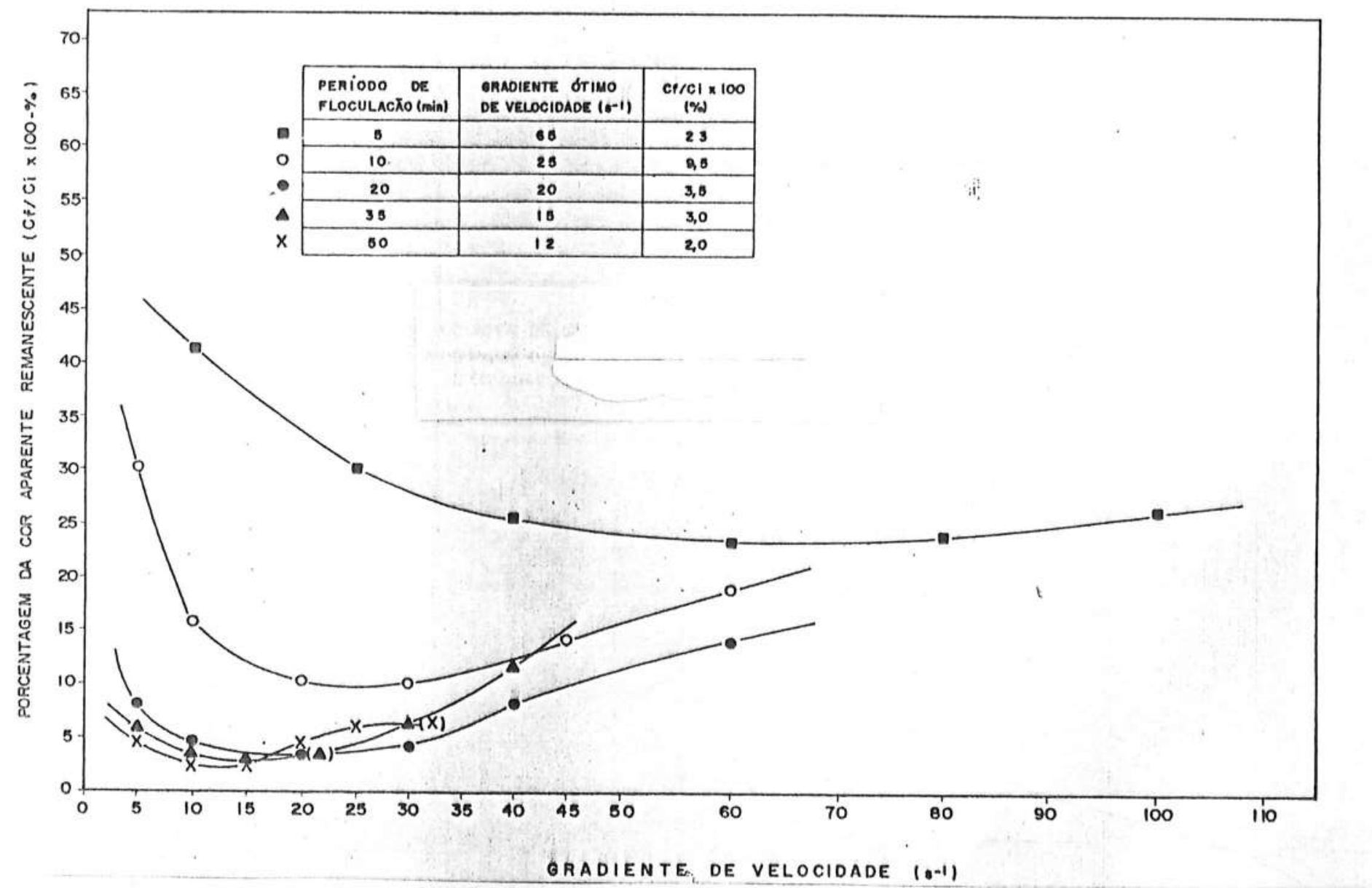

Figura 5.62 - Curvas de variação da cor aparente residual em função do gradiente de velocidade para vä rios períodos de floculação. Agua Tipo VIT. Mecanismo de varredura.

- turbidez inicial: 8,9 FTU; . cor verdadeira inicial: 18,7 mg Pt-Co/l; . cor aparente $\underline{i}$ nicial: $58,7 \mathrm{mg}$ Pt-Co/l; . dosagem de sulfato de aluminio: $25 \mathrm{mg} / \ell$; . pH do sobrenadante : 6,75; . período de sedimentação: $10 \mathrm{~min}$. 


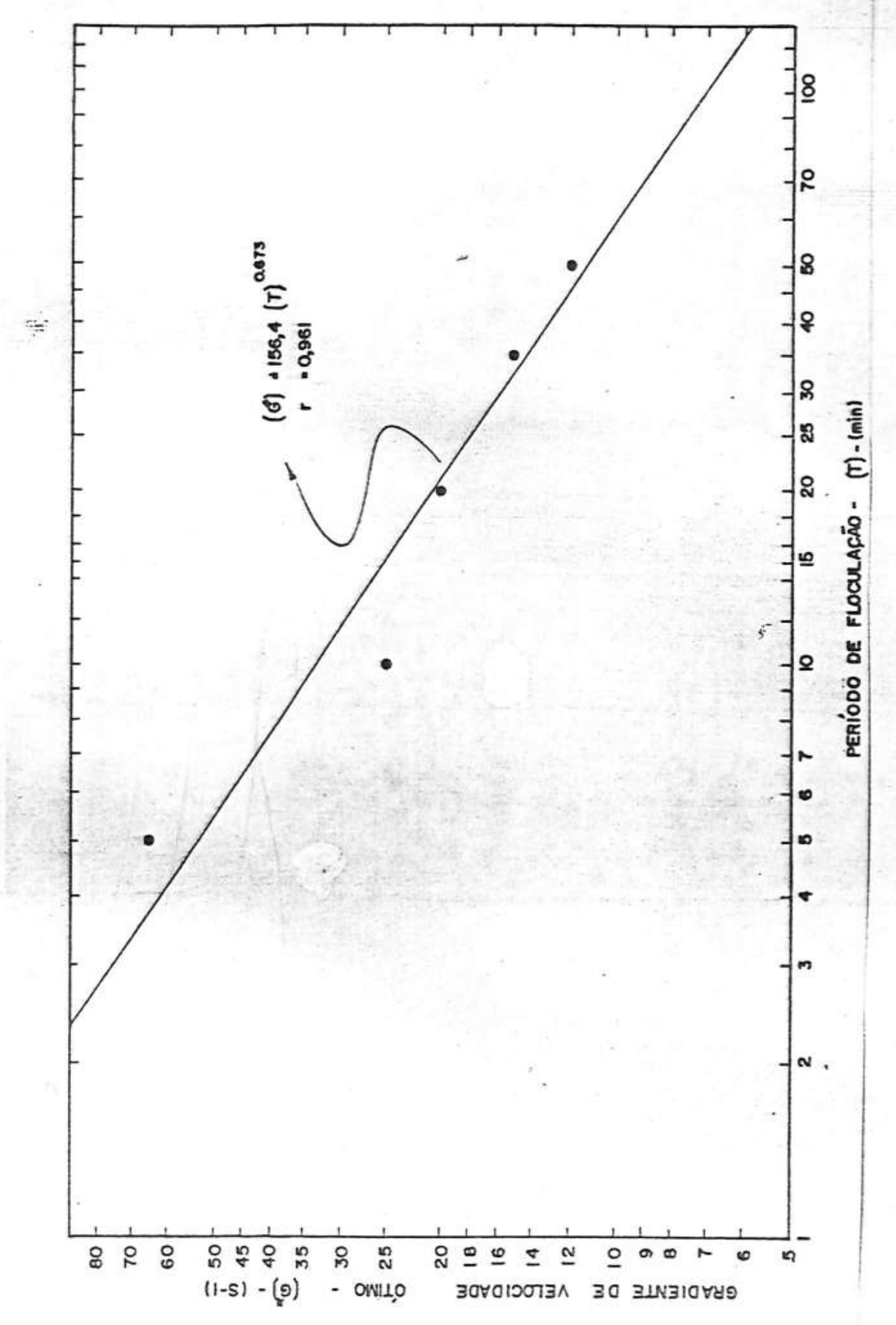

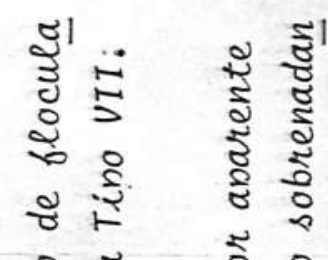

₹

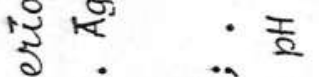

¿

ध छ

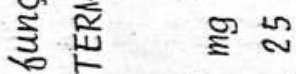

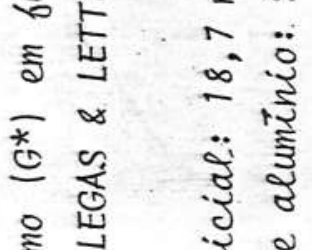

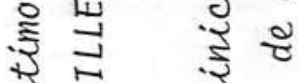

10 120

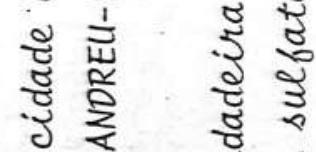

ปे इ \&

ว ट . ग =

ช ฐ

ॠँ

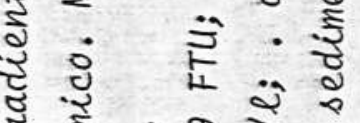

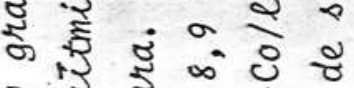

8 उ

, ช.

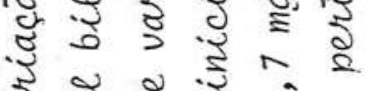

इ ई ช ₹

ช छ छ

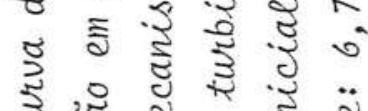

ป̛

1
$m$
0
5
5
$\vdots$
5
5
5 


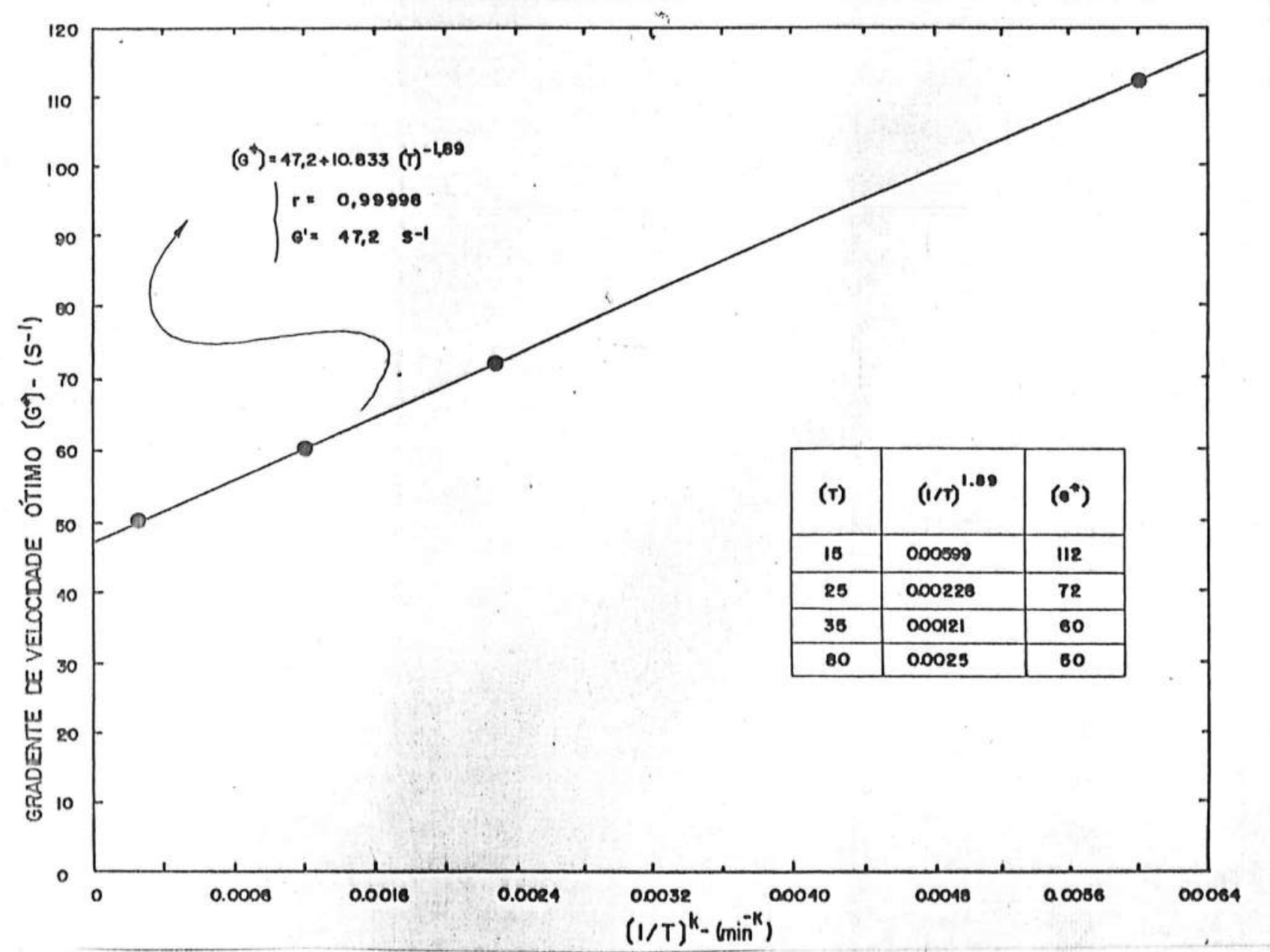

Figura 5.64 - Curva de variação do gradiente de velocidade ötimo $\left(G^{*}\right)$ em função de $(1 / T)^{n}$ para a Agua Tipo VII, onde $T \bar{e}$ o perĩodo de floculação. Mecanismo de adsorção-neutralização.

- turbidez inicial: 8,9 FTU; . cor verdadeira inicial: 18,7 mg Pt-Co/ $\ell$; cor aparente inicial: $58,7 \mathrm{mg} \mathrm{Pt}-\mathrm{Co} / \mathrm{l}$; . dosagem de sulfato de aluminio: $6 \mathrm{mg} / \ell$; $\mathrm{pH}$ do sobrenadante: 4,35 ; . periodo de sedimentação: $10 \mathrm{~min}$. 


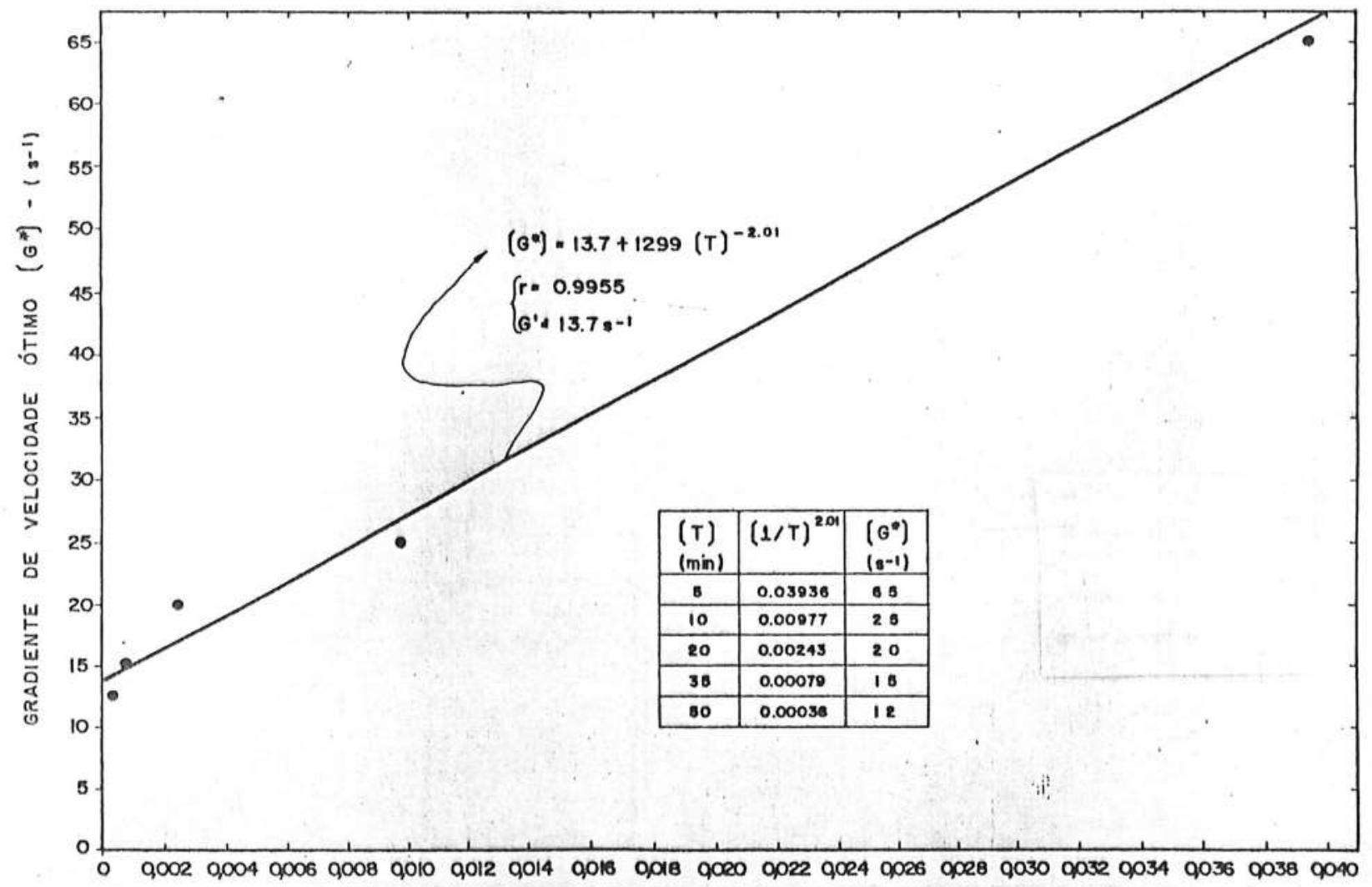

$(1 / T)^{k}-\left(\min ^{-k}\right)$

Figura 5.65 - Curva de variação do gradiente de velocidade ötimo $\left(G^{*}\right)$ em função de $(1 / T)^{n}$ para a Água Tipo VIT, onde $T \bar{e}$ o perïodo de floculação. Mecanismo de varredura.

- turbidez inicial: 8,9 FTU; . cor verdadeira inicial: $18,7 \mathrm{mg} \mathrm{Pt-Co/ \ell ;} \mathrm{.} \mathrm{cor} \mathrm{aparente}$ inicial: $58,7 \mathrm{mg} P t-C o / l$; . dosagem de sulfato de aluminio: $25 \mathrm{mg} / \ell$; . pH do sobrenadan te: 6,75 ; . período de sedimentação: 10 min. 


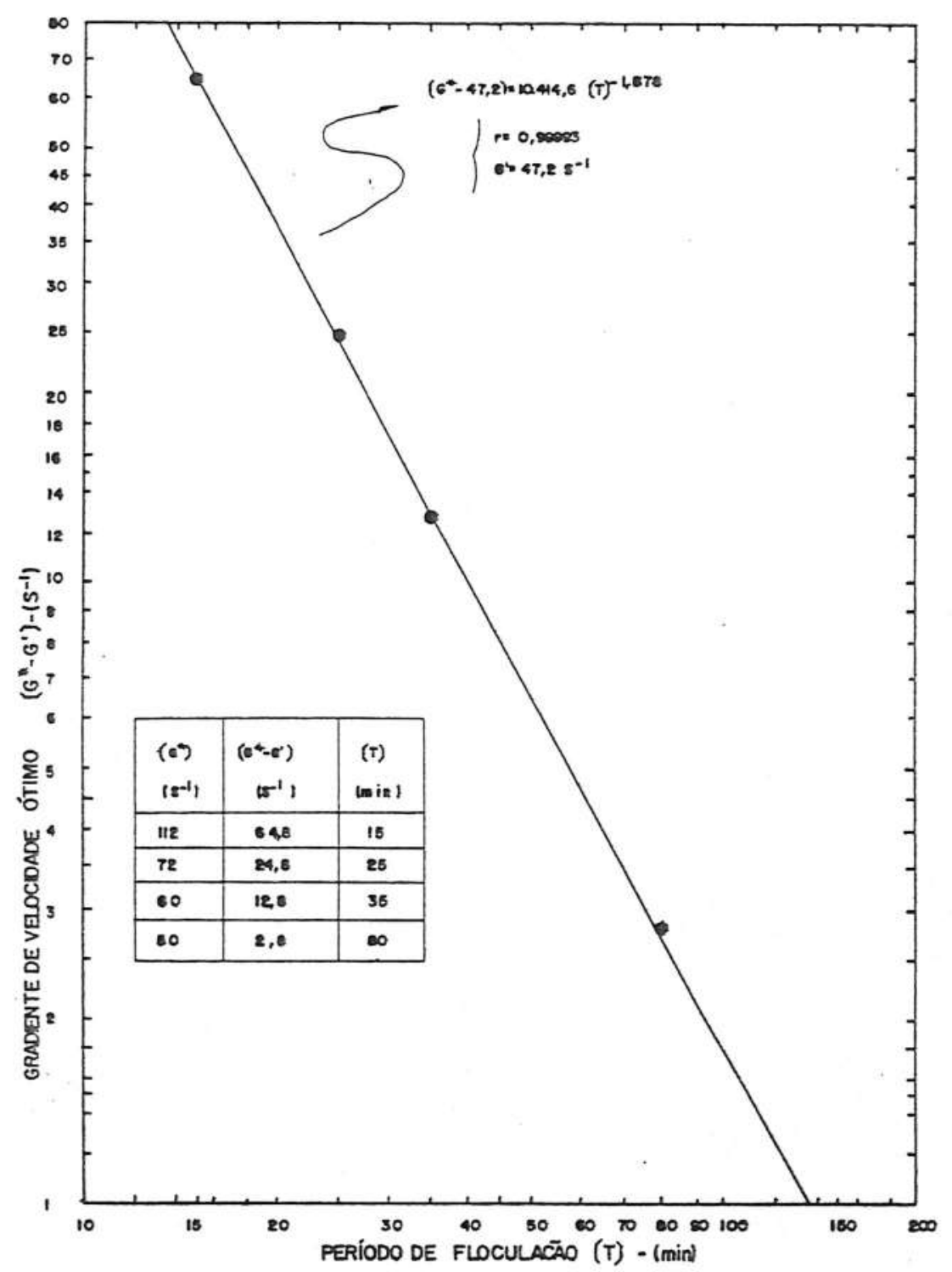

Figura 5.66 - Curva de variação do gradiente de velocidade $\left(G^{\star}\right.$ - $\left.G^{\prime}\right)$ em função do perĩodo de floculação. Agua Tipo VII. Me canismo de adsorção-neutralização. Modelo proposto.

- turbidez inicial: 8,9 FTU; . cor verdadeira inicial: $18,7 \mathrm{mg} \mathrm{Pt}-\mathrm{Co} / \mathrm{l}$; . Cor aparente inicial: $58,7 \mathrm{mg}$ Pt-Co ll; . dosagem de sulfato de aluminio: $6 \mathrm{mg} / \ell$; $\mathrm{pH}$ do sobrenadante: 4,35; . período de sedimentação: $10 \mathrm{~min}$. 


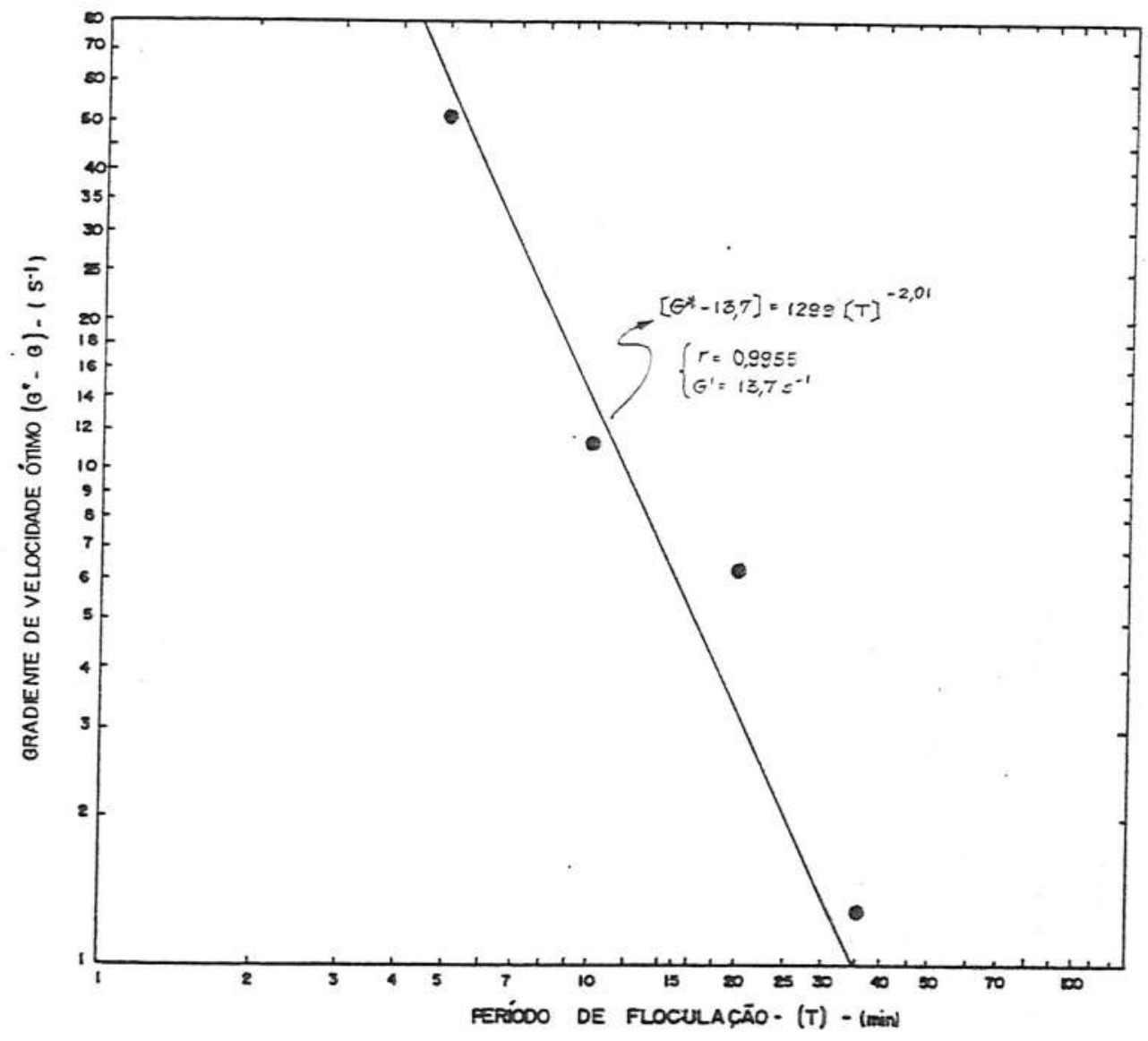

Figura 5.67 - Curva de variação do gradiente de velocidade $\left(G^{*}\right.$ - $\left.G^{\prime}\right)$ em função do perĩodo de floculação. Āaua Tipo VII. Me canismo de varredura. Modelo proposto.

- turbidez inicial: 8,9 FTU; . cor verdadeira inicial: $18,7 \mathrm{mg}$ Pt-Coll; . cor aparente inicial: $58,7 \mathrm{mg} P t-C_{0}$ ll; . dosagem de sulfato de aluminio: $25 \mathrm{ma} / \ell$; $\mathrm{pH}$ do sobrenadante: 6,75 ; periodo de sedimentação: 10 min. 


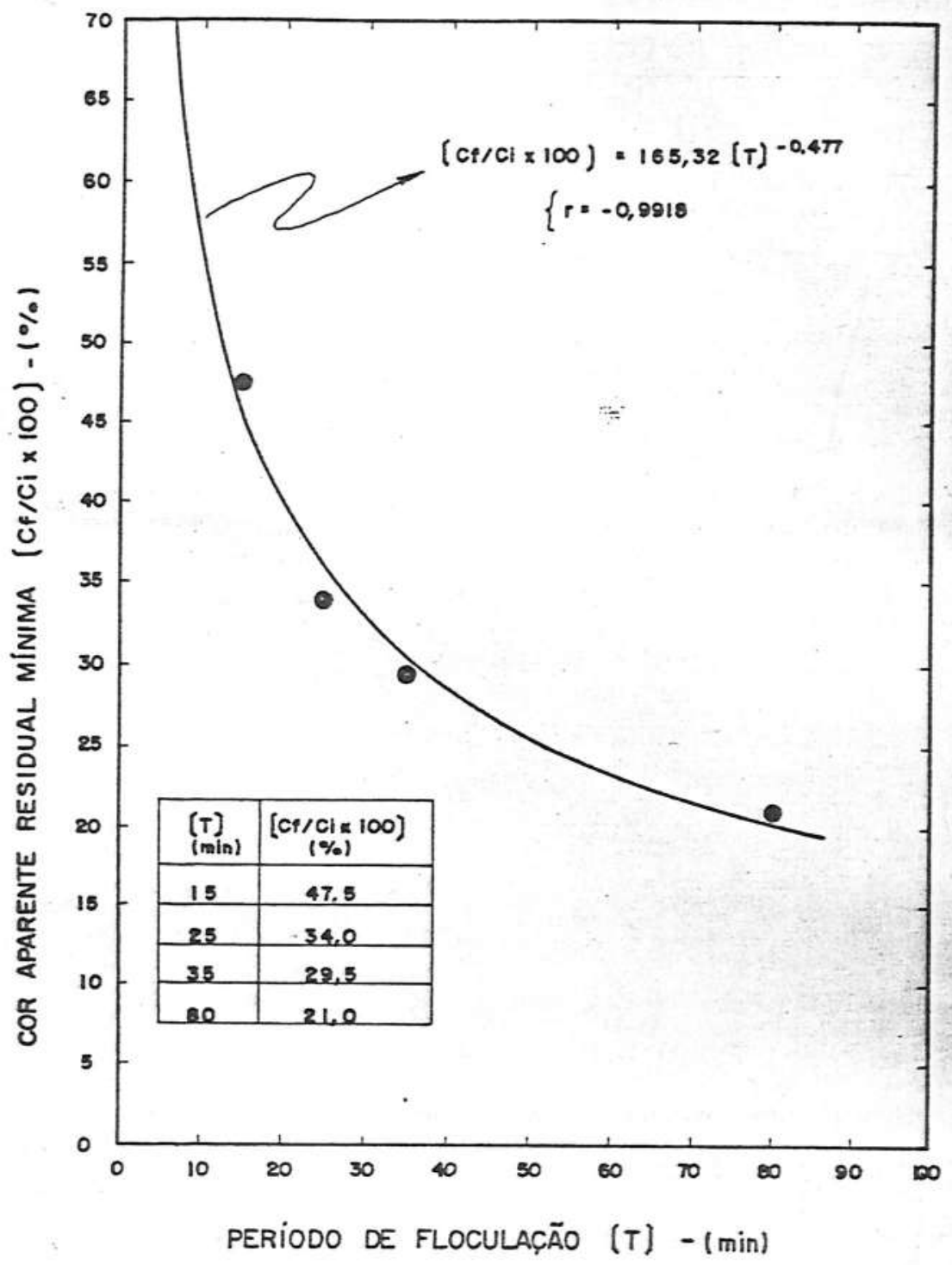

Figura 5.68 - Curva de variação da cor aparente residual minima em fun ção do período de floculação. Agua Típo VII. Mecanismo de adsorção-neutralização.

- turbidez inicial: 8,9 FTU; . cor verdadeira inicial : $18,7 \mathrm{mg}$ Pt-Co/l; . cor aparente inicial: $58,7 \mathrm{mg}$ Pt-Co/l - dosagem de sulfato de aluminio: $6 \mathrm{mg} / l$; pH do sobrenadante: 4,35; . período de sedimentação: $10 \mathrm{~min}$. 


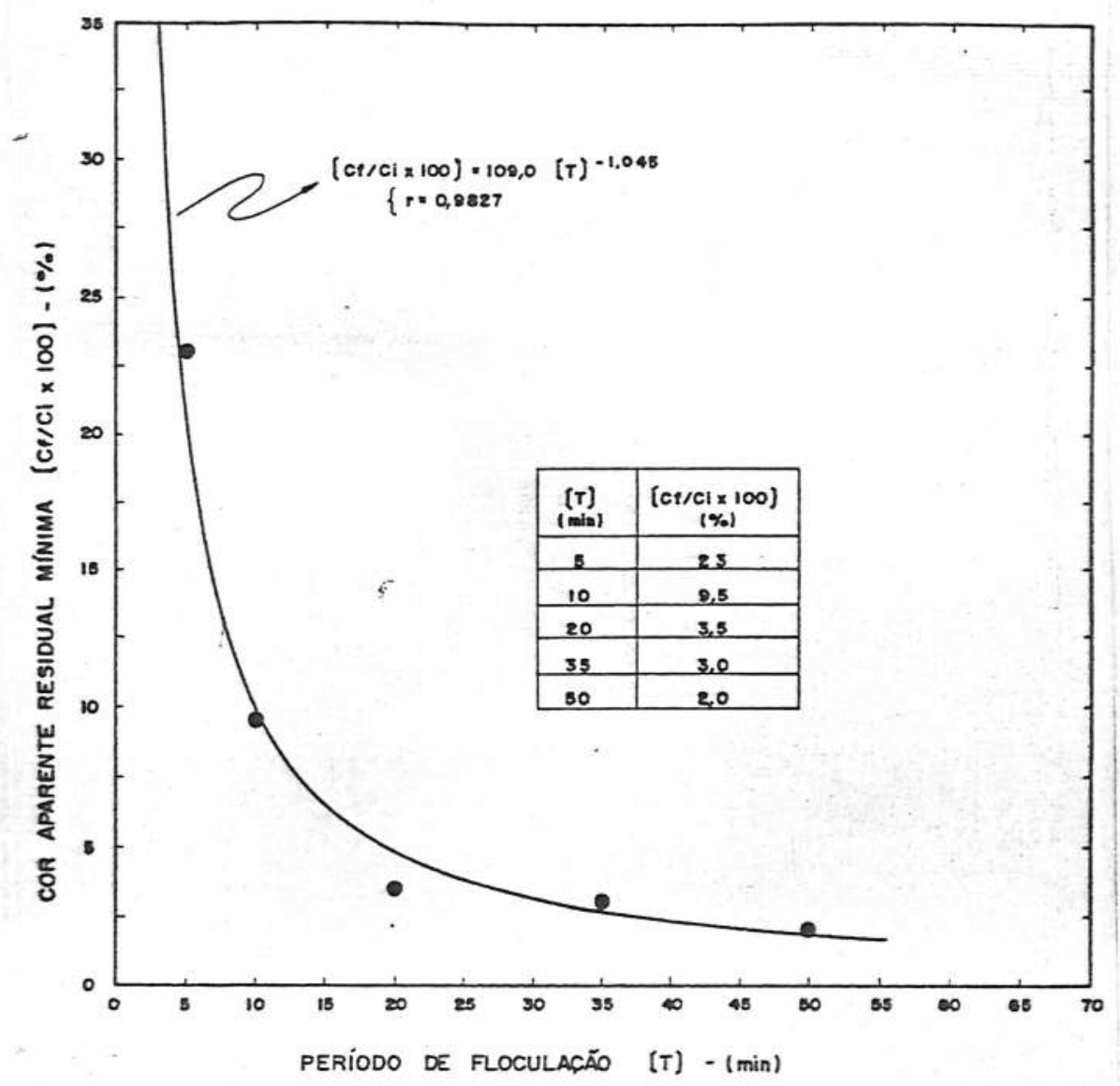

Figura 5.69 - Curva de variação da cor aparente residual minima em fun ção do período de floculação. Agua Típo VII. mecanismo de varredura.

- turbidez inicial: 8,9 FTU; . cor verdadeira inicial : $18,7 \mathrm{mg}$ Pt-Co/l; . cor aparente inicial: $58,7 \mathrm{mg}$ Pt-Co/l - dosagem de sulfato de aluminio: $25 \mathrm{mg} / \mathrm{l}$; $\mathrm{pH}$ do sobre nadante: 6,75 ; . período de sedimentacão: $10 \mathrm{~min}$. 


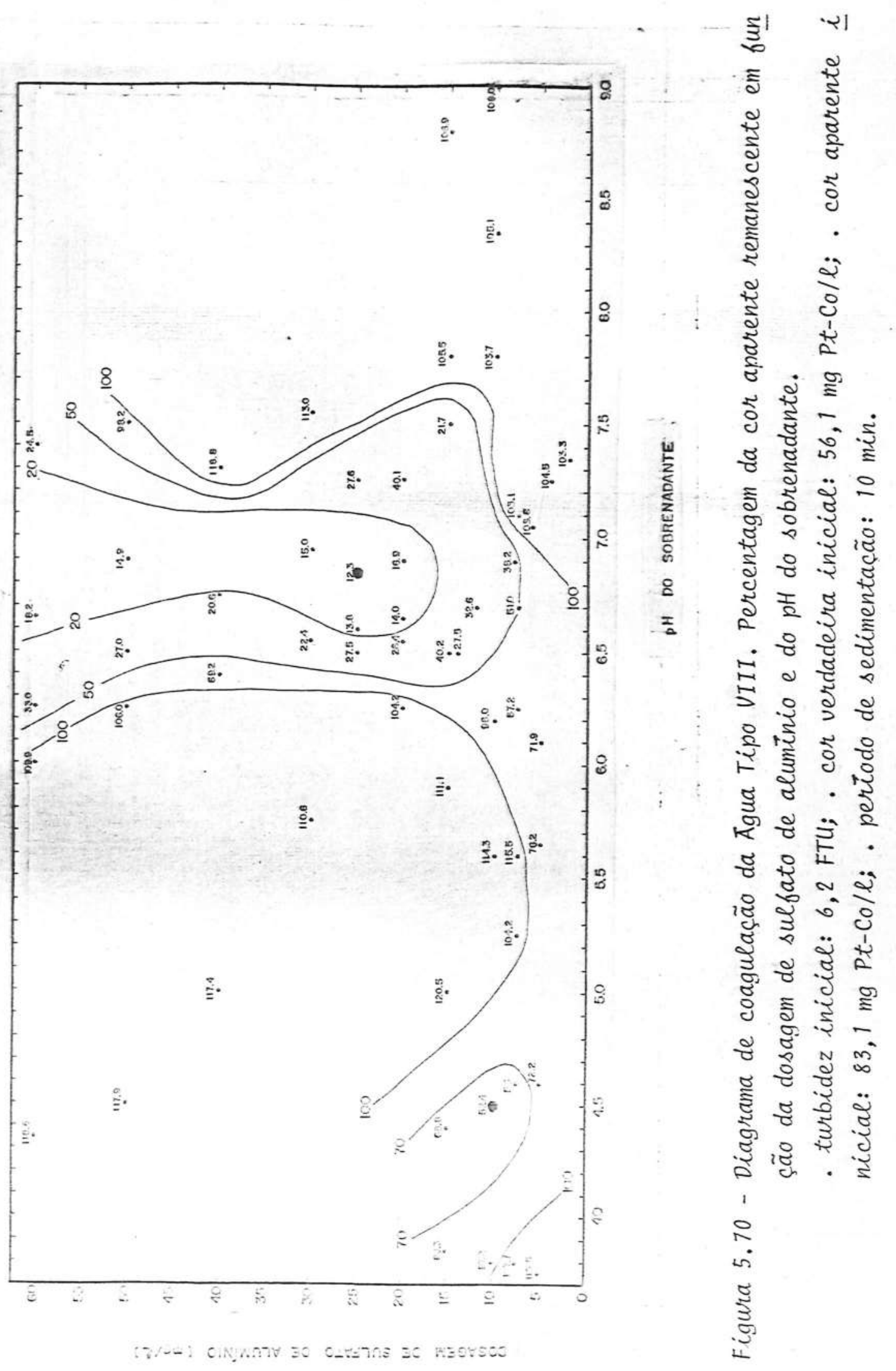




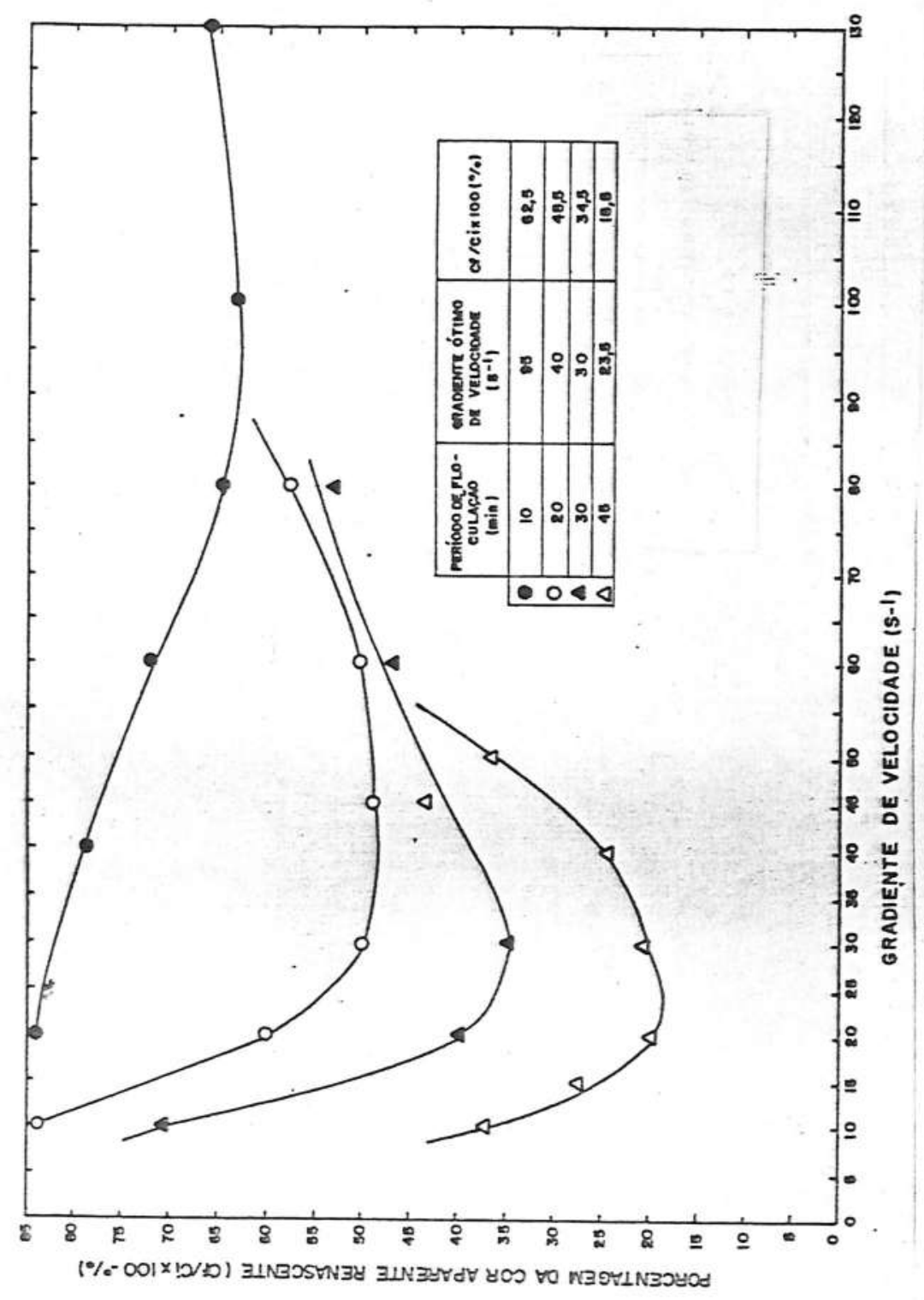

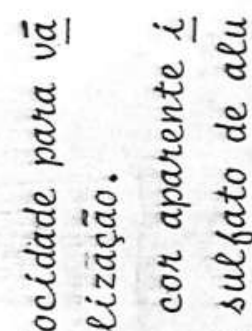

ఏँ

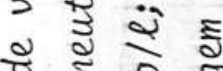

- 1008

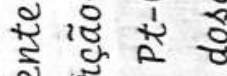

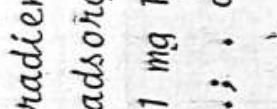

व.

ช ชี का ई

용

吾

इ रू र

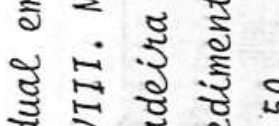

梂

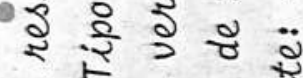

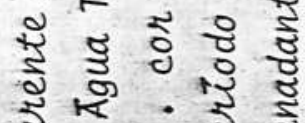

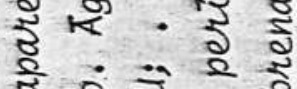

व

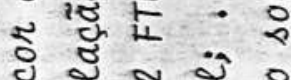

ช

-

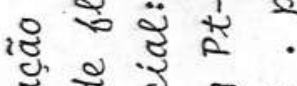

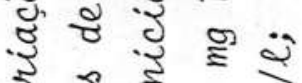

స

ช

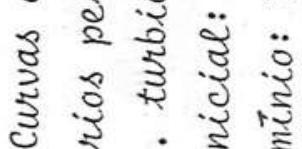

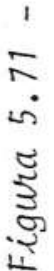



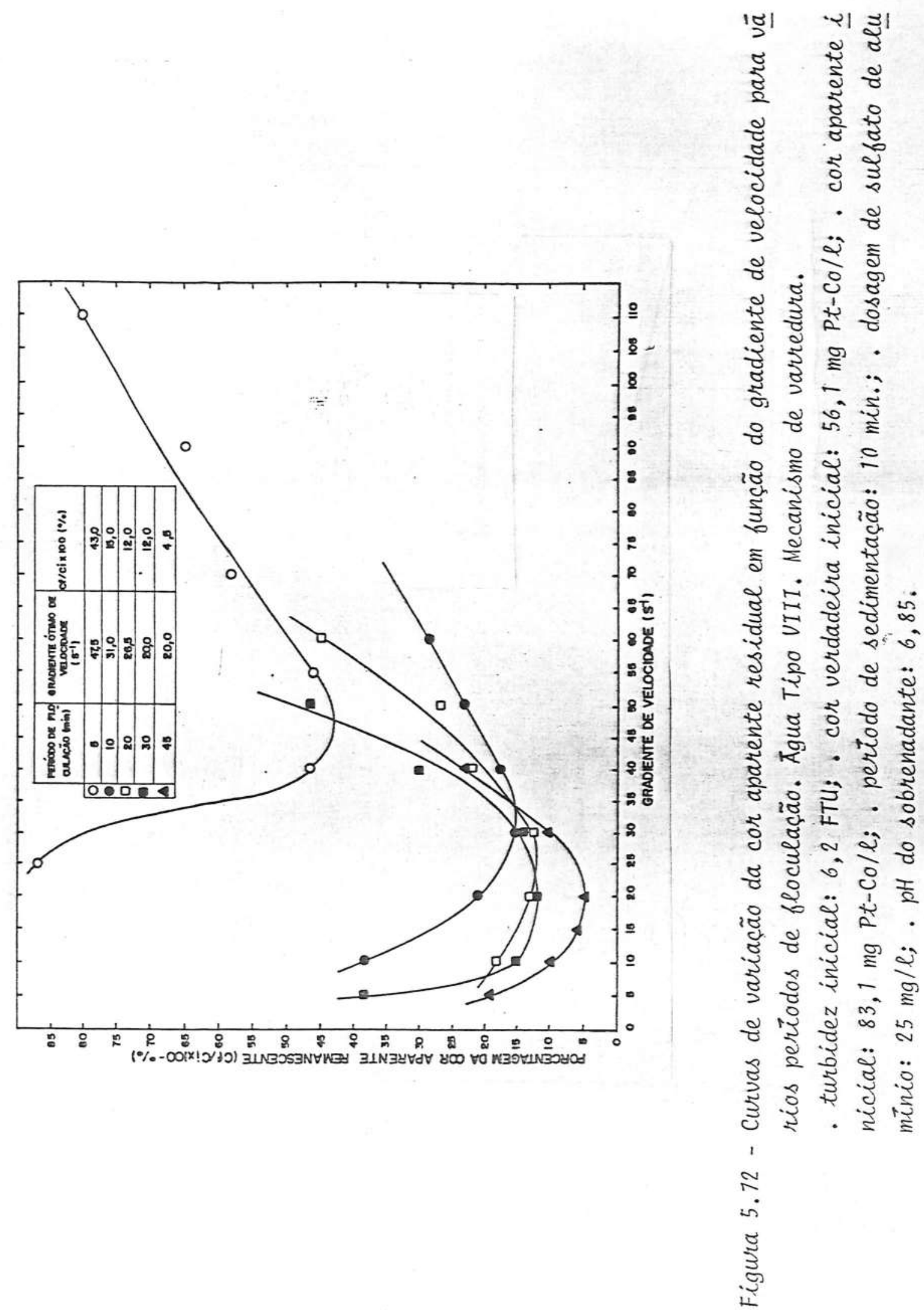


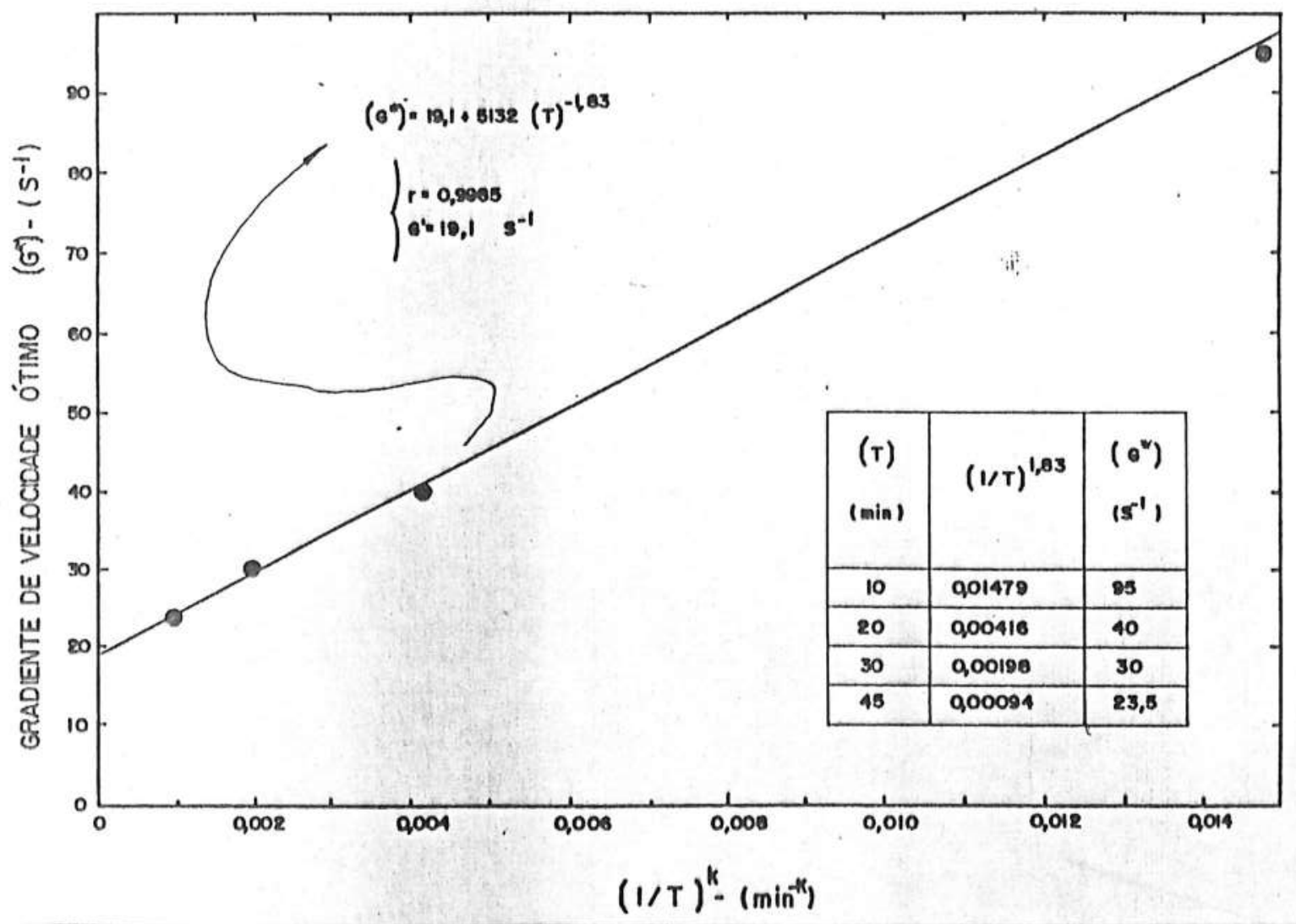

Figura 5.73 - Curva de variação do gradiente de velocidade ötimo $\left(G^{*}\right)$ em função de $(1 / T)^{n}$ para a Āgua Tipo VIII, onde T é o periodo de floculação. Mecanismo de adsorção-neutralizaçãa.

- turbidez inicial: 6,2 FTU; . cor verdadeira inicial: 56,1 mg Pt-Co/ $\ell$; cor aparente inicial: $83,1 \mathrm{mg}$ Pt-Coll; periodo de sedimentação: $10 \mathrm{~min}$.; . dosagem de sulfato de a luminio: $10 \mathrm{mg} / \mathrm{l}$; . $\mathrm{pH}$ do sobrenadante: 4,50 . 


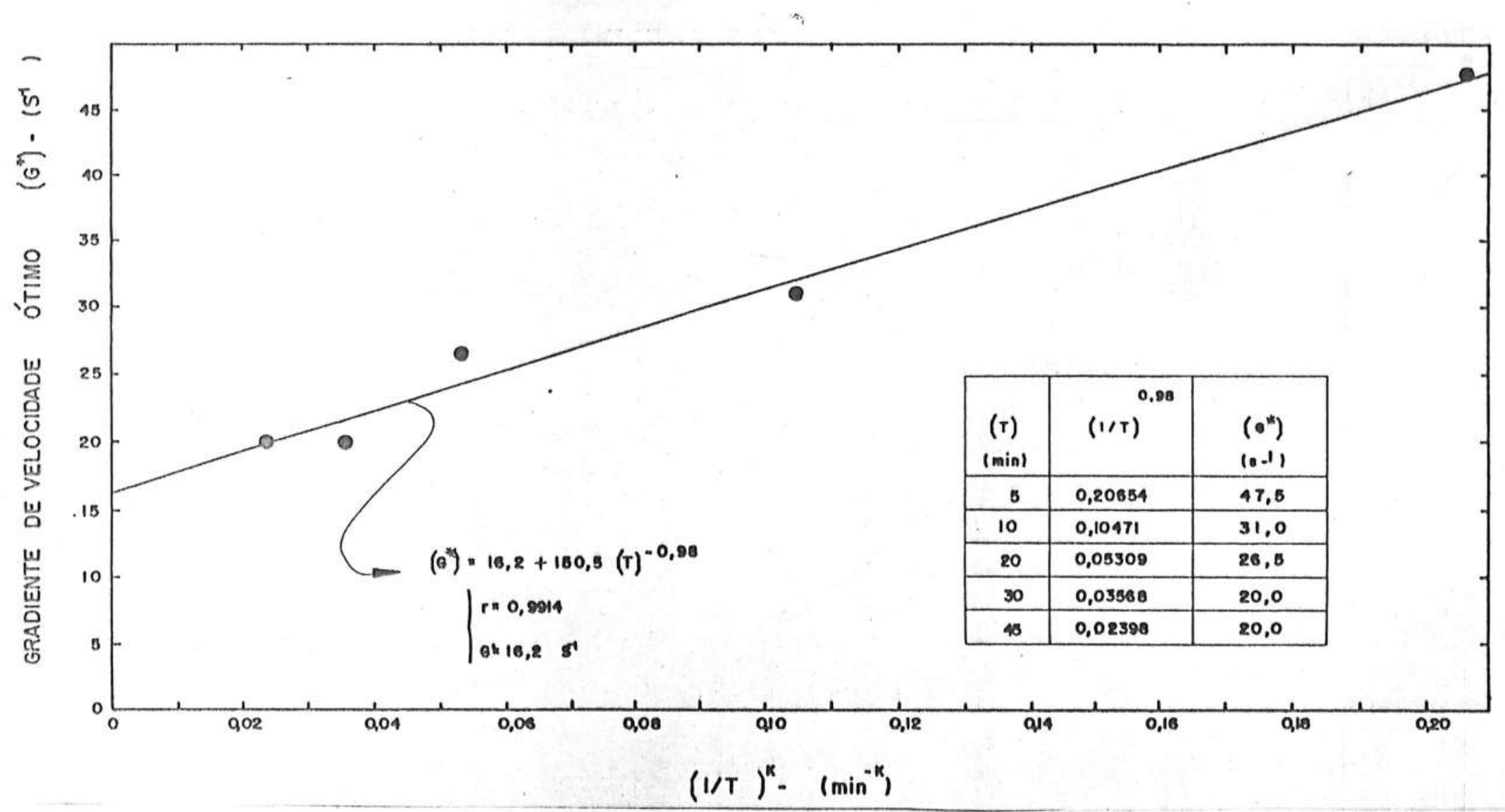

Figura 5.74 - Curva de variação do gradiente de velocidade ötimo $\left(G^{*}\right) \mathrm{em}$ função de $(1 / T)^{n}$ para a Ägua Tipo VITI, onde $T \bar{e} o$ periodo de floculação. Mecanismo de varredura.

- turbidez inicial: 6,2 FTU; . cor verdadeira inicial: 56,1 mg Pt-Co/l; . cor aparente inicial: $83,1 \mathrm{mg}$ Pt-Co/l ; período de sedimentação: $10 \mathrm{~min}$; . dosagem de sulfato de a luminio: $25 \mathrm{mg} / \ell$; $\mathrm{pH}$ do sobrenadante: 6,85 . 


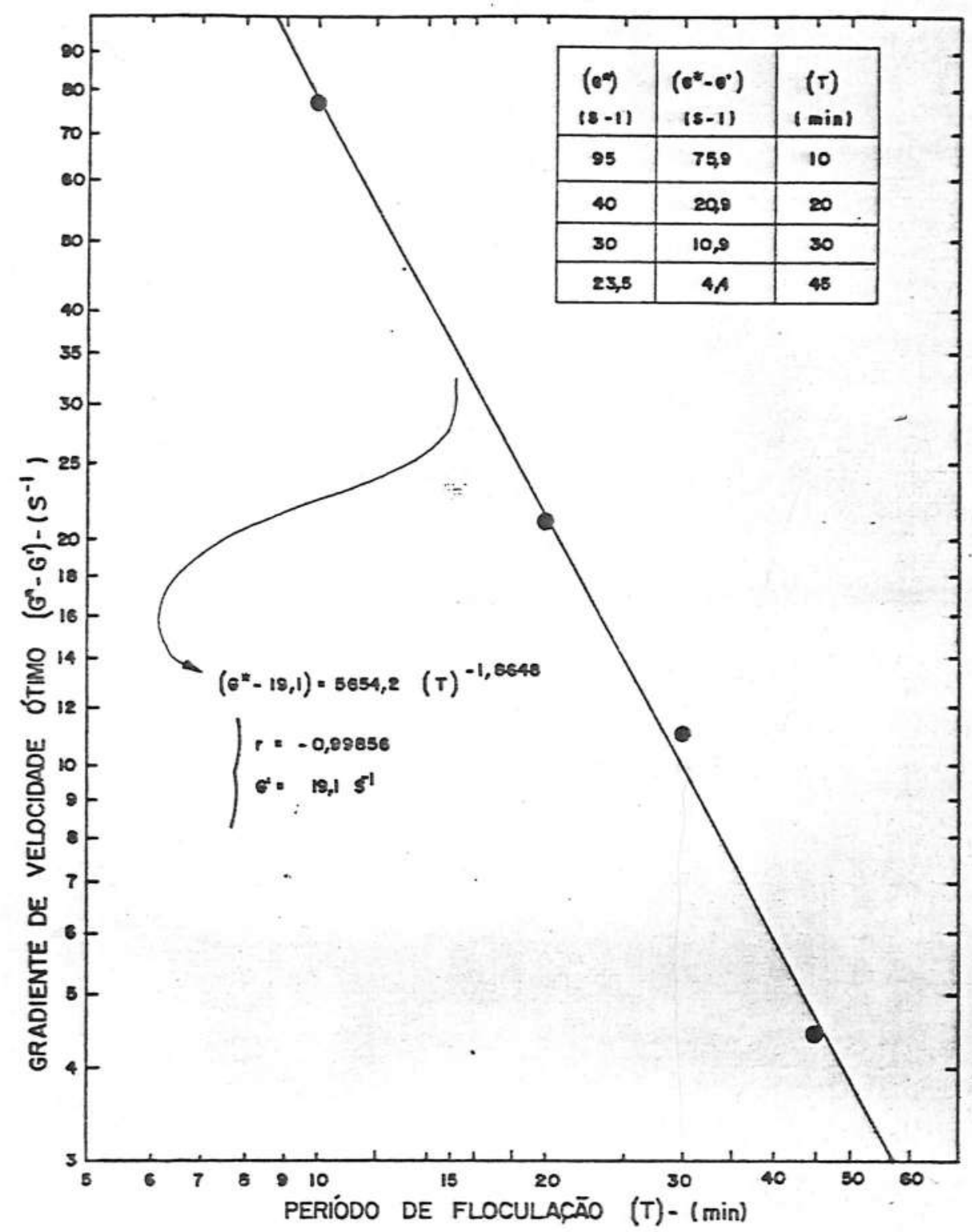

Figura 5.75 - Curva de variação do gradiente de velocidade $\left(G^{*}-G^{\prime}\right)$ em função do perĩodo de floculação. Agua Tipo VIII. Me canismo de adsorção-neutralização. Modelo proposto.

- turbidez inicial: 6,2 FTU; . cor verdadeira inicial: $56,1 \mathrm{mg}$ Pt-Coll; . cor aparente inicial: $83,1 \mathrm{mg}$ Pt-Co ll; . período de sedimentação: 10 min.; . dosagem de sulfato de aluminio: $10 \mathrm{mg} / \mathrm{l}$; $\mathrm{pH}$ do sobrenadante : 4,50 . 


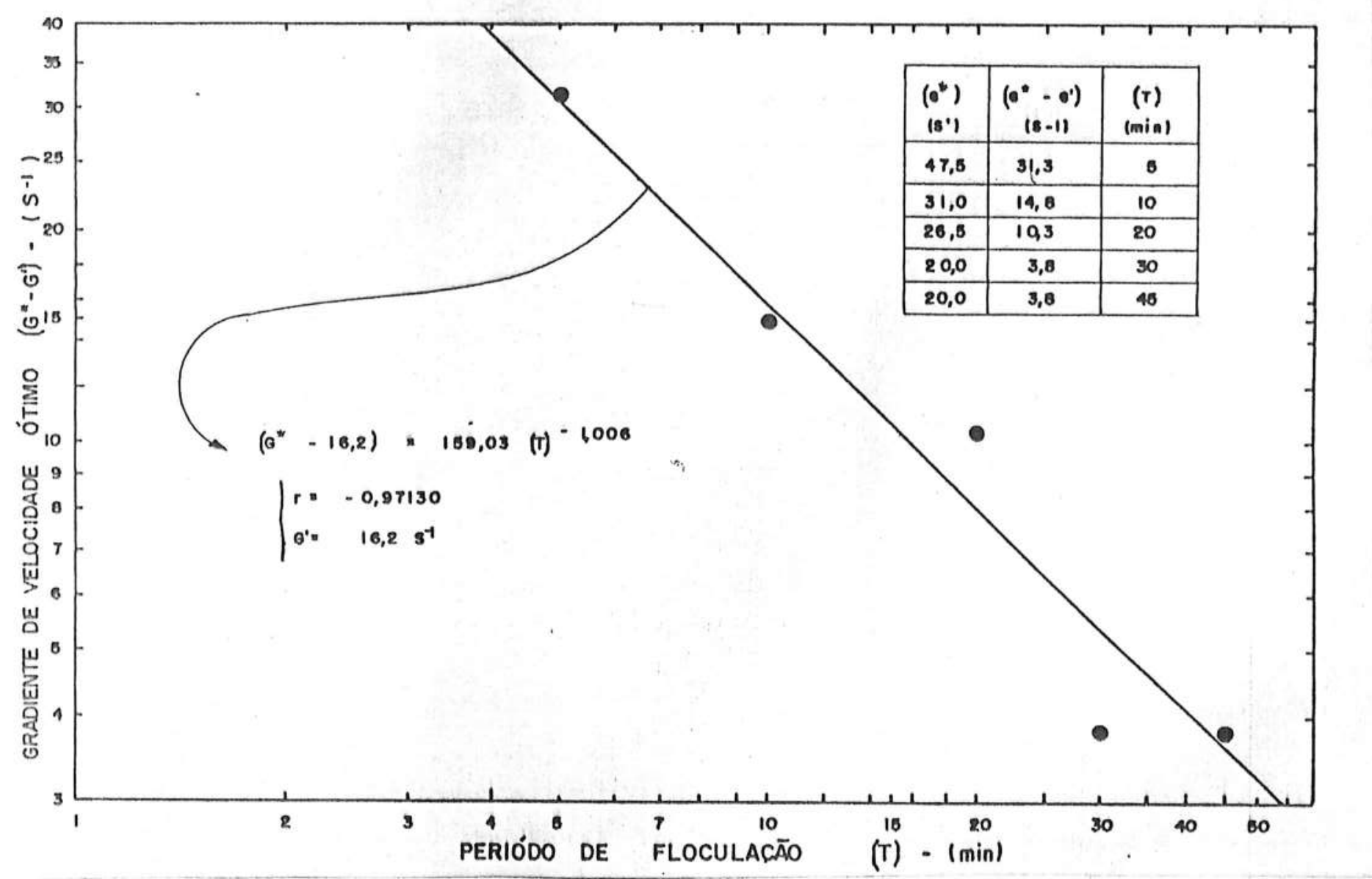

Figura 5.76 - Curva de variação do gradiente de velocidade $\left(G^{*}-G^{\prime}\right)$ em função do perïodo de flocula ção. Agua Tipo VIII. Mecanismo de varredura. Modelo proposto.

- turbidez inicial: 6,2 FTU; . cor verdadeira inicial: 56,1 mg Pt-Co/l; . cor aparente inicial: $83,1 \mathrm{mg}$ Pt-Coll; . perĩodo de sedimentação: $10 \mathrm{~min}$; . dosagem de sulfato de aluminio: $25 \mathrm{mg} / \ell$; . pH do sobrenadante: 6,85 . 


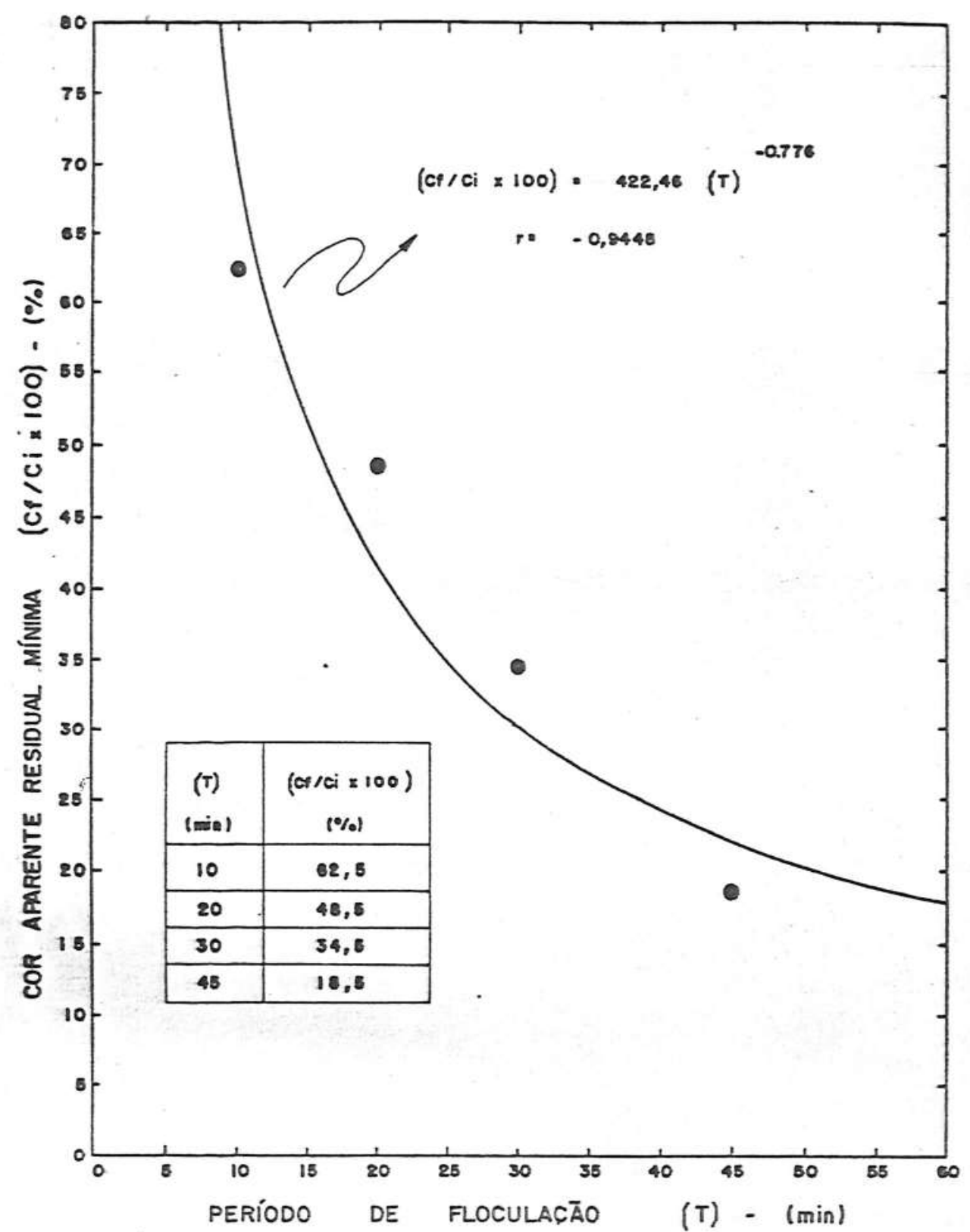

Figura 5.77 - Curva de variação da cor aparente residual minima em fun ção do perĩodo de floculação. Água Tipo VIII. Mecanismo de adsorção-neutralização.

- turbidez inicial: 6,2 FTU; . cor verdadeira inicial : $56,1 \mathrm{mg}$ Pt-Coll; . cor aparente inicial: $83,1 \mathrm{mg}$ Pt-Co/l - dosagem de sulfato de aluminio: $10 \mathrm{mg} / \mathrm{l}$; $\mathrm{pH}$ do sobre nadante: 4,50; . período de sedimentação: $10 \mathrm{~min}$. 


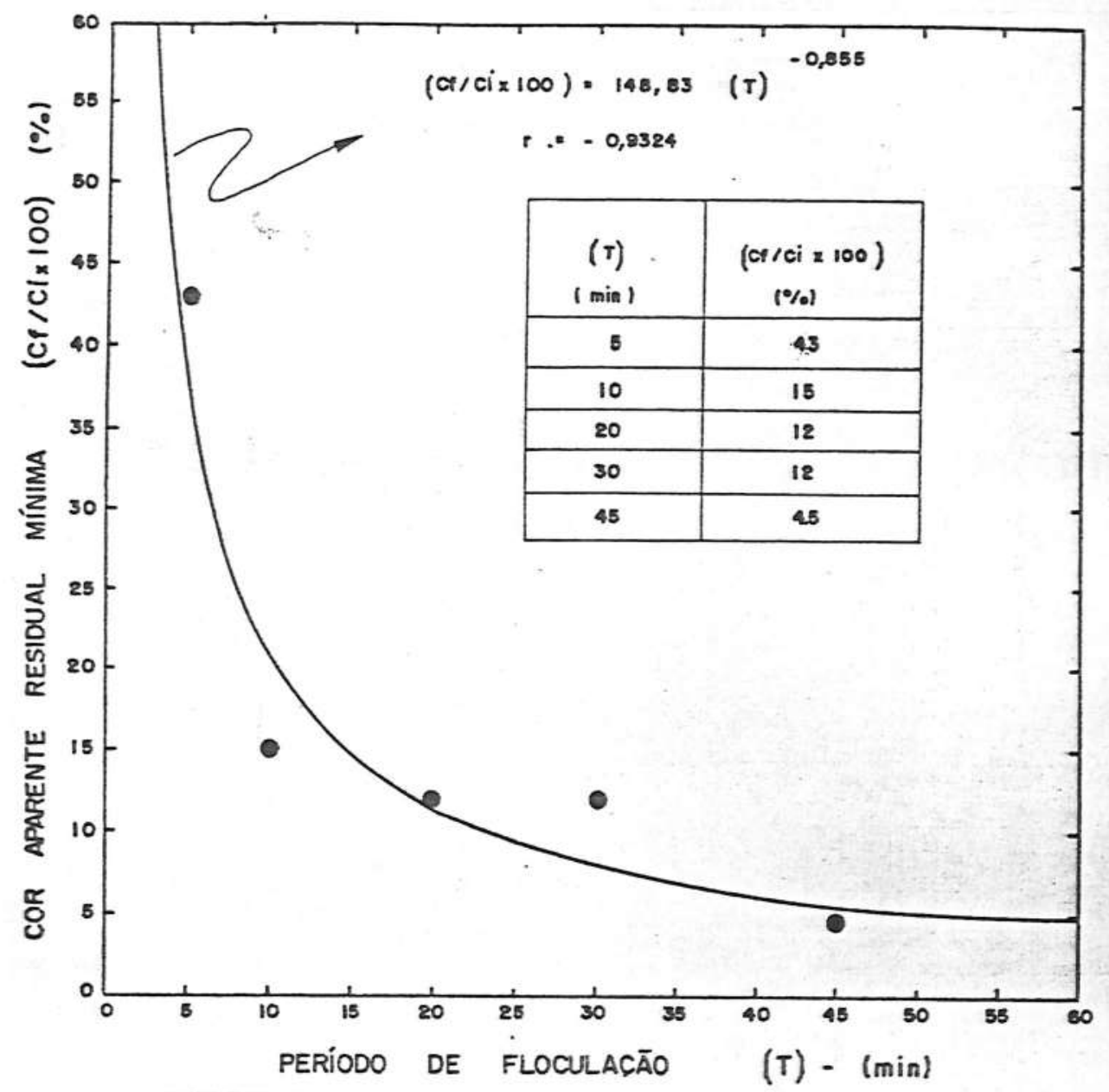

Figura 5.78 - Curva de variação da cor aparente residual minima em fun ção do período de floculação. Agua Tipo VIII. Mecanismo de varredura.

- turbidez inicial: 6,2 FTU; . cor verdadeira inicial : $56,1 \mathrm{mg}$ Pt-Coll; . Cor aparente inicial: $83,1 \mathrm{mg} \mathrm{Pt}-\mathrm{Co} / \mathrm{l}$ - dosagem de sulfato de aluminio: $25 \mathrm{mg} / \mathrm{l}$; . pH do sobre nadante: 6,85 ; . período de sedimentação: $10 \mathrm{~min}$. 


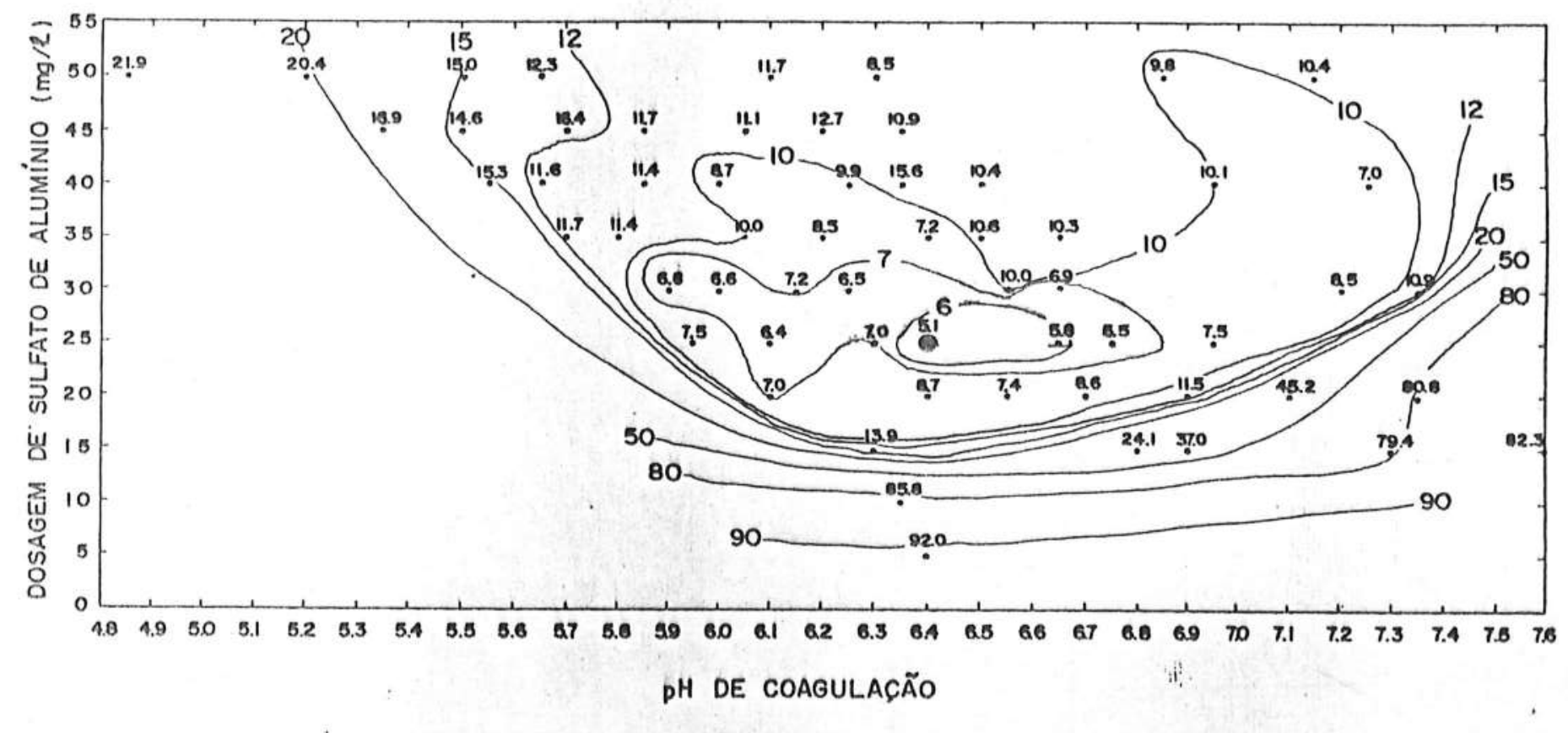

Fiaura 5.79 - Diagrama de coagulação da Agua Tipo IX. Percentagem da cor aparente remanescente em fun ção da dosagem de sulfato de aluménio e do $\mathrm{pH}$ do sobrenadante.

- turbidez inicial: $30 \mathrm{FTU}$; cor verdadeira inicial: $47,2 \mathrm{mg} \mathrm{Pt-Co/l}$; cor aparente inicial: $188,9 \mathrm{mg}$ Pt-Co/l; periodo de sedimentação: $10 \mathrm{~min}$. 


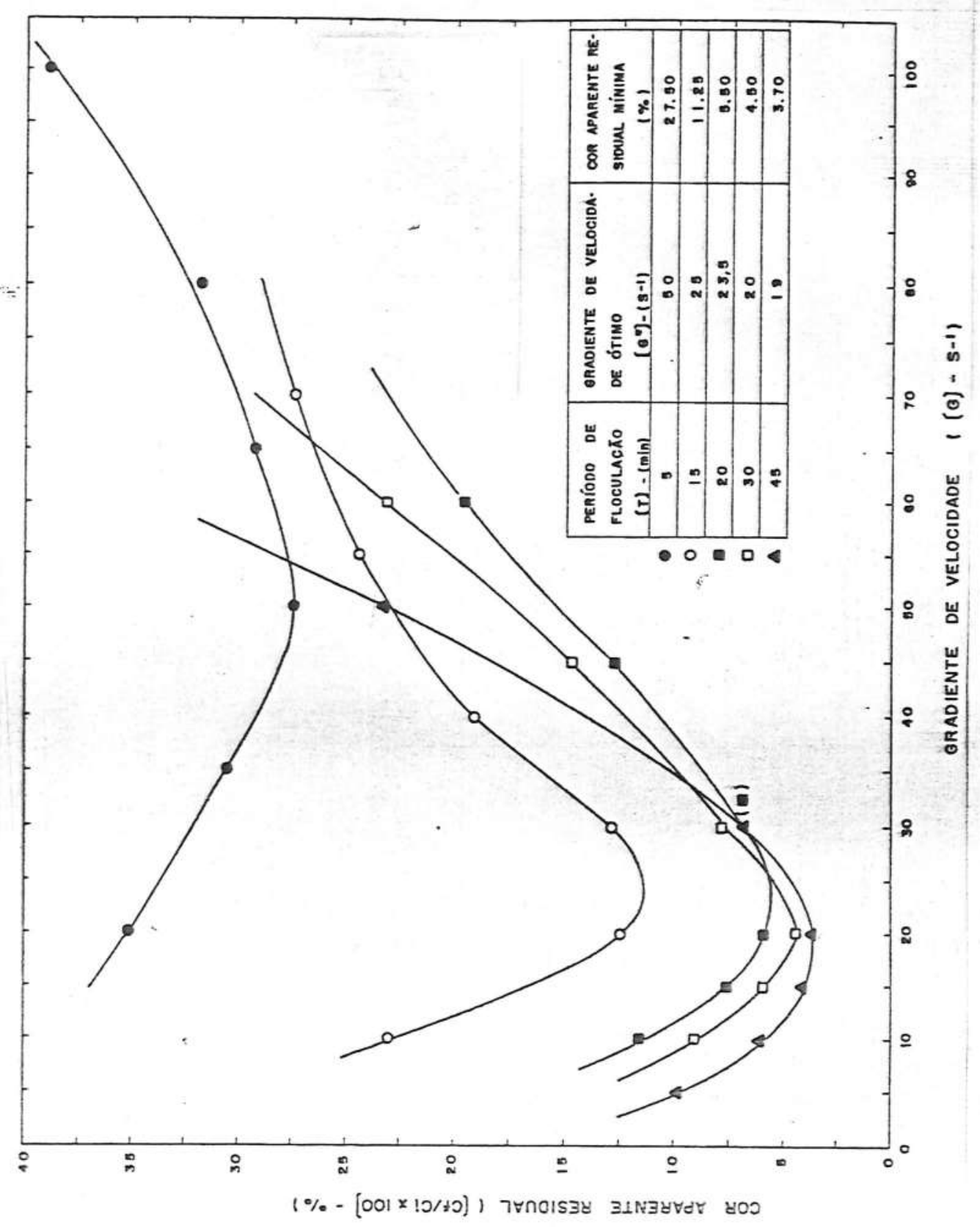

छु रा खा

ई

ग

ป गे

ปั

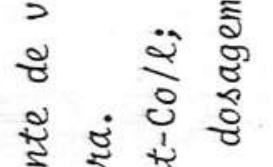

उ

ปั

- $\mathcal{8} \approx$

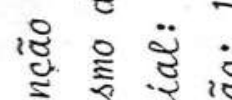

गี.

इ ठู ई

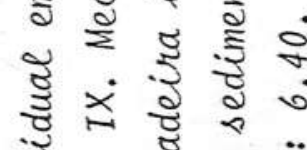

ई

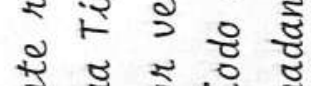

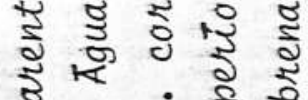

8. 0 은

多

ช

\&

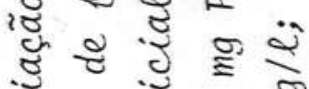

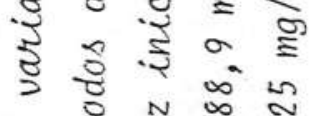

ช

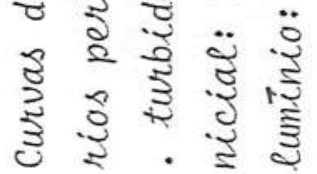

1
0
$\infty$
0
5
5
0
0
0 


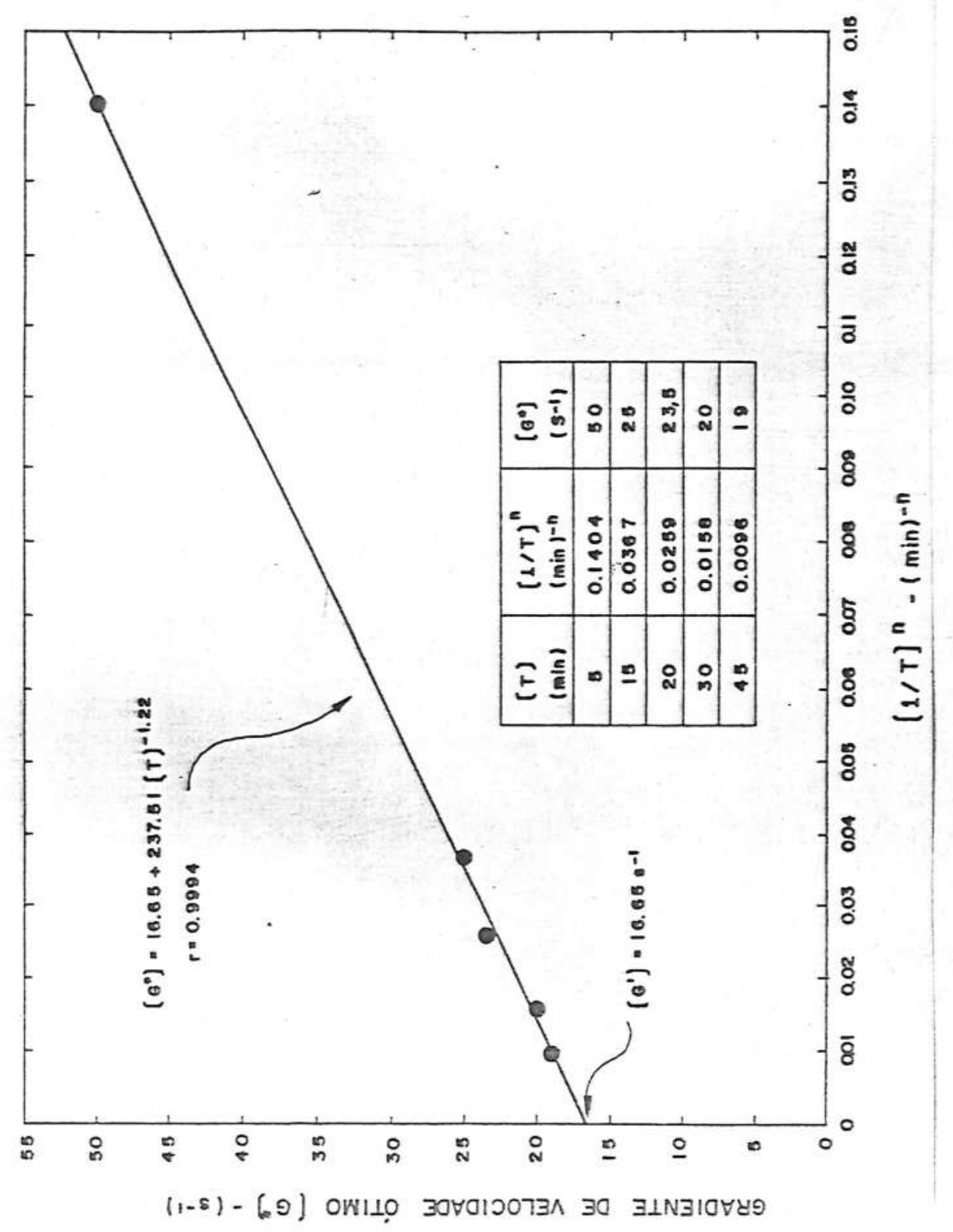

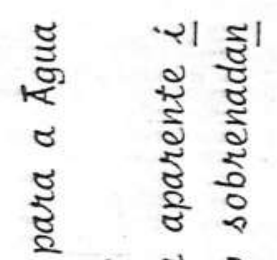

$=$ ป

E

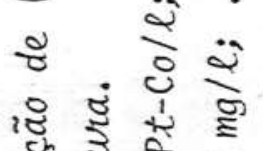

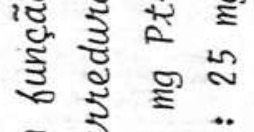

ป

* ข

잃

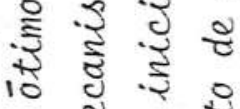

ชี $\frac{0}{2}$

ป্

ปร

ई

\& \&

ईँ 8 .

ग

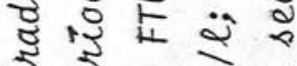

o ฐ

- $0 \ddot{2}$ 文

先 $10 . \overline{2}$

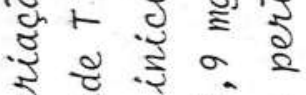

万.

ชै $x$. ปี

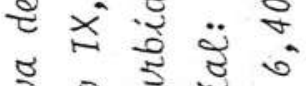

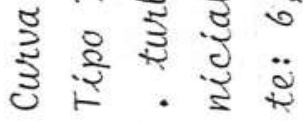

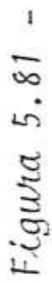




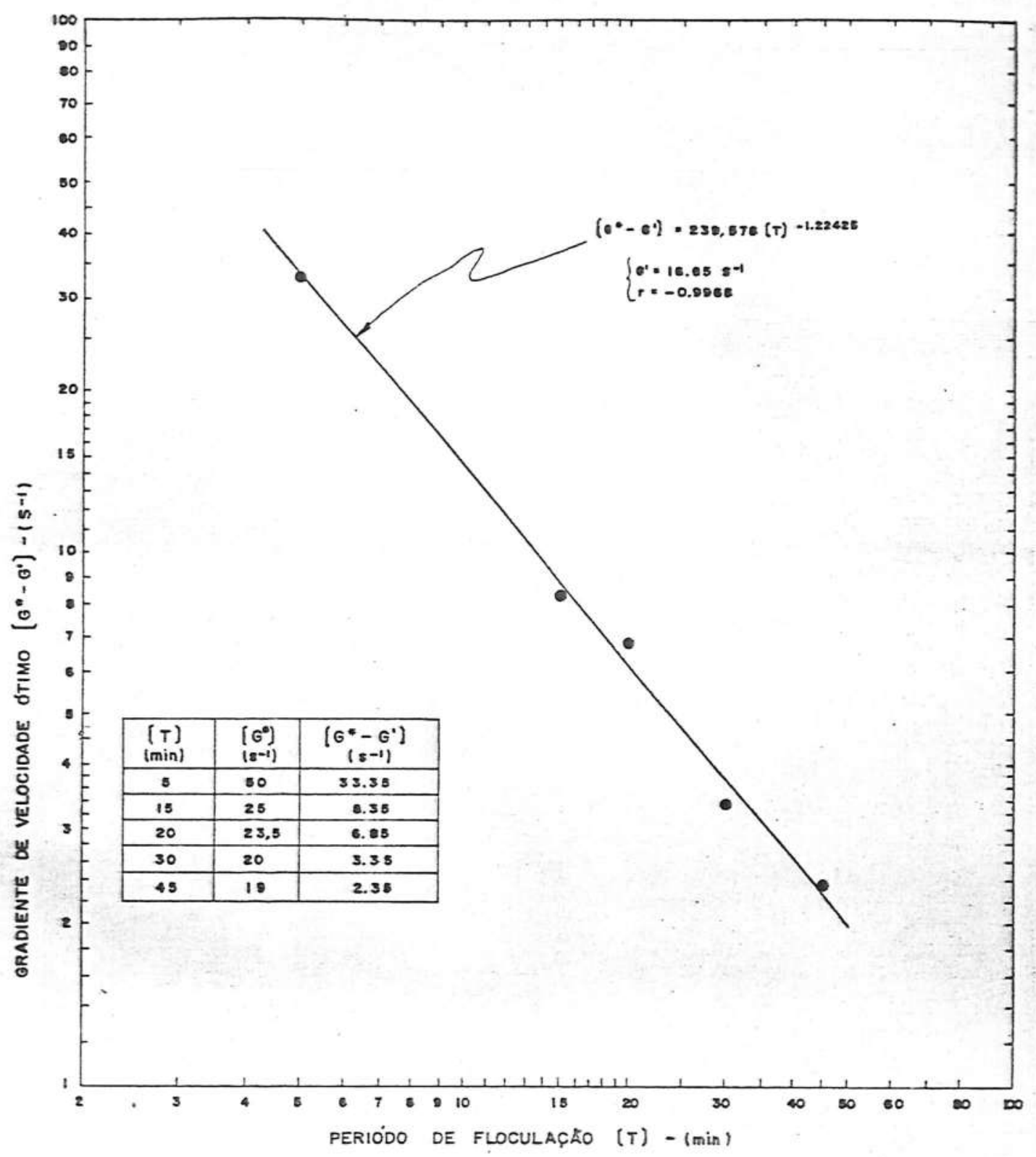

Figura 5.82 - Curva de variação do gradiente de velocidade (G* - $\left.G^{\prime}\right)$ em função do perĩodo de floculação. Agqua Tipo IX. Meca nismo de varredura.

- turbidez inicial: $30 \mathrm{FTU}$; cor verdadeira inicial : $47,2 \mathrm{mg}$ Pt-Co/l; . cor aparente inicial: $188,9 \mathrm{mg} P t-$ Coll; . dosagem de sulfato de aluminio: $25 \mathrm{mg} / \mathrm{l}$; $\mathrm{pH}$ do sobrenadante: 6,40; . período de sedimentação: 10 min. 


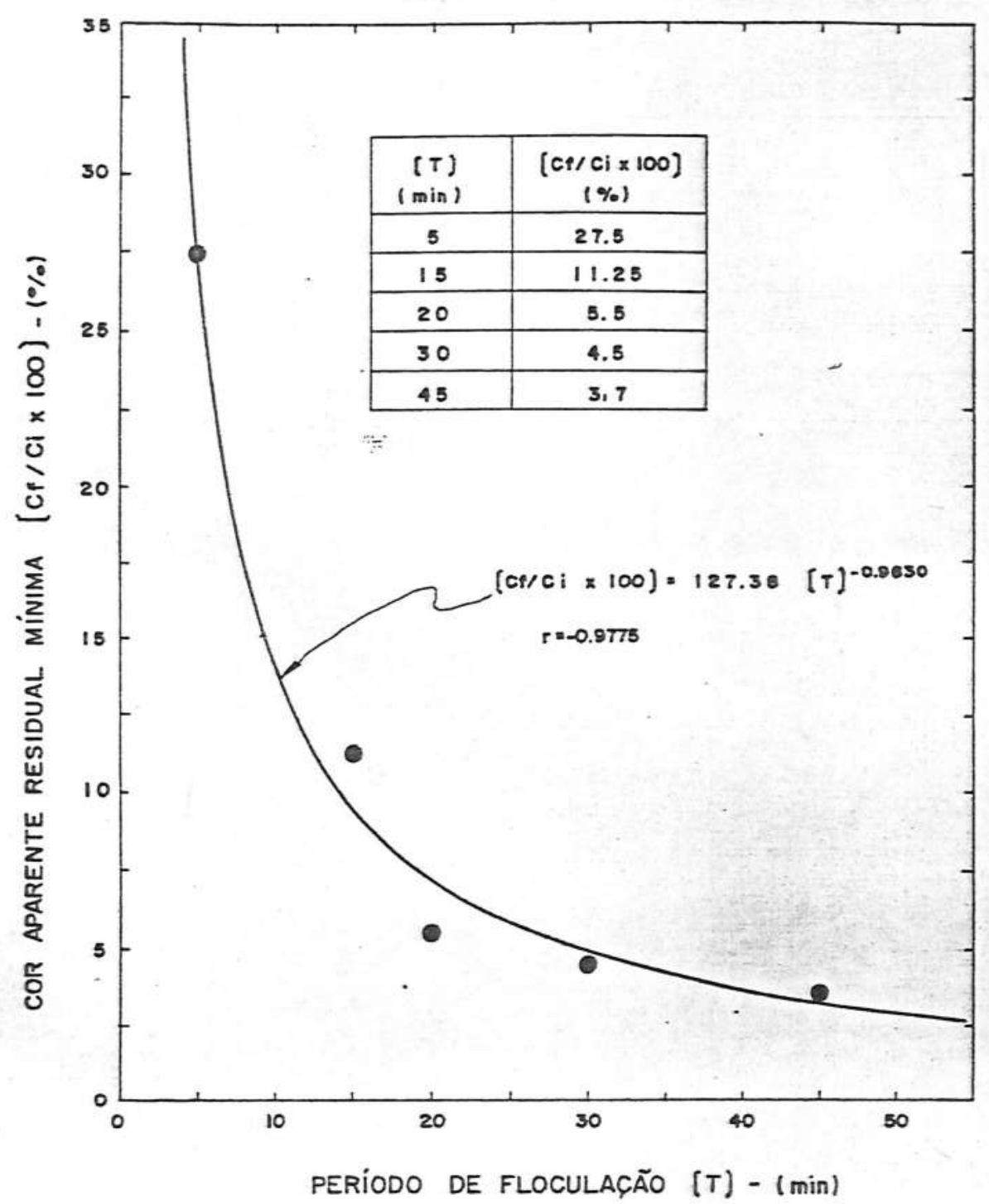

Figura 5.83 - Curva de variação da cor aparente residual minima em fun ção do perĩodo de floculação. Água Tipo IX. Mecanismo de varredura.

- turbidez inicial: 30 FTU; . car verdadeira inicial : $47,2 \mathrm{mg}$ Pt-Coll; . Cor aparente inicial: $188,9 \mathrm{mg}$ Pt-Col l; . dosagem de sulfiato de aluminio: $25 \mathrm{mg} / \mathrm{l}$; . pH do so brenadante: 6,40 ; período de sedimentação: 10 min. 


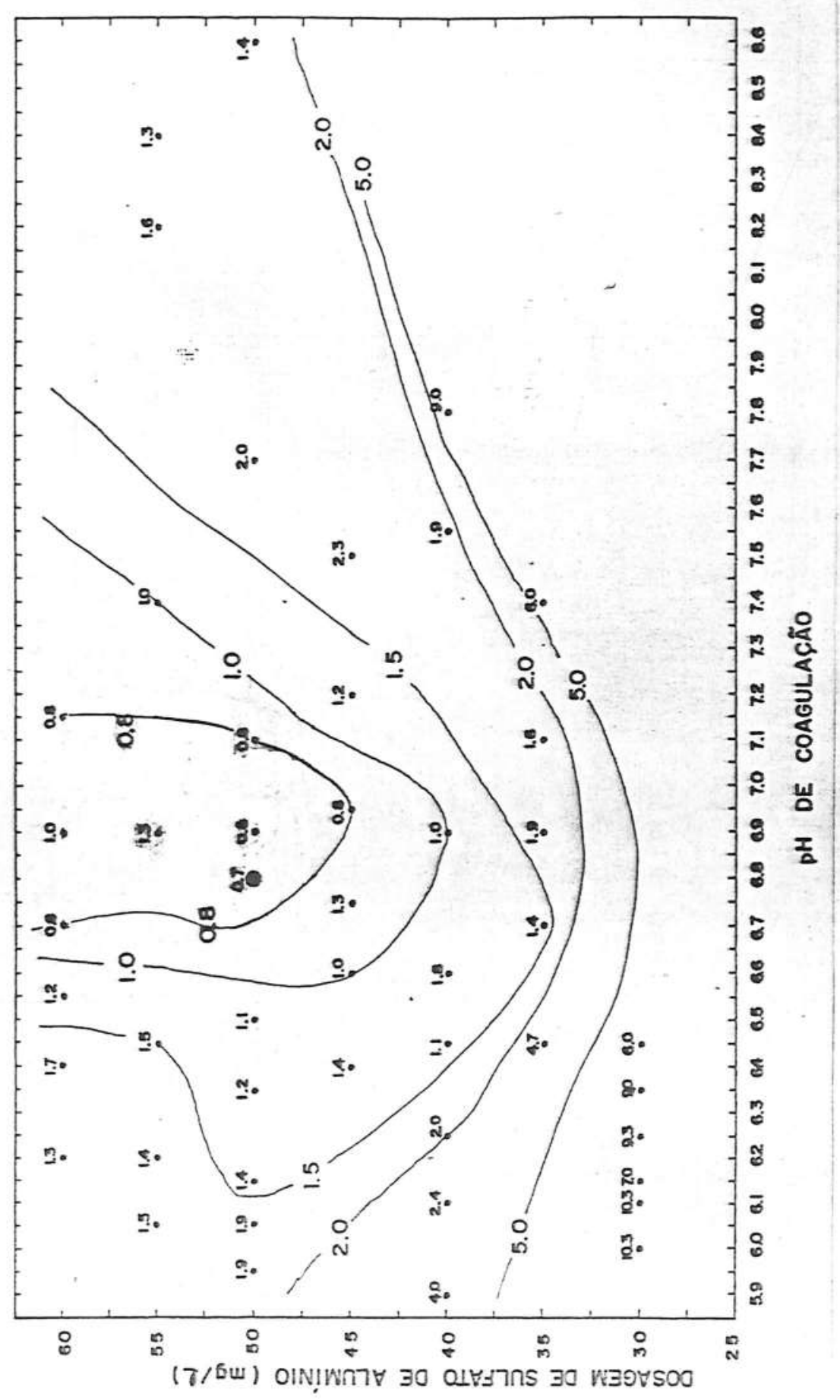

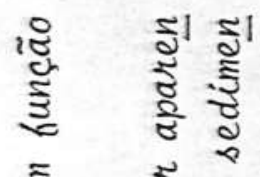

ป वे

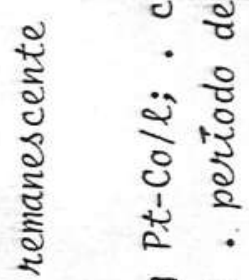

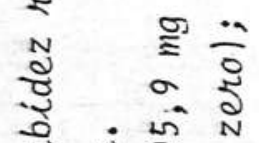

इัँ

ซ छี ซ్ ఫ్

₹ व.

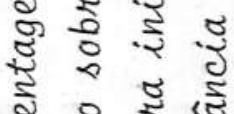

ปี 8.5

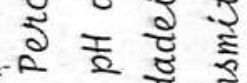

$\times 8$
8

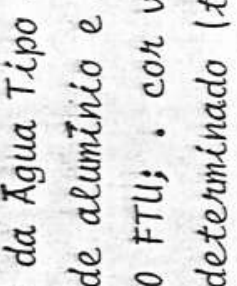

$8 \% 8$

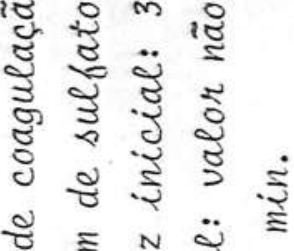

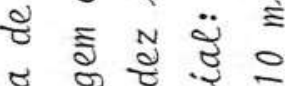

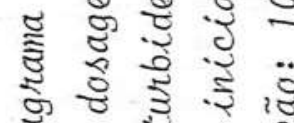

ఫิ

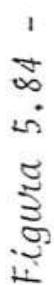




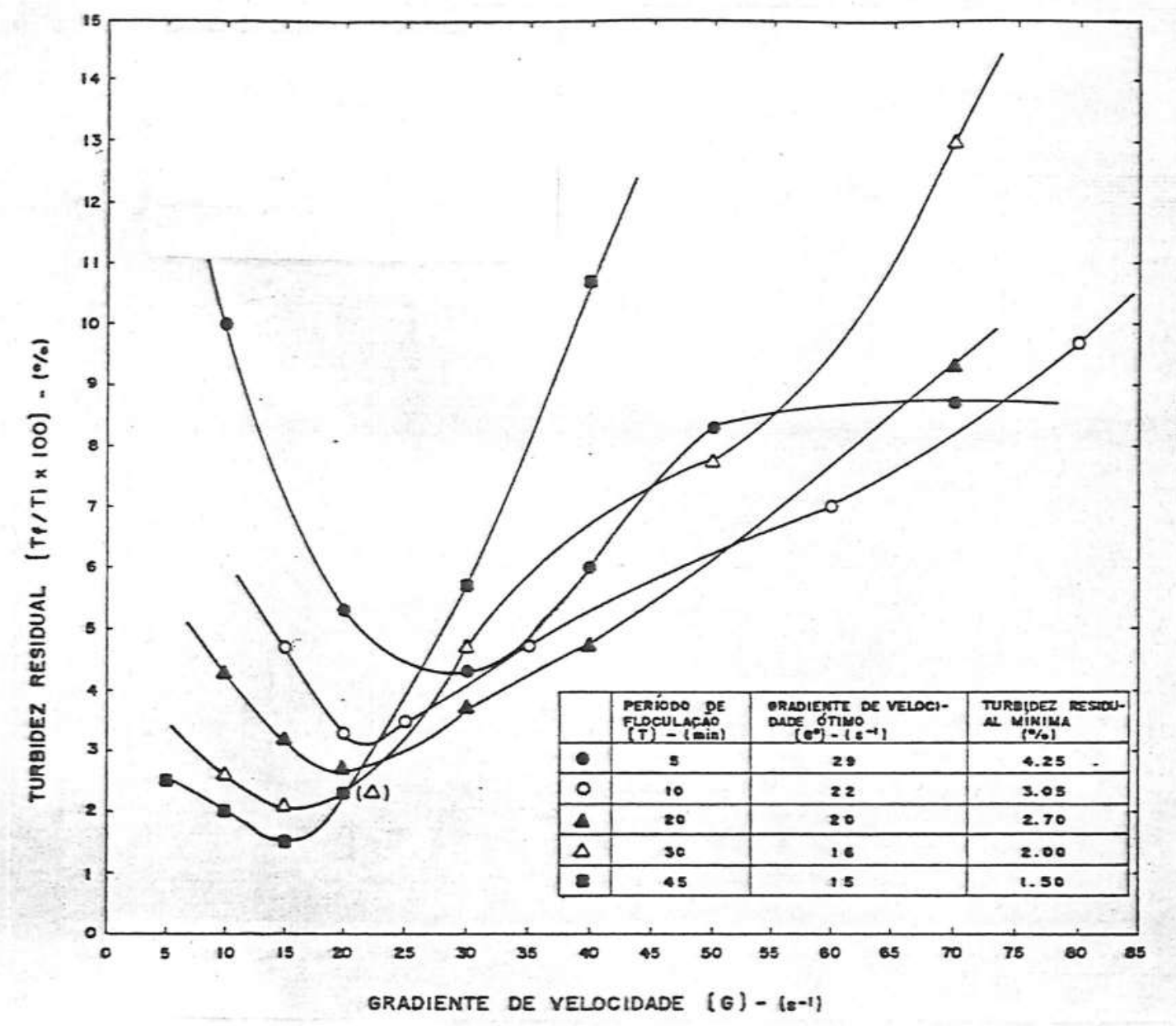

Figura 5.85 - Curvas de variação da turbidez residual em função do gra diente de velocidade para värios períodos de floculação. Agua Tipo X. Mecanismo de varredura.

- turbidez inicial : 300 FTU; . cor verdadeira inicial : $105,9 \mathrm{mg}$ Pt-Coll; . cor aparente inicial: valor não de terminado (transmitancia igual a zero); . dosagem de sul fato de aluminio: $50 \mathrm{mg} / \mathrm{l}$; pH do sobrenadante: 6,80; pe ríodo de sedimentação: 5 min. 


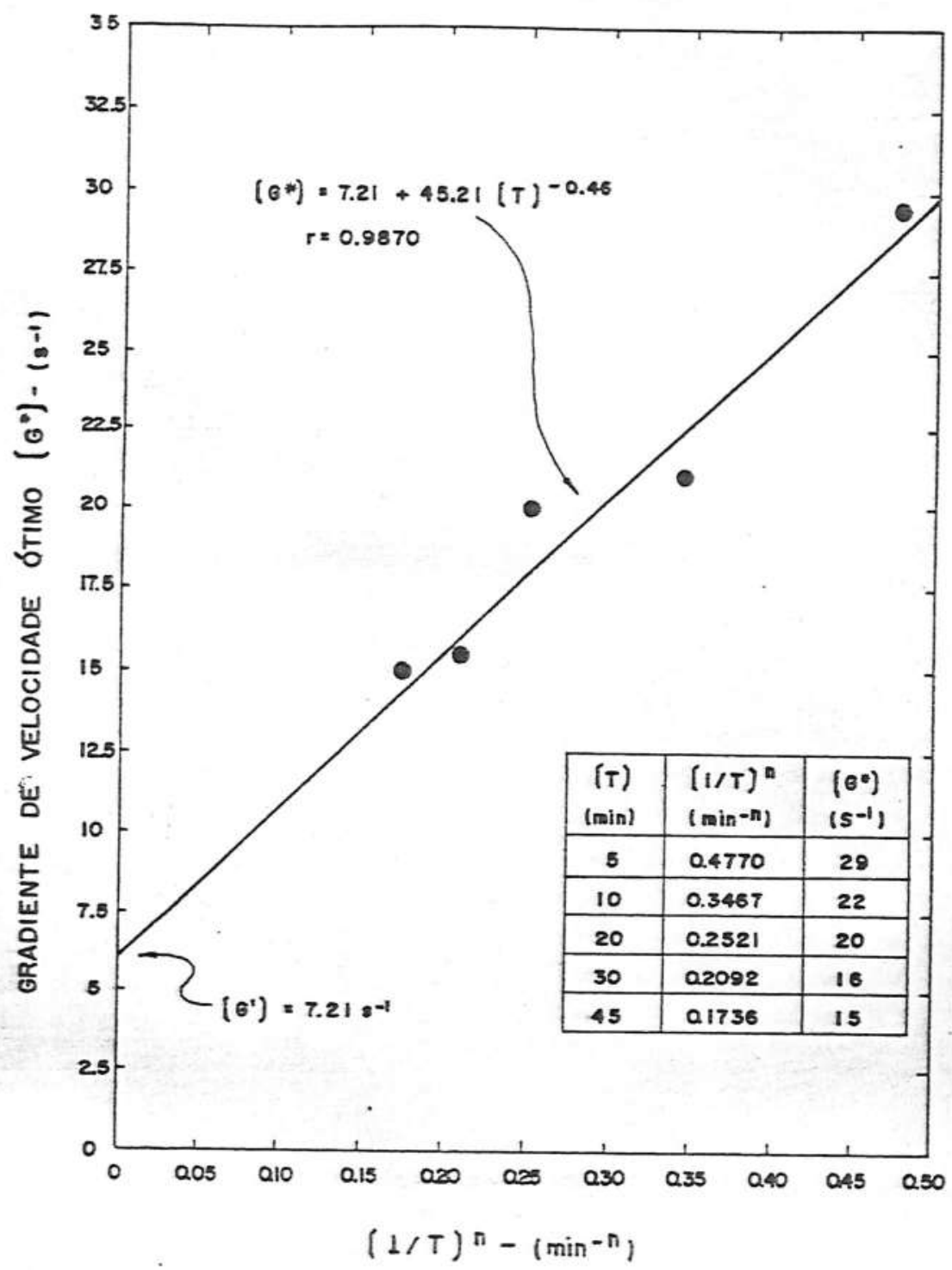

Figura 5.86 - Curva de variação do gradiente de velocidade ötimo $\left(G^{*}\right)$ em função de $(1 / T)^{n}$ para a Agua Tipo $X$, onde $T \bar{e} 0$ pe rĩodo de floculação. Mecanismo de varredura.

- turbidez inicial: 300 FTU; . cor verdadeira inicial : 105, 9 mg Pt-Co/l; . cor aparente inicial: valor não de terminado (transmitancia igual a zero); . dosagem de sul fato de aluminio: $50 \mathrm{mg} / \mathrm{l}$; . pH do sobrenadante: 6,80; - período de sedimentação: 5 min. 


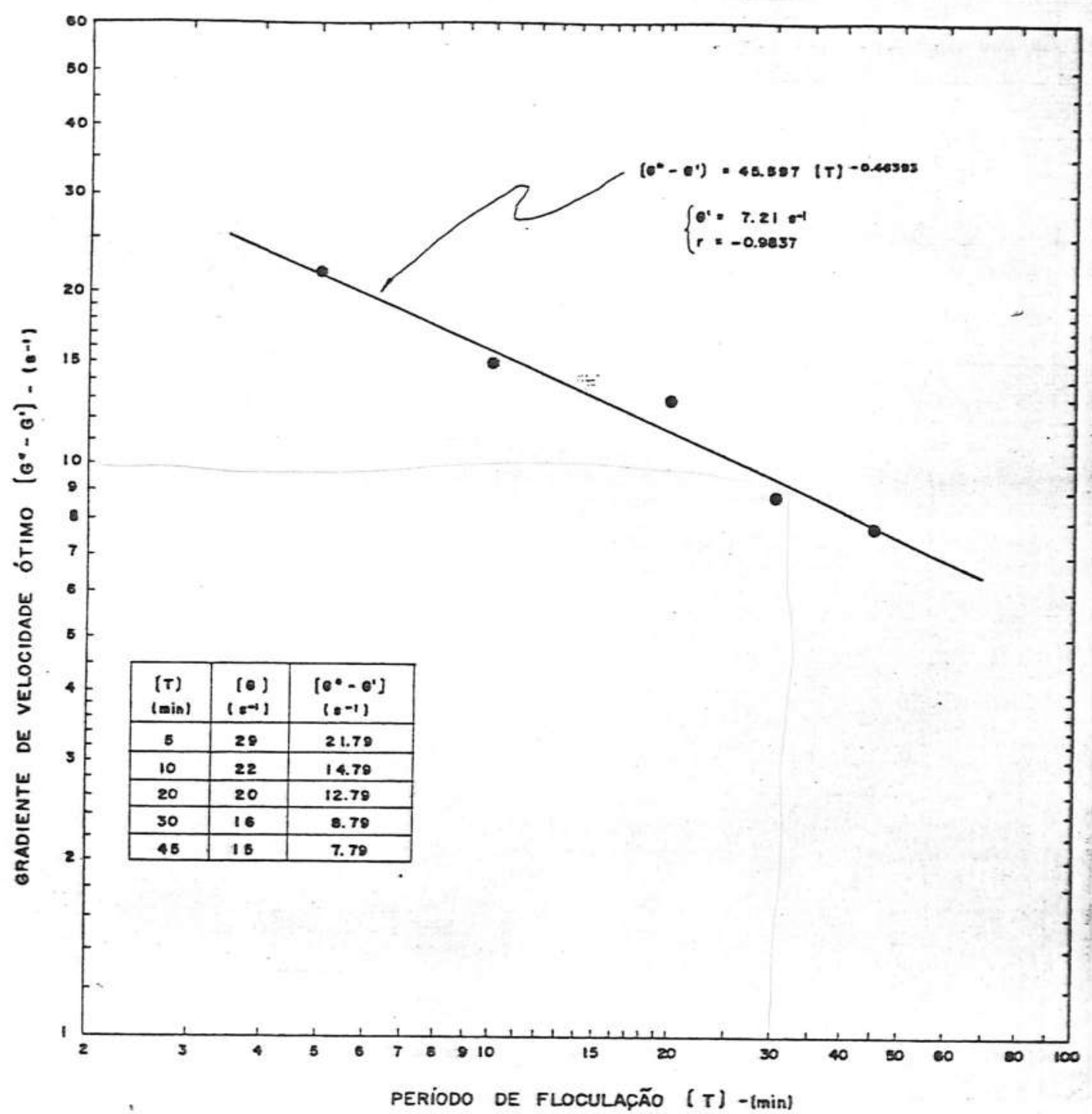

Figura 5.87 - Curva de variação do gradiente de velocidade $\left(G^{*}-G^{\prime}\right)$ em função do período de floculação. Agqua Típo X. Meca nismo de varredura.

- turbidez inicial: 300 FTU; . cor verdadeira inicial: $105,9 \mathrm{mg}$ Pt-Co/l; . cor aparente inicial: valor não de terminado (transmitancia igual a zero); . dosagem de sulfato de aluminio: $50 \mathrm{mg} / \mathrm{l}$; $\mathrm{pH}$ do sobrenadante : 6,80; . período de sedimentação: $5 \mathrm{~min}$. 


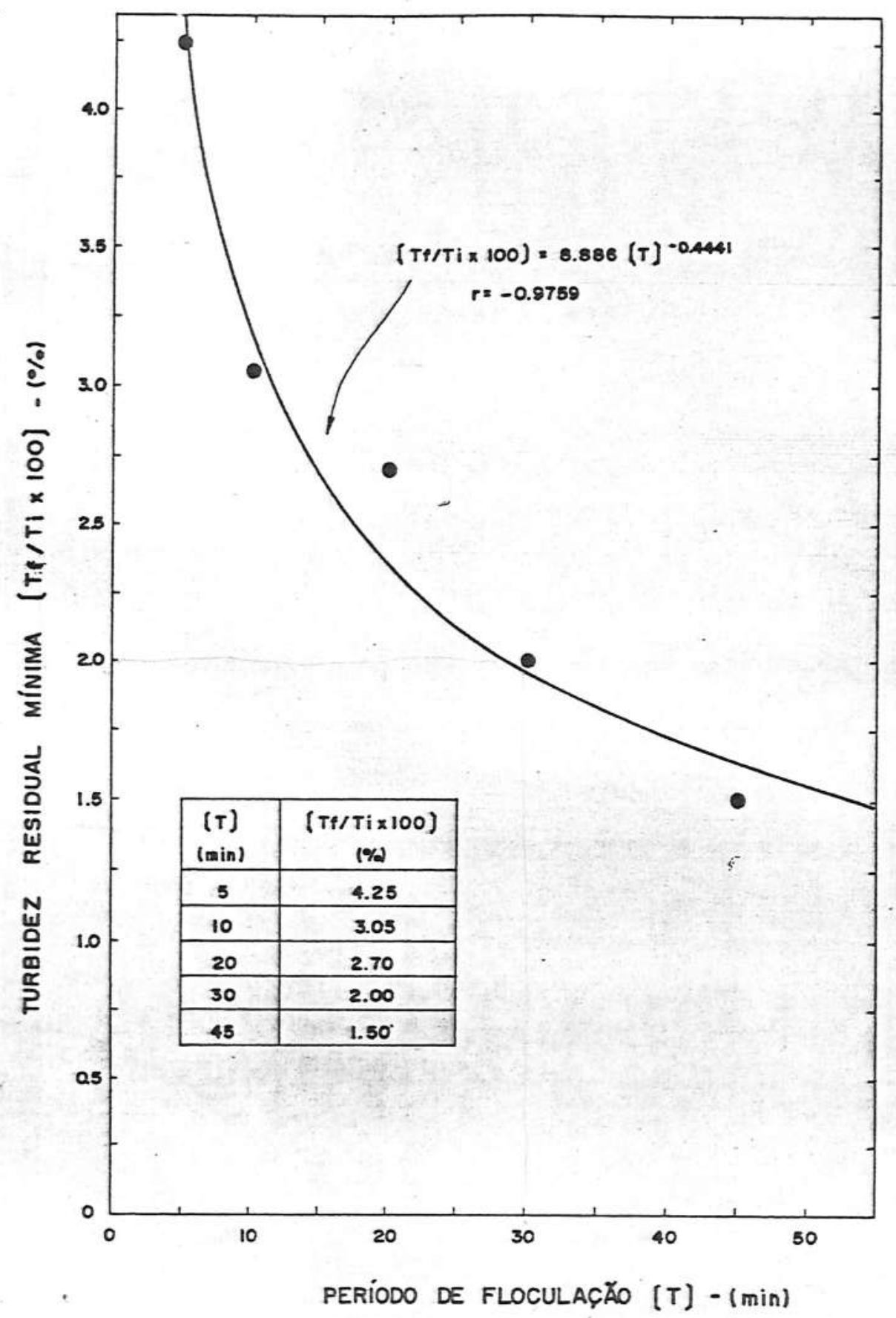

Figura 5.88 - Curva de variação da turbidez residual minima em função do período de floculação. Ägua Tipo X. Mecanismo de var redura.

- turbidez inicial: 300 FTU; . cor verdadeira inicial : $105,9 \mathrm{mg}$ Pt-Co/l; . cor aparente inicial: valor não de terminado (transmitância igual a zero); dosagem de sulfato de aluminio: $50 \mathrm{mg} / \mathrm{l}$; $\mathrm{pH}$ do sobrenadante : 6,80; . período de sedimentação: 5 min. 


\section{6 - CONCLUSOES E RECOMENDACOES}

Com base no trabalho realizado, conclui-se que:

a) A construção de diagramas de coagulação segundo a metodologia proposta, constitui-se em ferramenta de grande utilidade para 0 projeto e operação de sistemas de tratamento de äguas, evidenciando as faixas ötimas de dosagens de coagulante e pHs de coagulação que podem. ser empregados de forma a minimizar os custos de operação e maximizar as eficiências do tratamento;

b) E possivel a obtenção de bons resultados de coagulação pa ra posterior floculação e sedimentacão ou filtração direta em duas re giões, caracterizadas por faixas de pH de coagulação e dosagens de sulfá to de aluminio bastante distintas;

c) Na região cujo mecanismo de coagulação é chamado de adsor ção-neutralização, proporcionado por espécies solüveis mononucleares ou polinucleares adsorviveis de aluminio, carreaadas positivamente $\mathrm{AlOH}^{2+}$, $\mathrm{Al}(\mathrm{OH})_{2}^{+}, \mathrm{Al}_{2}(\mathrm{OH})_{2}^{4+}, \mathrm{Al}_{6}(\mathrm{OH})_{75}^{3+}, \mathrm{Al}_{8}(\mathrm{OH})_{20}^{4+}, \mathrm{Al}_{13}(\mathrm{OH})_{34}^{5+}$, etc), $\mathrm{O}$ consumo de sulfato de alumínio é minimizado e proporcional a concentra ção dos colóides presentes (turbidez e/ou substâncias hümicas);

d) A dosagem ötima de sulfato de aluminio é decrescente com - aumento dos valores do pH de coagulação variando entre 4,0 e 5,0 para a coagulação no mecanismo de adsorção-neutralização e āguas com turbidez elou substâncias hümicas.

Isto comprova a maior eficācia das espécies hidrolisadas de aluminio em comparação com o ion $\mathrm{Al}^{3+}$;

e) Para o mecanismo de adsorção-neutralizacão e àauas conten 
do turbidez elou substâncias hümicas, quanto maior for a concentração das particulas coloidais, maior $\bar{e}$ a amplitude de dosagens de sulfato de aluminio que podem ser empregadas e maiores as eficiências de remocãa dos flocos formados por sedimentação para um dado valor de pH;

6) 0 uso do mecanismo de adsorção-neutralização para a coagu lação de particulas causarioras de turbidez (caulinita) $\bar{e}$ otimizado quando anula-se a carga coloidal riginal das particulas. Apesar da não determinacão da m.e. das substâncias hümicas, tal conclusão pode ser éstendida às águas contenido cor verdadeira, devido às carac teristicas muito similares dos diagramas de coagulação obtidos;

9) As particulas coloidais causadoras de turbidez ou cor ver dadeira podem ser restabilizadas por reversão de suas cargas superficiais, provocada por un excesso de dosagem de sulfato de aluminio quando emprega-se o mecanismo de adsorção-neutralização;

h) No outro mecanismo de coagulação, conhecido como varredura e provocado pela espécie insolüvel amor fa $\mathrm{Al}(\mathrm{OH})_{3}(s)$, caracteriza-se uma região do diagrama de coagulação onde sãó necessärias dosagens de sulfato de aluminio mais elevadas, porém, proporcionando a criação de flocos com melhores caracteristicas de sedimentabilidade quando comparado com o mecanismo de adsorção-neutralização;

i) A região caracteristica do mecanismo de varredura mani festa-se em amplas faixas de valores de $\mathrm{pH}$ e dosagens de sulfato de aluminio. $O$ aumento da dosagem de coagulante implica num alargamento da faixa ótima de valores de pH de coagulação e, ao conträrio do observa do no mecanismo de adsorção-neutralização, não ocorre a possibilidade de restabilização das particulas coloidais causadoras de cor verdadeira el ou turbidez por uma super-dose de coagulante mantendo-se fixo o valor do pH de coagulação;

j) Os extremos laterais da região do mecanismo de varredu ra para os diagramas de coagulação executados, são, pela esquerta, uma região onde ocorre a restabilização das particulas coloidais devido a ação das espécies adsorvĩveis de aluminio, e pela direita, uma região de 
inalteração da estabilidade dos colóides, devido a predominância da es pécie $\mathrm{Al}(\mathrm{OH})_{4}^{-}$;

K) A otimização de dosagens de sulfato dé aluminio e valores de $\mathrm{pH}$ de coagulação no mecanismo de varredura não é obrigatoriamente a companhada da anulação da m.e. das particulas presentes, podendo haverem particulas com cargas superficiais diversificadas, e inclusive com car gas conträrias;

l) A coagulação de águas contendo turbidez elou substâncias hümicas pelo mecanismo de varredura apresenta uma relação não este quiomé trica entre a concentração de particulas coloidais e a dosagem de coagulante. Detectou-se que o aumento da concentração de substâncias hümicas não obrigatoriamente $\bar{e}$ acompanhado do aumento da dosagem ötima de sulfato de aluminio, desde que exista uma concentracão minima de particu las causadoras de turbidez (superiores a 5 FTU). Aguas contendo substâncias hümicas, cujos valores de cor verdadeira sejam superiores a $20 \mathrm{mg}$ $\mathrm{Pt}$-Co/l, podem ser tratadas com maior facilidade e até em dosagens ōti mas de sulfato de aluminio inferiores, caso eleve-se o teor de particu las causadoras de turbidez na āgua bruita;

m) O pH ótimo de coagulação de águas contendo altos teores de substancias hümicas e baixos teores de turbidez manifesta-se em valores menores que para as āguas com altos teores de turbidez e baixos teores de substâncias hümicas, para ambos os mecanismos de coagulação;

n) $0 \mathrm{pH}$ de ambos os mecanismos de coagulação de äguas conten do substâncias hümicas e particulas causadoras de turbidez, manifiesta-se em valores superiores que os obtidos para äguas contendo sómente um ou outro tipo de particulas coloidais;

o) As operações de filtração direta devem ser executadas com - emprego do mecanismo de adsorção-neutralizacão, na região denomina da por "corona" (02), caracterizada entre valores de $\mathrm{pH}$ variando entre 5,5 e 7,0; 
p) A variação do gradiente de velocidade para a mistura rāpi da entre valores de $500 \mathrm{e}^{2} 1200 \mathrm{~s}^{-1}$ teve pouca influência sobre as resultados, porém, o período de agitação não deve se estender por valores su periores a 10 segundos, principalmente quando a operação de coagulação dá-se pelo mecanismo de varredura;

q) Existe um gradiente de velocidade minimo $\left(G^{\prime}\right)$, que quando aplicado à āgua em processo de floculação, implica numa melhoria contí nua de qualidade do sobrenadante com o aumento indefinido do periodo de floculação. Isto foi verificado para todos os tipos de äquas investiga dos, quando coaguladas nos mecanismos de adsorção-neutralização ou varre dura;

r) 0 modelo proposto pela equação $\left(G^{*}-G^{\prime}\right)^{n} . T=K$ re presenta um melhor ajuste matemätico aos dados experimentais de floculação que o modelo até então utilizado to por ANDREU - VILLEGAS \& LETTERMAN (04); $\left(G^{*}\right)^{n} \cdot T=K$, propos

s) A operação de coagulação no mecanismo de varredura requer um periodo de floculação significativamente infferior que o necessärio pa ra a obtenção de uma mesma eficiência de remoção de turbidez e/ou cor aparente por sedimentação quando emprega-se o mecanismo de adsorção-neutralização;

t) Para cada período de floculação $(T)$ existe um único gra diente de velocidade ótimo $\left(G^{*}\right)$; que maximiza a remoção de turbidez elou cor aparente por sedimentação e quando $T$ tende para 0 infinito, $G^{*}$ tende para $G^{\prime}$;

u) Na faixa de valores investigados, a concentração da solu ção de estoque de sulfato de aluminio não exerceu influência significati va sobre as características de sedimentabilidado dos flocos para todos os tipas de āgua e mecanismos de coagulação utilizados neste estudo;

RECOMENDAÇOES:

a) Recomenda-se o empreao da metodologia utilizada na investigação experimental realizada, para a determinação de parâmetros ótimos 
de coagulação e floculação de äguas para abastecimento püblico;

b) Recomenda-se a realização de estudos mais abrangentes para a determinação das condiçães ótimas de coagulação e floculação de $\bar{a}$ guas tratadas por meio da filtração direta;

c) Recomenda-se a utilização dos parâmetros aqui obtidos para āguas com caracteristicas similares às investigadas quando da impos sibilidade do levantamento experimental de seus parâmetros expecificos;

d) Recomenda-se o estudo da influência do uso de polieletrólitos e polimeros naturais como auxiliares de coagulação sobre as diagra mas de coagulação e parâmetros ótimos de floculação: 


\section{REFERENCIAS BIBLIOGRAFICAS}

101) AlAERTS, G. \& VAN HAUTE, A. "Stability of Colloid Types and Optimal Dosing in water Flocculation". In: PA()LOWSKI, L., Physicochemical Methods For Water and wastewater Treatment. Ed. Elsevier, $1982 \mathrm{p}$. $12-29$.

(02) AMIRTHARAJAH; A. "The Use of Chemicals For Coaqulation", Trabalho não publicado, fornecido pessoalmente ao Prof. Dr. LUIZ DI BERNARDO em 1988.

103) AMIRTHARAJAH, A. \& MILLS, K. M. "Rapid-Mix Design For Mechanisms of Alum Coagulation". I. A(u(I)A, Denver, Colorado, 74 (4): $210-216$, Apr. 1982.

104) ANDREW - VILLEGAS, R. \& LETTRMAN, R. D. "Optmizing Flocculator Po wer Input". J. Environmental Eng. Div. ASCE, 102: 251 - 263, Apr. 1976:

105) APHA, AWIIA, WPCF - "Standard Methods for Examination of Water and Wastewater". 16. ed. Washington, 1985, $1268 \mathrm{p}$.

(06) ARALIJO, R. A. "Emprego da Coagulação - Floculação na Remoção de subs tâncias Hümicas (Cor) de Aguas para Abastecimento". São Carlos, 1985 272 p. Dissert. (mestr. hidr. san.) - Escola de Eng. de. S. Carlos Universidade de São Paulo.

107) ARgaman, Y. A. "Pilot-Plant Studies of Flocculation". I. AwUA, Denver, Colorado, 63: $775-777,1971$.

108) ARGAMAN, Y. A. \& KALFMAN, w. J. "Turbulence and Flocculation". Jour nal of Sanitary Engineering Division, ASCE, SA2, vol. 92, 233-241, Apr. 1970.

109) BABCOCK, D. B. \& SINGER, P. C. "Clorination and Coagulation of Humic and Fulvic Acids". I. AllvA, Denver, Colorado, 71 (3): 149-152, Mar., 1979.

(10) BENEFIEL, L. D. et alii "Process Chemistry for water and Nastewater Treatment". PRENTICE - HALL, INC., New Jersey, 1982. 
(11) BLACK, A. P., "Electrokinetic Characteristics of Hydrous Oxides of A luminum and Iron" In: Principles and Applications of water Chemistry, John Wiley \& Sons Inc. 19.67.

(12) BLACK, A. P., "Basic Mechanisms of Coagulation" I. AlvuA, Denver, Colorado, p. 492 - 504 , Apr. 1960.

(13) BLACK, A. P. \& CHEN, C. "Electrokinetic Behavior of Aluminum Species in Dilute Dispersed Kaolinite Systems", J. Al(l)A, : 1173-1183, Sep., 1967.

(14) BLACK, A. P. \& CHEN, C. "electrophoretic Studies of Coagulation and Flocculation of River Suspensions with Aluminum Sulfate", J. A(N)AA, 354-362, Mar., 1965.

(15) BLACK, A. P. \& CHRISTMAN, R. F. "Chemical Characteristics of Fulvic Acids" J. Aw(1)A. 55 (7): 897-912, Jul., 1963.

(16) BLACK, A. P. \& CHRISTMAN, R. F. "Characteristics of Colored Surface waters". J. AWWA, Denver, Colorado, 55 (6) : 753-770, Jun., 1963.

(17) BLACK, A. P. \& HANNAH, S. A. "Eletrophoretic Studies of Turbidity Removal by Coagulation with Aluminum Sulfate". I. AwwA, Denver, Co lorado, 53 (4): 439-451, Apr., 1961.

(18) BLACK, A. P. \& WILLEMS, D. G. "Electrophoretic Studies of Coagulation for Removal of Organic Color" J. Al(1)A, 53 (5): 589-604, May, 1961.

(19) BLACK, A. P.et alli - "Stoichiometry of the Coagulation of Color Causing Compounds with Ferric Sulfate". J.A(j)iA, 55 (7), 897 - 912 jul. 1963.

(20) CAMP, Thomas R. \& STEIN, P.C. - "Velocity Gradients and Internal llork in Fluid Motion", Jornal of the Boston Society of Civil Engineers, vol. 30, no4, pp. 219 - 237. Oct., 2943.

(21) CAMPos, josé Roberto - "Emprego de Amido de Batata como Auxiliar de Floculação de Aguas para Abastecimento". São Carlos, l980. 179 p. Tese (Dout. hidr, san.) - Escola de Eng. de São Carlos - Univ. São Paulo.

(22) CARRION, José M. Peréz vaRgas, Lidia Canena de - "Processos uni tärios - Laboratōrio/Floculacion". In: OPS/EHP/CEPIS, Programa Re gional OPS/EHP/CEPIS de mejoramiento de calidad de äguas para consumo humano. 1981.

(23) CEPIS "Evaluacion de Plantas de Tratamiento de İgua", Tomo I, Li ma, Dic. 1984. 
(24) CEPIS. Teoria, Diseño y Control de los Procesos de Clarificacion del Agua. Lima, Peru. 1973. 558p.

(25) CHRISTMAN, R. F. \& GHASSEMI, M. - "Chemical Nature of Organic Coloe in Mater". J.A(1)WA, Denver, Colorado, 58 (6): 723 - 741, June, 1966.

(26) COMMITTEE REPORT - "Organics Removal bu Coagulation: A review and re search needs". J.AwWA, Denver, Colorado, 71 (10): 588-603, Oct. 1979.

(27) DEMPSEY, Brian A. et alii - "Polyaluminum Chloride and Alum Coagulation of Clay - Fluvic Acid Suspensions". J.A(i)WA, Denver, Colorado. 77 (3): 74 - 80, Mar., 1985.

(28) DHARMARAJAH, A. H. - "Direct Filtration of Humic substin ces With Alum and Polmer". Ames, 1979. 144p. Thesis (Master) - Iowa university.

(29) DI BERNARDO, L. - Tratamento de Agüas de Abastecimento de Cor eleva da". Revista DAE, São Paulo, no 133, 61 -65, jun, 1983.

(30). EDWARDS, Gerald A. \& AMIRTHARAJAH, A. - "Removing Color Caused by Humic Acids". J.AliwA, Denver, Colorado, 77 (3): 50 - 57, Mar., 1985.

(31) EDZWALD, J.K. et alii - "Polymer Coagulation of Humic Acid Waters". J. Environmental Engineering Division, 103 (EE6): 989-1000, Dec 1971.

(32) FIESSINGER, François. - "Coagulation and Flocculation" Part I Coagulation. Sociēté Lyonnaise des Eaux et de L'Eclairage, Paris, 1978.

(33) GREGORY, J. "Flocculation by Inorganic Salts In: The Scientific Basis of Flocculation Sijthoff and Noordhof6. The Netherlands" 1278.

(34) GREGORY, J. "Effects of Polymers on Colloid Stability In: The Scienti fic Basis of Flocculation Sijthoff and Noordhof6. The Netherlands", 1278.

(35) GRIFFITH, J. David \& (IILIAMS, Robert G. - "Applicatin of jar- test Analysis at Phoenix, Ariz". J.AW(i)A, Denver, Colorado, 64 (12): 825 830, Dec., 1272.

(36) GUIMARAES, A. F. "Estudo da Coagulação - Floculação de Agua com Turbi dez ou Cor Elevada" Diss. de Mestr. da EESC, em 1987 - Universidade de São Paulo.

(37) GUPTA, V. S. et alii "Zeta Potencial Control for Alum Coagulation" I A(!)(I)A, Denver, Colorado, 67 (1): 21 - 23, Jan., 1975.

(38) HALL, E. S. \& PACKHAM, R. F. "Coagulation of Organic Color with Hydro lyzing Coagulants" I. Al!! A, Denver, Colorado, 57 (9): 1149 - 1165, sep tember, 1965. 
(39) HARRIS, Howord S. et alii - "Orthokinetic Flocculation in (Nater Purification". Journal of the Sanitary Engineering Division, ASCE, SA 6, vol. 92, $95-111$, Dec., 1966.

(40) HUDSON, H,E. Ir. - "Plysical Aspects of Flocculation". J.AWwA, Den ver, Colorado, 57 (7): 885 - 892, Jul. 1965.

(41) HUDSON, H. E. Jr. - "Evaluation of Plant Operating and Jar - Test Data". J.AW(NA, Denver, Colorado, 65 (5): 368 - 375, May., 1973.

(42) HUDSON, H.E. Ir. - "Water Clarification Processes Pratical Design and Evaluation". Litton Company International Publishing, Inc., 1981.

(43) HUDSON, H. E. Ir. "Water Clarification Processes - Practical . De sign and Evaluation". - cap. 3 e 4 by Litton Company International Publishing, Inc., 1981

(44) HLDSON, H. E. Jr. \& Singley; J.E. - "upgrading Existing Water Treatment Plants - Jar - Testing and Utilization of Jar - Test Data Aw(UA Annual Conference, Boston, Ma (USA), June 1974.

(45) JEFFCOAT, (1. Blake \& SINGLEY, J. Edwaed - "The Effect of Alum Con centration and Chemical - Addition Times on Coagulation". "J.AlWWA, Denver, Colorado, 67 (4): 177 -181, Apr., 1975.

(46) JIRGENSONS, B. \& STRALMANIS, M. E. - "A Short Textbook of Colloid Chemistry. 2.ed. New York. The Macmillan Company, 1962, 500 p.

(47) KAWAMURA, Susumu - "Coagulation Considerations". J.Alw(wA, Denver, - Colorado, 65 (6): $417-423$, Jun., 1973.

(48) KIM, w, et alii - "Cation-Exchange Capacity and pH en the Coagulation Process". J.AlvwA, Mar., 1965.

(49) LAI, Ruey J. et alii - "Velocity Gradient Calibration of jar -test Equipment". J.AwWA, Denver, Colorado, 67 (10): 553 - 557. Oct., 1975.

(50) LANGELIER, W. F. \& LUDWIG, H. F. - "Mechanism of Floculation in the Clarification of Turbid waters". J.AlnwA, 163-181, feb. 1949.

(51) LAMER, V. K. - "Coagufation Versus the Flocculation of Colloidal Dispersions of by High Polumers In: Principles and Applications of Water Chemistry John Wiley \&ns, Inc. 1967.

(50) LYKLEMA, J. - "Surface Chemistry of Colloidas in Connection with Stability In: The Scientific Basis of Flocculation Sijthoff and Noordhoff, the Netherlands".

(53) MANGRAVITE, Francis J. et alii - "Removal Humic Acid by Coagulation and Microflotation". J.Al(U)A, Denver, Colorado, 67 (02): 88 - 94, Feb., 1975. 
(54) MARION, S. P. \& THOMAS, A. W. "Efffect of Diverse Anions on the pH of Maximun Precipitantion of Aluminum Hydroxide". J.Coll-Sci, 1946.

(55) MATIJEVIC, Egon. - "Colloid Stability and Complex Chemistry". Journal of Colloid and Interface Science. vol 43, no 2, p. 217 - 245 - May 1973.

(56) MATIJEVIC; E., ABRAMSAN, M. B., OTTRUILL, R. H., SCHULZ, K. F. \& KARKER, M. - "Adsorption of Thorium Ions on Silver Iodide Sols" . J.of Physical:Chemistry, New York, 65 (10): 1724 - 1729, Oct., 1961.

(57) MATIJEVIC, E., ABRAMSON, M. B. SCHULZ, K. F. \& KERKER, M. "Dedection

- of Metal Ion Hydrolysis by coagulation". J. Physical Chemistry New York; 64: 1157 - 1161, sep., 1960.

158) MATIJEVIC, E., COUCH, J.P. \& KERKER, M. - "Detection of Metal Ion Hydrolysis by Coagulation. IV. Zinc". J. Of Physical Chemistry, New York; 66: 111 -114, Jan., 1962.

(59) MATIJEVIC, E. \& JANAUER, Gilbert E. - "Coagulation and Reversal of Charge of Lyophobic Colloids by Hydrolyzed Metal Ions. II. Ferric Ni trate". J. Of Colloid and Interface Science, New York, 21 : 197 223, 1966.

(60) MATIJEVIC, E., JANALIER, G.E., \& KERKER, M. - "Reversal of Charge of Lyophobic Colloids by Hydrolvzed Metal Ions I. Aluminum Nitrate" J. of Colloid Science, New York, 19: 333 - 346, 1964.

(61) MATIJEVIC, E., MATHAI, K.G. \& KERKER, M. - "Detection of Metal Ion Hydrolysis by Coagulation. V. Zirconium". J. of Physical Chemistry, New York, 66: 1799 - 1803. Oct., 1962.

(62) MATIJEVIC, E. , MATHAI, K. G., OTTEWILL, R. H. \& KERKER, M. - Detec tion of Metal Ion Hydrolysis by Coagulation. III. Aluminum". J. of Physical Chemistry, New York, 65: 826 - 830, May, 1961.

(63) MATIJEVIC, E. \& STRYKER, L. J. - "Coagulation and Reversal of Charge of Lyophobic Colloids by Hydrolyzed Metal Ions. III. Aluminum Sulfate". I. of Colloid and Interface Science, New York, 22: 68 -77 1966.

(64) MATIJEVIC, E. \& TEZAK, B. - "Coagulation Effects of Aluminum Nitrate and Aluminum Sulfate on Aaqueous Sols of Silver Halides in statu Nascendi. Detection of Polynuclear Complex Aluminum Ions by Means of Coagulation Measurements". I. Physical Chemistry, New York. 57: 951 - 954, Dec. 1953.

(65) MIDWOOD, R. B. \& FELBECK - "Analus is of Yellow Organic Matter from Freshwater". I. AwwA, Denver, Colorado, 60 (3): 357, Mar., 1968. 
(66) MOFFETT, J. Willian - "The Chemistry of High-Rate water Treatment" . J.AW(alA, 1255 - 1271, Nov. 1968.

(67) MOORE, G. N. - "Interaction of Fulvic Acids and Koalinite during Coagulation, Presented at the 97 th annual conference the, American water Works Association Anaheim, California, May 8-13, 1977.

(68) NARKIS, N. \&REBHUN, M. - "Stoichiometric Relationship Between Humic and Fulvic Acids and Fionculants." J.AWWA, 325 - 328, June, 1977.

(69) NARKS, N. \&REBHUN, M. - "The Mechanism of Flocculation Process in The presence of Humic substances". I.A(1)(1)A, Denver, Colorado, 67 (2): 101 -108, Feb. 1975.

(70) OLPHEN, V. H. "Clau Colloid Chemistry", Niley-Interscience Publishers JOHN WILEY \& SONS, 2nd edition, N. York, 1977.

(71) O'MELIA, C. R. - "Coagulation In: water Treatment Plant Design" Cap. 4 Ann Arbor Science Publishers, Inc. Edited by Robert L. Sanks, USA, 1979.

(72) O'MELIA, C. R. - A paper presented at the workshop on - "Aquatic Surface Chemistry", Ermatinger, Switzerland, Jan. 22-25, 1986, and submitted for publication in Aquatic Surface Chemistry, edited by werner Stumm, Wiley - Interscience, New York, 1987.

(73) PACKHAM, R. F. - "The Coagulation Process I. Effect of pH and the Nature of the Turbidity". J.Appl. Chem., 12: 556 - 564, Dec. 1962.

(74) PACKHAM, R. F. - "The Coagulation Process II. Effect of pH on the Precipitation of aluminium Hydroxide". J.Appl. Chem., 12: $564-568$ Dec., 1962.

(75) PACKHAM, R. F., - "Some Studies of the Coagulation of Dispersed Clays with Hydrolyzing Salts". J.Coll.Sci., 20, 81 - $92,1965$.

(76) PILIPOVICH, J. B. et alii - "Electrophoretic Studies of water Coagu lation" J.AWWA, 1467 - 1482, Nov. 1958.

(77) RIDDICK, T. M. - "Zeta Potencial and Its Application to Difficult waters". J.A(I) 53 (8): 1007 - 1030, 1961.

(78) ROOK, J. J. - "Haloforms in Drinking Water". J.AlwWA, Denver, Colorado. 68 (3): 168, Mar., 1976.

(79) SANKS, Robert L. - "water Treatment Plant Desing". Michigan, Ann Arbor Science Publishers, Inc., c. 1979. 845p.

(80) STENOUIST. R. J. \& KAUFMAN, W. J. - "Initial Mixing in Coagulation Processes". Environmental Protection Angency, EPA, Ohio, nov. 1972. 
(81) STEVENS, A. A. et al "Chlorination of Organics in Drinking water " I. Alwa, Denver, Colorado, 68 (11): 615, nov., 1976.

(82) STUMM, w. "Metal Ions in Aqueous Solution" In : Principles and Applications of Water Chemistry, John (Niley \& Sons, Inc. Edited by Samuel D. Faust and Joseph V. Hunter, USA, 1967.

(83) STLMM, W. \& MORGAN, J. J. "Chemical Aspects of Coagulation". J. AW(I)A, Denver, Colorado, 54 (8): 971 - 992, aug., 1962.

(84) STUMM, 10. \& O'MELIA, C. R. "Stoichiometry of Coagulation" I. AurlA, Denver, Colorado, 60 (5): 514 - 539, May., 1968.

(85) SULLIVAN Jr., J. H. \& SINGLEY, J. E. "Reactions of Metal Ions in Di lute Aqueous Solution: Hydrolysis of Aluminum" I. AWwA, 1280-1287, no ve., 1968.

(86) TOLEDO, A. P. P. de "Comunicação Pessoal".

(87) TOLEDO, A. P. P. de "Contribuição ao Estudo Físico-Químico de Acido Hümico Extraỉdo de Sedimento" São Paulo, 1973, 122p. Disser. de Mestr. Universidade de São Paulo.

(88) VIK, E. et alii "Removing Aquatic Humus From Norwegian Lakes" J. Au(vA, Denver, Colorado, 77 (3) : 58 - 66, Mar., 1985.

189) WAYMAN, C. H. "Adsorption on Clay Mineral Surfaces" In: Principles and Applications of water Chemistry, John wiley \& Sons, Inc. Edited by Sa muel D. Faust and Joseph V. Hunter, USA, 1967.

(90) WEBER, w. J. Jr. \& JODELLAH, A. M. "Removing Humic Substances by Chemi cal Treatment and Adsorption". I. AlwA, Denver, Colorado, $77(4): 132$ 137, Apr., 1985.

191) WILLIAMS, R. L. "Microelectrophoretic Studies of Coagulation With Aluminum Sulfate" J. AltulA, Denver, Colorado, $57(6): 801$ - 810, Jun., 1965.

(92) RICHTER, C. A. "Sistemas Simplificados de Floculação" Publicação da SA NEPAR. 